\title{
EERC Pilot-Scale CFBC Evaluation Facility \\ Project CFB Test Results
}

Topical Report

Task 1

\author{
Michael D. Mann \\ Douglas R. Hajicek \\ Ann K. Henderson \\ Thomas A. Moe
}

Work Performed Under Contract No.: DE-FC21-86MC10637

\author{
For \\ U.S. Department of Energy \\ Office of Fossil Energy \\ Morgantown Energy Technology Center \\ P.O. Box 880 \\ Morgantown, West Virginia 26507-0880 \\ University of North Dakota \\ Energy \& Environmental Research Center \\ Box 8213 \\ University Station \\ Grand Forks, North Dakota $\mathbf{5 8 2 0 2}$
}

September 1992 


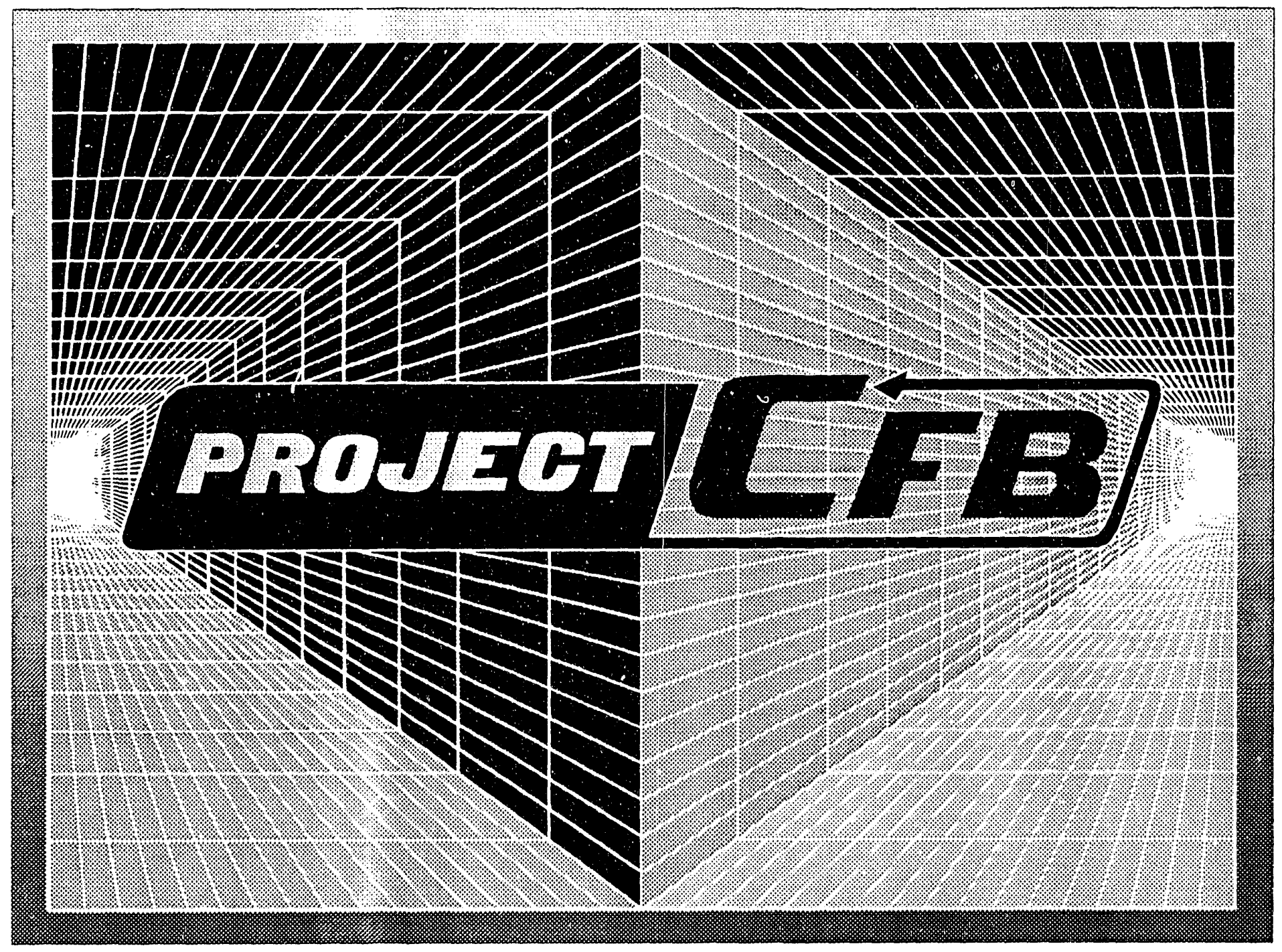

\section{-}

- ARCO Coal Company

- Consolidated Edison Company of New York

- Electric Power Research Institute

- Empire State Electric Energy Research Corporation

- North Dakota Lignite Research Council
- Northern States Power Company

- Ottertail Power Company

- Premier Refractories and Chemicals, Inc.

- TU Electric

- U.S. Department of Energy 


\title{
PROJECT CIRCULATING FLUIDIZED-BED
}

\begin{abstract}
Project CFB was initiated at the University of North Dakota Energy and Environmental Research Center (EERC) in May 1988. Specific goals of the project were to 1) construct a circulating fluidized-bed combustor (CFBC) facility representative of the major boiler vendors' designs with the capability of producing scalable data, 2) develop a database for use in making future evaluations of CFBC technology, and 3) provide a facility for evaluating fuels, free of vendor bias, for use in the energy industry. Five coals were test-burned in the 1-MWth unit: North Dakota and Asian lignites, a Wyoming subbituminous, and Colorado and Pennsylvania bituminous coals. A total of 54 steadystate test periods were conducted, with the key test parameters being the average combustor temperature, excess air, superficial gas velocity, calcium-to-sulfur molar ratio, and the primary air-to-secondary air split.
\end{abstract}

The sulfur capture for a coal fired in a CFBC is primarily dependent upon the total alkali-to-sulfur ratio. The required alkali-to-sulfur ratio for $90 \%$ sulfur retention ranged from 1.4 to 4.9 , depending upon coal type. While an allsali-to-sulfur ratio of 4.9 was required to meet $90 \%$ sulfur retention for the Salt Creek coal versus 1.4 for the Asian lignite, the total amount of sorbent addition required is much less for the Salt Creek coal, 4.2 pound sorbent per million Btu coal input, versus 62 pound/million Btu for the Asian lignite. The bituminous coals tested show optimal sulfur capture at combustor temperatures of approximately $1550^{\circ} \mathrm{F}$, with low-rank coals having optimal sulfur capture approximately $100^{\circ} \mathrm{F}$ lower.

$\mathrm{NO}_{x}$ and $\mathrm{N}_{2} \mathrm{O}$ emissions from the CFBC are highly coal dependent. The total amount of $\mathrm{NO}_{\mathrm{x}}$ emitted, as well as the rate at which it changes with changes in combustor temperatures, varies with coal type. The rate of change is smallest with the lignites and largest with the bituminous coals. $\mathrm{NO}_{\mathbf{x}}$ emissions also increase with increasing excess air and sorbent add rates. $\mathrm{N}_{2} \mathrm{O}$ emissions increased as the rank changed from subbituminous to lignite to bituminous. The distribution of the nitrogen between the volaiiles and the fixed carbon appears to be the most important fuel property affecting $\mathrm{N}_{2} \mathrm{O}$ emissions. $\mathrm{N}_{2} \mathrm{O}$ emissions show the opposite trend as $\mathrm{NO}_{\mathbf{z}}$, decreasing with increasing temperature and sorbent add rate, and a similar trend as $\mathrm{NO}_{\mathrm{x}}$ for excess air.

Overall collection efficiency of solids in the main cyclone ranged from $93.8 \%$ to 99.9\% and was adequate to maintain solids circulation for all the coals tested. For some tests, a secondary cyclone was employed to recycle some of the fine ash escaping the primary cyclone. The recycle of this material increased the recirculation rates. Recirculation rates decreased with decreasing velocity and bed inventory. Results indicated that for design of a full-scale system using low-ash, low-sulfur fuels, recycle from a secondary cyclone/multiclone or baghouse would be recommended to maintain bed inventory.

During testing with the North Dakota lignite, which contains $4 \%$ sodium in the ash, some bed material particle growth was observed, but did not lead to severe agglomeration. A fuel with slightly higher sodium or potassium could result in agglomeration problems. The fuels with high concentrations of organically bound calcium also showed potential to foul downstream convective and reheat sections of a boiler, indicating provisions for 
adequate soot-blower coverage should be considered. The combination of high ash and high sulfur in the Asian lignite resulted in very large quantities of solid waste. For the other coals tested, the amount of solid waste generated increased with the amount of ash in the coal and the amount of limestone added.

Combustion efficiency for the two lignites and the subbituminous coal approached $100 \%$ over the entire range of temperatures tested. The combustion efficiencies for the Salt Creek bituminous coal ranged from $97 \%$ to $99 \%$, while the combustion efficiencies for the Blacksville bituminous coal ranged from $90 \%$ to $97 \%$. These differences are due to the higher reactivity of the char for the lower-rank coals and the higher volatile content of these coals in relation to the fixed carbon. Recycle from a secondary cyclone system or baghouse would improve the combustion efficiency for the bituminous coals. Combustion efficiency also increased with increased excess air.

Testing was conducted to compare the performance of the EERC CFBC with both a utility-scale plant and a vendor-operated pilot plant using the same coal and limestone. The 110-MWe CFBC at the Colorado Ute Nucla Station has been successfully operating for the last several years and testing has been performed in cooperation with Electric Power Research Institute (EPRI). EPRI and Pyropower have also participated in testing in a pilot-scale CFBC in San Diego, California. Emissions of $\mathrm{SO}_{2}, \mathrm{NO}_{\mathbf{x}}$, and $\mathrm{CO}$ and the measured combustion efficiencies and heat flux for the three units were similar. Based upon this comparison and supported by the information presented in the following report, the EERC 1-MWth pilot-scale CFBC not only meets the original design objectives of Project CFB, but also provides data scalable to a full-scale unit. This unit, therefore, provides the energy industry a powerful tool for obtaining engineering design and environmental permitting data prior to building a new unit or switching fuels in an existing unit. 


\section{ACKNOWLEDGMENTS}

The EERC would like to acknowledge the efforts of Bob Midleton, now retired from the Otter Tail Power Company, for being the prime motivator in initiating Project CFB. We are grateful for the valuable input supplied by Stan Selle of Northwest Research, Inc., Michael Johnson, formerly with the EERC, and Nanak Grewal of the University of North Dakota Mechanical Engineering Department, during the design and construction period.

The authors would like to strongly acknowledge the efforts of Butch Riske and his operations staff at the EERC whose dedication and craftsinanship made on-site construction possible, the EERC machine shop personnel for their excellent workmanship during fabrication of the pilot plant components, Rick Fox and Jim Aarestad of the EERC instrument shop for their tireless efforts involved in completing the instrumentation of the unit in a timely manner, Tom Stokke for his efforts in getting the data acquisition and control system up and running, and Jim Larsien whose input and efforts always result in a more successful, efficiently constructed and functional piece of test equipment.

The authors would also like to thank Huichong LeNore and the other members of the EERC Office Services group for the exceptional job which was done in preparing this report, and Joyce Riske for her patience and understanding during the editing process. 


\section{TABLE OF CONTENTS}

$\underline{\text { Page }}$

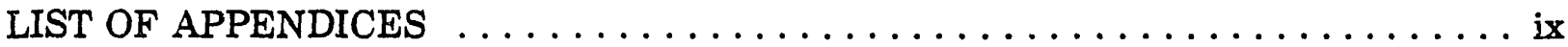

LIST OF FIGURES $\ldots \ldots \ldots \ldots \ldots \ldots \ldots \ldots \ldots \ldots \ldots \ldots \ldots \ldots \ldots \ldots \ldots$

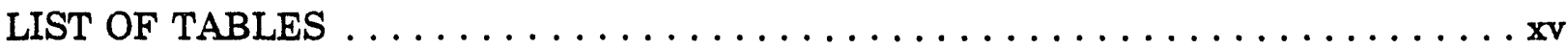

EXECUTIVE SUMMARY $\ldots \ldots \ldots \ldots \ldots \ldots \ldots \ldots \ldots \ldots \ldots \ldots$ ES-1*

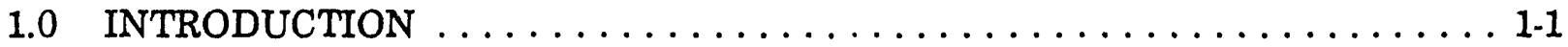

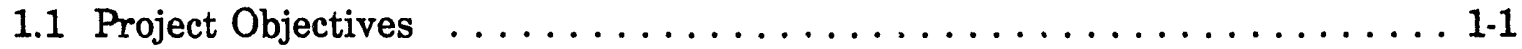

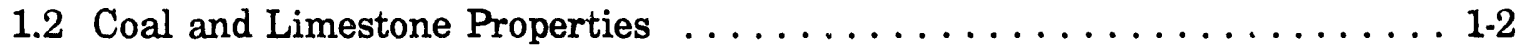

1.3 Test Matrices . . . . . . . . . . . . . . . . . . . . . . . 1-2

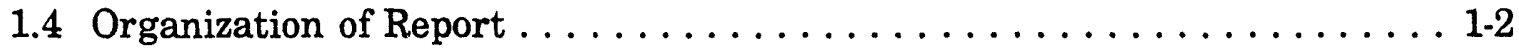

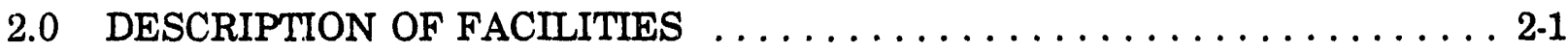

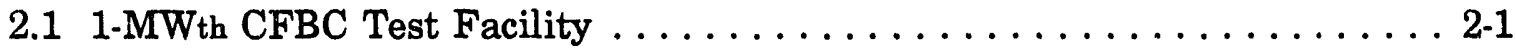

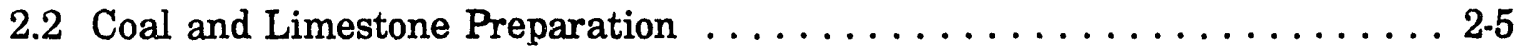

2.3 Flue Gas Emissions Monitoring . . . . . . . . . . . . . . . 2-5

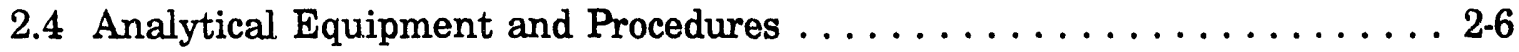

2.5 Scanning Electron Microscopy . . . . . . . . . . . . . 2-7

3.0 IMPACTS OF COAL AND LIMESTONE PROPERTIES ON OPERATIONAL PERFORMANCE ..........................

3.1 Overall Operability . . . . . . . . . . . . . . . . . . . 3

3.1.1 Bed Material Size Distribution and Recirculation Rates . . . . . . . 3-3

3.1 .2 Cyclone Efficiency . . . . . . . . . . . . . . . . . 6

3.1.3 Solid Waste Generation . . . . . . . . . . . . . . . 3-7

3.1.4 Agglomeration and Ash Deposition . . . . . . . . . . . . 3-8

3.1.5 Corrosion and Erosion of System Components . . . . . . . . . . . 3.8

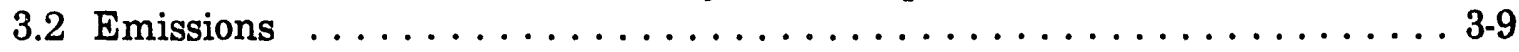

3.2.1 $\mathrm{SO}_{2}$ Emissions and Limestone Utilization . . . . . . . . . . 3-9

3.2.2 Nitrogen Oxide Emissions . . . . . . . . . . . . . . . 3-14

3.2.3 Carbon Monoxide Emissions . . . . . . . . . . . . . . 3-23

3.2 .4 Fly Ash Collectability . . . . . . . . . . . . . . . . 3-23

3.3 Thermal Performance . . . . . . . . . . . . . . . . . . . 3-24

3.3.1 Heat Flux and Heat-Transfer Coefficients . . . . . . . . . . . . 3-24

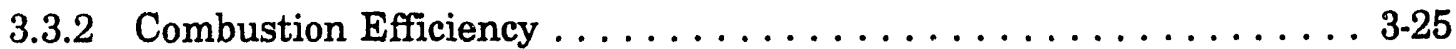

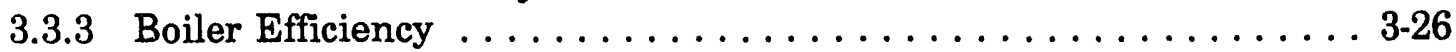

3.3.4 Impact of Load Control Method . . . . . . . . . . . . . 3-29

* Executive Summary 
Page

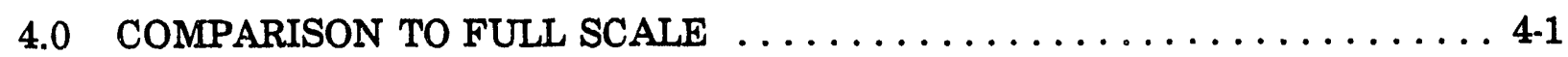

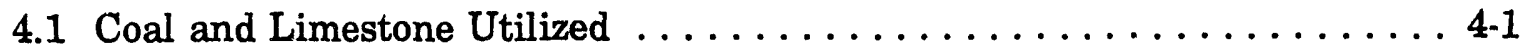

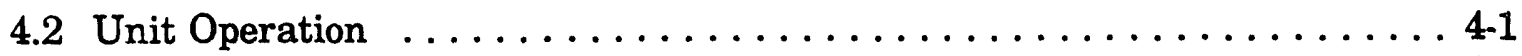

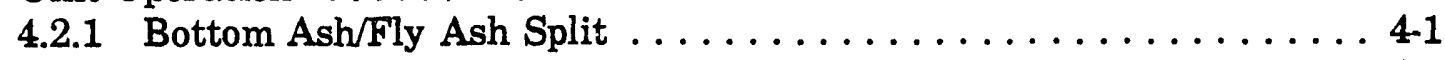

4.2.2 Bed Temperature ..................... 4-3

4.3 Thermal Performance $\ldots \ldots \ldots \ldots \ldots \ldots \ldots \ldots \ldots \ldots \ldots$

4.3.1 Heat Flux and Heat Transfer . . . . . . . . . . . . . 4-3

4.3.2 Combustion Efficiency and CO Emissions ............ 4-5

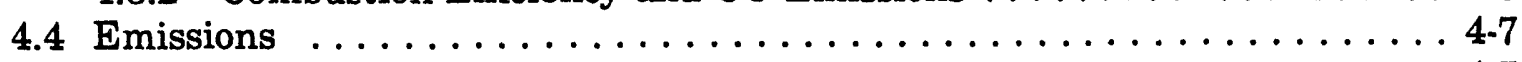

4.4.1 Sorbent Performance . . . . . . . . . . . . . . . . . . 4 4-7

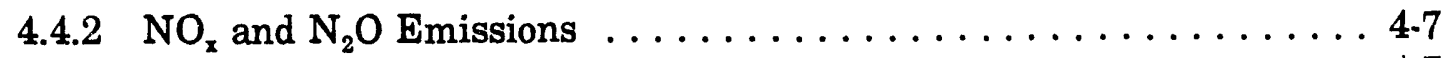

4.5 Summary $\ldots \ldots \ldots \ldots \ldots \ldots \ldots \ldots \ldots \ldots \ldots \ldots \ldots \ldots \ldots$

5.0 SUMMARY AND CONCLUSIONS $\ldots \ldots \ldots \ldots \ldots \ldots \ldots \ldots \ldots \ldots \ldots \ldots$

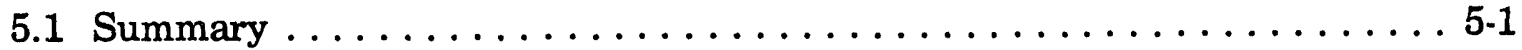

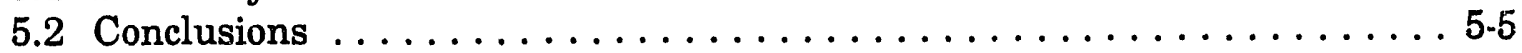

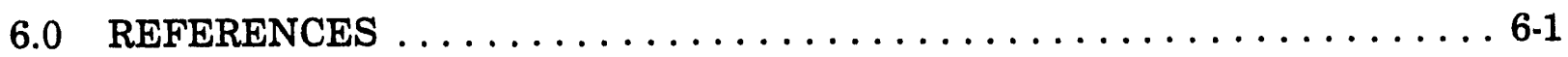




\section{LIST OF APPENDICES}

A SALT CREEK BITUMINOUS COAL TEST RESULTS

B CENTER LIGNITE TEST RESULTS

C BLACKSVILLE BITUMTNOUS COAL TEST RESULTS

D BLACK THUNDER SUBBITUMINOUS COAL TEST RESULTS

E ASIAN LIGNITE TEST RESULTS

F DESIGN, CONSTRUCTION, AND SYSTEM MODIFICATIONS

G CALCULATIONS 


\section{LIST OF FIGURES}

Figure

Page

ES-1 Schematic of EERC 1-MWth CFBC pilot plant

ES-2 Size distribution of baghouse ash from the Nucla Power Station and the Pyropower and EERC pilot plants $\ldots \ldots \ldots \ldots \ldots \ldots \ldots \ldots$ ES-5*

ES-3 $\mathrm{SO}_{2}$ retention as a function of calcium-to-sulfur ratio for the Nucla Power Station and the Pyropower and EERC pilot plants ...........

ES-4 $\mathrm{NO}_{\mathrm{x}}$ emissions as a function of temperature for the Nucla Power Station and the Pyropower and EERC pilot plants ...............

ES-5 $\quad \mathrm{N}_{2} \mathrm{O}$ emissions as a function of temperature and excess air for the Nucla Power Station and the EERC pilot plant. .............. ES-6*

ES.6 Combustion efficiency as a function of temperature for the Nucla Power Station and the Pyropower and EERC pilot plant ............

ES-7 Combustion efficiency at $25 \%$ excess air and 16 - $\mathrm{ft} / \mathrm{sec}$ velocity as a

function of temperature $\ldots \ldots \ldots \ldots \ldots \ldots \ldots \ldots \ldots$

ES-8 Heat split between combustor and flue gas as a function of coal type ...

ES-9 Boiler efficiency losses with no limestone addition at $1550^{\circ} \mathrm{F}$ ( $1607^{\circ} \mathrm{F}$ for Salt Creek), $26 \%$ excess air, 16 - $\mathrm{ft} / \mathrm{sec}$ velocity as a function of coal type $\ldots \ldots \ldots \ldots \ldots \ldots \ldots \ldots \ldots \ldots$

ES-10 Added alkali-to-sulfur ratio required for increasing sulfur capture at $1550^{\circ} \mathrm{F}$ as a function of coal type $\ldots \ldots \ldots \ldots \ldots \ldots \ldots$

ES-11 Added limestone required for increasing sulfur capture at $1550^{\circ} \mathrm{F}$ as a function of coal type $\ldots \ldots \ldots \ldots \ldots \ldots \ldots \ldots \ldots \ldots$

ES-12 CFBC performance as a function of limestone size and type . . . . . . ES-13*

ES-13 NO $\mathrm{NO}_{\mathrm{x}}$ emissions at 20\%-25\% excess air, 16-ft/sec velocity, and 1.5-2.5 alkali-to-sulfur ratio as a function of combustor temperature ........

ES-14 $\mathrm{NO}_{\mathrm{x}}$ and $\mathrm{N}_{2} \mathrm{O}$ emissions with no limestone addition at $1550^{\circ} \mathrm{F}, 26 \%$ excess air, and 16 -ft/sec velocity as a function of coal type .........

ES-15 Solid waste generated at increasing levels of sulfur retention as a function of coal type $\ldots \ldots \ldots \ldots \ldots \ldots \ldots \ldots \ldots \ldots \ldots \ldots \ldots$ ES-15*

* Executive Summary 


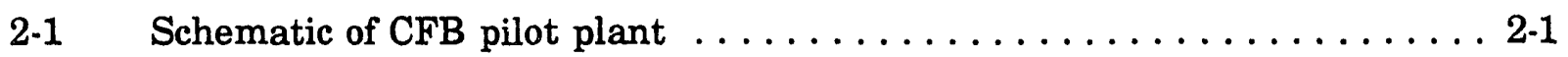

2-2 Schematic of solids preparation system $\ldots \ldots \ldots \ldots \ldots \ldots \ldots \ldots$

3-1 Comparison of average coal size distributions $\ldots \ldots \ldots \ldots \ldots \ldots \ldots$

3-2 Average limestone size distributions $\ldots \ldots \ldots \ldots \ldots \ldots \ldots \ldots \ldots$

3-3 Size distributions of bed material sampled from combustor $\ldots \ldots \ldots \ldots .5$

3-4 Size distributions of bed material sampled from downcomer $\ldots \ldots \ldots \ldots$ 3-5

3.5 Recirculation rate as a function of load $\ldots \ldots \ldots \ldots \ldots \ldots \ldots \ldots$

3-6 Solid waste generation as a function of coal property $\ldots \ldots \ldots \ldots \ldots \ldots$

3-7 Added alkali-to-sulfur ratio required for increasing sulfur capture at $\sim 1550^{\circ} \mathrm{F}$ as a function of coal type . . . . . . . . . . . . . . .

3-8 Added limestone required for increasing sulfur capture at $\sim 1550^{\circ} \mathrm{F}$ as a

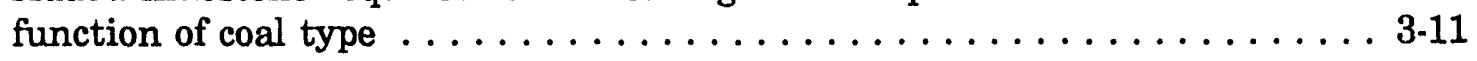

3-9 Sulfur retention as a function of average combustor temperature, showing the optimum temperature for maximum sulfur capture for each coal . . . 3.11

3-10 $\mathrm{SO}_{2}$ emissions as a function of average combustor temperature, showing the optimum temperature for maximum sulfur capture for each coal . . . . 3-12

3-11 CFBC performance as a function of limestone size and type $\ldots \ldots \ldots \ldots 3-13$

3-12 Calcium utilization as a function of added calcium-to-sulfur ratio . . . . 3-13

3-13 NO emissions in ppm at 20\%-25\% excess air, 16 -ft/sec velocity, and 1.5-2.5 alkali-to-sulfur ratio as a function of combustor temperature . . . . 3-15

3-14 $\mathrm{NO}_{\mathrm{x}}$ emissions in $\mathrm{lb} / \mathrm{MM}$ Btu at 20\%-25\% excess air, 16-ft/sec velocity, and 1.5-2.5 alkali-to-sulfur ratio as a function of combustor temperature . . . 3-15

3-15 $\mathrm{NO}_{\mathrm{x}}$ emissions at $\sim 1550^{\circ} \mathrm{F}\left(1623^{\circ}\right.$ for Salt Creek) as a function of excess air ........................... $3 . \ldots$

3-16 $\mathrm{NO}_{\mathrm{n}}$ emissions for Blacksville coal at $\sim 1550^{\circ} \mathrm{F}$ and $20 \%$ excess air as a function of primary-to-secondary air split $\ldots \ldots \ldots \ldots \ldots \ldots \ldots \ldots \ldots$ 3-17

3-17 $\mathrm{NO}_{\mathrm{x}}$ emissions at $-1550^{\circ} \mathrm{F}\left(1610^{\circ}\right.$ for Salt Creek), $16-\mathrm{ft} / \mathrm{sec}$ velocity, and $25 \%$ excess air as a function of limestone feed rate $\ldots \ldots \ldots \ldots \ldots \ldots$ 3-18 
3-18 Nitrogen emissions (ppm) at $\sim 1550^{\circ} \mathrm{F}, 16-\mathrm{ft} / \mathrm{sec}$ velocity, and $21 \%-34 \%$ excess air as a function of coal type

3-19 Nitrogen emissions ( $\mathrm{b} / \mathrm{MM} \mathrm{Btu})$ at $\sim 1550^{\circ} \mathrm{F}, 16-\mathrm{ft} / \mathrm{sec}$ velocity, and $21 \%-34 \%$ excess air as a function of coal type

3-20 $\quad \mathrm{N}_{2} \mathrm{O}$ emissions as a function of average combustor temperature, at $16-\mathrm{ft} / \mathrm{sec}$ velocity and $21 \%-34 \%$ excess air . . . . . . . . . . . . . . . . 3-19

3-21 $\mathrm{N}_{2} \mathrm{O}$ emissions as a function of sorbent add rate at $\sim 1550^{\circ} \mathrm{F}, 16-\mathrm{ft} / \mathrm{sec}$

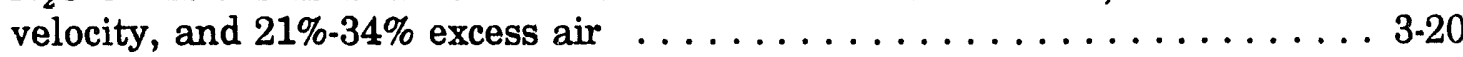

3-22 $\mathrm{N}_{2} \mathrm{O}$ and $\mathrm{NO}_{\mathrm{x}}$ emissions for Blacksville coal at $\sim 1550^{\circ} \mathrm{F}, 16$ - $\mathrm{ft} / \mathrm{sec}$ velocity, and $29 \%$ excess air as a function of sorbent add rate . . . . . . . . . 3-20

3.23 $\mathrm{N}_{2} \mathrm{O}$ emissions at $\sim 1550^{\circ} \mathrm{F}\left(1623^{\circ} \mathrm{F}\right.$ for Salt Creek) as a function of excess air as a function of sorbent add rate . . . . . . . . . . . . . . 3-21

3.24 $\mathrm{N}_{2} \mathrm{O}$ emissions for Blacksville coal at $\sim 1550^{\circ} \mathrm{F}$ and $20 \%$ excess air as a function of primary-to-secondary combustion air split . . . . . . . . . 3-21

3-25 Percent conversion of fuel-bound nitrogen to $\mathrm{NO}_{x}$ and $\mathrm{N}_{2} \mathrm{O}$ at $\sim 1550^{\circ} \mathrm{F}$, $16-\mathrm{ft} / \mathrm{sec}$ velocity, and $21 \%-34 \%$ excess air as a function of coal type . . . . 3-22

3-26 Total nitrogen oxide emissions at 16 -ft/sec velocity and $17 \%-31 \%$ excess air as a function of average combustor temperature $\ldots \ldots \ldots \ldots \ldots \ldots \ldots .22$

3-27 CO emissions at 16 -ft/sec velocity and $17 \%-31 \%$ excess air as a function of average combustor temperature $\ldots \ldots \ldots \ldots \ldots \ldots \ldots \ldots \ldots \ldots \ldots$

3-28 CO emissions at $\sim 1550^{\circ} \mathrm{F}\left(1623^{\circ} \mathrm{F}\right.$ for Salt Creek) as a function of

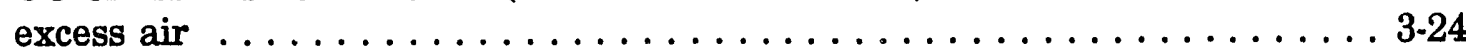

3-29 Combustion efficiency at $16-\mathrm{ft} / \mathrm{sec}$ velocity and $17 \%-31 \%$ excess air as a function of average combustor temperature $\ldots \ldots \ldots \ldots \ldots \ldots \ldots . \ldots \ldots$

3-30 Combustion efficiency at $\sim 1550^{\circ} \mathrm{F}\left(1623^{\circ} \mathrm{F}\right.$ for Salt Creek) as a function of excess air . . . . . . . . . . . . . . . . . . . . . . .

3-31 Energy generation at $\sim 1550^{\circ} \mathrm{F}, 16-\mathrm{ft} /$ sec velocity, and $21 \%-34 \%$ excess air as a function of coal type $\ldots \ldots \ldots \ldots \ldots \ldots \ldots \ldots \ldots \ldots \ldots \ldots \ldots \ldots$

3-32 Boiler efficiency losses with and without limestone at $\sim 1550^{\circ} \mathrm{F}$ (1610 ${ }^{\circ} \mathrm{F}$ for Salt Creek), 16 -ft/sec velocity, and $20 \%-34 \%$ excess air as a

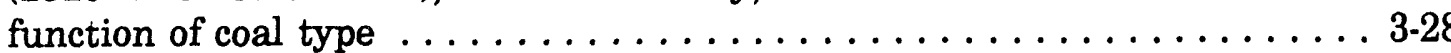

3-33 Boiler efficiency losses as a function of load, load reduction strategy, and coal type 
Figure $\quad \underline{\text { Page }}$

4-1 Size distributions of coal and limestone $\ldots \ldots \ldots \ldots \ldots \ldots \ldots \ldots .2$

4-2 Size distributions of fly ash collected $\ldots \ldots \ldots \ldots \ldots \ldots \ldots \ldots \ldots$

4-3 Combustor temperature distributions of the Fyropower and EERC pilot plants at full-load operation $\ldots \ldots \ldots \ldots \ldots \ldots \ldots \ldots \ldots \ldots .4$

4-4 Comparison of combustor temperatures of the Nucla Power Station and the Pyropower and EERC pilot plants at partial-load operation . . . . . . . 4-4

4-5 Comparison of combustion efficiency from the Nucla Power Station and the Pyropower and EERC pilot plant . . . . . . . . . . . . 4 -6

4-6 Comparison of CO emissions from the Nucla Power Station and the Pyropower and EERC pilot plants . . . . . . . . . . . . 6

4-7 Sulfur retention as a function of the calcium-to-sulfur ratio $\ldots \ldots \ldots \ldots$ 4-8

4-8 Effect of the calcium-to-sulfur ratio on calcium utilization $\ldots \ldots \ldots \ldots \ldots$

4.9 Comparison of $\mathrm{NO}_{\mathrm{x}}$ emissions $\ldots \ldots \ldots \ldots \ldots \ldots \ldots \ldots \ldots \ldots$

4-10 Comparison of $\mathrm{N}_{2} \mathrm{O}$ emissions $\ldots \ldots \ldots \ldots \ldots \ldots \ldots \ldots \ldots \ldots \ldots$ 


\section{LIST OF TABLES}

Table

ES-1 Effects of Coal Properties on CFBC System Design and Performance ... ES-2*

ES-2 Analyses of Coals Used in the EERC Comparative Study . . . . . . . ES-4*

ES-3 Boiler Efficiency Losses for Test Coals at 90\% Sulfur Retention and $1550^{\circ} \mathrm{F}$ Combustor Temperature . . . . . . . . . . . . ES-10*

1-1 Coal and Limestone Analyses $\ldots \ldots \ldots \ldots \ldots \ldots \ldots \ldots \ldots \ldots \ldots$

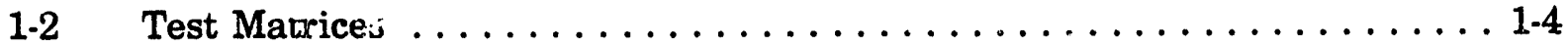

2-1 Flue Gas Analytical Instrumentation $\ldots \ldots \ldots \ldots \ldots \ldots \ldots \ldots \ldots$

3-1 Identification of EERC Test Parameters and Operational Results . . . . . 3-2

3-2 Solids Recirculation Configurations Utilized During Parametric CFB Pilot Plant Testing . . . . . . . . . . . . . . . . . . . . . .

3-3 Comparison of Sulfur Emissions and Sorbent Performance . . . . . . . . 3-10

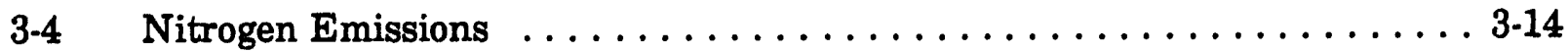

3-5 Secondary Cyclone and Baghouse Particulate Loading/Removal Efficiencies ............................ 3-24

3-6 Comparison of Heat Fluxes $\ldots \ldots \ldots \ldots \ldots \ldots \ldots \ldots \ldots \ldots \ldots \ldots$

3-7 Baseline Boiler Efficiency Data $\ldots \ldots \ldots \ldots \ldots \ldots \ldots \ldots \ldots \ldots$

3.8 Impact of Load Reduction Using Constant Heat-Transfer Surface Between Tests . . . . . . . . . . . . . . . . . . . . . 3-31

3-9 Impact of Load Reduction Using Constant Temperature Between Tests . . 3-32

4-1 Comparison of Coals Tested in the Nucla Power Station and the Pyropower and EERC Pilot Plants . ..................... 4-1

4-2 Importance of Physical Configuration on Scalability of CFB Data . . . . 4-10

4-3 Scalability of Operational Parameters from Pilot-Scale CFBC . . . . . . 4-11

4-4 Scalability of Measured Performance Parameters from Pilot-Scale CFBC . . 4-12

* Executive Summary 


\section{EXECUTIVE SUMMARY}

\section{INTRODUCTION}

Project CFB was initiated in May 1988 at the University of North Dakota Energy and Environmental Research Center (EERC) under funding provided from the U.S. Departinent of Energy, the Empire State Electric Energy Research Corporation, Northern States Power Company, the Electric Power Research Institute (EPRI), Otter Tail Power Company, ARCO Coal Company, TU Electric, Consolidated Edison of New York, Premier Refractories and Chemicals, and the North Dakota Lignite Research Council. The overall goal of the project was to provide a technical basis for assessing the economic and environmental feasibility of circulating fluidized-bed combustion (CFBC) technology, focusing on the effects of system configuration and coal properties on performance. Specific goals of the project were to 1) construct a CFBC facility representative of the major boiler vendors' designs with the capability of producing scalable data, 2) develop a database for use in making future evaluations of CFBC technology, and 3) provide a facility free of vendor bias for use in the energy industry. Five coals have been testburned in the unit: a North Dakota lignite, an Asian lignite, a Wyoming subbituminous, a Colorado bituminous, and a Pennsylvania bituminous. As expected, varying coal qualities did impact the overall performance of the CFBC.

The impact of coal quality on overall operability was assessed by comparing recirculation rates, the primary cyclone collector performance, bottom ash vs. fly ash split, and the size distribution of the circulating material resulting from burning the five different coals. Emissions are significantly impacted by coal quality. The following were evaluated: $\mathrm{SO}_{2}$ emissions and limestone utilization; $\mathrm{NO}_{\mathrm{x}}, \mathrm{N}_{2} \mathrm{O}$, and $\mathrm{CO}$ emissions; fly ash collectability; and solid waste generation. Thermal performance changes resulting from varying coal quality were assessed by comparing heat-transfer coefficients and heat flux, combustion efficiency, and overall boiler efficiency. A summary of the effects of coal properties on CFBC performance is presented in Table ES-1.

\section{BASIS OF CFBC COMPARISON-EQUIPMENT USED AND TEST CONDITIONS}

A schematic of the pilot-scale CFBC used in these studies is shown in Figure ES-1. The combustor has an internal diameter of 20 inches and is 42 feet tall. The combustor is refractory-lined with twelve heat exchange panels located throughout seven of the combustor sections to control and adjust heat removal to match the heat duty of any fuel and/or operating conditions. The typical full-load thermal input of the unit is approximately $1 \mathrm{MWth}$. A 25 -inch refractory-lined cyclone is used to collect and recirculate the solids through a combination loop seal and external heat exchanger. Solids flow through the external heat exchanger at all times, but water flow to the cooling coils can be shut off to effectively take the heat removal function of the external heat exchanger off-line.

Fuel and sorbent are metered separately through rotary valves, mixed, and fed by gravity into the combustor. Combustion air is preheated to approximately $600^{\circ} \mathrm{F}$ and split between primary and secondary air. Secondary air can be fed into the combustor at $6^{\prime}$ or 11 ' above the dist ibutor plate. Flue gas leaving the combustor passes across a convective fouling section that simulates the leading edge of a convective pass. Solids 
TABLE ES-1

Effects of Coal Properties on CFBC System Design and Performance

\begin{tabular}{|c|c|c|c|}
\hline Coal Property & $\begin{array}{l}\text { Fffect on Systam } \\
\text { Requirements and Deeign }\end{array}$ & $\begin{array}{l}\text { Effect on Syatem } \\
\text { Thermal Performance }\end{array}$ & $\begin{array}{l}\text { Effect on Syotem } \\
\text { Environmental Performance }\end{array}$ \\
\hline Heating Value & $\begin{array}{l}\text { Determines siro of feed } \\
\text { subøyetem, combustor, } \\
\text { particulate collection equipment, } \\
\text { and convective pass. }\end{array}$ & $\begin{array}{l}\text { Efficiency impacted by } \\
\text { moisture and ash content } \\
\text { ( }\end{array}$ & $\begin{array}{l}\text { Size of particulate collection } \\
\text { devices (baghouse or ESP). }\end{array}$ \\
\hline Moisture Content & $\begin{array}{l}\text { Can impact feed eystem design } \\
\text { and capacity and size of } \\
\text { convective paes. }\end{array}$ & $\begin{array}{l}\text { Higher moisture lowers } \\
\text { thermal efficiency. }\end{array}$ & $\begin{array}{l}\text { Very high moisture can } \\
\text { increase CO emissions due to } \\
\text { afterburning. }\end{array}$ \\
\hline Ash Content & $\begin{array}{l}\text { Determines siro and type of } \\
\text { purticulate control subeystem } \\
\text { and size of ash-bandling } \\
\text { subøystems. }\end{array}$ & $\begin{array}{l}\text { Higher ash lowers thermal } \\
\text { efficiency via heat losses } \\
\text { from hot solide removal. }\end{array}$ & $\begin{array}{l}\text { Size of particulate collection } \\
\text { devices. }\end{array}$ \\
\hline $\begin{array}{l}\text { Volatiles/Fired } \\
\text { Carbon Content }\end{array}$ & Impacts fuel feod method. & $\begin{array}{l}\text { Lower combuntion efficiency } \\
\text { for fuels with low V/FC } \\
\text { content. }\end{array}$ & None, with proper dosign. \\
\hline Sulfur Content" & $\begin{array}{l}\text { Determines required capacity of } \\
\text { sorbent subsystem and ash- } \\
\text { handling subsystem. }\end{array}$ & $\begin{array}{l}\text { Higher sulfur can lower } \\
\text { thermal efficiency via heat } \\
\text { losees from added solide for } \\
\mathrm{SO}_{\mathrm{x}} \text { control (seo ash content } \\
\text { above). }\end{array}$ & $\begin{array}{l}\text { None, or proportional, }{ }^{b} \text { if site } \\
\text { and oystem size regulated. } \\
\text { Determines } \mathrm{SO}_{2} \text { emissions (in } \\
\text { conjunction with alkaline ash) } \\
\text { if uncontrolled. }\end{array}$ \\
\hline Nitrogen Content & $\begin{array}{l}\text { None, with common designs and } \\
\text { typical regulations. }\end{array}$ & $\begin{array}{l}\text { Nune, : ith common } \\
\text { designo." }\end{array}$ & Impacte $\mathrm{NO}_{\mathrm{z}}$ emiseions. \\
\hline Chlorine Content & $\begin{array}{l}\text { Can impact selection of } \\
\text { materials for cool end } \\
\text { components. May cause higher } \\
\text { corrosion rates for in-bed tubes. }\end{array}$ & $\begin{array}{l}\text { Typically none. Very high } \\
\text { chlorides can lower thermal } \\
\text { efficiency by requiring } \\
\text { operation at higher exhaust } \\
\text { temperatures. }\end{array}$ & Impacts $\mathrm{HCl}$ emiseions. \\
\hline $\begin{array}{l}\text { Calcium Content } \\
\text { of the Ash }\end{array}$ & $\begin{array}{l}\text { Can reduce size of sorbent } \\
\text { subsystem. }\end{array}$ & Typically none. & $\begin{array}{l}\text { Higher ash calcium levels } \\
\text { lower uncontrolled } \mathrm{SO}_{\mathrm{z}} \\
\text { emisaions. }\end{array}$ \\
\hline $\begin{array}{l}\text { Sodium and } \\
\text { Potasgium } \\
\text { Content of the } \\
\text { Ash }\end{array}$ & $\begin{array}{l}\text { High sodium can dictate fouling } \\
\text { prevention measures and } \\
\text { allowance for agglomeration } \\
\text { (e.g., soot blowing, frequent bed } \\
\text { draining, aeration of } \\
\text { downcomer). }\end{array}$ & $\begin{array}{l}\text { Higher sodium can lower } \\
\text { thermal efficiency due to } \\
\text { tube fouling and heat losees } \\
\text { from more frequent hot } \\
\text { solids removal. }\end{array}$ & $\begin{array}{l}\text { Higher sodium lowers } \\
\text { uncontrolled SO emissions. } \\
\text { Sodium tonds to reduce fly ash } \\
\text { resiativity for ESP performance } \\
\text { improvement, may also } \\
\text { enhance fabric filter } \\
\text { performance. }\end{array}$ \\
\hline Ash Fusibility & $\begin{array}{l}\text { Low fusion temperatures can } \\
\text { impact design, due to allowance } \\
\text { for fouling and agglomeration } \\
\text { potential. }\end{array}$ & $\begin{array}{l}\text { Lower fusion temperatures } \\
\text { impact thermal efficiency in } \\
\text { the same way as higher } \\
\text { sodium. }\end{array}$ & Typically none. \\
\hline
\end{tabular}

- The forms of aulfur can have an impact, with high pyrite content requiring longer gas residence time in the bed. The result may be increased operating preseure and blower capacity.

- Sulfur content can determine $\mathrm{SO}_{\mathrm{x}}$ emisaions, depending on which regulation applie日 (e.g., New Source Performance Standards (NSPS) regulations atipulate fractional removals).

- For low-NO, regulations, a staged combustion or postcombustion $\mathrm{NH}_{\mathrm{g}}$-based suppression design may be required. Staged comburtion designs can bave higher $\mathrm{CO}$ emissions. Postcombuation NO suppression subsystems can lower the thermal efficiency alightly and do emit $\mathrm{NH}_{\mathrm{s}}$. 


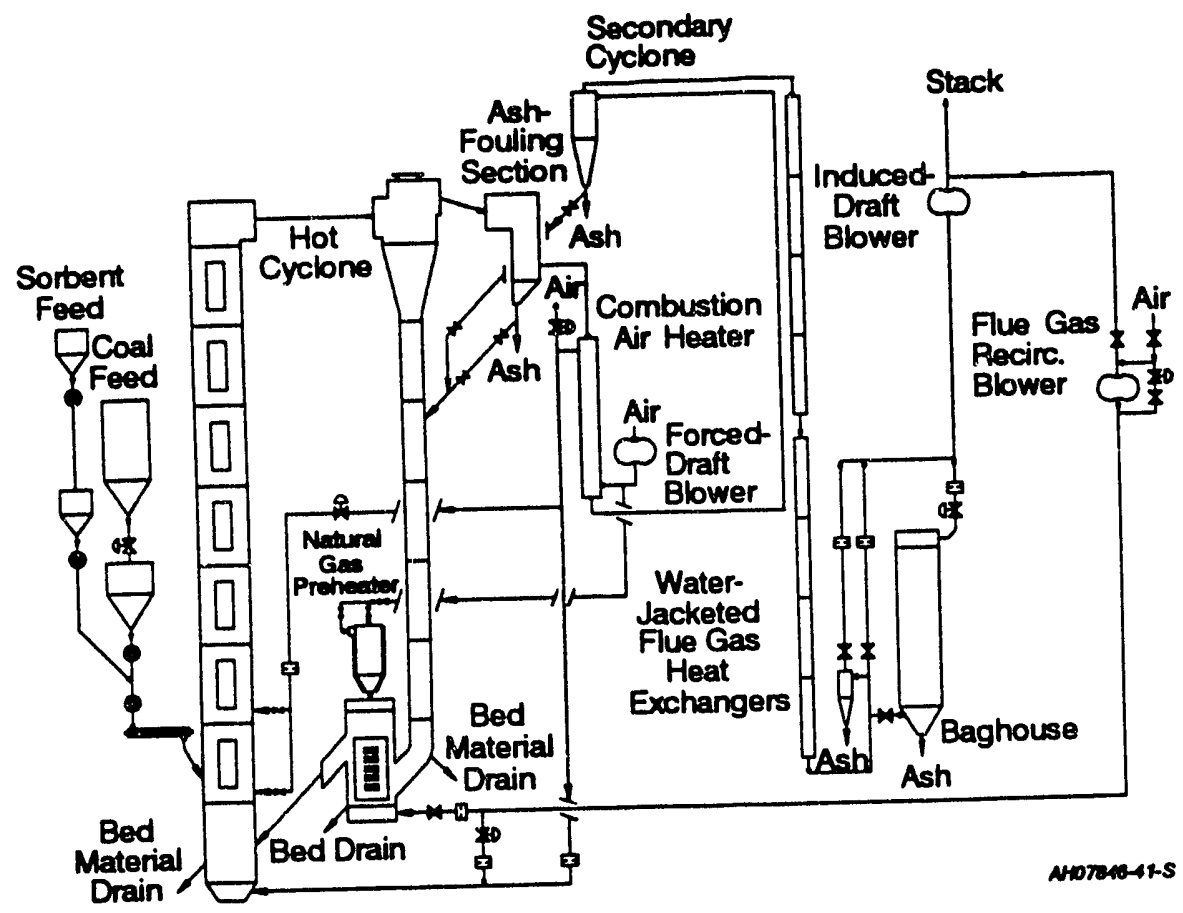

Figure ES-1. Schematic of EERC 1-MWth CFBC pilot plant.

collected in an 18-inch stainless steel secondary cyclone can either be returned to the combustor or collected to a barrel. The flue gas is then cooled by a series of water-cooled heat exchangers before entering a pulse-jet baghouse.

The data that follow summarize 54 steady-state tests performed over the following range of conditions:

Combustor Temperature, ${ }^{\circ} \mathrm{F}$

Excess Air, \%

Velocity, $\mathrm{ft} / \mathrm{sec}$

$\mathrm{Ca} / \mathrm{S}$, molar ratio

Primary Air, \% total air

Load, \%

$$
\begin{gathered}
1185-1698 \\
9 \cdot-125 \\
9-19 \\
0-5.6 \\
45-92 \\
50 \cdot 100(t)
\end{gathered}
$$

Properties of the coals used are presented in Table ES-2.

\section{UNIT VALIDATION}

The 110-MWe CFBC at the Colorado Ute Nucla Station has been successfully operating for the last several years. As it is one of the demonstration plants supported by EPRI, EPRI was able to assemble a large database characterizing the performance of this unit. In addition, EPRI and Pyropower participated in pilot plant testing in a pilot-scale CFBC in San Diego, California. The EERC obtained samples of the same coal and limestone used by those organizations and has operated its CFBC under similar operating conditions. This has provided the opportunity to compare the performance of the EERC CFBC with both a utility-scale plant and a vendor-operated pilot plant. 


\section{TABLE ES-2}

Analyses of Coals Used in the EERC Comparative Study

\begin{tabular}{|c|c|c|c|c|c|}
\hline & Salt Creok & Center Lignite & Asian Lignite & Blackeville & Black Thunder \\
\hline \multicolumn{6}{|c|}{ Proximate Analyeis, ae-received, wt\% } \\
\hline Moisture & 7.7 & 37.1 & 17.0 & 2.9 & 27.6 \\
\hline Volatile Matter & 31.0 & 29.0 & 37.4 & 36.1 & 33.2 \\
\hline Fired Carbon & 42.7 & 28.9 & 7.6 & 63.8 & 34.6 \\
\hline A\&h & 18.6 & 6.1 & 38.0 & 8.2 & 4.6 \\
\hline \multicolumn{6}{|c|}{ Ultimate Analysis, as-received, wt\% } \\
\hline Carbon & 68.8 & 40.9 & 25.0 & 74.4 & 49.9 \\
\hline Hydrogen & 5.0 & 7.0 & 4.3 & 6.3 & 6.6 \\
\hline Nitrogen & 1.1 & 0.6 & 0.7 & 1.3 & 0.6 \\
\hline Sulfur & 0.4 & 0.7 & 6.1 & 2.4 & 0.3 \\
\hline Oxygen & 16.0 & 46.8 & 26.1 & 8.4 & 38.0 \\
\hline Ash & 18.6 & 6.1 & 38.0 & 8.2 & 4.6 \\
\hline \multicolumn{6}{|c|}{ Ash Composition, as oxides, wt\% } \\
\hline Calcium, $\mathrm{CaO}$ & 1.6 & 22.6 & 19.9 & 6.6 & 24.4 \\
\hline Magne日ium, MgO & 1.6 & 10.2 & 3.3 & 1.2 & 7.9 \\
\hline Sodium, $\mathrm{Na}_{2} \mathrm{O}$ & 0.2 & 3.7 & 0.3 & 0.7 & 0.5 \\
\hline Silica, $\mathrm{SiO}_{2}$ & 69.9 & 14.5 & 30.6 & 43.6 & 28.5 \\
\hline Aluminum, $\mathrm{Al}_{2} \mathrm{O}_{8}$ & 30.9 & 9.7 & 12.4 & 22.7 & 16.4 \\
\hline Ferric, $\mathrm{Fe}_{2} \mathrm{O}_{3}$ & 3.0 & 16.1 & 13.7 & 16.6 & 6.4 \\
\hline Titanium, $\mathrm{TiO}_{2}$ & 1.1 & 0.3 & 0.2 & 0.7 & 1.4 \\
\hline Phosphorous, $\mathrm{P}_{2} \mathrm{O}_{5}$ & 0.4 & 0.7 & 0.5 & 0.4 & 1.3 \\
\hline Potassium, $\mathrm{K}_{2} \mathrm{O}$ & 1.0 & 0.4 & 1.1 & 1.7 & 0.9 \\
\hline Sulfur, $\mathrm{SO}_{3}$ & 1.0 & $\ldots+.9$ & 18.1 & 6.8 & 12.4 \\
\hline $\begin{array}{l}\text { High Heating Value, } \\
\text { as-received, Btulb }\end{array}$ & 10,274 & 6,939 & 3,898 & 13,274 & 8,650 \\
\hline
\end{tabular}

To simulate full-scale operation, the size distribution of the recirculating material and the fly ash from the pilot plant must be similar to that of a full-scale system. Figure ES-2 shows that the fly ash generated from the three units is similar. Operation of the system at typical full-scale conditions provides scalable heat flux and emissions data. Average heat flux in the combustor ranged from $18,200 \mathrm{Btu} / \mathrm{hr}-\mathrm{ft}^{2}$ at $55 \%$ load to $26,000 \mathrm{Btu} / \mathrm{hr}^{-\mathrm{ft}^{2}}$ at $88 \%$ load and $32,600 \mathrm{Btu} / \mathrm{hr}-\mathrm{ft}^{2}$ at full load. The measured heat flux from the Nucla Station averaged 22,300 Btu/hr- $\mathrm{ft}^{2}$ at half load and $32,800 \mathrm{Btu} / \mathrm{hr}-\mathrm{ft}^{2}$ at full load. Bed temperature distribution in the combustor for all full load tests was uniform over the entire length of the EERC combustor and was similar to that observed at the San Diego pilot plant.

Emissions of $\mathrm{SO}_{2}, \mathrm{NO}_{\mathrm{x}}$, and $\mathrm{CO}$ among the three units were also similar. Sulfur retention for the three units is shown in Figure ES-3, with $\mathrm{NO}_{\mathrm{x}}$ shown in Figure ES-4. Some $\mathrm{NO}_{\mathrm{x}}$ emissions from the EERC combustor were high and reflect high excess air test corditions. Figure ES-5 compares $\mathrm{N}_{2} \mathrm{O}$ emissions, and shows higher emissions from the EERC CFBC as compared to the Nucla Station. This trend is consistent with observations made by other researchers and is probably due to wall effects and other features associated with the smaller scale. The measured combustion efficiencies, shown in Figure ES-6, were comparable for the three units. 


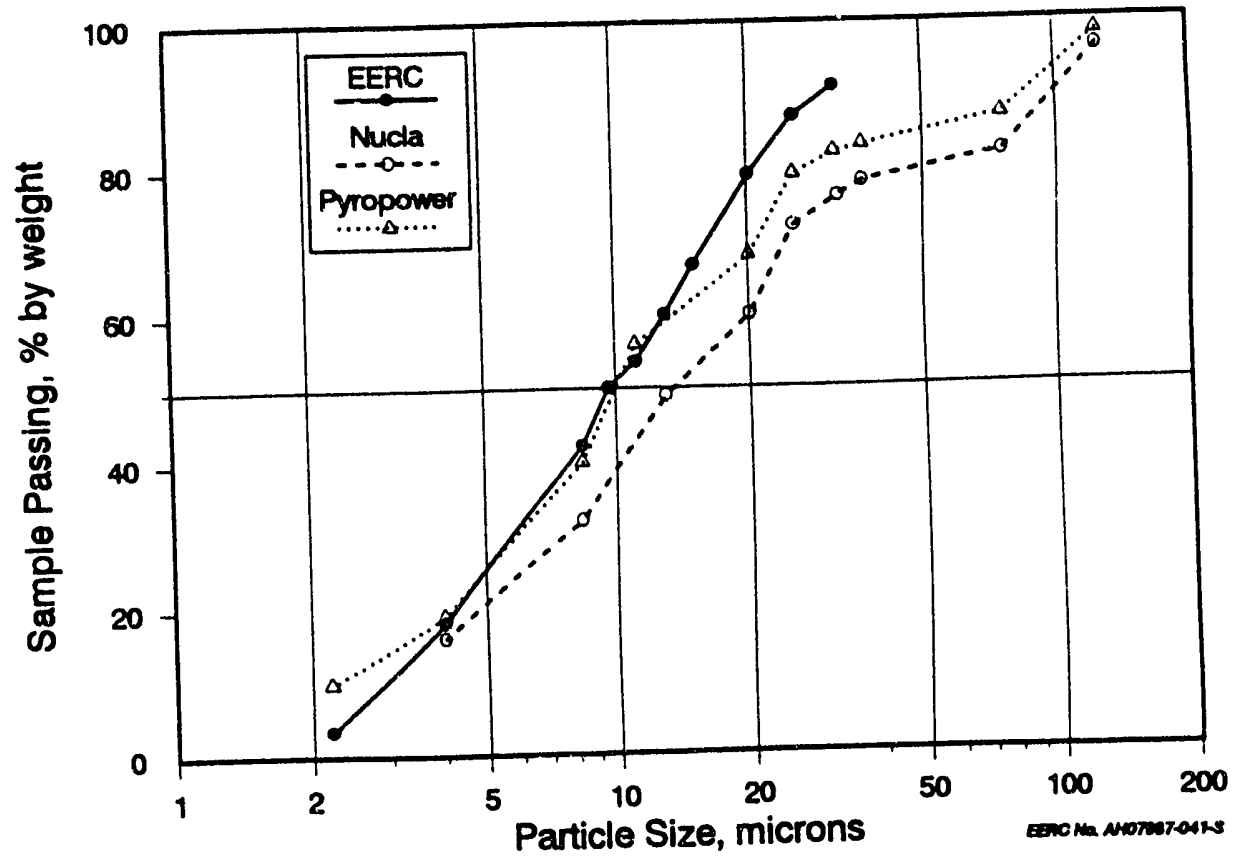

Figure ES-2. Size distribution of baghouse ash from the Nucla Power Station and the Pyropower and EERC pilot plants.

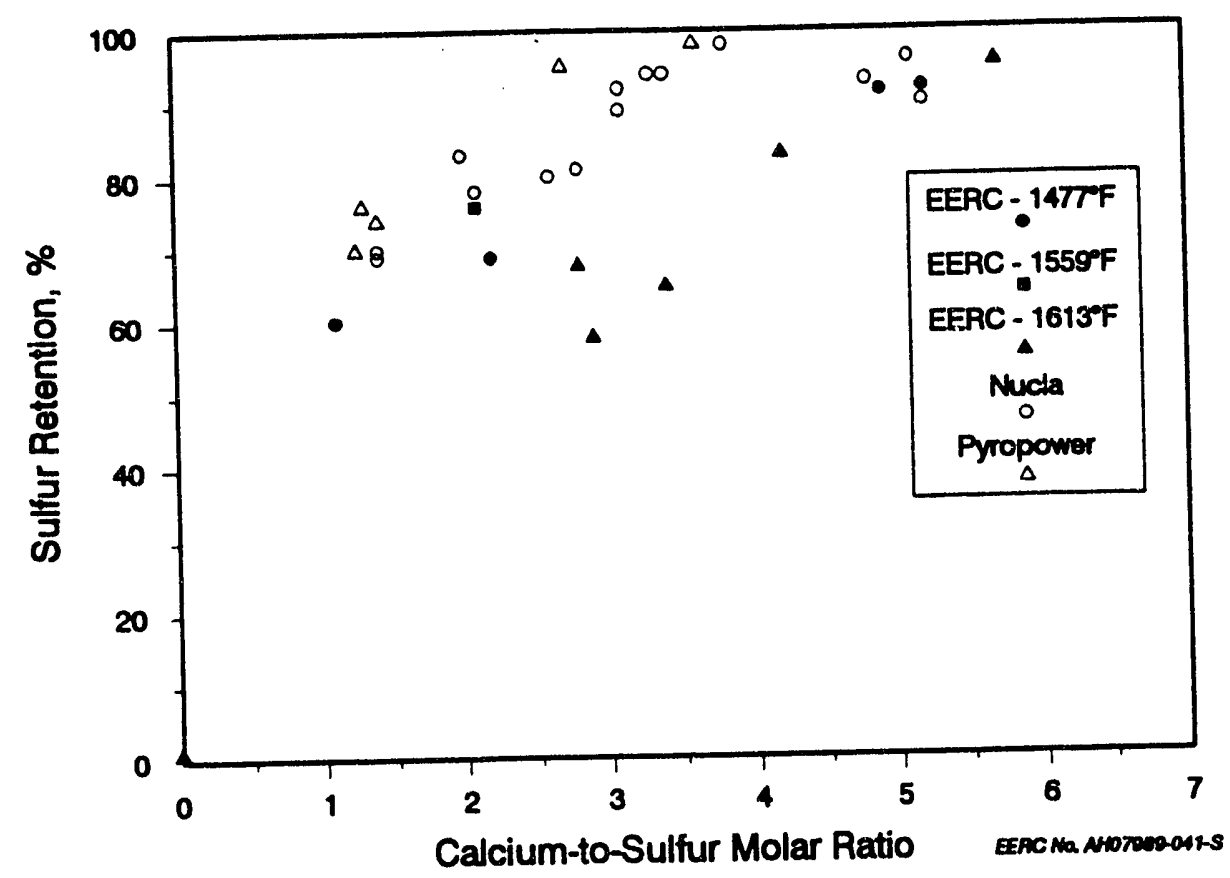

Figure ES-3. $\mathrm{SO}_{2}$ retention as a function of calcium-to-sulfur ratio for the Nucla Power Station and the Pyropower and EERC pilot plants. 


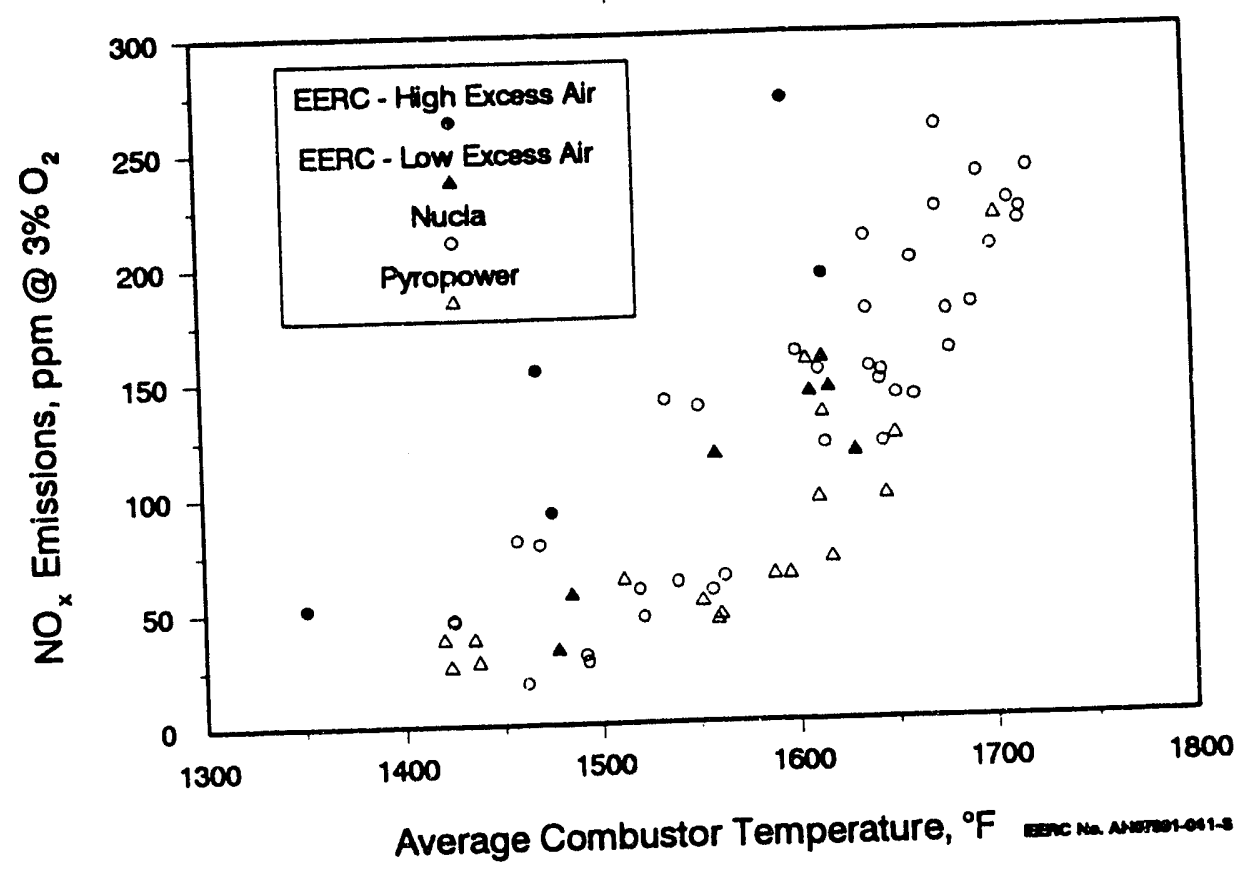

Figure ES-4. $\mathrm{NO}_{\mathrm{x}}$ emissions as a function of temperature for the Nucla Power Station and the Pyropower and EERC pilot plants.

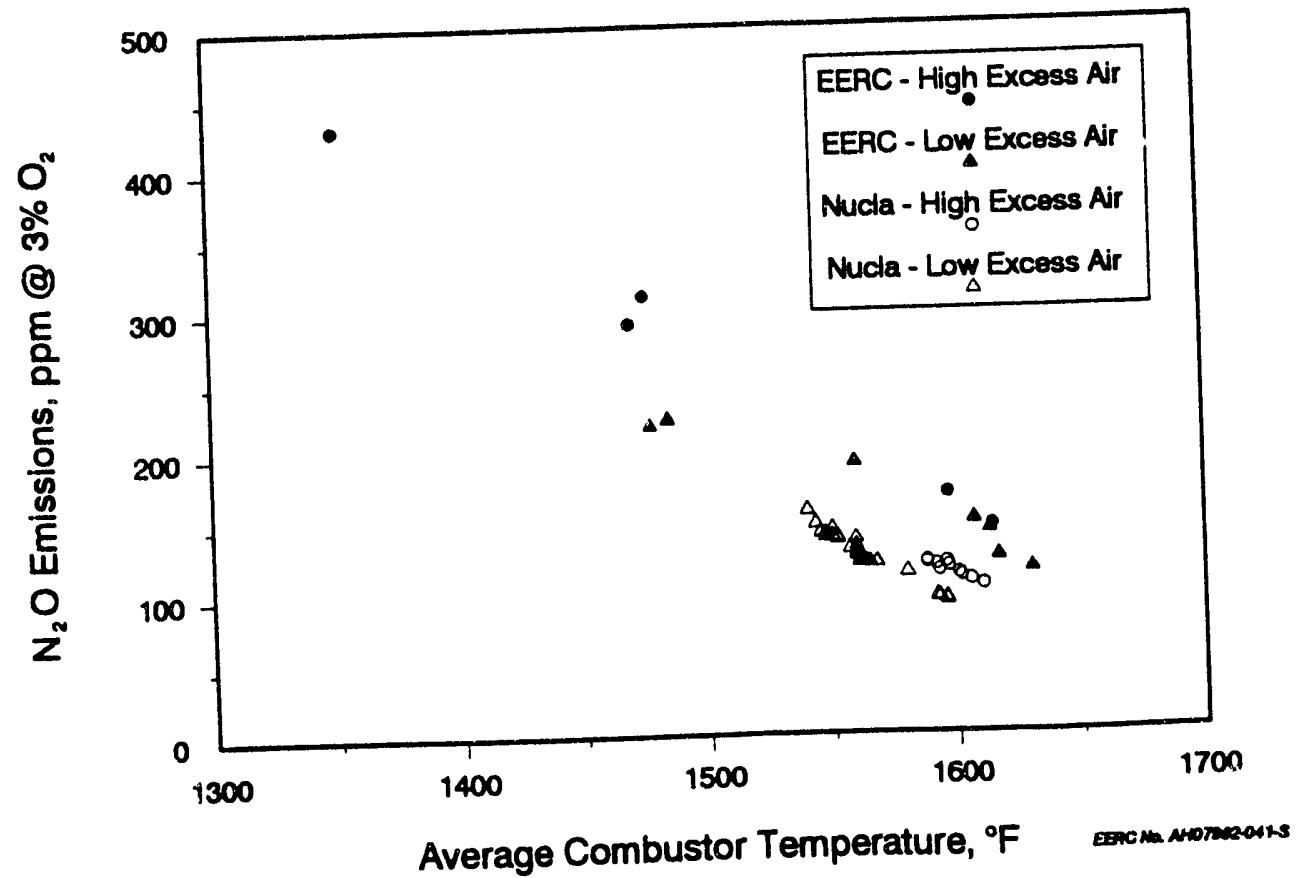

Figure ES-5. $\mathrm{N}_{2} \mathrm{O}$ emissions as a function of temperature and excess air for the Nucla Power Station and the EERC pilot plant. 


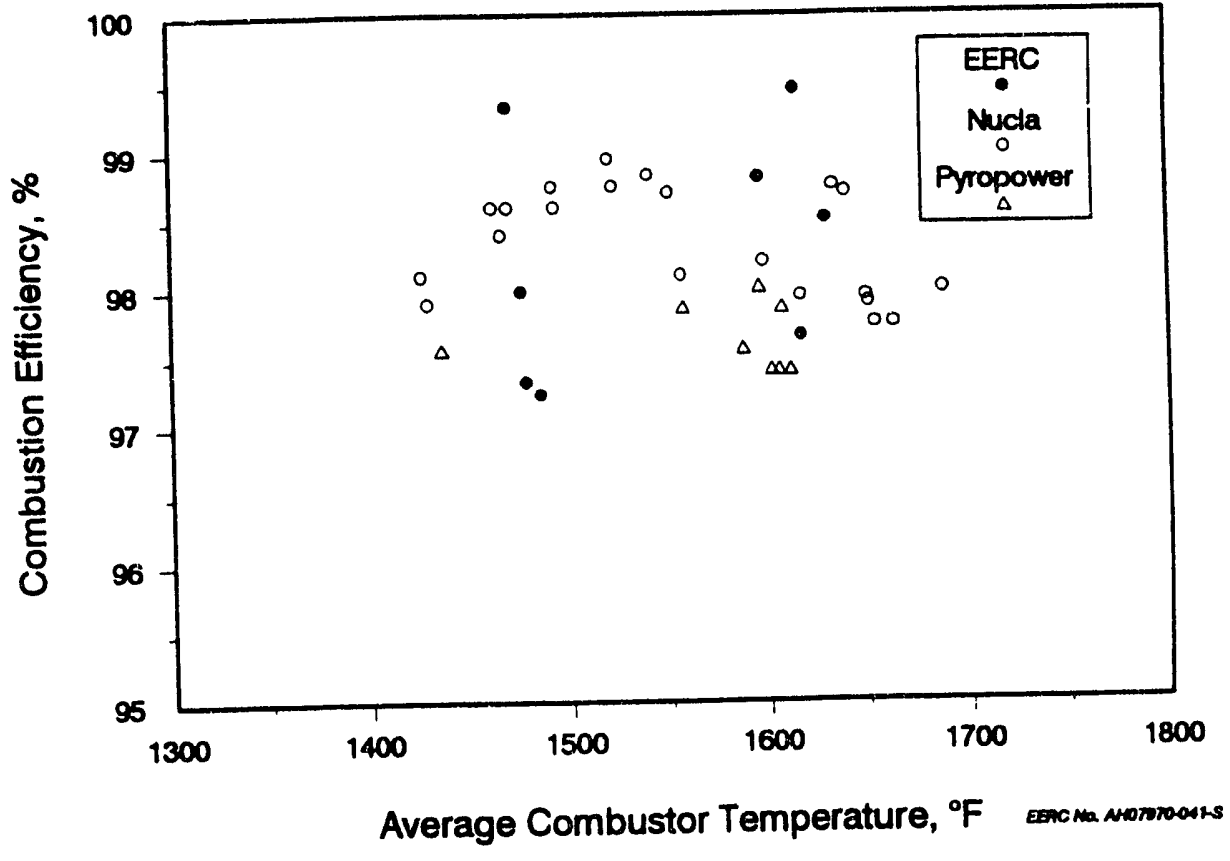

Figure ES-6. Combustion efficiency as a function of temperature for the Nucla Power Station and the Pyropower and EERC pilot plant.

Based on this comparison and supported by the information presented in this report, EERC personnel feel confident that the EERC 1-MWth pilot-scale CFBC meets the original design objectives of Project CFB and has a system that can provide data scalable to full-scale units.

\section{THERMAL PERFORMANCE}

\section{Heat Flux}

Because of the action of the circulating solids, the CFBC typically operates with a high heat flux. The heat flux for full-load conditions ranged from about 25,000 to 35,000 $\mathrm{Btu} / \mathrm{hr}-\mathrm{ft}^{2}$. The heat flux increased with increasing temperature and velocity, but was generally independent of fuel type. Fuel type may indirectly affect heat flux, to a small degree, by its effects on recirculation rates and particle-size distributions.

\section{Combustion Efficiency}

Figure ES-7 presents combustion efficiency for the five test coals as a function of combustor temperature. All tests included on the graph were performed at $20 \%$ excess air, 16-ft/sec velocity, $60 \%$ primary air, and a $\mathrm{Ca} / \mathrm{S}$ add rate to achieve $90 \%$ sulfur retention. The combustion efficiency for the two lignites and the subbituminous coal approached $100 \%$ over the entire range of temperatures tested. The combustion efficiencies for the Salt Creek bituminous coal ranged from $97 \%$ to $99 \%$, while the 


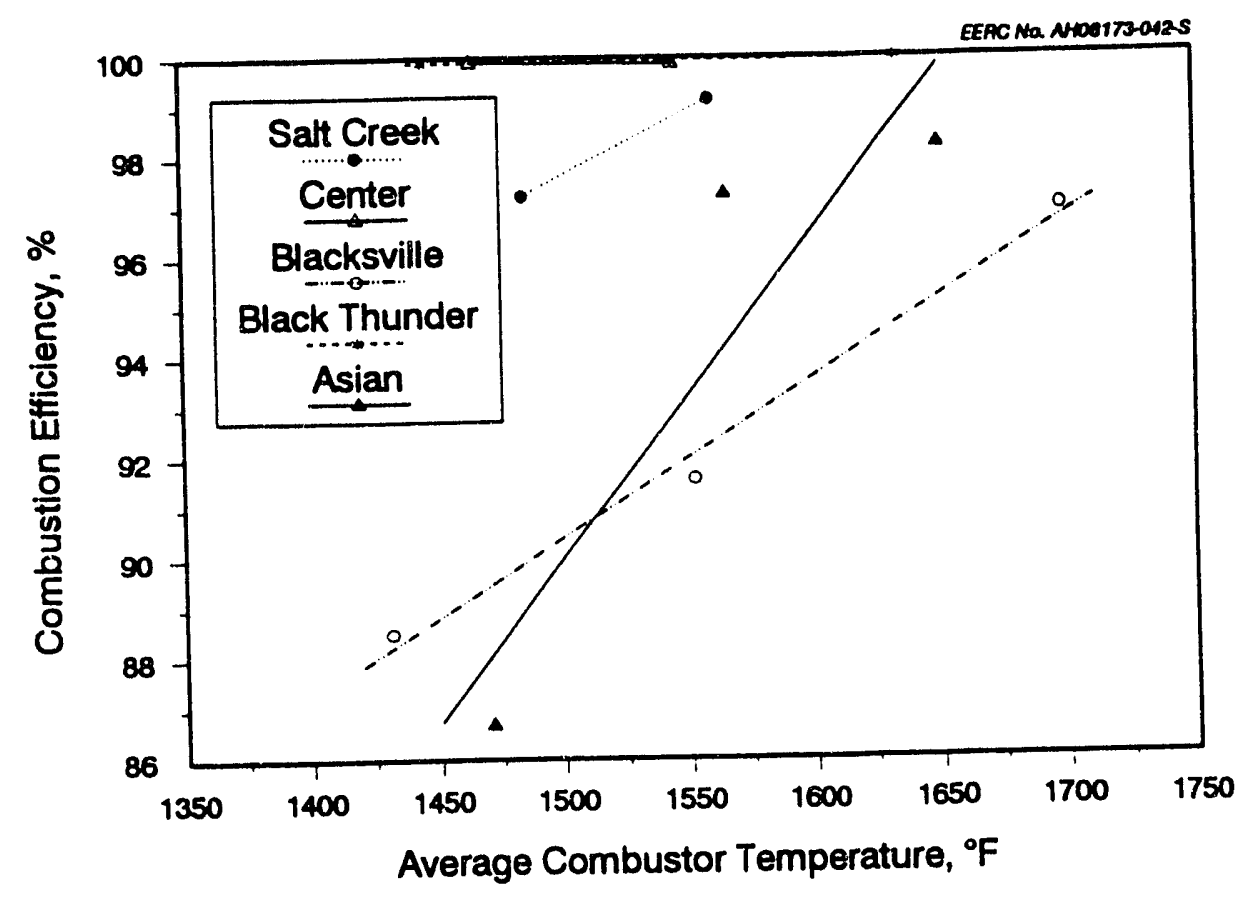

Figure ES-7. Combustion efficiency at $25 \%$ excess air and $16-\mathrm{ft} / \mathrm{sec}$ velocity as a function of temperature.

combustion efficiencies for the Blacksville bituminous coal ranged from $90 \%$ to $97 \%$. These differences are due to the higher reactivity of the char for the lower-rank coals and the higher volatile content of these coals in relation to the fixed carbon. Recycle from a secondary cyclone system or baghouse would improve the combustion efficiency for the bituminous coals. Combustion efficiency also increased with increases in excess air.

\section{Boiler Efficiency}

The overall boiler efficiency is affected by a number of other parameters in addition to the carbon burnout of the fuel. Since low-rank coals typically contain higher levels of moisture than do bituminous coals, more heat is required (lost) during the combustion of low-rank coals to vaporize the extra moisture. When operating at a specific temperature and excess air, the high-moisture fuels generate increased mass flows through the system per delivered Btu than low-moisture fuels, resulting in a higher fraction of the energy being recovered in the downstream convective heat recovery unit. Figure ES-8 shows that, for the coals tested, the amount of energy generated ending up in the flue gas varied from $65 \%$ for the very moist Asian lignite to $43 \%$ for the relatively dry Blacksville bituminous. The shift of energy back to the convective pass results in a reduction of boiler efficiency due to greater stack losses for the high-moisture coals. Other losses in boiler efficiency result from the conversion of fuel hydrogen to water, unrecoverable heat from the discharge of ash and spent sorbent, and the calcination of the raw sorbent. A boiler efficiency credit is given for the sulfation of the sorbent, as this process produces usable heat. 


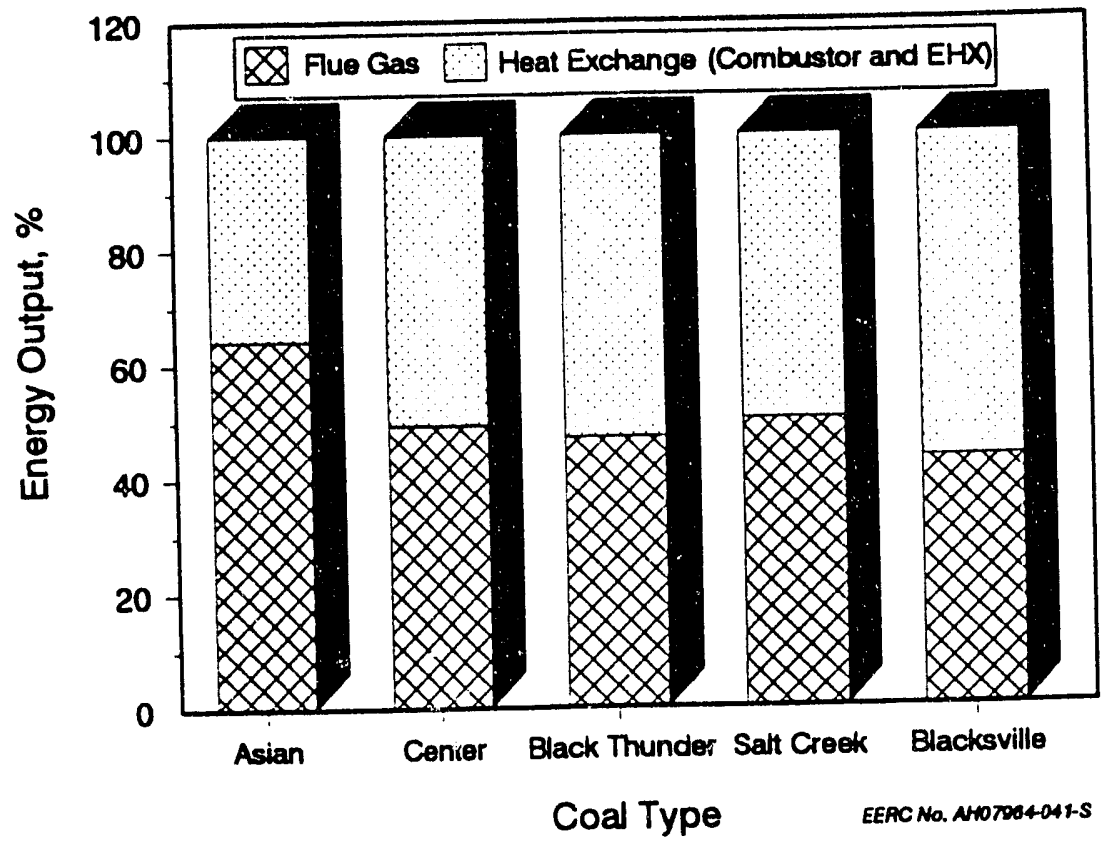

Figure ES-8. Heat split between combustor and flue gas as a function of coal type.

Boiler efficiency losses for the baseline cases with no sorbent addition are shown in Figure ES-9. Table ES-3 presents a similar comparison for $90 \%$ sulfur capture at baseline conditions. The combined losses due to the moisture and hydrogen in the fuel (evaporation and unrecovered sensible heat in the flue gas) range from a high of 13.5 for the Asian lignite to a low of 6.7 for the Blacksville bituminous. Heat losses due to ash and spent sorbent are much lower and depend upon the total ash content of the coal relative to its heating values and sorbent requirements needed to meet New Source Performance Standards (NSPS). These losses amouinted to 6.9\% for the high-sulfur, highash Asian lignite and ranged from $0.2 \%$ to $1 \%$ for the other coals tested. The total efficiency losses ranged from $10.5 \%$ for the Salt Creek bituminous to $22.4 \%$ for the Asian lignite. It is interesting to note that the Center lignite and the Black Thunder subbituminous both had higher boiler efficiencies than the Blacksville bituminous coal, due primarily to their high carbon burnout.

\section{ENVIRONMENTAL PERFORMANCE}

Emissions from a CFBC operating on a given fuel can generally be controlled using proper system design and operation. While system requirements are dependent upon coal properties, the actual emissions are dependent upon the system design and operation. It is currently possible to meet all present and proposed national standards with state-of-theart CFBC technology. 


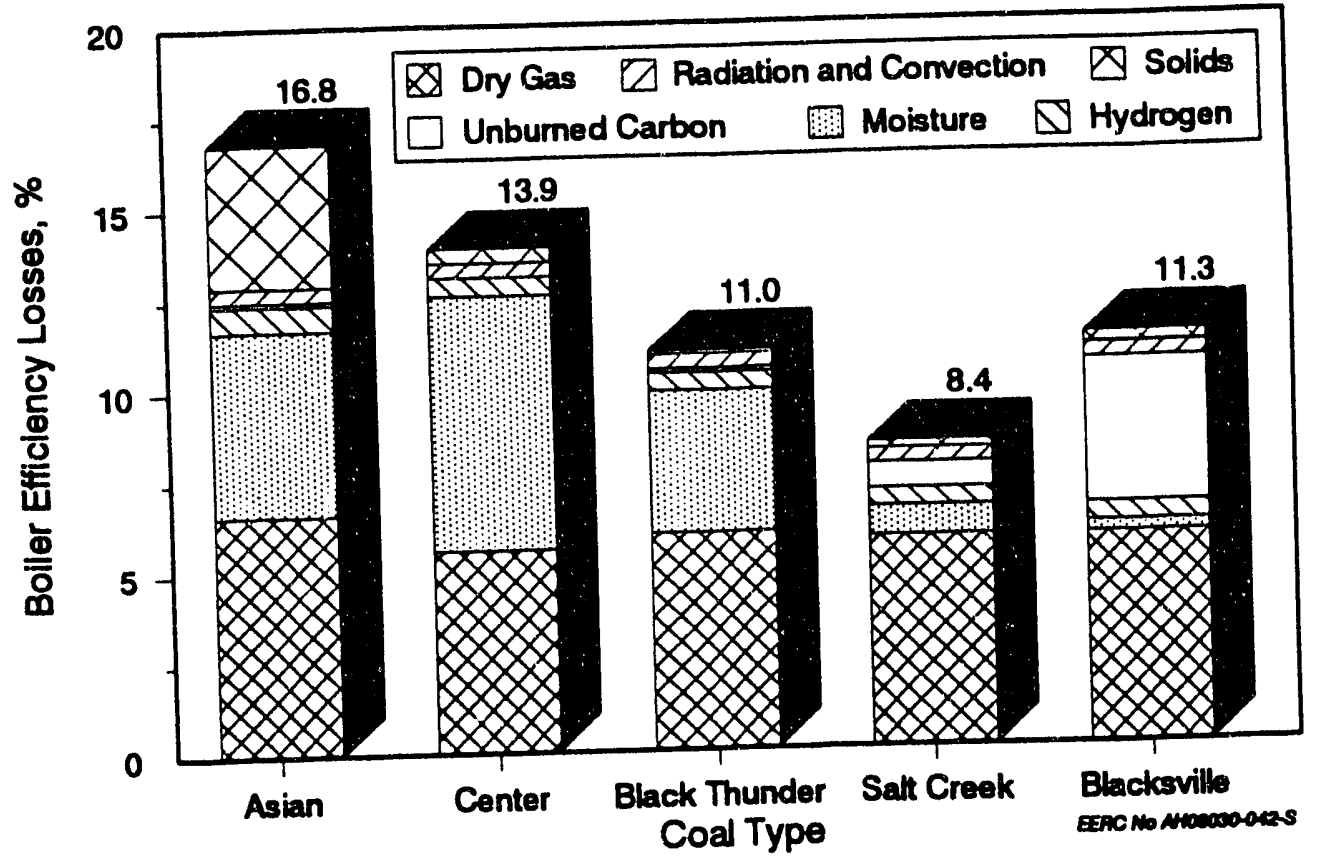

Figure ES-9. Boiler efficiency losses with no limestone addition at $1550^{\circ} \mathrm{F}\left(1607^{\circ} \mathrm{F}\right.$ for Salt Creek), 26\% excess air, 16-ft/sec velocity as a function of coal type.

\section{TABLE ES-3}

Boiler Efficiency Losses for Test Coals at $90 \%$ Sulfur Retention and $1550^{\circ} \mathrm{F}$ Combustor Temperature

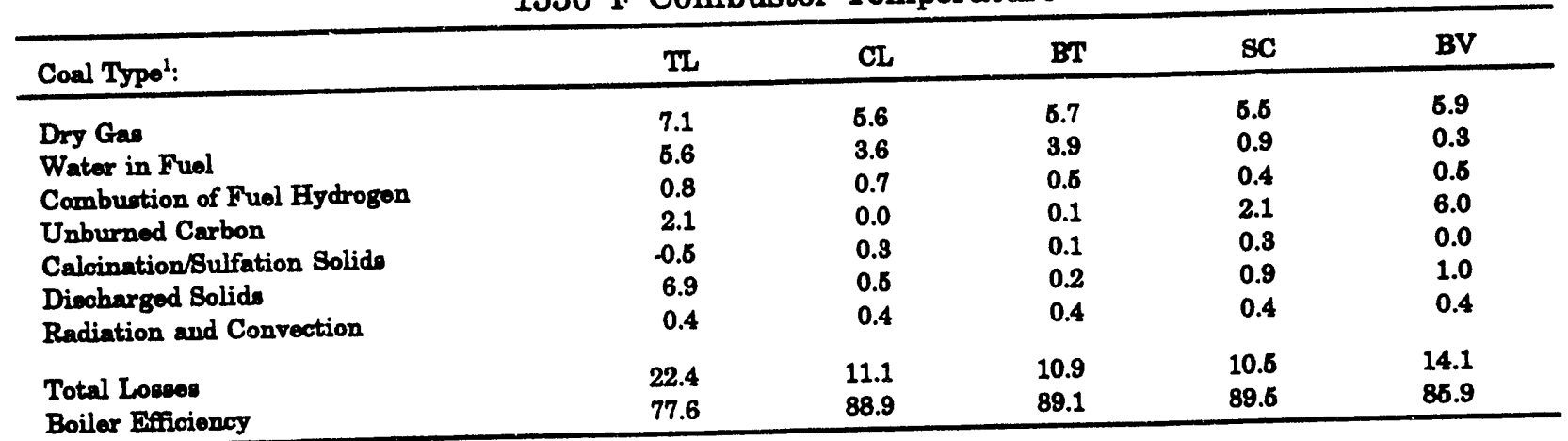

$1 \mathrm{TL}=$ Asian lignite, $\mathrm{CL}=$ Center lignito, $\mathrm{BT}=$ Black Thunder subbituminous, SC = Salt Creek bituminous, BV = Blackerillo bituminoue

\section{Sulfur Emissions and Limestone Performance}

While firing coals in a CFBC, the amount of sulfur capture is primarily determined by the total alkali-to-sulfur ratio. The alkali is provided by the mineral matter and cations contained within the coal and any added sorbent. The forms of alkali in the coal and combustor operating conditions, primarily temperature, are also important. Once the coal and sorbent properties are known, system design and operating specifications can be set to achieve the required level of sulfur capture, such as mandated by NSPS. 
In specifying design and operating conditions for the CFBC, it is critical to know how much sorbent addition is required to meet applicable emissions stan daids. This can vary greatly with coal and sorbent types. For example, the data in Figure ES-10 show that, to retain $90 \%$ sulfur, the required alkali-to-sulfur ratio ranges from 1.4 to 4.9 , depending upon coal type. Looking only at the alkali-to-sulfur ratio, however, can be misleading. For example, although an alkali-to-sulfur ratio of 4.9 is required to meet $90 \%$ sulfur retention for the Salt Creek coal versus 1.4 for the Asian lignite, the total amount of sorbent addition required is much less for the Salt Creek coal. A sorbent add rate of 4.2 pounds per million Btu of Salt Creek coal input is required, versus 62 pounds per million Btu of Asian lignite, due to differences in the level of sulfur and the alkali in the coal. The add rates of sorbent for the other coals testea in relation to varying levels of sulfur retention are presented in Figure ES-11.

The optimum bed temperature resulting in maximum sulfur capture varies somewhat with coal type. The bituminous coals tested show optimal sulfur capture at combustor temperatures of approximately $1550^{\circ} \mathrm{F}$. The low-rank coals tested, however, exhibit optimal temperature for sulfur capture approximately $100^{\circ} \mathrm{F}$ lower. This is partially due to the coal structure and the forms and relationships of the sulfur and the alkali in the coal itself.

The source and size of limestone can also have an impact on sulfur capture. As a part of the test series discussed in this report, two different limestones were tested while burning the Blacksvilla bituminous coal. Limestone size was also a test parameter. Using a coarse limestone (-20 mesh), $40 \%$ of the calcium in the limestone was utilized for sulfur capture. A fine limestone (-40 mesh) of the same type resulted in a sorbent utilization of only $29 \%$. A second limestone (Colorado Ute) of fine particle size ( -40 mesh) showed similar performance, with approximately $29 \%$ utilization. To capture $70 \%$ of the sulfur, alkali-to-sulfur ratios of 1.8 for the coarse limestone and 2.3 for the two fine limestones tested would be required. In this case, the reactivities of the two limestones were similar. While the smaller-sized limestone had a greater surface-to-volume ratio, which would be expected to result in more efficient sulfur capture, the poorer utilization was probably the result of shorter sorbent residence time in the combustor. Cyclone collection efficiencies decrease with decreasing particle size, and smaller sorbent particles may leave the system without being recirculated. For limestones with different reactivities, the add rates can also vary as a function of limestone type. Results obtained on the impact of limestone size and type on other parameters are shown in Figure ES-12.

\section{Nitrogen Oxide Emissions}

Regulated nitrogen oxide emissions currently include $\mathrm{NO}$ and $\mathrm{NO}_{2}$, collectively termed $\mathrm{NO}_{\mathrm{x}}$ emissions. $\mathrm{NO}_{\mathrm{x}}$ emissions from the CFBC are highly coal dependent. Figure ES-13 compares $\mathrm{NO}_{x}$ emissions for the five test coals as a function of temperature. These different $\mathrm{NO}_{x}$ levels are caused by inherent differences in the nitrogen in the coals. The nitrogen in the bituminous coals is released as $\mathrm{CN}$, while the lower-rank coals release more of their nitrogen as $\mathrm{NH}_{3}$. The distribution of nitrogen between the volatiles and the fixed carbon also varies significantly between coal ranks and is partially responsible for the trends shown in Figure ES-13. Not only does the total amount of $\mathrm{NO}_{\mathrm{x}}$ emitted vary with coal type, the rate of $\mathrm{NO}_{\mathrm{x}}$ emissions with changes in operating temperature also varies with coal type. The rate of change is the smallest with the lignites and the greatest with the bituminous coals. Therefore, the lignites are higher emitters of $\mathrm{NO}_{\mathbf{x}}$ 


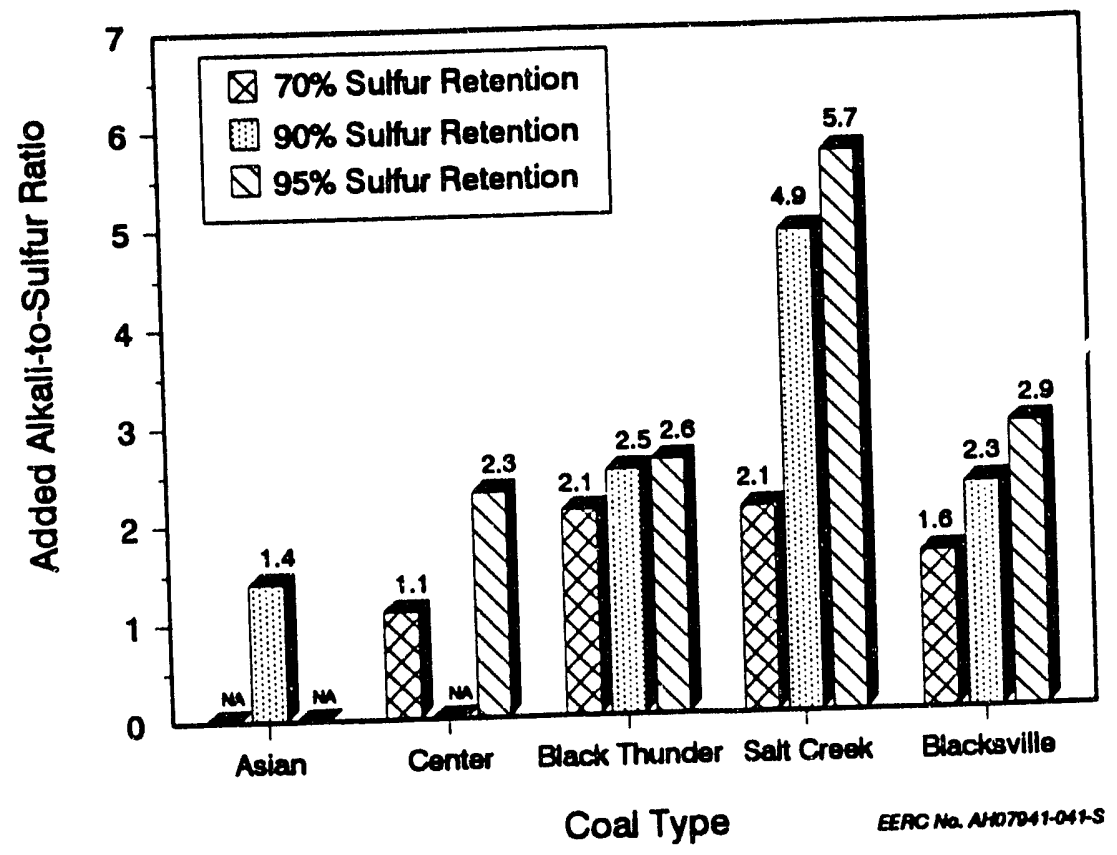

Figure ES-10. Added alkali-to-sulfur ratio required for increasing sulfur capture at $1550^{\circ} \mathrm{F}$ as a function of coal type.

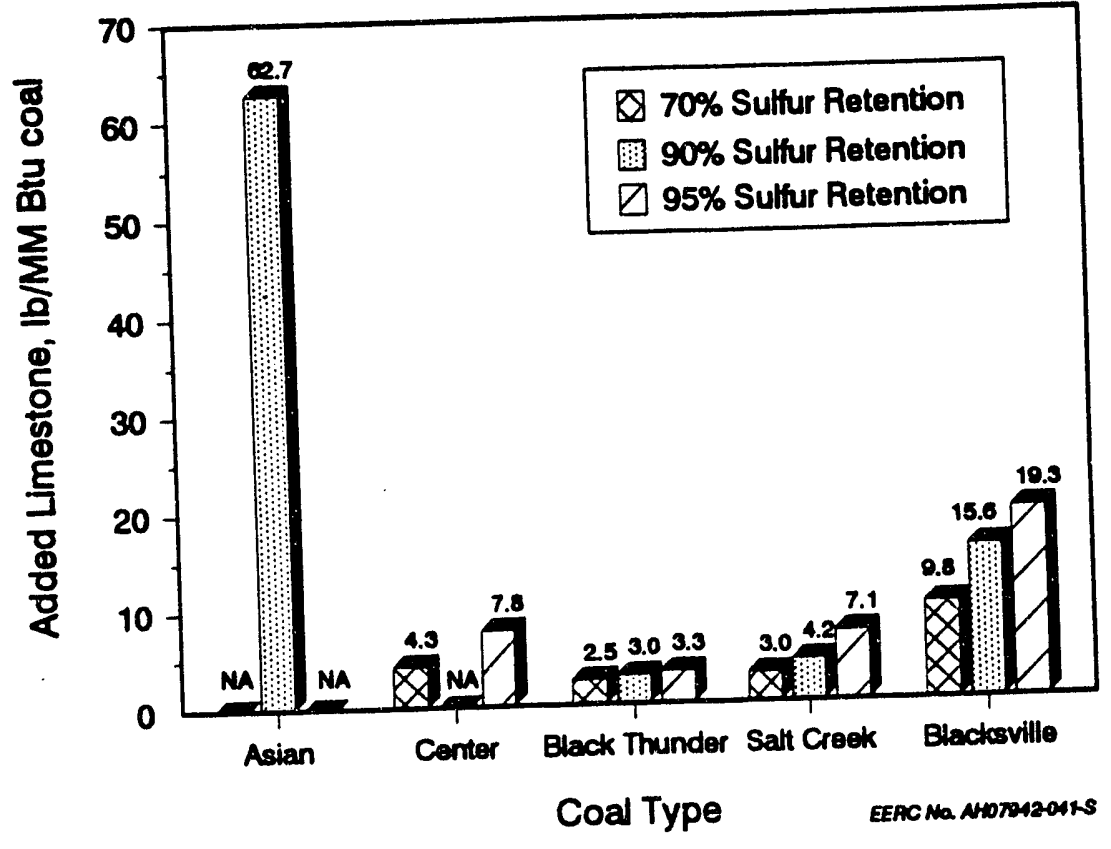

Figure ES-11. Added limestone required for increasing sulfur capture at $1550^{\circ} \mathrm{F}$ as a function of coal type. 


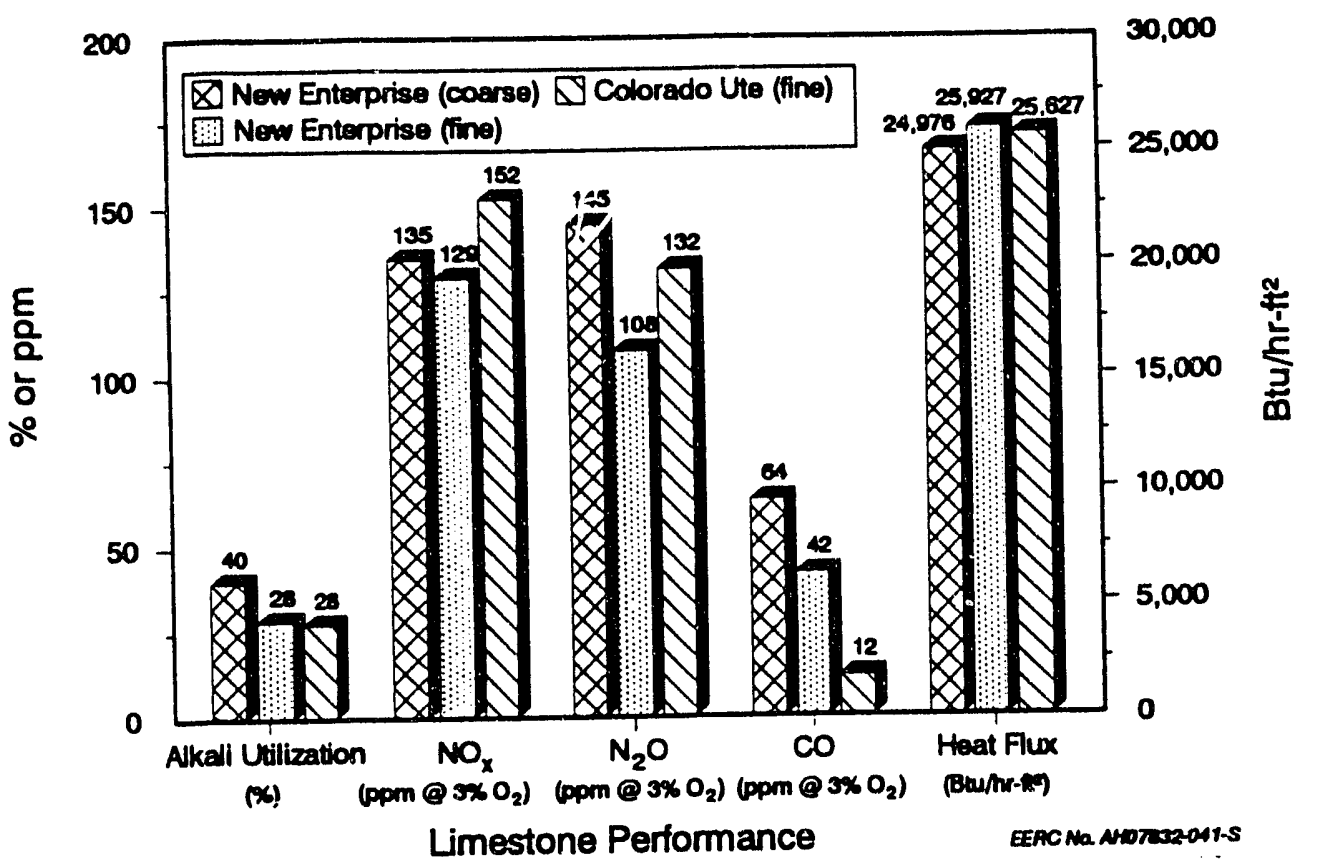

Figure ES-12. CFBC performance as a function of limestone size and type.

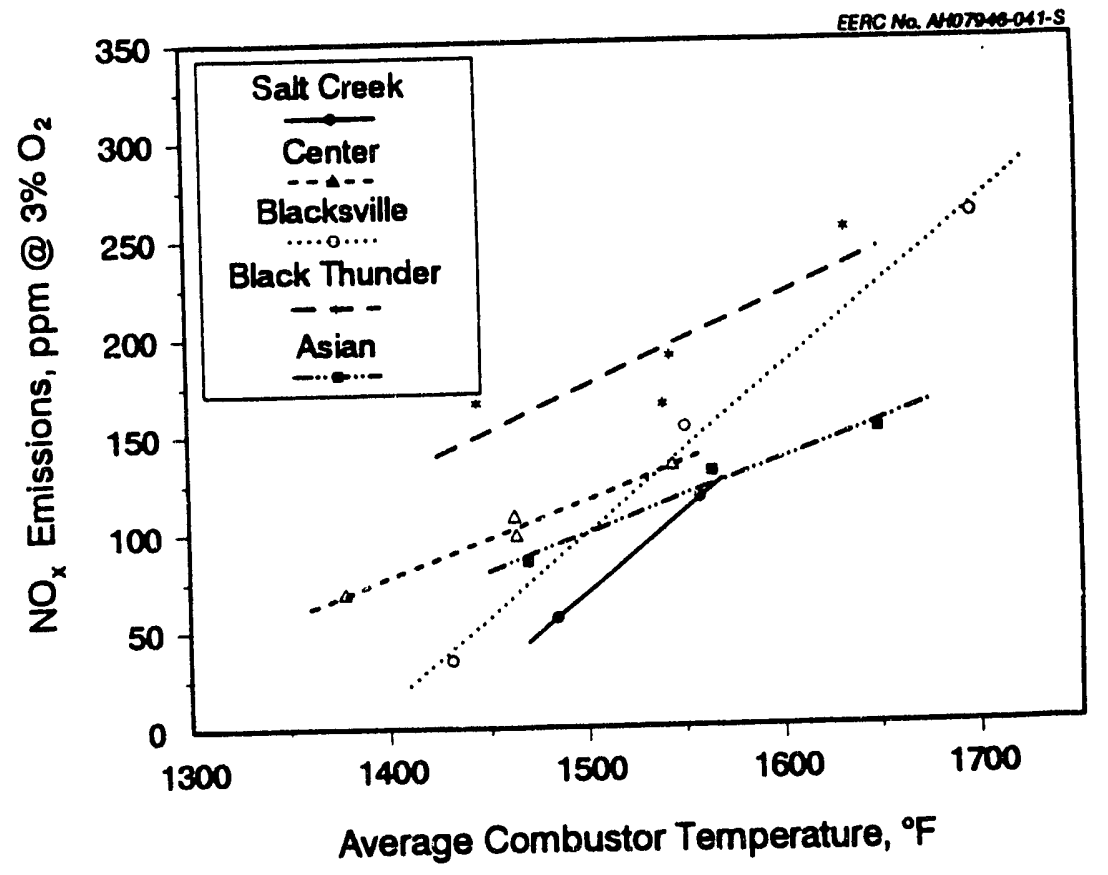

Figure ES-13. NO emissions at 20\%-25\% excess air, 16-ft/sec velocity, and 1.5-2.5 alkalito-sulfur ratio as a function of combustor temperature. 
than the bituminous coals at lower temperatures $\left(1450^{\circ} \mathrm{F}\right)$, but emit less $\mathrm{NO}_{\mathrm{z}}$ at higher temperatures. $\mathrm{NO}_{\mathrm{x}}$ emissions also increase with increasing excess air and sorbent add rates.

Recently, relatively high emissions of nitrous oxide $\left(\mathrm{N}_{2} \mathrm{O}\right)$ have been measured from CFBCs. Although these are currently not regulated, they may become important in the future. $\mathrm{N}_{2} \mathrm{O}$ emissions are even more dependent upon fuel properties than $\mathrm{NO}_{\mathrm{x}}$. The trends noted during this study were increasing emissions of $\mathrm{N}_{2} \mathrm{O}$ as the rank changed from subbituminous to lignite to bituminous. These trends are shown in Figure ES-14. The distribution of the nitrogen between the volatiles and the fixed carbon appears to be the most important fuel property affecting $\mathrm{N}_{2} \mathrm{O}$ emissions. $\mathrm{N}_{2} \mathrm{O}$ emissions show the opposite trend as $\mathrm{NO}_{x}$, decreasing with increasing temperature and sorbent add rate, and a similar trend as $\mathrm{NO}_{\mathrm{z}}$ for excess air.

\section{Fly Ash Collectability}

To provide an indication of the impacts of coal properties on fly ash collectability, dust loadings before and after the baghouse were performed. The dust loading into the baghouse for the high-ash, high-sulfur Asian lignite was the highest for the coals tested, at 2.13 grains $/ \mathrm{scf}$. Dust loadings for the other coals ranged from 0.60 to 0.90 grains/scf. For all of the coals, collection efficiencies using woven fiberglass bags in a pulse-jet baghouse were above $99.9 \%$.

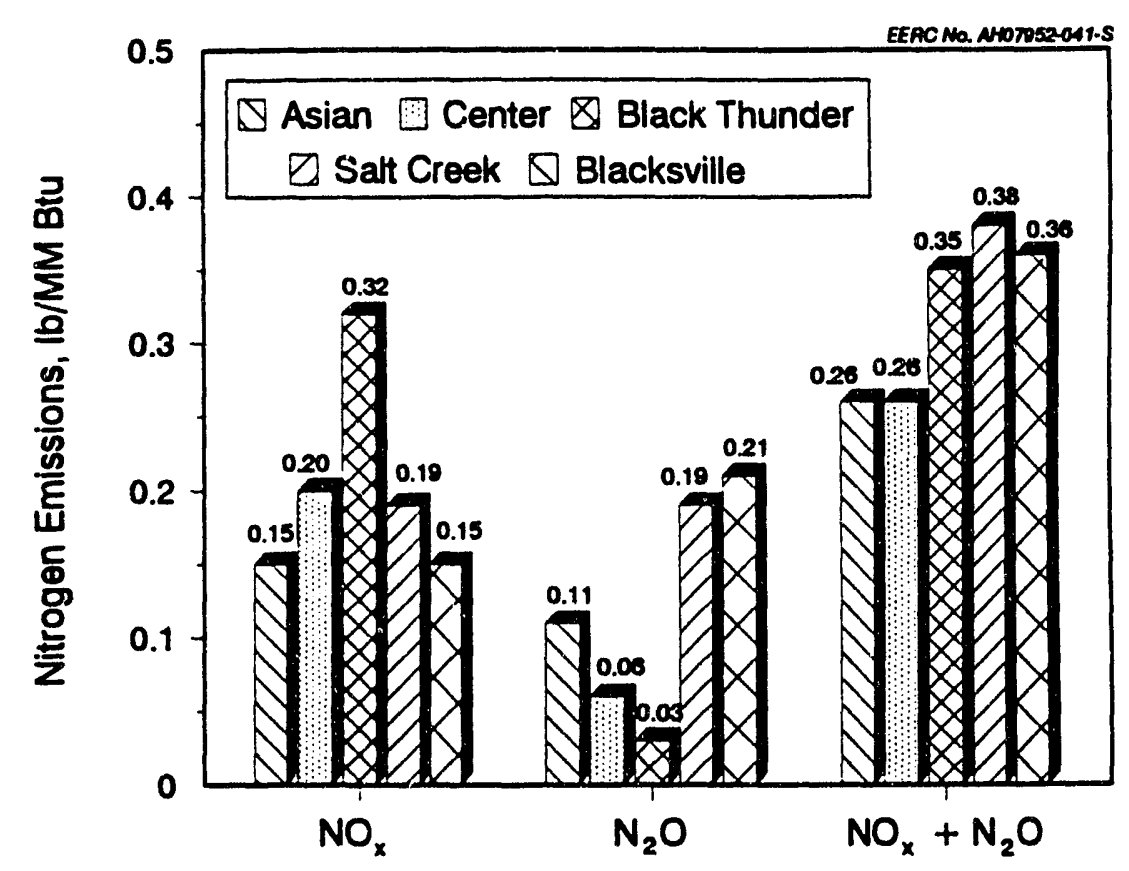

Figure ES-14. $\mathrm{NO}_{2}$ and $\mathrm{N}_{2} \mathrm{O}$ emissions with no limestone addition at $1550^{\circ} \mathrm{F}, 26 \%$ excess air, and 16-ft/sec velocity as a function of coal type. 


\section{Solid Waste Generation}

An important aspect of the design of the CFBC is sizing of the solids handling systems. From an operational standpoint, disposal of the solid wastes (coal ash and spent sorbent) becomes a very important economical consideration. The amount of solids generated is very dependent upon coal properties, as shown in Figure ES-15. The combination of high ash and high sulfur in the Asian lignite results in very large quantities of solid waste. For the other coals tested, the amount of solid waste generated increased with the amount of ash in the coal and the amount of limestone added. The two bituminous coals generated more solid wastes than the two low-rank coals. Limestone requirements are highest for high-sulfur, low-alkali coals and increase with increasing sulfur capture. The baseline and $70 \%$ retention tests for the Salt Creek run were performed at different temperatures than the other tests. This shift away from the optimum temperature for sulfur capture resulted in higher solid waste generation for these tests.

\section{operational performance}

There are several different aspects of the CFBC operation that are of concern. These include primary cyclone performance, solids recirculation rates or mass flux in the combustor, size distribution of the circulating solids, refractory wear, and deposition and agglomeration of ash. Many of these are determined primarily by system design and by

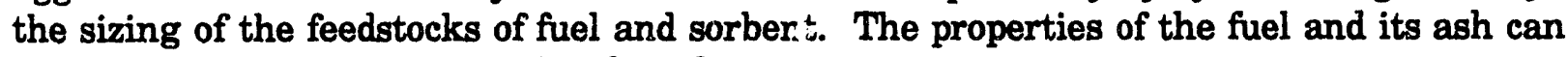
also have an impact on operational performance.

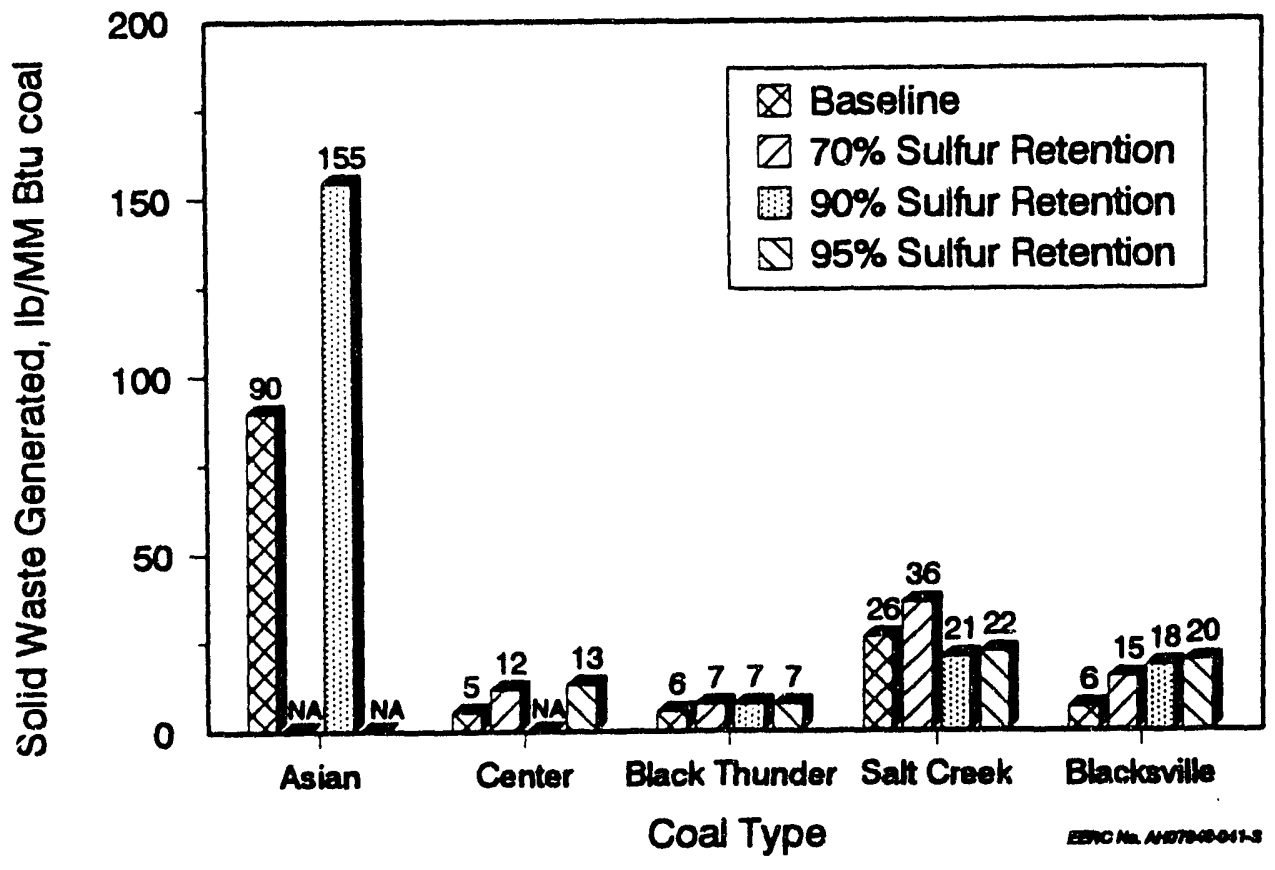

Figure ES-15. Solid waste generated at increasing levels of sulfur retention as a function of coal type. 


\section{Solids Performance}

For the five coals tested, cyclone efficiency appeared to be primarily a function of operating conditions. Cyclone efficiency is defined as one minus the fly ash discharge rate divided by the recirculation rate. Cyclone efficiency is used here to collectively describe total system efficiency for capture of solids using a primary, and sometimes a secondary, collection device for solids recirculation. Solids capture is influenced by the collector geometry, as well as operational parameters including the combustor gas velocity and fuel and limestone properties.

Cyclone efficiencies ranged from a low of $93.8 \%$ with the Asian lignite to $99.9 \%$ with Black Thunder bituminous. For testing conducted with Center, Black Thunder, and Salt Creek fuels, secondary cyclone ash was recycled to maintain adequate bed inventory and recirculation rates. These three coals had relatively low coal ash and sulfur contents, resulting in low quantities of solids available for recirculation. Additionally, the size of the limestone used for Salt Creek testing was relatively small, making it difficult to keep in the system. The Blacksville bituminous was a low-ash coal, but required relatively high limestone feed rates due to its high sulfur content, and subsequently no secondary cyclone recycle was required to maintain sufficient bed inventory. Although the cyclone efficiencies for the Asian lignite (low Btu, high ash, and high sulfur) were significantly lower than for the other four test coals, no secondary cyclone recycle was required to maintain adequate bed inventory at all operating conditions.

In no case did additional bed material need to be added to maintain bed inventory. However, for the Black Thunder coal, which is very low in sulfur and ash, the only bed drain that was used during the tests was for sampling. This indicates that a system with a cyclone efficiency less than that of this pilot plant would not have been able to maintain bed inventory for this coal. For the other coals, the amount of ash in the coal and the added sorbent were sufficient to continually build bed inventory, requiring sizable bed drain. For design of a full-scale system using low-ash, low-sulfur fuels, recycle from a secondary cyclone/multiclone or baghouse would be recommended.

Recirculation rates and mass flux were primarily determined by operating parameters and were not directly affected by fuel type. Recirculation rates decreased with velocity and bed inventory. The recycle of secondary cyclone solids increased the recirculation rates. Recycle of secondary cyclone material would not be necessary to maintain high recirculation when burning high-sulfur coals, due to the large amount of limestone being added to the system, or when burning high-ash coals. Therefore, coal properties can indirectly have an impact on recirculation rates and mass flux by requiring recycle of ash from a secondary collection system.

One aspect of system operation that is directly impacted by fuel ash properties is agglomeration and deposition. The North Dakota lignite has a relatively high sodium level in the ash (4\%). During the tests, particle growth was observed, but did not lead to severe agglomeration. However, a fuel with a slightly higher sodium or potassium level would likely result in agglomeration problems. The fuels with high concentrations of organically bound calcium also showed the potential for fouling in the convective and reheat sections of a boiler. A very hard, fine-grained calcium sulfate-based deposit formed on the ash-fouling probes and the primary flue gas heat exchanger during the tests with the Asian and North Dakota lignites. Therefore, a prudent design for fuels similar to these would include adequate soot-blower coverage.

Executive Summary-16 


\section{IMPACT OF LOAD CONTROL METHOD}

Two different operational procedures were used to simulate load reduction for CFB systems: one with and one without an external heat exchanger. Boiler efficiencies decreased when load was decreased by either of the methods. Operation with an external heat exchanger resulted in little change in operating temperature over the load range tested while those tests that simulated operation without an external heat exchanger had decreasing temperatures as the load decreased. The impacts of the load control method were directly related to these temperature differences.

No clear trend was evident to show how sulfur dioxide emissions are affected for either method of load control. For operation without an external heat exchanger, $\mathrm{NO}_{\mathrm{x}}$ emissions tended to decrease, while $\mathrm{N}_{2} \mathrm{O}$ and $\mathrm{CO}$ emissions increased, as load was decreased. These followed expected trends based on changes in temperature and excess air. For testing simulating operation with an external heat exchanger, $\mathrm{NO}_{\mathrm{z}}$ emissions increased slightly due to increases in excess air, while $\mathrm{N}_{2} \mathrm{O}$ and $\mathrm{CO}$ emissions were mostly unaffected as load was reduced, as these emissions are less sensitive to changes in excess air.

Combustor efficiencies were not affected for the reduced load testing for the more reactive lignites. Reducing load using either method appeared to improve combustion efficiency for the bituminous coals. This could have been due to the decreased operational velocities that accompanied the load reduction, resulting in less carbon blowing out of the system. Heat transfer coefficients and heat flux showed a decreasing trend with decreasing load. 


\section{PROJECT CFB TEST' RESULTS}




\subsection{INTRODUCTION}

Project CFB was initiated in May of 1988 to establish an independent CFBC test facility for the generation of comprehensive, reliable, and accessible data for utility and industrial applications. Otter Tail Power Company approached the EERC and played a key role in providing the impetus to get the project going. Sponsorship was sought from private companies and organizations and government agencies. Sponsors that agreed to participate include:

- ARCO Coal Company.

- Consolidated Edison of New York.

- Electric Power Research Institute (EPRI).

- Empire State Electric Energy Research Corporation (ESEERCO).

- North Dakota Lignite Research Council.

- Northern States Power Company (NSP).

- Otter Tail Power Company.

- Premier Refractories and Chemicals.

- TU Electric.

- U.S. Department of Energy (DOE).

Additionally, as the project proceeded, the EERC contributed internal funds to help see the project through to completion.

\subsection{Project Objectives}

Specific objectives of the project were:

- Obtain and compile available information about CFBs to provide a centralized resource for use by both EERC staff and sponsoring organizations of Project CFB.

- Within the constraints of the available budget and the available space for installation at the EERC, design a CFBC pilot plant system of a generic nature to provide data to assess the combustion of various coals over a wide range of operational conditions with and without the use of an external heat exchanger. The pilot plant should be representative of the major boiler vendor designs.

- Complete construction of the CFBC pilot plant system in the available EERC facilities.

- Perform shakedown of the pilot plant to ensure that the overall system is in operational status, provides data of high integrity, and is scalable to a full-scale system.

- The original goal was to perform parametric testing on two coals, an eastern bituminous coal with moderately high sulfur content (3\%-5\%) and a western coal with a high alkaline ash content (greater than $5 \%$ ). Based upon further input from the sponsors, plus additional contributions from the DOE, NSP, EPRI, ARCO, and the Center North Dakota mine, it was decided to test four coals: Salt Creek bituminous coal used at the Nucla Power Generating Station, Center lignite supplied by BNI Coal, Ltd., Blacksville bituminous coal supplied by 
ESEERCO, and Black Thunder subbituminous coal supplied by ARCO Coal Company from the Powder River Basin. An Asian lignite tested in the CFB was also included in this report for comparison to the other coals tested, even though it was conducted as a contract separate from Project CFB.

- Complete a final report detailing the results of all parametric testing for the five different coals.

\subsection{Coal and Limestone Properties}

Proximate and ultimate analyses of the coal and x-ray fluorescence analyses of the coal ash and limestone were performed. Results of the coal and limestone analyses for each run were averaged and are presented in Table 1-1.

\subsection{Test Matrices}

Table 1-2 is a comprehensive listing of all of the tests performed during Project CFB. The matrices show the target values for the test variables used during operation of the CFB on the five test coals. The following parameters were investigated during this program:

- Coal type

- Limestone type

- Limestone size

- Combustor temperature

- Superficial gas velocity

- Excess air level

- Primary-to-secondary combustion air split

- Secondary combustion air injection height

- Calcium-to-sulfur ratio/sulfur retention

- Load

- Load control method

\subsection{Organization of Report}

The report contains the following sections:

1.0 Introduction

2.0 Description of Facilities

3.0 Impacts of Coal and Limestone Properties on Operational Performance

4.0 Comparison to Full Scale

5.0 Summary and Conclusions

\subsection{References}

Appendices 
TABLE 1.1

Coal and Limestone Analyses

\begin{tabular}{|c|c|c|c|c|c|}
\hline & Salt Crook & $\begin{array}{l}\text { Center } \\
\text { Lignite }\end{array}$ & $\begin{array}{c}\text { Agian } \\
\text { Lignite }\end{array}$ & Blackoville & $\begin{array}{c}\text { Black } \\
\text { Thunder } \\
\end{array}$ \\
\hline \multicolumn{6}{|l|}{ Average Coal Analyges } \\
\hline \multicolumn{6}{|l|}{ Proximate Analyøis, as-received, wt\% } \\
\hline $\begin{array}{l}\text { Moisture } \\
\text { Volatile Matter } \\
\text { Fixed Carbon } \\
\text { A日b }\end{array}$ & $\begin{array}{r}7.7 \\
31.0 \\
42.7 \\
18.6\end{array}$ & $\begin{array}{r}37.1 \\
29.0 \\
28.9 \\
6.1\end{array}$ & $\begin{array}{r}17.0 \\
37.4 \\
7.6 \\
38.0\end{array}$ & $\begin{array}{r}2.9 \\
35.1 \\
63.8 \\
8.2\end{array}$ & \begin{tabular}{r|}
27.6 \\
33.2 \\
34.6 \\
4.6
\end{tabular} \\
\hline \multicolumn{6}{|l|}{ Ultimate Analysis, as-received, wt\% } \\
\hline $\begin{array}{l}\text { Carbon } \\
\text { Hydrogen } \\
\text { Nitrogen } \\
\text { Sulfur } \\
\text { Oxygen } \\
\text { Ash }\end{array}$ & $\begin{array}{r}58.8 \\
5.0 \\
1.1 \\
0.4 \\
16.0 \\
18.6\end{array}$ & $\begin{array}{r}40.9 \\
7.0 \\
0.5 \\
0.7 \\
46.8 \\
6.1\end{array}$ & $\begin{array}{r}25.0 \\
4.3 \\
0.7 \\
6.1 \\
26.1 \\
38.0\end{array}$ & $\begin{array}{r}74.4 \\
6.3 \\
1.3 \\
2.4 \\
8.4 \\
8.2\end{array}$ & $\begin{array}{r}49.9 \\
6.6 \\
0.6 \\
0.3 \\
38.0 \\
4.6\end{array}$ \\
\hline \multicolumn{6}{|l|}{ Ash Composition, as oxiden, wt\% } \\
\hline $\begin{array}{l}\text { Calcium, } \mathrm{CaO} \\
\text { Magnesium, } \mathrm{MgO}_{8} \\
\text { Sodium, } \mathrm{Na}_{2} \mathrm{O} \\
\text { Silica, } \mathrm{SiO}_{2} \\
\text { Aluminum, } \mathrm{Al}_{2} \mathrm{O}_{9} \\
\text { Ferric, } \mathrm{Fe}_{2} \mathrm{O}_{9} \\
\text { Titanium, } \mathrm{TiO}_{2} \\
\text { Phosphorous, } \mathrm{P}_{2} \mathrm{O}_{6} \\
\text { Potassium, } \mathrm{K}_{2} \mathrm{O} \\
\text { Sulfur, } \mathrm{SO}_{9}\end{array}$ & $\begin{array}{r}1.6 \\
1.6 \\
0.2 \\
69.9 \\
30.9 \\
3.0 \\
1.1 \\
0.4 \\
1.0 \\
1.0\end{array}$ & $\begin{array}{r}22.6 \\
10.2 \\
3.7 \\
14.6 \\
9.7 \\
16.1 \\
0.3 \\
0.7 \\
0.4 \\
21.9\end{array}$ & $\begin{array}{r}19.9 \\
3.3 \\
0.3 \\
30.6 \\
12.4 \\
13.7 \\
0.2 \\
0.6 \\
1.1 \\
18.1\end{array}$ & $\begin{array}{r}6.6 \\
1.2 \\
0.7 \\
43.6 \\
22.7 \\
16.6 \\
0.7 \\
0.4 \\
1.7 \\
6.8\end{array}$ & $\begin{array}{r}24.4 \\
7.9 \\
0.5 \\
28.6 \\
16.4 \\
6.4 \\
1.4 \\
1.3 \\
0.9 \\
12.4\end{array}$ \\
\hline High Heating Value, moisture-free, Btu/lb & 11,131 & 11,071 & 4,698 & 13,670 & 11,941 \\
\hline High Heating Value, as-received, Btu/lb & 10,274 & 6,939 & 3,898 & 13,274 & 8,650 \\
\hline \multicolumn{6}{|l|}{ Average Limestone Analyees, as oxides, \% } \\
\hline $\begin{array}{l}\text { Silica } \\
\text { Aluminum } \\
\text { Iron } \\
\text { Titanium } \\
\text { Calcium } \\
\text { Magnesium } \\
\text { Sulfur } \\
\text { Sodium } \\
\text { Potassium }\end{array}$ & $\begin{array}{r}2.62 \\
0.38 \\
0.31 \\
0.02 \\
54.06 \\
0.00 \\
0.17 \\
0.00 \\
0.00 \\
\end{array}$ & $\begin{array}{r}3.45 \\
0.61 \\
0.36 \\
0.03 \\
61.35 \\
3.01 \\
0.27 \\
0.07 \\
0.52 \\
\end{array}$ & $\begin{array}{r}1.76 \\
0.00 \\
0.26 \\
0.03 \\
64.26 \\
0.61 \\
0.06 \\
0.26 \\
0.16 \\
\end{array}$ & $\begin{array}{r}2.96 \\
0.78 \\
0.42 \\
0.03 \\
51.77 \\
2.77 \\
0.21 \\
0.06 \\
0.32 \\
\end{array}$ & $\begin{array}{r}2.96 \\
0.78 \\
0.42 \\
0.03 \\
61.77 \\
2.77 \\
0.21 \\
0.06 \\
0.32 \\
\end{array}$ \\
\hline
\end{tabular}

Section 2.0 contains an overview of the EERC CFBC test facility; the EERC coal and limestone preparation facility and procedures; the CFBC flue gas components, which were regularly monitored, and the equipment used for on-line analysis; the equipment and procedures used for analysis of solid samples taken during each run (coal, limestone, and various ash streams); and a brief description of the advanced electron microscopy equipment used for in-depth ash analysis.

The ways in which coal and limestone properties affect CFBC performance are discussed in Section 3.0 in terms of overall operability of the system, flue gas emissions, and thermal performance for the tests performed on the EERC pilot plant. 


\section{TABLE 1-2}

Test Matrices

\begin{tabular}{|c|c|c|c|c|c|c|}
\hline $\begin{array}{l}\text { Coal Type } \\
\text { Tert Number }\end{array}$ & $\begin{array}{l}\text { Average Combuator } \\
\text { Temperature }\left({ }^{\circ} \mathrm{F}\right)\end{array}$ & Laad (\%) & $\begin{array}{l}\text { Sulfur Retention (\%) } \\
\text { or } \mathrm{Ca} / \mathrm{S}\end{array}$ & PASA $^{1}$ & $\begin{array}{c}\text { Flue Gas } \\
\text { Velocity (ft/s) }\end{array}$ & $\begin{array}{l}\text { Excess } \\
\text { Air }(\%)\end{array}$ \\
\hline \multicolumn{7}{|l|}{ Salt Croek } \\
\hline 1 & 1616 & 100 & 0.54 & $54: 46$ & 16.0 & 20 \\
\hline 2 & 1616 & 100 & 2.04 & $54: 46$ & 16.0 & 20 \\
\hline 3 & -2 & 75 & 2.04 & $66: 44$ & -2 & 20 \\
\hline 4 & -2 & 60 & 2.04 & -2 & $--^{2}$ & 30 \\
\hline 5 & 1476 & 100 & 1.54 & $70: 30$ & 16.0 & 46 \\
\hline 6 & 1475 & 100 & 1.64 & $60: 60$ & 16.0 & 15 \\
\hline 7 & 1625 & 100 & 1.54 & $70: 30$ & 16.0 & 15 \\
\hline 8 & 1626 & 100 & 1.64 & $60: 50$ & 16.0 & 45 \\
\hline 9 & 1626 & 100 & 3.64 & $70: 30$ & 16.0 & 46 \\
\hline 10 & 1625 & 100 & 3.54 & $60: 60$ & 16.0 & 15 \\
\hline 11 & 1475 & 100 & 3.64 & $70: 30$ & 16.0 & 15 \\
\hline 12 & 1475 & 100 & 3.54 & $60: 60$ & 16.0 & 46 \\
\hline \multicolumn{7}{|l|}{ Center Lignite } \\
\hline 0 & 1650 & 100 & No $18^{3}$ food & $60: 40$ & 16.0 & 25 \\
\hline 1 & 1550 & 100 & $70 \%$ & $60: 40$ & 16.0 & 25 \\
\hline 2 & -2 & 75 & $70 \%$ & $60: 40$ & 16.0 & -2 \\
\hline 3 & -2 & 60 & $70 \%$ & $60: 40$ & 16.0 & $-^{2}$ \\
\hline 4 & 1550 & 50 & $70 \%$ & $60: 40$ & 16.0 & 25 \\
\hline 5 & 1560 & 76 & $70 \%$ & $60: 40$ & 16.0 & 26 \\
\hline 6 & 1650 & 100 & $50 \%$ & $60: 40$ & 16.0 & 25 \\
\hline 7 & 1660 & 100 & $70 \%$ & $60: 40$ & 16.0 & 25 \\
\hline 8 & 1475 & 100 & $70 \%$ & $60: 40$ & 16.0 & 25 \\
\hline 9 & 1400 & 100 & $70 \%$ & $60: 40$ & 16.0 & 25 \\
\hline 10 & 1476 & 100 & $70 \%$ & $60: 40$ & 16.0 & 25 \\
\hline \multicolumn{7}{|l|}{ Asian Lignite } \\
\hline 1 & 1660 & 100 & $90 \%$ & $60: 40$ & 18.6 & 20 \\
\hline 2 & 1460 & 100 & same $\mathrm{Ca} / \mathrm{S}$ as 1 & $60: 40$ & $18.5(-)$ & 20 \\
\hline 3 & 1650 & 100 & game $\mathrm{Ca} / \mathrm{S}$ as 1 & $60: 40$ & $18.5(t)$ & 20 \\
\hline 4 & 1650 & 100 & No ls foed & $60: 40$ & 18.6 & 20 \\
\hline \multicolumn{7}{|l|}{ Black Thunder } \\
\hline 1 & 1650 & 100 & No ls food & $60: 40$ & 16.0 & 25 \\
\hline 2 & 1650 & 100 & $90 \%$ & $60: 40$ & 16.0 & 25 \\
\hline 3 & 1460 & 100 & same $\mathrm{Ca} / \mathrm{S}$ as 2 & $60: 40$ & 16.2 & 25 \\
\hline 4 & 1650 & 100 & same $\mathrm{Ca} / \mathrm{S}$ as 2 & $60: 40$ & 16.0 & 5 \\
\hline 5 & 1650 & 100 & $70 \%$ & $60: 40$ & 16.0 & 25 \\
\hline 7 & 1650 & 76 & same $\mathrm{Ca} / \mathrm{S}$ as 2 & $80: 20$ & 12.0 & 25 \\
\hline 8 & 1650 & 100 & $\operatorname{sam} \theta \mathrm{Ca} / \mathrm{S}$ as 2 & $60: 40$ & 16.0 & 45 \\
\hline 9 & 1650 & 100 & garne $\mathrm{Ca} / \mathrm{S}$ as 2 & $60: 40$ & 16.8 & 25 \\
\hline
\end{tabular}

1 Primary-to-secondary combustion air aplit.

2 Varied as needed to maintain the deaired load.

8 Limestone.

continued... 
Table 1-2 (continued)

\begin{tabular}{|c|c|c|c|c|c|c|}
\hline $\begin{array}{l}\text { Coal Type } \\
\text { Tert Number }\end{array}$ & $\begin{array}{c}\text { Average Comburtor } \\
\text { Temperature }\left({ }^{\circ} \mathrm{F}\right)\end{array}$ & Load (\%) & $\begin{array}{l}\text { Sulfur Rotontion (\%) } \\
\text { or } \mathrm{Ca} / \mathrm{B}\end{array}$ & PA/SA ${ }^{1}$ & $\begin{array}{c}\text { Flue Gas } \\
\text { Velocity (ft/B) }\end{array}$ & $\begin{array}{l}\text { Excoss } \\
\text { Air (\%) }\end{array}$ \\
\hline \multicolumn{7}{|l|}{ Blacksville } \\
\hline 1 & 1650 & 100 & No ls food & $60: 40$ & 16.0 & 25 \\
\hline 2 & 1650 & 100 & $90 \%$ & $60: 40$ & 16.0 & 25 \\
\hline 3 & 1425 & 100 & same $\mathrm{Ca} / \mathrm{S}$ as 2 & $60: 40$ & $16.0^{4}$ & 26 \\
\hline 4 & 1650 & 100 & samo $\mathrm{Ca} / \mathrm{S}$ as 2 & $70: 30$ & 19.0 & 15 \\
\hline 6 & 1660 & 100 & $\operatorname{sam} 0 \mathrm{Ca} / \mathrm{S}$ as 2 & $60: 60$ & 19.0 & 45 \\
\hline 6 & 1675 & 100 & same $\mathrm{Ca} / \mathrm{B}$ as 2 & $60: 40$ & $17.0^{4}$ & 25 \\
\hline 7 & 1650 & 100 & same $\mathrm{Ca} / \mathrm{S}$ as 2 & $50: 50$ & 13.0 & 16 \\
\hline 8 & 1660 & 100 & samo $\mathrm{Ca} / \mathrm{S}$ as 2 & $70: 30$ & 13.0 & 45 \\
\hline 9 & 1660 & 75 & same $\mathrm{Ca} / \mathrm{S}$ as 2 & $80: 20$ & $12.0^{4}$ & 26 \\
\hline 10 & 1650 & 60 & same $\mathrm{Ca} / \mathrm{S}$ as 2 & $100: 0$ & $8.0^{4}$ & 25 \\
\hline 11 & $1000^{4}$ & 50 & game Ca/s as 2 & $100: 0^{4}$ & $13.2^{4}$ & $>100^{4}$ \\
\hline 12 & $1400^{4}$ & 75 & same Cas as 2 & $100: 0^{4}$ & $13.8^{4}$ & $60^{4}$ \\
\hline $12 \mathrm{~A}$ & $1400^{4}$ & 75 & same Ca/S as 2 & $60: 40$ & $13.8^{4}$ & $60^{4}$ \\
\hline 13 & 1650 & 100 & $96 \%$ & $60: 40$ & 16.0 & 25 \\
\hline $14^{6}$ & 1560 & 100 & $\operatorname{sam} \theta \mathrm{Ca} / \mathrm{S}$ as 2 & $60: 40$ & 16.0 & 25 \\
\hline 15 & 1650 & 100 & $70 \%$ & $60: 40$ & 16.0 & 25 \\
\hline $16^{6}$ & 1650 & 100 & same $\mathrm{Ca} / \mathrm{S}$ as 2 & $60: 40$ & 16.0 & 25 \\
\hline $17^{7}$ & 1650 & 100 & samo Cas as 2 & $60: 40$ & 16.0 & 25 \\
\hline 18 & 1650 & 100 & No lo foed & $60: 40$ & 16.0 & 26 \\
\hline
\end{tabular}

1 Primary-to-secondary combustion air split.

4 Estimated value.

- Secondary air introduced into the comburtor at level 3.

- Fine limestone.

7 Salt Croek limestone.

Section 4.0 compares the test results from operation on one of the test coals (Colorado Salt Creek bituminous) to the results of test burns performed on two other CFB systems: a vendor-operated pilot plant, and a full-scale unit, both operated on the same type of coal and limestone, to determine the scalability of data from the EERC pilot plant.

The results of testing for Project CFB are summarized, and conclusions are set forth in Section 5.0. A list of references is given in Section 6.0.

The appendices contain separate sections for each particular test run which outline specific procedures and results for each coal tested. The appendices also contain a section which details the design and construction of the EERC pilot-scale CFBC, and modifications which were made to the system as testing progressed. The final appendix lists calculations used during operation of the pilot plant and during data reduction. 


\subsection{DESCRIPTION OF FACILITIES}

\subsection{1-MWth CFBC Test Facility}

A schematic of the overall CFBC system in its latest configuration (as of January 1, 1992) is shown in Figure 2-1. The overall system is divided into the following subsystems:

- Combustion Air System

- Flue Gas System

- Flue Gas Recirculation System

- Ash-Fouling Section

- Coal and Sorbent System

- Combustor

- Solids Recirculation System

- Natural Gas-Fired Preheater

- Combustor Heat Exchange System

- External Heat Exchange System

- Flue Gas Cooling Water System

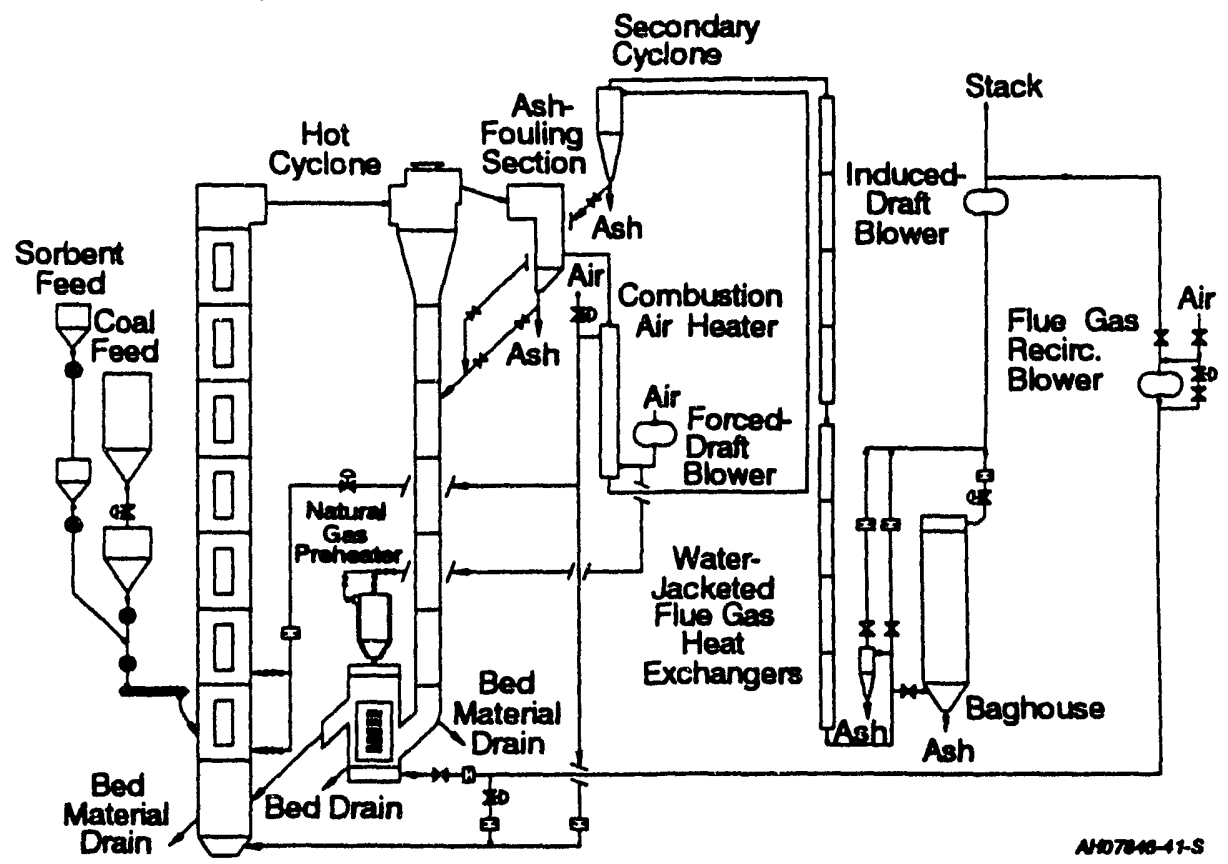

Figure 2-1. Schematic of CFB pilot plant. 
A forced-draft blower supplies combustion air and secondary air to the combustor. The combustion air heater is a shell and tube heat exchanger that uses hot flue gas to preheat the combustion air before it enters the combustor. Total combustion air flow is controlled by the amount of bypass through the combustion air bypass valve located directly after the combustion air heat exchanger. The secondary combustion air control valve determines the ratio of the amount of combustion air which enters the test furnace above the distributor plate to the amount of combustion air introduced into the combustor plenum below the distributor plate. The secondary combustion air can be introduced through manifolds at two different levels, located 5'9" and 10'6" above the distributor plate in Sections 2 and 3, respectively, of the combustor. There are four 3-inch manual gate valves at each level used to select where overfire air is introduced into the combustor. Secondary air addition was through Section 2 during all tests with the exception of Test 14 of the Blacksville run.

Flue gas exits the top of the combustor, then flows through a refractory-lined primary cyclone with an inside diameter of 25 inches, the ash-fouling section, the combustion air heater, an 18-inch stainless steel secondary cyclone, eight water-jacketed flue gas heat exchangers, and through either the flue gas bypass, the baghouse, or par ijally through a 10-inch stainless steel cyclone. Temperatures and pressures are monitored throughout the flue gas system. Flue gas is drawn through the induced-draft (ID) blower where it enters a stack for release to the atmosphere. The ID blower speed is regulated with an electronic speed controller to maintain a zero-pressure balance point in the primary cyclone.

The flue gas recirculation blower is used to supply either air or flue gas to the external heat exchanger (EHX) and to supply flue gas to the combustor for flue gas recirculation testing. Manual gate valves located upstream of the blower allow either air or flue gas to enter the blower. Air was used as the EHX fluidizing gas during all testing.

Primary and secondary combustion air, flue gas recirculation, and flue gas flow rates are measured using orifice plates. Instrumentation is interfaced with the data acquisition/control system to record and display the flow rates. Orifice differential and static pressures are also monitored with magnehelic pressure gages.

The ash-fouling section is located at the exit of the primary cyclone. Two air-cooled stainless steel probes that are maintained at $1000^{\circ} \mathrm{F}$ are present in the ash-fouling section to detect potential ash deposition or slagging. There are provisions for the installation of six additional probes further downstream for a better indication of ash fouling that could occur in the convective pass tube bundle in a CFB boiler. A hopper attached to the base of the ash-fouling section collects ash which drops out of the flue gas stream due to an abrupt change in the direction of flue gas flow. The ash-fouling hopper is connected to the downcomer by a 4-inch stainless steel pipe for ash recirculation. Two pneumatically actuated gate valves are present in the return piping to prevent the bypass of flue gas back from the downcomer.

Coal is delivered to the combustor via two hoppers. The storage hopper has a capacity of about 3000 pounds of coal, which is transferred to a permanent feed hopper in 600-pound increments. A gate valve is used to recharge the coal feed hopper. The coal feed hopper is suspended from a load cell; approximate coal feed rates are calculated from the weight loss of the hopper over time. At the bottom of the weigh hopper, a rotary 
valve connected to an electronic speed controller is used to regulate the coal feed rate. The original sorbent feed system was identical to the coal feed system in most respects, but was sized somewhat smaller. The only significant differences between the two feed systems, other than overall size, are the capacity of the movable sorbent storage hoppers (1000 pounds) and the method of transferring material from the storage hopper to the feed hopper. A rotary valve is used for bulk sorbent transfer, whereas a pneumatically actuated gate valve is used for coal transfer. A completely different sorbent feed system was used for the final Blacksville bituminous test which required the addition of limestone (Test 17) and the entire Black Thunder subbituminous run. Limestone was fed directly into the sorbent rotary valve through a screw feeder which has a variable-speed screw and self-contained charge hopper. Limestone calibrations were performed manually every few hours, and/or every time the feed rate was adjusted. The charge hopper was filled by hand as needed with preweighed volumes of limestone. The sorbent rotary valve that the limestone was fed into also served as a partial seal against back pressure from the combustor. The coal and sorbent feed into a common pipe, which is equipped with another rotary valve to isolate the feed systems from system pressure in the combustor. The coal/limestone mixture drops into a 3-inch horizontal auger that conveys it to the combustor. At this point, the mixture drops downward through a 3-inch pipe and feeds by gravity with air assist into the combustor.

The combustor is a series of refractory-lined sections bolted together. All refractory used was castable and was supplied by Premier Refractories and Chemicals, Inc. Each combustor section contains 2 inches of hard-face abrasion-resistant refractory, type AR$153^{\circ} \mathrm{VC}$, used in combination with 7 inches of insulating refractory. Type 304 stainless steel fibers were incorporated into all of the hard-face refractory cast into the system for increased toughness and shock resistance. The bottom two sections of the combustor contain LITE WATE ${ }^{\star} 58 \mathrm{LI}$ insulating refractory which is designed for use under reducing conditions. The remaining combustor sections were insulated with CER LITE ${ }^{T M}$ 50 which is formulated for use in oxidizing atmospheres. The bottom plenum section contains the primary combustion air entrance and a bed material drain. The solids recirculation return from the external heat exchanger flows to the first combustor section (Section 1). A removable stainless steel nozzle distributor plate is installed between the plenum and first combustor section. The next seven sections (Sections 2-8) each have two doorways on opposite sides for the installation of either blank refractory doors or heat exchanger panels. At this time, twelve of the possible fourteen heat exchanger panels are installed in the combustor: two each in Sections 2,3,4,7, and 8, and one each in Sections 5 and 6 . Section 2 contains the entrance for gravity feed of coal and sorbent and the first set of secondary combustion air ports. Section 3 has the second set of four secondary combustion air ports. Section 9 , the combustor exit, connects to the primary refractorylined cyclone. Thermocouples and pressure taps are present in all of the combustor sections. All pressure taps are continuously purged to keep them open for accurate pressure measurements.

The refractory-lined components of the solids recirculation system include the primary cyclone, the downcomer sections, and the external heat exchanger (EHX). CER LITE ${ }^{\mathrm{TM}} 50$ was used as insulating refractory for all of these components. AR-153 VC hard-face abrasion-resistant refractory was used in the barrel section of the cyclone. FSC-9 ${ }^{\mathrm{TM}}$ VC was selected as the hard-face refractory for the remainder of the solids recirculation components because of its greater resistance to the thermal shock which occurs in this portion of the system while maintaining its abrasion resistance. Solids that 
are captured by the primary cyclone drop into the downcomer and travel downward into the EHX. Thermocouples monitor the temperature at the entrance and exit of the primary cyclone. Additional solids that drop out in the ash-fouling section hopper and that are collected by the secondary cyclone can be either added back into the downcomer or collected separately.

The EHX has a plenum section into which either air or flue gas can be introduced. A removable stainless steel nozzle distributor plate is installed between the plenum and the main body of the EHX. The natural gas-fired preheater, described later, is attached to the top section of the EHX. Sixteen U-shaped stainless steel water-cooled heat exchanger tubes are installed in a removable refractory-lined door in the EHX. There are thermocouples and pressure taps distributed along the sections of the downcomer and in the external heat exchanger.

The natural gas-fired burner is bolted on top of the preheater and fires downward. The preheater combustion chamber is constructed with inner and outer stainless steel shells. To maintain an acceptable operational temperature on the inside surface of the preheater, air is circulated through a baffled cooling jacket. Cooling air enters at the top of the preheater and flows downward where it combines with the combustion gases at the bottom of the preheater transition cone. Preheater combustion air and the cooling jacket air are supplied by the forced-draft blower. A butterfly valve in the 4-inch supply line from the FD blower to the preheater and a gate valve between the preheater and the EHX isolate the preheat system when it is not being used. There are two additional butterfly valves in the combustion air and cooling air lines to the preheater for control purposes. There are also orifice plates in each line with magnehelics to monitor the flow rates. Gas flows to the natural gas burner and pilot burner are controlled with flowmeters located in the control room. There is a flame safety system located in the control room to shut off the flow of natural gas to the preheater if 1) a flame is not present in the preheater, 2) combustion air is not being supplied to the preheater or cooling jacket, or 3 ) the combustion air pressure is greater than the natural gas pressure supplied to the preheater.

The rate of water flow to the combustor heat exchangers (CHX) is measured individually for each door by flowmeters and controlled by globe valves installed above the flowmeters in the CHX panel boards. Total flow is measured with an in-line turbine flowmeter, which includes a bypass to allow for maintenance or repair during operation. An air system is connected to the inlet manifolds of each of the heat exchange panels. Air is used to cool the heat exchanger panels down during operation prior to the introduction of water. Each inlet manifold has a selector switch to allow for the proper distribution of either air or water through the manifold into the heat exchanger tubes of the panels.

There are sixteen heat exchange coils installed in the external heat exchanger door. Each U-shaped heat exchanger is constructed out of 1 -inch stainless steel pipe with $1 / 2$-inch stainless steel tubing at each end. Each of eight circuits has a flowmeter and flow control valve mounted in a panel board to monitor and control the flow of water. Total flow is measured with an in-line turbine flowmeter, installed with a bypass to allow for maintenance or repair during operation. There are eight different EHX heat exchanger circuits, two using a single tube, four with two tubes in series, and two with three heat exchanger tubes connected in series. There is a thermocouple located in the exit of each circuit to measure the exit water temperature. 


\subsection{Coal and Limestone Preparation}

The coal and limestone were prepared in the solids preparation system shown in Figure 2-2. Crushing was performed with a Williams hammer-mill crusher. The material exited tise crusher and was conveyed to a vibrating screen. Various sereens were used during classification of the coals and limestones, with oversized material returned to the crusher.

The sized coal was routed into standby 2-ton capacity totes. The coal was then transferred as needed by forklift and crane to storage hoppers having net capacities of approximately 3000 pounds. The crushed and classified limestone was placed into two 1000-pound capacity storage hoppers. Any remaining prepared limestone was placed into 55-gallon drums and held in storage.

\subsection{Flue Gas Emissions Monitoring}

Flue gas composition was monitored continuously throughout the runs. The results of these analyses were recorded in the data acquisition system, as well as displayed in the control room. The flue gas was sampled at a location just prior to the baghouse (Sample Line A); in addition, a flue gas sample was taken at the primary cyclone exit (Sample Line B). $\mathrm{SO}_{2}, \mathrm{O}_{2}, \mathrm{CO}_{2}, \mathrm{CO}, \mathrm{NO}_{2}$, and $\mathrm{N}_{2} \mathrm{O}$ were measured at the first location; only $\mathrm{SO}_{2}$ and $\mathrm{O}_{2}$ emissions were measured at the second location. The duplication provides a method to ensure that no major leaks exist in the combustion air heater. Table 2-1 shows the instrument and technique used for each flue gas component analysis. The flue gas system analyzers were calibrated at least three times a day.

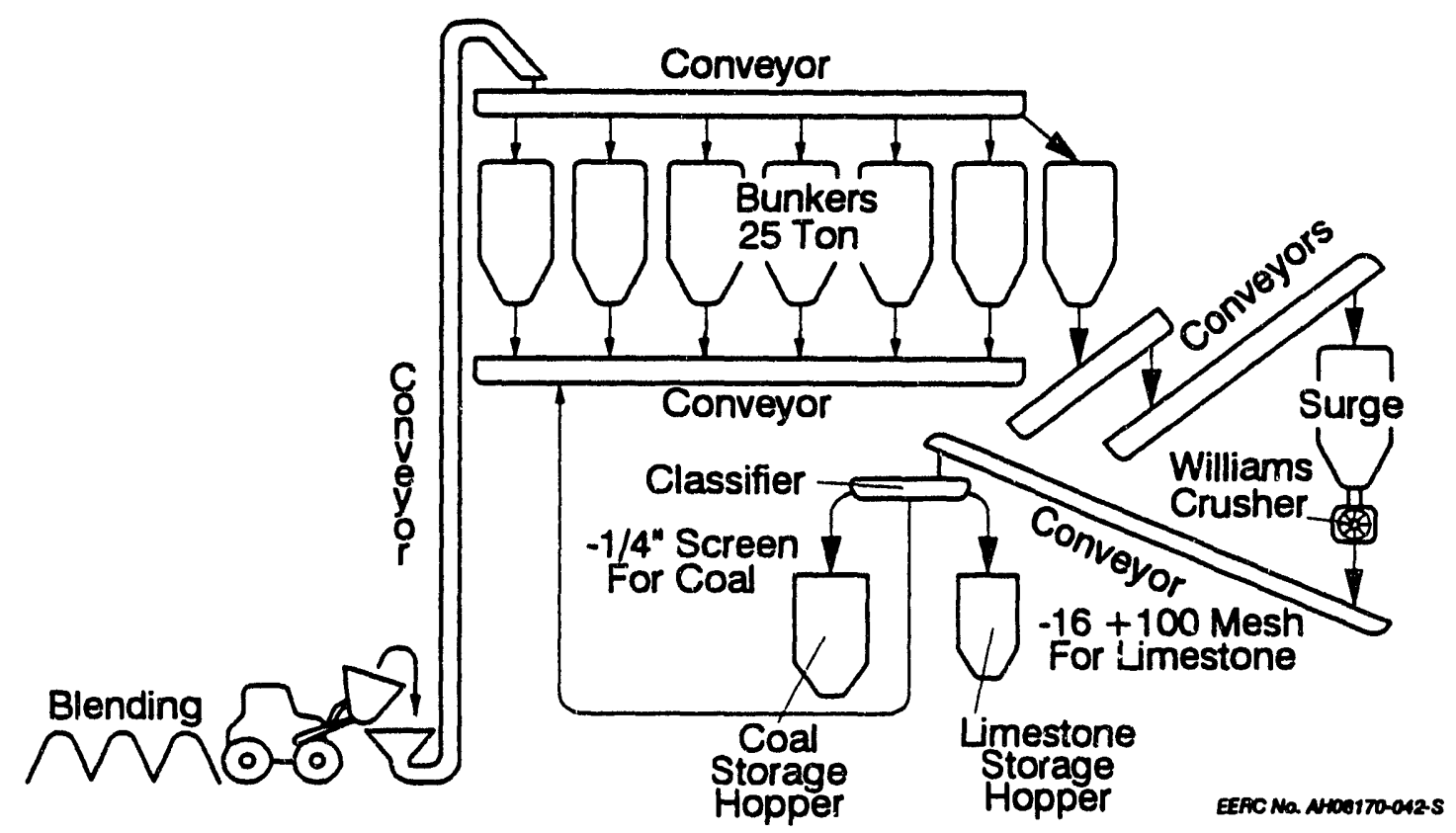

Figure 2-2. Schematic of solids preparation system. 
TABLE 2-1

Flue Gas Analytical Instrumentation

\begin{tabular}{ccc}
\hline Gas Component & Analyzer & Detection Technique \\
\hline $\mathrm{O}_{2}$ & Beckman Model 755 & Paramagnetic \\
$\mathrm{SO}_{2}$ & Dupont Model 400 & Photometric Light Absorption \\
$\mathrm{NO}_{x}$ & Thermo-Electron Series 10 & Chemiluminescent in a \\
& & Photomultiplier Tube \\
$\mathrm{N}_{2} \mathrm{O}$ & Siemens Ultramat 5E & Infrared \\
$\mathrm{CO}, \mathrm{CO}_{2}$ & Beckman Model 865 & Infrared \\
\hline
\end{tabular}

\subsection{Analytical Equipment and Procedures}

The following equipment and procedures were used for the analysis of coal, fly ash, limestone, and bed material samples:

- Proximate analysis was performed to determine moisture, ash, volatile matter, and fixed carbon levels of the coal. Moisture, ash, and volatile contents were determined with a Fischer 490 coal analyzer. Fixed carbon was calculated by subtracting the sum of the percentage moisture, ash, and volatile matter from $100 \%$.

- Ultimate analysis was performed to determine the carbon, hydrogen, nitrogen, sulfur, ash, and oxygen content of the coal. A Perkin-Elmer Model 240 elemental analyzer was used to determine CHN concentrations. Trtal sulfur content was determined with a Fischer sulfur analyzer. Ash was determined as described above in the proximate analysis. Oxygen was calculated by subtracting from $100 \%$ the sum of percentages of moisture and the other components of the ultimate analysis.

- Heating (calorific) value of the coal was measured by ASTM Method D 2015-77 using a Parr adiabatic calorimeter and master controller.

- Particle-size distributions of the coal, limestone, bed material, downcomer material, secondary cyclone ash, and baghouse ash were determined by sieve analysis according to ASTM Method D 410-38 utilizing U.S. standard screens. Malvern (particle-size distribution by laser light scattering), wet sieve, and Coulter Counter analyses were also performed on the ash and limestone as needed for comparative purposes.

- Major mineral oxides (Al, Si, $\mathrm{Na}, \mathrm{Mg}, \mathrm{Ca}, \mathrm{P}, \mathrm{K}, \mathrm{Fe}, \mathrm{Ti}$, and $\mathrm{S}$ ) were determined by $\mathrm{X}$-ray fluorescence using a Kevex $0700 \mathrm{x}$-ray spectrometer.

- The amount of carbonate (uncalcined limestone) in ash samples was determined by ASTM Method D 1756-62. 


\subsection{Scanning Electron Microscopy}

Various solids samples were analyzed using scanning electron microscopy (SEM) with the Noran automated digital electron microscope (ADEM). The ADEM has the capacity for imaging and photography at magnifications ranging from 10 to 80,000 . It is linked to a personal computer to allow for data manipulation. 


\subsection{IMPACTS OF COAL AND LIMESTONE PROPERTIES ON OPERATIONAL PERFORMANCE}

Coals are ranked based on established ASTM guidelines according to their heating value, amount of volatiles, and fixed carbon content. The low-rank coals are characterized as having low heating value, high volatile content, and high moisture. Conversely, highrank coals are characterized by high heating values and a high fixed carbon content. Generally speaking, the reactivity of the coal increases with decreasing rank.

The quantity and nature of the ash can vary widely and is more a function of the region of the country and the geological conditions under which the coal was formed rather than a function of rank. Many western U.S. coal ashes have relatively high alkaline contents as compared to their eastern counterparts; however, many of the coals in the Southwest have several of the same ash components as do typical eastern coals. Sulfur content, another critical coal property, is also more dependent upon location rather than rank, although most eastern coals have higher sulfur levels than do western coals. Therefore, it is critical to compare operational performance based on individual coal parameters independent of rank.

The EERC has built up an extensive database characterizing the performance of five coals under Project CFB. Detailed analysis of the coal composition and size are presented in Appendices $A$ through $E$ of this report. A list of the coals tested, along with their properties, was presented in Table 1-1. Figure 3-1 is a comparison of the average size distribution of the coals tested. Abbreviations of the coals used in this paper are CL-Center lignite, TL-Asian lignite, BT--Black Thunder subbituminous, SC--Salt Creek bituminous, and BV--Blacksville bituminous.

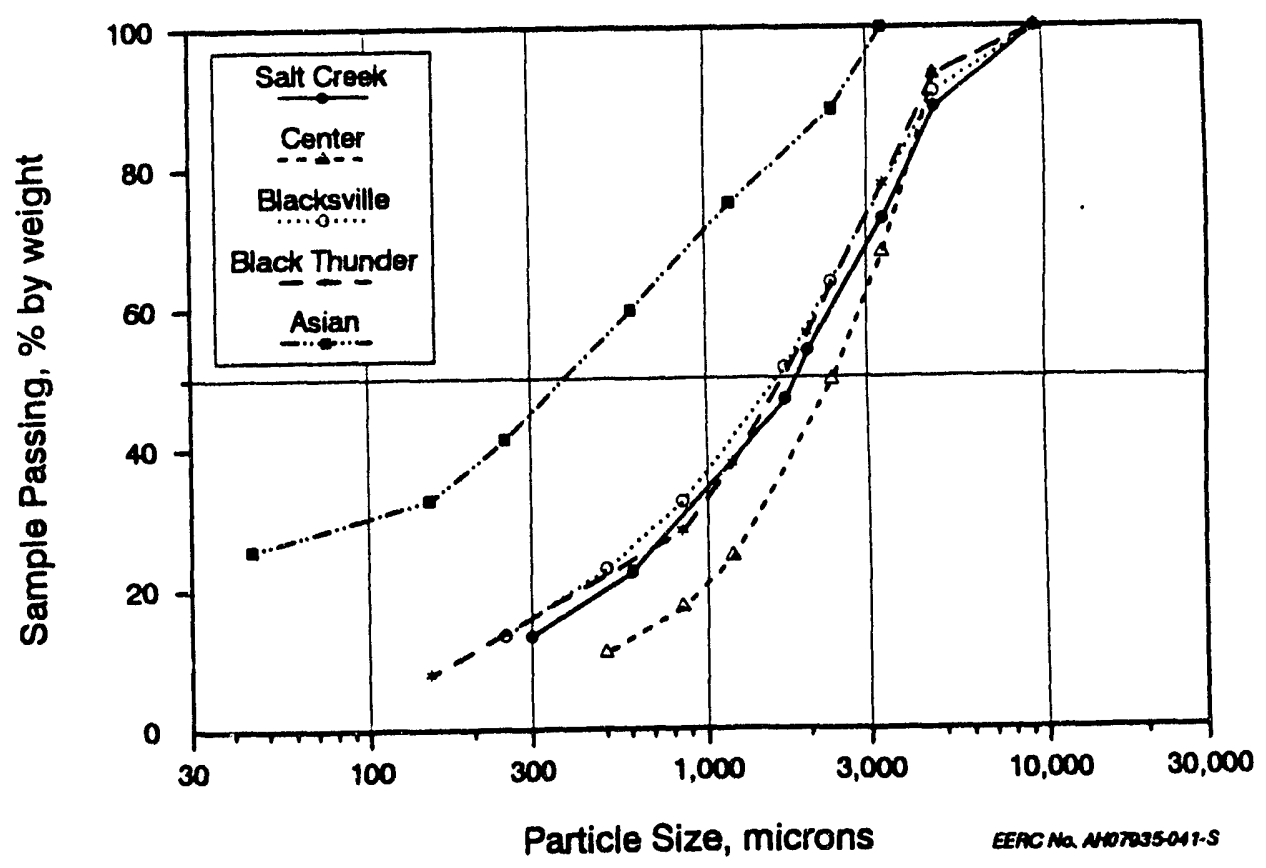

Figure 3-1. Comparison of average coal size distributions. 
Table 3-1 shows a comprehensive list of selected critical test parameters that affect CFB performance along with a list of the critical operational performance results that were routinely determined for the test matrices conducted with the five different coals at the EERC. With the exception of replacement of the particulate collection device with a cyclone, the system geometry remained constant during all five test matrices. The operational test parameters selected for testing included average bed temperature, load (defined as a percentage of the coal feed rate at baseline conditions), either the calcium-tosulfur ratio or sulfur retention, the primary/secondary combustion air split, superficial gas velocity, and excess air. Heat-transfer surface was varied as required to maintain the desired load. One test period during Blacksville testing was also performed at a different level of secondary air addition. The use of solids recycle from the secondary cyclone is an additional variable that was considered during examination of test results.

\section{TABLE 3-1}

Identification of EERC Test Parameters and Operational Results

\section{Critical Operational Test Parameters}

Coal Size Distribution

Coal Composition

Limestone Size Distribution

Limestone Composition

Average Bed Temperature

Load

$\mathrm{Ca} / \mathrm{S}$ Ratio or Sulfur Retention

Primary/Secondary Combustion Air Split
Superficial Gas Velocity

Excess Air

Recycle of Secondary Cyclone Solids

Secondary Air Addition

Heat-Transfer Surface

- Combustor

- External Heat Exchanger

\section{Critical Operational Performance Results}

Combustor Bed Material

- Size Distribution

- Composition

- Quantity

Downcomer Material

- Size Distribution

- Composition

- Quantity

Secondary Cyclone Ash

- Size Distribution

- Composition

- Quantity

Baghouse Ash

- Size Distribution

- Composition

- Quantity
Coal Feed Rate

Limestone Feed Rate

Combustor Temp. Distribution

Combustor Pressure Distribution

Downcomer Temp. Distribution

Downcomer Pressure Distribution

Recirculation Rate

Solids Collection Efficiency

Limestone Utilization

Sulfur Retention or $\mathrm{Ca} / \mathrm{S}$ Ratio

$\mathrm{SO}_{2}$ Emissions

$\mathrm{NO}_{\mathrm{x}}$ Emissions

$\mathrm{N}_{2} \mathrm{O}$ Emissions

CO Emissions

Combustion Efficiency

Heat Transfer 
Three of the five test matrices (Blacksville bituminous, Black Thunder subbituminous, and Center lignite) were conducted with the New Enterprise limestone to, as much as possible, eliminate limestone selection from affecting test results. The first test matrix was with the Salt Creek subbituminous coal and limestone that were used for testing at the Colorado-Ute Nucla full-scale CFB electrical generating station. This test matrix addressed scalability of the EERC CFB pilot plant test results to the full-scale results from Nucla. Both the coal and limestone used for the Asian lignite test were from the same region. Table 1-1 has the average composition of the limestones utilized for each of the five test matrices, while Figure 3-2 shows the average limestone size distributions.

\subsection{Overall Operability}

\subsubsection{Bed Material Size Distribution and Recirculation Rates}

The bed material size distribution and recirculation rates are dependent upon the coal and limestone properties, operational parameters like superficial gas velocity and primary-to-secondary air split, and the performance of the particulate collection device used. During all of the first test matrix with Salt Creek bituminous coal, and through most of the second test matrix with Center lignite, an impaction-type collection device (the Chevron impactors) was used to capture solids for recirculation, along with a secondary cyclone to enhance overall solids collection efficiency. For the remaining test matrices, the primary cyclone was used both with and without secondary cyclone ash recycle for additional solids recirculation. Collection configurations are summarized in Table 3-2. Chevron impactor configurations are identified in Appendix F.

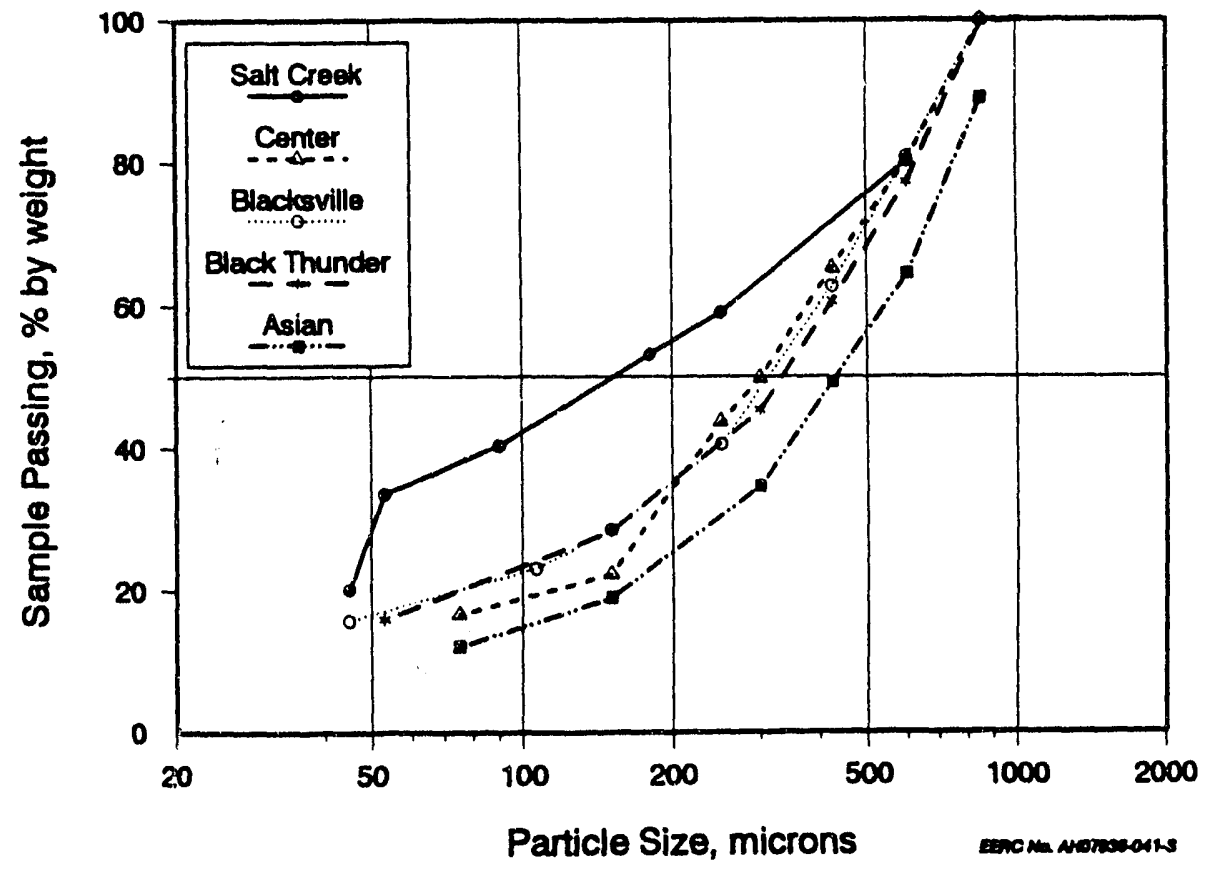

Figure 3-2. Average limestone size distributions. 
TABLE 3-2

Solids Recirculation Configurations Utilized

During Parametric CFB Pilot Plant Testing

\begin{tabular}{|c|c|c|}
\hline Test Identification & Primary Collection Device & Secondary Collection Device \\
\hline $\begin{array}{l}\text { Salt Creek } \\
\text { Tests } 1-12\end{array}$ & $\begin{array}{l}\text { Chevron Impactors - } \\
\text { Configuration \#1 }\end{array}$ & 18" Stainless Steel Cyclone \\
\hline $\begin{array}{l}\text { Center } \\
\text { Tests } 0.6\end{array}$ & $\begin{array}{l}\text { Chevron Impactors - } \\
\text { Configuration } \# 2\end{array}$ & 18" Stainless Steel Cyclone \\
\hline $\begin{array}{l}\text { Center } \\
\text { Tests 7-10 }\end{array}$ & 25" Refractory Cyclone & 18" Stainless Steel Cyclone \\
\hline $\begin{array}{l}\text { Blacksville } \\
\text { Tests } 1-18\end{array}$ & 25" Refractory Cyclone & None \\
\hline $\begin{array}{l}\text { Black Thunder } \\
\text { Test } 1\end{array}$ & 25" Refractory Cyclone & None \\
\hline $\begin{array}{l}\text { Black Thunder } \\
\text { Tests } 2-9\end{array}$ & 25" Refractory Cyclone & 18" Stainless Steel Cyclone \\
\hline $\begin{array}{l}\text { Asian } \\
\text { Tests 1-4 }\end{array}$ & 25" Refractory Cyclone & None \\
\hline
\end{tabular}

Figures 3-3 and 3-4 show the size distribution of the bed material sampled from the combustor and the bed material collected from the downcomer, respectively, from a representative test period from each of the five test matrices completed.

Addition of secondary combustion air is normally through Section 2 of the combustor, 5.75 feet above the distributor plate. To keep the solids fluidized in the bottom of the combustor, Section 1 is tapered, starting with an inside diameter of 14 inches at the bottom and increasing to 20 inches at the top. The remaining combustor sections above Section 1 all have a 20-inch inside diameter. During Test 14 with the Blacksville coal, secondary air addition was through Section 3 at a height of 10.5 feet above the distributor plate. This created a low-velocity region in combustor Section 2, allowing less solids to be carried up to Section 3, resulting in decreased solids recirculation compared to other Blacksville tests conducted at equivalent operating conditions.

One of the most significant factors affecting solids recirculation was whether or not the secondary cyclone was used to recirculate additional fines back into the system. For testing with the Blacksville bituminous coal and with the Asian lignite, it was not necessary to utilize secondary cyclone ash recycle. For the other low-ash, low-sulfur coals, secondary cyclone ash recycle was used to maintain solids inventory in the combustor. These tests tended to have lower recirculation rates compared to the Black Thunder subbituminous and Salt Creek bituminous tests. An exception to this trend was the Center lignite testing which had low recirculation rates even though secondary cyclone ash recycle was utilized. It appears that the cohesive ash properties, possibly due to the high sodium in the coal, might have resulted in reduced solids recirculation rates. It appears that solids recirculation is somewhat related to coal ash properties. It would take 


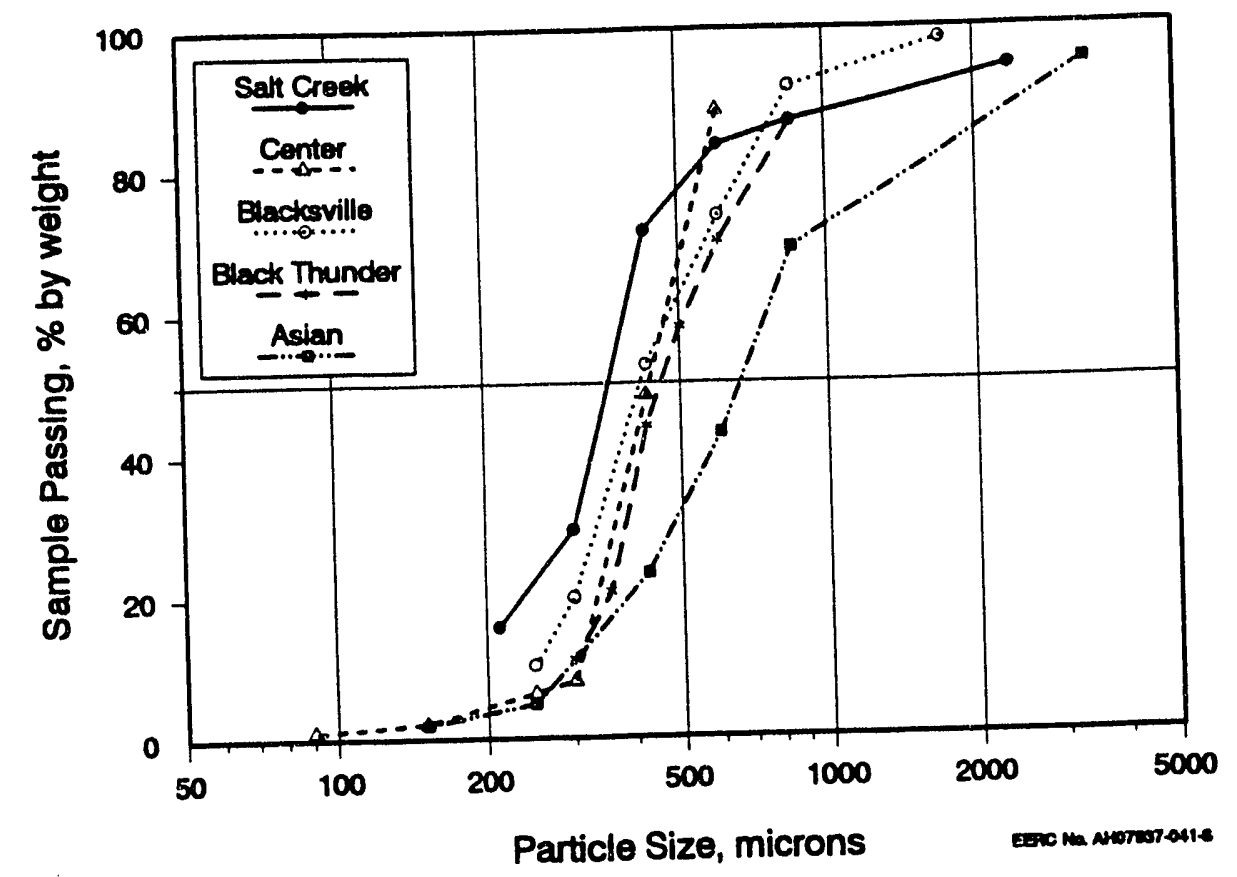

Figure 3-3. Size distributions of bed material sampled from combustor.

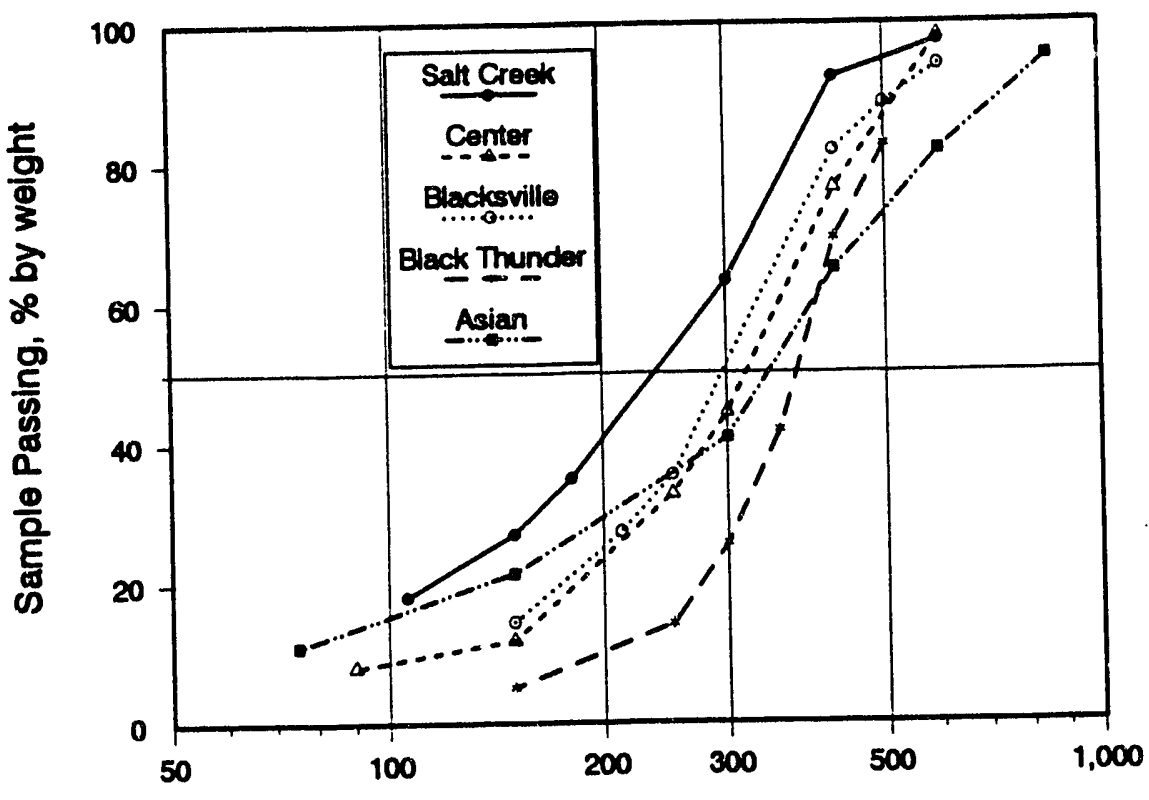

Particle Size, microns

Figure 3-4. Size distributions of bed material sampled from downcomer. 
a more specifically designed test matrix to better define the extent that coal properties affect solids recirculation. A carefully designed system, which would allow the reinjection of multicyclone or baghouse ash back into the recirculation loop, could likely be used to more closely control recirculation rates. Therefore, more efficient operation, in terms of heat transfer and emissions, could be obtained in the event that a fuel other than the design coal was to be used.

Figure 3-5 shows recirculation rate as a function of load. To decrease load, the superficial gas velocity is decreased along with the coal feed rate, which results in decreased solids recirculation. It can also be seen from these data that the Center, Black Thunder, and Salt Creek tests which employed secondary cyclone recycle resulted in increased solids recirculation rates.

\subsubsection{Cyclone Efficiency}

Cyclone efficiency is defined as one minus the fly ash discharge rate divided by the recirculation rate. Cyclone efficiency is used here to collectively describe total system efficiency for the capture of solids using a primary, and a secondary (if recycled), collection device for solids recirculation. Solids capture is determined by the collector geometry as well as operational parameters, including the combustor velocity and fuel and limestone properties. The collector configuration used for all five test coals was previously identified in Table 3-2. Adequate recirculation rates were maintained by some combination of high cyclone efficiency and a high input of solids into the system.

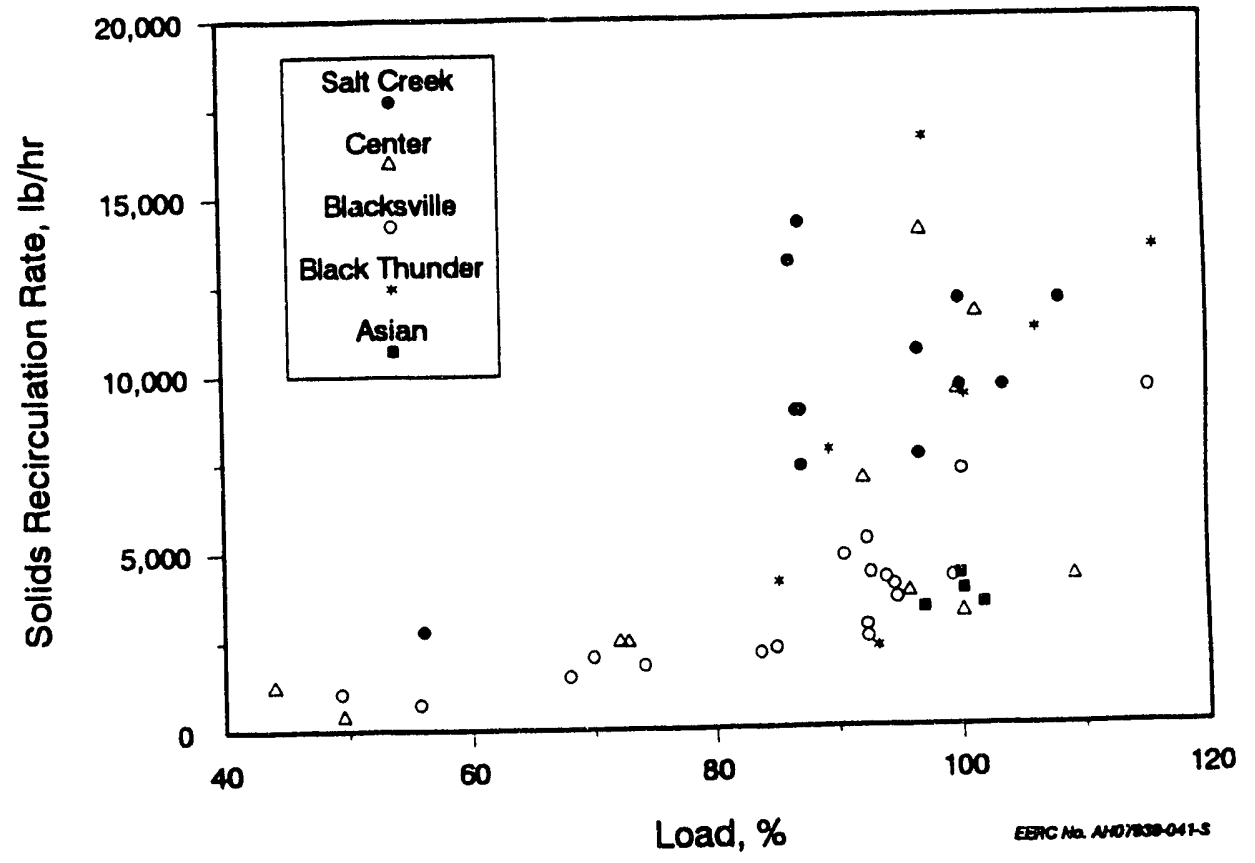

Figure 3-5. Recirculation rate as a function of load. 
Cyclone efficiencies ranged from a low of $93.8 \%$ with the Asian lignite to $99.9 \%$ with Black Thunder bituminous. For testing conducted with Center, Black Thunder, and Salt Creek fuels, secondary cyclone recycle was used to maintain adequate bed inventory and recirculation rates. These three coals had relatively low coal ash and sulfur content, resulting in low quantities of solids available for recirculation. Additionally, the size of the limestone used for Salt Creek testing was relatively small, making it difficult to keep in the system. The Blacksville bituminous was a low-ash coal, but required relatively high limestone feed rates due to its high sulfur content, and subsequently no secondary cyclone recycle was required to maintain sufficient bed inventory. Although the cyclone efficiencies for the Asian lignite were significantly lower than for the other four test coals, no secondary cyclone recycle was required to maintain adequate bed inventories due to the high solids input of sorbent and the low-Btu, high-sulfur, high-ash fuel.

\subsubsection{Solid Waste Generation}

An important aspect of the design of the CFBC is sizing of the solids-handling systems. From an operational standpoint, disposal of the solid wastes (coal ash and spent sorbent) becomes a very important economical consideration. The amount of solids generated is highly dependent upon coal properties, as shown in Figure 3-6. The combination of high ash and high sulfur in the Asian lignite results in very large quantities of solid waste. For the other coals tested, the amount of solid waste generated increased with the amount of ash in the coal and the amount of limestone added. The two bituminous coals generated more solid wastes than the two low-rank coals. Sorbent. addition rates are highest for high-sulfur, low-alkaline-ash coals and increase with increasing sulfur capture requirements. In designing the CFBC solids-handling system and determining waste disposal requirements, it is important to design for the highest solid waste generating fuel, otherwise derating will be required due to the inability to handle the large volume of wastes generated from these fuels.

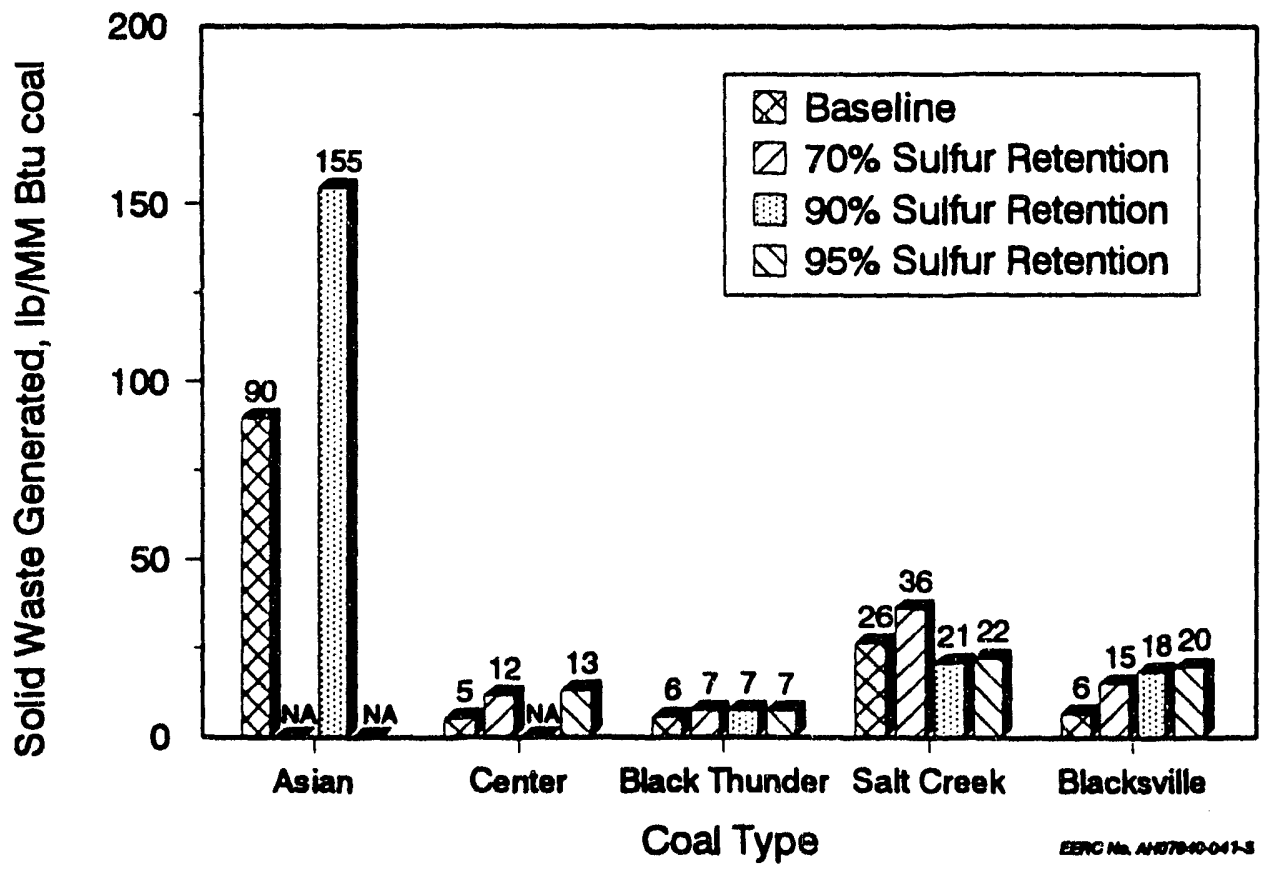

Figure 3-6. Solid waste generation as a function of coal property. 


\subsubsection{Agglomeration and Ash Deposition}

One aspect of system operation that is directly impacted by fuel ash properties is agglomeration and deposition. The Center lignite has a relatively high sodium level in the ash (4\%). During the tests, particle growth was observed, but did not lead to severe agglomeration. However, a fuel with slightly higher levels of sodium or potassium would likely result in problems due to agglomeration. Fuels with high levels of organically bound calcium have been shown to have the potential to cause problems with fouling in the convective and reheat sections of a boiler. A very hard, fine-grained calcium sulfatebased deposit formed on the ash-fouling probes and the primary flue gas heat exchanger during the tests with the Asian and Center lignites. Therefore, a prudent design for fuels similar to these would include adequate soot-blower coverage. More complete discussions of the agglomeration and deposition potential of the lignites can be found in Appendices $B$ and $E$.

\subsubsection{Corrosion and Erosion of System Components}

While there was no specific testing performed to examine the corrosion and erosion of the CFBC components for the coals tested, it is possible to offer some subjective observations based upon visual inspections. Discussion is limited here to the refractory and metal surfaces exposed to hot flue gases and circulating bed material in the combustor, primary cyclone, downcomer, and external heat exchanger. Metal surfaces include the combustor heat exchangers, the heat exchange tubes (type 304 stainless steel) in the external heat exchanger, the primary cyclone vortex finder (1/4-inch-thick type 310 stainless steel), and the thermocouple thermowells (3/8-inch schedule 80 type 310 stainless steel pipe).

The combined shakedown and testing performed for Project CFB resulted in more than 1000 hours of operation over a wide range of conditions. The refractory has been subjected to numerous heating cycles during start-ups, process upsets, and shutdowns. There have also been short-duration temperature excursions in the combustor to over $2000^{\circ} \mathrm{F}$. To date, the refractory has required no maintenance of any sort and has shown absolutely no signs of any erosive or corrosive deterioration.

Regions where erosion is most likely to occur in the EERC CFBC system are in the combustor and primary cyclone. An unknown amount of internal circulation occurs in the combustor, and the entrance to the primary cyclone is subjected to the continuous flow of high-velocity (approximately $60 \mathrm{ft} / \mathrm{sec}$ ) and high-temperature solids from the combustor. Some limited erosion to a patch of about one foot square has occurred inside the primary cyclone barrel where the bed material enters and makes its first turn. Typically a thin layer of ash is deposited on uncooled refractory and metal surfaces in the combustor and primary cyclone. Visual inspections following each run revealed the ash had eroded off at the cyclone entrance without causing any noticeable damage to the refractory surface.

All thermocouples (type $K$ with a 3/8-inch-diameter type 304 stainless steel sheath) located in the high-temperature refractory-lined regions of the system are inserted into type 310 stainless steel thermowells to provide additional protection. No evidence of any significant corrosion or erosion to the thermocouple thermowells has been noted, including those in the combustor. Combustor heat exchangers are almost totally recessed inside the refractory walls of the combustor to protect them from erosion. No measurable erosion 
has been detected for any of the exposed surfaces of the combustor heat exchangers. As would be expected, no indication was found of any erosion of the heat exchange tubes and thermocouples located in the EHX since these components are exposed to low-velocity (1 to $2 \mathrm{ft} / \mathrm{sec}$ ) bubbling solids. The vortex finder in the primary cyclone has survived the harsh conditions to which it has been subjected without any noticeable corrosion or erosion.

\subsection{Emissions}

\subsection{1 $\mathrm{SO}_{2}$ Emissions and Limestone Utilization}

A comparison of sulfur emissions and sorbent performance is presented in Table 3-3. Sorbent performance is addressed as a function of sulfur capture ranging from $70 \%$ up to $95 \%$. The amount of sulfur capture is mainly determined by the total alkali-to-sulfur ratio. Total alkali is provided by the inherent alkali, mineral matter and cations contained within the coal, and the added alkali supplied by sorbent addition. For all of the tests, limestone was the sorbent which was used to supply added alkali in the form of calcium.

Figure 3.7 shows the added alkali-to-sulfur ratio required for $70 \%, 90 \%$, and $95 \%$ sulfur capture for the various coals tested. To retain $90 \%$ of the sulfur present in the coal, the required alkali-to-sulfur ratio ranged from 1.4 to 4.9 depending upon the coal type. However, looking only at the alkali-to-sulfur ratio is misleading. For example, although an alkali-to-sulfur ratio of 4.9 is required to meet $90 \%$ sulfur retention for the Salt Creek coal versus 1.4 for the Asian lignite, the total amount of sorbent addition required is much less for the Salt Creek coal. A sorbent add rate of 4.2 lb/MM Btu of Salt Creek coal input is required versus $62 \mathrm{lb} / \mathrm{MM}$ Btu of Asian lignite, due to differences in the level of sulfur and the alkali in the coal. Figure 3-8 presents the required limestone addition rates in relation to varying levels of sulfur capture for the five coals tested.

The optimum bed temperature resulting in maximum sulfur capture varies somewhat with coal type (Figures 3-9 and 3-10). The bituminous coals tested at the EERC show optimal sulfur capture at combustor temperatures of approximately $1550^{\circ} \mathrm{F}$. Most of the low-rank coals tested, however, exhibited optimal temperature for sulfur capture approximately $100^{\circ} \mathrm{F}$ lower. This is partially due to the coal structure and the forms and relationships of the sulfur and the alkali in the coal itself.

The source and size of limestone can also have an impact on sulfur capture. Two different limestones were tested while burning the Blacksville bituminous coal, as well as two different limestone sizes. Using a coarse limestone $(-20 \mathrm{mesh}), 40 \%$ of the calcium in the limestone was utilized for sulfur capture. A fine limestone $(-40$ mesh) of the same type resulted in a sorbent utilization of only $29 \%$. A second type of limestone (Colorado Ute) of fine particle size ( -40 mesh) showed similar performance, with approximately $29 \%$ utilization. To capture $70 \%$ of the sulfur, alkali-to-sulfur ratios of 1.8 for the coarse limestone and 2.3 for the two fine limestones tested would be required. In this case, the reactivities of the two limestones were similar. While the smaller-sized limestone had a greater surface-to-volume ratio, which would be expected to result in more efficient sulfur capture, the poorer utilization was probably the result of shorter sorbent residence time in the combustor. Cyclone collection efficiencies decrease with decreasing particle size, and smaller sorbent particles may leave the system without being recirculated. For 
TABLE 3-3

Comparison of Sulfur Emissions and Sorbent Performance

\begin{tabular}{|c|c|c|c|c|c|}
\hline Coal Type & Anian & Conter & Black Thunder & Balt Creok & Blectevillo \\
\hline Total Sulfur, $\%$ & 6.9 & 0.68 & 0.3 & 0.46 & 2.4 \\
\hline Inhoront Alleali/Sulfur Ratio & 0.63 & 0.9 & 2.1 & 0.3 & 0.1 \\
\hline Inhorent Sulfur Capture, \% & 70 & 29 & 3 & 2 & 14 \\
\hline Inhoront Alkali Utilization, $\%$ & 112 & 26 & 1.4 & 3 & 64 \\
\hline $\begin{array}{l}\text { Optimum Tomperature for } \\
\text { Sulfur Capturo, }{ }^{\circ} \mathbf{F}\end{array}$ & & & & & \\
\hline Sulfur Capture, 1 & 1666 & 1875 & 1466 & 1620 & 1030 \\
\hline \multicolumn{6}{|l|}{ 70\% Sulfur Capture } \\
\hline $\begin{array}{l}\text { Toot Number } \\
\text { Added Ca/s }\end{array}$ & -1 & CL6 & BT6 & sc3 & BV16 \\
\hline Added Ca/S & -1 & 1.1 & 2.1 & 2.1 & 1.6 \\
\hline Added Sorbont, lb/MMM Btu ${ }^{2}$ & -1 & 4.3 & 2.6 & 3.0 & 9.8 \\
\hline Utilization, $\%$ & -1 & 39 & 31 & 36 & 43 \\
\hline \multirow{2}{*}{\multicolumn{6}{|c|}{ 90\% Sulfur Capture }} \\
\hline Test Number & TL1 & -1 & & & \\
\hline Added Ca/s & 1.4 & -1 & $\begin{array}{r}\text { BT2 } \\
2.6\end{array}$ & $\begin{array}{r}\mathrm{SC} 11 \\
4.9\end{array}$ & $\begin{array}{r}0.3 \\
2.3\end{array}$ \\
\hline Added Sorbont, lb/MM Btu & 62.7 & -1 & 3.0 & 4.2 & 16.6 \\
\hline Utilization, \% & 63 & -2 & 31 & 19 & 39 \\
\hline \multirow{2}{*}{\multicolumn{6}{|c|}{ 96\% Sulfur Capture }} \\
\hline Test Number & -1 & CL8 & & & \\
\hline Addod Ca/S & -1 & 2.3 & $\begin{array}{r}\text { B18 } \\
2.6\end{array}$ & 6.7 & 2.9 \\
\hline Added Sorbent, lb/MM Btu & -1 & 7.8 & 3.3 & 7.1 & 19.3 \\
\hline Utilization, \% & -1 & 36 & 37 & 17 & 32 \\
\hline
\end{tabular}

1 No teats were porformed at $1560^{\circ} \mathrm{F}$ and a corresponding sulfur capture.

2 Pounds sorbent added per million Btu cosl input.

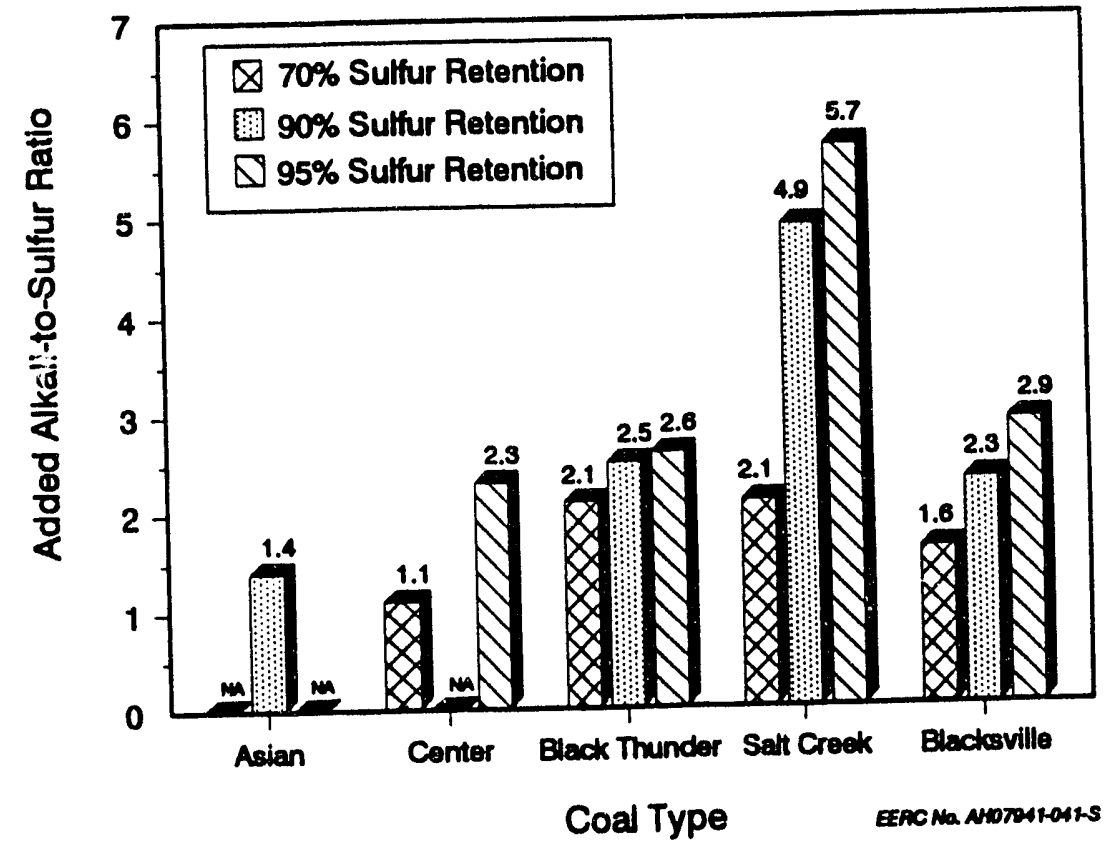

Figure 3-7. Added alkali-to-sulfur ratio required for increasing sulfur capture at $\sim 1550^{\circ} \mathrm{F}$ as a function of coal type. 


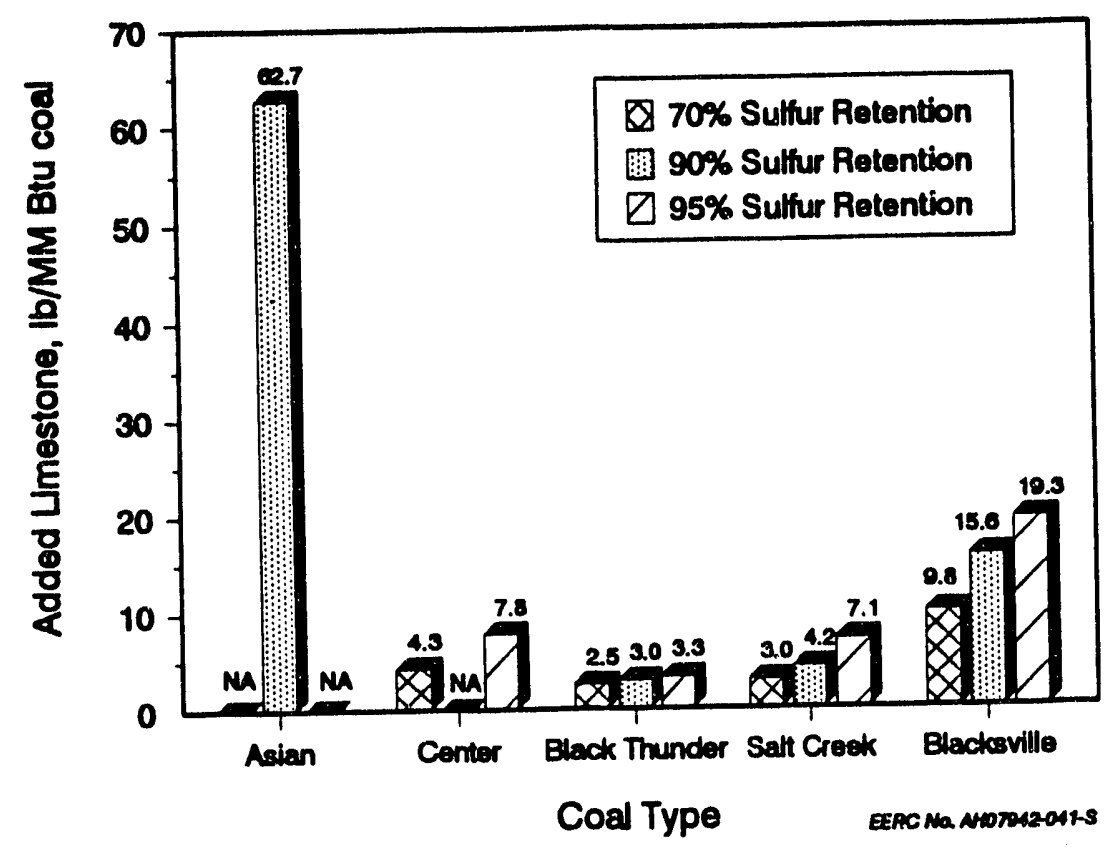

Figure 3-8. Added limestone required for increasing sulfur capture at $\sim 1550^{\circ} \mathrm{F}$ as a function of coal type.

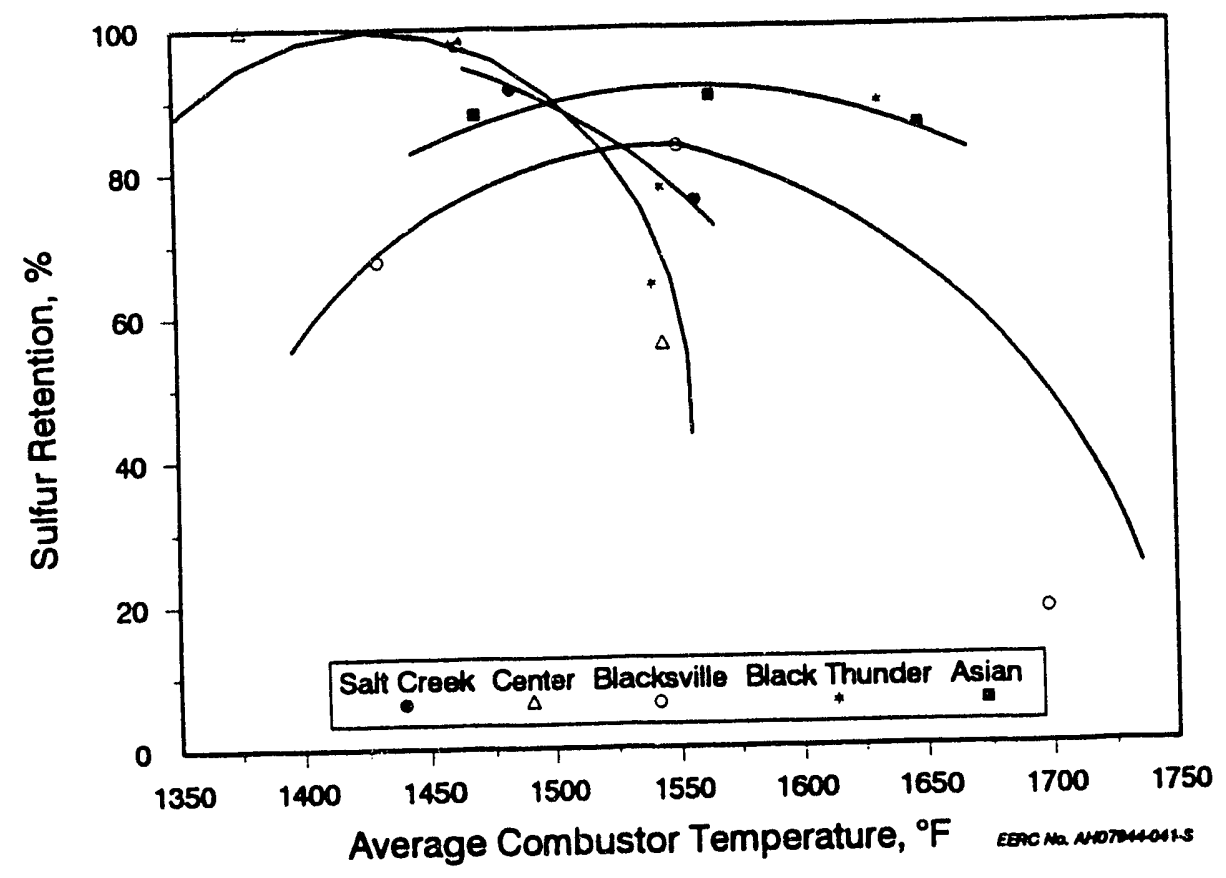

Figure 3-9. Sulfur retention as a function of average combustor temperature, showing the optimum temperature for maximum sulfur capture for each coal. 


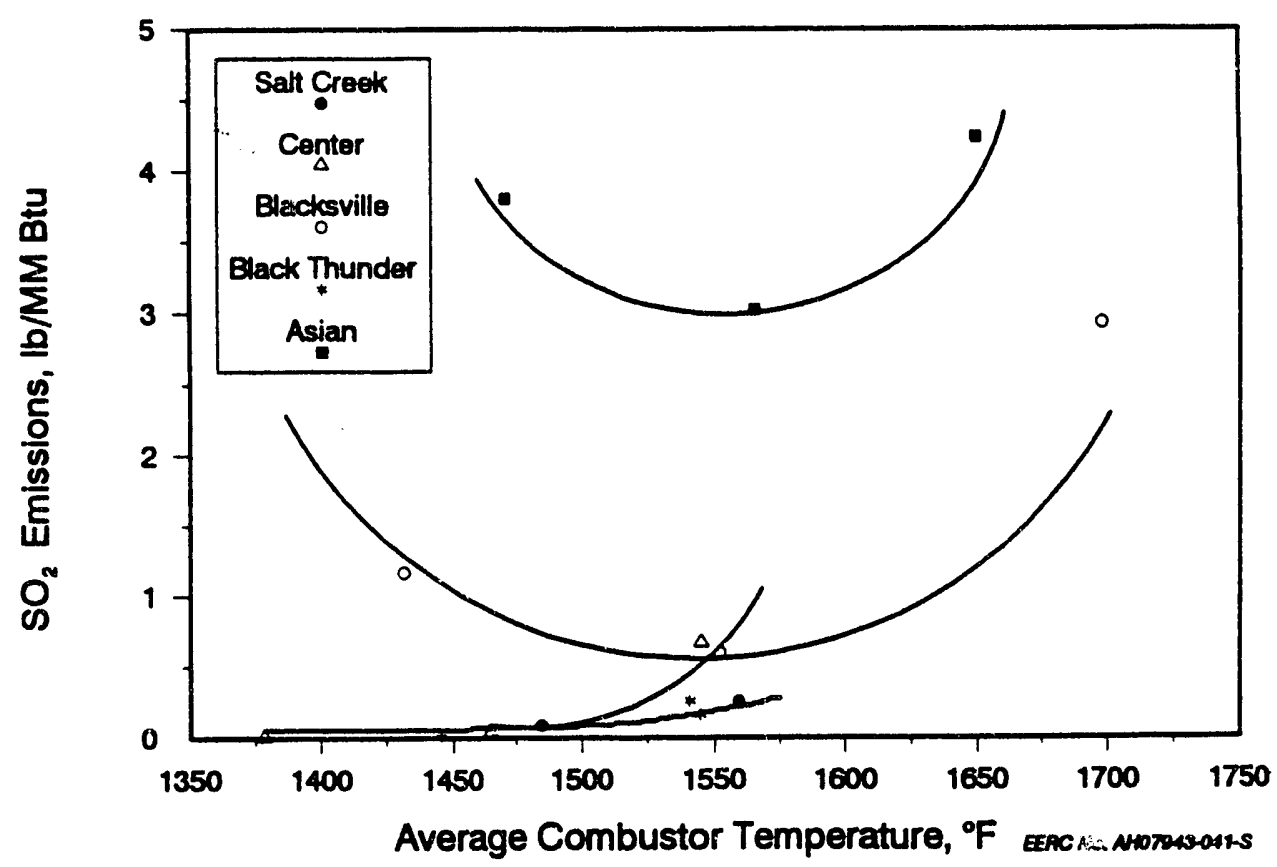

Figure 3-10. $\mathrm{SO}_{2}$ emissions as a function of average combustor temperature, showing the optimum temperature for maximum sulfur capture for each coal.

limestones with different reactivities, the add rates can also vary as a function of limestone type. Results obtained on the impact of limestone size and type on other parameters are shown in Figure 3-11.

The coal properties that most affect the required amount of added alkali are total sulfur and inherent alkali present in the coal (indicated in Table 3-3 by the inherent alkali-to-sulfur ratio). Some generalizations on expected sulfur capture behavior as it relates to coal properties can be made based upon the testing performed. As the sulfur content of the coal increases, more limestone will be required, but utilization of the available calcium in the limestone will be higher due to the higher driving force supplied by the greater concentration of $\mathrm{SO}_{2}$ in the combustor. The combination of a low-sulfur coal and a low inherent alkali-to-sulfur ratio will require sorbent addition at a low feed rate, but because of the diminished driving force within the combustor due to low $\mathrm{SO}_{2}$ concentrations, the additional alkali-to-sulfur ratio required will be high. For a given amount of sulfur in the coal, as the inherent alkali-to-sulfur ratio increases, less added limestone will be required due to the increased capture of sulfur by the alkali inherent to the coal ash. Overall calcium utilization as a function of added calcium-to-sulfur ratio is shown in Figure 3-12. 


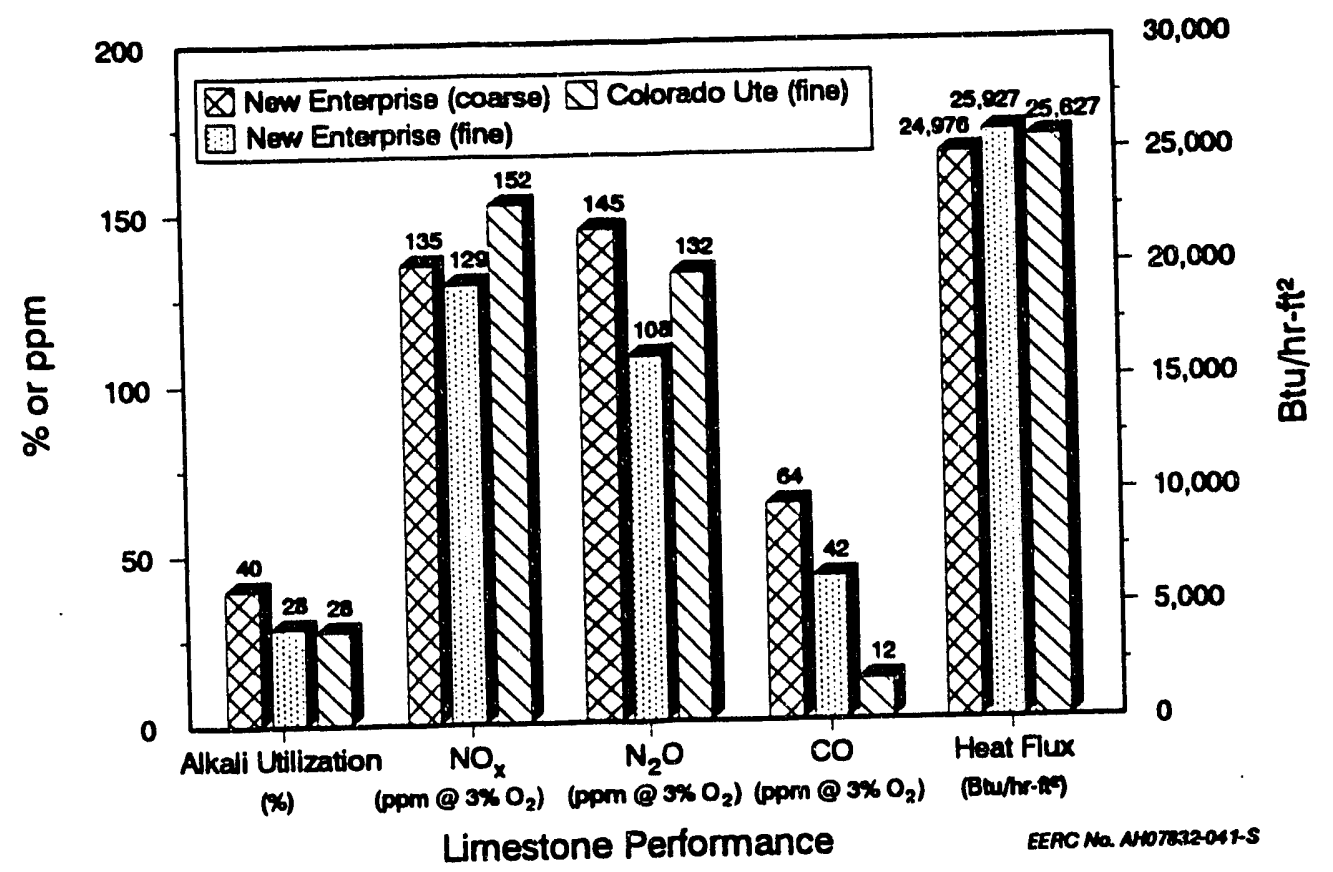

Figure 3-11. CFBC performance as a function of limestone size and type.

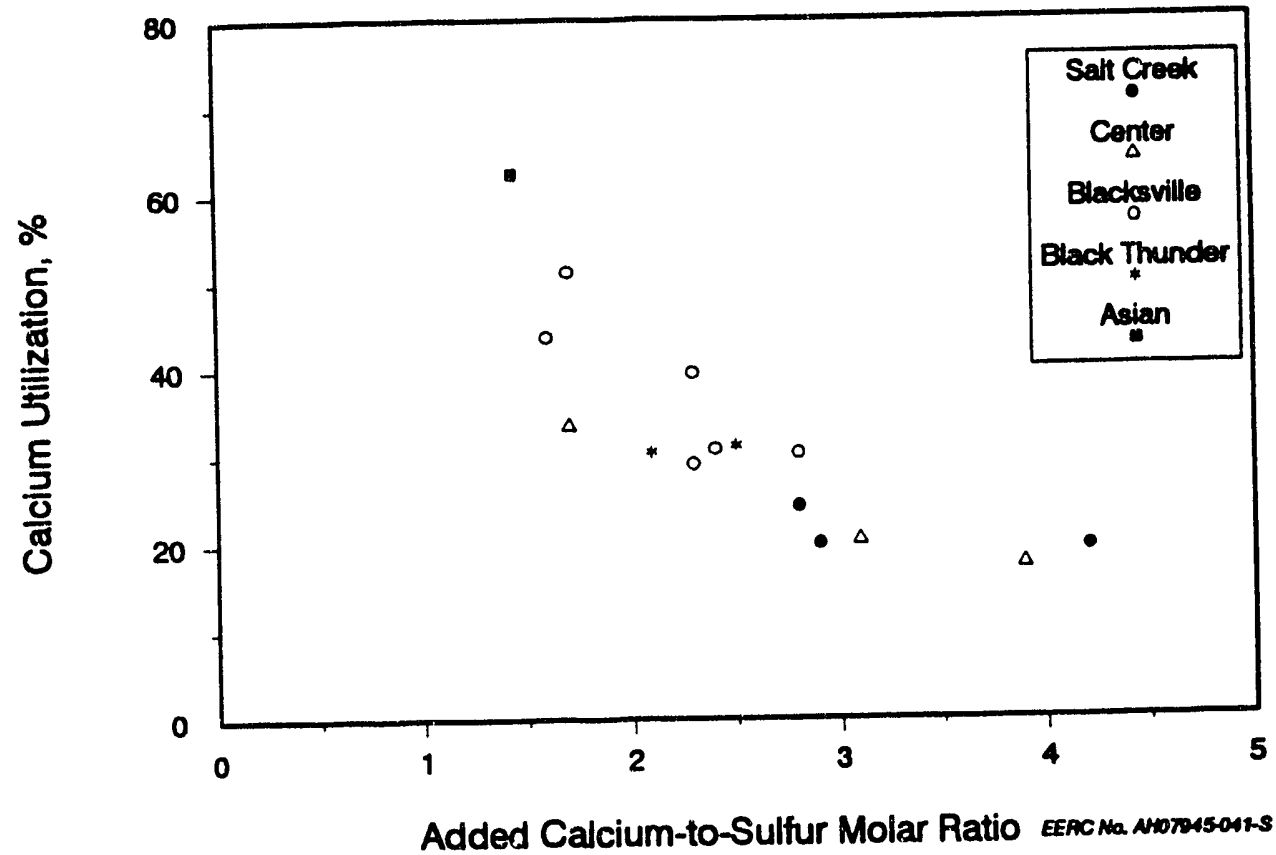

Figure 3-12. Calcium utilization as a function of added calcium-to-sulfur ratio. 


\subsubsection{Nitrogen Oxide Emissions}

Regulated nitrogen oxide emissions currently include $\mathrm{NO}$ and $\mathrm{NO}_{2}$, collectively termed $\mathrm{NO}_{\mathrm{x}}$ emissions. $\mathrm{NO}_{\mathrm{x}}$ emissions from the CFBC are highly coal dependent.

Table 3-4 summarizes nitrogen emissions data for all five of the coals tested. Figures 3-13 and 3-14 compare $\mathrm{NO}_{\mathrm{z}}$ emissions for the five test coals as a function of temperature. The different $\mathrm{NO}_{\mathrm{x}}$ levels are caused by inherent differences in the nitrogen in the coals. The nitrogen in the bituminous coals is released as $\mathrm{CN}$, while the lower-rank coals release more of their nitrogen as $\mathrm{NH}_{3}$. The distribution of nitrogen between the volatiles and the fixed carbon also varies significantly between coal ranks and is partially responsible for the trends shown in Figures 3-13 and 3-14. Not only does the total amount of $\mathrm{NO}_{\mathrm{x}}$ emitted vary with coal type, the rate at which the $\mathrm{NO}_{\mathrm{x}}$ emissions increase when temperature increases also varies with coal type. The rate of change is the smallest with the lignites and the greatest with the bituminous coals. Therefore, the lignites are higher emitters of $\mathrm{NO}_{\mathrm{x}}$ than the bituminous coals at lower temperatures $\left(1450^{\circ} \mathrm{F}\right)$, but emit less $\mathrm{NO}_{\mathrm{x}}$ at higher temperatures. $\mathrm{NO}_{\mathrm{z}}$ emissions also increase with increasing excess air and sorbent add rates.

\section{TABLE 3-4}

Nitrogen Emissions

\begin{tabular}{|c|c|c|c|c|c|}
\hline Coal: & Asian & Center & Black Thunder & Salt Creok & Blackaville \\
\hline $\begin{array}{l}\text { Fuel Nitrogen } \\
\text { ae-received, } \% \\
\text { lb/MM Btu }\end{array}$ & $\begin{array}{r}0.7 \\
1.38\end{array}$ & $\begin{array}{r}0.5 \\
0.76\end{array}$ & $\begin{array}{r}0.6 \\
0.72\end{array}$ & $\begin{array}{r}1.2 \\
1.12\end{array}$ & $\begin{array}{r}1.3 \\
1.02\end{array}$ \\
\hline Baseline Case, No Limestone & & & & & \\
\hline Test Number & TL4 & CLO & BT1 & $\underline{\mathbf{S C 1}}$ & BV1 \\
\hline Average Combustor Temperature, ${ }^{\circ} \mathbf{F}$ & 1664 & 1526 & 1675 & 1607 & 1658 \\
\hline $\begin{array}{l}\text { Emissions, ppm } \\
\mathrm{NO}_{\mathrm{x}} \\
\mathrm{N}_{2} \mathrm{O} \\
\mathrm{NO}_{\mathrm{x}}+\mathrm{N}_{2} \mathrm{O}\end{array}$ & $\begin{array}{r}106 \\
81 \\
186\end{array}$ & $\begin{array}{r}141 \\
48 \\
189\end{array}$ & $\begin{array}{r}248 \\
25 \\
273\end{array}$ & $\begin{array}{l}142 \\
160 \\
292\end{array}$ & $\begin{array}{l}121 \\
168 \\
289\end{array}$ \\
\hline $\begin{array}{l}\text { Emissions, lb/MM Btu } \\
\mathrm{NO}_{\mathrm{x}} \\
\mathrm{N}_{2} \mathrm{O} \\
\mathrm{NO}_{2}+\mathrm{N}_{2} \mathrm{O}\end{array}$ & $\begin{array}{l}0.16 \\
0.11 \\
0.26\end{array}$ & $\begin{array}{l}0.20 \\
0.06 \\
0.26\end{array}$ & $\begin{array}{l}0.32 \\
0.03 \\
0.35\end{array}$ & $\begin{array}{l}0.19 \\
0.19 \\
0.38\end{array}$ & $\begin{array}{l}0.15 \\
0.21 \\
0.36\end{array}$ \\
\hline $\begin{array}{l}\text { Converaion of Fuel Nitrogen, } \% \\
\mathrm{NO}_{2} \\
\mathrm{~N}_{2} \mathrm{O} \\
\mathrm{NO}_{2}+\mathrm{N}_{2} \mathrm{O}\end{array}$ & $\begin{array}{l}3.45 \\
5.29 \\
8.74\end{array}$ & $\begin{array}{r}7.23 \\
4.90 \\
12.13\end{array}$ & $\begin{array}{r}14.06 \\
2.83 \\
16.88\end{array}$ & $\begin{array}{r}4.84 \\
10.20 \\
15.04\end{array}$ & $\begin{array}{r}3.87 \\
11.91 \\
15.78\end{array}$ \\
\hline$\frac{\text { Full Load, 90\% Sulfur Capture }}{\text { Test Number }}$ & & & & & \\
\hline $\begin{array}{l}\text { Test Number } \\
\text { Average Combustor Temperature, }{ }^{\circ} \mathbf{F}\end{array}$ & $\underline{T L 1}$ & $\underline{\text { CL1 }}$ & $\underline{B T 2}$ & SC11 & BV2 \\
\hline $\begin{array}{l}\text { Average Combustor Temperature, }{ }^{\circ} \mathbf{F} \\
\text { Emissions, ppm }\end{array}$ & 1566 & 1654 & 1647 & 1485 & 1544 \\
\hline $\begin{array}{l}\mathrm{NO}_{2} \\
\mathrm{~N}_{2} \mathrm{O} \\
\mathrm{NO}_{8}+\mathrm{N}_{2} \mathrm{O}\end{array}$ & $\begin{array}{r}130 \\
69 \\
189\end{array}$ & $\begin{array}{r}202 \\
22 \\
224\end{array}$ & $\begin{array}{r}189 \\
44 \\
233\end{array}$ & $\begin{array}{r}56 \\
223 \\
279\end{array}$ & $\begin{array}{r}94 \\
146 \\
239\end{array}$ \\
\hline $\begin{array}{l}\text { Emissions, lb/MM Btu } \\
\mathrm{NO}_{\mathrm{x}} \\
\mathrm{N}_{2} \mathrm{O} \\
\mathrm{NO}_{\mathrm{x}}+\mathrm{N}_{2} \mathrm{O}\end{array}$ & $\begin{array}{l}0.18 \\
0.08 \\
0.26\end{array}$ & $\begin{array}{l}0.27 \\
0.03 \\
0.30\end{array}$ & $\begin{array}{l}0.24 \\
0.06 \\
0.30\end{array}$ & $\begin{array}{l}0.29 \\
0.29 \\
0.58\end{array}$ & $\begin{array}{l}0.11 \\
0.16 \\
0.27\end{array}$ \\
\hline $\begin{array}{l}\text { Conversion of Fuel Nitrogen, \% } \\
\mathrm{NO}_{2} \\
\mathrm{~N}_{2} \mathrm{O} \\
\mathrm{NO}_{\mathrm{x}}+\mathrm{N}_{2} \mathrm{O}\end{array}$ & $\begin{array}{l}4.24 \\
3.84 \\
8.08 \\
\end{array}$ & $\begin{array}{r}10.26 \\
2.26 \\
12.61 \\
\end{array}$ & $\begin{array}{r}10.73 \\
4.63 \\
16.36 \\
\end{array}$ & $\begin{array}{r}2.10 \\
16.40 \\
18.60 \\
\end{array}$ & $\begin{array}{r}3.23 \\
10.28 \\
13.51 \\
\end{array}$ \\
\hline
\end{tabular}




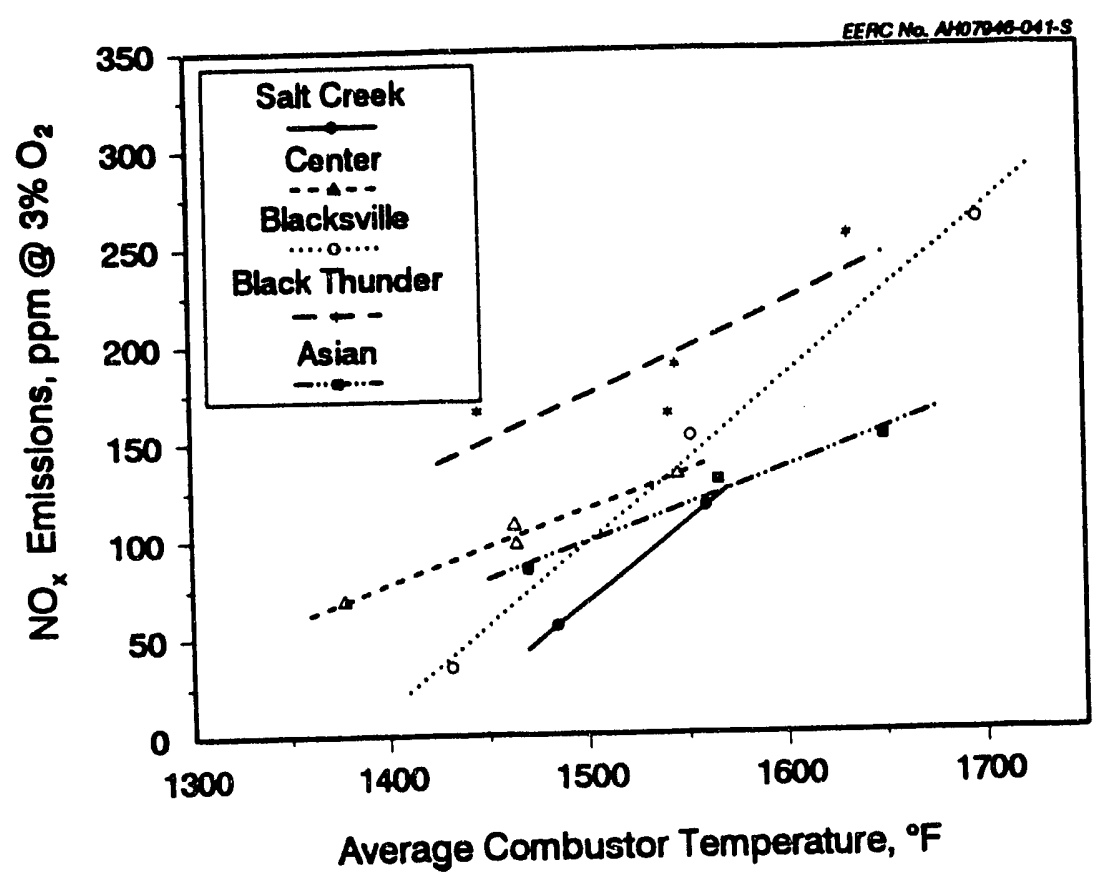

Figure 3-13. NO emissions in ppm at 20\%-25\% excess air, 16-ft/sec velocity, and 1.5-2.5 alkali-to-sulfur ratio as a function of combustor temperature.

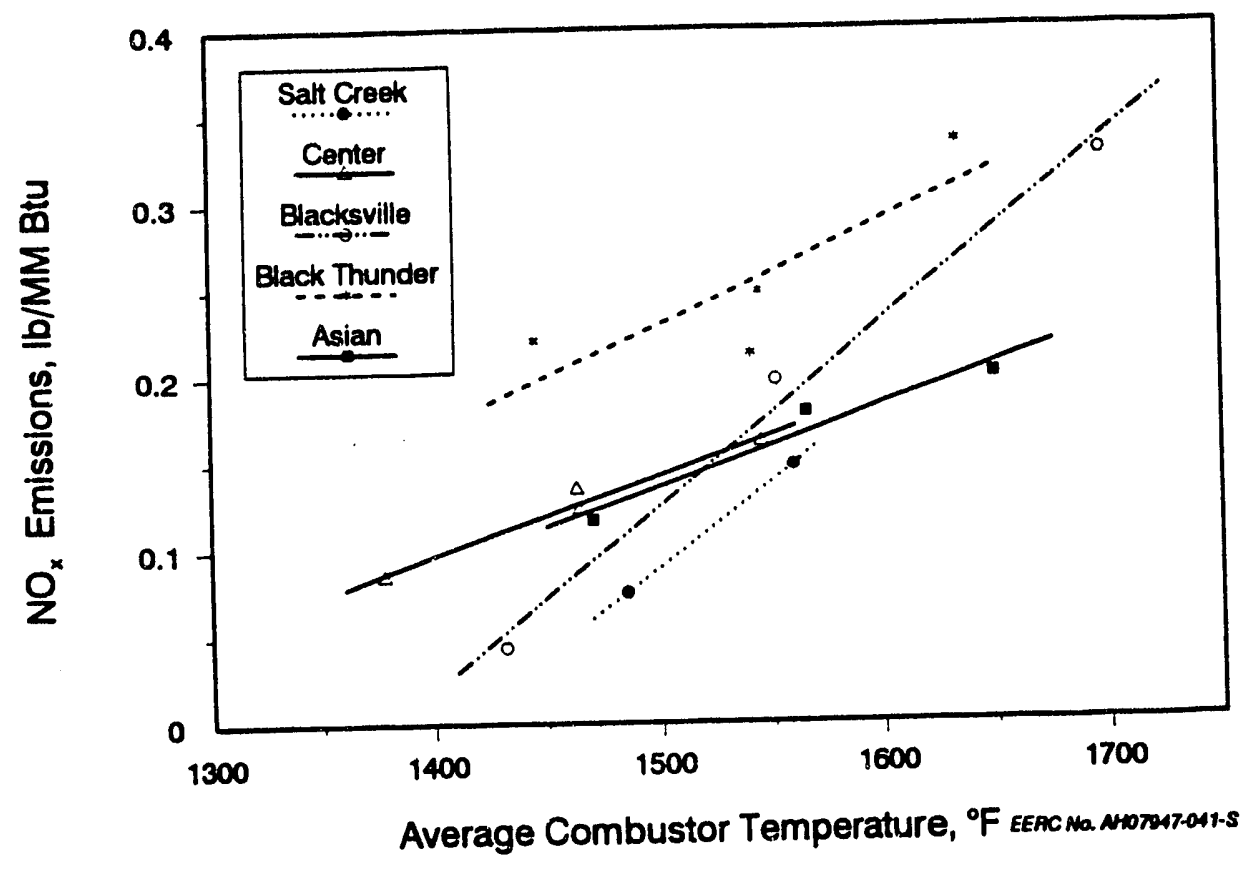

Figure 3-14. NO emission in lb/MM Btu at $20 \%-25 \%$ excess air, $16-\mathrm{ft} / \mathrm{sec}$ velocity, and 
Figure 3-15 compares $\mathrm{NO}_{\mathrm{x}}$ emissions as a function of excess air for four different coals (no excess air tests were performed during the Asian lignite run). In all cases, $\mathrm{NO}_{\mathrm{x}}$ emissions increased with increasing amounts of excess air. Figure 3-16, showing $\mathrm{NO}_{\mathrm{z}}$ emissions as a function of primary-to-secondary air split, illustrates a typical trend on how the staging of combustion air affects $\mathrm{NO}_{\mathrm{x}}$ emissions. Secondary air is introduced at about 5.5 feet above the distributor plate level. As the percentage of the total combustion air supplied through the distributor plate increased, increasing the amount of oxygen in the bottom of the combustor, the $\mathrm{NO}_{\mathbf{x}}$ emissions correspondingly increased.

The effect of increasing limestone addition on $\mathrm{NO}_{\mathrm{x}}$ emissions is shown in Figure 3-17. With the exception of the Black Thunder subbituminous coal, nitrogen oxide emissions increased with increasing limestone feed rates for the various ranks of coals tested. The opposite trend that occurred during Black Thunder testing cannot be explained at this time. However, it is believed to be a real trend.

New analytical techniques have recently made it possible to measure flue gas nitrous oxide $\left(\mathrm{N}_{2} \mathrm{O}\right)$ levels. $\mathrm{N}_{2} \mathrm{O}$ emissions from pulverized coal-fired systems are typically less than $10 \mathrm{ppm}$, while those from FBCs range from 25 to $150 \mathrm{ppm}$ for most fuels on fullscale units. Although $\mathrm{N}_{2} \mathrm{O}$ emissions are currently not regulated, they may become important in the future. The trends noted during this study were increasing emissions of $\mathrm{N}_{2} \mathrm{O}$ as the rank changed from subbituminous to lignite to bituminous. These trends are shown in Figures 3-18 and 3-19. Similar trends have been noted on full-scale units. However, the $\mathrm{N}_{2} \mathrm{O}$ emissions from full-scale systems are lower than those measured from the pilot scale. This has been attributed to increased wall effects inherent to small-scale systems. $\mathrm{N}_{2} \mathrm{O}$ emissions are even more dependent on fuel properties thar, ${ }^{\mathrm{N}} \mathrm{OO}_{\mathrm{z}}$. The distribution of the nitrogen between the volatiles and the fixed carbon appears to be the most important fuel property affecting $\mathrm{N}_{2} \mathrm{O}$ emissions.

$\mathrm{N}_{2} \mathrm{O}$ emissions follow a trend opposite to that of $\mathrm{NO}_{x}$, decreasing with increasing temperature (Figures 3-20) and sorbent add rate (Figures 3-21 and 3-22), and a similar trend as $\mathrm{NO}_{\mathrm{x}}$ for excess air (Figure 3-23). No clear relationship between $\mathrm{N}_{2} \mathrm{O}$ emissions and primary-to-secondary air split was evident from the results of testing (Figure 3-24). A strong interaction exists between $\mathrm{N}_{2} \mathrm{O}$ emissions and temperature and excess air, as shown in Figures 3-20 and 3-23. Temperature has a stronger effect on $\mathrm{N}_{2} \mathrm{O}$ emissions at lower excess air levels, while excess air has a much stronger effect at lower temperatures.

The percent conversion of fuel-bound nitrogen to $\mathrm{NO}_{\mathrm{x}}$ and $\mathrm{N}_{2} \mathrm{O}$ is illustrated in Figure 3-25. This assumes that only the fuel-bound nitrogen is converted and that nitrogen introduced with the combustion air is not converted at the comparatively low operational temperature typical in CFBs. Total nitrogen oxide emissions tend to increase as the rank of the coal increases.

$\mathrm{N}_{2} \mathrm{O}$ emissions tend to decrease with increasing temperature, while $\mathrm{NO}_{\mathrm{x}}$ usually will increase with increasing temperature, no matter what the coal rank is. No apparent consistent trend exists for total nitrogen oxide emissions, $\mathrm{NO}_{x}$ plus $\mathrm{N}_{2} \mathrm{O}$, as a function of average combustion temperature for the different ranks of coals tested, as shown in Figure 3-26. 


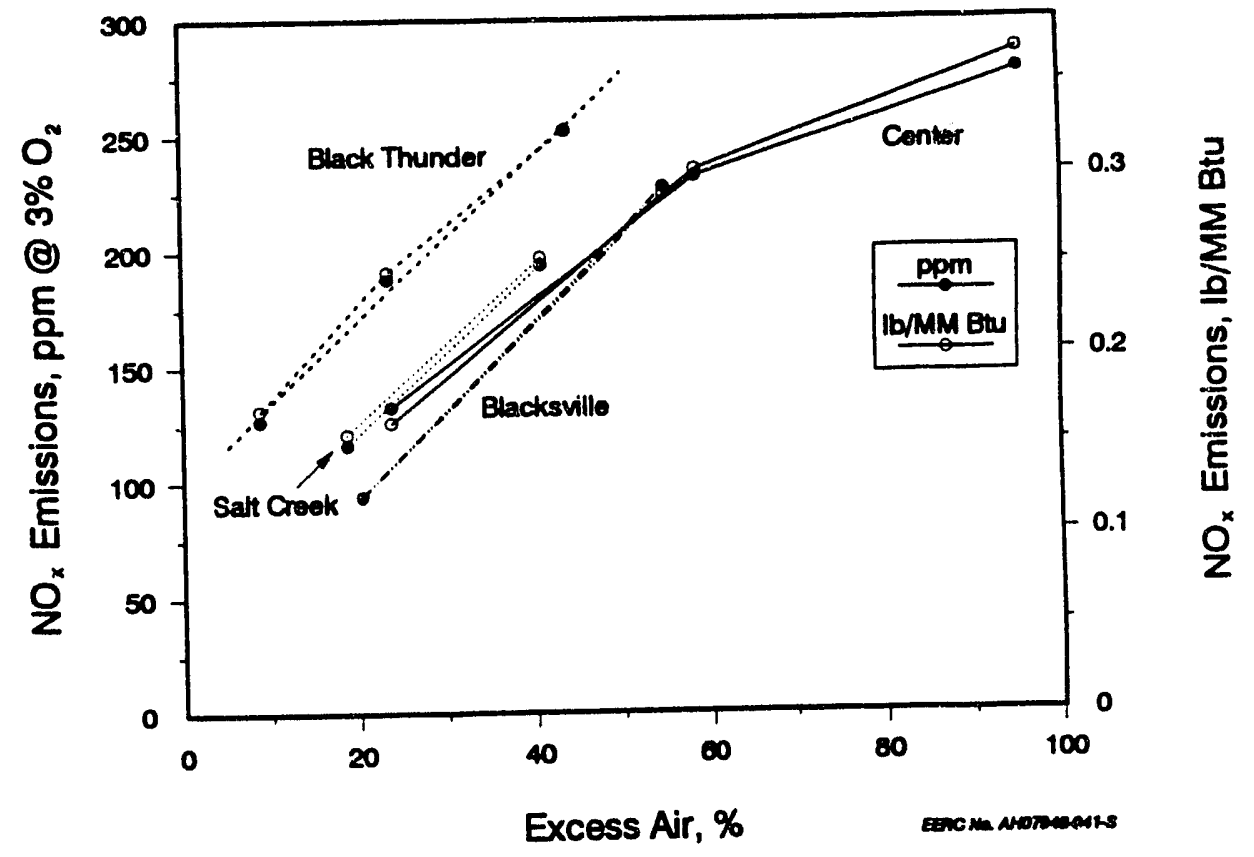

Figure 3-15. $\mathrm{NO}_{\mathrm{x}}$ emissions at $\sim 1550^{\circ} \mathrm{F}\left(1623^{\circ}\right.$ for Salt Creek) as a function of excess air.

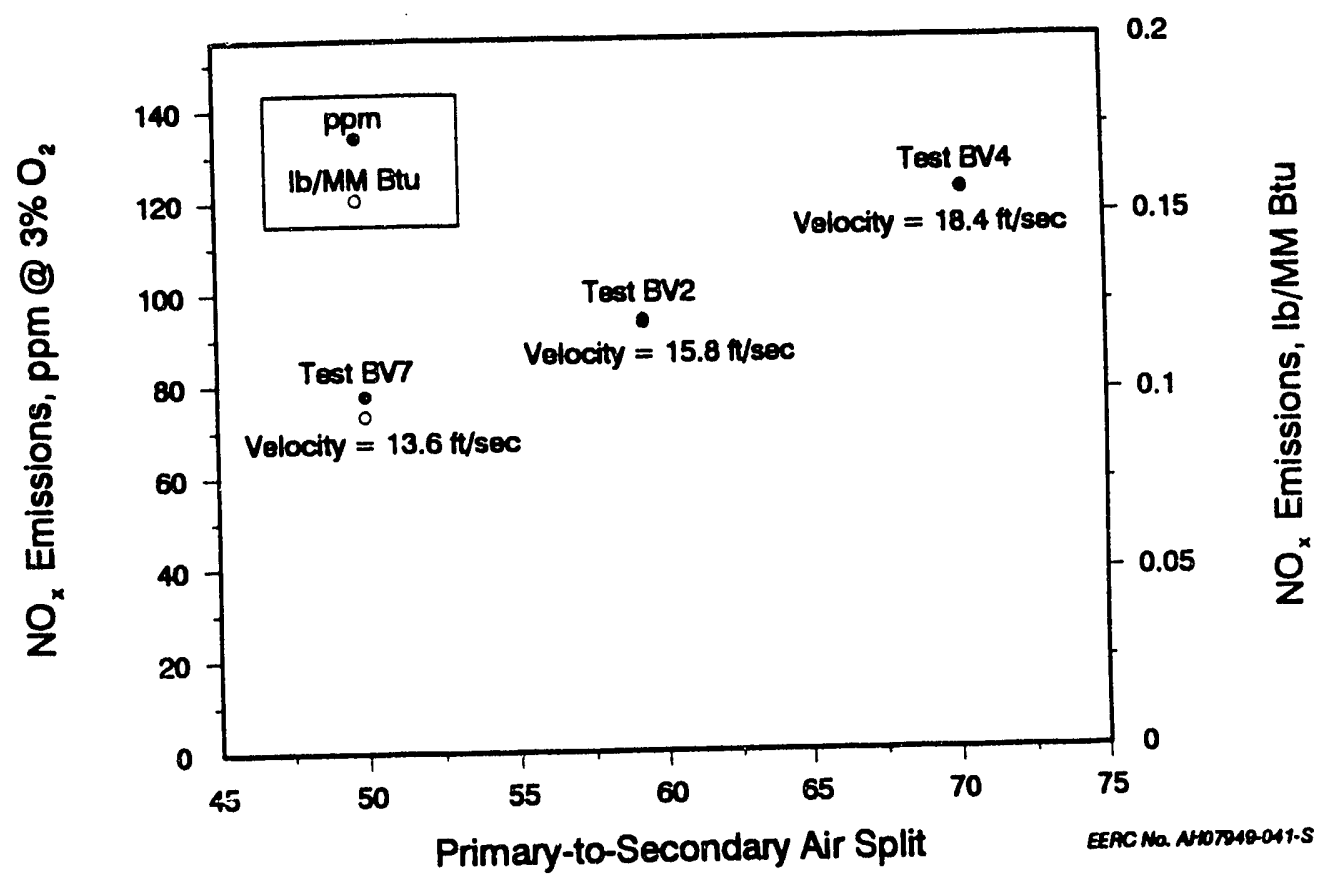

Figure 3-16. $\quad \mathrm{NO}_{\mathrm{z}}$ emissions for Blacksville coal at $\sim 1550^{\circ} \mathrm{F}$ and $20 \%$ excess air as a function of primary-to-secondary air split. 


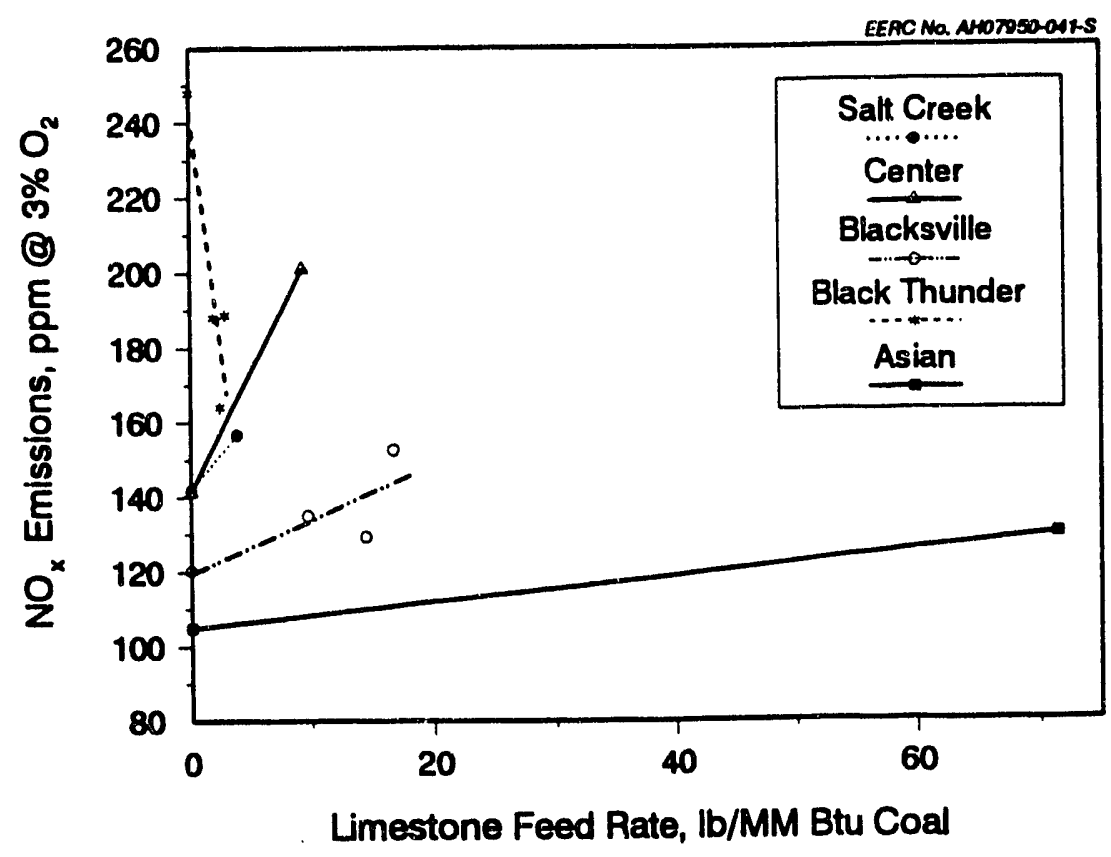

Figure 3-17. $\mathrm{NO}_{\mathrm{x}}$ emissions at $\sim 1550^{\circ} \mathrm{F}\left(1610^{\circ}\right.$ for Salt Creek), 16 -ft/sec velocity, and $25 \%$ excess air as a function of limestone feed rate.

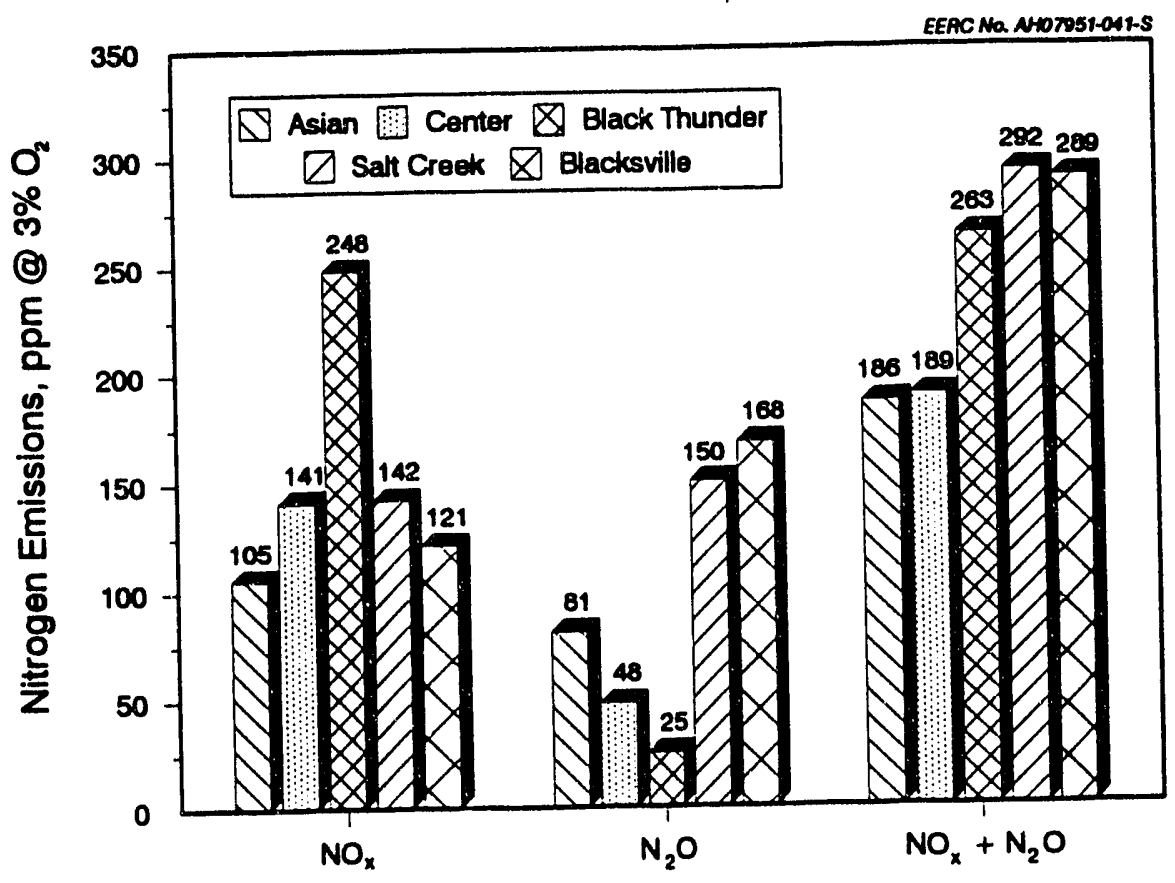

Figure 3-18. Nitrogen emissions (ppm) at $\sim 1550^{\circ} \mathrm{F}, 16-\mathrm{ft} / \mathrm{sec}$ velocity, and $21 \%-34 \%$ excess air as a function of coal type. 


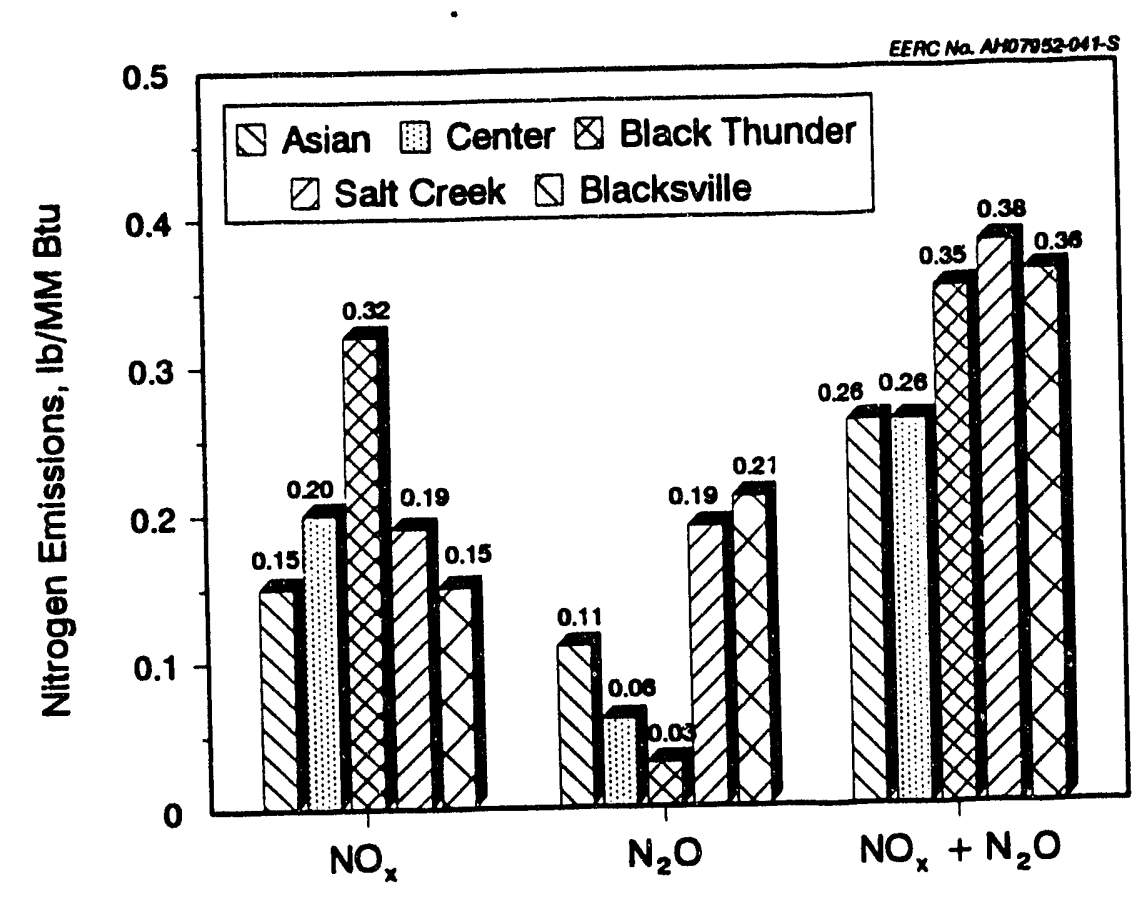

Figure 3-19. Nitrogen emissions (lb/MM Btu) at $\sim 1550^{\circ} \mathrm{F}, 16-\mathrm{ft} / \mathrm{sec}$ velocity, and $21 \%$ $34 \%$ excess air as a function of coal type.

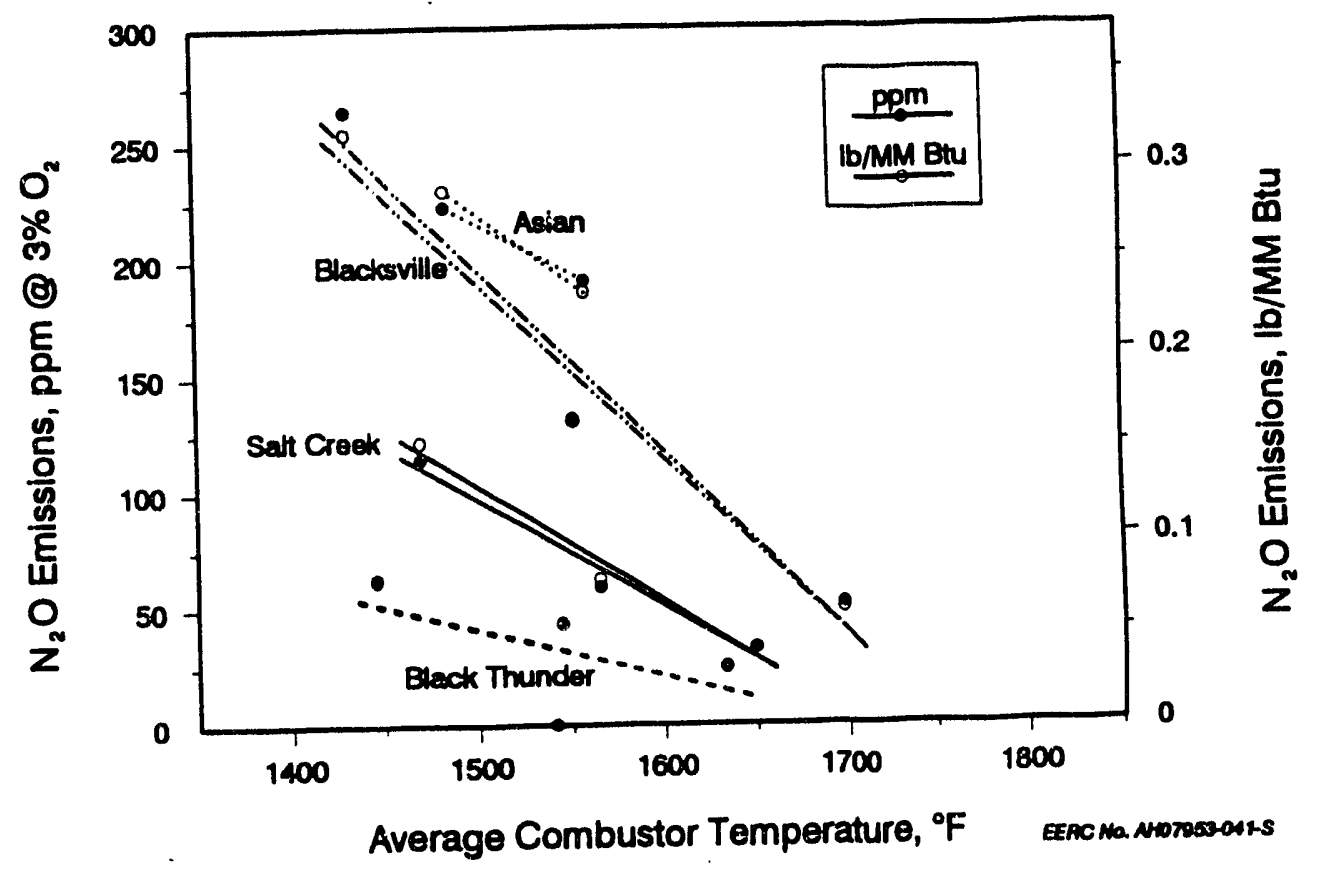

Figure 3-20. $\quad \mathrm{N}_{2} \mathrm{O}$ emissions as a function of average combustor temperature, at $16-\mathrm{ft} / \mathrm{sec}$ velocity and $21 \%-34 \%$ excess air. 


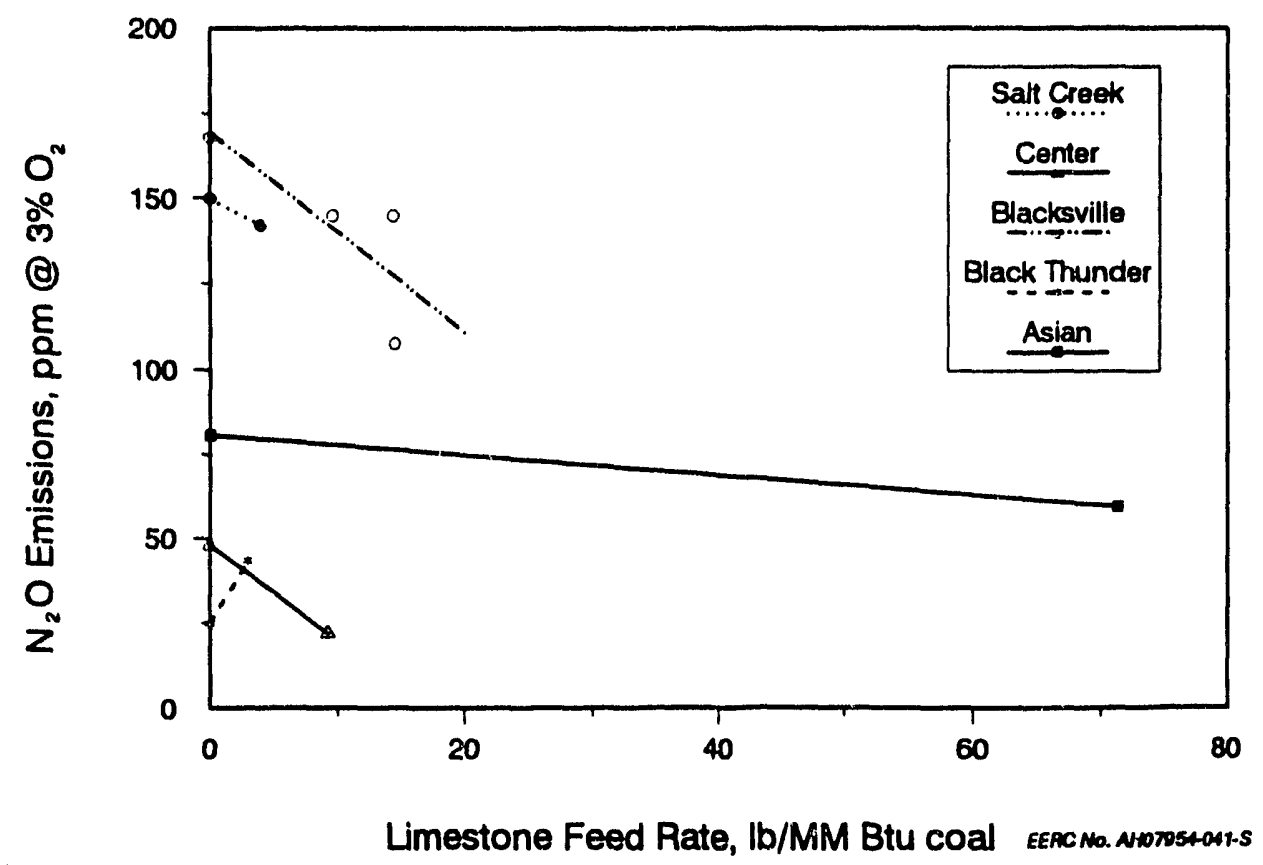

Figure 3-21. $\quad \mathrm{N}_{2} \mathrm{O}$ emissions as a function of sorbent add rate at $\sim 1550^{\circ} \mathrm{F}, 16-\mathrm{ft} / \mathrm{sec}$ velocity, and $21 \%-34 \%$ excess air.

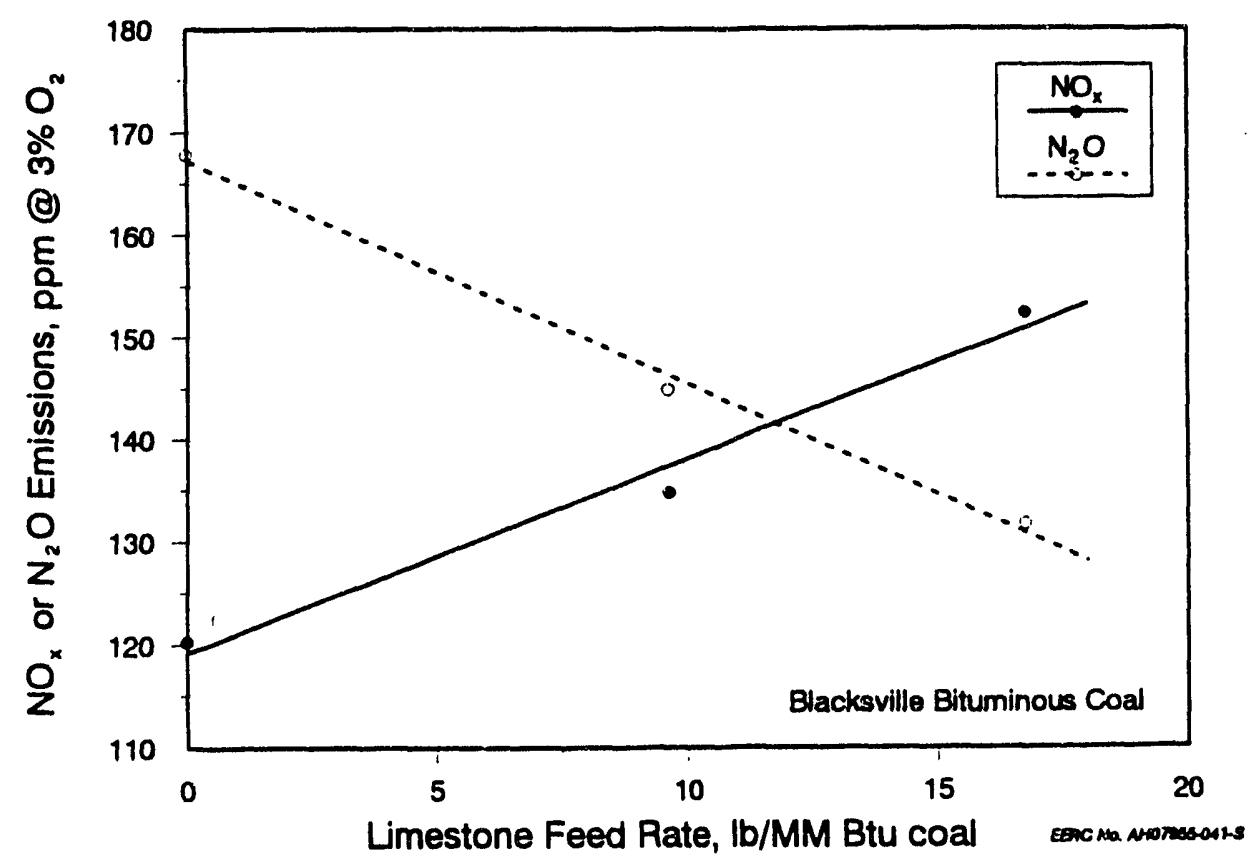

Figure 3-22. $\quad \mathrm{N}_{2} \mathrm{O}$ and $\mathrm{NO}_{\mathrm{x}}$ emissions for Blacksville coal at $\sim 1550^{\circ} \mathrm{F}, 16$-ft/sec velocity, and $29 \%$ excess air as a function of sorbent add rate. 


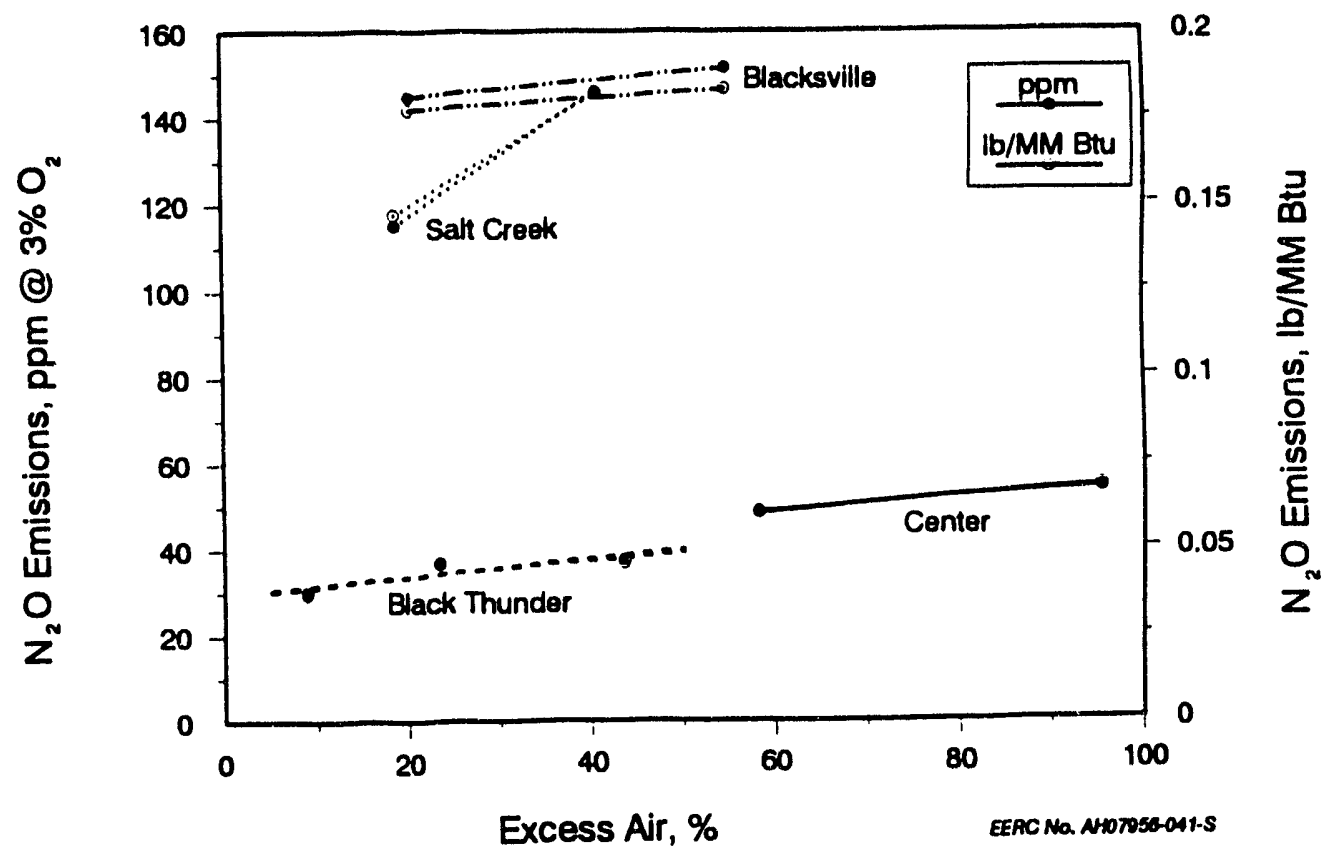

Figure 3-23. $\mathrm{N}_{2} \mathrm{O}$ emissions at $\sim 1550^{\circ} \mathrm{F}\left(1623^{\circ} \mathrm{F}\right.$ for Salt Creek) as a function of excess air.

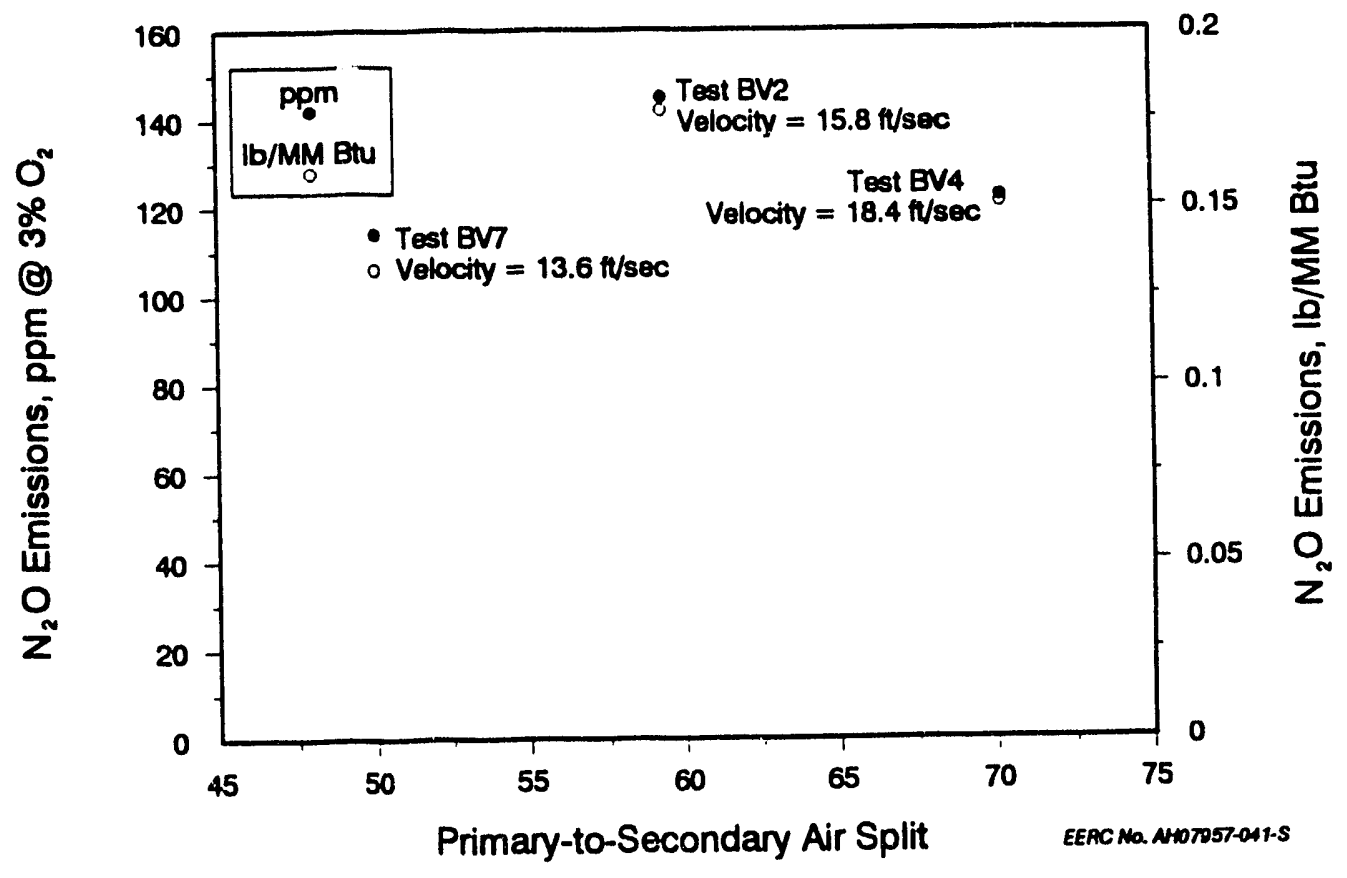

Figure 3-24. $\quad \mathrm{N}_{2} \mathrm{O}$ emissions for Blacksville coal at $\sim 1550^{\circ} \mathrm{F}$ and $20 \%$ excess air as a function of primary-to-secondary combustion air split. 


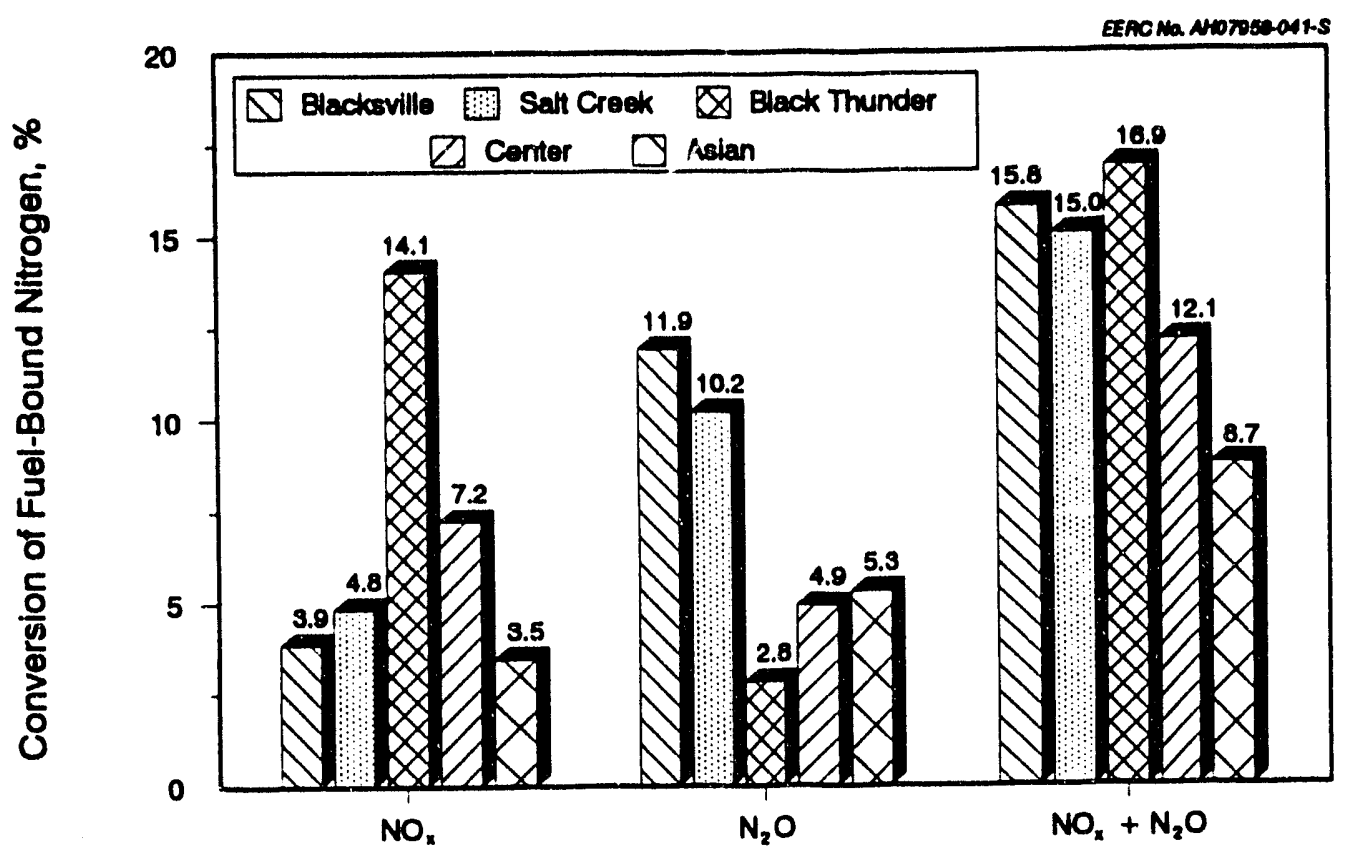

Figure 3-25. Percent conversion of fuel-bound nitrogen to $\mathrm{NO}_{\mathrm{z}}$ and $\mathrm{N}_{2} \mathrm{O}$ at $\sim 1550^{\circ} \mathrm{F}$, $16-\mathrm{ft} / \mathrm{sec}$ velocity, and $21 \%-34 \%$ excess air as a function of coal type.

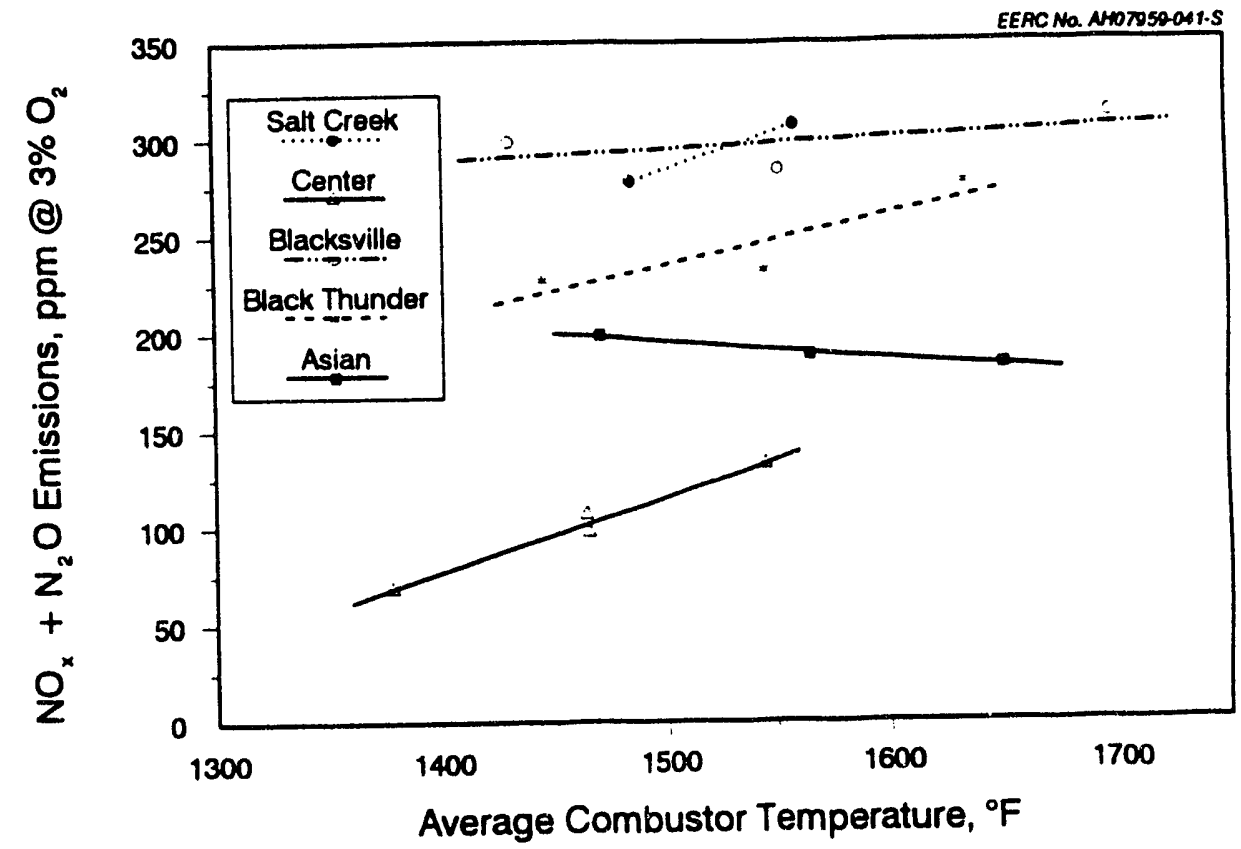

Figure 3-26. Total nitrogen oxide emissions at $16-\mathrm{ft} / \mathrm{sec}$ velocity and $17 \%-31 \%$ excess air as a function of average combustor temperature. 


\subsubsection{Carbon Monoxide Emissions}

Carbon monoxide (CO) emissions are the result of incomplete conversion of the coal carbon to carbon dioxide. CO emissions tend to decrease with increasing temperature for all ranks of coal (Figure 3-27). As shown in Figure 3-28, CO emissions also decrease as excess air increases for all ranks of coal tested. Both of these conditions, higher temperatures and higher concentrations of oxygen, favor more complete conversion of the coal carbon to carbon dioxide.

\subsubsection{Fly Ash Collectability}

The ash formed from the combustion of coal and the sorbent added for sulfur control will either be removed as fly ash or bottom ash. The quantity of fly ash generated will primarily be a function of the quantity of ash and sulfur in the coal and the collection efficiency of the primary cyclone. Coal with higher ash and higher sulfur will typically generate more fly ash. The amount of the coal ash ending up as fly ash will also, to a lesser extent, be a function of the size of coal and sorbent and the friability of the sorbent, with finer grinds and friable sorbents generating a higher percentage of fly ash than bottom ash.

To provide an indication of the impact of coal properties on fly ash collectability, dust loadings before and after the baghouse were performed. The dust loading into the baghouse for the high-ash, high-sulfur Asian lignite was the highest for the coals tested, at 2.13 grains $/ \mathrm{scf}$. Dust loadings for the other coals ranged from 0.60 to $0.90 \mathrm{grains} / \mathrm{scf}$. For all of the coals, collection efficiencies using woven fiberglass bags in a pulse-jet baghouse were above $99.9 \%$. Table 3.5 summarizes the secondary cyclone and baghouse particulate loadings and removal efficiencies.

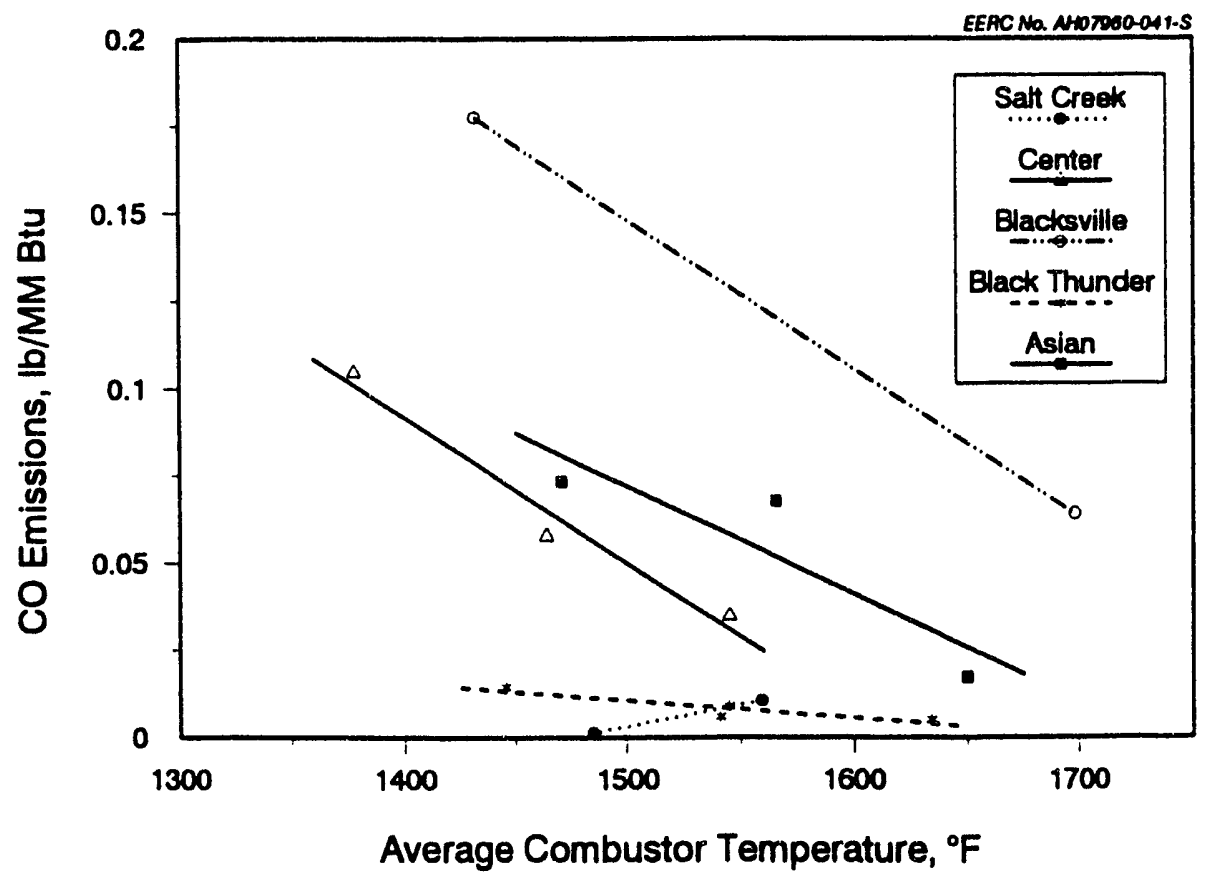

Figure 3-27. CO emissions at $16-\mathrm{ft} / \mathrm{sec}$ velocity and $17 \%-31 \%$ excess air as a function of average combustor temperature. 
TABLE 3.5

Secondary Cyclone and Baghouse Particulate Loading/Removal Efficiencies

\begin{tabular}{|c|c|c|c|c|c|c|c|c|c|c|}
\hline \multirow[b]{2}{*}{ Teat Number } & \multicolumn{2}{|c|}{ Secondary Crolone } & \multicolumn{2}{|c|}{ Baghoues } & \multicolumn{2}{|c|}{ Secondarr Crolone } & \multicolumn{2}{|c|}{ Bachoure } & \multicolumn{2}{|c|}{ Efriononose $\%$} \\
\hline & $\begin{array}{l}\text { Inlet } \\
\text { gromef }\end{array}$ & $\begin{array}{l}\text { Outlet } \\
\text { gr/ecf }\end{array}$ & $\begin{array}{l}\text { Inlot } \\
\text { gr/mef }\end{array}$ & $\begin{array}{l}\text { Outlot } \\
\text { gr/ect }\end{array}$ & $\begin{array}{l}\text { Inlet } \\
\mathrm{lb} / \mathrm{hr}\end{array}$ & $\begin{array}{l}\text { Outlet } \\
\mathrm{lb} / \mathrm{hr}\end{array}$ & $\begin{array}{l}\text { Inlot } \\
\mathrm{lb} / \mathrm{hr}\end{array}$ & $\begin{array}{l}\text { Outlet } \\
\mathbf{l b} / \mathbf{h r}\end{array}$ & $\begin{array}{l}\text { Secondary } \\
\text { Cyolone }\end{array}$ & Baghouse \\
\hline CL1-0291 & 69.23 & 0.901 & 0.901 & 0.00036 & 299.36 & 4.96 & 4.96 & 0.0019 & 98.70 & 99.96 \\
\hline CL3 $^{1}$ & 28.91 & 0.261 & 0.261 & 0.00007 & 146.62 & 1.32 & 1.32 & 0.0004 & 99.10 & 99.97 \\
\hline TL1 & 114.67 & 4.263 & 4.263 & N8 & 614.60 & 26.99 & 26.99 & NS & 96.28 & $\mathbf{N A}^{+}$ \\
\hline Th2 & 36.07 & 2.132 & 2.132 & 0.00161 & 201.46 & 11.66 & 11.66 & 0.0090 & 93.92 & 99.92 \\
\hline BV1 & NS & 0.604 & 0.604 & 0.00050 & NS & 3.67 & 3.67 & 0.0027 & NA & 99.92 \\
\hline $\mathrm{BT}^{2}{ }^{2}$ & NS & 0.864 & 0.864 & 0.00000 & NS & 6.13 & 6.13 & 0.0000 & NA & 100.00 \\
\hline
\end{tabular}

1 Two of the three baghouse outlet dust-loading sample filtora loat woight. No visible dust on oither filtor.

2 Small amount of baghouse outlet sample filter stuok to support screen, removed and woighed as much as possiblo.

S Not sampled.

4 Not avilable.

\subsection{Thermal Performance}

\subsubsection{Heat Flux and Heat-Transfer Coefficients}

Table 3-6 compares the heat fluxes measured for the five different coals tested at the EERC. It has been attempted to limit comparison to similar conditions of average bed temperature, excess air level, superficial gas velocity, and the primary-to-secondary combustion air split. The as-tested higher heating value is included in the table as an indicator of the coal rank. The average size of the recirculated bed material is indicated by the $d_{s 0}$ (average size of the material).

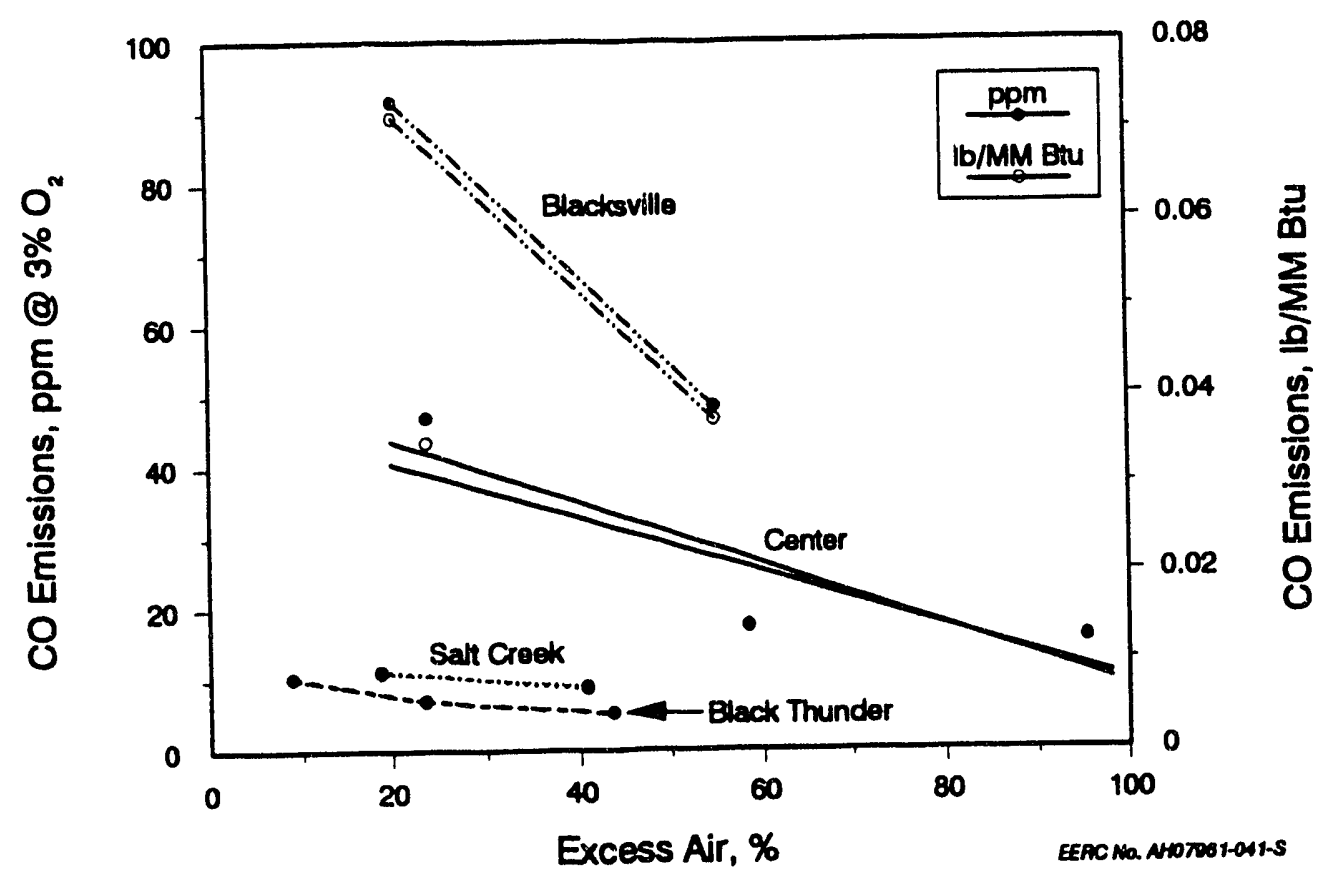

Figure 3-28. $\mathrm{CO}$ emissions at $\sim 1550^{\circ} \mathrm{F}\left(1623^{\circ} \mathrm{F}\right.$ for Salt Creek) as a function of excess air. 
TABLE 3-6

Comparison of Heat Fluxes

\begin{tabular}{|c|c|c|c|c|c|c|c|c|c|}
\hline \multicolumn{10}{|c|}{ Combuntor } \\
\hline Test & $\begin{array}{l}\text { HHV, } \\
\text { Btu/b }\end{array}$ & $\begin{array}{l}\text { Rocirculaiton } \\
\text { Rate, lb/hr }\end{array}$ & $\begin{array}{c}\text { Bed } \\
\text { Temperature, }{ }^{\circ} \mathbf{F}\end{array}$ & $\begin{array}{l}\text { SGV, } \\
\mathrm{ft} / \mathrm{Bec}\end{array}$ & $\begin{array}{l}\text { Ercoess } \\
\text { Air, } \%\end{array}$ & $\begin{array}{l}\text { PA/SA } \\
\text { Split }\end{array}$ & $\begin{array}{l}\text { Bod Mat. } \\
\mathrm{d}_{80,} \mu \mathrm{m}\end{array}$ & $\begin{array}{l}\text { HT Cooffioient } \\
\text { Btu/hr-ft }{ }^{2} \cdot{ }^{\circ} \mathrm{F}\end{array}$ & $\begin{array}{l}\text { Hoat Flux, } \\
\text { Btw/hr.ft }\end{array}$ \\
\hline CL6 & 6,900 & 3,800 & 1,670 & 16.6 & 22.1 & $60 / 40$ & $410^{*}$ & 16.6 & 23,900 \\
\hline TL1 & 3,800 & 3,800 & 1,665 & 16.6 & 24.4 & $60 / 40$ & 668 & 16.9 & 24,000 \\
\hline BV16 & 13,300 & 4,200 & 1,672 & 16.9 & 21.7 & $60 / 40$ & 503 & 17.9 & 25,900 \\
\hline BT6 & 8,700 & 9,300 & 1,641 & 16.9 & 22.6 & $60 / 40$ & $440^{*}$ & 23.6 & 33,100 \\
\hline $\mathrm{SC2}$ & 10,000 & 12,000 & 1,613 & 16.6 & 21.6 & $46 / 64$ & 361 & 22.3 & 32,700 \\
\hline \multicolumn{10}{|c|}{ External Heat Exchanger } \\
\hline Test & $\begin{array}{l}\text { HHV, } \\
\text { Btu/bb }\end{array}$ & $\begin{array}{l}\text { Recirc. } \\
\text { Rate, } \mathrm{lb} / \mathrm{hr}\end{array}$ & Bed Tomp., ${ }^{\circ} \mathbf{F}$ & \multicolumn{2}{|c|}{$\mathrm{SGV}, \mathrm{ft} / \mathrm{Bec}$} & \multicolumn{2}{|c|}{$\begin{array}{c}\text { Downcomer } \\
\mathrm{d}_{80}, \mu \mathrm{m}\end{array}$} & 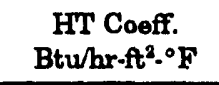 & $\begin{array}{l}\text { Heat Flux, } \\
\text { Btu/hr.ft }\end{array}$ \\
\hline CL6 & 6,900 & 3,800 & 1,077 & \multicolumn{2}{|c|}{1.7} & \multicolumn{2}{|c|}{$300^{*}$} & 68.8 & 65,700 \\
\hline TL1 & 3,800 & 3,800 & 1,289 & \multicolumn{2}{|c|}{1.7} & \multicolumn{2}{|c|}{348} & 68.1 & 66,300 \\
\hline BV16 & 13,300 & 4,200 & 1,137 & \multicolumn{2}{|c|}{2.0} & \multicolumn{2}{|c|}{343} & 71.4 & 73,100 \\
\hline BT5 & 8,700 & 9,300 & 1,339 & \multicolumn{2}{|c|}{1.8} & \multicolumn{2}{|r|}{$316^{*}$} & 81.9 & 96,700 \\
\hline sc2 & 10,000 & 12,000 & 1,436 & \multicolumn{2}{|c|}{2.2} & \multicolumn{2}{|c|}{210} & 98.7 & 127,900 \\
\hline
\end{tabular}

* Estimated size based on several test periods.

The most important factor affecting heat flux was the recirculation rate. The heat flux increased with increasing solids recirculation rates. This would be expected since solid densities are higher at correspondingly higher recirculation rates, and at higher solid densities there is more material to radiate and conduct heat to heat-transfer surfaces.

Because of the action of the circulating solids, CFBCs operate with a relatively high heat flux. The heat flux for full load conditions typically ranged from about 24,000 to $33,000 \mathrm{Btu} / \mathrm{hr}-\mathrm{ft}^{2}$. The heat flux increased with increasing temperature and velocity. As would be expected, the combustor heat-transfer coefficients followed the same trends as did the heat fluxes when comparing results obtained with the different coals tested (Table 3-6).

\subsubsection{Combustion Efficiency}

In comparing the properties of common solid fuels, the lignitic and subbituminous coals fall between the high fixed carbon content and heating value of the higher-rank fossil fuels and the more reactive high-volatile content biomass fuels. Reactivity of the low-rank coals is related to porosity and surface area, volatiles-to-fixed carbon ratio, partially oxygenated organic structure, and catalytic effects of metallic cations within the coal structure. Thus lower-rank coals will burn more completely and more rapidly than will a bituminous coal under similar operating conditions. Higher reactivity gives greater combustion efficiency, as measured by carbon conversion. 
Figure 3-29 presents combustion efficiency for the five test coals as a function of combustor temperature. All tests were performed at equivalent conditions of approximately $20 \%$ excess air, 16 -ft/sec velocity, $60 \%$ primary combustion air, and a limestone feed rate to achieve $90 \%$ sulfur retention. The combustion efficiencies for two lignites and the subbituminous coals approached $100 \%$ over the entire range of temperatures tested. The combustion efficiencies for the Salt Creek bituminous coal ranged from $97 \%$ to $99 \%$, while the combustion efficiencies for the Blacksville bituminous coal ranged from $90 \%$ to $97 \%$. These differences are primarily due to the higher reactivity of the char for the lower-rank coals and the higher volatile content of these coals in relation to the fixed carbon. Combustion efficiencies for the Blacksville testing were also low because no secondary cyclone ash was recirculated. The combustion efficiencies obtained during the Asian lignite testing were not as significantly affected by not recirculating secondary cyclone ash.

Figure 3-30 shows combustion efficiency as a function of excess air for testing conducted at $1538^{\circ} \mathrm{F}$. The Blacksville and Salt Creek bituminous coals showed improved combustion efficiency as the level of excess air increased. Lower-ranked coals had high combustion efficiencies, so increased levels of excess air had little or no effect.

\subsubsection{Boiler Efficiency}

Boiler efficiency for each test point was calculated using a modified ASME PTC 4.1 as recommended by EPRI (4) and assuming a $300^{\circ} \mathrm{F}$ stack gas exit temperature and a 0.4\% loss due to radiative and convective losses. Operational parameters that affect boiler efficiency include the coal moisture and total solids (coal ash and limestone) input into the

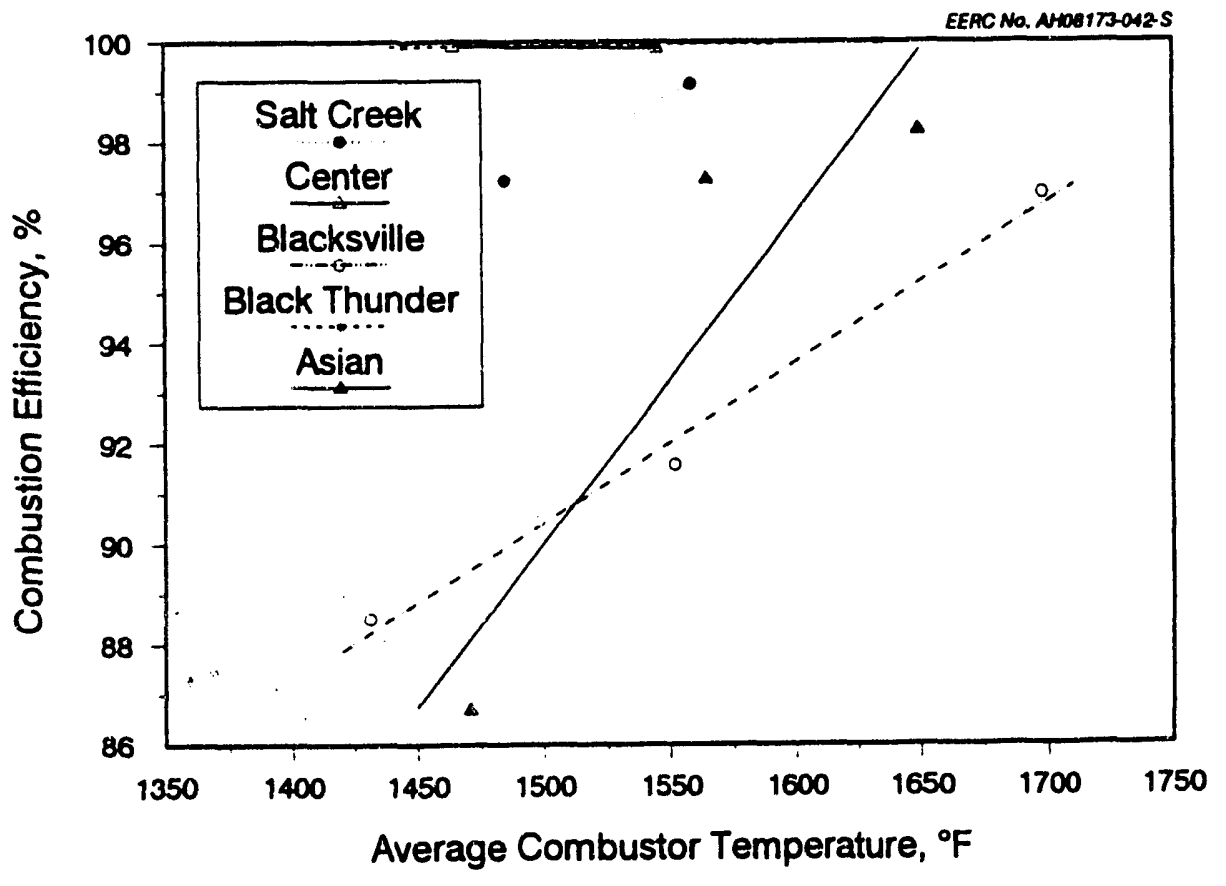

Figure 3-29. Combustion efficiency at 16 - $\mathrm{ft} / \mathrm{sec}$ velocity and $17 \%-31 \%$ excess air as a function of average combustor temperature. 


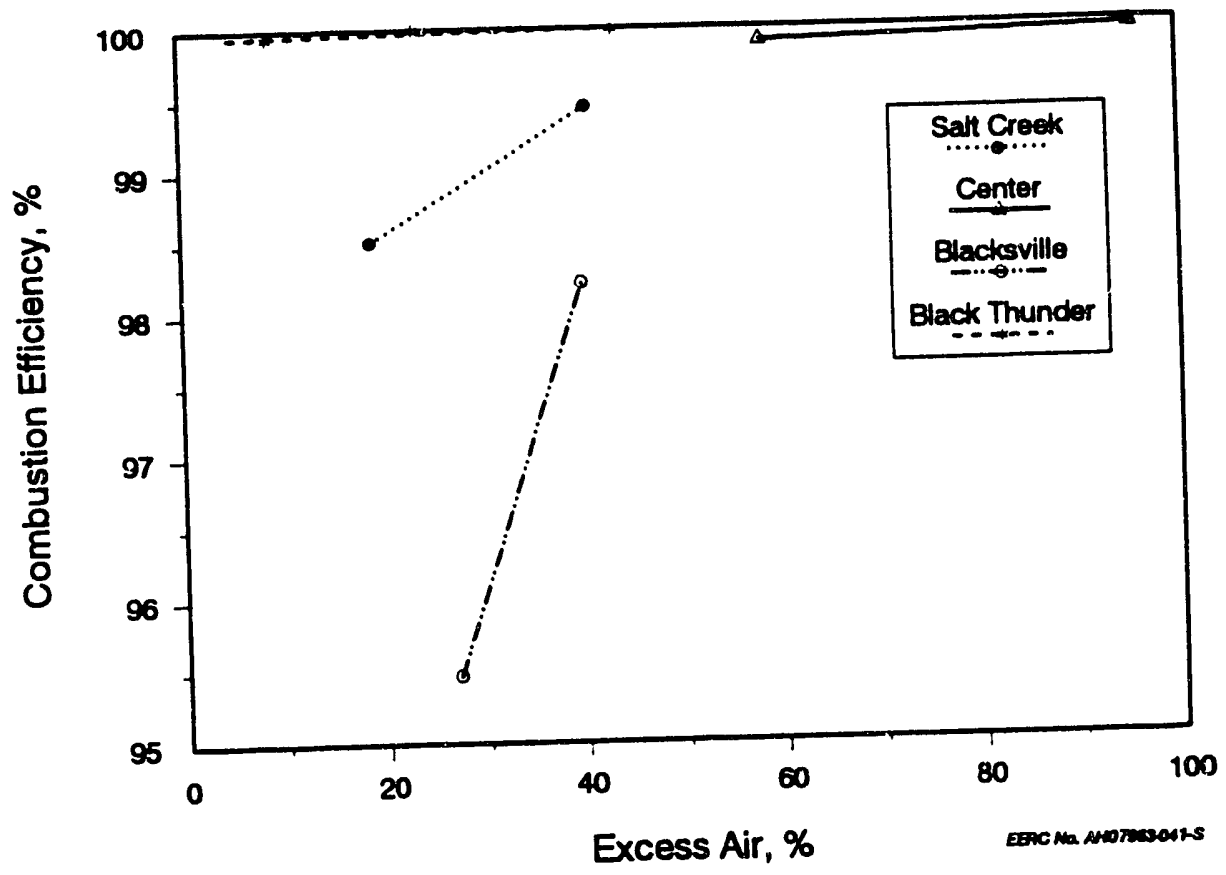

Figure 3-30. Combustion efficiency at $\sim 1550^{\circ} \mathrm{F}$ ( $1623^{\circ} \mathrm{F}$ for Salt Creek) as a function of excess air.

system, excess air, secondary cyclone capture and recirculation of the fly ash downstream of the primary particulate collection device (usually a cyclone), and the operational combustor temperature. Operational changes that will result in improved boiler efficiency include those that decrease the amounts of mass flow (primarily gases and, less significantly, the solids) exiting the cyclone and those that increase levels of carbon burnout of the fuel.

Low-rank coals that typically contain higher levels of moisture than do bituminous coals will result in lower boiler efficiencies. The low-rank fuels require more energy during combustion to vaporize the additional moisture. When operating at a specific temperature and excess air level, the high-moisture fuels generate increased mass flows through the system per delivered Btu than lower-moisture fuels, resulting in a higher fraction of the energy being recovered in the lower-efficiency downstream convective heat recovery unit. Figure 3-31 shows that, for the coals tested, the amount of energy generated that ended up in the flue gas varied from $65 \%$ for the very moist Asian lignite to $43 \%$ for the relatively dry Blacksville bituminous. The shift of energy back to the convective pass results in a reduction of boiler efficiency due to greater stack losses for the high-moisture coals. Other losses in boiler efficiency result from the conversion of fuel hydrogen to water, unrecoverable heat from the discharge of ash and spent sorbent, and the calcination of the raw sorbent. A boiler efficiency credit is given for the sulfation of the sorbent, as this process produces usable heat.

Boiler efficiency losses for the baseline cases with and without limestone addition are presented in Table 3-7 and Figure 3-32. Critical operational data are also included for each test condition. The combined losses due to the moisture and hydrogen in the fuel 


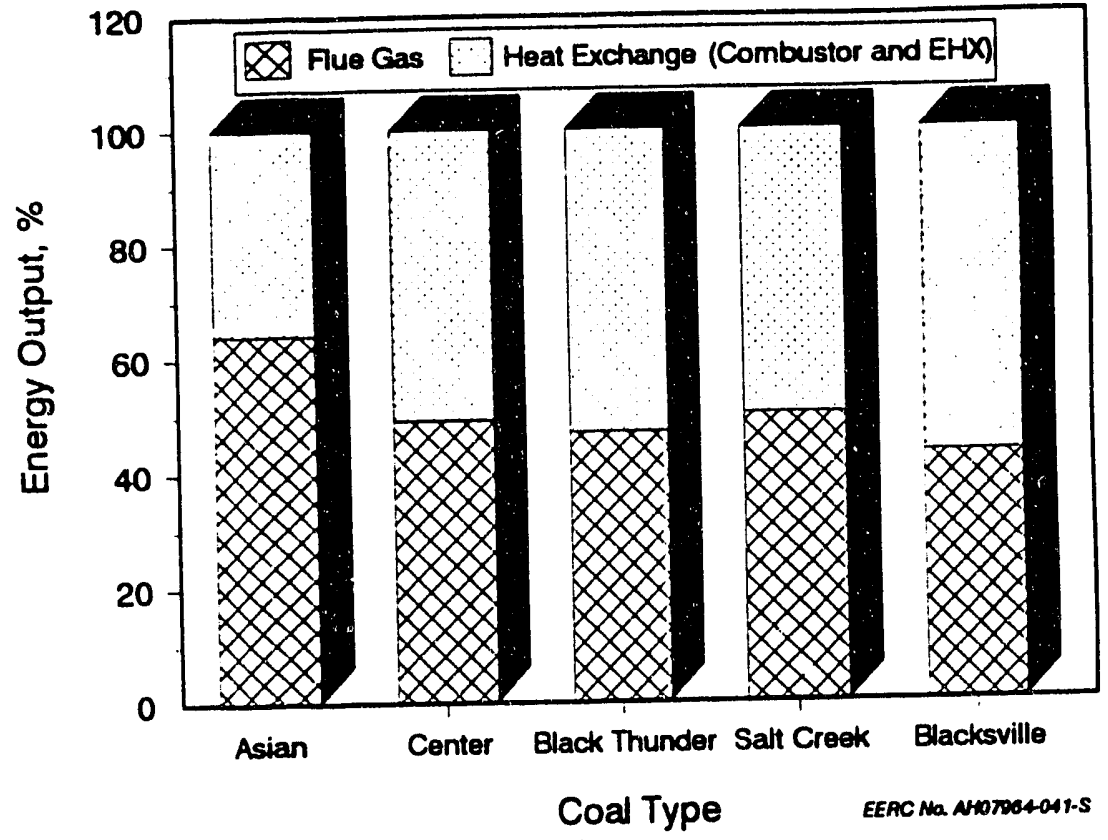

Figure 3-31. Energy generation at $\sim 1550^{\circ} \mathrm{F}, 16-\mathrm{ft} / \mathrm{sec}$ velocity, and $21 \%-34 \%$ excess air as a function of coal type.

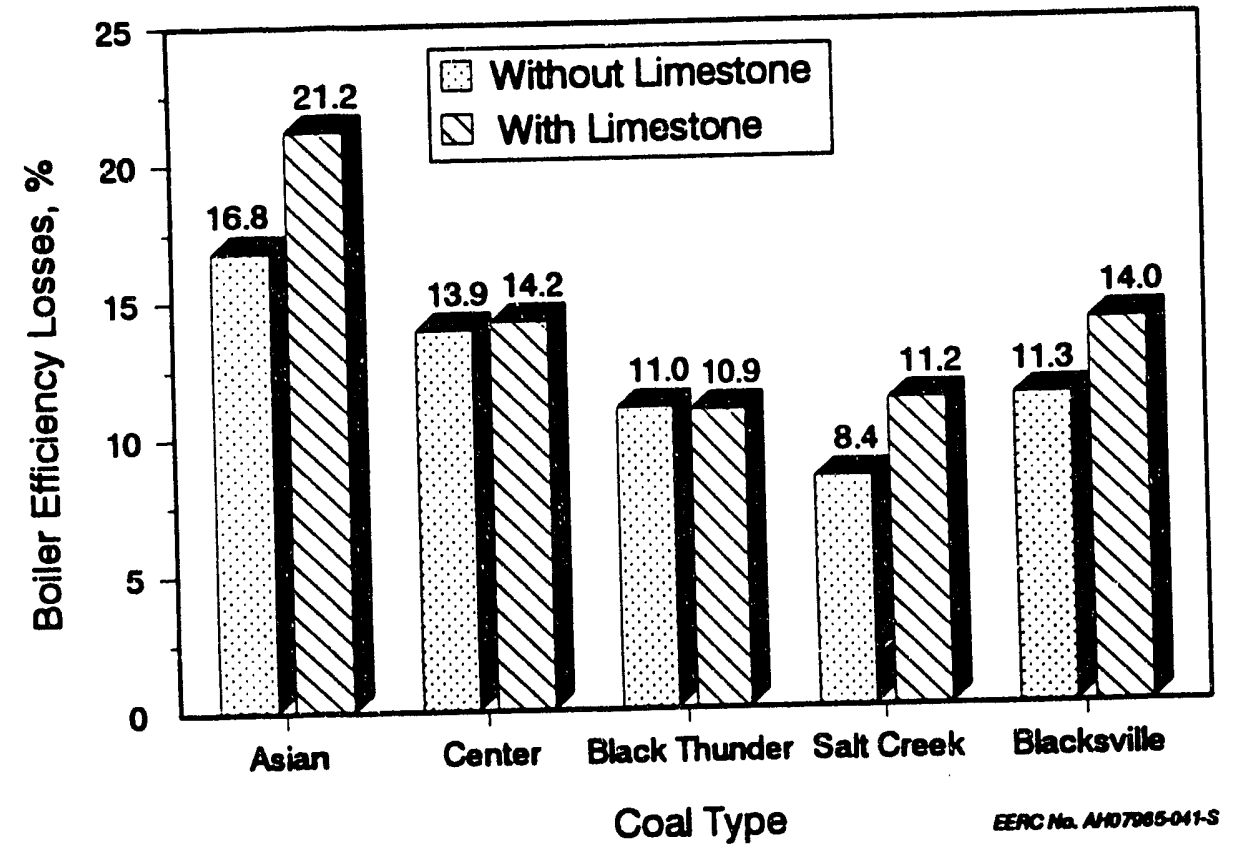

Figure 3-32. Boiler efficiency losses with and without limestone at $1550^{\circ} \mathrm{F}\left(1610^{\circ} \mathrm{F}\right.$ for Salt Creek), 16-ft/sec velocity, and 20\%-34\% excess air as a function of coal type. 
(evaporation and unrecovered sensible heat in the flue gas) range from a high of $6.6 \%$ for the Asian lignite, to a low of $0.8 \%$ for the Blacksville bituminous. Heat losses due to ash and spent sorbent are much lower and depend upon the total ash content of the coal relative to its heating values and sorbent requirements needed to meet the required sulfur capture. These losses amounted to $6.8 \%$ for the high-sulfur, high-ash Asian lignite and ranged from $0.2 \%$ to $1.4 \%$ for the other coals tested. The total efficiency losses ranged from $8.4 \%$ for the Salt Creek bituminous to $21.2 \%$ for the Asian lignite. Both Center lignite and Black Thunder subbituminous had higher boiler efficiencies than the Blacksville bituminous coal, due primarily to their high carbon burnout. Carbon combustion efficiency for the Blacksville coal could be improved with secondary ash recycle from the baghouse or other mechanical collector.

A system designed for a high-moisture fuel would require a larger fuel feed system to generate the same amount of steam and/or electricity as a unit designed for a lowmoisture fuel. Downstream heat recovery equipment would have to be larger for highermoisture fuels to account for the higher flue gas flow rates. Units designed for bituminous coals would likely be required to utilize ash recycle from a secondary cyclone system or baghouse to obtain acceptable levels of carbon burnout, while burnout of the more reactive low-rank coals are acceptable without secondary recycle.

\subsubsection{Impact of Load Control Method}

Low-load tests were performed with the Center lignite, Salt Creek bituminous, and Blacksville bituminous. Load was determined for each test by dividing the coal feed rate by the coal feed rate of the full-load baseline (with limestone) test for that coal type. Two different operational procedures were used to simulate load reduction. In the first, fullload heat-transfer surface was held constant, and combustor temperature decreased with load. In the second, average combustor temperature was held constant (the same as fullload baseline testing) by removing heat-transfer surface in the combustor and the external heat exchanger as load was reduced. In both cases, air flow rates were reduced, resulting in lower superficial gas velocities than during the full-load tests. Excess air was allowed to increase as load decreased. As a result, combustion air flow rates did not decrease in proportion to the coal feed rate, permitting operation at slightly higher velocities in the combustor to ensure adequate solids recirculation rates during the reduced-load tests.

Tables 3-8 and 3-9 present data on how reduced load, using constant heat-transfer surface and constant temperature, respectively, affected emissions and other operational results. Full load operation (100\%) is compared to operation at approximately $75 \%$ and $50 \%$ for three coals in Table 3-8, and for two coals in Table 3-9.

The combined effects of temperature, velocity, excess air, and calcium-to-sulfur ratio make it difficult to identify any clear trends relating how sulfur capture was affected by either load reduction method. For operation with constant heat-transfer surface, $\mathrm{NO}_{\mathrm{z}}$ emissions tended to decrease and $\mathrm{N}_{2} \mathrm{O}$ and $\mathrm{CO}$ emissions to increase as load decreased. These trends were expected, based on changes in temperature and excess air. For the constant temperature tests, $\mathrm{NO}_{\mathrm{x}}$ emissions increased slightly due to increases in excess air, while $\mathrm{N}_{2} \mathrm{O}$ and $\mathrm{CO}$ emissions were mostly unaffected as load was reduced, as these flue gas components are less sensitive to changes in excess air level. 
TABLE 3-7

Baseline Boiler Efficiency Data

\begin{tabular}{|c|c|c|c|c|c|}
\hline \multicolumn{6}{|c|}{ Baseline Case Without Limestone Addition } \\
\hline Coal: & TL4 & CLO & BT1 & SC1 & BV1 \\
\hline \multicolumn{6}{|l|}{ Operational Conditions } \\
\hline $\begin{array}{l}\text { Load, \% } \\
\text { Avg. Comb. Temp., }{ }^{\circ} \mathrm{F} \\
\text { SGV, ft/sec } \\
\text { Excess Air, \% } \\
\text { Sulfur Retention, \% } \\
\text { Solids Recirc., lb/hr } \\
\text { Comb. HXs on-line } \\
\text { EHX HXs on-line }\end{array}$ & $\begin{array}{r}92 \\
1564 \\
16.1 \\
26.6 \\
70.1 \\
3450 \\
7 \\
8\end{array}$ & $\begin{array}{r}112 \\
1526 \\
14.6 \\
22.0 \\
23.2 \\
4160 \\
8 \\
9\end{array}$ & $\begin{array}{r}90 \\
1573 \\
16.1 \\
33.8 \\
2.9 \\
2250 \\
10 \\
9\end{array}$ & $\begin{array}{r}97 \\
1607 \\
16.7 \\
20.8 \\
0.9 \\
7660 \\
8 \\
4\end{array}$ & $\begin{array}{r}94 \\
1558 \\
16.1 \\
28.3 \\
7.1 \\
4170 \\
12 \\
7\end{array}$ \\
\hline \multicolumn{6}{|l|}{ Boiler Efficiency Losses, \% } \\
\hline $\begin{array}{l}\text { Dry Gas } \\
\text { Water in Fuel } \\
\text { Combustion of Fuel Hydrogen } \\
\text { Unburned Carbon } \\
\text { Calcination/Sulfation } \\
\text { Radiation \& Convection }{ }^{2} \\
\text { Discharged Solids }\end{array}$ & $\begin{array}{l}6.6 \\
5.1 \\
0.7 \\
0.1 \\
-- \\
0.4 \\
3.9\end{array}$ & $\begin{array}{r}5.4 \\
6.7 \\
0.5 \\
0.0 \\
.- \\
0.4 \\
0.4\end{array}$ & $\begin{array}{r}6.0 \\
3.9 \\
0.5 \\
0.3 \\
-\overline{0} \\
0.4 \\
0.3\end{array}$ & $\begin{array}{r}5.8 \\
0.8 \\
0.5 \\
0.7 \\
-- \\
0.4 \\
0.2\end{array}$ & $\begin{array}{r}5.8 \\
0.3 \\
0.5 \\
4.0 \\
-- \\
0.4 \\
0.3\end{array}$ \\
\hline Total & 16.8 & 13.4 & 11.4 & 8.4 & 11.3 \\
\hline Boiler Efficiency, \% & 83.2 & 86.5 & 88.6 & 91.6 & 88.7 \\
\hline \multicolumn{6}{|l|}{ Baseline Case With Limestone Addition } \\
\hline Coal: & TL1 & CL1 & BT2 & SC2 & BV2 \\
\hline \multicolumn{6}{|l|}{$\overline{\text { Operational Conditions }}$} \\
\hline $\begin{array}{l}\text { Load, \% } \\
\text { Avg. Comb. Temp., }{ }^{\circ} \mathrm{F} \\
\text { SGV, ft/sec } \\
\text { Excess Air, \% } \\
\text { Sulfur Retention, \% } \\
\text { Solids Recirc., lb/hr } \\
\text { Comb. HXs on-line } \\
\text { EHX HXs on-line }\end{array}$ & $\begin{array}{r}100 \\
1565 \\
16.8 \\
24.4 \\
90.3 \\
3830 \\
4 \\
7\end{array}$ & $\begin{array}{r}100 \\
1554 \\
14.1 \\
25.7 \\
67.5 \\
3170 \\
7 \\
6\end{array}$ & $\begin{array}{r}100 \\
1545 \\
16.1 \\
26.7 \\
77.7 \\
10270 \\
10 \\
8\end{array}$ & $\begin{array}{r}100 \\
1607 \\
16.6 \\
21.5 \\
67.7 \\
12050 \\
8 \\
3\end{array}$ & $\begin{array}{r}100 \\
1544 \\
15.8 \\
20.4 \\
90.1 \\
7220 \\
12 \\
7\end{array}$ \\
\hline \multicolumn{6}{|l|}{ Boiler Efficiency Losses, \% } \\
\hline $\begin{array}{l}\text { Dry Gas }{ }^{1} \\
\text { Water in Fuel } \\
\text { Combustion of Fuel Hydrogen } \\
\text { Unburned Carbon } \\
\text { Calcination/Sulfation } \\
\text { Radiation \& Convection }{ }^{2} \\
\text { Discharged Solids }\end{array}$ & $\begin{array}{r}7.1 \\
5.6 \\
0.8 \\
2.1 \\
-0.5 \\
0.4 \\
6.9\end{array}$ & $\begin{array}{l}5.7 \\
6.3 \\
0.5 \\
0.1 \\
0.4 \\
0.4 \\
0.4\end{array}$ & $\begin{array}{l}5.7 \\
3.9 \\
0.5 \\
0.1 \\
0.1 \\
0.4 \\
0.2\end{array}$ & $\begin{array}{l}5.9 \\
0.9 \\
0.5 \\
2.0 \\
0.1 \\
0.4 \\
1.4\end{array}$ & $\begin{array}{l}5.9 \\
0.3 \\
0.5 \\
6.0 \\
0.0 \\
0.4 \\
1.0\end{array}$ \\
\hline Total & 22.4 & 13.8 & 10.9 & 11.2 & 14.1 \\
\hline Boiler Efficiency, \% & 77.6 & 86.2 & 89.1 & 88.8 & 85.9 \\
\hline
\end{tabular}

${ }^{1}$ Assumes stack gas exit temperature $=300^{\circ} \mathrm{F}$

${ }^{2}$ Assumes radiative and convective losses $=0.4 \%$ 


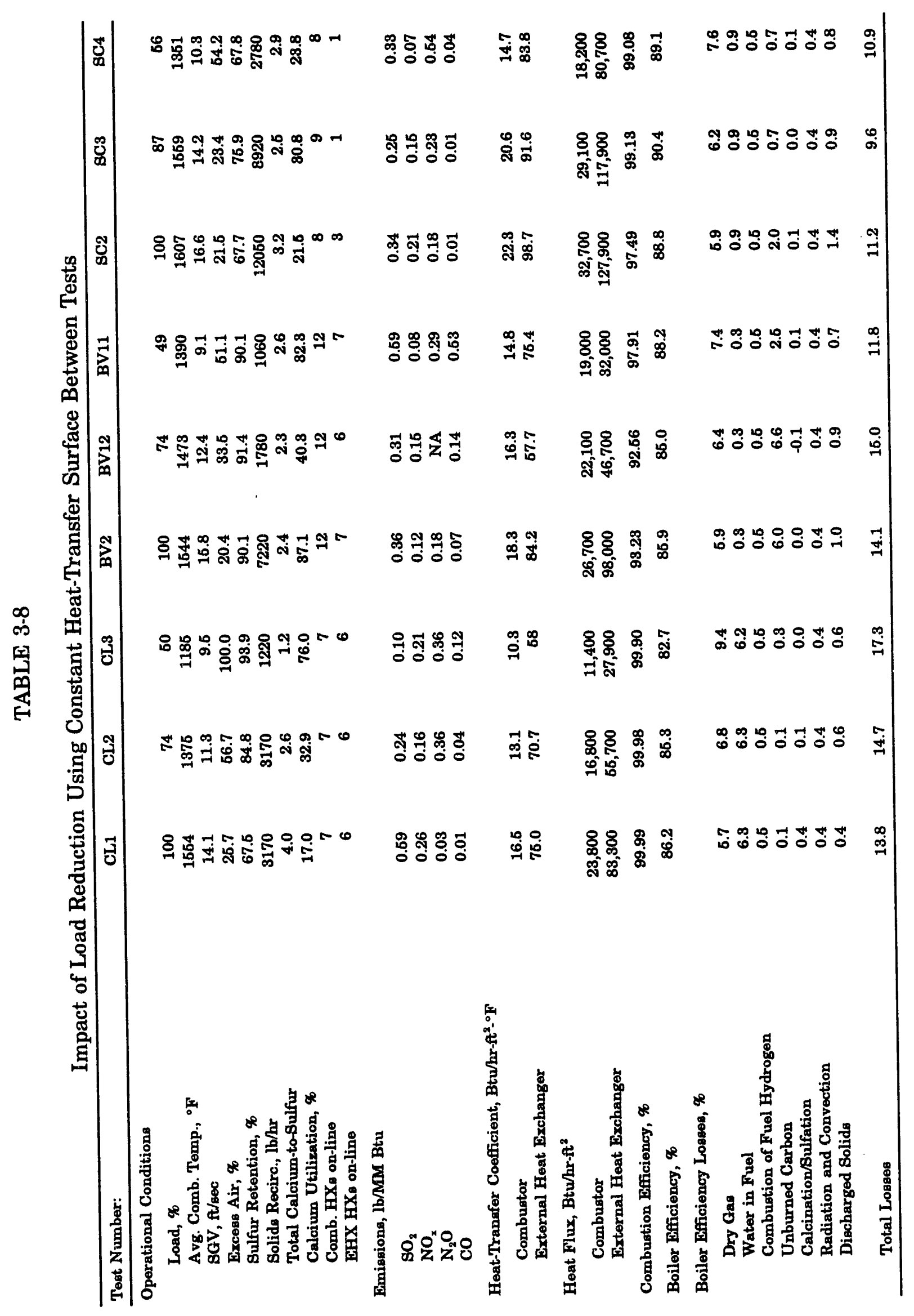


TABLE 3-9

Impact of Load Reduction Using Constant Temperature Between Tests

\begin{tabular}{|c|c|c|c|c|c|c|}
\hline & \multicolumn{6}{|c|}{ Test Number } \\
\hline & CL1 & CL5 & CL4 & BV2 & BV9 & BV10 \\
\hline \multicolumn{7}{|l|}{ Operational Conditions } \\
\hline $\begin{array}{l}\text { Load, \% } \\
\text { Avg. Comb. Temp., }{ }^{\circ} \text { F } \\
\text { SGV, ft/sec } \\
\text { Excess Air, \% } \\
\text { Sulfur Retention, \% } \\
\text { Solids Recirc., lb/hr } \\
\text { Total Ca/S } \\
\text { Calcium Utilization, \% } \\
\text { Comb. HXs on-line } \\
\text { EHX HXs on-line }\end{array}$ & $\begin{array}{r}100 \\
1554 \\
14.1 \\
25.7 \\
67.5 \\
3170 \\
4.0 \\
17.0 \\
7 \\
6\end{array}$ & $\begin{array}{r}75 \\
1522 \\
12.9 \\
58.3 \\
74.4 \\
2430 \\
1.9 \\
38.8 \\
3 \\
4\end{array}$ & $\begin{array}{c}54 \\
1537 \\
11.6 \\
95.3 \\
51.1 \\
\text { NA* } \\
2.2 \\
23.0 \\
1 \\
0\end{array}$ & $\begin{array}{r}100 \\
1544 \\
15.8 \\
20.4 \\
90.1 \\
7220 \\
2.4 \\
37.1 \\
12 \\
7\end{array}$ & $\begin{array}{r}70 \\
1539 \\
11.7 \\
27 \\
85.8 \\
2030 \\
1.8 \\
48.0 \\
10 \\
4\end{array}$ & $\begin{array}{r}56 \\
1566 \\
10.6 \\
40.9 \\
86.4 \\
730 \\
2.3 \\
37.8 \\
5.5 \\
3\end{array}$ \\
\hline \multicolumn{7}{|l|}{ Emissions, lb/MM Btu } \\
\hline $\begin{array}{l}\mathrm{SO}_{2} \\
\mathrm{NO}_{x} \\
\mathrm{~N}_{2} \mathrm{O} \\
\mathrm{CO}\end{array}$ & $\begin{array}{l}0.59 \\
0.26 \\
0.03 \\
0.01\end{array}$ & $\begin{array}{l}0.58 \\
0.30 \\
0.06 \\
0.01\end{array}$ & $\begin{array}{l}0.81 \\
0.37 \\
0.07 \\
0.01\end{array}$ & $\begin{array}{l}0.36 \\
0.12 \\
0.18 \\
0.07\end{array}$ & $\begin{array}{l}0.51 \\
0.11 \\
0.19 \\
0.09\end{array}$ & $\begin{array}{l}0.49 \\
0.15 \\
0.14 \\
0.06\end{array}$ \\
\hline \multicolumn{7}{|c|}{ Heat-Transfer Coefficient, Btu/hr-ft $\mathrm{t}^{2}{ }^{\circ} \mathrm{F}$} \\
\hline $\begin{array}{l}\text { Combustor } \\
\text { External Heat Exchanger }\end{array}$ & $\begin{array}{l}16.5 \\
75.0\end{array}$ & $\begin{array}{l}17.0 \\
81.6\end{array}$ & $\begin{array}{r}19.0 \\
\text { NA }\end{array}$ & $\begin{array}{l}18.3 \\
84.2\end{array}$ & $\begin{array}{l}18.6 \\
79.7\end{array}$ & $\begin{array}{l}17.8 \\
58.5\end{array}$ \\
\hline \multicolumn{7}{|l|}{ Heat Flux, Btu/hr-ft ${ }^{2}$} \\
\hline $\begin{array}{l}\text { Combustor } \\
\text { External Heat Exchanger }\end{array}$ & $\begin{array}{l}23,800 \\
83,300\end{array}$ & $\begin{array}{l}23,800 \\
85,300\end{array}$ & $\begin{array}{r}27,900 \\
\text { NA }\end{array}$ & $\begin{array}{l}26,700 \\
98,000\end{array}$ & $\begin{array}{l}26,200 \\
77,800\end{array}$ & $\begin{array}{l}25,600 \\
43,700\end{array}$ \\
\hline Combustion Efficiency, \% & 99.99 & 99.96 & 99.97 & 93.23 & 95.52 & 98.31 \\
\hline Boiler Efficiency, \% & 86.2 & 84.8 & 82.9 & 85.9 & 88.9 & 89.4 \\
\hline \multicolumn{7}{|l|}{ Boiler Efficiency Losses, \% } \\
\hline $\begin{array}{l}\text { Dry Gas } \\
\text { Water in Fuel } \\
\text { Combustion of Fuel Hydrogen } \\
\text { Unburned Carbon } \\
\text { Calcination/Sulfation } \\
\text { Radiation and Convection } \\
\text { Unburned Solids }\end{array}$ & $\begin{array}{l}5.7 \\
6.3 \\
0.5 \\
0.1 \\
0.4 \\
0.4 \\
0.4\end{array}$ & $\begin{array}{l}7.0 \\
6.4 \\
0.5 \\
0.1 \\
0.0 \\
0.4 \\
0.7\end{array}$ & $\begin{array}{l}8.8 \\
6.4 \\
0.5 \\
0.0 \\
0.1 \\
0.4 \\
0.8\end{array}$ & $\begin{array}{l}5.9 \\
0.3 \\
0.5 \\
6.0 \\
0.0 \\
0.4 \\
1.0\end{array}$ & $\begin{array}{r}6.0 \\
0.3 \\
0.5 \\
3.7 \\
-0.3 \\
0.4 \\
0.5\end{array}$ & $\begin{array}{l}7.3 \\
0.3 \\
0.5 \\
1.6 \\
0.0 \\
0.4 \\
0.5\end{array}$ \\
\hline Total Losses & 13.8 & 15.2 & 17.1 & 14.1 & 11.1 & 10.6 \\
\hline
\end{tabular}

* Not available. 
Heat-transfer coefficients and heat fluxes in both the combustor and external heat exchanger were significantly reduced during operation with constant heat-transfer surface. This was due to a combination of decreased operational temperatures and recirculation rates as load was decreased. For constant temperature operation, overall heat-transfer coefficients and heat flux decreased in the external heat exchanger, and the overall heat-transfer coefficients and heat fluxes were relatively unaffected by load reduction in the combustor.

Combustion efficiencies were not affected for the reduced load testing with the more reactive Center lignite. Reducing load using either method resulted in improved combustion efficiency for Blacksville and Salt Creek testing, due to lower superficial gas velocities in the combustor. Lower operational velocities resulted in increased gas residence time and reduced the amount of carbon carried out of the system, which improved carbon burnout.

Figure 3.33 shows boiler efficiency losses at the $75 \%$ and $50 \%$ load conditions for the Center lignite and Blacksville bituminous using the two different methods of load reduction. Comparisons of the boiler efficiency losses shown in the figure must be made with caution, since a $300^{\circ} \mathrm{F}$ stack gas exit temperature was assumed for the boiler efficiency calculations for each test period (See Appendix $\mathrm{G}$ for the calculations used). In an operational CFB boiler, as load is reduced, there would likely be a corresponding change in the stack gas exit temperature, which would not decrease the boiler efficiency losses as significantly as reported here for the hot gases exiting the system. Another consideration when comparing the different test coals and load conditions is the level of excess air used at each test condition. An increase in excess air typically results in a decrease in boiler efficiency.

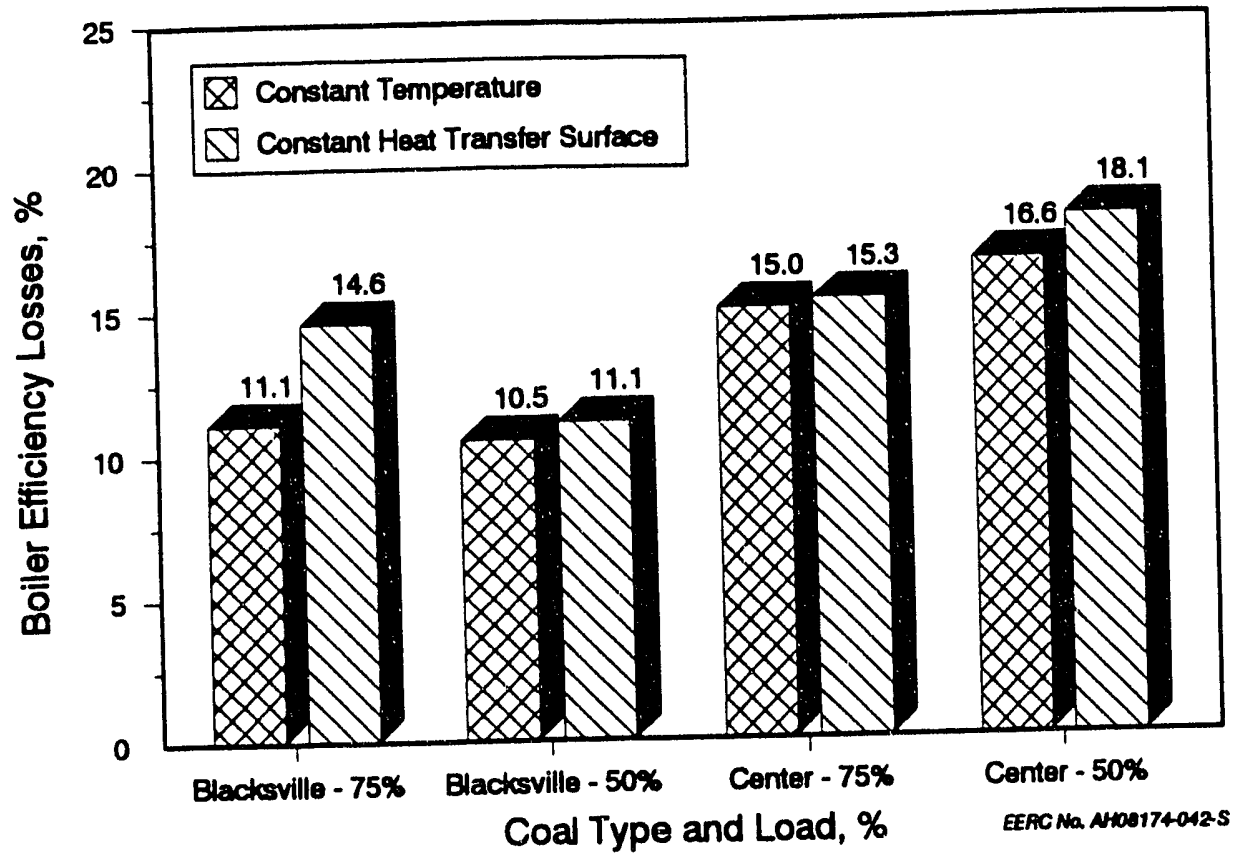

Figure 3-33. Boiler efficiency losses as a function of load, load reduction strategy, and coal type. 
Reduced load operation at constant temperature resulted in higher boiler efficiencies (85.0\% for Center and $88.9 \%$ for Blacksville at $75 \%$ load, $83.4 \%$ for Center and $89.5 \%$ for Blacksville at $50 \%$ load) than reduced load operation with constant heat-transfer surface (84.7\% for Center and $85.4 \%$ for Blacksville at $75 \%$ load, $81.9 \%$ for Center and $88.9 \%$ for Blacksville at $50 \%$ load). This was mostly due to the greater quantities of fluidizing air required at lower operational temperatures to maintain similar velocities as a test at the same load but higher temperature. Again, no consideration was given here to the effect that this would actually have on the stack gas exit temperature in an operational CFB boiler. Boiler efficiencies were higher with the Blacksville bituminous coal than with the Center lignite because of the high moisture content in the lignite. 


\subsection{COMPARISON TO FULL SCALE}

An excellent opportunity was available during this program to determine how well the EERC pilot-scale CFB simulates full scale. Tests were conducted on the EERC CFB pilot plant system at similar conditions to those already conducted at the $110 \mathrm{MWe}$ Colorado Ute Nucla CFBC power station. Similar tests were also conducted at a Pyropower, Inc., pilot plant system in San Diego, California. In all three cases, the coal and limestone utilized were from the same source. The comparison here is limited in scope to the available published test data for the full-scale Nucla system and the Pyropower pilot plant system.

\subsection{Coal and Limestone Utilized}

Table 4-1 compares the range of coal properties reported for the three different systems. Other than slightly lower coal moisture for testing at the EERC, the analyses reported for the three locations are very similar. An analysis of the limestone used at the EERC is shown in Table 1-1. The size distributions of the coal and limestone utilized at the EERC are shown in Figure 4-1.

\subsection{Unit Operation}

\subsubsection{Bottom Ash/Fly Ash Split}

The percentage of ash which remains in the combustor or downcomer as bed material compared to that which is carried out of the combustor is a function of the coal ash and sorbent size and of the cyclone cut point (50\% of this particle size would be captured). Figure 4-2 shows size distributions of fly ash collected. It can be extrapolated

\section{TABLE 4-1}

Comparison of Coals Tested in the Nucla Power Station and Pyropower and EERC Pilot Plants

\begin{tabular}{|c|c|c|c|}
\hline & Nucla & Pyropower & EERC \\
\hline \multicolumn{4}{|l|}{ Proximate Analysis, wt\% } \\
\hline $\begin{array}{l}\text { Moisture } \\
\text { Volatile } \\
\text { Fixed Carbon } \\
\text { Ash }\end{array}$ & $\begin{array}{r}7.8 \cdot 10.2 \\
28.8 \cdot 33.7 \\
40.4-45.1 \\
12.1-23.0\end{array}$ & $\begin{array}{r}7.2-10.0 \\
32.1 \cdot 32.8 \\
41.3 \cdot 42.7 \\
14.6 \cdot 18.7\end{array}$ & $\begin{array}{c}6.8-7.9 \\
30.2 \cdot 31.9 \\
41.6 \cdot 44.7 \\
16.9 \cdot 20.2\end{array}$ \\
\hline \multicolumn{4}{|l|}{ Ultimate Analysis, wt\% } \\
\hline $\begin{array}{l}\text { Carbon } \\
\text { Hydrogen } \\
\text { Nitrogen } \\
\text { Sulfur } \\
\text { Oxygen } \\
\text { Ash } \\
\text { Moisture }\end{array}$ & $\begin{array}{r}55.6-63.2 \\
3.42-3.73 \\
0.52-1.61 \\
0.43-0.58 \\
8.22-10.4 \\
12.1-23.0 \\
7.8-10.2\end{array}$ & $\begin{array}{r}57.6 \cdot 60.0 \\
3.7 \cdot 4.7 \\
1.1 \cdot 1.3 \\
0.4 \cdot 0.6 \\
8.7 \cdot 10.0 \\
14.6 \cdot 18.7 \\
7.2 \cdot 10.0\end{array}$ & $\begin{array}{c}57.6-60.4 \\
3.8-4.5 \\
1.1 \cdot 1.3 \\
0.4-0.5 \\
8.5 \cdot 9.9 \\
16.9 \cdot 20.2 \\
6.8 \cdot 7.9\end{array}$ \\
\hline $\mathrm{HHV}$, as-received, Btu/lb & $9,674-11,090$ & $10,500-11,300$ & $9,976 \cdot 10,563$ \\
\hline
\end{tabular}




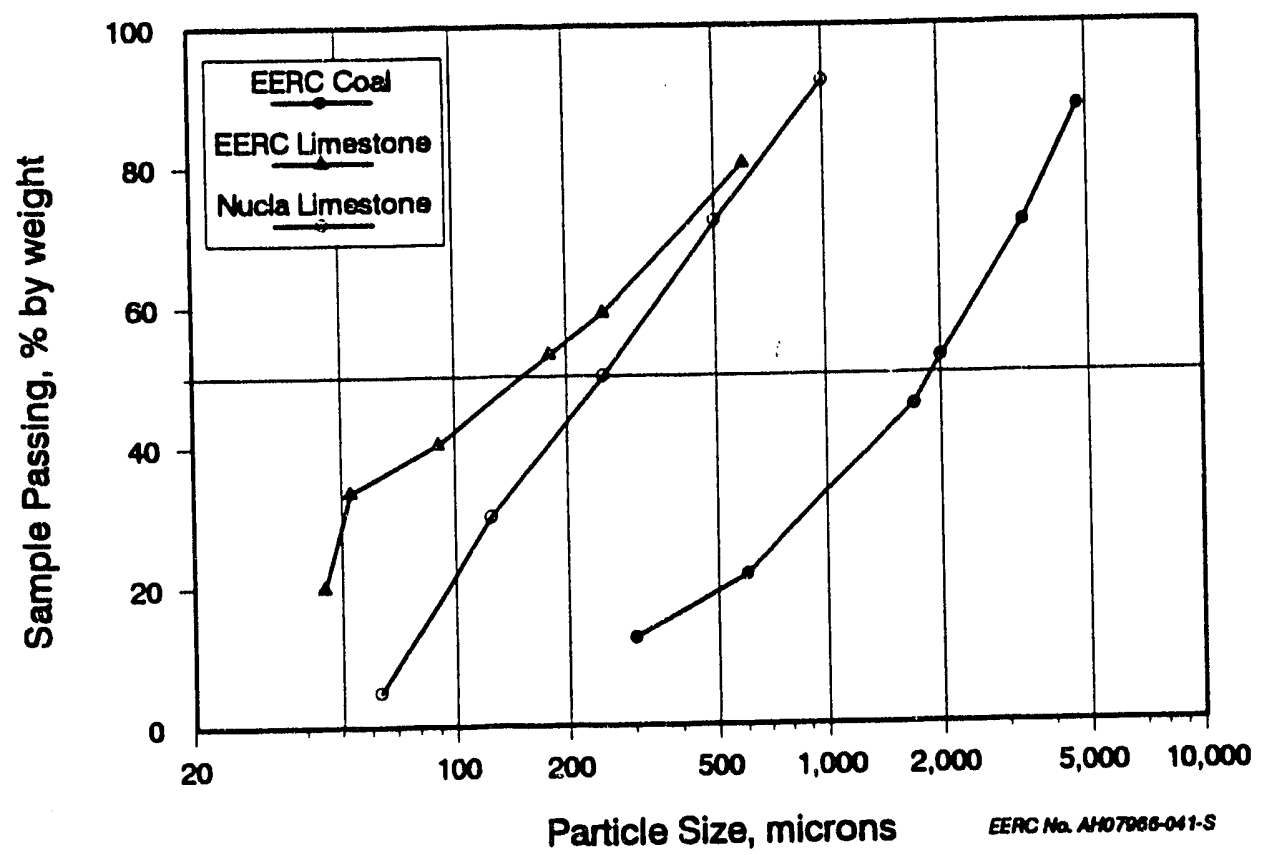

Figure 4-1. Size distributions of coal and limestone.

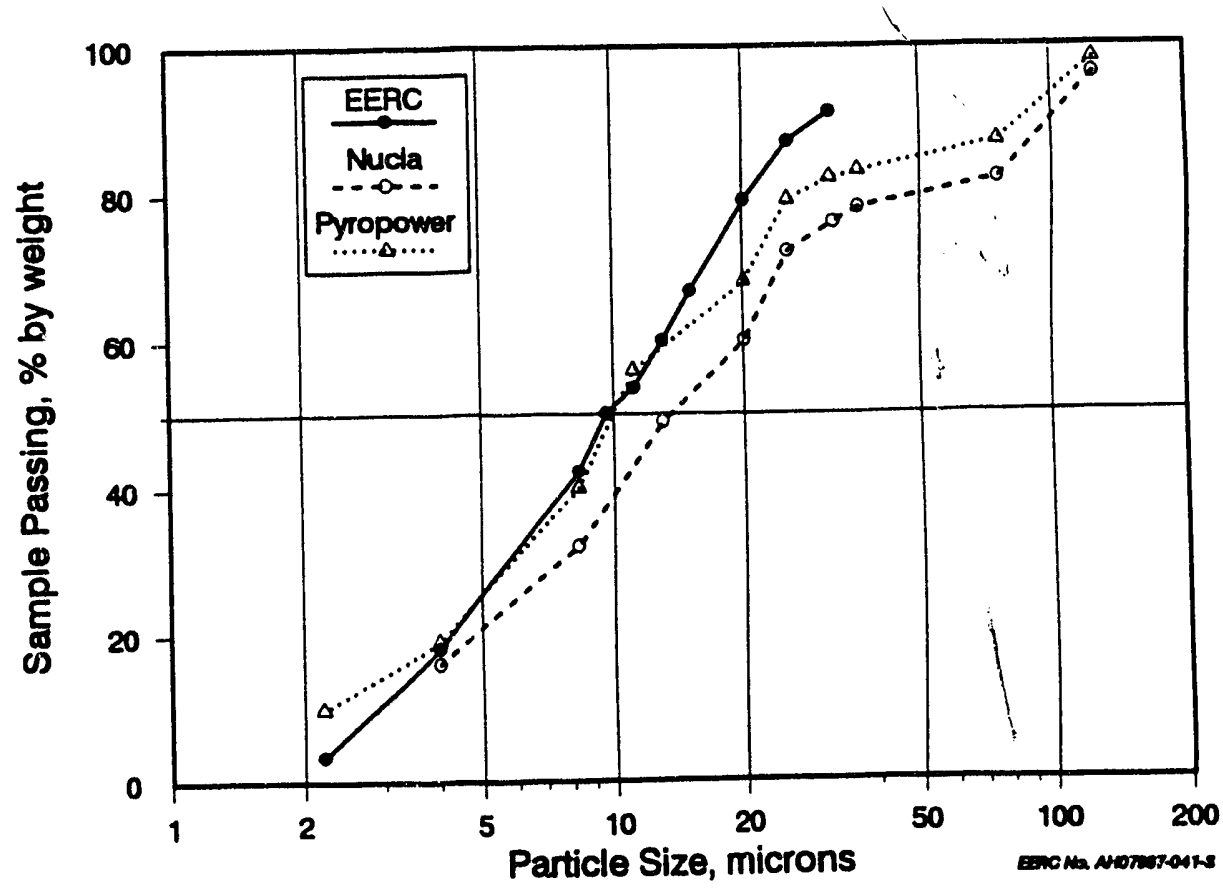

Figure 4-2. Size distributions of fly ash collected. 
from this graph that the EERC was operating with a smaller cut point than Nucla and about the same cut point as Pyropower. Overall, the EERC fly ash top size was considerably smaller than either Nucla or Pyropower. Full-load operation at the EERC resulted in a bottom ash/total split of $26 \%$. For the Pyropower pilot plant and the Nucla generating station, bottom ash splits ranged from approximately $10 \%$ to $19 \%$ and $11 \%$ to $17 \%$, respectively. In addition to the difference in cut size, the high bottom ash split at the EERC may also have been due to various operational difficulties. A hole was found in one of the bags at the end of the run, and there was a tendency for the fly ash to hang up in the baghouse hopper. Either of these conditions may have caused the amount of ash retrieved from the baghouse to be artificially low, as evidenced by poor material balances.

\subsubsection{Bed Temperature}

Full-load testing was conducted on the EERC and Pyropower pilot plants at average bed temperatures similar to those obtained at the Nucla generating station. Figure 4-3 shows reasonably similar combustor temperature distributions for the two pilot units at full-load conditions. Cooled solids recirculating back into the bottom section of the EERC combustor from the external heat exchanger resulted in a slightly lower temperature distribution in the lower portion compared to the Pyropower combustor.

Partial-load tests were achieved by reducing the coal feed rate to a percentage of the full-load rate while maintaining the full-load heat-transfer surface configuration in the combustor. At partial-load conditions, the EERC combustor was at a lower average combustor temperature than was measured for either the Nucla or Pyropower systems, as shown in Figure 4-4. This could have been caused by operational differences in the recirculation rate since the EERC system had a smaller average recirculating material size. The presence of the external heat exchanger could also have caused the lower average temperature, even though it was extracting only minimal heat with a single cooling coil. Neither the Nucla or Pyropower systems utilizes an external heat exchanger.

\subsection{Thermal Performance}

\subsubsection{Heat Flux and Heat Transfer}

The heat flux and heat-transfer coefficients are influenced primarily by bed hydrodynamics. The solids recirculation rate, bed particle size and composition, superficial gas velocity, and bed temperature all influence heat transfer in the CFBC. These parameters were duplicated fairly well in the EERC pilot plant as compared to the commercial plant. Therefore, one may expect the bed hydrodynamics to be similar between the pilot- and full-scale units. However, combustor geometry also plays a key role in determining bed hydrodynamics. The increased wall effects for the smaller pilotscale unit offset, to some degree, the increased height for larger units, resulting in similar bed densities for both systems. The relative degree of the differences in bed hydrodynamics and their importance in process comparison between pilot- and full-scale is difficult to assess, and further research is needed to quantify hydrodynamic differences between pilot- and full-scale systems. 


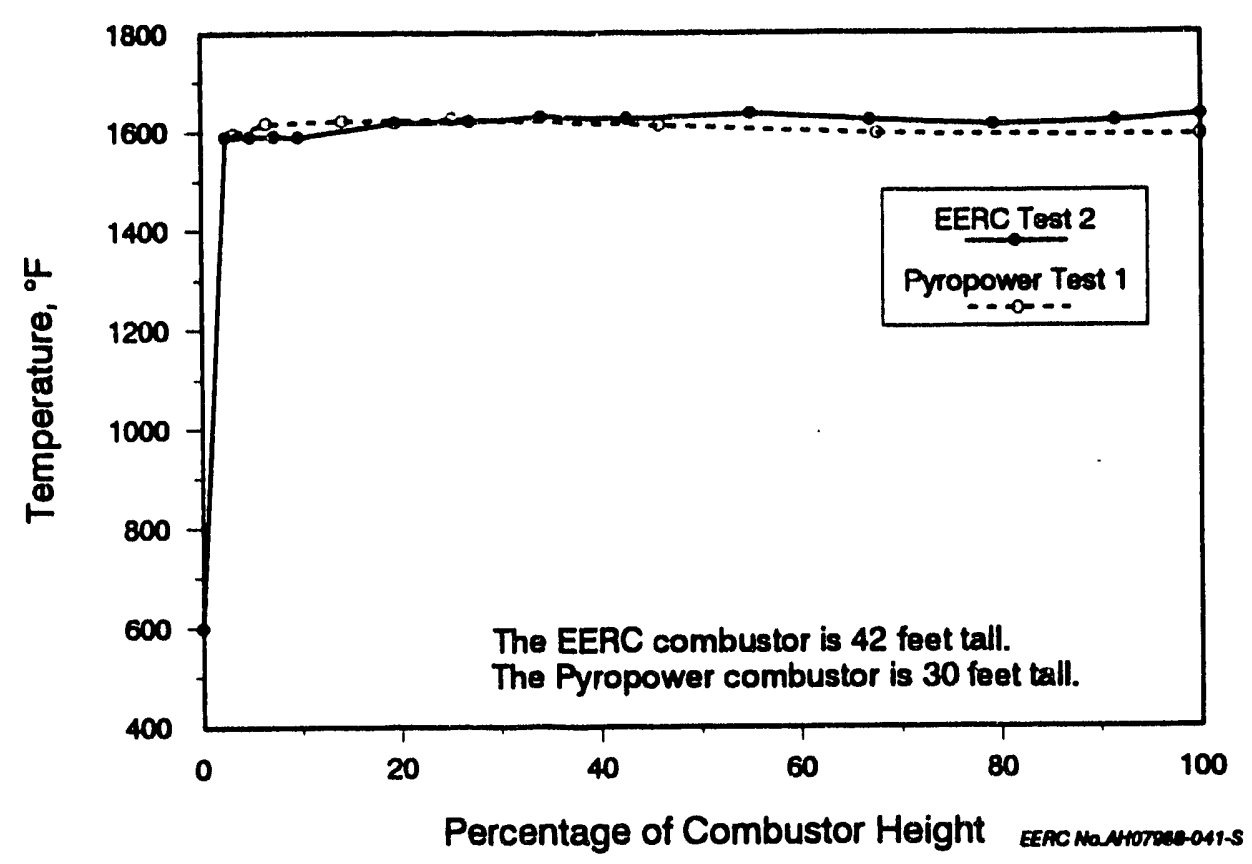

Figure 4-3. Combustor temperature distributions of the Pyropower and EERC pilot plants at full-load operation.

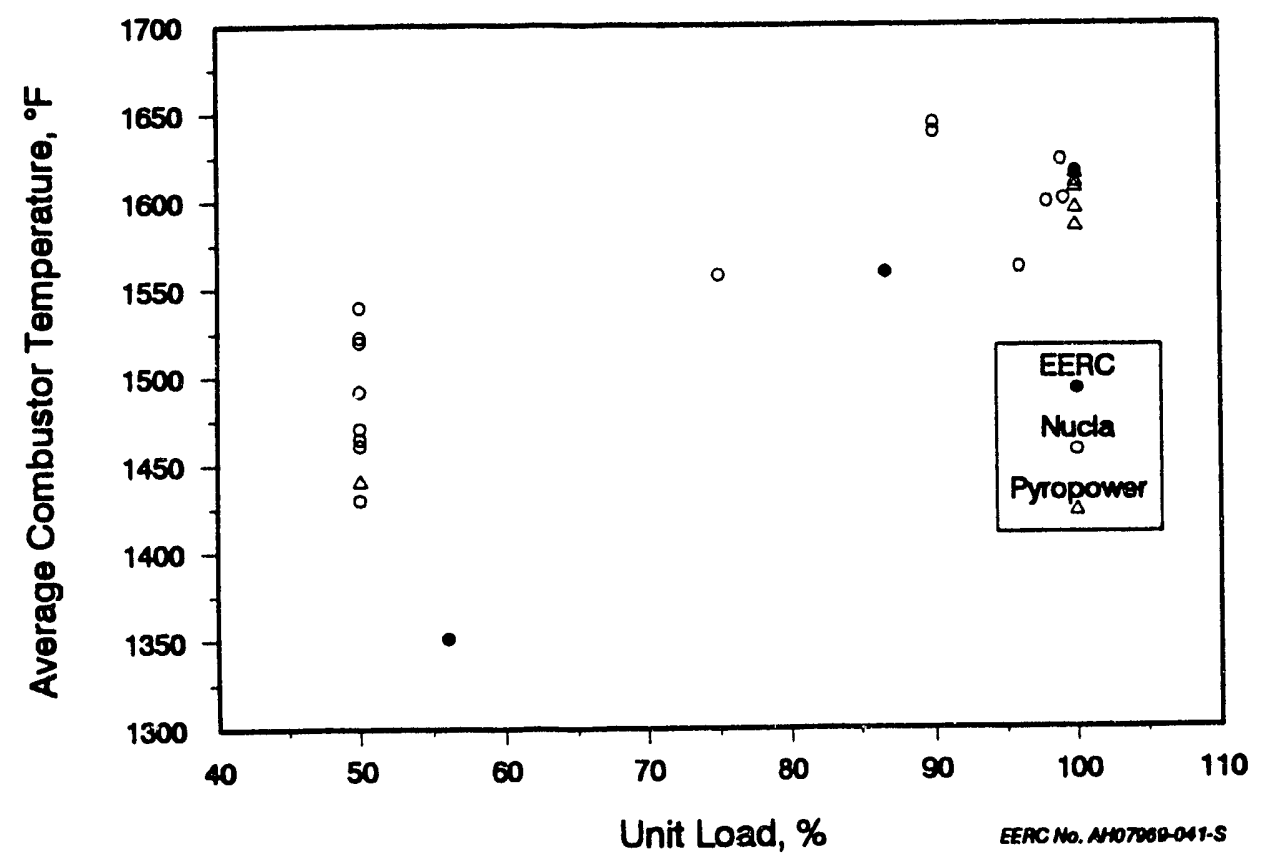

Figure 4-4. Comparison of combustor temperatures of the Nucla Power Station and the Pyropower and EERC pilot plants at partial-load operation. 
A comparison of the heat flux data from the pilot- and full-scale plarits indicates that a reasonable assessment of average heat flux can be measured in the pilot-scale unit. There appears to be a wider variation in localized heat flux measurements from the pilotscale system. The measured overall heat flux from the pilot-scale testing ranged from $18,200 \mathrm{Btu} / \mathrm{hr}-\mathrm{ft}^{2}$ at $55 \%$ load to $26,000 \mathrm{Btu} / \mathrm{hr}-\mathrm{ft}^{2}$ at $88 \%$ load condition up to 32,600 $\mathrm{Btu} / \mathrm{hr}-\mathrm{ft}^{2}$ at full-load condition. The measured heat flux from the Colorado Ute Nucla Station ranged from 21,200 to $23,400 \mathrm{Btu} / \mathrm{hr}$ - $\mathrm{ft}^{2}$ at part load (55 MWe) and from 31,700 to $33,900 \mathrm{Btu} / \mathrm{hr}^{-\mathrm{ft}^{2}}$ at full-load conditions (105 MWe). The differences in heat flux at the low-load condition were likely due to the lower combustor temperature in the pilot unit $\left(1350^{\circ} \mathrm{F}\right)$, as compared to the Nucla system $\left(1500^{\circ} \mathrm{F}\right)$. The calculations for heat flux and heat-transfer coefficient from the EERC CFB combustor heat exchange panels were based on the exposed area of the tubes plus the area included in the $1 / 8$-inch weld gaps between the tubes.

At full-load conditions, localized heat fluxes measured in the pilot plant varied from a maximum of $53,650 \mathrm{Btu} / \mathrm{hr}$ - $\mathrm{ft}^{2} 7.5$ feet above the distributor plate down to 27,700 $\mathrm{Btu} / \mathrm{hr}-\mathrm{ft}^{2} 32.5$ feet above the distributor plate. At low-load conditions, localized heat fluxes measured in the pilot plant varied from a maximum of $25,000 \mathrm{Btu} / \mathrm{hr}-\mathrm{ft}^{2} 7.5$ feet above the distributor plate down to $17,100 \mathrm{Btu} / \mathrm{hr}-\mathrm{ft}^{2} 32.5$ feet above the distributor plate. At both load conditions with the EERC pilot plant, the localized heat flux increased slightly just before the combustor exit.

The heat-transfer coefficient in the EERC combustor dropped from $22.3 \mathrm{Btu} / \mathrm{hr}-\mathrm{ft}^{2}{ }^{\circ} \mathrm{F}$ (Test Period 2 at full load) down to $14.4 \mathrm{Btu} / \mathrm{hr}-\mathrm{ft}^{2} \cdot{ }^{\circ} \mathrm{F}$ (Test Period 4 at $55 \%$ of full load). The external heat exchanger, operated in a bubbling bed mode, had the heat-transfer coefficient decrease less significantly from $98.7 \mathrm{Btu} / \mathrm{hr}-\mathrm{ft}^{2}{ }^{\circ} \mathrm{F}$ (three cooling coils in service) to $83.8 \mathrm{Btu} / \mathrm{hr}-\mathrm{ft}^{2}{ }^{\circ} \mathrm{F}$ (one cooling coil in service) during reduced load testing.

\subsubsection{Combustion Efficiency and CO Emissions}

Combustion efficiency is a function of temperature, excess air, particle size, and residence time, the last two depending on the design of the combustor. Typically, fullscale units have greater residence time, leading to potentially better carbon burnout, but this can be offset at the pilot scale by increased wall effects and better cyclone efficiency.

The EERC combustion efficiencies shown in Figure 4-5 are for Tests 5 through 12, conducted at both high and low excess air conditions. While the low excess air tests are comparable to the Pyropower data, the EERC pilot plant may have slightly higher combustion efficiencies due to greater residence time, since the EERC combustor is 12 feet taller than the Pyropower unit. Combustion efficiencies from the EERC pilot unit are comparable to those from the Colorado Ute Nucla Station.

The level of carbon monoxide in the flue gas is an indication of comburion efficiency. The levels of $\mathrm{CO}$ emissions from the EERC pilot plant are comparable to the Pyropower unit and lower than those from Nucla, as shown in Figure 4-6. Better mixing at the pilot scale could account for the improvement over Nucla. 


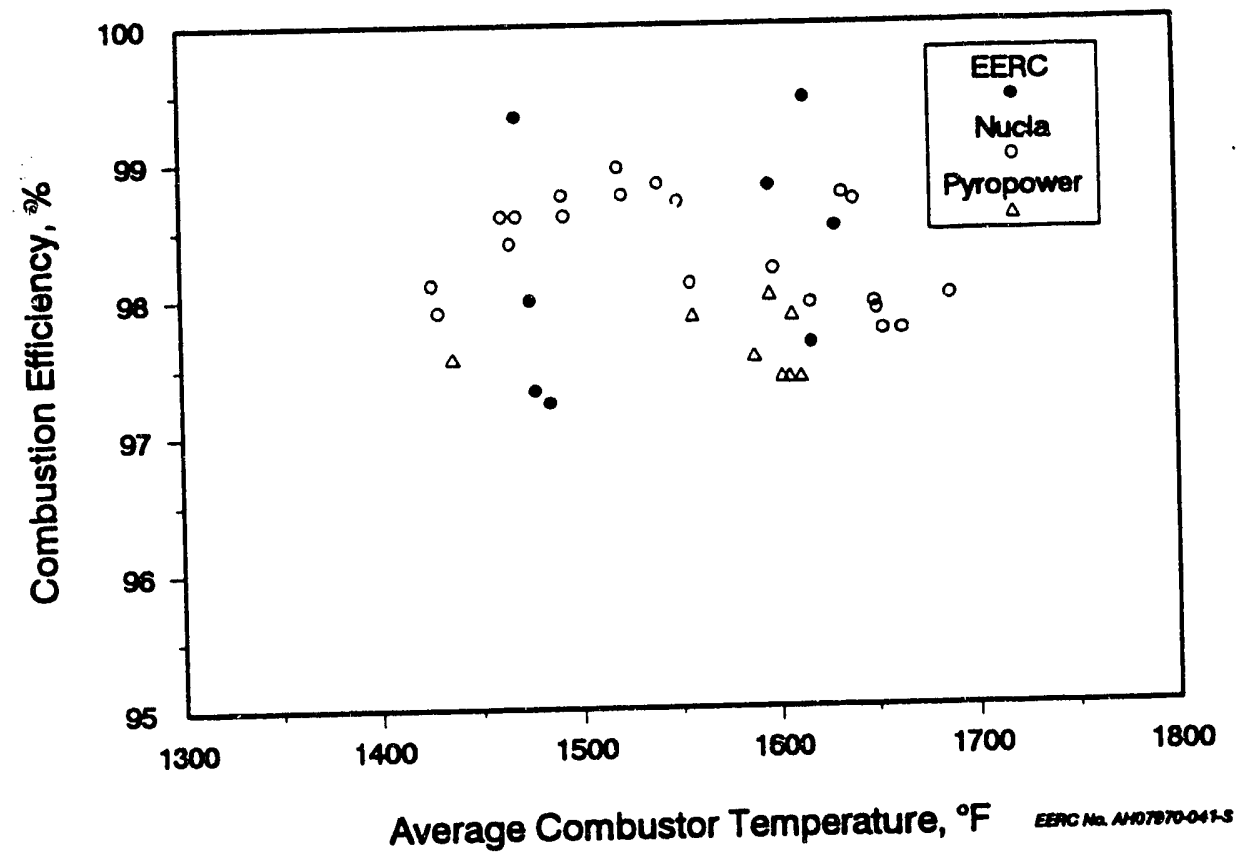

Figure 4-5. Comparison of combustion efficiency from the Nucla Power Station and the Pyropower and EERC pilot plant.

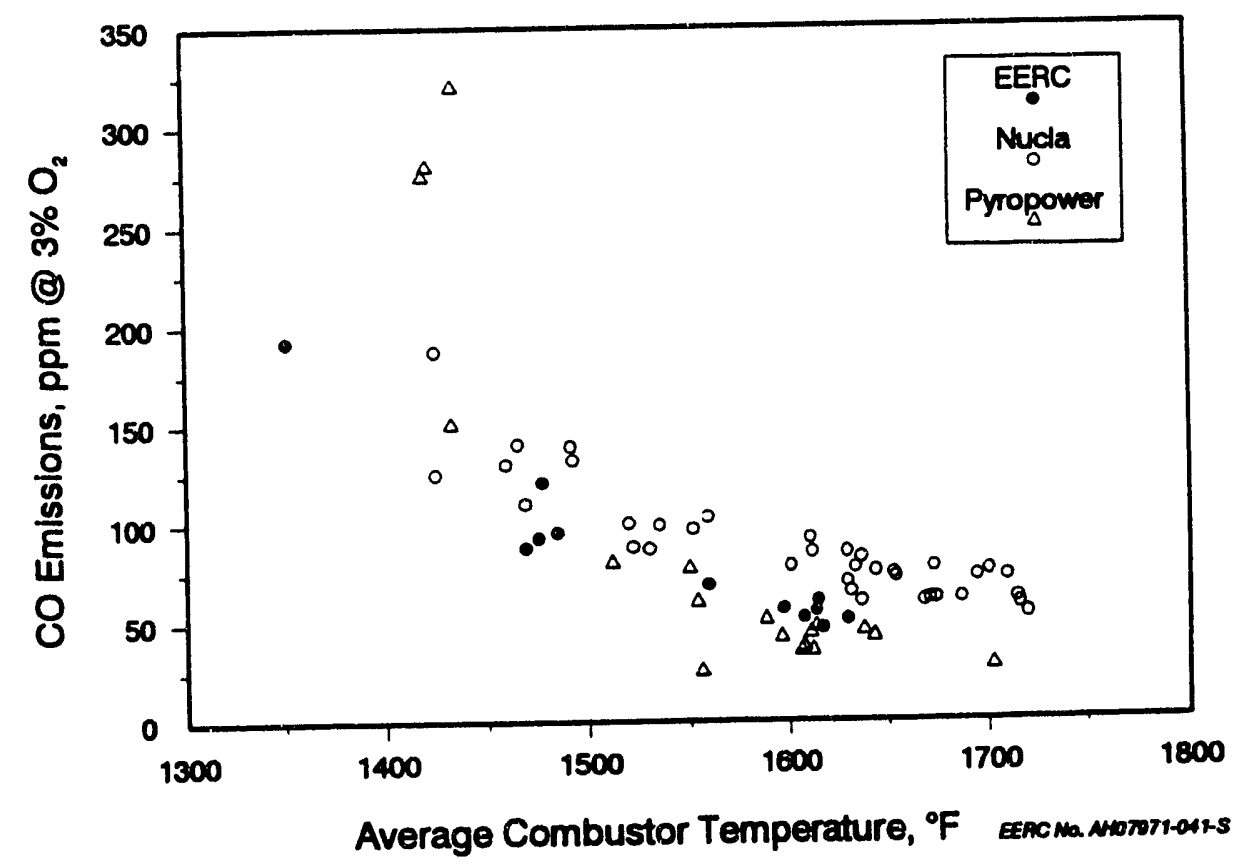

Figure 4-6. Comparison of CO emissions from the Nucla Power Station and the Pyropower and EERC pilot plants. 


\subsection{Emissions}

\subsubsection{Sorbent Performance}

Some of the factors affecting sulfur capture in a fluidized-bed combustor are temperature, reactivity and particle size of the sorbent, adequate mixing of coal and sorbent, and residence time. In the comparison among the full-scale Nucla station, the Pyropower pilot plant, and the EERC pilot plant, the same coal and limestone were used, eliminating coal and sorbent properties as variables. The limestone was prepared at the Nucla Station for all pilot- and full-scale tests. Maximum sulfur capture for a number of coals has been noted to occur at a temperature of about $1550^{\circ} \mathrm{F}$; the full-load tests performed at these facilities had average combustor temperatures above $1610^{\circ} \mathrm{F}$. Since increasing residence time generally provides better sulfur capture, the full-scale plant, with its taller combustion chamber and operating at similar gas velocity, would be expected to achieve greater sulfur capture. However, pilot-scale units typically have better mixing than full-scale units due to increased wall effects, contributing to sulfur capture capabilities. The $\mathrm{SO}_{2}$ retention as a function of the calcium-to-sulfur ratio is shown in Figure 4-7. Sulfur retention was generally lower in the EERC tests. Temperature variations both above and below the optimum temperature of $1550^{\circ} \mathrm{F}$ resulted in reduced sulfur capture.

Figure 4-8 shows the effect of the calcium-to-sulfur ratio on calcium utilization. The EERC data points are slightly lower than those reported by Pyropower and Nucla. This is consistent with the $\mathrm{SO}_{2}$ retention findings.

\subsection{2 $\mathrm{NO}_{3}$ and $\mathrm{N}_{2} \mathrm{O}$ Emissions}

A significant advantage of fluidized-bed combustion is the fact that lower operating temperatures result in lower $\mathrm{NO}_{\mathrm{x}}$ emissions than those seen in a pulverized coal-fired process. Figure 4-9 shows good agreement among the three plants for $\mathrm{NO}_{\mathrm{z}}$ emissions as a function of temperature. The $\mathrm{NO}_{\mathbf{x}}$ emissions were higher for those EERC tests performed at a high level of excess air, as expected.

$\mathrm{N}_{2} \mathrm{O}$ emissions are inversely proportional to temperature and directly proportional to oxygen content. Figure 4-10 shows a comparison between the EERC pilot plant data and those obtained at the Nucla station, both at high and low oxygen levels. The trends are similar in the two units; the higher $\mathrm{N}_{2} \mathrm{O}$ emissions in the pilot plant versus the full-scale plant are consistent with reports from other researchers.

\subsection{Summary}

Tables 4-2, 4-3, and 4-4 summarize factors affecting the scalability of CFB data. Both physical parameters and operating conditions have an effect on unit performance. These tables indicate which parameters can be reliably scaled up, which need to be matched closely to full scale, and which require further research before scalability can be adequately assessed. 


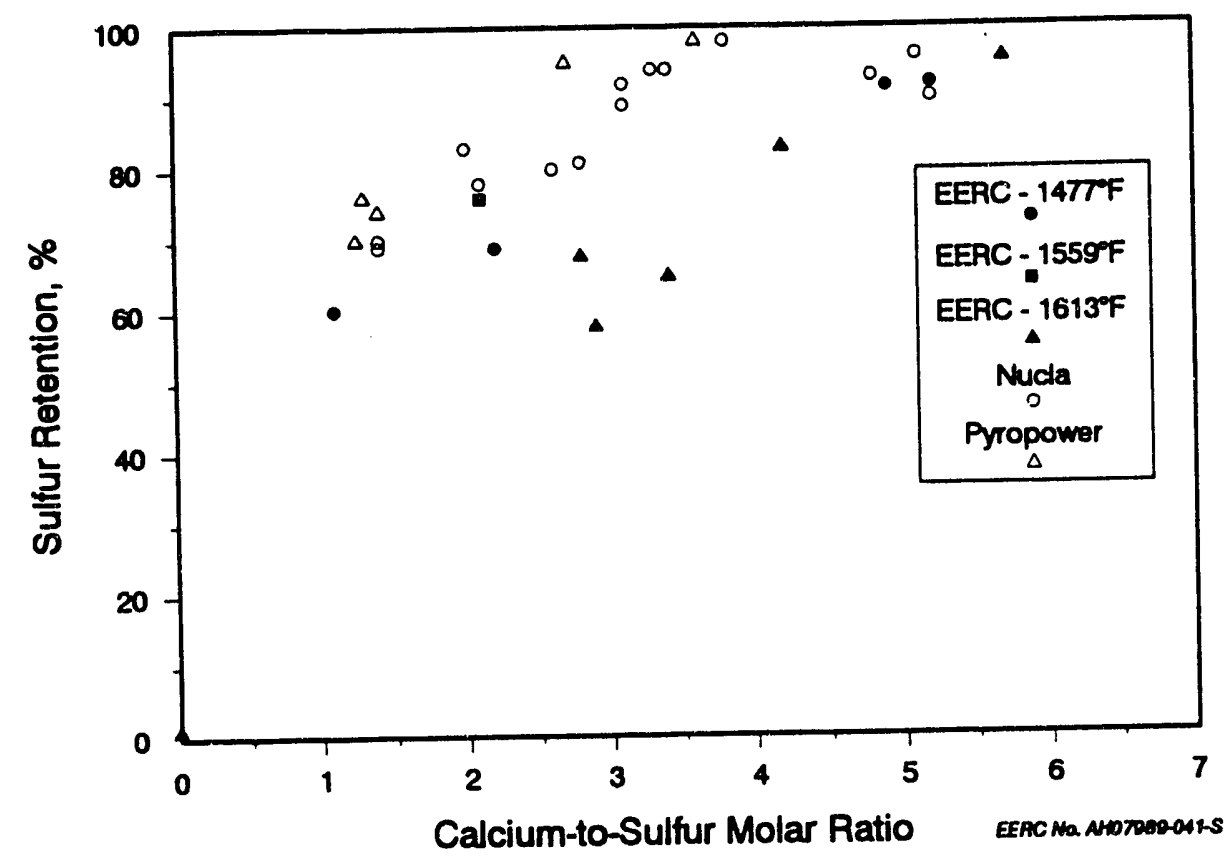

Figure 4-7. Sulfur retention as a function of the calcium-to-sulfur ratio.

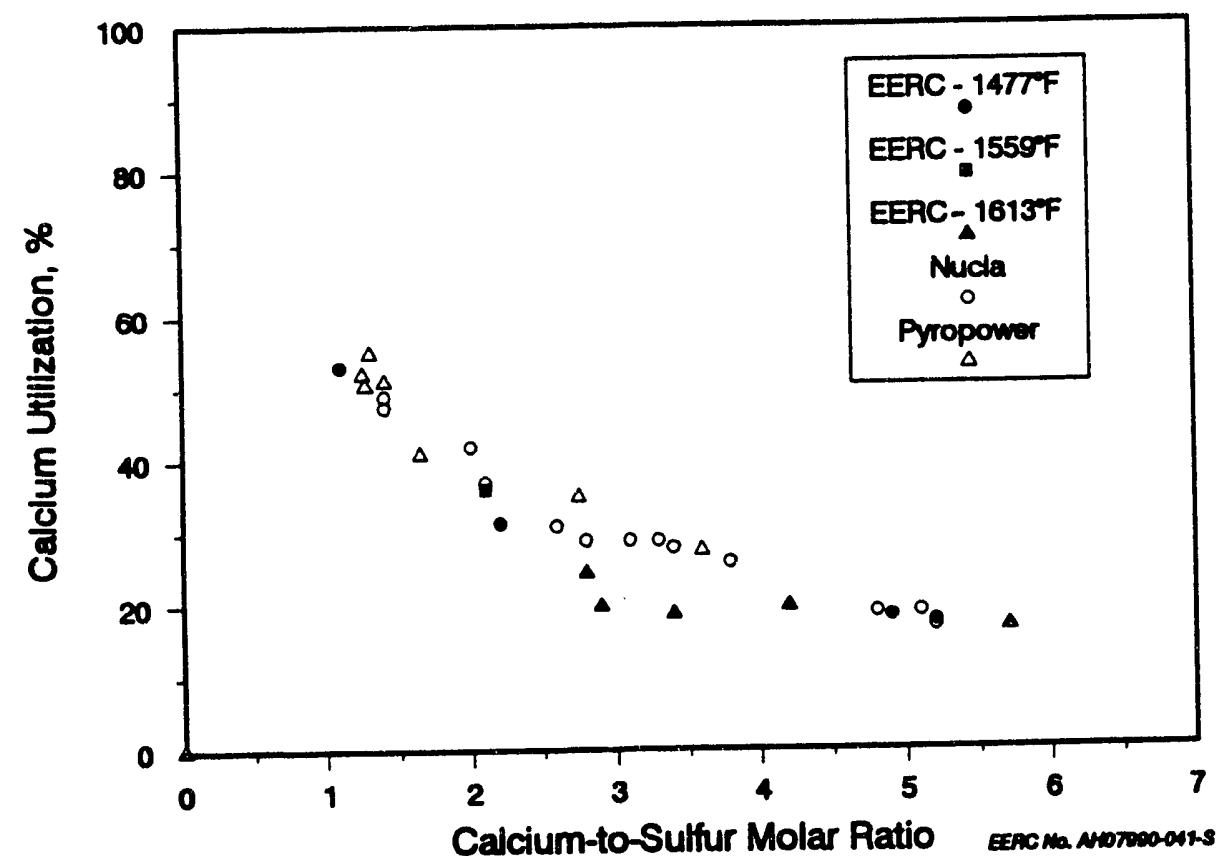

Figure 4-8. Effect of the calcium-to-sulfur ratio on calcium utilization. 


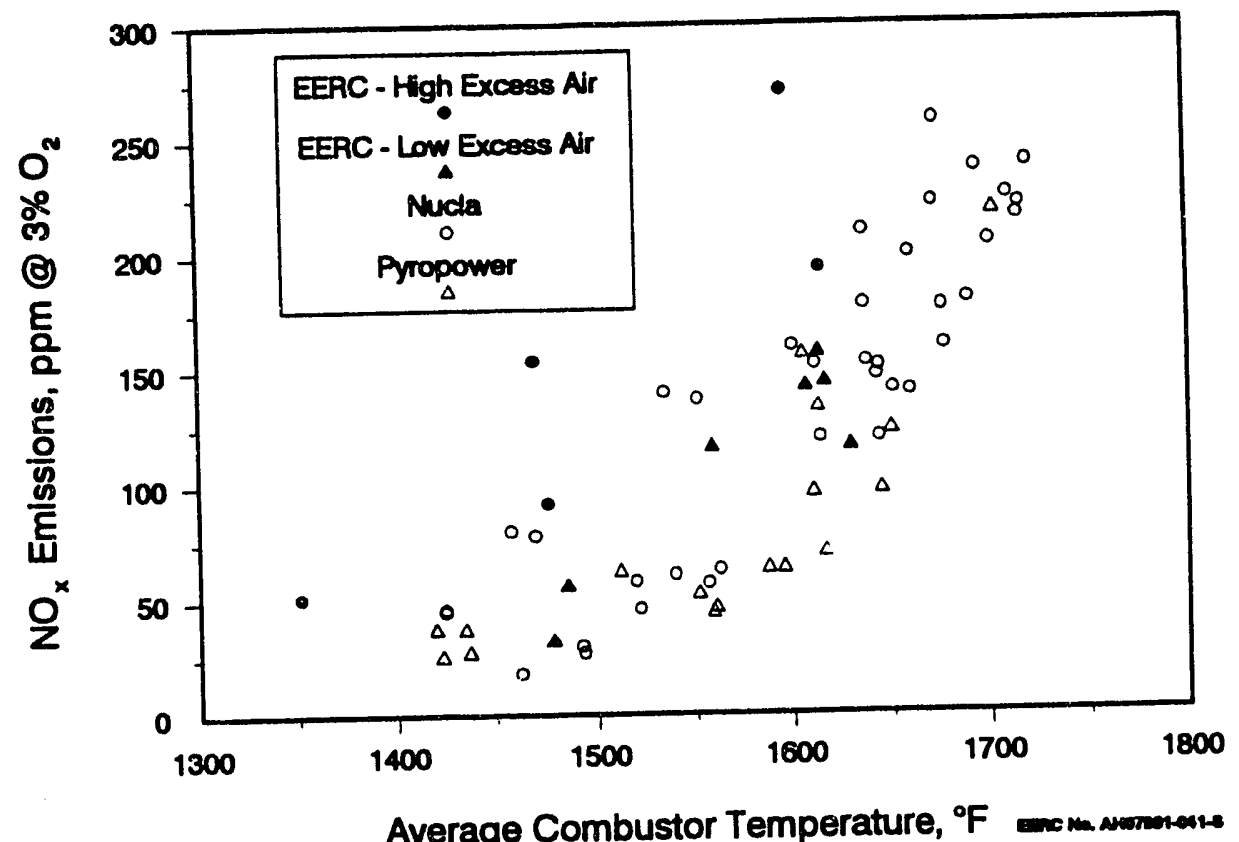

Figure 4-9. Comparison of $\mathrm{NO}_{\mathrm{x}}$ emissions.

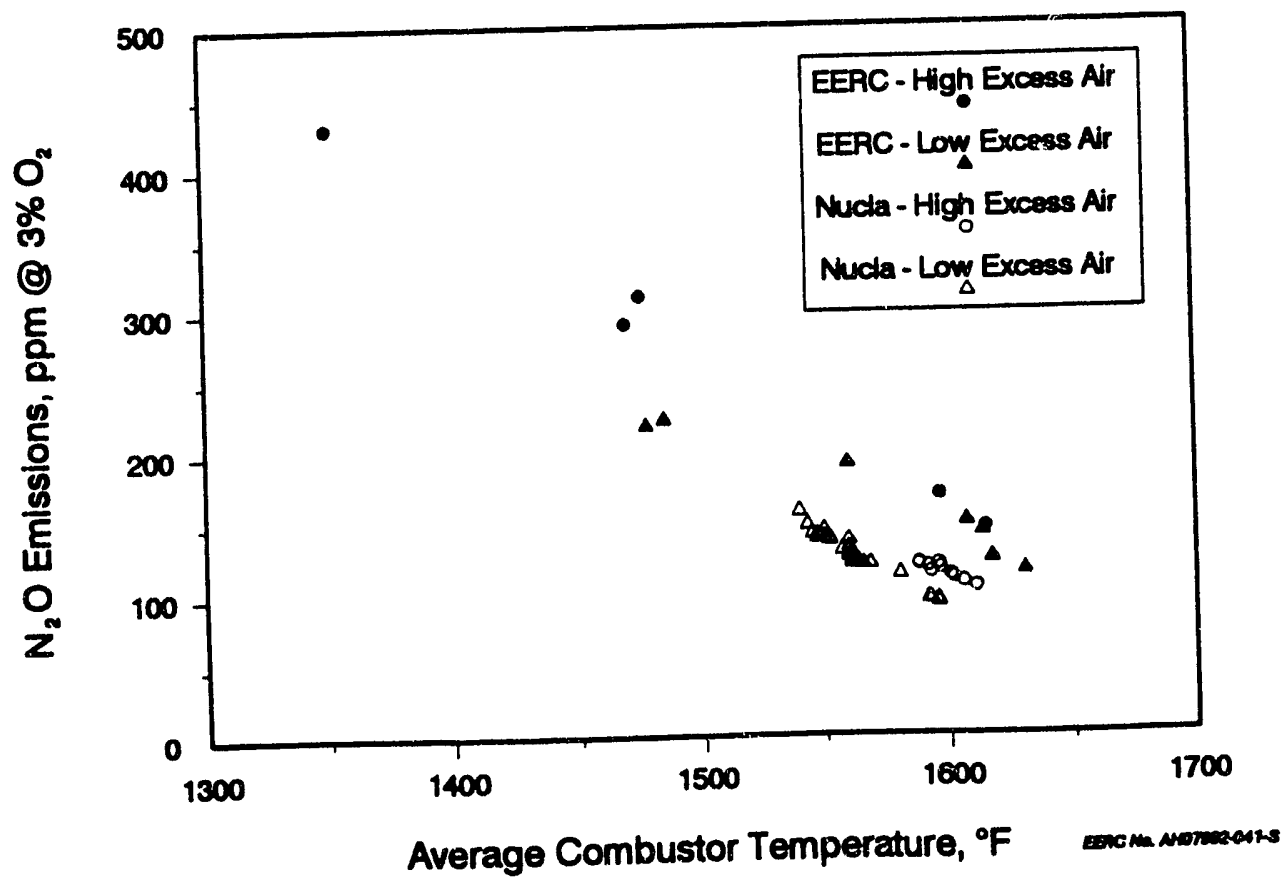

Figure 4-10. Comparison of $\mathrm{N}_{2} \mathrm{O}$ emissions. 


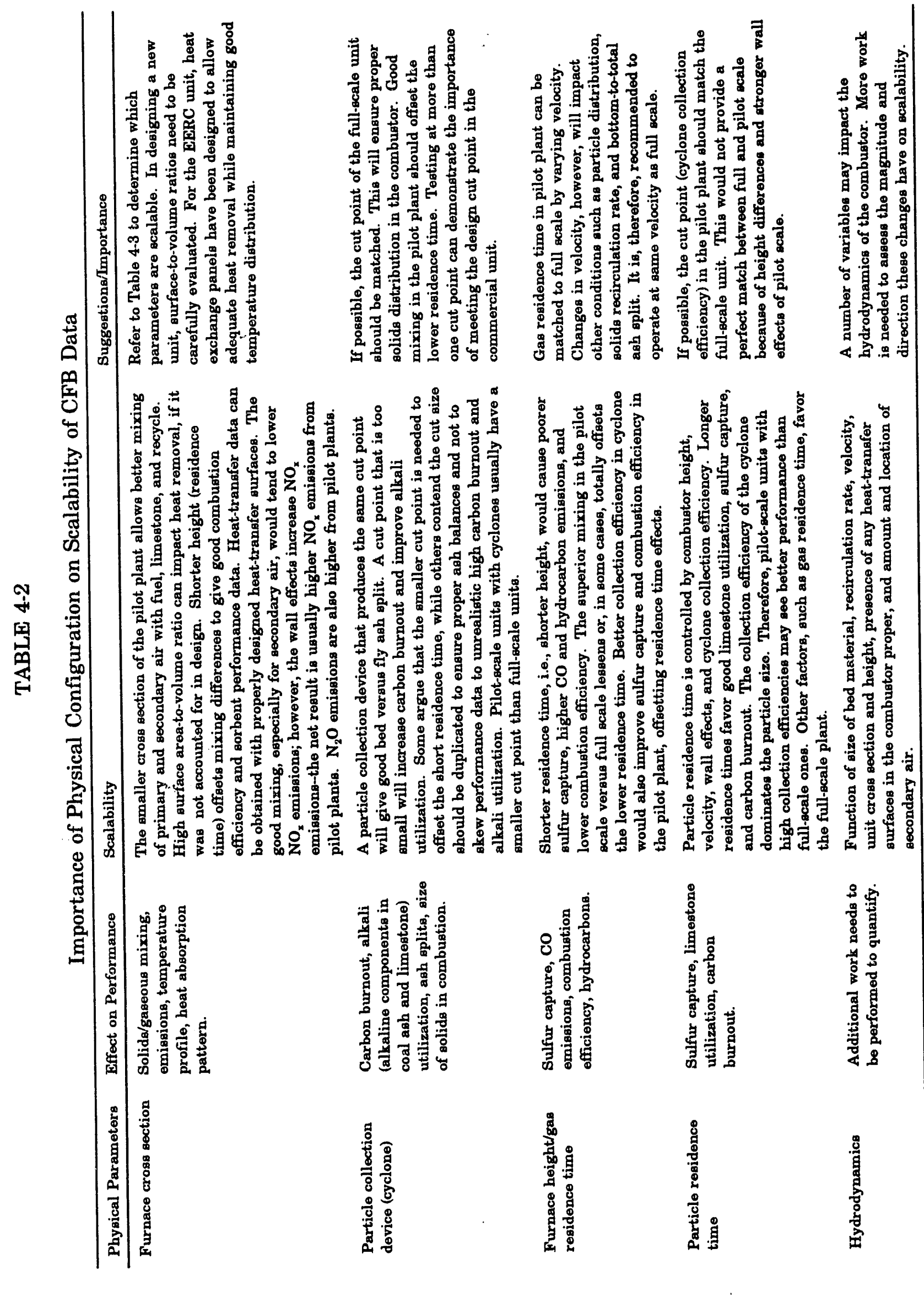




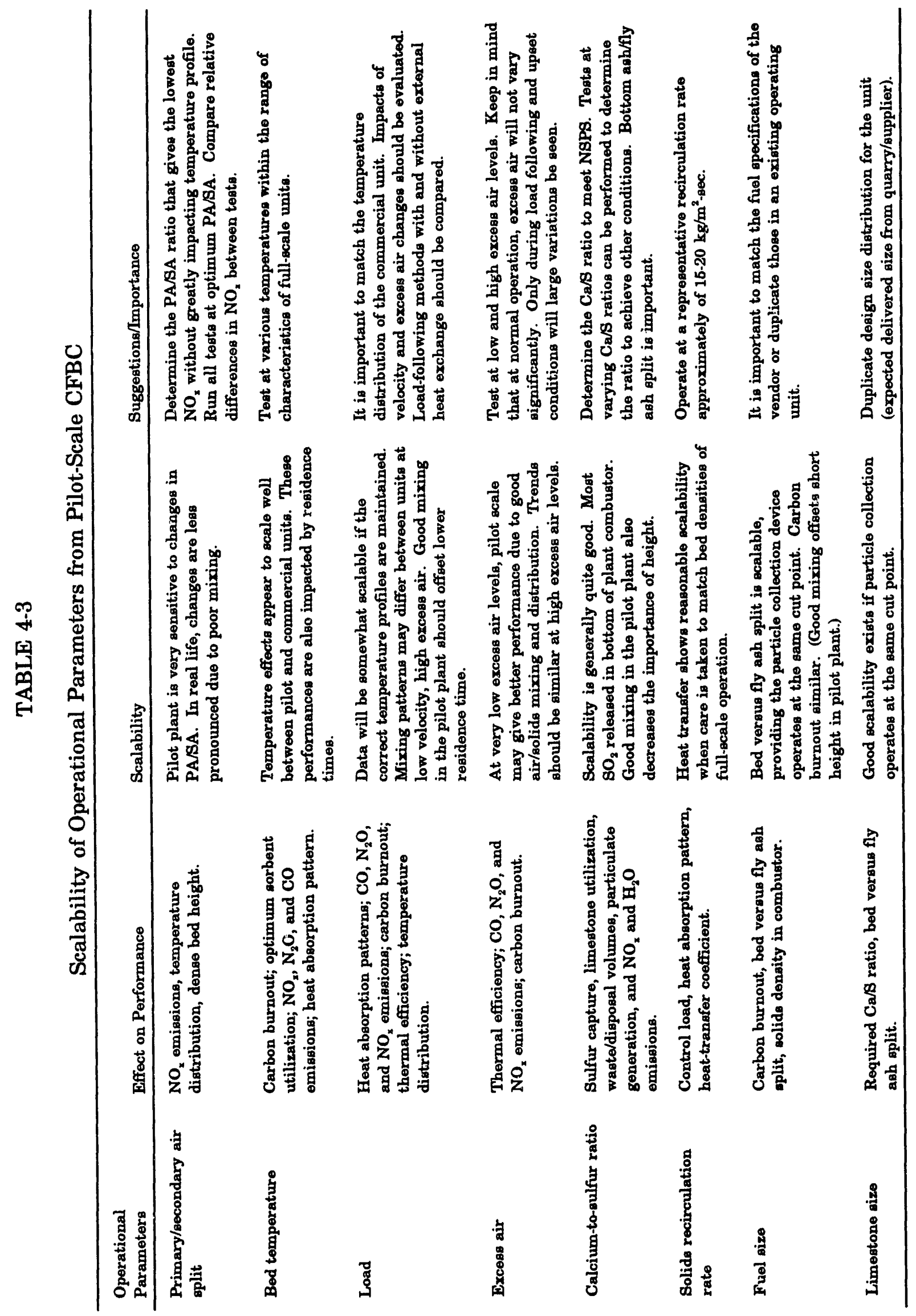




\section{TABLE 4-4}

\section{Scalability of Measured Performance Parameters from Pilot-Scale CFBC}

\begin{tabular}{|c|c|}
\hline Performance Parameter & Scalability \\
\hline Heat tranafer & $\begin{array}{l}\text { Heat transfer is primarily a function of the recirculation rate and the particle-eize } \\
\text { distribution in the combustor. Good correlation between the pilot- and full-scale } \\
\text { units can be expected if these two parameters can be controlled, as seen by the } \\
\text { EERC data. }\end{array}$ \\
\hline Combuation efficiency & $\begin{array}{l}\text { Carbon burnout will be controlled mainly by the cut point of the cycione, with } \\
\text { better carbon burnout being achieved for smaller cut points. CO will decrease as } \\
\text { the gas residence, or combustor height, decreases, but should increase for well- } \\
\text { mixed systems. Therefore, carbon burnout should be similar between full- and pilot- } \\
\text { scale units if the cut point is similar. The impact of combustor height versus gas } \\
\text { mixing offeet each other from full- to pilot-Bcale systems, making overall combustion } \\
\text { efficiency a scalable parameter. }\end{array}$ \\
\hline Bottom ash/total ash oplit & $\begin{array}{l}\text { The percentage of bottom ash will be primarily determined by size of the coal ash } \\
\text { and limestone and by the cut size of the cyclone. Assuming the same coal and } \\
\text { limestone sizing is used for the pilot- and full-scale testing, eimilar ash splits will be } \\
\text { obtained only if the cyclone cut size is the same. If a smaller cut size is obtained in } \\
\text { the pilot scale, as was done at the EERC versus the Colorado Ute Nucla Station, a } \\
\text { bigher fraction of the ash will be bottom ash. }\end{array}$ \\
\hline Bed grain size & $\begin{array}{l}\text { Assuming the same coal and limestone sizes are used for both systems, the bed } \\
\text { grain size will be primarily a function of the cut size of the cyclone. However, } \\
\text { unless there is a large difference in cut size between the full- and pilot-scale units, } \\
\text { the bed grain size will be approximately the same. }\end{array}$ \\
\hline $\begin{array}{l}\text { Limestone utilization, sulfur } \\
\text { capture, } \mathrm{Ca} / \mathrm{S} \text { ratio }\end{array}$ & $\begin{array}{l}\text { Sulfur capture and limestone utilization between the full- and pilot-scale units are } \\
\text { similar. Shorter combustor heights in pilot plants are offeet by better particle and } \\
\text { gas mixing. Smaller cyclone cut points in many pilot plants also favor better } \\
\text { performance. Data from the EERC and the Pyropower pilot plant indicate similar } \\
\text { performance to the Colorado Ute Nucla Station. The scalability of these data may } \\
\text { change with differing full-ecale designs. }\end{array}$ \\
\hline CO emiseions & $\begin{array}{l}\text { CO emissions would be expected to increase in pilot plants because of the shorter } \\
\text { residence times, but decrease because of the improved gas mixing. The net effect } \\
\text { for the EERC pilot plant is a decrease in CO emiseions as compared to full scale. }\end{array}$ \\
\hline $\mathrm{NO}_{z}, \mathrm{~N}_{2} \mathrm{O}$ emissions & 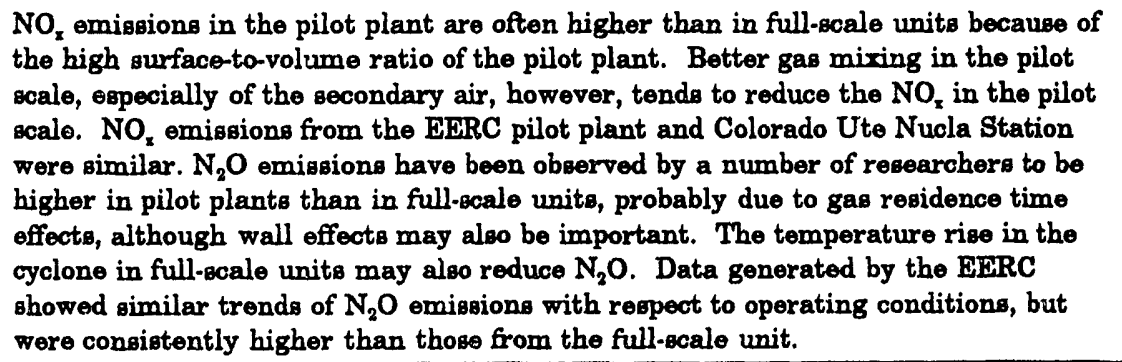 \\
\hline
\end{tabular}

Table 3-6 compared the heat fluxes measured for the five different coals tested at the EERC. It has been attempted to limit comparison to similar conditions of average bed temperature, excess air level, superficial gas velocity, and the primary-to-secondary air split. The as-tested higher heating value is included in the table as an indicator of the coal rank. The average size of the recirculated bed material is indicated by the $d_{50}$ (average size of the material). The most important factor affecting heat flux was the recirculation rate. The heat flux increased with increasing solids recirculation rates. This would be expected since solid densities are likely higher at correspondingly higher recirculation rates, and at higher solid densities there is more material to radiate and 
conduct heat to heat-transfer surfaces. This is consistent with the Nucla data from the tests with Salt Creek coal that clearly show that the heat flux increases as the normalized bed density increases.

As would be expected, the combustor heat-transfer coefficients followed the same trends as did the heat fluxes when comparing results obtained with the different coals tested (Table 3-6). The recirculation rate appears to have the most influence, because at higher recirculation rates the bed density is likely higher, as previously mentioned. 


\subsection{SUMMARY AND CONCLUSIONS}

\subsection{Summary}

The following points summarize overall operability of the EERC CFB for the five different coals tested:

- The recirculation rate, overall solids system collection efficiency, amount of solid waste generated, and the bottom ash-to-total ash split were all affected by coal properties (ash and sulfur contents), lime tone properties (size, reactivity, and hardness), geometry of the system (combustor cross section, location of secondary combustion air addition, and configuration of solids collection device used), and operating conditions (primary-to-secondary combustion air split and combustor velocity).

- Reinjection of ash from the secondary cyclone significantly increased the recirculation rate and decreased the average size of the material being recirculated.

- Operation on coals with ash containing high levels of sodium increased the potential for bed agglomeration, while some high-calcium-content coals promoted ash deposition downstream of the primary cyclone.

Results concerning sulfur capture and gaseous and solid emissions are summarized as follows:

- The amount of sulfur capture was primarily a function of the total alkali-to-sulfur ratio, with alkali being provided by the inherent alkali in the coal and added alkali supplied with limestone sorbent addition.

- The alkali-to-sulfur ratio required to capture $90 \%$ of the sulfur present in the coal usually decreased as the sulfur content increased, even though the total amount of sorbent required increased as the sulfur content increased.

- The optimum bed temperature resulting in maximum sulfur capture varied somewhat with coal type, with optimal sulfur capture at combustor temperatures of approximately $1550^{\circ} \mathrm{F}$ for the bituminous coals tested and approximately $100^{\circ} \mathrm{F}$ lower for most of the low-rank coals tested.

- There appeared to be an optimal sorbent size for maximum limestone utilization: small enough to be fluidized and circulated, while large enough not to pass through the primary solids capture device. For operation with the same type of limestone and the same coal type, use of a larger limestone size distribution resulted in improved sulfur capture.

- $\mathrm{NO}_{\mathrm{x}}$ emissions were dependent upon the coal type and increased with increasing combustor operational temperatures, excess air levels, ratio of primary-tosecondary combustion air, and, with the exception of the Black Thunder subbituminous coal, increased with increasing sorbent feed rates. 
- The low-rank lignites were higher emitters of $\mathrm{NO}_{\mathrm{z}}$ than the higher-ranked bituminous coals at lower temperatures $\left(1450^{\circ} \mathrm{F}\right)$, but emitted less $\mathrm{NO}_{\mathrm{z}}$ at higher temperatures.

- $\mathrm{N}_{2} \mathrm{O}$ emissions were even more dependent upon fuel properties than $\mathrm{NO}_{2}$ emissions, $\mathrm{N}_{2} \mathrm{O}$ emissions being lowest with subbituminous, increasing with the lignite, and highest with bituminous. The distribution of the nitrogen between the volatiles and the fixed carbon was found to be the most important fuel property affecting $\mathrm{N}_{2} \mathrm{O}$ emissions.

- $\mathrm{N}_{2} \mathrm{O}$ emissions decreased with increasing temperature and sorbent add rate, increased as excess air levels increased, and did not show a clear trend as a function of the primary-to-secondary combustion air split.

- Total nitrogen oxides emissions, $\mathrm{NO}_{\mathbf{x}}$ plus $\mathrm{N}_{2} \mathrm{O}$, tended to increase as the rank of the coal increased, but no apparent consistent trend emerged for total nitrogen oxide emissions as a function of average combustion temperature for the five coals tested.

- Carbon monoxide (CO) emissions tended to decrease with increasing temperature and decreasing levels of excess air for all ranks of coal.

- Dust loading into the baghouse for the high-ash, high-sulfur Asian lignite was the highest at 2.13 grains/scf, while dust loadings for the other coals ranged from 0.60 to 0.90 grains/scf; collcction efficiency using woven fiberglass bags in the EERC pulse-jet baghouse was above $\mathbf{9 9 . 9 \%}$ for each of the coals tested.

Results are summarized as follows for thermal performance with the five different coals tested using the EERC CFBC:

- Heat transfer (heat flux and heat-transfer coefficients) in the combustor and external heat exchanger was highly dependent upon the recirculation rate, improving as the recirculation rate increased, due largely to the increased concentration of hot solids particles in the system and partially to the increased amount of fines present that more effectively transfer heat to heat-transfer surfaces in the combustor and external heat exchanger.

- Combustor and external heat exchanger heat flux and heat-transfer coefficients usually increased with increasing combustor temperatures and velocities.

- Combustion efficiency generally increased with decreasing ranks of coal, due to the higher reactivity of the char for the lower-rank coals and their higher volatile content-to-fixed carbon ratio; over the range of test conditions, lignites generally approached $100 \%$ combustion efficiency independent of secondary ash addition, while combustion efficiencies as low as $90 \%$ were obtained for the Blacksville bituminous coal with no secondary ash addition.

- Combustion efficiency improved with increased amounts of excess air for all the high-rank coals tested. 
- Operational parameters that affected boiler efficiencies included the coal properties (char reactivity, moisture, ash, and sulfur contents), amount of excess air, secondary ash recirculation, and the operational combustor temperature.

- Low-rank coals with higher levels of moisture than the other coals tested resulted in lower boiler efficiencies due to the increased amounts of energy required during combustion to vaporize the additional moisture.

- Heat losses due to ash and spent sorbent were dependent upon the total ash content of the coal relative to its heating value and to limestone feed rates; losses amounted to $6.8 \%$ for the high-sulfur, high-ash Asian lignite and ranged from $0.2 \%$ to $1.4 \%$ for the other coals tested.

The following points summarize the impacts of load reduction methods utilized for the EERC CFBC:

- For all coals, independent of the method of load reduction, boiler efficiencies decreased when load was reduced.

- Reduced load operation at constant temperature resulted in slightly higher boiler efficiencies than reduced load operation with constant heat-transfer surface; this was mostly due to the greater quantities of fluidizing air required at lower operational temperatures to maintain similar velocities as a test at the same load but higher temperature. However, comparisons of the boiler efficiency losses must be made with caution, since a $300^{\circ} \mathrm{F}$ stack gas exit temperature was assumed for the boiler efficiency calculations for each test period, and may not be representative of an operational boiler.

- The boiler efficiency did not decrease with load in every case, due to differences in the unburned carbon losses for a given coal at different load conditions.

- For each of the coals tested, dry gas losses (usually the most significant factor affecting boiler efficiencies) increased as load was reduced by either method, suggesting that boiler efficiency could be expected to decrease with decreasing load; because of the assumed exit gas temperature used in these calculations, dry gas losses in an operational boiler would not be as significant as reported here.

- $\mathrm{SO}_{2}$ emissions were not significantly affected by turndown method. Operation with constant heat-transfer surface decreased $\mathrm{NO}_{\mathrm{z}}$ emissions and increased $\mathrm{N}_{2} \mathrm{O}$ and $\mathrm{CO}$ emissions as load (and temperature) decreased; at constant temperature, $\mathrm{NO}_{x}$ emissions increased slightly, while $\mathrm{N}_{2} \mathrm{O}$ and $\mathrm{CO}$ emissions were unaffected by load reduction.

- Heat fluxes and heat-transfer coefficients in both the combustor and external heat exchanger showed definite decreases using the constant heat-transfer surface load reduction method, due to a combination of decreased operational temperatures and recirculation rates as load was decreased. 
- As load was decreased using the constant-temperature load reduction method, overall heat fluxes and heat-transfer coefficients decreased in the external heat exchanger and remained relatively unaffected in the combustor.

- Combustion efficiencies for the reactive Center lignite were not affected by load reduction. Reducing load with either method improved combustion efficiency for both the Salt Creek and Blacksville bituminous coals, likely due to lower superficial gas velocities in the combustor. Lower operational velocity increases gas residence time and reduces the amount of carbon carried out of the system, resulting in improved carbon burnout.

The following is a summary provided on testing conducted with the EERC pilot-scale CFBC for comparison to similar testing conducted with the full-scale Colorado Ute Nucla CFB boiler and at another pilot plant system owned and operated by Pyropower, Inc.:

- Test conditions (solids recirculation rate, bed particle size and composition, superficial gas velocity, and average bed temperature) that have a significant influence on heat transfer in a CFBC were well duplicated in the EERC pilot plant compared to the full-scale operation at Nucla.

- The increased wall effects of the EERC pilot-scale unit offset to some degree the increased height for the larger full-scale system resulting in similar bed density distributions for both systems.

- A comparison of the heat-transfer data from the pilot- and full-scale plants indicates that a reasonable assessment of average heat flux over a wide range of conditions can be measured in the pilot-scale unit, even though there is a wider variation in localized heat flux measurements in a pilot-scale system.

- Combustion efficiencies obtained with the EERC pilot unit were comparable to those from the Colorado Ute Nucla Station, even though full-scale units with increased gas residence times have greater potential for better carbon burnout; this was offset on the pilot scale by increased wall effects, better gas/solids mixing, and better cyclone efficiency.

- The levels of CO emissions from the EERC pilot plant were slightly lower than Nucla, probably due to better mixing of solids on the pilot scale.

- Limestone utilization and sulfur capture as a function of either the average bed temperature or the alkali-to-sulfur ratio were also slightly lower with the EERC pilot plant as compared to Nucla.

- $\mathrm{NO}_{\mathrm{x}}$ emissions as a function of temperature showed good agreement.

- The trends for $\mathrm{N}_{2} \mathrm{O}$ emissions were similar in the two units; the higher $\mathrm{N}_{2} \mathrm{O}$ emissions in the pilot-scale versus the full-scale plant are consistent with reports from other researchers. 


\subsection{Conclusions}

In conclusion, all of the project goals originally established were met or surpassed for Project CFB. A pilot-scale CFBC system was successfully designed, constructed, and operated. It was demonstrated that several critical operational results can be obtained that are representative of full-scale operation. Due to the ability to easily alter the amount of heat-transfer surface utilized in either the combustor or the external heat exchanger, the EERC CFBC can be operated over a wide range of conditions with all ranks of coals.

While the original goal was to conduct testing with two different coals, additional testing was successfully conducted which resulted in the generation of a CFB database for five different coals. The EERC has established a pilot-scale CFBC system that can be operated free from vendor bias for the rapid transfer of technology in a free and open manner. The EERC CFB pilot plant system can be utilized for fundamental CFB research and is available for use by the public and private sectors to generate valuable data which will expand the current database. 


\subsection{REFERENCES}

1. Bryers, R.W. "Examination of Fouling of Convective Heat-Transfer Surface by Calcium and Sodium Using Micro-Analytical Techniques," ASME/IEEE Power Generation Conference, Portland, OR, Oct. 1986.

2. Bechtel Group, Inc. "Colorado-Ute Nucla Station Circulating Fluidized-Bed (CFB) Demonstration: Test Program Results," final report, EPRI Project 2683-7, Oct. 1991, Vol. 2.

3. Lundqvist R.; Basak, A.K.; Smedley, J.; Boyd, T.J. "An Evaluation of Process Performance and Scale-Up Effects for Ahlstrom Pyroflow Circulating Fluidized-Bed Boilers Using Results from the $100 \mathrm{MWe}$ Nucla Boiler and a 0.6 MWth Pilot Plant," In Proceedings of the 1991 International Conference on Fluidized-Bed Combustion; ASME, 1991, Vol. 1, p 131.

4. Sotelo, E. "Atmospheric Fluidized-Bed Combustion Performance Guidelines," final report, EPRI Project 2683-15, Mar. 1991. 


\section{APPENDIX A}

SALT CREEK BITUMINOUS COAL TEST RESULTS 


\section{TABLE OF CONTENTS}

Page

LIST OF FIGURES $\ldots \ldots \ldots \ldots \ldots \ldots \ldots \ldots \ldots \ldots \ldots \ldots \ldots \ldots \ldots \ldots \ldots \ldots$

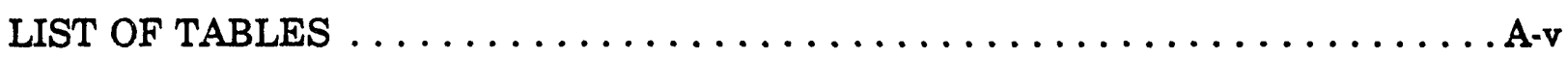

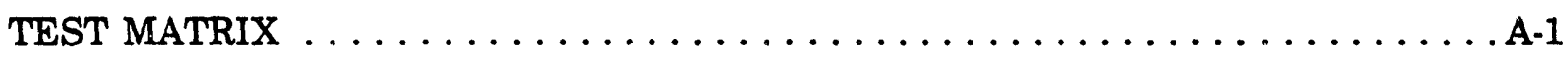

COAL AND LIMESTONE PROPERTIES $\ldots \ldots \ldots \ldots \ldots \ldots \ldots \ldots \ldots \ldots$

OPERATIONAL PERFORMANCE $\ldots \ldots \ldots \ldots \ldots \ldots \ldots \ldots \ldots \ldots \ldots$

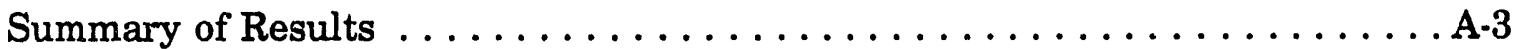

General Operability .......................

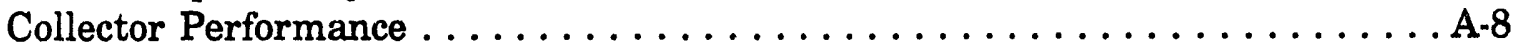

Recirculation Rates and Size Distributions .................. A

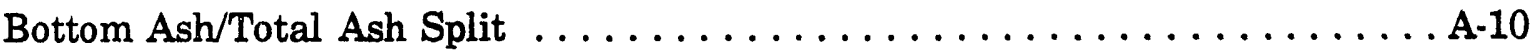

Coal Ash/Limestone Split . . . . . . . . . . . . . . . . A-10

THERMAL PERFORMANCE $\ldots \ldots \ldots \ldots \ldots \ldots \ldots \ldots \ldots \ldots \ldots \ldots$

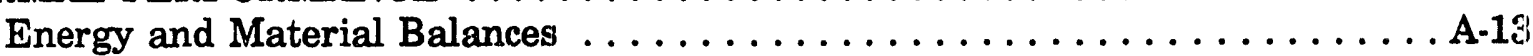

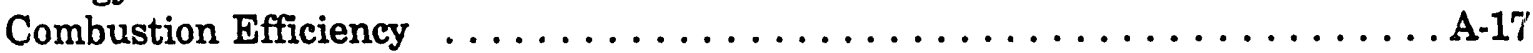

Boiler Efficiency . . . . . . . . . . . . . . . . . . . . 22

Heat-Transfer Coefficient and Heat Flux $\ldots \ldots \ldots \ldots \ldots \ldots \ldots$ A-24:

Pressure and Temperature Profiles ..................... A-29

ENVIRONMENTAL PERFORMANCE $\ldots \ldots \ldots \ldots \ldots \ldots \ldots \ldots \ldots \ldots \ldots$

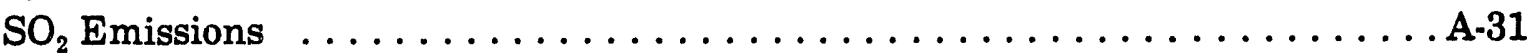

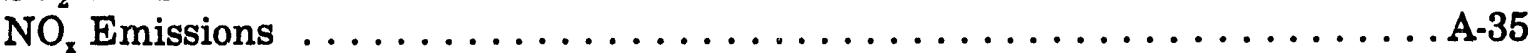

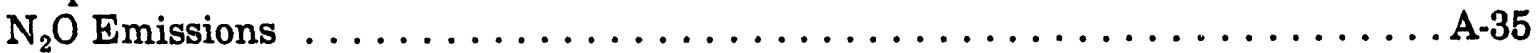

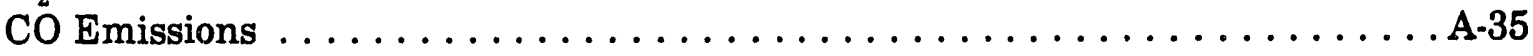

SUMMARIES OF TEST DATA $\ldots \ldots \ldots \ldots \ldots \ldots \ldots \ldots \ldots \ldots \ldots \ldots \ldots$ 


\section{LIST OF FIGURES}

Figure

$\underline{\text { Page }}$

A-1 Average particle-size distribution of Salt Creek Coal $\ldots \ldots \ldots \ldots \ldots \ldots$ A-3

A-2 Size distribution of Salt Creek limestone from Test 2 using several

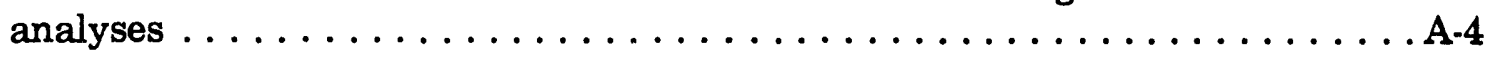

A-3 Particle-size distributions of downcomer material for Tests 1 and $4 \ldots \ldots$ A-11

A-4 Combustor, downcomer, and baghouse material particle-size distributions

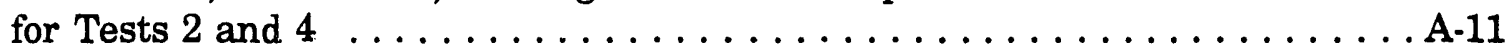

A-5 Combustion efficiencies as a function of average combustor temperature

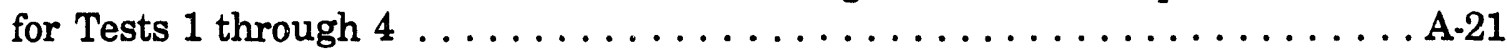

A-6 Percentage of unburned carbon in the combustor bed material as a function of temperature for Tests 1 through $4 \ldots \ldots \ldots \ldots \ldots \ldots \ldots$ A-21

A-7 Percentage of unburned carbon in the fly ash as a function of gas residence time for Tests 1 through 4

A-8 Combustion efficiencies as a function of temperature for Tests 5 through 12

A-9 Percentage of unburned carbon in the bed material drain as a function of temperature for Tests 5 through 12

A-10 Percentage of unburned carbon in the fly ash as a function of temperature for Tests 5 through 12

A-11 Heat flux as a function of combustor height $\ldots \ldots \ldots \ldots \ldots \ldots \ldots \ldots$ A-28

A-12 Heat-transfer coefficient as a function of combustor height $\ldots \ldots \ldots \ldots \ldots$ A-28

A-13 Heat flux as a function of average bed temperature . . . . . . . . . . A-29

A-14 Pressure profiles of Tests 1 through $6 \ldots \ldots \ldots \ldots \ldots \ldots \ldots \ldots \ldots$

A-15 Pressure profiles of Tests 7 through $12 \ldots \ldots \ldots \ldots \ldots \ldots \ldots \ldots \ldots$

A-16 Temperature profiles of all tests $(1$ through 12$) \ldots \ldots \ldots \ldots \ldots \ldots$ A-31

A-17 Flue gas emissions as functions of load $\ldots \ldots \ldots \ldots \ldots \ldots \ldots \ldots \ldots$

A-18 $\mathrm{SO}_{2}$ retention as a function of alkali-to-sulfur ratio for Tests 1,2 , and 10 
Figure $\quad \underline{\text { Page }}$

A-19 Sulfur retention as a function of total alkali-to-sulfur ratio for all tests except the $55 \%$ load test $\ldots \ldots \ldots \ldots \ldots \ldots \ldots \ldots \ldots \ldots \ldots \ldots$

A-20 Impact of alkali-to-sulfur ratio and temperature on sulfur emissions $\ldots \ldots \ldots \ldots \ldots \ldots \ldots \ldots \ldots \ldots \ldots \ldots \ldots \ldots \ldots \ldots \ldots \ldots \ldots \ldots$

A-21 Calcium utilization as a function of added calcium-to-sulfur ratio $\ldots \ldots \ldots$ A-35

A-22 The effects of calcium-to-sulfur ratio, excess air, and temperature

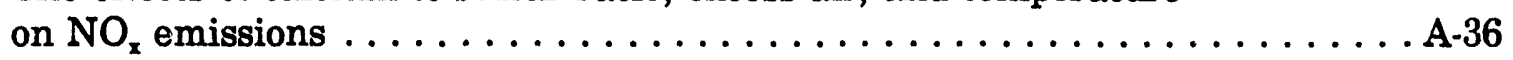

A-23 The effects of temperature and excess air on $\mathrm{N}_{2} \mathrm{O}$ emissions $\ldots \ldots \ldots \ldots$. . .

A-24 $\mathrm{CO}$ emissions as a function of temperature $\ldots \ldots \ldots \ldots \ldots \ldots \ldots \ldots$ 


\section{LIST OF TABLES}

Table

Page

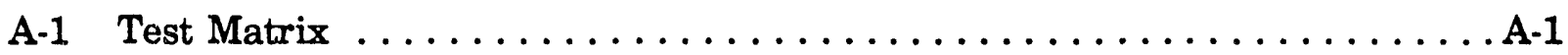

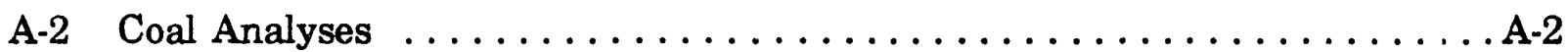

A-3 Average Limestone Analysis $\ldots \ldots \ldots \ldots \ldots \ldots \ldots \ldots \ldots \ldots \ldots \ldots$

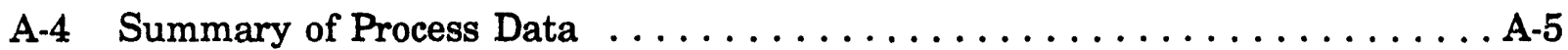

A-5 Solids Recirculation and Heat-Transfer Data . . . . . . . . . . . . A-9

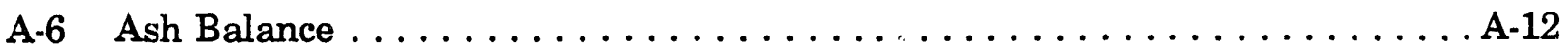

A-7 Material Derived from Coal Ash and Limestone Based on Aluminum Material Balance .......................... A-13

A-8 Aluminurn Material Balance $\ldots \ldots \ldots \ldots \ldots \ldots \ldots \ldots \ldots \ldots \ldots$ A-14

A-9 Fuel Balance $\ldots \ldots \ldots \ldots \ldots \ldots \ldots \ldots \ldots \ldots \ldots \ldots \ldots \ldots \ldots \ldots$

A-10 Flue Gas Balance $\ldots \ldots \ldots \ldots \ldots \ldots \ldots \ldots \ldots \ldots \ldots \ldots \ldots \ldots$

A-11 Energy Balance $\ldots \ldots \ldots \ldots \ldots \ldots \ldots \ldots \ldots \ldots \ldots \ldots \ldots \ldots \ldots$

A-12 Material Balance $\ldots \ldots \ldots \ldots \ldots \ldots \ldots \ldots \ldots \ldots \ldots \ldots \ldots \ldots \ldots$

A-13 Combustion Efficiency $\ldots \ldots \ldots \ldots \ldots \ldots \ldots \ldots \ldots \ldots \ldots \ldots \ldots$

A-14 Unburned Carbon $\ldots \ldots \ldots \ldots \ldots \ldots \ldots \ldots \ldots \ldots \ldots \ldots \ldots \ldots \ldots$

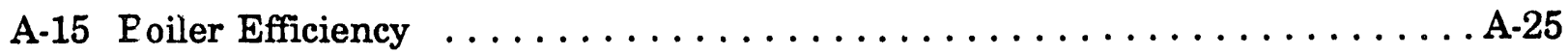

A-16 Individual Heat-Transfer Coefficients $\ldots \ldots \ldots \ldots \ldots \ldots \ldots \ldots \ldots \ldots$

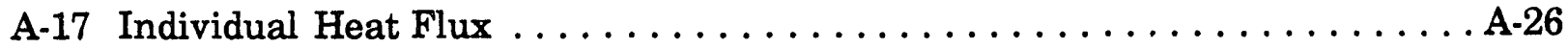

A-18 Average Heat-Transfer Coefficient, Heat Flux, and Bed Density . . . . . . A-27

A-19 Emissions Data ........................... A 


\section{TEST MATRIX}

The matrix of test parameters is shown in Table A-1. The calcium-to-sulfur ratio shown in the table includes calcium in the coal i's well as in the limestone. Test 1 was performed at full load with no limestone addition to establish baseline sulfur emission data for the Salt Creek coal. Test 2 is a full-load test with the addition of limestone for sulfur capture. Tests 3 and 4 were partial-load tests, based on coal feed rate. In both partial-load tests, the temperature and superficial gas velocity were allowed to decrease, the excess air was not controlled, and the total heat-transfer surface in the combustor and external heat exchanger was held constant.

Tests 5 through 12 were all full-load tests. Temperature, Ca/S ratio, excess air level, and primary-to-secondary air split were varied to determine their effects on flue gas emissions and combustion efficiency. High and low values of each parameter were tested.

\section{COAL AND LIMESTONE PROPERTIES}

Salt Creek coal and limestone were provided by EPRI. The coal was crushed and sized to $-1 / 4 "$. A sample of the coal was taken during crushing and grinding, and samples were obtained during each test period. These samples were submitted for proximate, ultimate, and sieve analysis. Additionally, the coal ash was analyzed by $x$-ray fluorescence for the determination of major mineral oxides and by computer-controlled scanning electron microscope (CCSEM) to define the size distribution of major mineral species. Table A-2 lists the results of the coal and mineral oxide analyses for each test period. The moisture ranged from $6.8 \%$ to $8.2 \%$; the ash content ranged from $16.9 \%$ to $20.2 \%$. The heating value, which ranged from 9,976 to $10,563 \mathrm{Btu} / \mathrm{lb}$ for the EERC tests, was a bit lower than the $11,100 \mathrm{Btu} / \mathrm{lb}$ observed at the Nucla station. The average particle-size distribution of the coal is shown in Figure A-1.

TABLE A-1

Test Matrix

\begin{tabular}{rcccccc}
\hline & & & & & \multicolumn{2}{c}{ Velocity } \\
Test \# & Temperature $\left({ }^{\circ} \mathrm{F}\right)$ & Load $(\%)$ & Ca/S & Excess Air (\%) & PASA & (ft/sec) \\
\hline 1 & 1616 & 100 & 0.54 & 20 & $54: 46$ & 16 \\
2 & 1616 & 100 & 2.04 & 20 & $54: 46$ & 16 \\
3 & $* *$ & 75 & 2.04 & 20 & $56: 44$ & $* *$ \\
4 & $* *$ & 50 & 2.04 & 30 & $* *$ & $* *$ \\
5 & 1475 & 100 & 1.54 & 45 & $70: 30$ & 16 \\
6 & 1475 & 100 & 1.54 & 15 & $50: 50$ & 16 \\
7 & 1625 & 100 & 1.54 & 15 & $70: 30$ & 16 \\
8 & 1625 & 100 & 1.54 & 45 & $50: 50$ & 16 \\
9 & 1625 & 100 & 3.54 & 45 & $70: 30$ & 16 \\
10 & 1625 & 100 & 3.54 & 15 & $50: 50$ & 16 \\
11 & 1475 & 100 & 3.54 & 15 & $70: 30$ & 16 \\
12 & 1475 & 100 & 3.54 & 45 & $50: 50$ & 16 \\
\hline
\end{tabular}

** These conditions were varied as needed to obtain the desired load. 


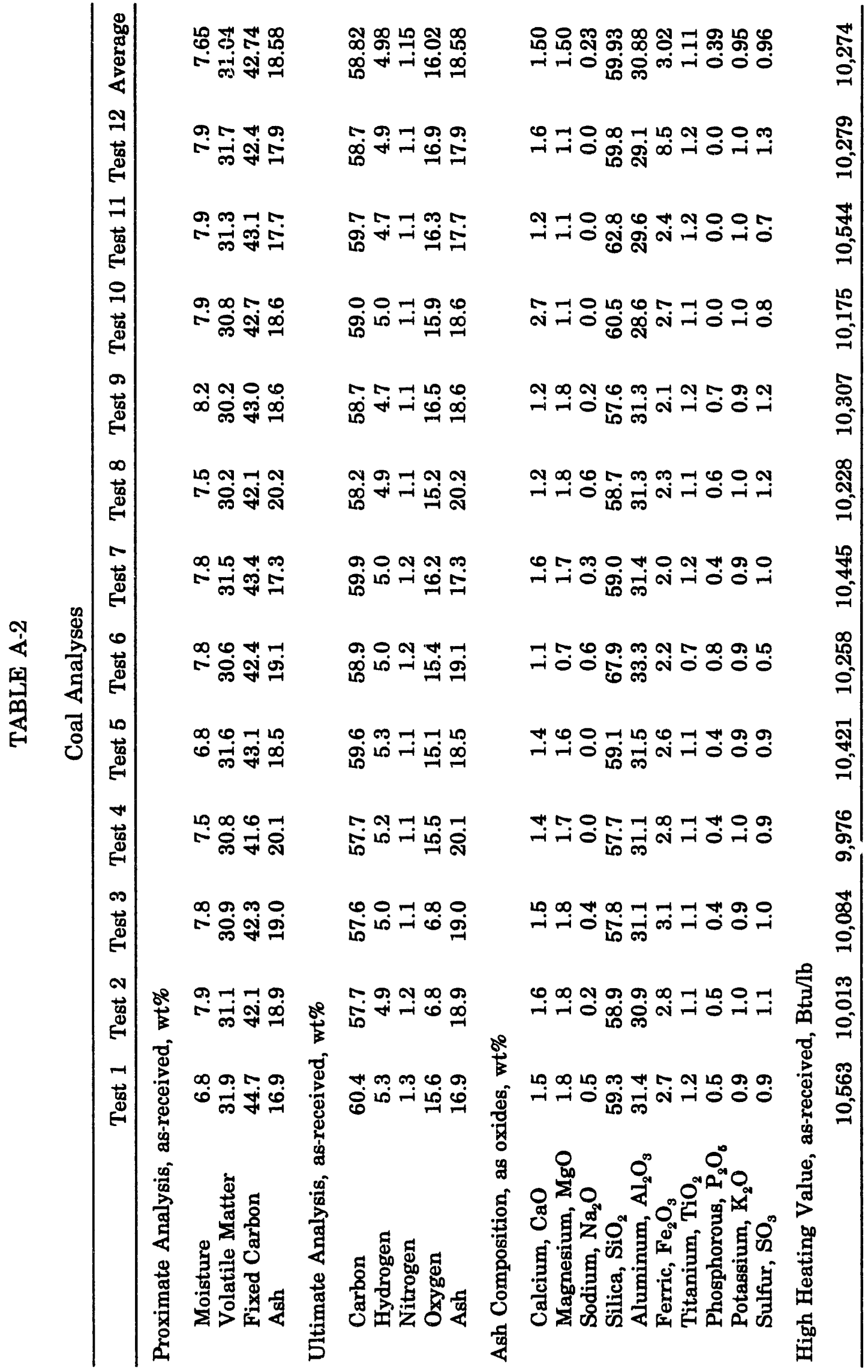




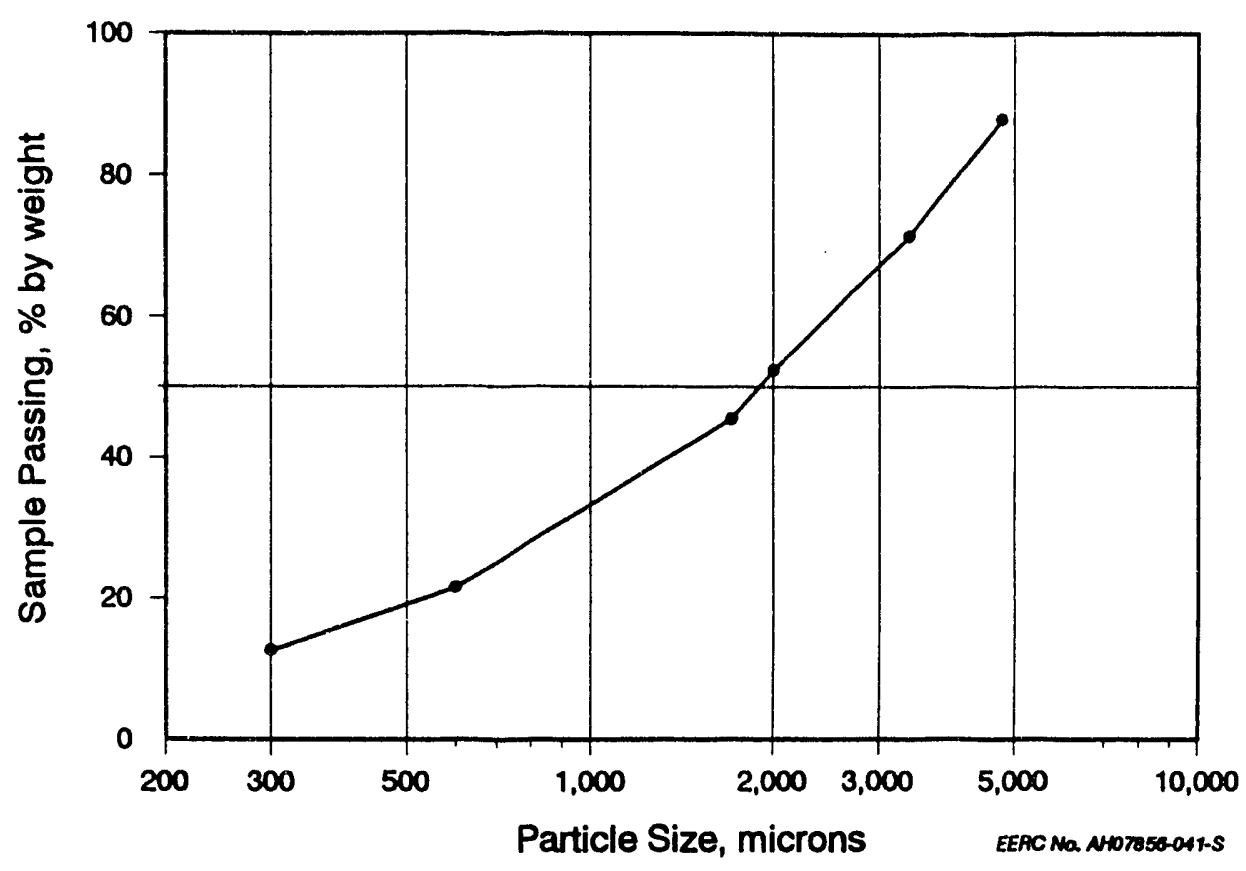

Figure A-1. Average particle-size distribution of Salt Creek coal.

The results of limestone analyses are shown in Table A-3. The limestone used for these tests had an elemental calcium content of $37 \%$ and no magnesium, compared to $36.3 \%$ calcium and $0.53 \%$ magnesium in the limestone used during the Nucla testing. The limestone was crushed and sized at the Nucla station prior to shipping to the EERC. The limestone particle-size distributions from test to test were consistent; however, there was a great deal of variability in particle size depending on the method of analysis, as shown in Figure A-2. The limestone was extremely cohesive and tended to agglomerate when subjected to vibration, such as that used in the sieve analyses. Subsequently, both Malvern and Coulter counter tests were performed, and results were obtained which were more consistent with the visual inspection of the limestone. The limestone used at Colorado Ute was sized by dry sieve analysis; Figure A-2 shows the size distribution similarity between the EERC and Colorado Ute limestones.

\section{OPERATIONAL PERFORMANCE}

\section{Summary of Results}

Upon completion of the run, data for each of the steady-state test periods were averaged. A summary of the process data for each test is presented in Table A-4. The twelve test periods correspond to those presented in the test matrix listed in Table A-1.

In general, the unit performed within the parameters specified in the original test plan. One notable exception was the actual calcium-to-sulfur ratio which was calculated at the conclusion of the run. The calcium-to-sulfur ratio was typically higher than specified in the test matrix. This can be attributed to limestone feed problems which will be discussed, along with specific results, in subsequent sections. 
TABLD A-3

Average Limestone Analysis (\% as oxide)

\begin{tabular}{lc}
\hline Component & Average \\
\hline Silica & 2.62 \\
Aluminum & 0.38 \\
Iron & 0.31 \\
Titanium & 0.02 \\
Calcium & 54.05 \\
Magnesium & 0.00 \\
Sulfur & 0.17 \\
Sodium & 0.00 \\
\hline
\end{tabular}

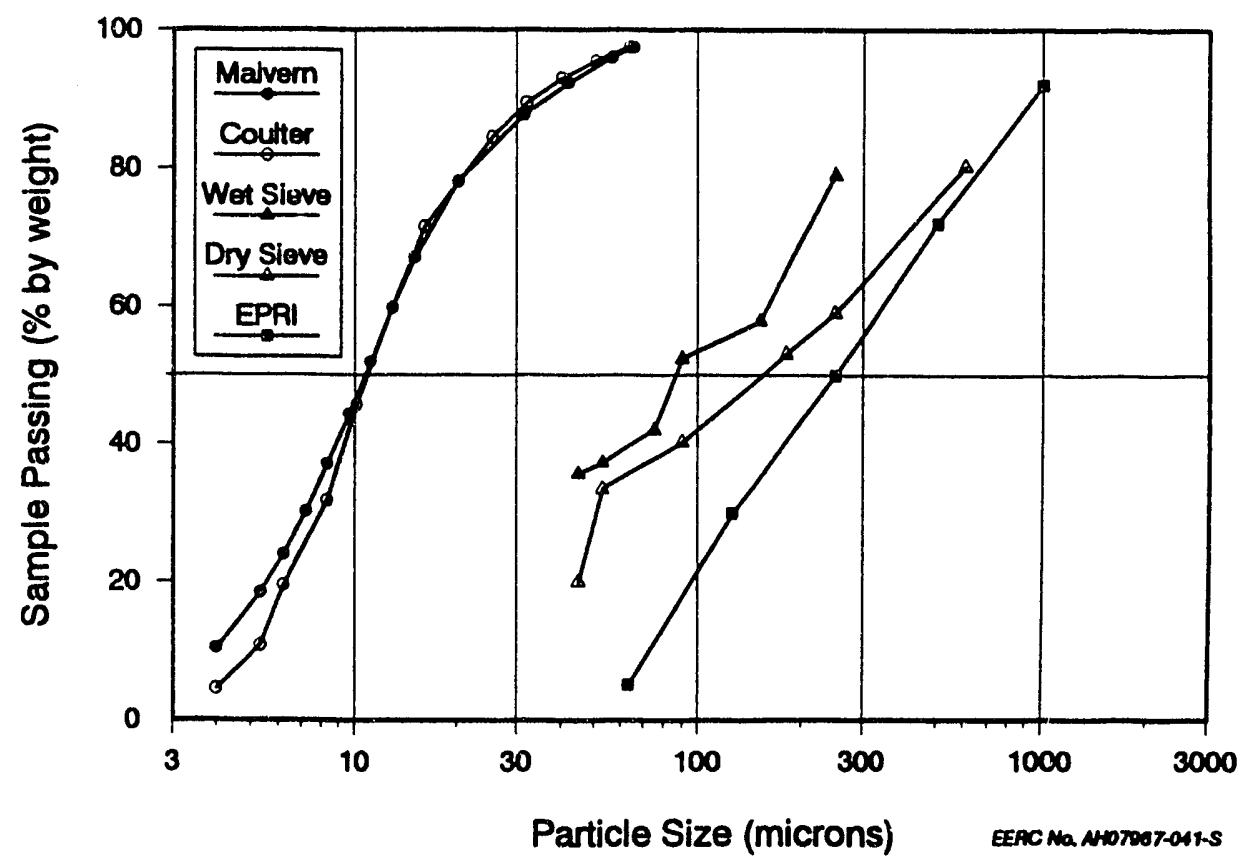

Figure A-2. Size distribution of Salt Creek limestone from Test 2 using several analyses.

\section{General Operability}

The unit performed well during testing of the Salt Creek coal. No major problems were encountered with the unit or auxiliary equipment. The coal was crushed and sized to $-1 / 4$ inch and placed into storage hoppers. A rotary valve was used to transfer the coal from the storage hopper into the 1000-pound capacity main feed hopper as needed. The feed hopper was suspended from a load cell to determine the coal feed rate. A second rotary valve was used to feed and meter the coal to a horizontal screw feeder. In addition 


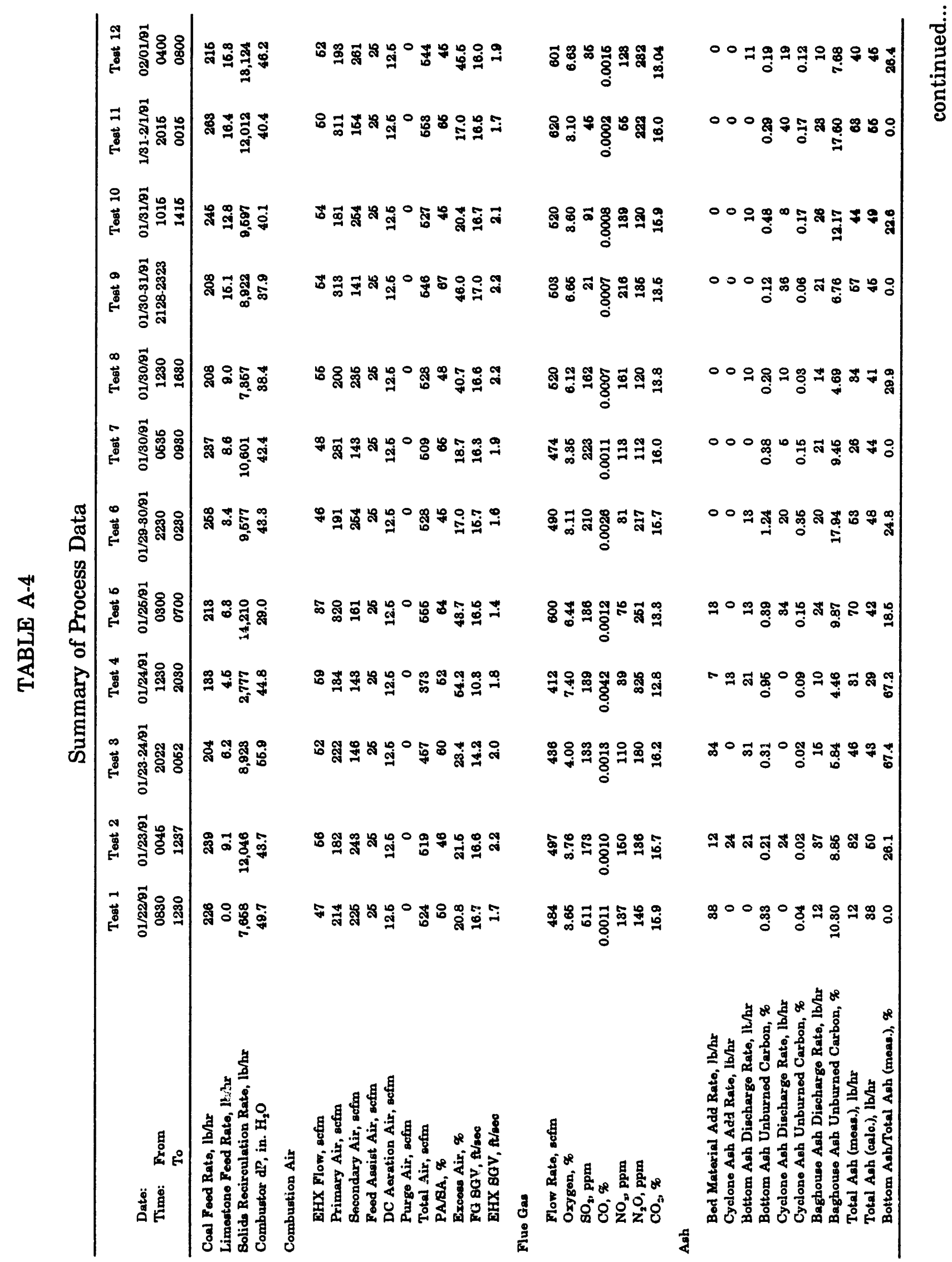




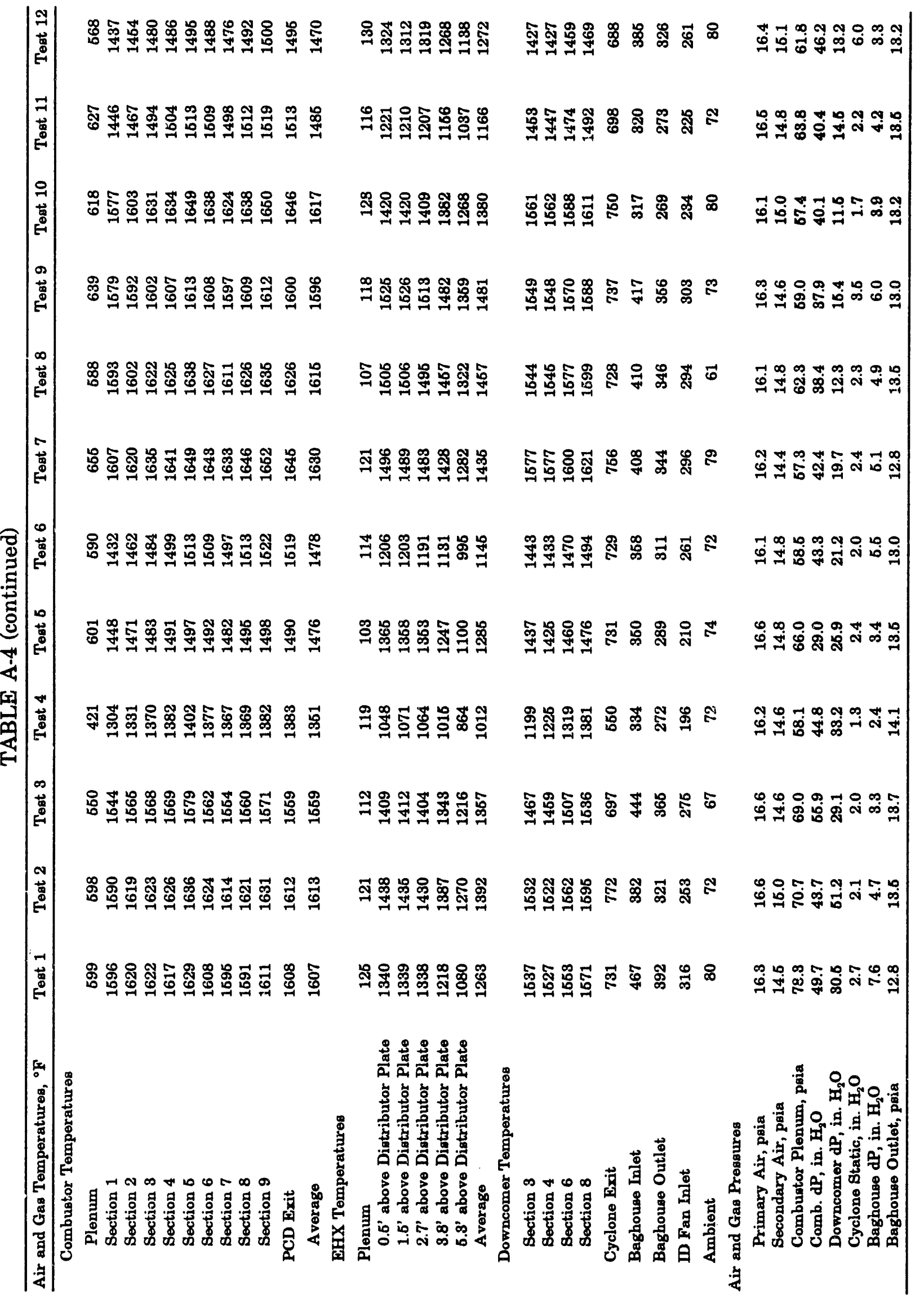


to controlling the coal feed rate, the rotary valve serves to isolate the feed hopper from system pressure in the combustor. Isolation is necessary to prevent possible ignition of the coal before it reaches the combustor, as well as to maintain stable feed rates and weigh cell measurements. The horizontal screw feeder conveyed the feed material to a section of 3 " pipe, vertical at the top and entering the combustor at an angle of approximately $30^{\circ}$ from vertical. Coal and limestone were fed by gravity through this pipe. An air lance was used to assist the flow of material through the angled section of the gravity feed leg.

The limestone, crushed and sized prior to shipping and supplied along with the Salt Creek coal, was transferred to a 1000-pound capacity storage hopper. The configuration of the limestone feed system was identical to the fuel feed side, and metered limestone flowed by gravity to the horizontal screw feeder where it combined with the feed coal. Some minor problems were encountered with the screw feeder due to binding. Additional minor problems arose due to blockage of feed material in the gravity feed leg beneath the auger. A somewhat more persistent problem was encountered with the flow of limestone out of the feed hopper. The crushed limestone had a very high angle of repose which caused frequent "ratholing" and subsequent loss of sorbent feed. As a result, considerable attention had to be paid to the limestone feed hopper to maintain a continuous supply of sorbent to the combustor.

It is not anticipated that there would be any major coal feed problems unless there were significant differences in the surface moisture of the coal tested at the EERC and that used at a commercial plant. Limestone feed may present some problems at a commercial CFB using a feed system similar to that employed at the EERC. However, it is believed that minor design modifications would alleviate the limestone feed problems experienced during the EERC pilot plant test run.

One additional problem which surfaced during the course of testing was blinding of the baghouse bags over time. The combination of a relatively thick layer of ash on the baghouse bags with a high baghouse static pressure resulted in deformation of some of the bag cages and the development of a hole in at least one bag. The observed high pressure drop across the baghouse may be a function of the ash, considering the cohesive nature of the material. This could present problems in a commercial plant, but it is believed that a cage design which provided for more rigid constructions and on-line bag-cleaning procedures would alleviate any baghouse problems encountered during pilot-scale testing at the EERC. Another area of concern with regards to the fly ash is the design of commercial ash-handling systems. Particular attention must be paid to the design of fly ash hoppers to compensate for the cohesiveness of the ash and allow for adequate removal during operation.

The pilot-scale CFB has nineteen thermocouples located along the length of the combustor in nine sections. Also, there are five thermocouples in place along the length of the downcomer. During full-load testing, the temperature distribution throughout the combustor and downcomer was very uniformi and, on the average, did not vary by more than $100^{\circ} \mathrm{F}$, indicating good solids recirculation within the system. During partial-load tests, the combustor temperature distribution remained fairly uniform. However, temperatures in the downcomer were up to $200^{\circ} \mathrm{F}$ lower than the highest combustor temperatures, as would be expected due to proportional heat loss through refractory-lined walls. 


\section{Collector Performance}

Chevron collectors with internal, sloped deflector plates were used in the particulate collection device during this test. The Chevron collectors were designed with an internal opening (drain) which ran vertically along the length of the rear of each collector. The geometry of the collectors was such that incoming solids entrained in the gas stream were forced to the back and downward out the angle of the deflector plates to the drain. Particulates entering the collector drains flowed by gravity into collection hoppers which fed into the downcomer. The particulate collection device housing the chevron collectors had three ducts into which the combustor exited. The main middle duct used during this test was referred to as Duct A, while the outside two ducts were referred to as Ducts B and $\mathrm{C}$. Ducts $\mathrm{B}$ and $\mathrm{C}$ were designed to be brought on-line, if required, for higher velocity testing. Three stages of collectors were utilized in Duct A during this test. The first two stages are intended to capture the majority of the solids, while the third stage was designed with the intention of capturing smaller particles. The first stage used four chevron collectors, two in each of two rows. The second stage had a total of twelve chevron collectors, four in each of three rows. The third stage had a single row of four chevron collectors using a venturi-type configuration as an inlet to accelerate the flow into them. The Chevron collectors are described in more detail in Appendix F.

At the conclusion of the two weeks of testing, the three sets of collectors were removed for inspection. It appeared that all four collectors in stage one had been operating properly. In the second stage, the four collectors in the back row were plugged with fine bed material, while the first two rows appeared to have been operating with some slight blockages at their top and bottom. The third stage of collectors were entirely plugged with bed material fines. The outer two inlet venturies of Stage three had also warped, blocking much of the flow to the outside collectors. It appears that a combination of factors caused the blinding of the back row of stage two and all of the stage three collectors. All of the stage two and three collectors were one-half the size of the ones used in stage one, resulting in a smaller exit to the collection hoppers. All of the individual collectors that drained onto the back slope of the hopper plugged ofi. There did not appear to be sufficient spacing between the collector drains and the refractory to allow for a sufficient volume of solids to flow through. The stage three inlet venturies funneled all other remaining fines into four collectors, overloading this stage with more material than could be handled.

Operational temperatures in the downcomer remained high throughout testing, indicating good collector performance even though approximately half of the chevron collectors were plugged for, at least, the latter portion of testing. Use of chevron collectors appears to have resulted in a collector that more closely simulates the operation of a large cyclone collector used for a CFB utility or industrial boiler.

The design used for this test was not able to handle the large amount of recirculating fines. The recycle of the secondary cyclone catch back to the downcomer may have influenced the plugging problems noted above. Some of the plugging problems encountered during this test were specific to the limestone used; it was a smaller size than had been originally specified for operation with this pilot facility and was extremely cohesive. 
No problems were encountered with the durability of the chevron collectors. They experienced more than 200 hours of high-temperature exposure at temperatures averaging approximately $1500^{\circ} \mathrm{F}$ and, on occasion, temperatures approaching $1700^{\circ} \mathrm{F}$ for short durations of a couple hours. The material of construction was 304 stainless steel. No apparent warpage was present, with many of the sharp edges only slightly dulled. The only damage that occurred was to the one-eighth-inch stainless steel sheet that was used to construct the inlet venturies for the third stage. This appears to be due to a combination of expansion and inadequate strength.

\section{Recirculation Rates and Size Distributions}

The solids recirculation rate was determined by calculating the heat balance around the external heat exchanger. The average solids recirculation rates for each test are shown in Table A-5. The recirculation ratio is the ratio of the solids recirculation rate to the input of coal ash and limestone into the combustor. Test 4 had low coal and sorbent feed rates to achieve the 55\% load condition; however, the low superficial gas velocity in the combustor produced a very low recirculation rate, with a correspondingly low recirculation ratio.

The cyclone collection efficiency for this unit was very good. The higher the cyclone efficiency, the greater the proportion of material that stays within the system as opposed to escaping to the baghouse. In a commercial combustor, a cyclone collection efficiency of $99.0 \%$ to $99.5 \%$ or more is required to maintain sufficient solids in the system for stable operation. Consistency in the sulfur emissions, heat-transfer coefficient, and the temperature distribution in the combustor, downcomer, and external heat exchanger indicates uniform mixing and solids distribution throughout the system.

\section{TABLE A-5}

Solids Recirculation and Heat-Transfer Data

\begin{tabular}{|c|c|c|c|c|c|c|c|c|c|c|}
\hline Test & $\begin{array}{c}\text { Temperature } \\
\left({ }^{\circ} \mathrm{F}\right)\end{array}$ & $\mathrm{Ca} / \mathrm{S}$ & $\begin{array}{l}\text { Excens } \\
\text { Air (\%) }\end{array}$ & $\begin{array}{l}\text { Primary } \\
\text { Air (\%) }\end{array}$ & $\begin{array}{c}\text { Solids } \\
\text { Recirculation } \\
(\mathrm{b} / \mathrm{hr})\end{array}$ & $\begin{array}{c}D C^{1} \\
d_{60}(\mu \mathrm{m})\end{array}$ & $\mathrm{H}_{0}{ }^{2}$ & $\begin{array}{l}\text { Heat Flux } \\
\left.\text { (Btu/hr-ft }{ }^{2}\right)\end{array}$ & $\begin{array}{l}\text { Cyclono } \\
\text { Efficioncy } \\
\text { (\%) }\end{array}$ & $\begin{array}{c}\text { Recirculation } \\
\text { Ratio }\end{array}$ \\
\hline 1 & 1,607 & 0.3 & 20.8 & 60 & 7,660 & 300 & 19.1 & 32,600 & 99.84 & 202 \\
\hline 2 & 1,613 & 3.2 & 21.5 & 46 & 12,050 & 210 & 22.3 & 32,700 & 99.49 & 227 \\
\hline 3 & 1,569 & 2.5 & 23.4 & 60 & 8,920 & 240 & 20.6 & 29,100 & 99.83 & 202 \\
\hline 4 & 1,351 & 2.9 & 54.2 & 52 & 2,780 & 110 & 14.7 & 18,200 & 99.63 & 91 \\
\hline 5 & 1,476 & 2.5 & 43.7 & 64 & 14,210 & 220 & 20.8 & 27,600 & 99.60 & 326 \\
\hline 6 & 1,478 & 1.4 & 17.0 & 45 & 9,580 & 240 & 20.4 & 27,600 & 99.69 & 196 \\
\hline 7 & 1,630 & 3.3 & 18.7 & 65 & 10,600 & 240 & 23.4 & 34,800 & 99.76 & 226 \\
\hline 8 & 1,615 & 3.8 & 40.7 & 48 & 7,360 & 220 & 20.6 & 30,600 & 99.68 & 149 \\
\hline 9 & 1,596 & 6.0 & 46.0 & 67 & 8,920 & 270 & 22.7 & 32,900 & 99.36 & 170 \\
\hline 10 & 1,617 & 4.9 & 20.4 & 46 & 9,600 & 220 & 19.8 & 29,300 & 99.64 & 172 \\
\hline 11 & 1,485 & 6.2 & 17.0 & 65 & 12,010 & 250 & 20.6 & 27,400 & 99.47 & 198 \\
\hline 12 & 1,470 & 5.6 & 45.6 & 45 & 13,120 & 220 & 19.6 & 26,000 & 99.78 & 254 \\
\hline
\end{tabular}

1 Downcomer.

2 Heat-tranofer coefficient (Btu/hr-ft $\left.{ }^{2} \cdot{ }^{\circ} \mathrm{F}\right)$. 
The particle-size distributions throughout the run were fairly consistent. Figure A-3 shows the particle-size distributions in the downcomer for Test 1 , Test 4 , and the average of the remaining tests which were very similar. Test 1 had proportionally larger particles in the downcomer because it was performed early in the run and without limestone addition. Therefore, the bed was composed primarily of coal ash and relatively large-size start-up sand. Limestone was fed during Tests 2 through 12, which resulted in progressively smaller bed particle sizes as the bed turned over from predominantly silica sand and coal ash, to limestone and coal ash. The low velocity of Test 4 prevented larger particles from being carried out of the combustor, giving the smaller particle size shown in Figure A-3. Figure A-4 shows the particle sizes found in the combustor, downcomer, and baghouse during Tests 2 and 4.

\section{Bottom Ash/Total Ash Split}

An ash balance for each test period is given in Table A-6. Ash input to the system $w \approx$ composed of calculated quantities of coal ash, limestone ash, secondary cyclone ash, and bed material. The limestone-derived ash was further broken down into estimates of the sorbent which either was calcined or had undergone sulfation. The output of ash from the CFB system consisted of measured quantities of bottom ash (combustor and downcomer bed material), ash removed from the secondary cyclone, and baghouse ash (fly ash).

The ratios of bottom ash-to-total ash, as well as the percent closure, were calculated and are included in Table A-6. The a-erage closure for the entire run was about $84 \%$, but increased to near $90 \%$ with Test 1 taken out of the average. It is believed that significant quantities of fly ash were adhering to the bags and hopper in the baghouse during various tests and may not have been properly accounted for during the run, resulting in some relatively high bottom ash-to-total ash ratios.

\section{Coal Ash/Limestone Split}

Table A-7 shows the makeup of the bed material, secondary cyclone ash, and baghouse ash, as well as the solids input, based on an aluminum balance. Alumina was used as the tracer, since it makes up about $30 \%$ of the coal ash, and is virtually nonexistent in the limestone. This material balance was used to determine the contributions of coal ash and limestone at each solids removal point. Because secondary cyclone ash and bed material were added during some tests, the sum of the coal and limestone input do not always equal $100 \%$. The closure is based on coal ash only. The contribution from the coal was determined by the aluminum material balance, shown in Table A-8, and the total contribution from the limestone and cyclone ash was obtained by difference. In those tests where bed material and/or secondary cyclone ash were added to the system, the calculated coal contribution may be artificially high; there was a high percentage of aluminum in the secondary cyclone ash, and a small amount in the bed material, that was not accounted for in the aluminum balance. The aluminum in the secondary cyclone ash was assumed to be the same as that in the baghouse ash. 


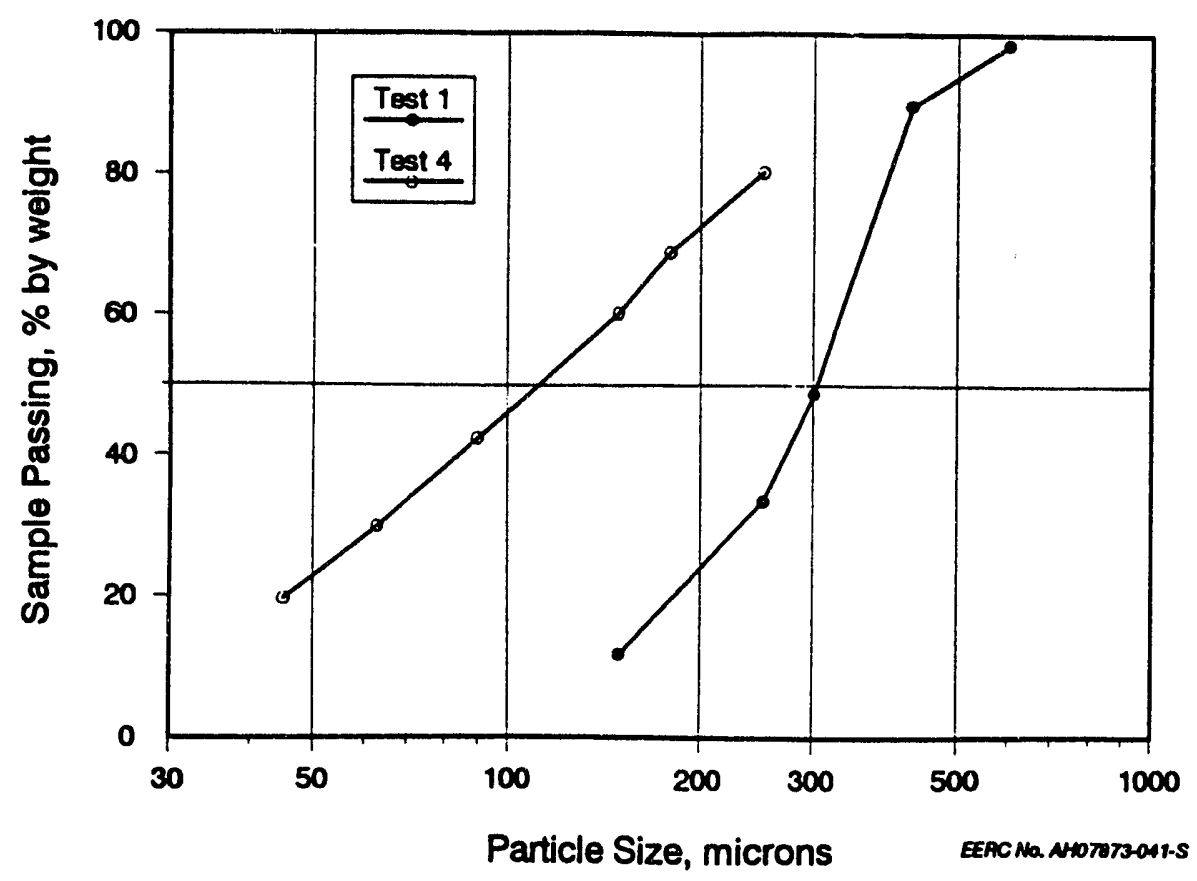

Figure A-3. Particle-size distributions of downcomer material for Tests 1 and 4 .

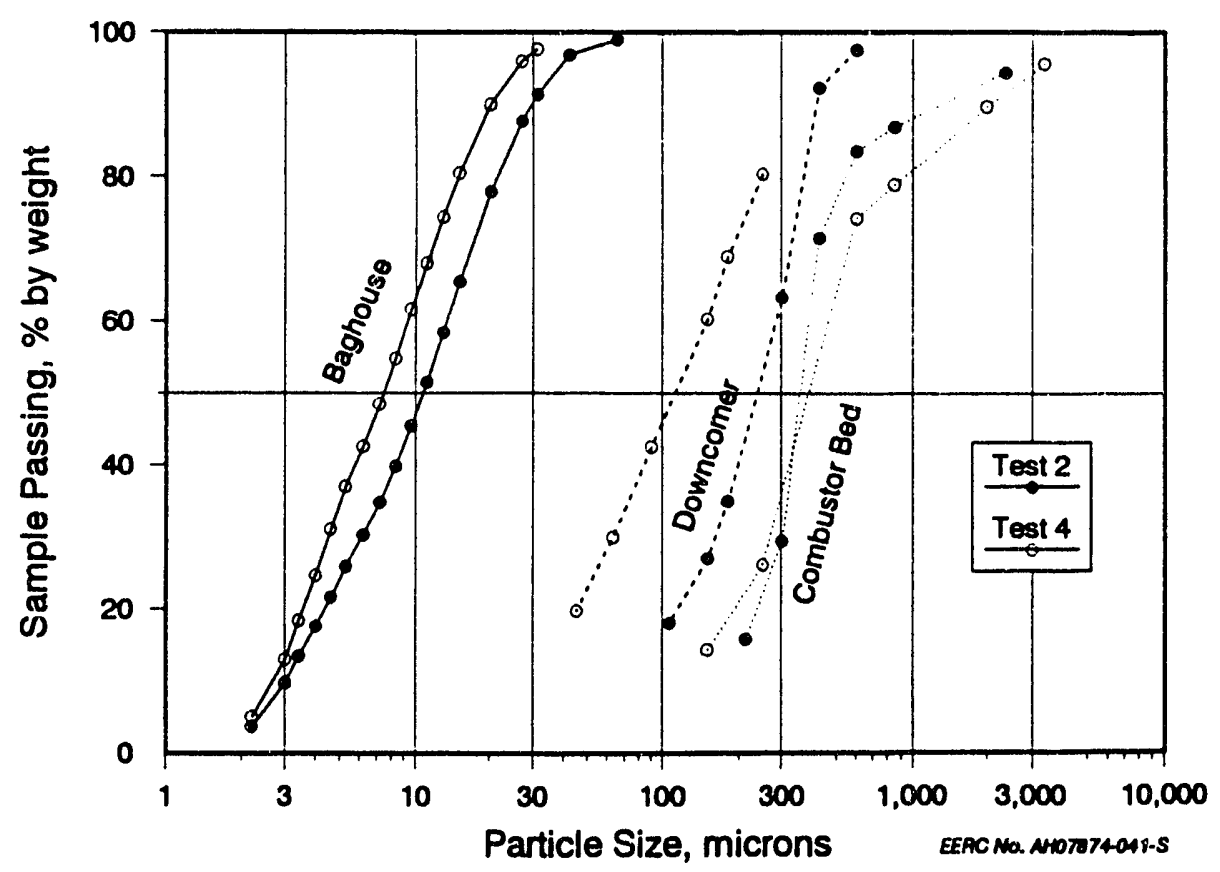

Figure A-4. Combustor, downcomer, and baghouse material particle-size distributions for Tests 2 and 4. 


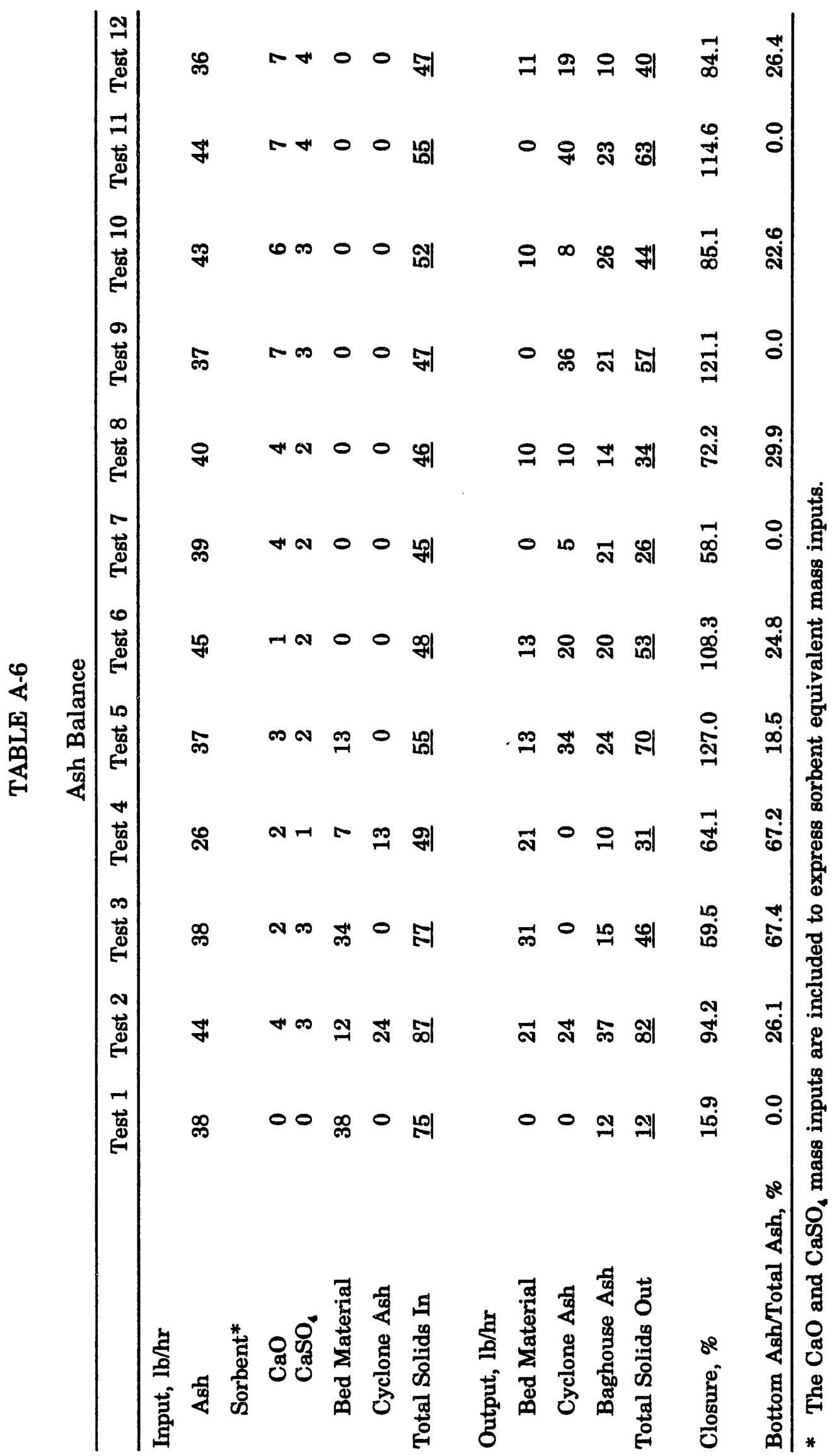


TABLE A-7

Material Derived from Coal Ash and Limestone Based on Aluminum Material Balance (\%)

\begin{tabular}{|c|c|c|c|c|c|c|c|c|}
\hline & Coal & $1 s^{*}$ & Coal & ls & Coal & ls & Coal & ls \\
\hline & \multicolumn{2}{|c|}{ Test 1} & \multicolumn{2}{|c|}{ Test 2} & \multicolumn{2}{|c|}{ Test 3} & \multicolumn{2}{|c|}{ Test 4} \\
\hline Solids Input & 50.28 & 0.00 & 50.18 & 8.01 & 49.27 & 6.47 & 53.30 & 6.15 \\
\hline Bed Drain & NA & NA & 35.60 & 64.40 & 37.94 & 62.06 & 45.66 & 54.34 \\
\hline Cyclone Catch & NA & NA & 87.38 & 12.62 & NA & NA & NA & NA \\
\hline Baghouse Catch & 97.77 & 0.00 & 87.38 & 12.62 & 91.96 & 8.04 & 95.82 & 4.18 \\
\hline \multirow[t]{2}{*}{ Closure } & \multicolumn{2}{|c|}{30.94} & \multicolumn{2}{|c|}{89.12} & \multicolumn{2}{|c|}{67.09} & \multicolumn{2}{|c|}{50.46} \\
\hline & \multicolumn{2}{|c|}{ Test 5} & \multicolumn{2}{|c|}{ Test 6} & \multicolumn{2}{|c|}{ Test 7} & \multicolumn{2}{|c|}{ Test 8} \\
\hline Solids Input & 67.46 & 9.04 & 93.81 & 6.19 & 86.54 & 13.46 & 87.07 & 12.93 \\
\hline Bed Drain & 48.25 & 51.75 & 51.05 & 48.95 & NA & NA & 35.78 & 64.21 \\
\hline Cyclone Catch & 80.32 & 19.68 & 81.68 & 18.32 & 85.99 & 14.01 & 92.97 & 7.02 \\
\hline Baghouse Catch & 80.32 & 19.68 & 81.68 & 18.32 & 85.99 & 14.01 & 92.97 & 7.02 \\
\hline \multirow[t]{2}{*}{ Closure } & \multicolumn{2}{|c|}{140.06} & \multicolumn{2}{|c|}{85.54} & \multicolumn{2}{|c|}{57.76} & \multicolumn{2}{|c|}{62.94} \\
\hline & \multicolumn{2}{|c|}{ Test 9} & \multicolumn{2}{|c|}{ Test 10} & \multicolumn{2}{|c|}{ Test 11} & \multicolumn{2}{|c|}{ Test 12} \\
\hline Solids Input & 78.86 & 21.14 & 82.67 & 17.33 & 80.06 & 19.94 & 76.74 & 23.25 \\
\hline Bed Drain & NA & NA & 55.24 & 44.76 & NA & NA & 53.61 & 46.39 \\
\hline Cyclone Catch & 74.76 & 25.24 & 84.97 & 15.03 & 81.76 & 18.24 & 87.63 & 12.37 \\
\hline Baghouse Catch & 74.76 & 25.24 & 84.97 & 15.03 & 81.76 & 18.24 & 87.63 & 12.37 \\
\hline Closure & \multicolumn{2}{|c|}{114.79} & \multicolumn{2}{|c|}{80.49} & \multicolumn{2}{|c|}{117.05} & \multicolumn{2}{|c|}{86.13} \\
\hline
\end{tabular}

* Limestone,

\section{THERMAL PERFORMANCE}

\section{Energy and Material Balances}

Fuel and flue gas balances were calculated, and the results are presented in Tables A-9 and A-10, respectively. The theoretical fuel feed rates were calculated using actual fuel characteristics and measured $\mathrm{O}_{2}$ and $\mathrm{CO}_{2}$ flue gas concentrations. The theoretical flue gas rates were calculated using the theoretical coal feed rates, coal analyses, and excess air levels. The measured fuel feed rates were all slightly higher than the theoretical values, while the measured flue gas flow rates varied from $6.9 \%$ greater to $13.8 \%$ less than theoretical.

The energy balances for the twelve tests are presented in Table A-11, both in Btu/hr and as percentages. The energy input was made up of the energy potential of the fuel, the primary and secondary combustion air, the external heat exchanger fluidizing air, the energy released from the sulfation of the sorbent, and the energy available from the unburned carbon present in the ash added back to the system. Measurable heat loss sources were the combustor heat exchange doors, the external heat exchanger cooling coils, the flue gas, the unburned carbon in the ash removed, the heat present in the drained ash, and the energy absorbed during calcination of the sorbent. The unmeasurable heat loss due to convection and radiation was estimated using a correlation 


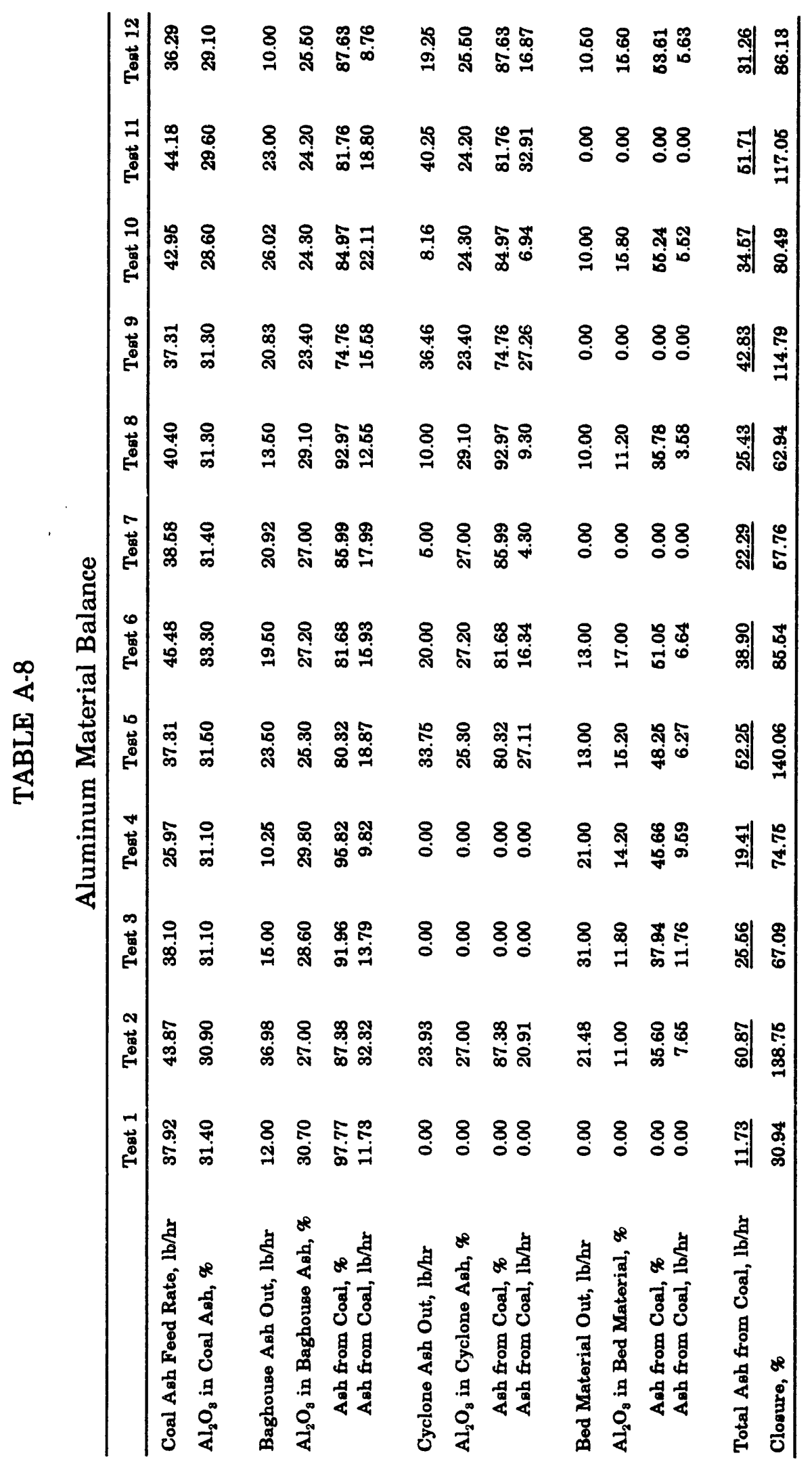




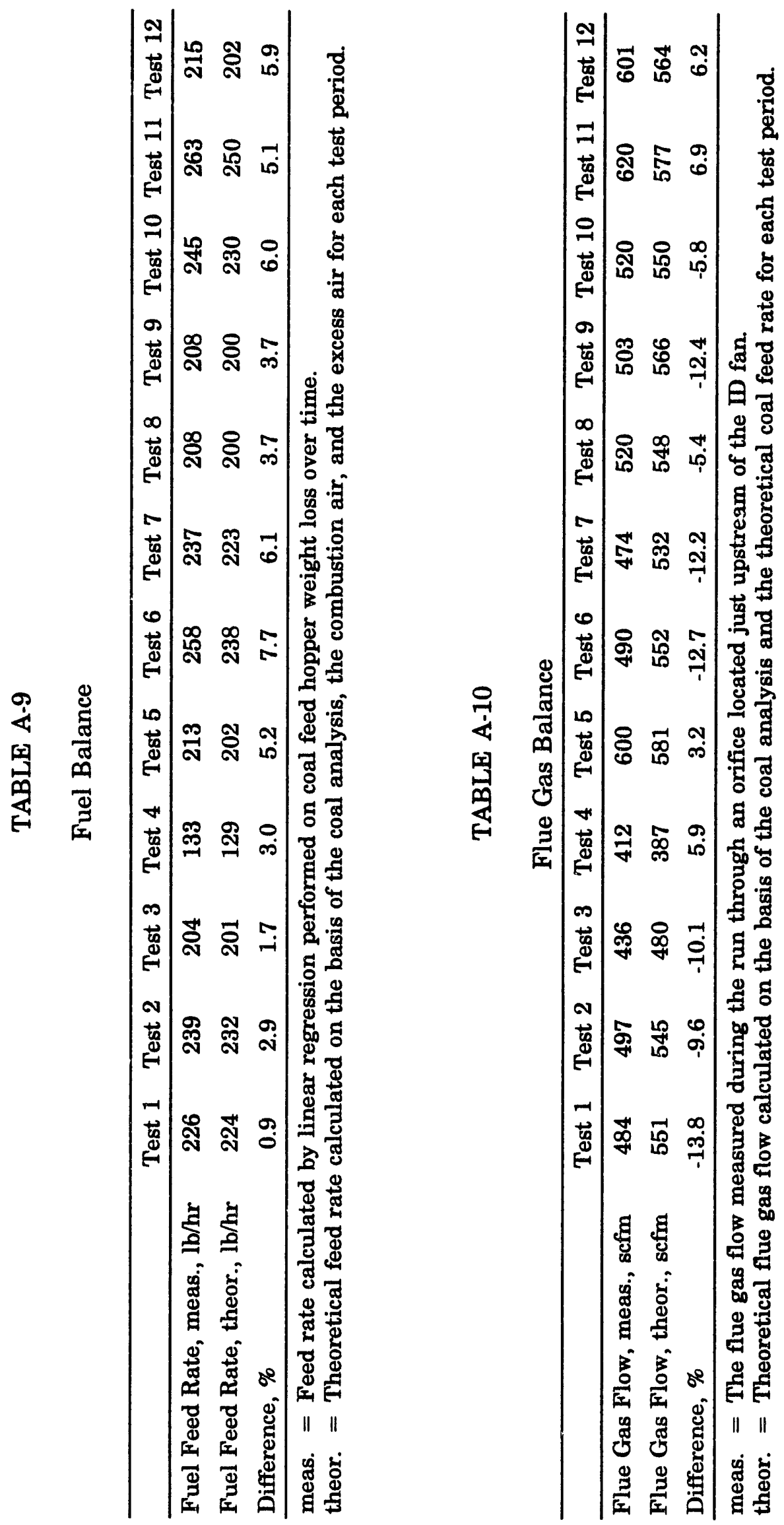




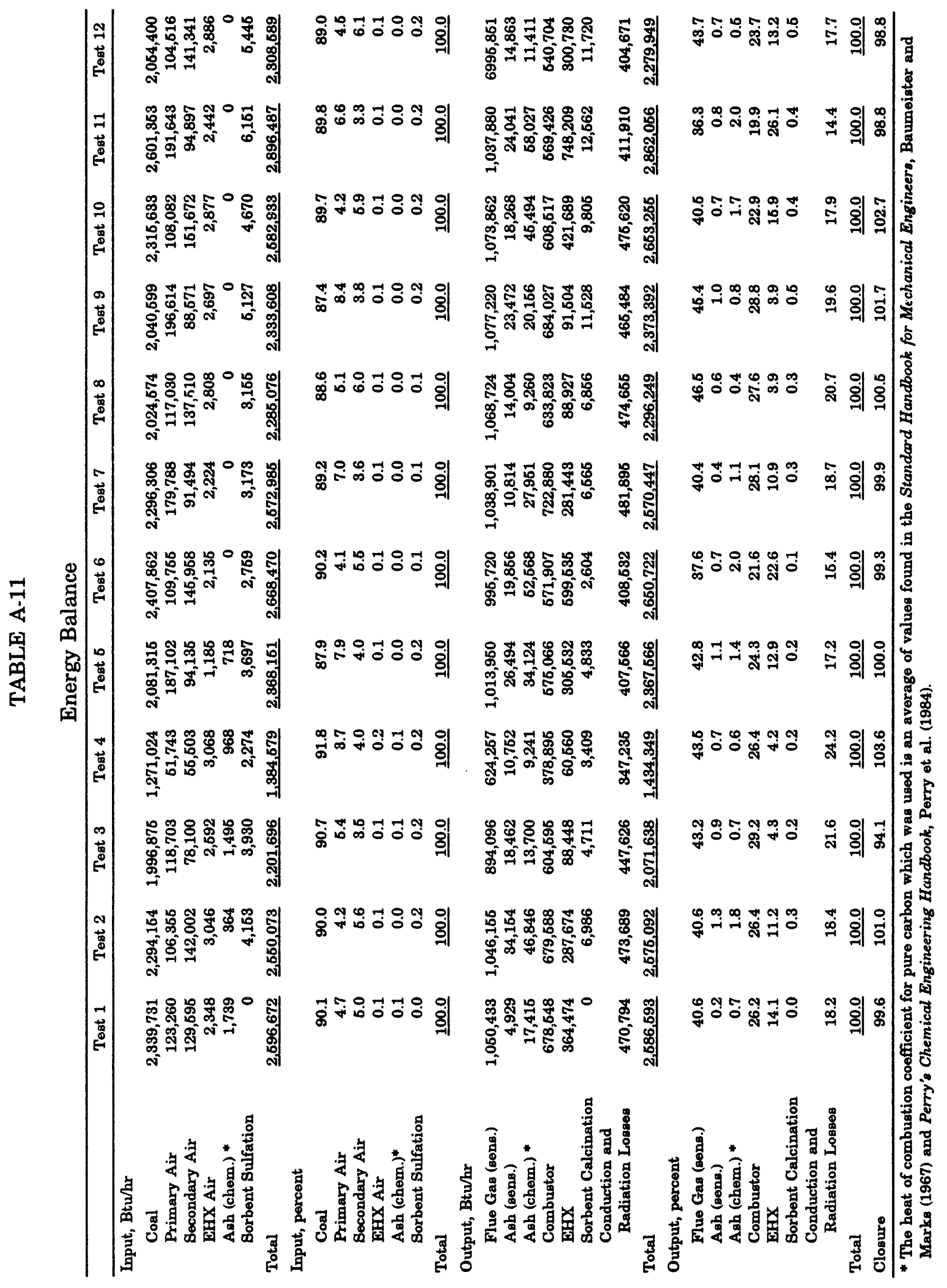


developed from a number of tests on this unit, relating average combustor temperature to heat loss. Approximately $40 \%$ of the heat was removed by the flue gas, while $31 \%$ to $46 \%$ of the heat was removed through the combustor heat exchange doors and external heat exchanger cooling coils. Average wall losses accounted for about 19\% of the total heat loss.

The material balances for the twelve test periods are shown in Table A-12. The material balance closures were generally good, with the greatest deviation from complete closure occurring in Test 1 at $97.6 \%$.

\section{Combustion Efficiency}

Combustion efficiencies for all twelve tests are shown in Table A-13. The combustion efficiency calculation is based on the amount of unburned carbon removed in the bottom ash and fly ash as a function of the carbon input as coal feed and bed material addition. The percentage of unburned carbon in each ash stream was calculated as the difference between the loss-on-ignition (LOI) and the carbonate as $\left(\mathrm{CO}_{2}\right)$ present in the sample. Results of the unburned carbon calculations are shown in Table A-14.

The combustion efficiencies for Tests 1 through 4 are shown as a function of bed temperature in Figure A-5. Tests 1, 2, and 3 were performed at relatively low levels of excess air (21\% - 24\%), while the excess air in Test 4 was 54\%. Tests 3 and 4 were low load tests, $85 \%$ and $55 \%$, respectively. The high calculated combustion efficiency for Test 1 can be attributed in part to the fact that no bottom ash was removed during the test, and the baghouse discharge rate was relatively low. During this test, the unit was operated with a sand bec; irmestone feed was not initiated until Test 2.

The expected trend of higher combustion efficiency with higher temperature is not seen for the first 4 tests (see Figure A-5). The average superficial gas velocity for each test is given in Table A-4. In Tests 3 and 4, the gas velocity was decreased from a nominal $16 \mathrm{ft} / \mathrm{sec}$ to 13.9 and $10.0 \mathrm{ft} / \mathrm{sec}$, respectively. This impacts the system in two ways. The gas and solids residence times increase with the decrease in velocity. A second effect was a shift in particle-size distribution. As shown in Figure A-4, the size distribution in the downcomer and baghouse shifted to a smaller size for Test 4. The increased gas residence time and the decreased cut point caused an increase in carbon burnout for Tests 3 and 4 that offset the expected temperature effects.

Figures A-6 and A-7 show the impacts of changing bed temperature and velocity on carbon burnout. In Figure A-6 the percentage of unburned carbon in the bed material is plotted as a function of temperature. As expected, the amount of unburned carbon increases as temperature decreases. This would tend to indicate a poorer combustion efficiency at lower temperatures. The opposite trend is noted with the baghouse catch; that is, the low-temperature tests have less unburned carbon in the baghouse catch than the high-temperature tests. However, if one plots the unburned carbon in the baghouse catch versus velocity as in Figure A-7, it can be seen that as the velocity decreases (increased residence time and decreased cut point), the amount of unburned carbon decreases. This would indicate a higher combustion efficiency as velocity decreases. The improved burnout at the lower velocities apparently offset the poorer burnout caused by the lower temperature, with the net effect being no significant difference in carbon burnout for the three load tests. 


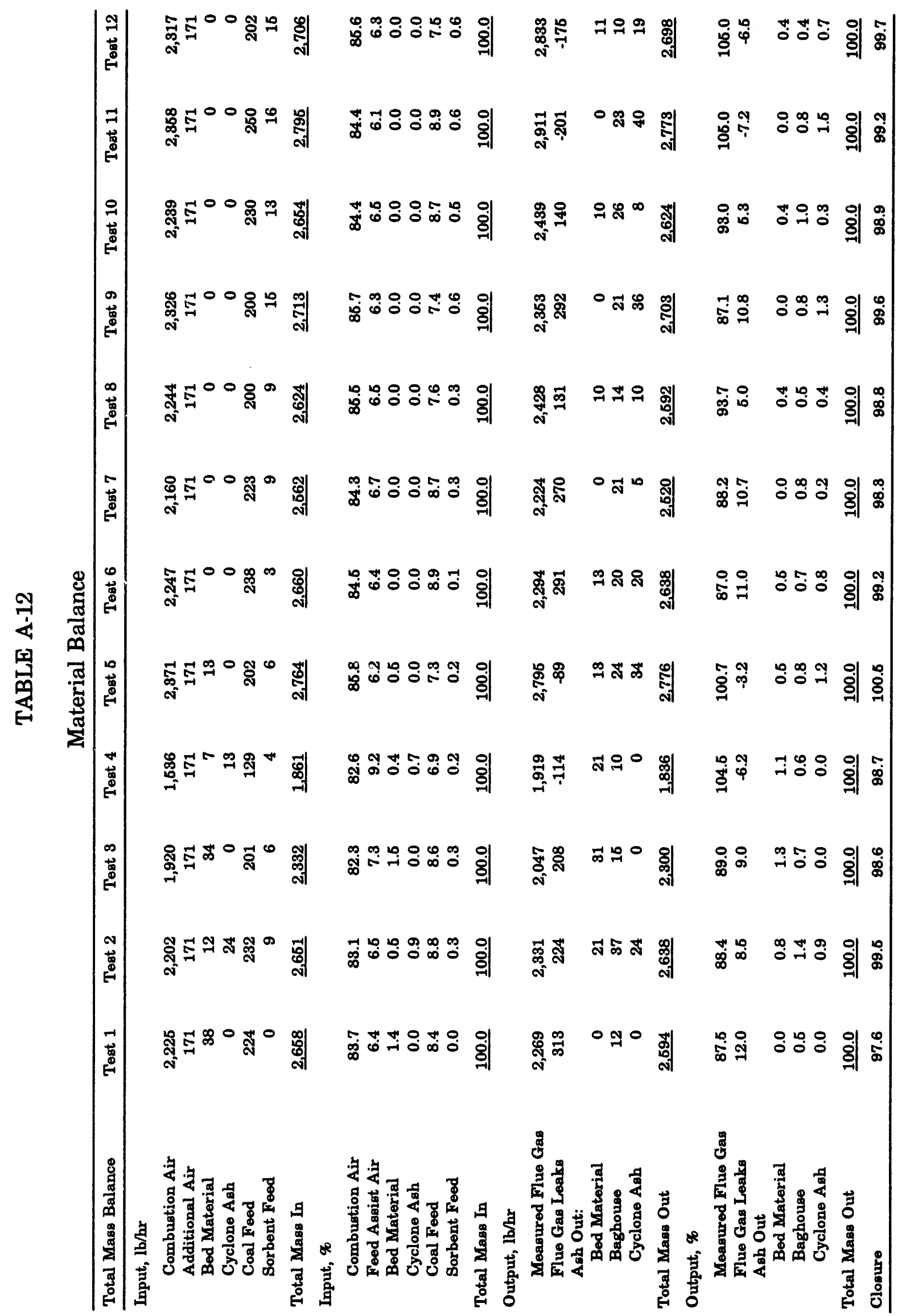




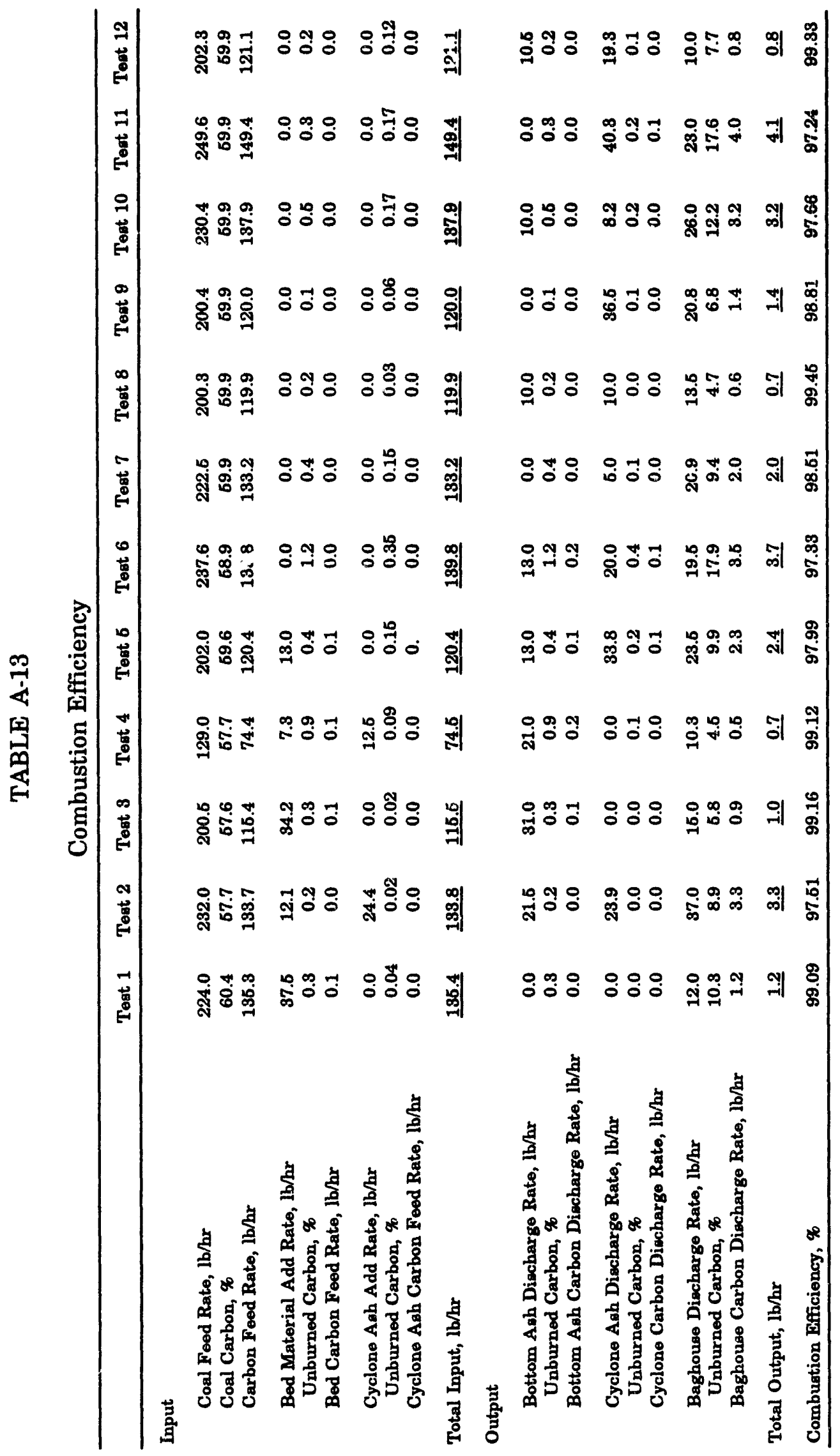




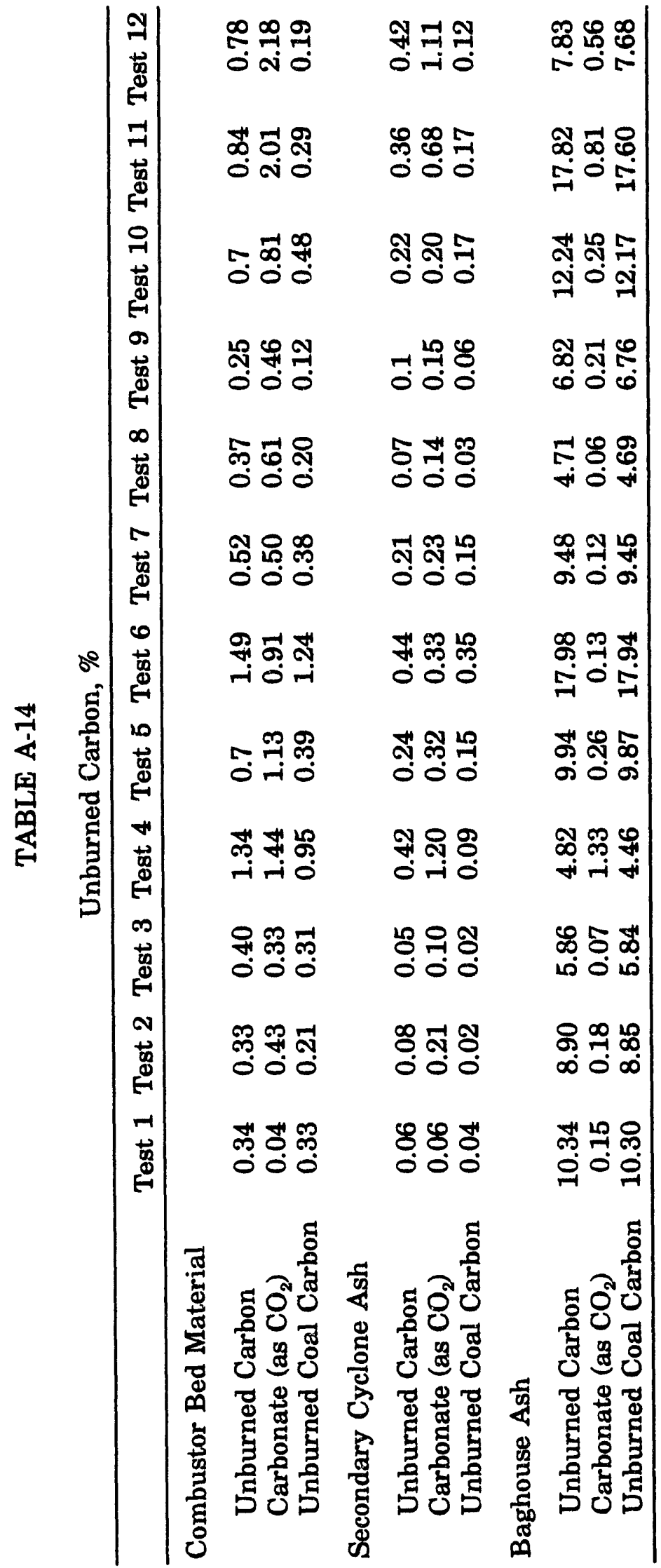




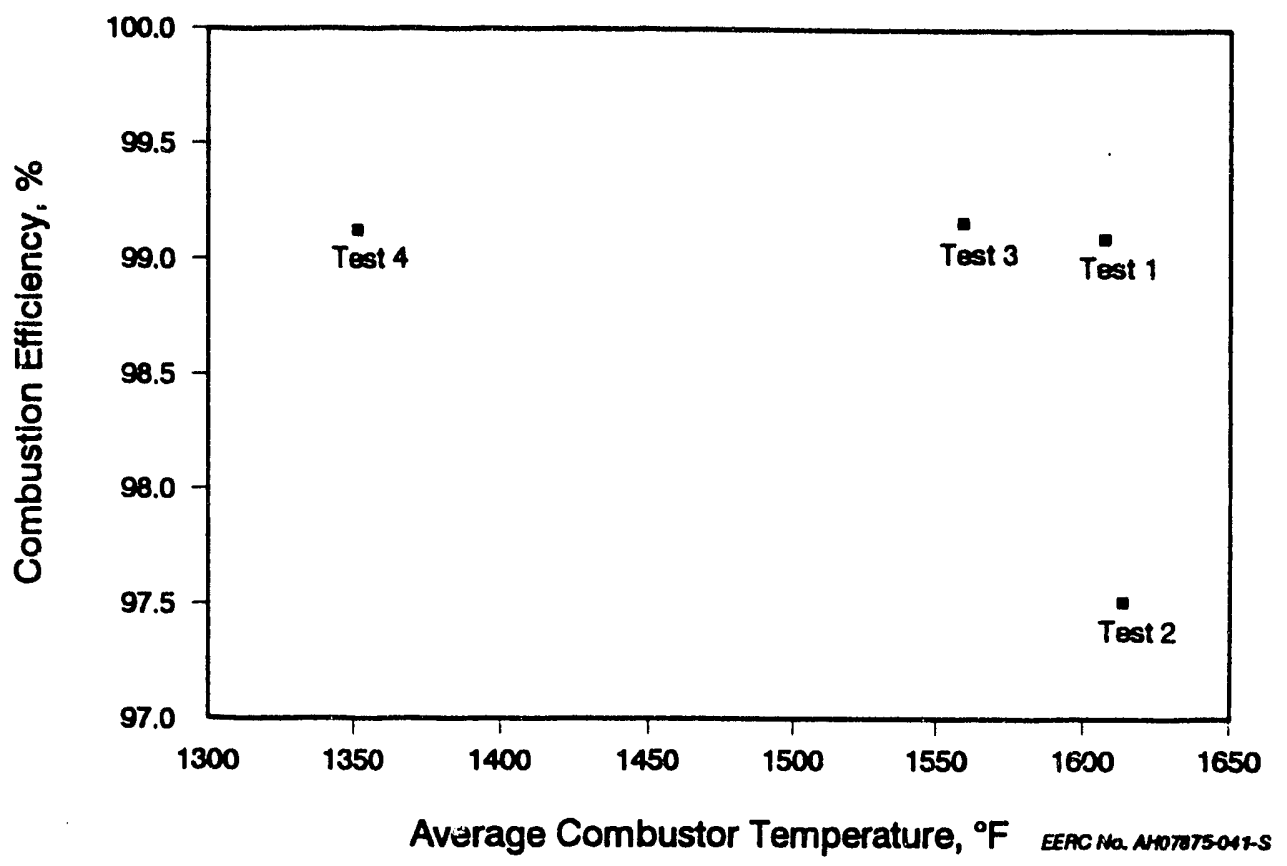

Figure A-5. Combustion efficiencies as a function of average combustor temperature for Tests 1 through 4.

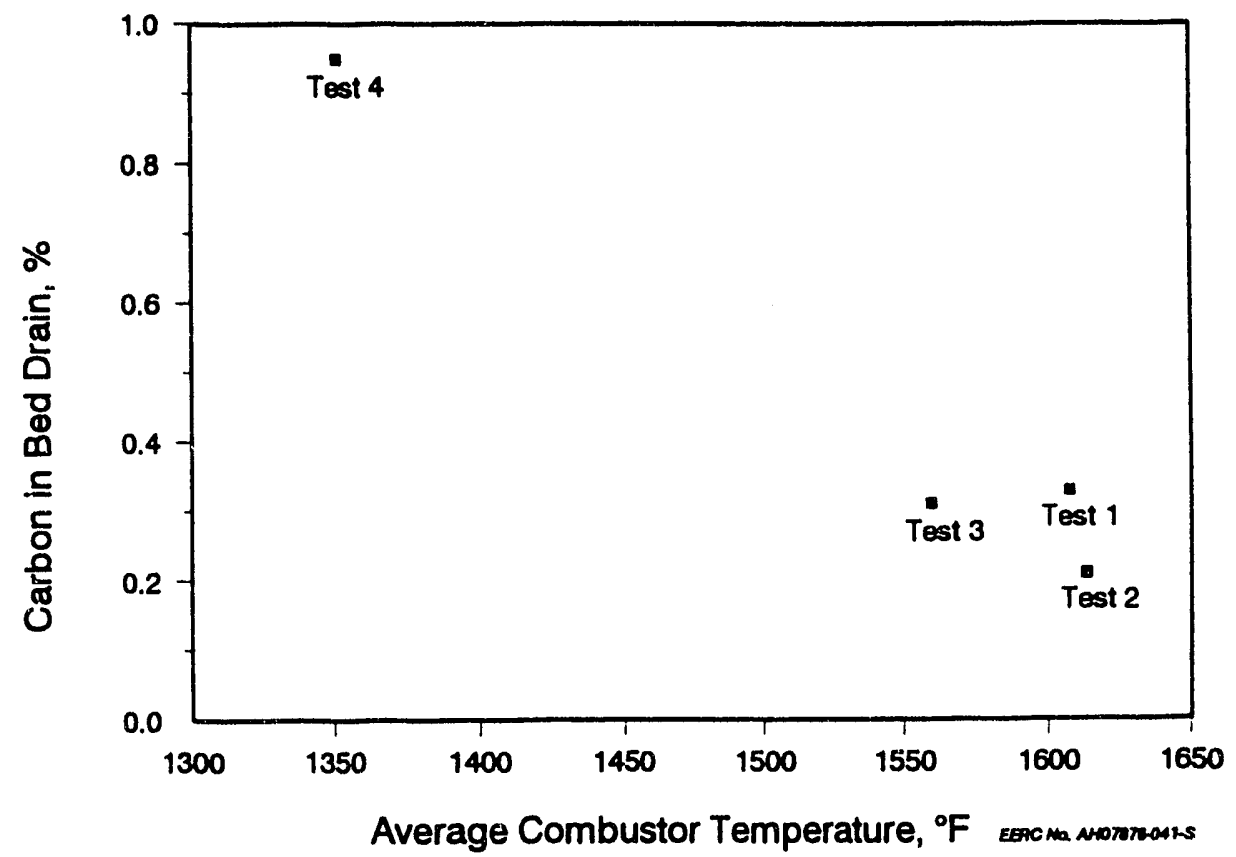

Figure A-6. Percentage of unburned carbon in the combustor bed material as a function of temperature for Tests 1 through 4. 


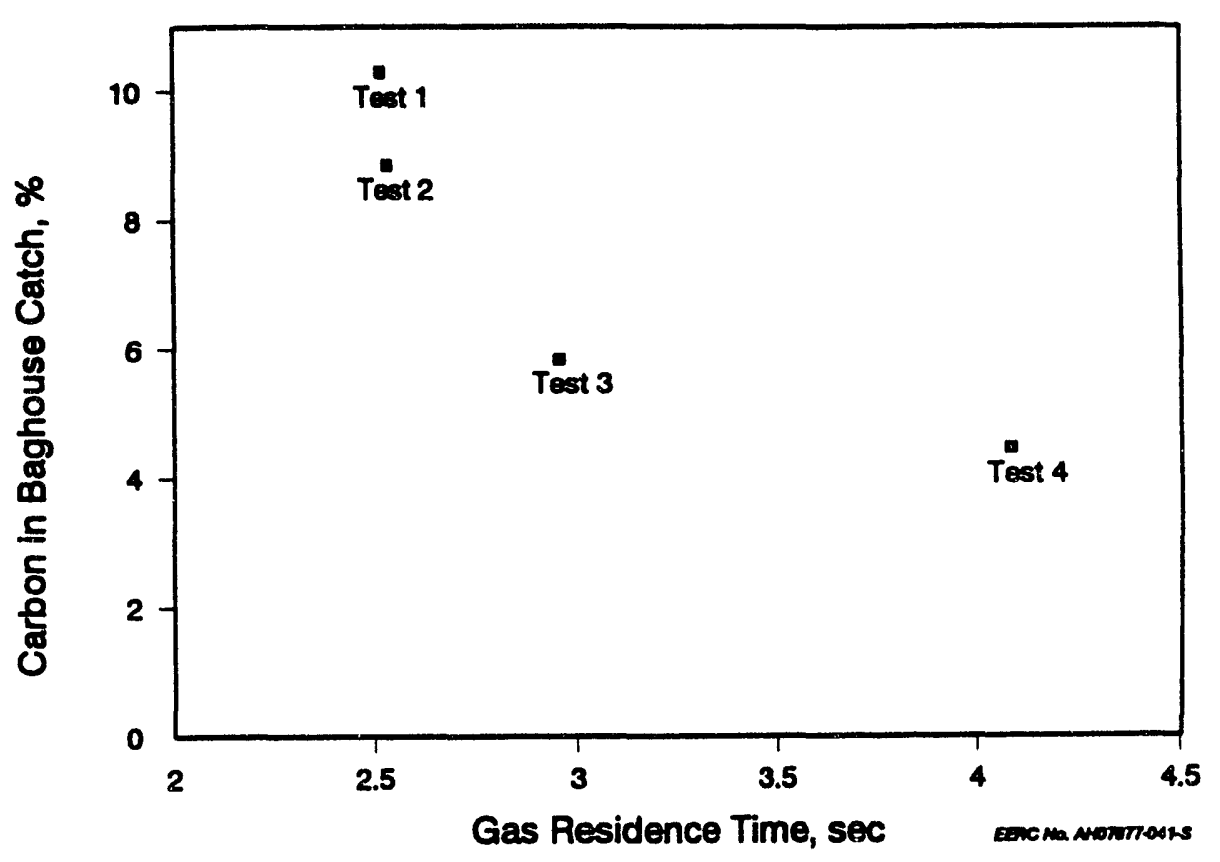

Figure A-\%. Percentage of unburned carbon in the fly ash as a function of gas residence time for Tests 1 through 4.

Figure A-8 shows the combustion efficiencies for Tests 5 through 12 as a function of temperature. Combustion efficiency increased with increasing bed temperature and excess air level. The relatively high combustion efficiency in Test 12 may be the result of insufficient bag cleaning at the end of the test, suggested by the low baghouse discharge rate for this test. Figures A-9 and A-10 show the amount of unburned carbon in the bed drain and baghouse catch as a function of temperature for Tests 5 through 12 . The percentage carbon in both the bed drain and baghouse catch is higher at the lower temperatures and excess air levels. This is different than that noted for Tests 2 through 4, and reinforces the previous observations of the effect of velocity on carbon burnout and overall combustion efficiency.

\section{Boiler Efficiency}

Boiler efficiencies were calculated for each test period using a modified version of ASME PTC 4.1. The modifications to PTC 4.1 are those recommended in EPRI's "Atmospheric Fluidized-Bed Combustion Performance Guidelines." Basically, the modification is a method to account for heat losses and gains associated with calcination and sulfation of the sorbent.

Table A-15 summarizes the results of the boiler efficiency calculations. For each test, boiler radiation and convective losses were assumed to be $0.4 \%$ of the heat input from the coal. While these losses were actually much greater for the EERC pilot plant, $0.4 \%$ was chosen to be representative of a full-scale system. An exit gas temperature of $300^{\circ} \mathrm{F}$ was used in the calculations. 


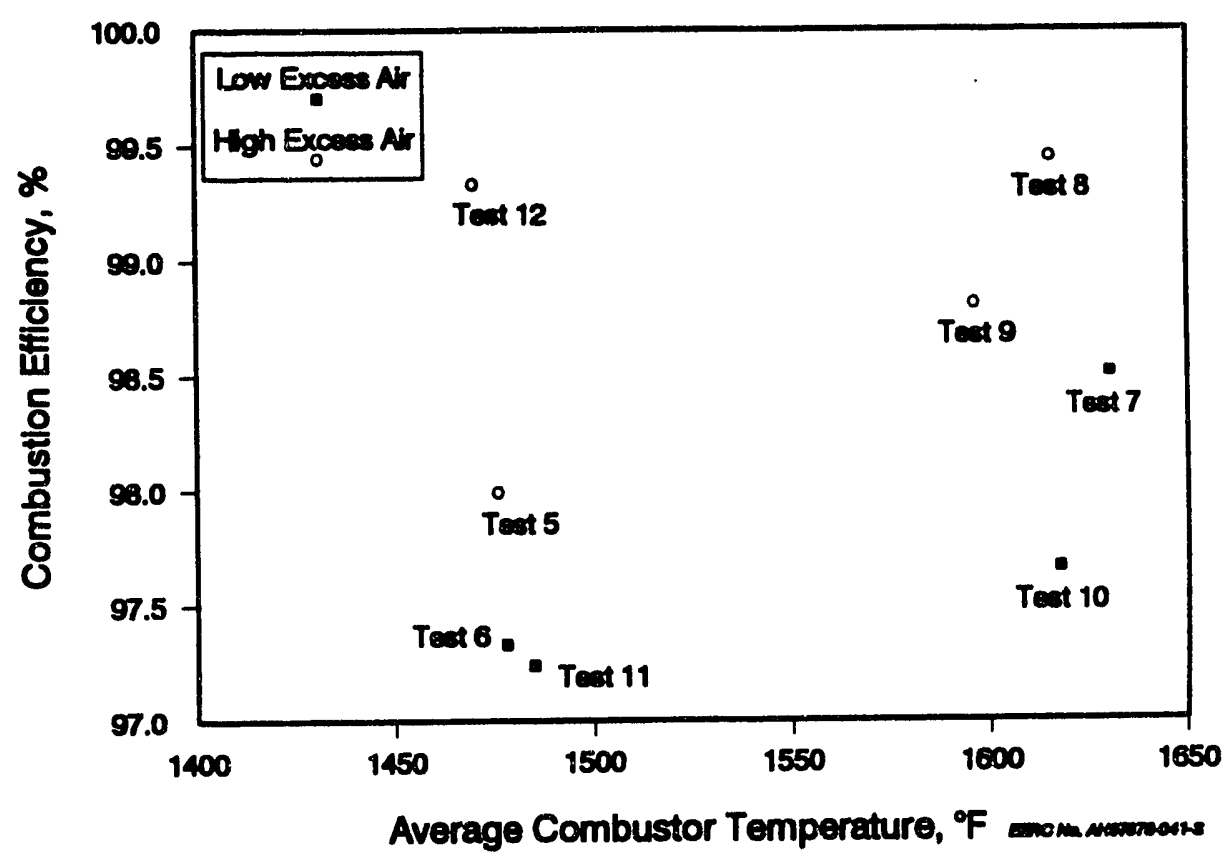

Figure A-8. Combustion efficiencies as a function of temperature for Tests 5 through 12.

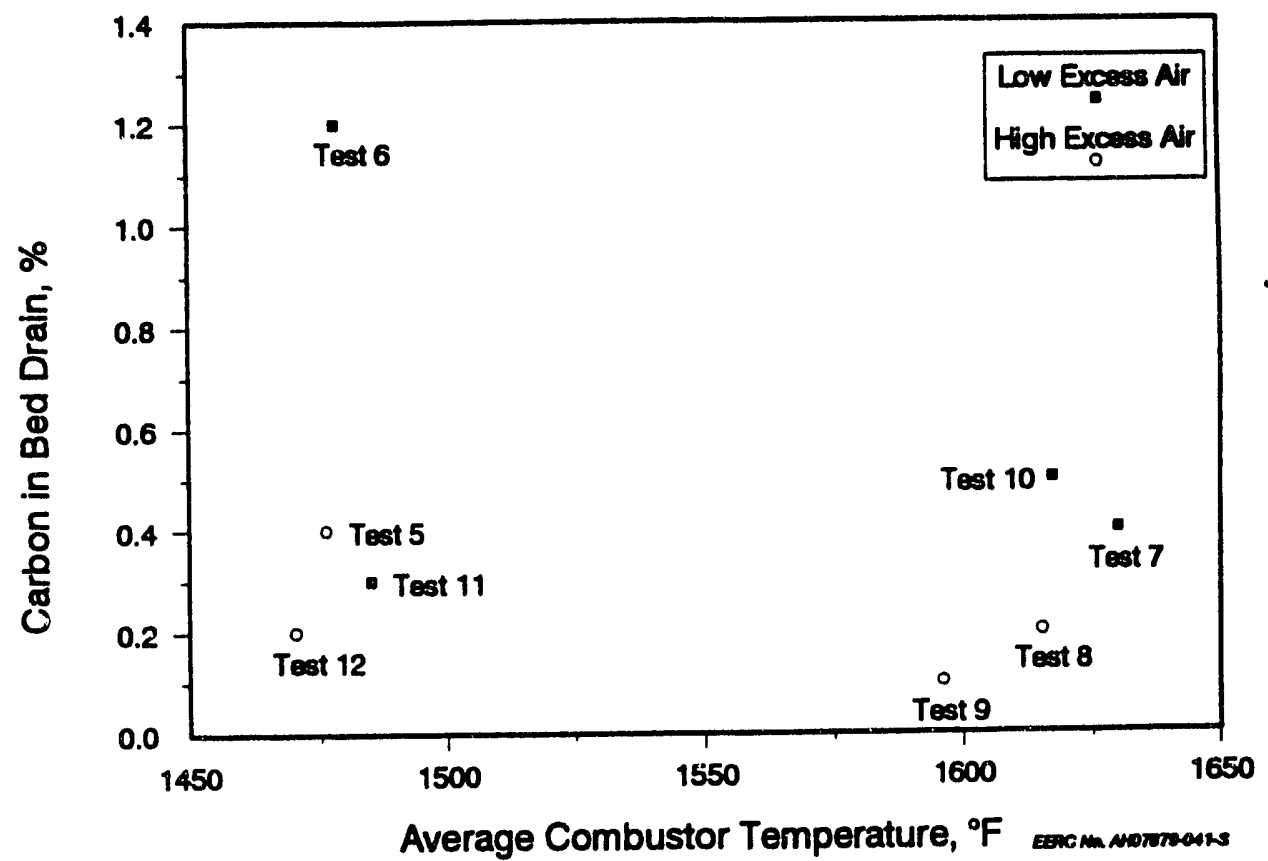

Figure A-9. Percentage of unburned carbon in the bed material drain as a function of temperature for Tests 5 through 12. 


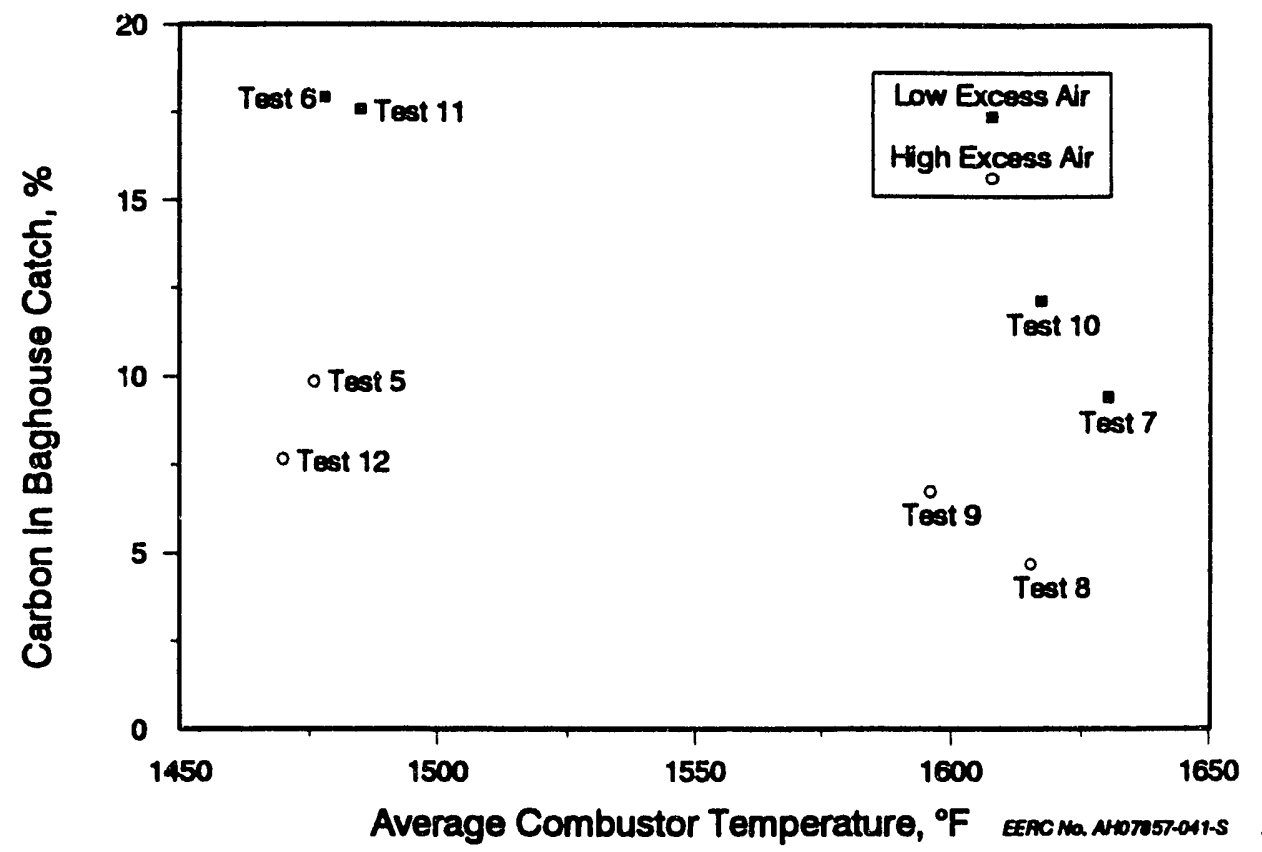

Figure A-10. Percentage of unburned carbon in the fly ash as a function of temperature for Tests 5 through 12.

The boiler efficiencies for all twelve tests were close to $90 \%$, even under low-load conditions in Test 4. The greatest loss were in the dry flue gas (5.4\% to $7.6 \%$ ). Depending on the test, the water in the fuel, unburned carbon in the ash, or hot solids removal was the next largest contributor to boiler efficiency loss. The combustion of fuel hydrogen, sorbent calcination and sulfation, and, of course, radiation and convection losses were fairly consistent for all twelve tests.

\section{Heat-Transfer Coefficient and Heat Flux}

During testing, the combustor heat exchange surface used for heat removal included the doors in Sections 2, 3, 4, 6, 7, and 8. Flow rates and the temperatures of the cooling water used in these heat exchange surfaces was monitored to allow the calculation of heat-transfer coefficients and heat flux as a function of position in the combustor. In the external heat exchanger, the number of cooling coils used to control the temperature ranged from 1 to 11. Heat-transfer coefficient and heat flux are calculated for the EHX as a whole. The average values of heat-transfer coefficient and heat flux for each combustor section which contains one or more heat exchange doors, and for the external heat exchanger, have been calculated for each of the twelve tests and are presented in Tables A-16 and A-17. Table A-18 presents the average heat-transfer coefficient and heat flux for all twelve tests, along with the average pressure drop across combustor Sections $2,4,6$, and 8. These data are also summarized in Table A-5 to help facilitate comparison to test conditions. The average heat flux for the Colorado Ute Nucla Station is in the range of 31,700 to $33,900 \mathrm{Btu} / \mathrm{hr}$ - $\mathrm{ft}^{2}$ at full load and 21,200 to $23,400 \mathrm{Btu} / \mathrm{hr}^{-\mathrm{ft}^{2}}$ at low load. For the twelve tests reported here, the heat flux in the combustor ranged from about 26,000 to $34,750 \mathrm{Btu} / \mathrm{hr}$ - $\mathrm{ft}^{2}$ for full-load tests and about $18,200 \mathrm{Btu} / \mathrm{hr}^{-\mathrm{ft}^{2}}$ at $55 \%$ load; in the external heat exchanger, full-load heat flux ranged from about 88,800 to $127,900 \mathrm{Btu} / \mathrm{hr}-\mathrm{ft}^{2}$, and the $55 \%$ load test has an $\mathrm{EHX}$ heat flux of $80,750 \mathrm{Btu} / \mathrm{hr}-\mathrm{ft}^{2}$. 


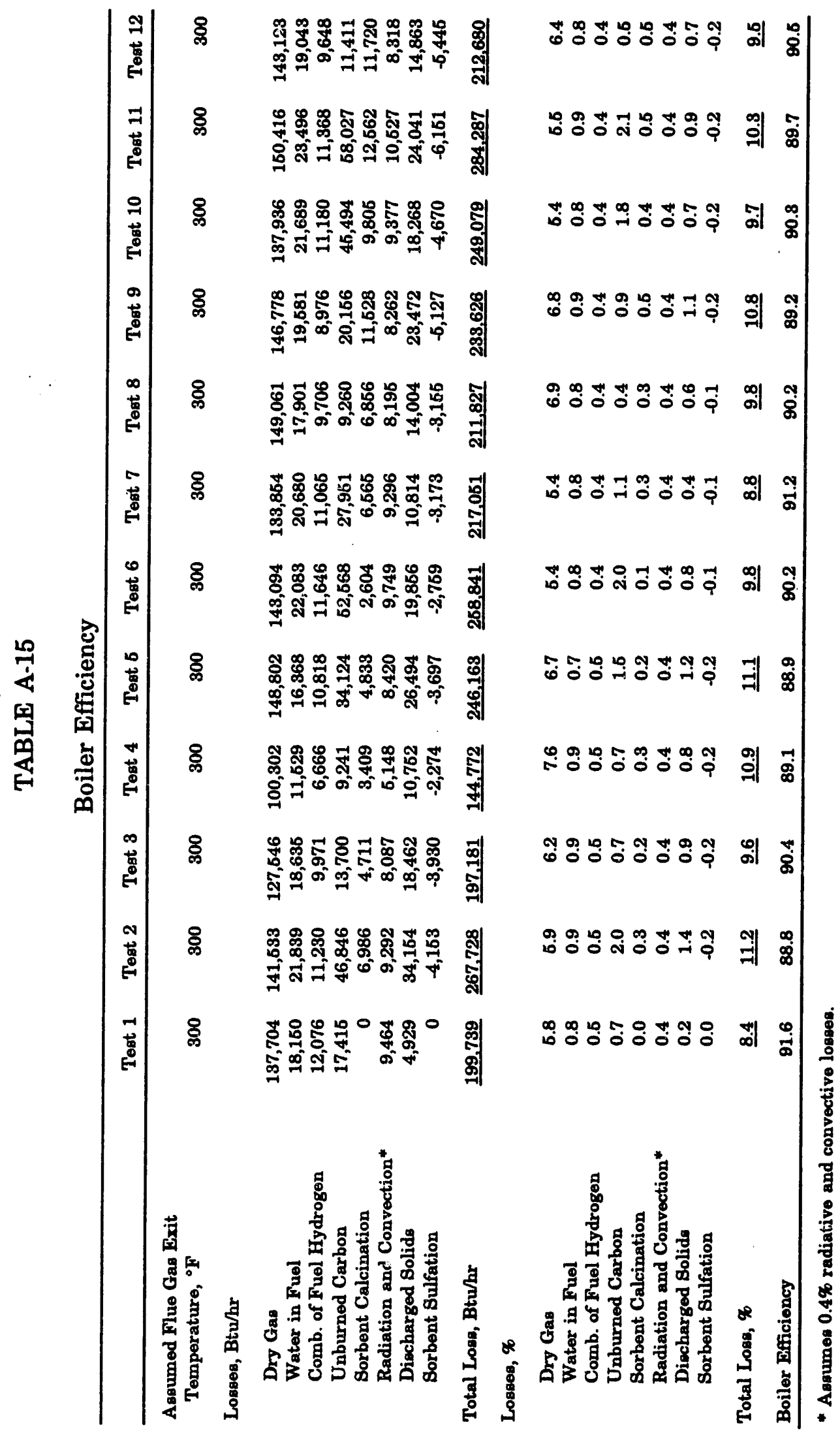



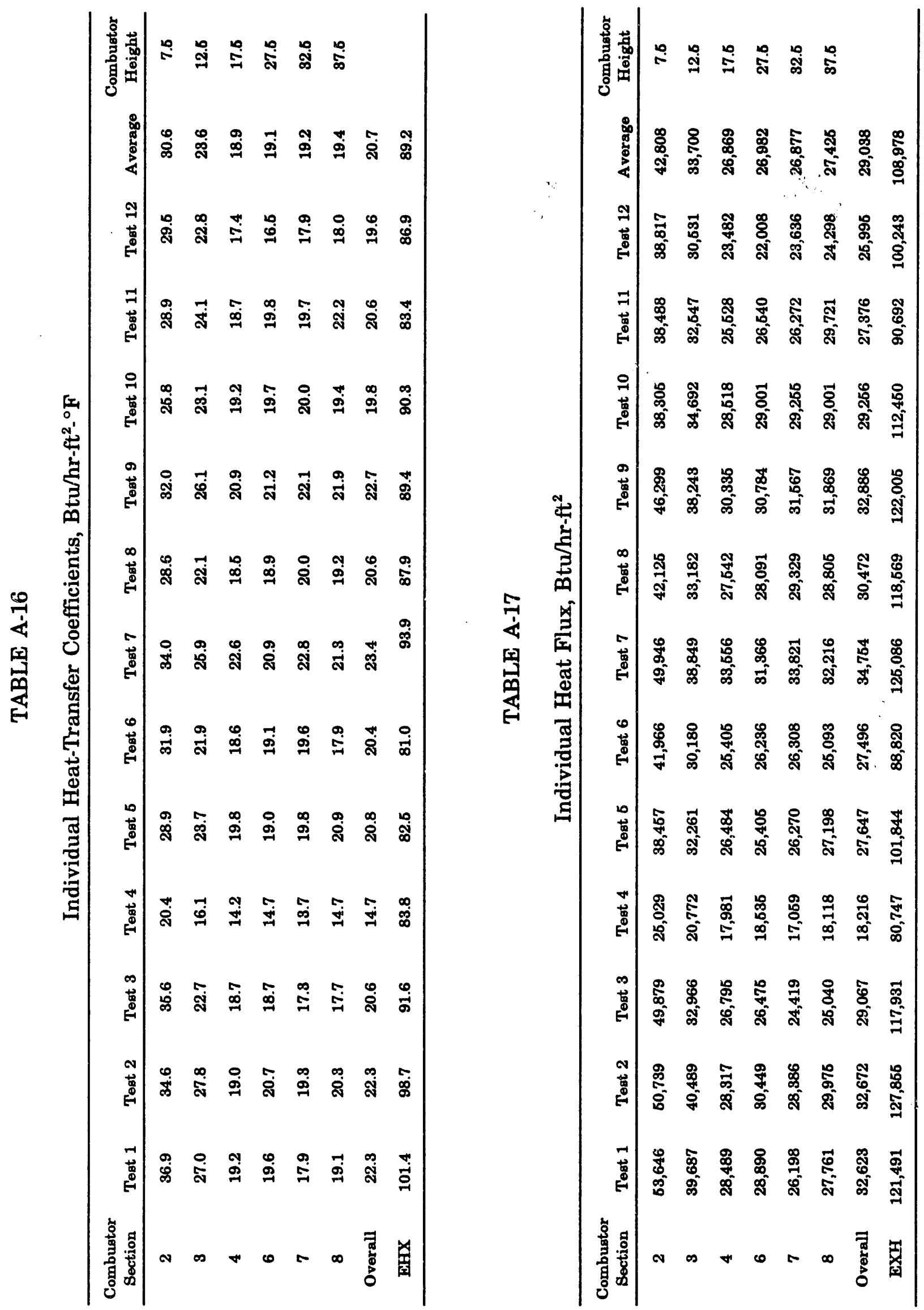
TABLE A-18

Average Heat-Transfer Coefficient, Heat Flux, and Bed Density

\begin{tabular}{ccccc}
\hline Section & $\mathrm{dP}$ (in. $\mathrm{H}_{2} \mathrm{O}$ col.) & $\mathrm{H}_{\circ}\left(\mathrm{Btu} / \mathrm{hr}_{-} \mathrm{ft}^{2}-{ }^{\circ} \mathrm{F}\right)$ & Flux $\left(\mathrm{Btu} / \mathrm{hr}-\mathrm{ft}^{2}\right)$ & Bed Density $\left(\mathrm{lb} / \mathrm{ft}^{9}\right)$ \\
\hline 2 & 38.6 & 30.6 & 38,900 & 40.32 \\
4 & 3.2 & 18.9 & 24,300 & 1.67 \\
6 & 1.5 & 19.0 & 24,400 & 0.78 \\
8 & 0.2 & 18.4 & 22,400 & 0.10 \\
1.8 & 44.2 & 20.7 & 26,400 & \\
\hline
\end{tabular}

One of the expected trends is the decrease in heat-transfer coefficient and heat flux as a function of height (see Figures A-11 and A-12). The overall mass density of bed material in the combustor decreases with combustor height. The decrease in pressure drop with combustor height provides a measure of this decrease in mass density. At the bottom of the combustor, below the secondary air port, there is a relatively dense bed, and high heat fluxes and heat-transfer coefficients similar to those of bubbling beds are present. In the higher velocity region above the secondary air ports, the bed is less dense. This transition from a dense to a dilute bed is common for all CFBCs, irrespective of the type and location of secondary air ports, or if secondary air is used at all. The transition point from dense to dilute bed will change somewhat, however, depending upon the design of the unit. The heat flux and heat-transfer coefficients are expected to follow a similar trend for all units.

The impact of operating conditions on heat transfer can be seen by comparing values from test to test. As load is decreased, the velocity also decreases, causing a decrease in solids recirculation rate and a decrease in the density within the upper regions of the bed. As expected, both the combustor heat flux and heat-transfer coefficients decrease, as shown graphically in Figures A-11 and A-12, respectively, for full and 55\% load situations. Another expected trend is the impact of operating temperature on heat flux. As shown in Figure A-13, the heat flux increases as the average-bed temperature (driving force for heat transfer) increases. The heat-transfer coefficient did not vary with temperature over this range of test conditions.

Other conditions appear to have smaller impacts on the heat flux and heat-transfer coefficients. It should be noted that the differences measured were within the standard deviation of the averages and, therefore, may not be statistically significant. As the $\mathrm{Ca} / \mathrm{S}$ was increased from an average of 2.1 to 4.0 , the heat flux and heat-transfer coefficient decreased. It would be expected that as the limestone feed rate increased, the amount of fine solids would increase, thereby increasing the solids recirculation rate, and increase the heat flux and heat-transfer coefficient. Therefore, this effect may be due to random error in measurement. The other effect noted was a slight increase in the heat flux and heat-transfer coefficient as the primary-to-total air split was increased from an average of $48 \%$ to $67 \%$. This could be a real effect, resulting from more solids in the primary zone being carried into the upper reaches of the combustor as the amount of primary air increased. Higher velocities exist in the primary zone at higher primary air ratios. 


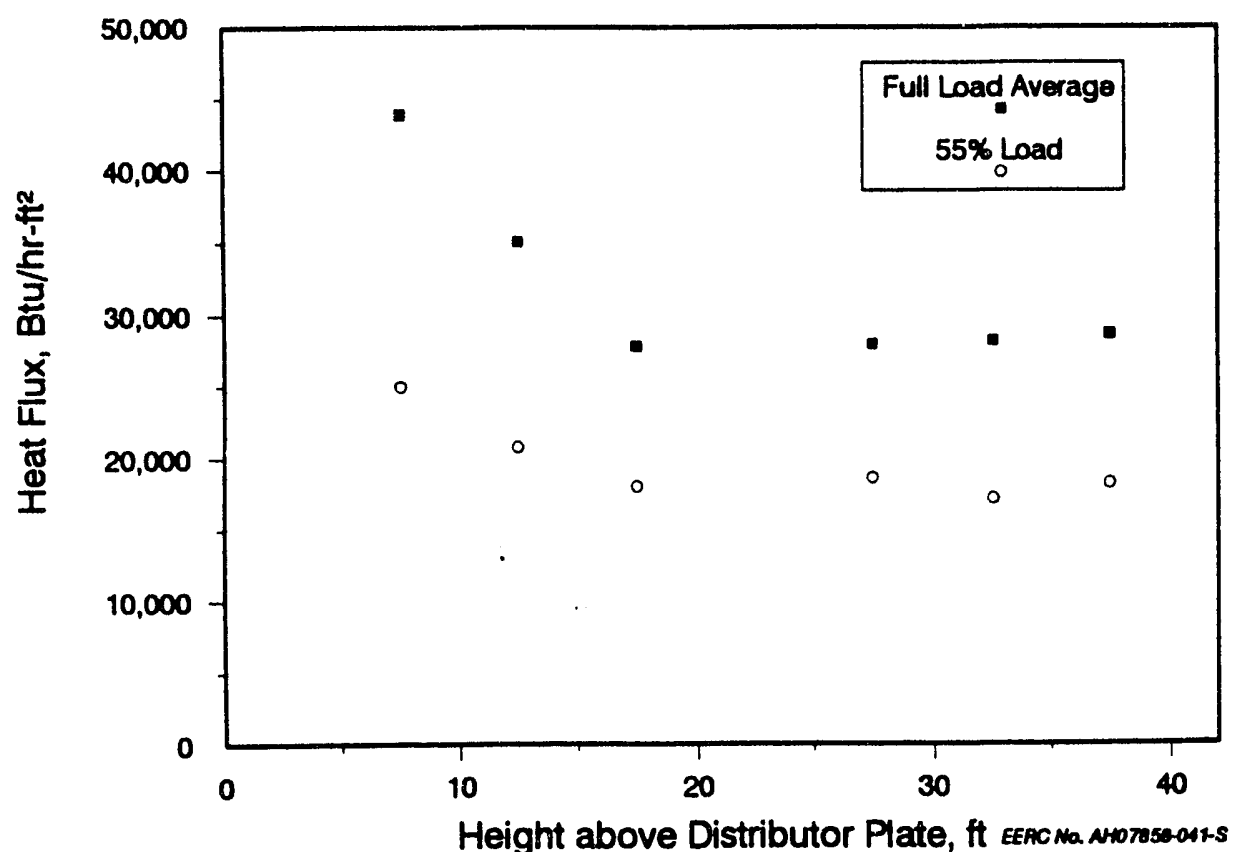

Figure A-11. Heat flux as a function of combustor height.

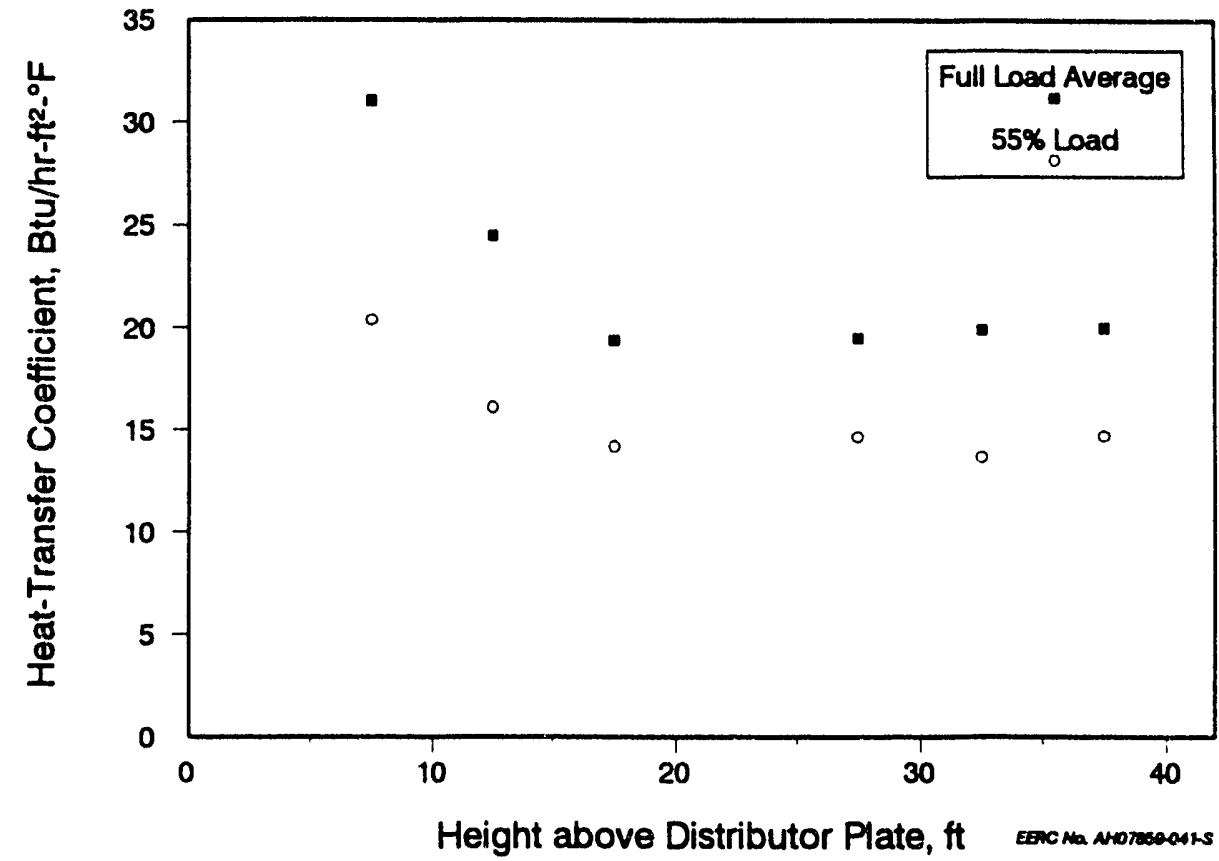

Figure A-12. Heat-transfer coefficient as a function of combustor height. 


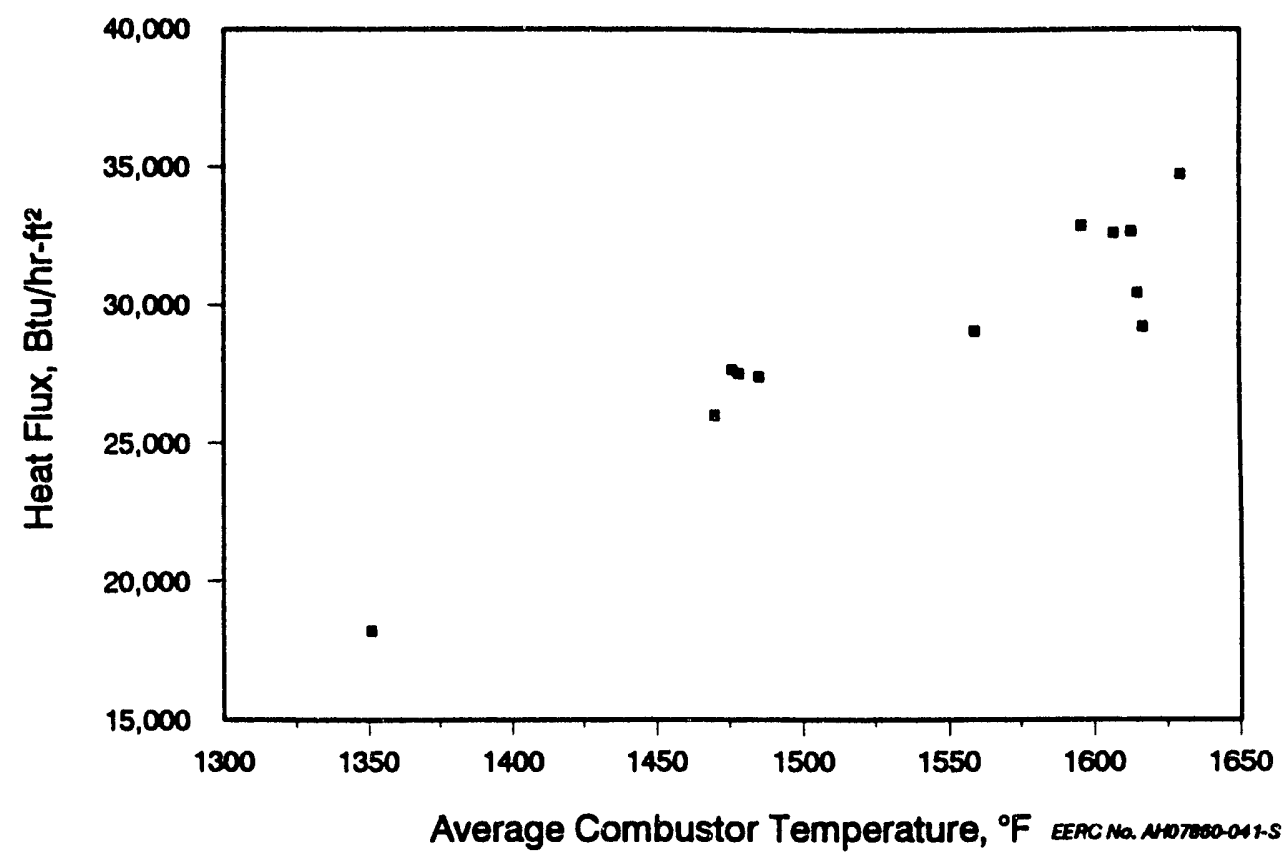

Figure A-13. Heat flux as a function of average bed temperature.

\section{Pressure and Temperature Profiles}

The pressure profiles for the run are shown in Figures A-14 and A-15 and are typical of a circulating fluidized-bed combustor. The figures show a dense phase in the lower portion of the combustor, similar to a bubbling bed, and a dilute phase in the remainder of the combustor. Variations in the pressure profiles from test to test are due to differences in bed inventory and combustor velocity.

Figure A-16 illustrates the temperature profile for the Salt Creek run. The temperature profiles are relatively uniform; areas of lower temperature are caused by heat-transfer doors in those sections of the combustor.

\section{ENVIRONMENTAL PERFORMANCE}

The flue gas emissions for each test period are shown in Table A-19. Figure A-17 shows the average emission levels at different load conditions. Reduced load was obtained by decreasing the coal feed rate to $85 \%$ or $55 \%$ of the full-load feed rate. Heat exchange surfaces in the combustor and external heat exchanger remained constant, so that the temperature in the partial-load conditions dropped accordingly. Excess air (54\%) was allowed to increase during the 55\% load test. Furthermore, superficial gas velocity in the combustor decreased, as a result of lower air flow rates and lower combustor temperatures. The $\mathrm{N}_{2} \mathrm{O}$ emissions were highest at the $55 \%$ load condition, as expected; the formation of $\mathrm{N}_{2} \mathrm{O}$ is inversely proportional to temperature and directly proportional to excess air. $\mathrm{NO}_{\mathrm{x}}$ showed the opposite trend, but to a lesser degree. In terms of the three load tests, the $\mathrm{SO}_{2}$ emissions were lowest during the $85 \%$ load test, when the average temperature was $1559^{\circ} \mathrm{F}$. Calcium utilization was greatest at this temperature, as shown in Table A-19. 


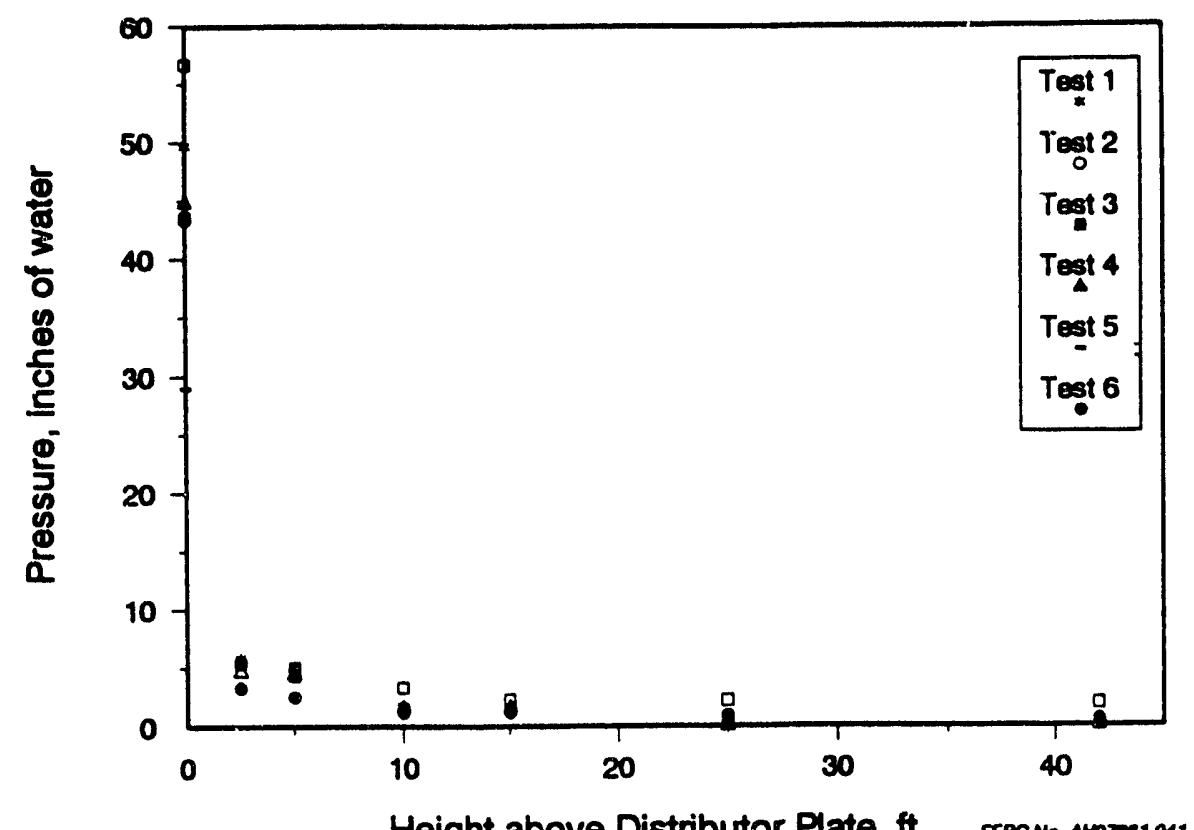

Height above Distributor Plate, ft EACNa. NHotoor-otr-s

Figure A-14. Pressure profiles of Tests 1 through 6.

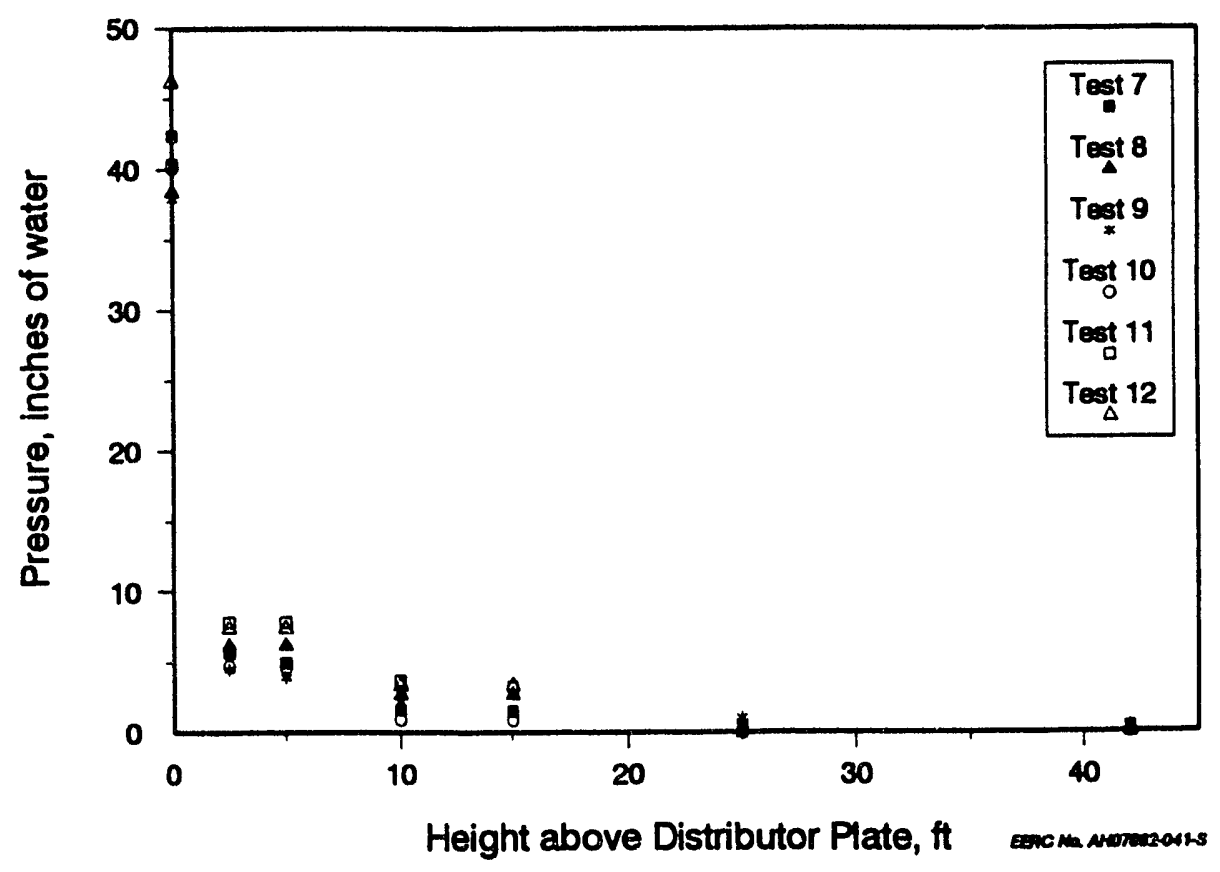

Figure A-15. Pressure profiles of Tests 7 through 12. 


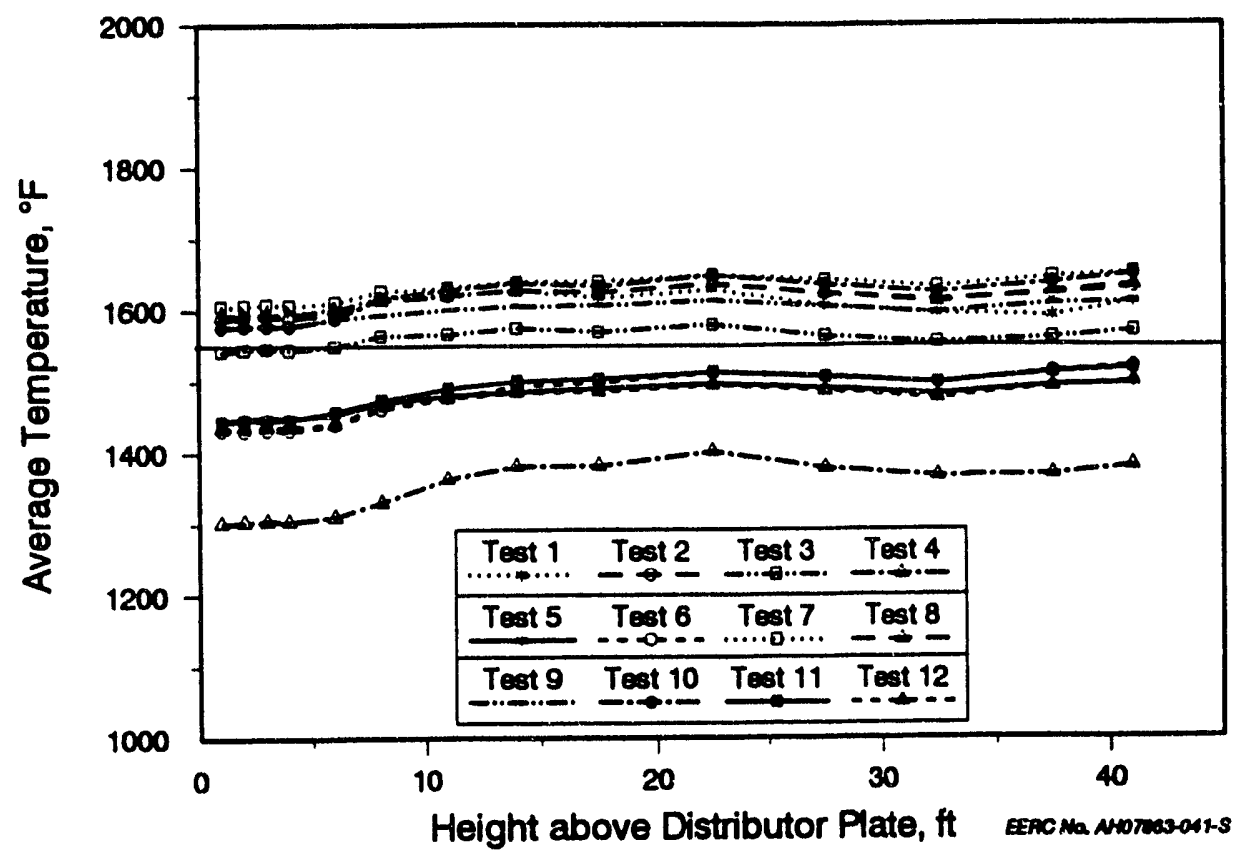

Figure A-16. Temperature profiles of all tests (1 through 12).

\section{$\mathrm{SO}_{2}$ Emissions}

Figure A-18 shows $\mathrm{SO}_{2}$ retention as a function of alkali-to-sulfur (A/S) ratio for fullload Tests 1, 2, and 10, presented as both alkali in the limestone alone as well as total alkali content. These three tests were performed at the same bed temperature, excess air level, and primary air split. $\mathrm{SO}_{2}$ retention increased with greater alkali addition. In order to achieve $70 \%$ retention, an added AVS ratio of about 2.5 would be required at these operating conditions. The average bed temperature of $1625^{\circ} \mathrm{F}$ used for these tests is above the optimal temperature window for sulfur capture $\left(1500^{\circ}\right.$ to $\left.1550^{\circ} \mathrm{F}\right)$. Therefore, lower add rates of sorbent would be needed to meet $70 \%$ retention within the optimal sulfur capture window. About $7 \%$ to $10 \%$ of the sulfur retention was due to the alkali inherent to the coal.

Figure A-19 presents the sulfur retention as a function of total alkali-to-sulfur ratio for all of the tests, with the exception of the 55\% load test. The increase in sulfur retention with increasing A/S ratio is evident. Also important is the effect of temperature on sulfur retention. At a given AVS ratio, the lowest retention was obtained at $1613^{\circ}$, higher at $1417^{\circ}$, and the highest at $1559^{\circ} \mathrm{F}$. This trend is as expected, as the optimal sulfur capture is usually achieved in the range of $1500^{\circ}$ to $1550^{\circ} \mathrm{F}$. The impact of alkalito-sulfur ratio and temperature on $\mathrm{SO}_{2}$ emissions is shown in Figure A-20.

Figure A-21 shows that the calcium utilization was greatest at a low calcium-tosulfur ratio, decreased as $\mathrm{Ca} / \mathrm{S}$ ratio was increased to about 3.0, then leveled off at a calcium utilization of about $20 \%$ with increasing $\mathrm{Ca} / \mathrm{S}$. This is the normal trend for any calcium-based sulfur control system. At low $\mathrm{Ca} / \mathrm{S}$ ratios, only a portion of the sulfur is captured, so there is a relatively high driving force. As the $\mathrm{Ca} / \mathrm{S}$ ratio increases, more sulfur is captured and less is available in the gas stream for capture, thereby reducing the sulfur concentration driving force. 


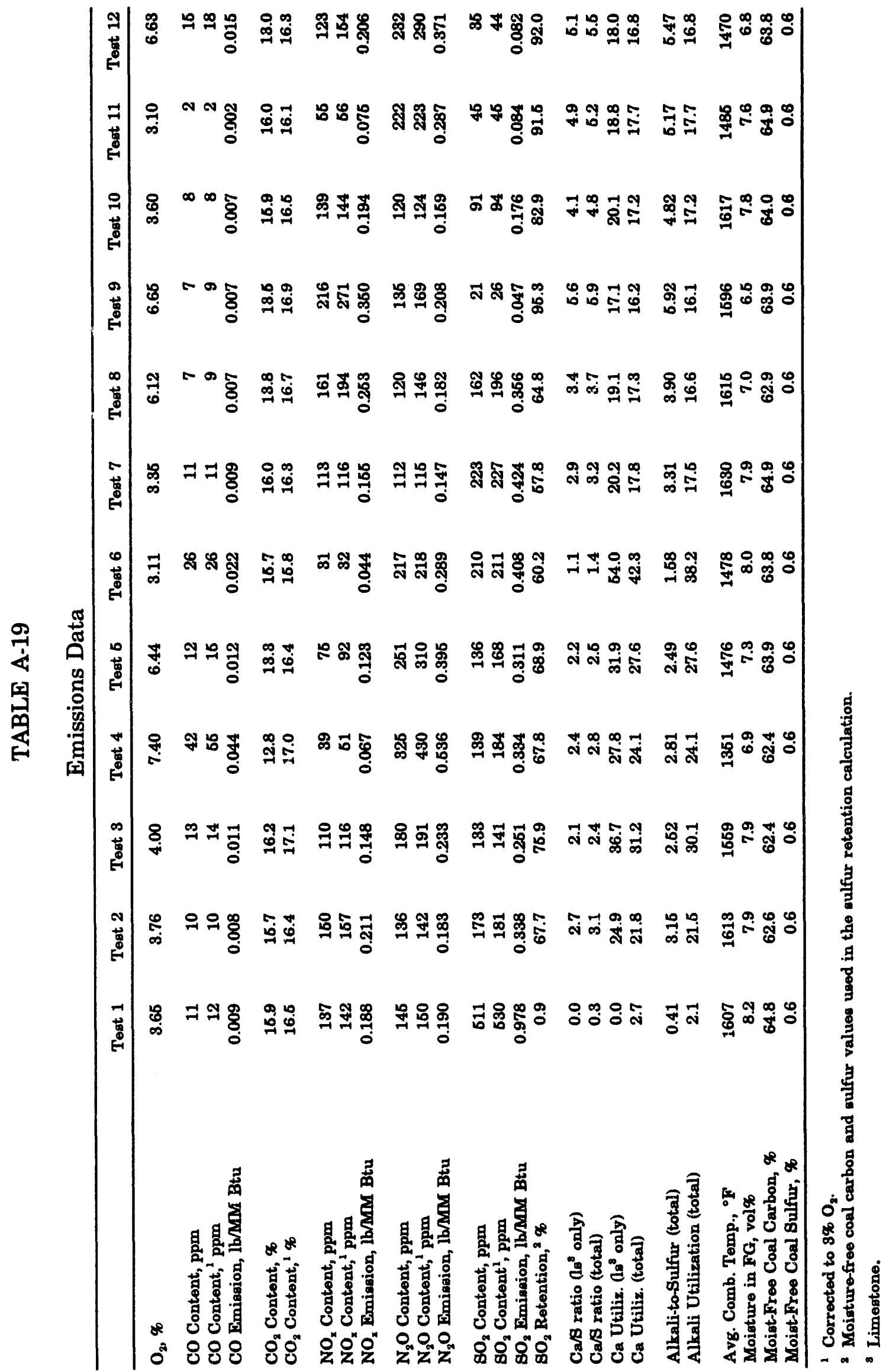




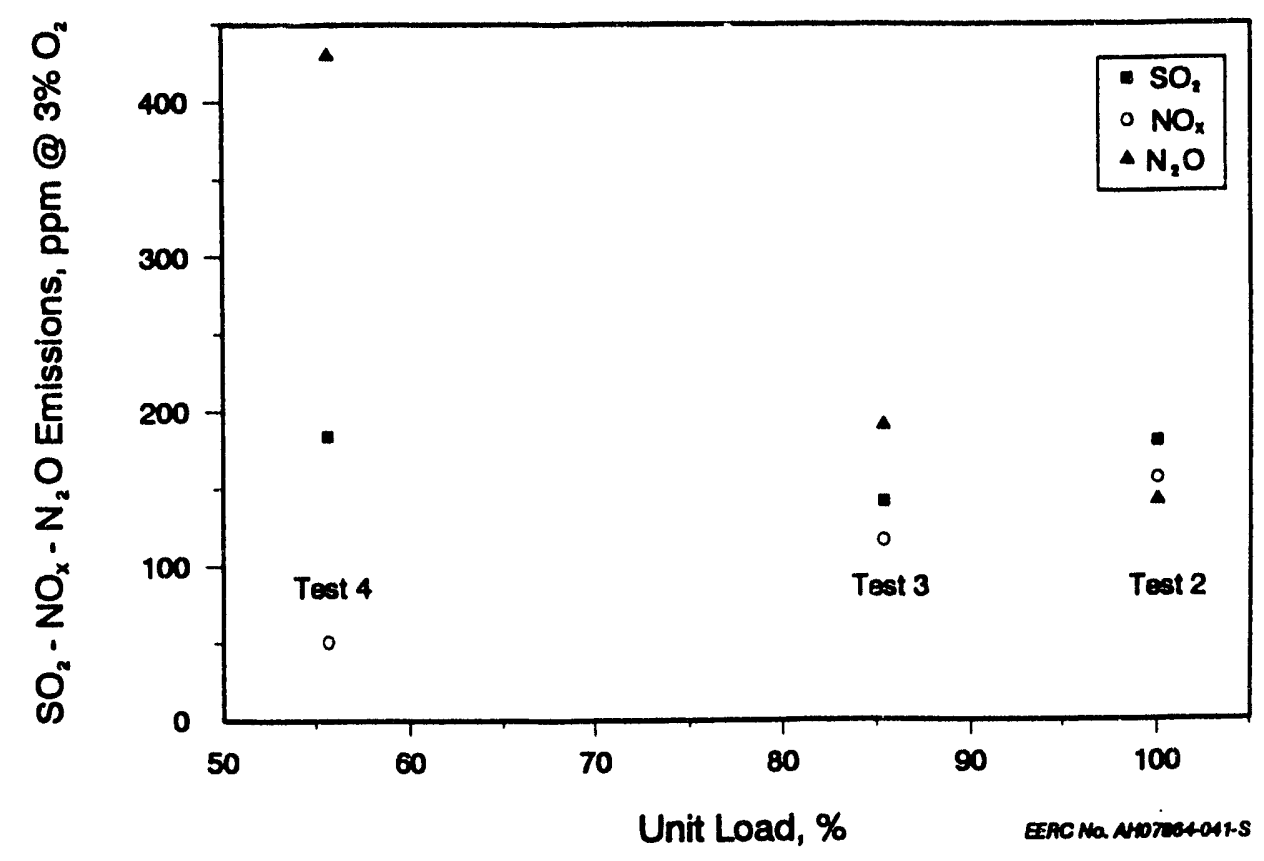

Figure A-17. Flue gas emissions as functions of load.

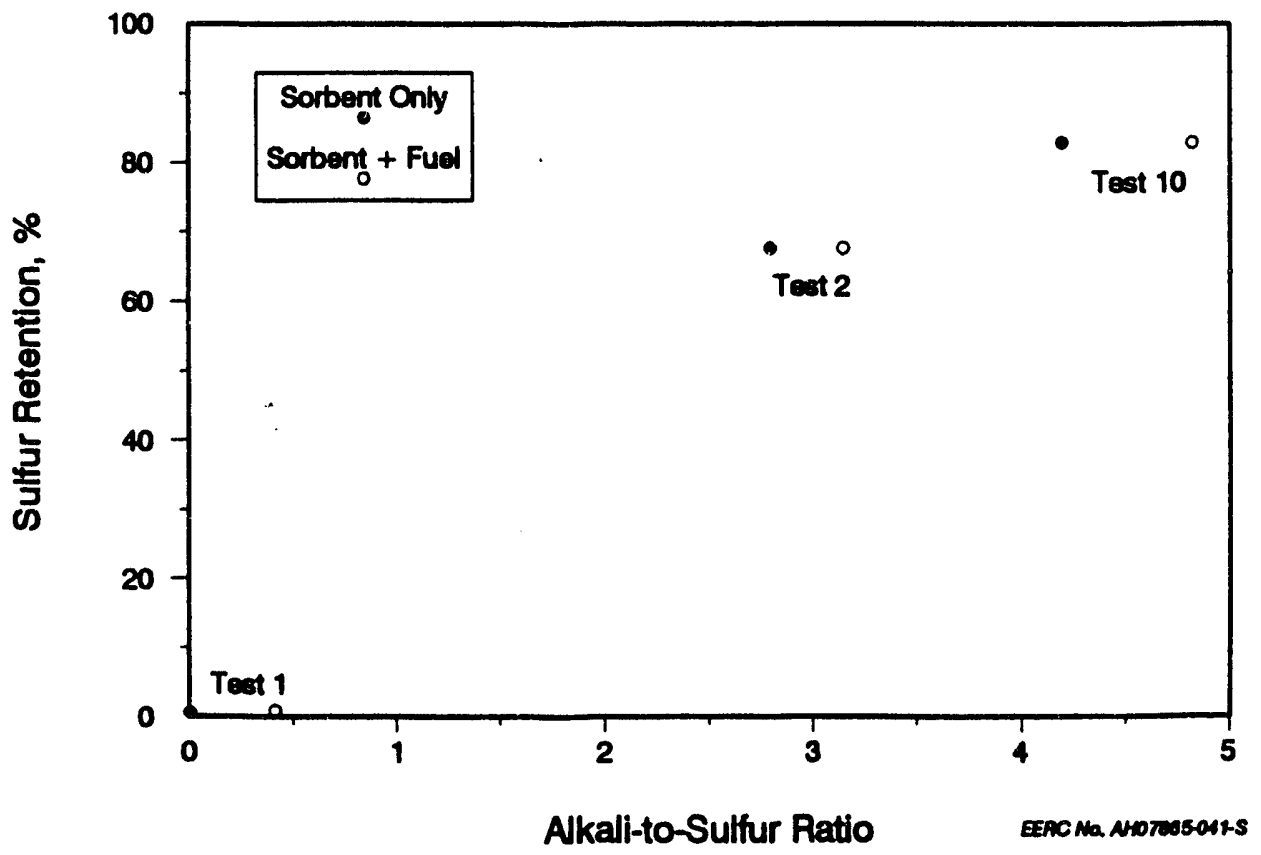

Figure A-18. $\mathrm{SO}_{2}$ retention as a function of alkali-to-sulfur ratio for Tests 1,2 , and 10 . 


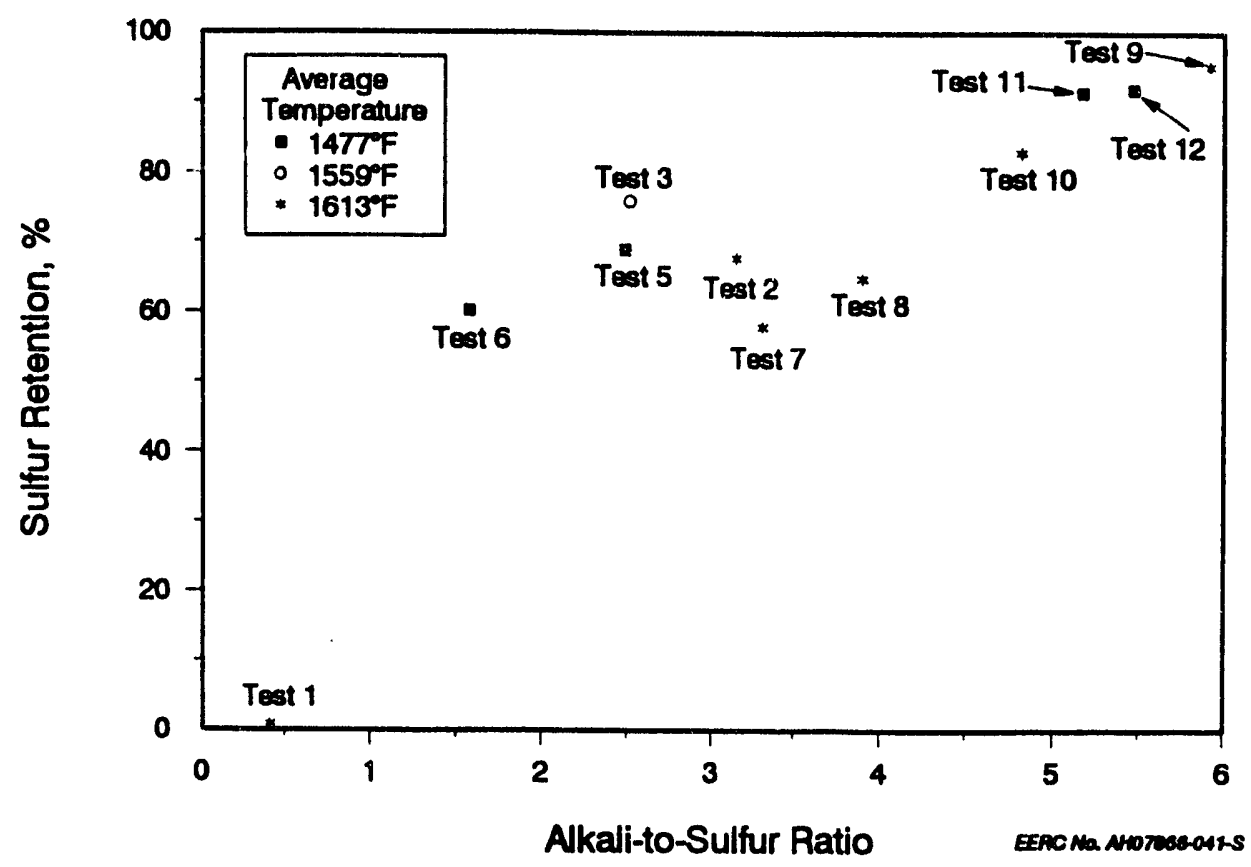

Figure A-19. Sulfur retention as a function of total alkali-to-sulfur ratio for all tests except the $55 \%$ load test.

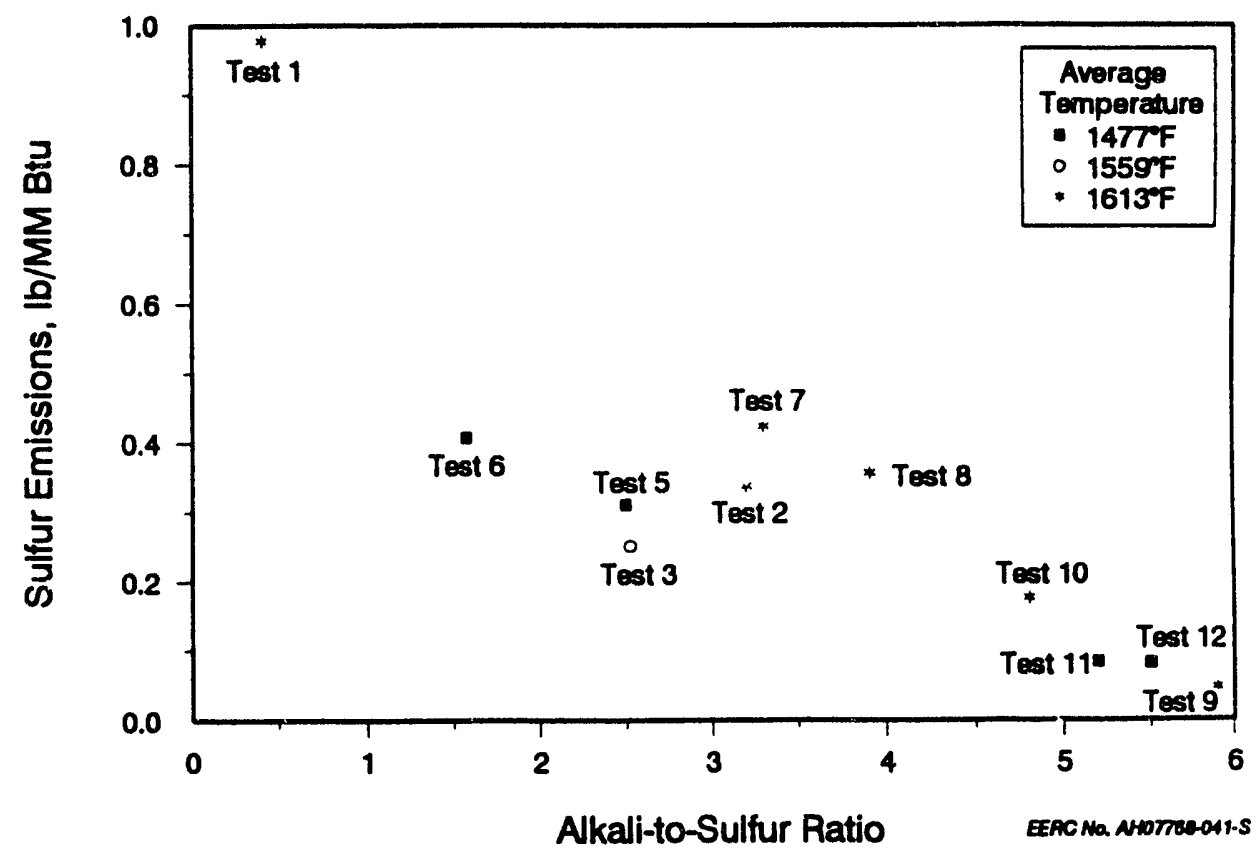

Figure A-20. Impact of alkali-to-sulfur ratio and temperature on sulfur emissions. 


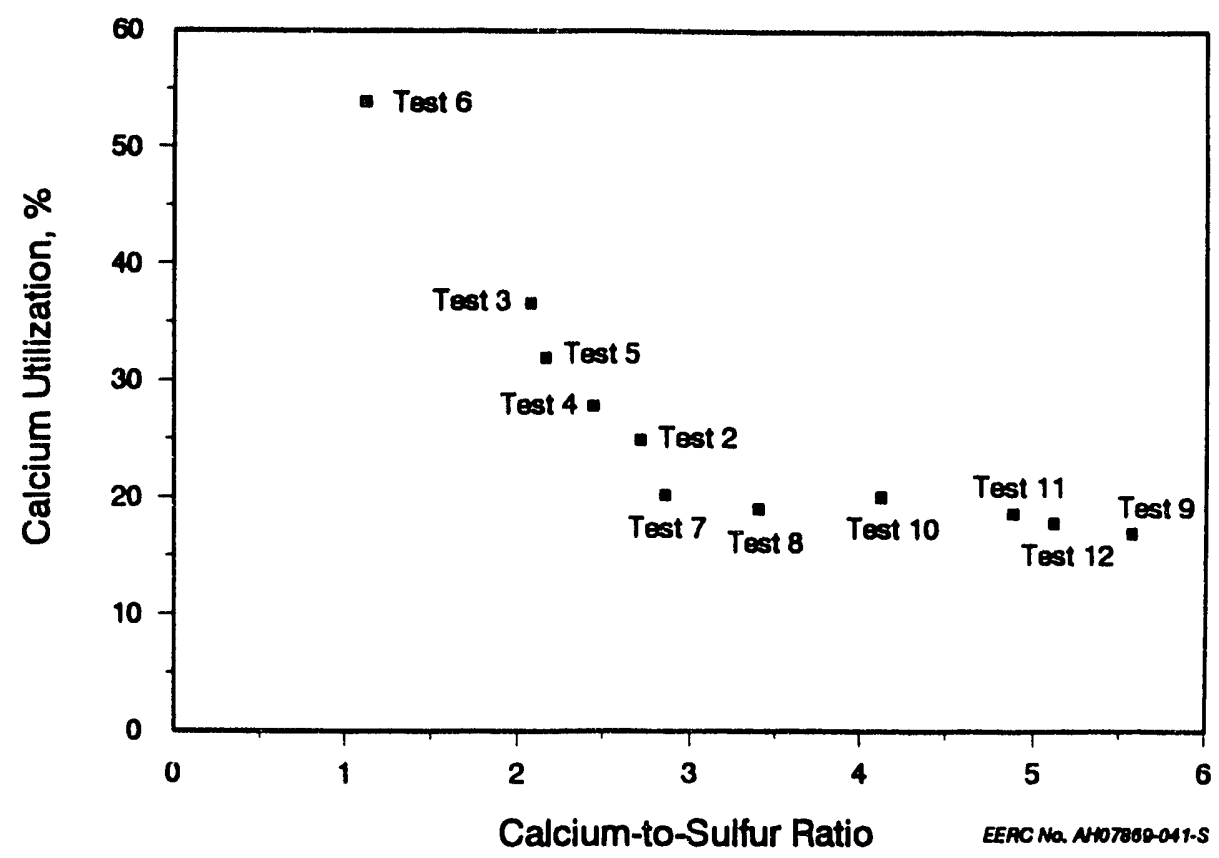

Figure A-21. Calcium utilization as a function of added calcium-to-sulfur ratio.

NO Emissions

$\mathrm{NO}_{\mathrm{x}}$ emissions ranged from 32 to $271 \mathrm{ppm}(0.04$ to $0.35 \mathrm{lb} / \mathrm{MM} \mathrm{Btu}$ ), corrected to $3 \%$ $\mathrm{O}_{2}$. $\mathrm{NO}_{\mathrm{x}}$ emissions are dependent upon several factors, including temperature, oxygen content, and alkali-to-sulfur ratio. Figure A-22 shows some of these effects. At low temperature and low excess air (oxygen content), the $\mathrm{NO}_{\mathrm{x}}$ levels were predictably low. $\mathrm{NO}_{\mathrm{z}}$ increased with an increase in temperature and/or an increase in excess air. High temperature and high excess air produced the greatest $\mathrm{NO}_{\mathrm{x}}$ emissions. In each temperature-excess air system, more $\mathrm{NO}_{2}$ was released at the higher calcium-to-sulfur ratio. These trends are similar to those produced in other FBC systems, both bubbling and circulating designs.

\section{$\mathrm{N}_{2} \mathrm{O}$ Emissions}

$\mathrm{N}_{2} \mathrm{O}$ emissions were greatest at low temperature, as shown in Figure A-23. The effect of excess air on $\mathrm{N}_{2} \mathrm{O}$ emissions is negligible at high temperature (greater than $1500^{\circ} \mathrm{F}$ ); however, at lower temperature, the $\mathrm{N}_{2} \mathrm{O}$ emissions are significantly greater at the higher level of excess air. This trend is evident at a temperature of approximately $1475^{\circ} \mathrm{F}$ in Figure A-23, although the test matrix did not include a low temperature $\left(1350^{\circ} \mathrm{F}\right.$ )-low excess air $(20 \%)$ operating condition to verify the trend. Values of $\mathrm{N}_{3} \mathrm{O}$, corrected to $3 \% \mathrm{O}_{2}$, ranged from 115 to $430 \mathrm{ppm}(0.15$ to $0.54 \mathrm{lb} / \mathrm{MM} \mathrm{Btu})$. Currently, there are no federal standards controlling $\mathrm{N}_{2} \mathrm{O}$ emissions.

\section{CO Emissions}

Table A-19 indicated that the $\mathrm{CO}$ emissions from all tests were very low (2 to 55 ppm corrected to $3 \% \mathrm{O}_{2}$ ). Figure $\mathrm{A}-24$ is a graph of the CO concentration corrected to $3 \%$ $\mathrm{O}_{2}$ as a function of temperature which shows that the $\mathrm{CO}$ emissions were greatest at low temperatures, as expected. 


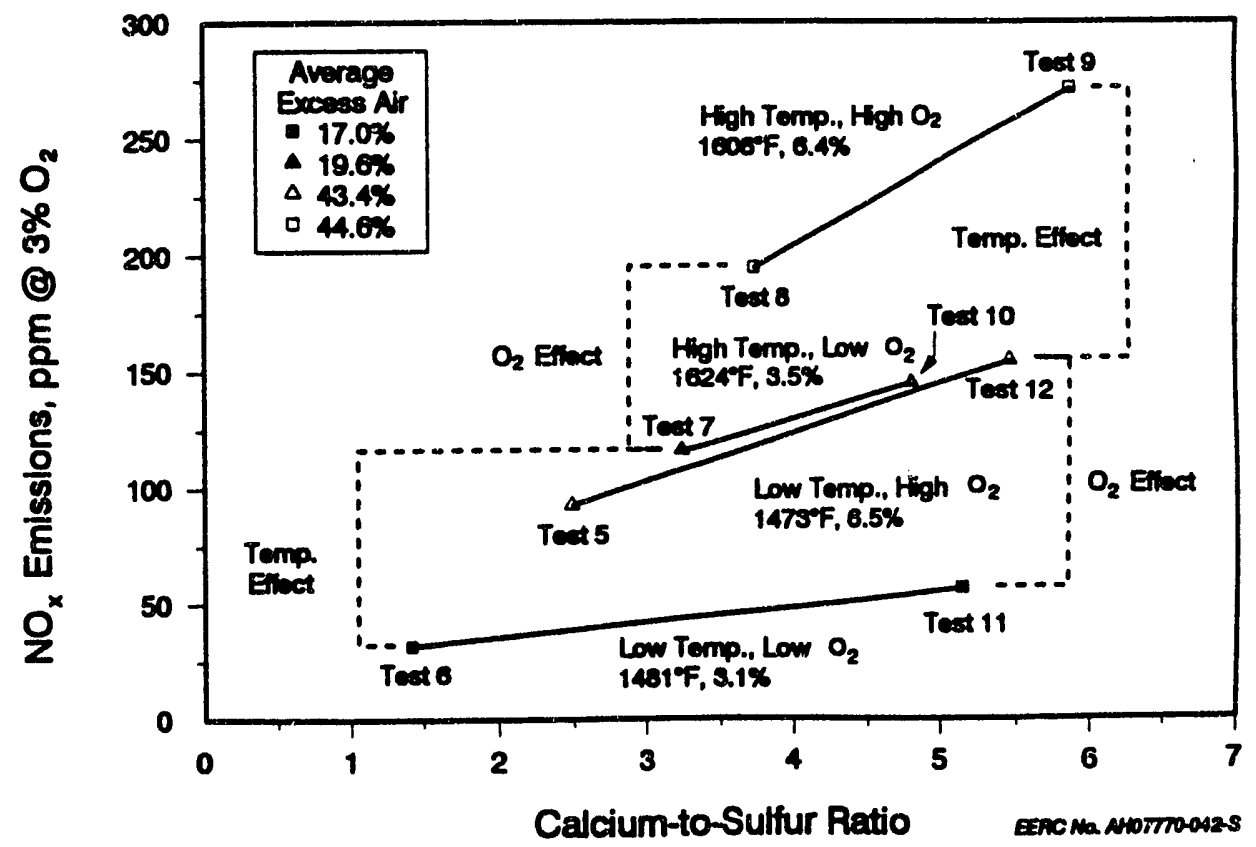

Figure A-22. The effects of calcium-to-sulfur ratio, excess air, and temperature on $\mathrm{INO}_{\mathrm{x}}$ emissions.

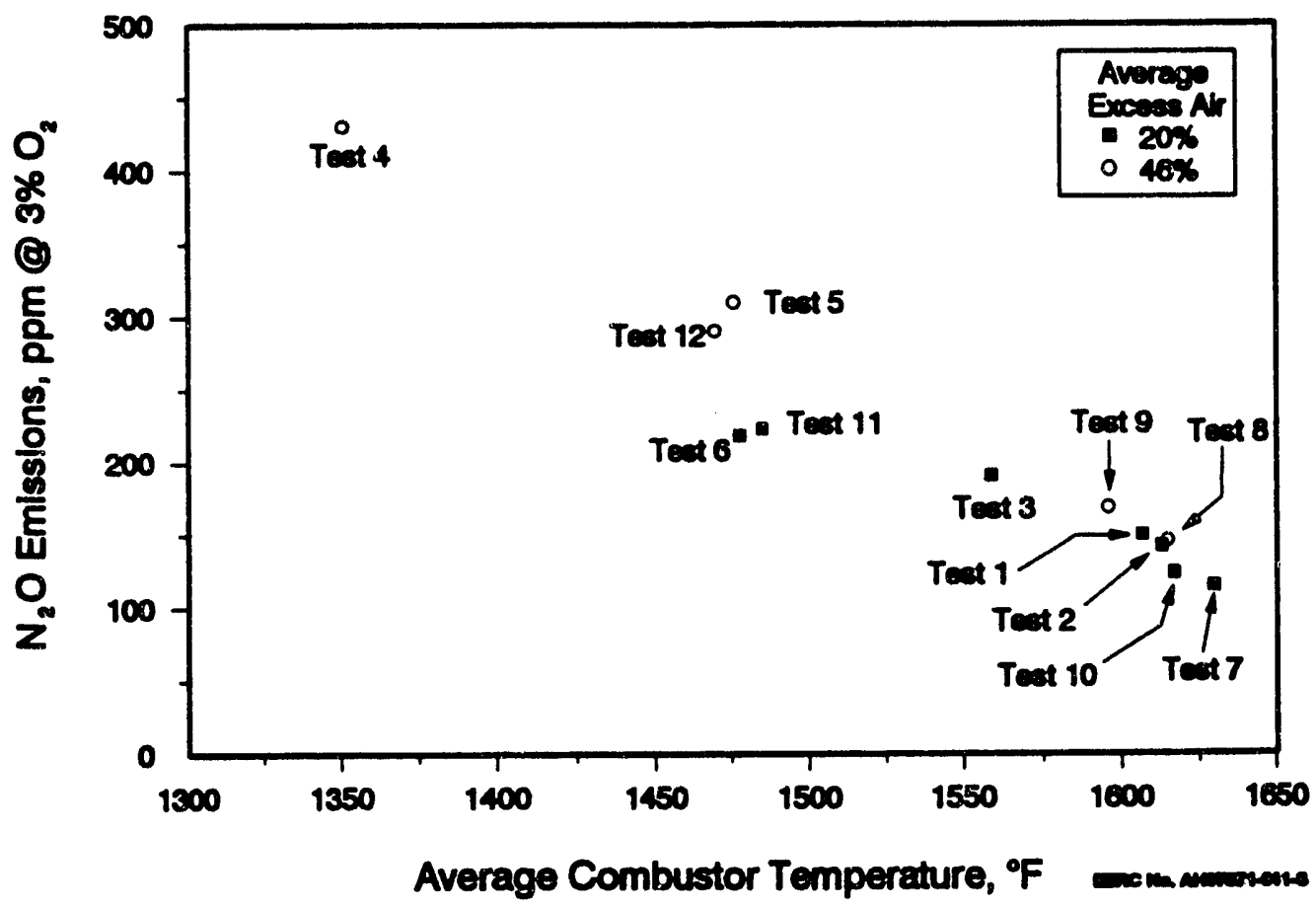

Figure A-23. The effects of temperature and excess air on $\mathrm{N}_{2} \mathrm{O}$ emissions. 


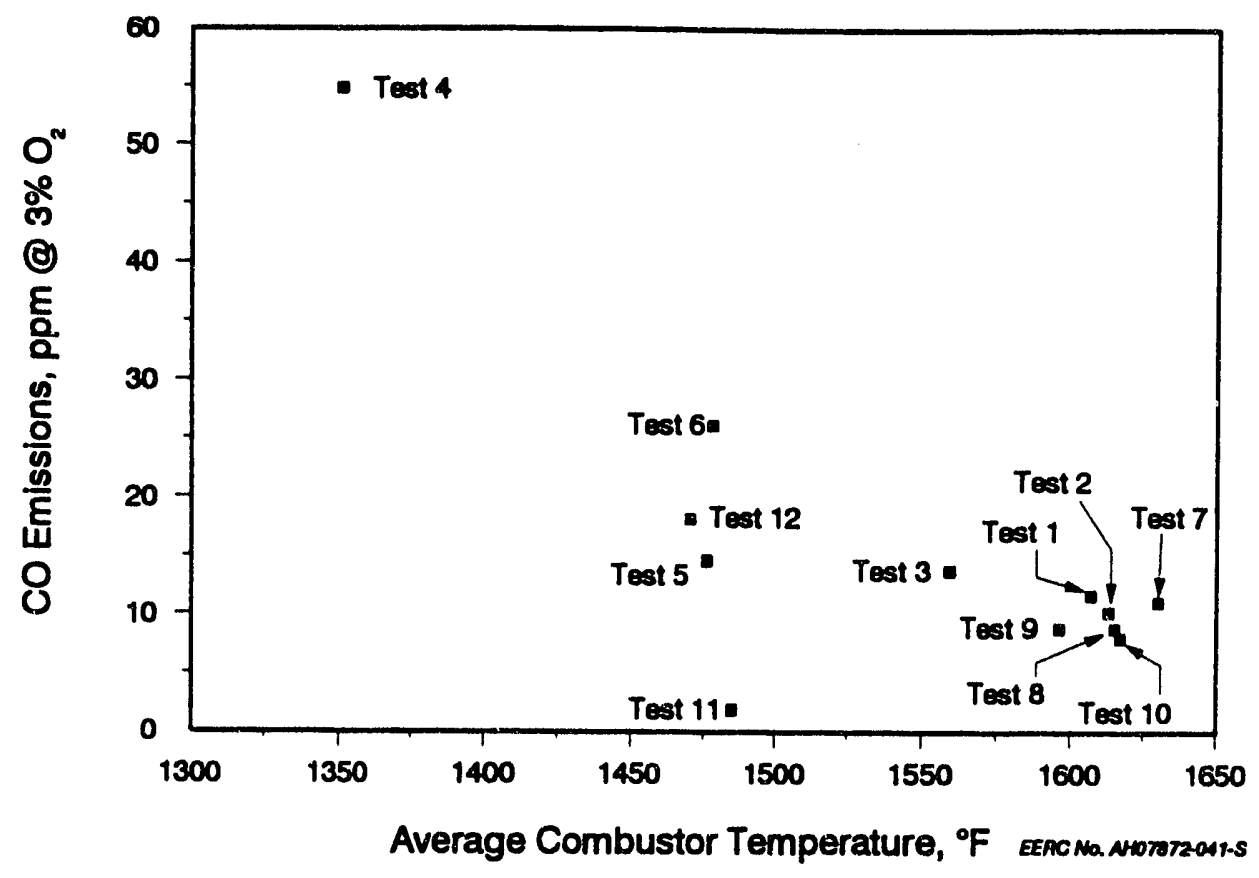

Figure A-24. CO emissions as a function of temperature.

\section{SUMMARIES OF TEST DATA}

This section contains the summaries of test data for each test period, including averages and standard deviations of many of the data points recorded by the computerized data acquisition system. 


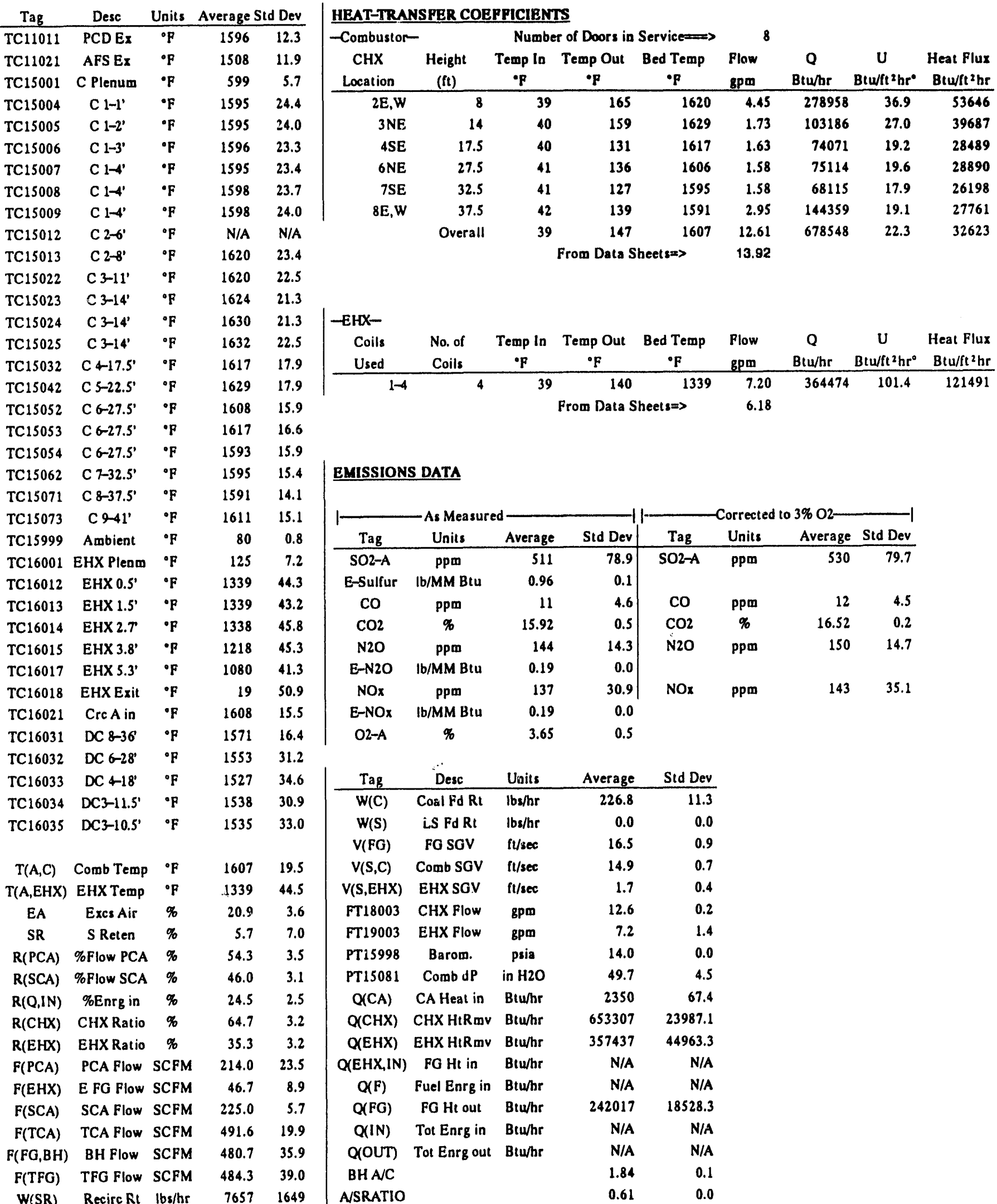




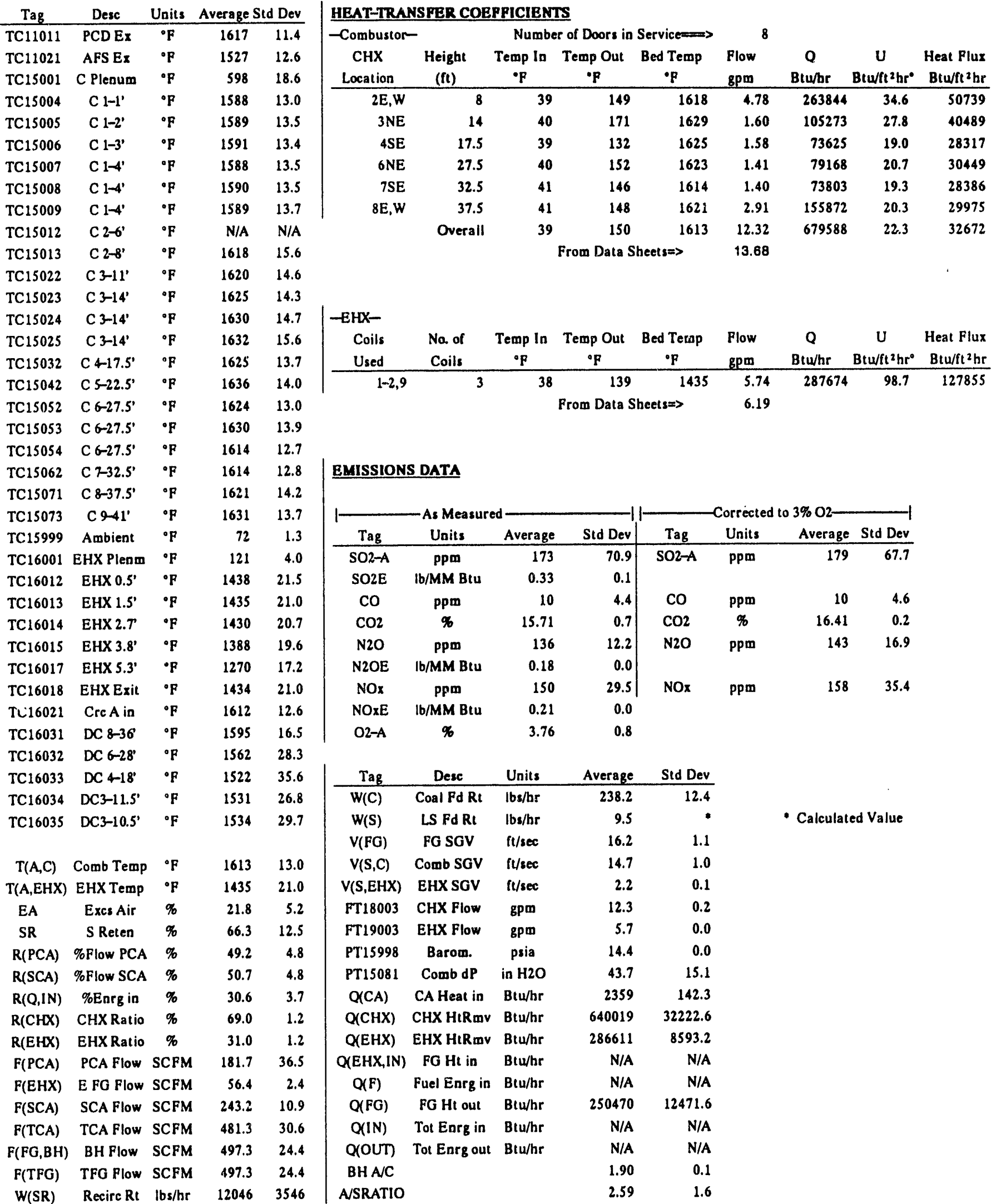




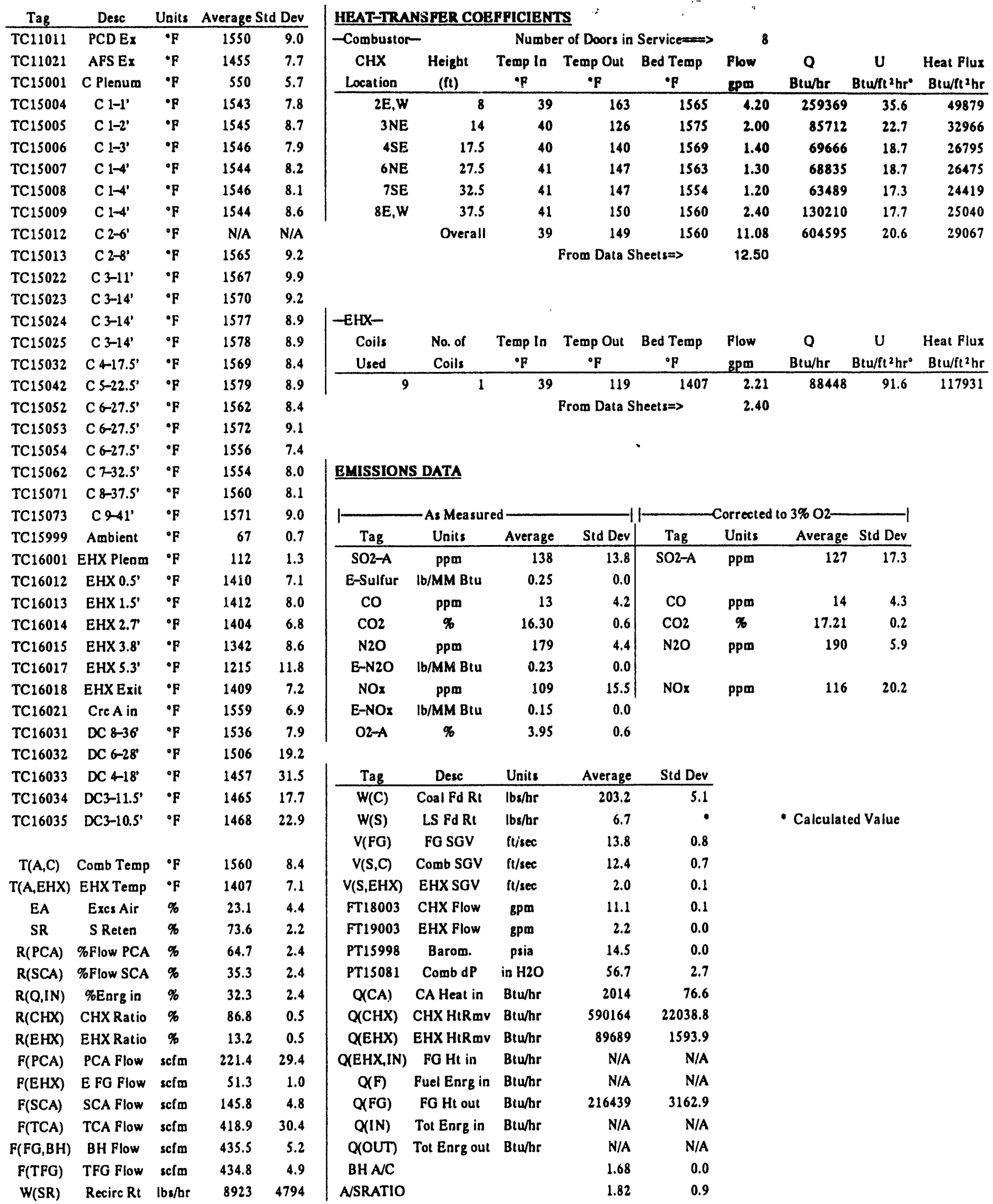




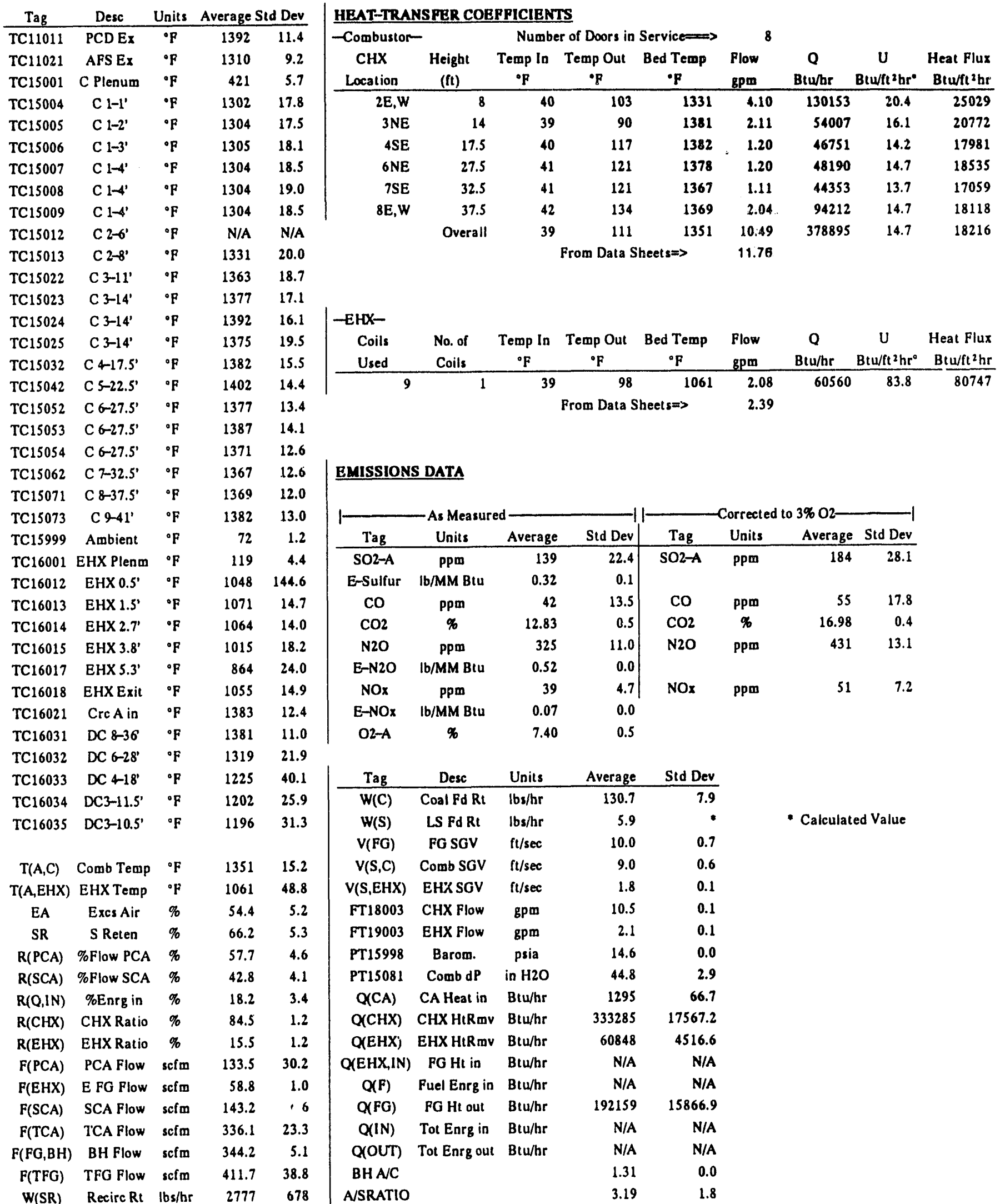




\begin{tabular}{|c|c|c|c|c|c|c|c|c|c|c|c|c|c|}
\hline \multirow{3}{*}{$\frac{\text { Tag }}{\text { TC11011 }}$} & \multirow{2}{*}{$\frac{\text { Desc }}{\text { PCD Ex }}$} & \multirow{2}{*}{$\frac{\text { Units }}{{ }^{\circ} \mathbf{F}}$} & \multicolumn{2}{|c|}{ Average Std Dev } & \multicolumn{9}{|c|}{ HRAT-TRANSPER COEPPICIENTS } \\
\hline & & & 1482 & 14.3 & \multicolumn{2}{|c|}{ Combustor- } & \multicolumn{3}{|c|}{ Number of Doors in Service $\Longrightarrow$} & \multicolumn{2}{|l|}{8} & \multirow{3}{*}{$\begin{array}{c}U \\
\text { Btufft }{ }^{2} h r^{\circ}\end{array}$} & \multirow{3}{*}{$\begin{array}{l}\text { Heat Flux } \\
\text { Btu/ft'hr }\end{array}$} \\
\hline & AFS Ex & $\cdot \mathbf{F}$ & 1405 & 12.6 & $\mathrm{CHX}$ & Height & Temp In & Temp Out & Bed Temp & Plow & $\mathbf{Q}$ & & \\
\hline TC15001 & C Plenum & ${ }^{\circ} \mathbf{F}$ & 601 & 6.2 & Location & (fi) & $\bullet \mathbf{p}$ & $\bullet \mathbf{P}$ & $\bullet \boldsymbol{P}$ & gpo & Btw/hr & & \\
\hline TC15004 & C 1-1' & 'F & 1446 & 12.2 & $2 E, W$ & 8 & 39 & 140 & 1471 & 3.96 & 199974 & 28.9 & 38457 \\
\hline TC15005 & C $1-2^{\prime}$ & ${ }^{\circ} \mathbf{F}$ & 1449 & 12.4 & $3 N E$ & 14 & 39 & 123 & 1487 & 2.00 & 83879 & 23.7 & 32261 \\
\hline TC15006 & C $1-3$ & ${ }^{\circ} \mathbf{F}$ & 1450 & 12.7 & 4SE & 17.5 & 40 & 155 & 1491 & 1.20 & 68857 & 19.8 & 26484 \\
\hline TC15007 & C 1-4' & ${ }^{\circ} \mathbf{p}$ & 1448 & 12.7 & 6NE & 27.5 & 40 & 150 & 1490 & 1.20 & 66053 & 19.0 & 25405 \\
\hline $\mathrm{TC} 15008$ & C 1-4' & ${ }^{\circ} \mathrm{F}$ & 1451 & 12.5 & 7SE & 32.5 & 41 & 155 & 1482 & 1.20 & 68302 & 19.8 & 26270 \\
\hline TC15009 & C 1-4' & ${ }^{\circ} \mathrm{F}$ & 1448 & 11.8 & $8 \mathrm{E}, \mathrm{W}$ & 37.5 & 42 & 191 & 1494 & 1.90 & 141432 & 20.9 & 27198 \\
\hline TC15012 & C 2-6' & ${ }^{\circ} \mathbf{P}$ & N/A & N/A & & Overall & 40 & 150 & 1476 & 10.48 & 575066 & 20.8 & 27647 \\
\hline $\mathrm{TC} 15013$ & C 2-8' & ${ }^{\circ} \mathrm{P}$ & 1471 & 16.7 & & & \multicolumn{3}{|c|}{ From Data Sheetsm> } & 11.46 & & & \\
\hline TC15022 & C 3-11' & ${ }^{\circ} \mathrm{F}$ & 1480 & 15.3 & & & & & & & & & \\
\hline TC15023 & C 3-14' & ${ }^{\circ} \mathrm{F}$ & 1485 & 15.6 & & & & & & & & & \\
\hline TC15024 & C 3-14' & ${ }^{\circ} \mathrm{F}$ & 1487 & 14.6 & $-\mathrm{EHX}-$ & & & & & & & & \\
\hline TC15025 & C 3-14' & ${ }^{\circ} \mathrm{F}$ & 1488 & 16.7 & Coils & No. of & Temp In & Temp Out & Bed Temp & Flow & $\mathbf{Q}$ & $\mathrm{U}$ & Heat Flux \\
\hline TC15032 & C 4-17.5' & ${ }^{\circ} \mathbf{F}$ & 1491 & 16.2 & Used & Coils & ${ }^{\circ} \mathbf{F}$ & ${ }^{\circ} \mathrm{F}$ & ${ }^{\circ} \mathrm{F}$ & gpw & Btu/hr & Btu/ft ${ }^{2} \mathrm{hr}^{\circ}$ & $\mathrm{Btu} / \mathrm{ft}^{2} \mathrm{hr}$ \\
\hline TC15042 & C 5-22.5' & ${ }^{\circ} \mathrm{F}$ & 1497 & 15.8 & $1-2,8,9$ & 4 & 39 & 123 & 1358 & 7.24 & 305532 & 82.5 & 101844 \\
\hline $\mathrm{TC} 15052$ & C 6-27.5' & ${ }^{\circ} \mathbf{F}$ & 1492 & 16.1 & \multicolumn{5}{|c|}{ From Data Sheets $\Rightarrow$} & 7.74 & & & \\
\hline TC15053 & C 6-27.5' & ${ }^{\circ} \mathbf{F}$ & 1494 & 16.1 & & & & & & & & & \\
\hline TC15054 & C 6-27.5' & ${ }^{\circ} \mathrm{F}$ & 1483 & 14.3 & & & & & & & & & \\
\hline $\mathrm{TC} 15062$ & C 7-32.5' & ${ }^{\circ} \mathrm{F}$ & 1482 & 14.4 & \multicolumn{2}{|c|}{ EMISSIONS DATA } & & & & & & & \\
\hline $\mathrm{TC} 15071$ & C 8-37.5' & ${ }^{\circ} \mathrm{F}$ & 1494 & 16.2 & & & & & & & & & \\
\hline TC15073 & C $9-41^{\prime}$ & ${ }^{\circ} \mathbf{F}$ & 1498 & 16.1 & \multicolumn{4}{|c|}{-As Measured - } & \multicolumn{4}{|c|}{ Corrected to $3 \%$ O2 } & \\
\hline TC15999 & Ambient & ${ }^{\circ} \mathbf{F}$ & 74 & 1.3 & Tag & Units & Average & Std Dev & Tag & Units & Average & Std Dev & \\
\hline TC16001 & EHX Plenm & ${ }^{\circ} \mathrm{F}$ & 103 & 4.4 & SO2-A & $\overline{p p m}$ & 136 & 10.3 & SO2-A & ppm & 168 & 11.8 & \\
\hline TCl6012 & EHX 0.5' & ${ }^{\circ} \mathbf{F}$ & 1365 & 13.4 & E-Sulfur & $\mathrm{lb} / \mathrm{MM} \mathrm{Btu}$ & 0.31 & 0.0 & & & & & \\
\hline $\mathrm{TCl} 16013$ & EHX 1.5' & ${ }^{\bullet} \mathbf{F}$ & 1358 & 12.2 & $\mathrm{CO}$ & ppm & 12 & 4.1 & $\mathrm{CO}$ & ppm & 15 & 5.3 & \\
\hline $\mathrm{TC} 16014$ & EHX 2.7 & ${ }^{\circ} \mathrm{p}$ & 1353 & 14.3 & $\mathrm{CO} 2$ & $\%$ & 13.31 & 0.6 & $\mathrm{CO} 2$ & $\%$ & 16.45 & 0.2 & \\
\hline TC16015 & EHX 3.8' & ${ }^{\circ} \mathbf{F}$ & 1247 & 23.0 & $\mathrm{~N} 2 \mathrm{O}$ & ppm & 251 & 5.1 & $\mathrm{~N} 2 \mathrm{O}$ & ppm & 310 & 12.3 & \\
\hline TC16017 & EHX 5.3' & ${ }^{\circ} \mathrm{F}$ & 1100 & 22.0 & $\mathrm{E}-\mathrm{N} 2 \mathrm{O}$ & $\mathrm{lb} / \mathbf{M M} \mathrm{Btu}$ & 0.39 & 0.0 & & & & & \\
\hline TC16018 & EHX Exit & ${ }^{\circ} \mathbf{P}$ & 1331 & 10.4 & NOx & ppm & 75 & 9.0 & NOx & ppm & 93 & 13.8 & \\
\hline TC16021 & Crc $A$ in & ${ }^{\circ} \mathrm{F}$ & 1490 & 15.9 & E-NOx & Ib/MM Btu & 0.12 & 0.0 & & & & & \\
\hline TC16031 & DC $8-36^{\prime}$ & ${ }^{\circ} \mathrm{F}$ & 1476 & 15.0 & O2-A & $\%$ & 6.44 & 0.6 & & & & & \\
\hline TC16032 & DC 6-28 & ${ }^{\circ} \mathrm{F}$ & 1460 & 19.3 & & & & & & & & & \\
\hline $\mathrm{TC} 16033$ & DC 4-18' & ${ }^{\circ} \mathrm{F}$ & 1425 & 29.2 & Tag & Desc & Units & Average & Std Dev & & & & \\
\hline $\mathrm{TC} 16034$ & DC3-11.5' & ${ }^{\circ} \mathbf{p}$ & 1437 & 24.3 & $W(C)$ & Coal Fd Rt & lbs/hr & 211.9 & 10.9 & & & & \\
\hline TC16035 & DC3-10.5' & ${ }^{\circ} \mathrm{F}$ & 1437 & 26.0 & $\mathbf{W}(\mathbf{S})$ & LS Fd Rt & lbs/hr & 7.0 & * & & - Calculate & ed Value & \\
\hline & & & & & $V(F G)$ & FG SGV & $\mathrm{ft} / \sec$ & 16.0 & 0.5 & & & & \\
\hline $\mathrm{T}(\mathrm{A}, \mathrm{C})$ & Comb Temp & ${ }^{\circ} \mathrm{F}$ & 1476 & 14.4 & $V(S, C)$ & Comb SGV & $\mathrm{ft} / \mathrm{sec}$ & 14.7 & 0.5 & & & & \\
\hline $\mathrm{T}(\mathrm{A}, \mathrm{EHX})$ & EHX Temp & ${ }^{\circ} \mathbf{F}$ & 1358 & 13.0 & $\mathrm{~V}(\mathrm{~S}, \mathrm{EHX})$ & EHX SGV & $\mathrm{ft} / \mathrm{sec}$ & 1.4 & 0.1 & & & & \\
\hline EA & Excs Air & $\%$ & 43.9 & 5.7 & FT18003 & CHX Flow & gpm & 10.5 & 0.1 & & & & \\
\hline$S R$ & S Reten & $\%$ & 68.1 & 2.2 & FT19003 & EHX Flow & gpm & 7.2 & 0.1 & & & & \\
\hline$R(P C A)$ & \%Flow PCA & $\%$ & 68.7 & 3.6 & PT15998 & Barom. & psia & 14.5 & 0.0 & & & & \\
\hline$R(S C A)$ & \%Flow SCA & $\%$ & 31.2 & 3.5 & PT15081 & Comb dP & in $\mathrm{H} 2 \mathrm{O}$ & 29.0 & 6.1 & & & & \\
\hline$R(Q, 1 N)$ & \%Enrg in & $\%$ & 24.4 & 3.6 & $Q(C A)$ & CA Heat in & Btu/hr & 2431 & 42.4 & & & & \\
\hline $\mathrm{R}(\mathrm{CHX})$ & CHX Ratio & $\%$ & 63.1 & 1.6 & $Q(\mathrm{CHX})$ & CHX HIRmv & Btu/hr & 523339 & 22039.0 & & & & \\
\hline$R(E H X)$ & EHX Ratio & $\%$ & 36.9 & 1.6 & $Q(E H X)$ & EHX HtRmv & Btu/hr & 306413 & 11745.2 & & & & \\
\hline$F(P C A)$ & PCA Flow & $\operatorname{sefm}$ & 320.3 & 23.2 & $Q(E H X, I N$ & FG $\mathrm{Ht}$ in & Btu/hr & N/A & N/A & & & & \\
\hline$F(E H X)$ & E FG Flow & $\operatorname{scfm}$ & 36.9 & 2.9 & $Q(F)$ & Fuel Enrg in & Btu/hr & N/A & $\mathbf{N} / \mathbf{A}$ & & & & \\
\hline $\mathrm{F}(\mathrm{SCA})$ & SCA Flow & $\operatorname{scfm}$ & 160.8 & 19.2 & $Q(F G)$ & FG Ht out & Btu/hr & 293439 & 18856.3 & & & & \\
\hline $\mathrm{F}(\mathrm{TCA})$ & TCA Flow & $\operatorname{scfm}$ & 514.2 & 14.8 & $Q(I N)$ & Tot Enrg in & Btu/hr & N/A & N/A & & & & \\
\hline$F(F G, B H)$ & BH Flow & $\operatorname{scfm}$ & 421.2 & 7.3 & $Q(O U T)$ & Tot Enrg out & Btu/hr & N/A & $N / A$ & & & & \\
\hline$F(T F G)$ & TFG Flow & $\operatorname{scfm}$ & 599.9 & 36.1 & $\mathrm{BH} A / \mathrm{C}$ & & & 1.61 & 0.0 & & & & \\
\hline W(SR) & Recirc Rt & Ibs/hr & 14210 & 2883 & A/SRATIO & & & 2.03 & 0.6 & & & & \\
\hline
\end{tabular}




\begin{tabular}{|c|c|c|c|c|c|c|c|c|c|c|c|c|c|}
\hline \multirow{2}{*}{$\frac{\text { Tag }}{\text { TC11011 }}$} & \multirow{2}{*}{$\frac{\text { Desc }}{\text { PCD Ex }}$} & \multirow{2}{*}{$\frac{\text { Units }}{{ }^{\circ} \mathrm{F}}$} & \multicolumn{2}{|c|}{ Average Std Dev } & \multicolumn{9}{|c|}{ HRAT-TRANSPER COEPPICIENTS } \\
\hline & & & 1540 & 15.7 & \multicolumn{2}{|c|}{ Combustor- } & \multicolumn{3}{|c|}{ Number of Doors in Servicem } & \multicolumn{2}{|l|}{8} & \multirow{3}{*}{$\begin{array}{c}U \\
\text { Btu/ft }{ }^{2} h r^{\circ}\end{array}$} & \multirow{3}{*}{$\begin{array}{l}\text { Heat Flux } \\
\text { Btu/ft }{ }^{2} h r\end{array}$} \\
\hline $\mathrm{TC} 11021$ & AFS Ex & ${ }^{\circ} \mathrm{F}$ & 1474 & 11.6 & CHX & Height & Temp In & Temp Out & Bed Temp & Flow & $\mathbf{Q}$ & & \\
\hline TC15001 & C Plenum & ${ }^{\circ} \mathbf{P}$ & 590 & 5.0 & Location & $(\mathrm{ft})$ & $\bullet \mathbf{P}$ & F & $\bullet \mathbf{p}$ & epm & Btu/hr & & \\
\hline TC15004 & C 1-1' & ${ }^{\circ} \mathrm{F}$ & 1433 & 10.4 & $2 E, W$ & 8 & 39 & 147 & 1462 & 4.03 & 218225 & 31.9 & 41966 \\
\hline TC15005 & C $1-2$ & ${ }^{\circ} \mathrm{P}$ & 1431 & 10.5 & 3NE & 14 & 38 & 117 & 1494 & 2.00 & 78467 & 21.9 & 30180 \\
\hline TC15006 & C 1-3' & ${ }^{\circ p} \mathbf{p}$ & 1433 & 10.3 & 4SE & 17.5 & 38 & 132 & 1499 & 1.40 & 66053 & 18.6 & 25405 \\
\hline $\mathrm{TC} 15007$ & C 1-4' & $\cdot \mathbf{P}$ & 1431 & 9.8 & 6NE & 27.5 & 39 & 131 & 1507 & 1.48 & 68212 & 19.1 & 26236 \\
\hline TC15008 & C $1-4^{\prime}$ & ${ }^{\circ} \mathrm{F}$ & 1434 & 10.6 & TSE & 32.5 & 40 & 154 & 1497 & 1.20 & 68400 & 19.6 & 26308 \\
\hline TC15009 & C 1-4' & ${ }^{\circ} \mathrm{F}$ & 1433 & 10.2 & $8 \mathrm{E}, \mathrm{W}$ & 37.5 & 40 & 109 & 1513 & 3.80 & 130483 & 17.9 & 25093 \\
\hline TC15012 & C 2-6' & ${ }^{\circ} \mathrm{P}$ & N/A & $\mathbf{N} / \mathbf{A}$ & & Overall & 39 & 130 & 1478 & 12.60 & 571907 & 20.4 & 27496 \\
\hline $\mathrm{TC} 15013$ & C 2-8' & ${ }^{\circ} \mathrm{F}$ & 1462 & 10.6 & & & \multicolumn{3}{|c|}{ From Data Sheetsm> } & 13.91 & & & \\
\hline $\mathrm{TC} 15022$ & c 3-11' & ${ }^{\circ} \mathbf{F}$ & 1477 & 11.2 & & & & & & & & & \\
\hline $\mathrm{TC} 15023$ & C 3-14' & ${ }^{\circ} \mathbf{P}$ & 1491 & 10.3 & & & & & & & & & \\
\hline $\mathrm{TC} 15024$ & C 3-14' & ${ }^{\circ} \mathrm{F}$ & 1497 & 11.1 & EHX- & & & & & & & & \\
\hline TC15025 & C 3-14' & ${ }^{\circ} \mathbf{F}$ & 1494 & 11.5 & Coils & No. of & Temp In & Temp Out & Bed Temp & Plow & $\mathbf{Q}$ & $\mathrm{U}$ & Heat Flux \\
\hline $\mathrm{TC} 15032$ & C 4-17.5' & ${ }^{\circ} \mathrm{F}$ & 1499 & 12.2 & Used & Coils & $\circ \mathrm{P}$ & 'F & $\cdot \mathbf{P}$ & gpm & Btu/hr & Btu/ft ${ }^{2} \mathrm{hr}^{\circ}$ & $\mathrm{Btu} / \mathrm{ft}^{2} \mathrm{hr}$ \\
\hline TC15042 & C 5-22.5' & ${ }^{\circ} \mathbf{F}$ & 1513 & 11.6 & $1-4,8-12$ & 9 & 38 & 103 & 1200 & 18.52 & 599535 & 81.0 & 88820 \\
\hline $\mathrm{TC} 15052$ & C 6-27.5 & ${ }^{\circ} \mathrm{F}$ & 1509 & 12.2 & & & \multicolumn{3}{|c|}{ From Data Sheets $=>$} & 19.88 & & & \\
\hline $\mathrm{TC} 15053$ & C 6-27.5' & ${ }^{\mathbf{a}} \mathbf{P}$ & 1514 & 13.1 & & & & & & & & & \\
\hline TC15054 & C 6-27.5' & ${ }^{\circ} \mathrm{F}$ & 1498 & 11.5 & & & & & & & & & \\
\hline $\mathrm{TC} 15062$ & C 7-32.5' & ${ }^{\circ} \mathbf{p}$ & 1497 & 12.2 & \multicolumn{2}{|c|}{ EMISSIONS DATA } & & & & & & & \\
\hline TC15071 & C \&-37.5' & ${ }^{\circ} \mathrm{F}$ & 1513 & 13.0 & & & & & & & & & \\
\hline $\mathrm{TC} 15073$ & C 9-41' & ${ }^{\circ} \mathrm{p}$ & 1522 & 13.6 & \multicolumn{4}{|c|}{-As Measured } & \multicolumn{4}{|c|}{-Corrected to $3 \%$ O2- } & \\
\hline TC15999 & Ambient & ${ }^{\circ} \mathrm{F}$ & 72 & 1.5 & $\mathrm{Tag}$ & Units & Average & Std Dev & Tag & Units & Average & Std Dev & \\
\hline TC16001 & EHX Plenm & ${ }^{\circ} \mathrm{F}$ & 114 & 3.7 & SO2-A & ppm & 210 & 27.2 & $\mathrm{SO} 2-\mathrm{A}$ & ppm & 211 & 22.3 & \\
\hline $\mathrm{TC} 16012$ & EHX 0.5' & ${ }^{\circ} \mathrm{F}$ & 1206 & 19.1 & E-Sulfur & $\mathrm{Ib} / \mathrm{MM} \mathrm{Btu}$ & 0.40 & 0.0 & & & & & \\
\hline TC16013 & EHX 1.5' & ${ }^{\circ} \mathbf{F}$ & 1203 & 19.0 & $\mathrm{CO}$ & ppm & 26 & 3.4 & co & ppm & 26 & 3.7 & \\
\hline TC16014 & $\mathrm{EHX} 2 . \tau$ & ${ }^{\circ} \mathrm{F}$ & 1191 & 18.0 & $\mathrm{CO} 2$ & $\%$ & 15.74 & 0.5 & $\mathrm{CO} 2$ & $\%$ & 15.83 & 0.2 & \\
\hline TC16015 & EHX 3.8' & ${ }^{\circ} \mathrm{F}$ & 1131 & 19.8 & $\mathbf{N} 20$ & ppm & 217 & 15.8 & $\mathrm{~N} 2 \mathrm{O}$ & ppm & 219 & 22.9 & \\
\hline TC16017 & EHX 5.3' & ${ }^{\circ} \mathbf{F}$ & 995 & 17.2 & E-N2O & $\mathrm{Ib} / \mathrm{MM}$ Btu & 0.28 & 0.0 & & & & & \\
\hline TC16018 & EHX Exit & ${ }^{\circ} \mathbf{p}$ & 1160 & 19.9 & NOx & ppm & 31 & 1.9 & NOx & ppm & 32 & 2.4 & \\
\hline TC16021 & CreA in & ${ }^{\circ} \mathrm{F}$ & 1519 & 13.3 & E-NOx & $\mathrm{Ib} / \mathrm{MM}$ Btu & 0.04 & 0.0 & & & & & \\
\hline $\mathrm{TC} 16031$ & DC \&-36 & ${ }^{\circ} \mathrm{F}$ & 1494 & 13.8 & $O 2-A$ & $\%$ & 3.11 & 0.6 & & & & & \\
\hline TC16032 & DC 6-28' & ${ }^{\circ} \mathbf{F}$ & 1470 & 25.0 & & & & & & & & & \\
\hline TC16033 & DC 4-18' & ${ }^{\circ} \mathrm{F}$ & 1433 & 41.7 & $\mathrm{Tag}$ & Desc & Units & Average & Std Dev & & & & \\
\hline TC16034 & DC3-11.5' & ${ }^{\circ} \mathrm{F}$ & 1443 & 30.2 & $W(C)$ & Coal Fd Rt & $\mathrm{lbs} / \mathrm{hr}$ & 257.5 & 11.0 & & & & \\
\hline TC16035 & DC3-10.5' & ${ }^{\circ} \mathbf{P}$ & 1444 & 33.3 & $\mathbf{W}(\mathbf{S})$ & LS Fd Rt & lbs/hr & 6.4 & - & & - Calculatec & ed Value & \\
\hline & & & & & $V(F G)$ & FG SGV & $\mathrm{ft} / \mathrm{sec}$ & 15.6 & 0.6 & & & & \\
\hline$T(A, C)$ & Comb Temp & ${ }^{\circ} \mathrm{P}$ & 1478 & 11.1 & $V(S, C)$ & Comb SGV & $\mathrm{ft} / \mathrm{sec}$ & 14.1 & 0.4 & & & & \\
\hline $\mathrm{T}(\mathrm{A}, \mathrm{EHX})$ & EHX Temp & ${ }^{\circ} \mathrm{F}$ & 1200 & 18.6 & $\mathrm{~V}(\mathrm{~S}, \mathrm{EHX})$ & EHX SGV & $\mathrm{ft} / \mathrm{sec}$ & 1.6 & 0.1 & & & & \\
\hline EA & Excs Air & $\%$ & 17.1 & 4.0 & FT18003 & CHX Flow & gpm & 12.6 & 0.0 & & & & \\
\hline $\mathrm{SR}$ & S Reten & $\%$ & 58.5 & 4.6 & FT19003 & EHX Flow & gpm & 18.5 & 0.0 & & & & \\
\hline $\mathrm{R}(\mathrm{PCA})$ & \%Flow PCA & $\%$ & 48.9 & 2.1 & PT15998 & Barom. & psia & 14.3 & 0.0 & & & & \\
\hline $\mathrm{R}(\mathrm{SCA})$ & \%Flow SCA & $\%$ & 51.5 & 1.8 & PT15081 & Comb dP & in $\mathrm{H} 2 \mathrm{O}$ & 43.3 & 0.6 & & & & \\
\hline$R(Q, I N)$ & \%Enrg in & $\%$ & 27.5 & 2.7 & $Q(C A)$ & CA Heat in & Btu/hr & 2352 & 36.8 & & & & \\
\hline $\mathrm{R}(\mathrm{CHX})$ & CHX Ratio & $\%$ & 48.5 & 1.4 & $Q(C H X)$ & CHX HtRmv & Btu/hr & 562086 & 26040.0 & & & & \\
\hline$R(E H X)$ & EHX Ratio & $\%$ & 51.5 & 1.4 & $Q(E H X)$ & EHX HtRmv & Btu/hr & 597310 & 29669.5 & & & & \\
\hline $\mathbf{F}(\mathrm{PCA})$ & PCA Flow & $\operatorname{scfm}$ & 191.1 & 17.5 & Q(EHX,IN & FG Ht in & Btu/hr & N/A & $\mathbf{N} / \mathbf{A}$ & & & & \\
\hline$F(E H X)$ & E FG Flow & $\operatorname{sefm}$ & 45.8 & 2.3 & $Q(F)$ & Fuel Enrg in & Btu/hr & N/A & $\mathbf{N} / \mathbf{A}$ & & & & \\
\hline $\mathrm{F}(\mathrm{SCA})$ & SCA Flow & $\operatorname{sefm}$ & 254.4 & 4.2 & $Q(F G)$ & FG Ht out & Btu/hr & 241541 & 1905.8 & & & & \\
\hline $\mathrm{F}(\mathrm{TCA})$ & TCA Flow & $\operatorname{scfm}$ & 492.2 & 15.1 & $Q(I N)$ & Tot Enrg in & Btu/hr & N/A & $\mathbf{N} / \mathbf{A}$ & & & & \\
\hline $\mathrm{F}(\mathrm{FG}, \mathrm{BH})$ & BH Flow & $\operatorname{scfm}$ & 490.1 & 2.9 & QOUT) & Tot Enrg out & $B t u / h r$ & N/A & $\mathbf{N} / \mathbf{A}$ & & & & \\
\hline F(TFG) & TFG Flow & $\operatorname{scfm}$ & 490.1 & 2.9 & BH AVC & & & 1.87 & 0.0 & & & & \\
\hline$W(S R)$ & Recirc Rt & $\mathrm{lbs} / \mathrm{hr}$ & 9577 & 1109 & A/SRATIO & & & 1.33 & 0.7 & & & & \\
\hline
\end{tabular}




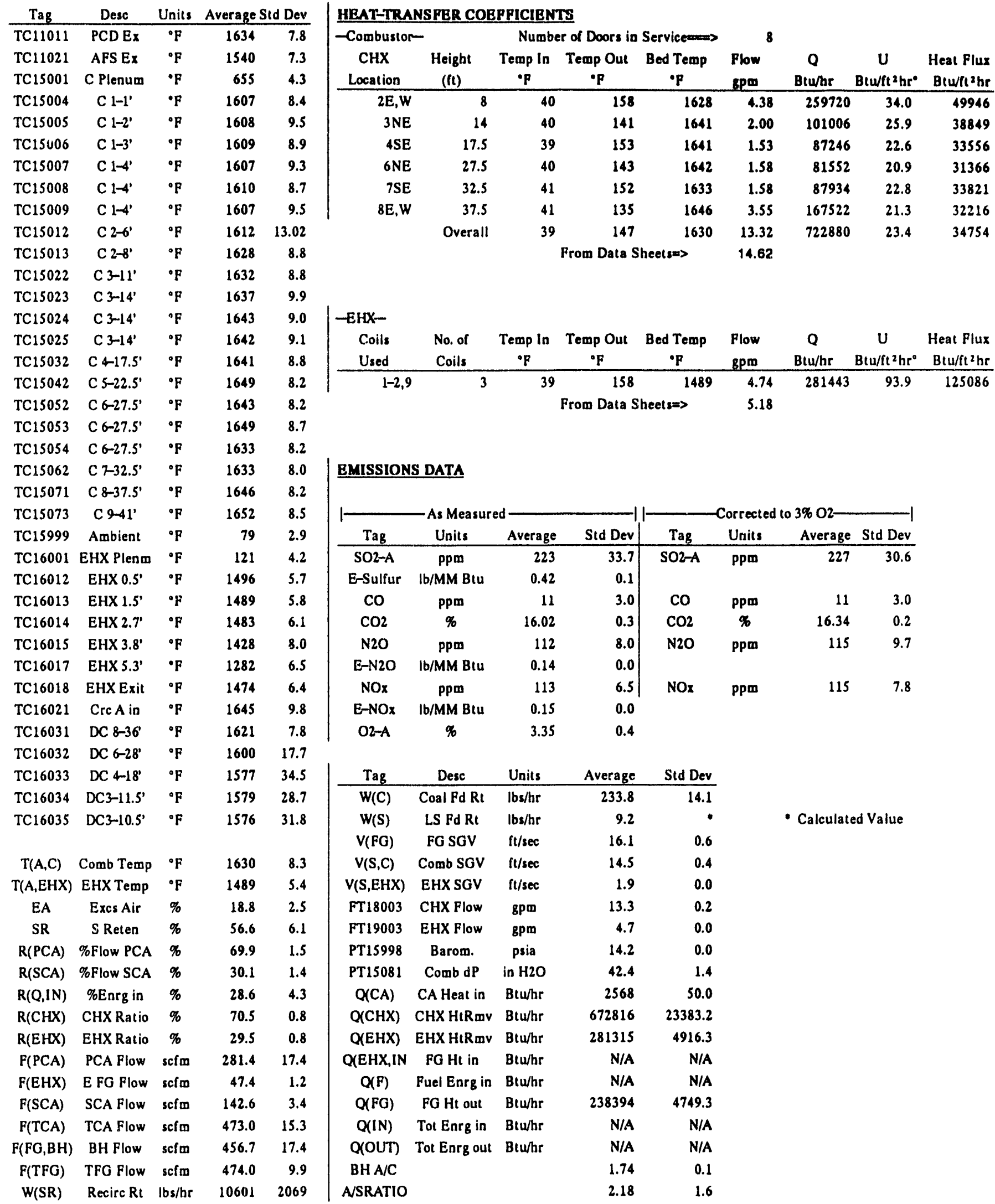




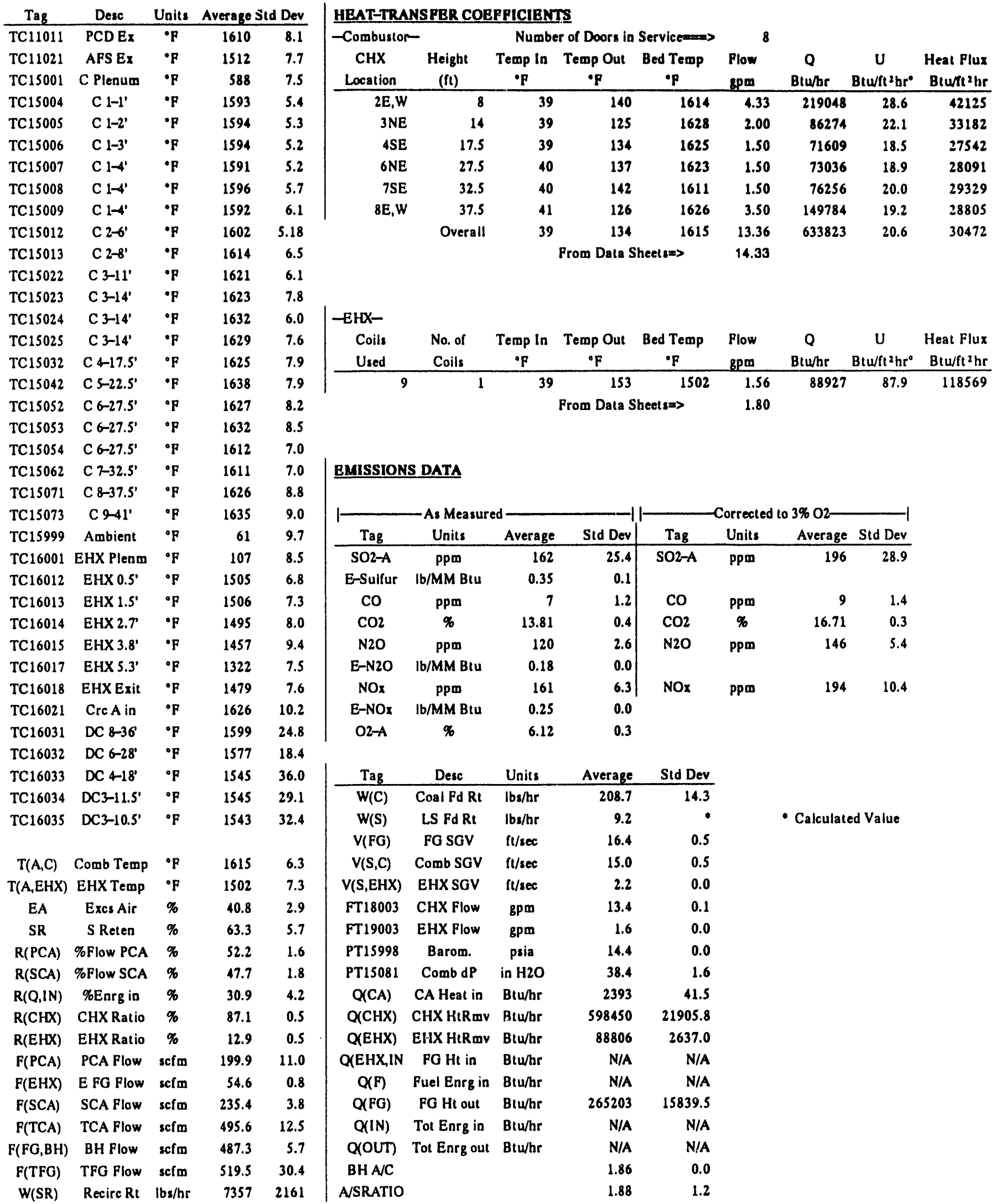




\begin{tabular}{|c|c|c|c|c|c|c|c|c|c|c|c|c|c|}
\hline \multirow{2}{*}{$\frac{\text { Tag }}{\text { TC11011 }}$} & \multirow{2}{*}{$\frac{\text { Dese }}{\text { PCD Ex }}$} & \multirow{2}{*}{$\frac{\text { Units }}{{ }^{\circ} \mathrm{P}}$} & \multicolumn{2}{|c|}{ Average Std Dev } & \multicolumn{9}{|c|}{ HEAT-TRANSPER COBPPICIENTS } \\
\hline & & & 1585 & 5.8 & \multicolumn{2}{|c|}{ - Combustor- } & \multicolumn{3}{|c|}{ Number of Doors in Service } & \multicolumn{2}{|l|}{8} & \multirow{3}{*}{$\begin{array}{c}U \\
\text { Btu/ft }{ }^{2} h r^{\circ}\end{array}$} & \multirow{3}{*}{$\begin{array}{l}\text { Heat Flux } \\
\text { Btu/ft }\end{array}$} \\
\hline TC11021 & AFS Ex & $\bullet \mathbf{F}$ & 1495 & 7.2 & CHX & Height & Temp in & Temp Out & Bed Temp & Plow & $\mathbf{Q}$ & & \\
\hline TC15001 & C Plenum & $\bullet \mathbf{P}$ & 639 & 2.4 & Location & (ft) & $\cdot \boldsymbol{P}$ & $\bullet \mathbf{p}$ & $\bullet \mathbf{F}$ & gpm & Btwhr & & \\
\hline TC15004 & C 1-1' & ${ }^{\circ} \mathbf{P}$ & 1578 & 5.6 & $2 E, W$ & 8 & 40 & 149 & 1595 & 4.40 & 240755 & 32.0 & 46299 \\
\hline TC15005 & C $1-2$ & $\bullet \mathbf{P}$ & 1578 & 5.8 & $3 N E$ & 14 & 40 & 140 & 1606 & 2.00 & 99432 & 26.1 & 38243 \\
\hline TC15006 & C 1-3' & $\bullet \mathbf{p}$ & 1581 & 5.0 & 4SE & 17.5 & 40 & 153 & 1607 & 1.40 & 78871 & 20.9 & 30335 \\
\hline TC15007 & C 1-4' & $\bullet \mathbf{F}$ & 1578 & 5.2 & 6NE & 27.5 & 41 & 155 & 1605 & 1.40 & 80039 & 21.2 & 30784 \\
\hline TC15008 & C $1-4^{\prime}$ & $\bullet \mathbf{F}$ & 1581 & 5.5 & $7 \mathrm{SE}$ & 32.5 & 41 & 168 & 1597 & 1.30 & 82075 & 22.1 & 31567 \\
\hline TC15009 & $\mathrm{C}^{1-4^{\prime}}$ & ${ }^{\bullet} \mathbf{F}$ & 1577 & 6.0 & $8 E, W$ & 37.5 & 41 & 151 & 1609 & 3.00 & 165719 & 21.9 & 31869 \\
\hline TC15012 & C 2-6' & $\cdot \mathbf{F}$ & 1589 & 5.26 & & Overall & 39 & 151 & 1597 & 12.23 & 684027 & 22.7 & 32886 \\
\hline TC 15013 & C 2-8' & ${ }^{\circ} \mathbf{F}$ & 1595 & 6.1 & & & \multicolumn{3}{|c|}{ From Data Sheets $\Rightarrow$} & 13.50 & & & \\
\hline TC15022 & C 3-11' & ${ }^{\circ} \mathbf{F}$ & 1601 & 5.7 & & & & & & & & & \\
\hline $\mathrm{TC} 15023$ & C 3-14' & ${ }^{\circ} \mathbf{P}$ & 1604 & 6.2 & & & & & & & & & \\
\hline $\mathrm{TC} 15024$ & C 3-14' & ${ }^{\circ} \mathbf{F}$ & 1608 & 6.0 & -EHX- & & & & & & & & \\
\hline $\mathrm{TC} 15025$ & C 3-14' & ${ }^{\circ} \mathbf{F}$ & 1607 & 6.8 & Coils & No. of & Temp In & Temp Out & Bed Temp & Plow & $Q$ & $\mathrm{U}$ & Heat Flux \\
\hline $\mathrm{TC} 15032$ & $C 4-17.5^{\prime}$ & $\cdot F$ & 1607 & 6.9 & Used & Coils & ${ }^{\circ} \mathrm{F}$ & ${ }^{\circ} \mathbf{F}$ & ${ }^{\circ} \mathbf{F}$ & gpm & Blu/hr & $\mathrm{Btu} / \mathrm{ft}^{2} \mathrm{hr}^{\circ}$ & $\mathrm{Btu} / \mathrm{ft}^{2} \mathrm{hr}$ \\
\hline $\mathrm{TC} 15042$ & $C-22.5^{\prime}$ & ${ }^{\circ} \mathbf{F}$ & 1613 & 6.5 & 9 & 1 & 40 & 158 & 1522 & 1.55 & 91504 & 89.4 & 122005 \\
\hline TC15052 & C 6-27.5 & ${ }^{\circ} \mathbf{F}$ & 1608 & 6.3 & & & \multicolumn{3}{|c|}{ From Data Sheets $\Rightarrow$} & 1.80 & & & \\
\hline $\mathrm{TC} 15053$ & C 6-27.5' & ${ }^{\circ} \mathbf{F}$ & 1610 & 6.0 & & & & & & & & & \\
\hline $\mathrm{TC} 15054$ & C 6-27.5' & $\bullet \mathbf{F}$ & 1598 & 5.7 & & & & & & & & & \\
\hline TC15062 & C 7-32.5' & $\cdot \mathbf{F}$ & 1597 & 5.3 & \multicolumn{2}{|c|}{ EMISSIONS DATA } & & & & & & & \\
\hline TC15071 & C \&-37.5' & ${ }^{\circ} \mathbf{P}$ & 1609 & 6.5 & & & & & & & & & \\
\hline $\mathrm{TC} 15073$ & C 9-41' & ${ }^{\circ} \mathbf{F}$ & 1612 & 6.7 & \multicolumn{4}{|c|}{-As Measured } & \multicolumn{4}{|c|}{ Corrected to $3 \% 02$} & \\
\hline TC15999 & Ambient & ${ }^{\circ} \mathbf{F}$ & 73 & 0.8 & Tag & Units & Average & Std Dev & $\mathrm{Tag}$ & Units & Average & Std Dev & \\
\hline TC16001 & EHX Plenm & $\bullet P$ & 118 & 2.3 & $\mathrm{SO} 2-\mathrm{A}$ & ppm & 21 & 6.0 & SO2-A & ppm & 26 & 7.3 & \\
\hline $\mathrm{TC} 16012$ & EHX 0.5' & $\bullet \mathbf{F}$ & 1525 & 5.5 & E-Sulfur & lb/MM Btu & 0.05 & 0.0 & & & & & \\
\hline TC16013 & EHX 1.5' & ${ }^{\circ} \mathbf{P}$ & 1526 & 5.9 & $\mathrm{Co}$ & ppm & 7 & 0.4 & $\mathrm{co}$ & ppm & 9 & 0.5 & \\
\hline $\mathrm{TC} 16014$ & $\mathrm{EHX} 2.7^{\prime}$ & ${ }^{\circ} \mathbf{F}$ & 1513 & 5.2 & $\mathrm{CO} 2$ & $\%$ & 13.46 & 0.3 & $\mathrm{CO} 2$ & $\%$ & 16.89 & 0.2 & \\
\hline $\mathrm{TC} 16015$ & EHX 3.8' & ${ }^{\circ} \mathrm{F}$ & 1482 & 4.9 & $\mathrm{~N} 2 \mathrm{O}$ & ppm & 135 & 2.6 & $\mathrm{~N} 2 \mathrm{O}$ & ppm & 169 & 4.3 & \\
\hline $\mathrm{TC} 16017$ & EHX 5.3' & $\cdot \mathbf{P}$ & 1359 & 6.9 & $\mathrm{E}-\mathrm{N} 2 \mathrm{O}$ & $\mathrm{Ib} / \mathrm{MM} \mathrm{Btu}$ & 0.21 & 0.0 & & & & & \\
\hline TC16018 & EHX Exit & ${ }^{\circ} \mathbf{P}$ & 1503 & 4.9 & NOx & ppm & 216 & 11.4 & NOx & ppm & 272 & 17.2 & \\
\hline TC16021 & $\operatorname{CrcA}$ in & ${ }^{\circ} \mathbf{F}$ & 1600 & 7.7 & E-NOx & $\mathrm{Ib} / \mathrm{MM} \mathrm{B} t \mathrm{u}$ & 0.35 & 0.0 & & & & & \\
\hline TC16031 & DC 8-36 & ${ }^{\circ} \mathbf{F}$ & 1588 & 8.5 & O2-A & $\%$ & 6.65 & 0.2 & & & & & \\
\hline $\mathrm{TC} 16032$ & DC 6-28' & ${ }^{\circ} \mathrm{F}$ & 1570 & 16.0 & & & & & & & & & \\
\hline TC16033 & DC 4-18' & ${ }^{\circ} \mathbf{F}$ & 1548 & 26.3 & $\mathrm{Tag}$ & Desc & Units & Average & Std Dev & & & & \\
\hline TC16034 & DC3-11.5' & ${ }^{\circ} \mathbf{F}$ & 1550 & 22.6 & $W(C)$ & Coal Fd Rt & $\mathrm{lbs} / \mathrm{hr}$ & 208.8 & 13.4 & & & & \\
\hline TC16035 & DC3-10.5' & ${ }^{\circ} \mathbf{P}$ & 1549 & 25.5 & $\mathbf{W}(\mathbf{S})$ & LS Fd Rt & lbs/hr & 16.6 & $\bullet$ & & - Calculate & ed Value & \\
\hline & & & & & $V(F G)$ & FG SGV & $\mathrm{ft} / \mathrm{sec}$ & 16.7 & 0.4 & & & & \\
\hline$T(A, C)$ & Comb Temp & ${ }^{\circ} \mathrm{F}$ & 1597 & 5.5 & $V(S, C)$ & Comb SGV & $\mathrm{ft} / \mathrm{sec}$ & 15.2 & 0.4 & & & & \\
\hline $\mathrm{T}(\mathrm{A}, \mathrm{EHX})$ & EHX Temp & ${ }^{\circ} \mathbf{F}$ & 1522 & 4.8 & $V(S, E H X)$ & EHX SGV & $\mathrm{ft} / \mathrm{sec}$ & 2.2 & 0.0 & & & & \\
\hline EA & Excs Air & $\%$ & 46.1 & 2.2 & FT18003 & CHX Flow & gpm & 12.2 & 0.2 & & & & \\
\hline SR & S Reten & $\%$ & 95.1 & 1.3 & FT19003 & EHX Flow & gPm & 1.6 & 0.0 & & & & \\
\hline$R(P C A)$ & \%Flow PCA & $\%$ & 71.7 & 1.0 & PT15998 & Barom. & psia & 14.5 & 0.0 & & & & \\
\hline $\mathrm{R}(\mathrm{SCA})$ & \%Flow SCA & $\%$ & 28.4 & 1.2 & PT15081 & Comb dP & in $\mathrm{H} 2 \mathrm{O}$ & 37.9 & 1.4 & & & & \\
\hline$R(Q, I N)$ & \%Enrg in & $\%$ & 30.2 & 4.3 & $Q(C A)$ & CA Heat in & Btu/hr & 2596 & 26.5 & & & & \\
\hline $\mathrm{R}(\mathrm{CHX})$ & CHX Ratio & $\%$ & 87.3 & 0.5 & $Q(C H X)$ & CHX HIRmv & Btu/hr & 631326 & 21662.4 & & & & \\
\hline$R(E H X)$ & EHX Ratio & $\%$ & 12.7 & 0.5 & $Q(E H X)$ & EHX HtRmv & Btu/hr & 91498 & 3067.2 & & & & \\
\hline$F(P C A)$ & PCA Flow & $\operatorname{sefm}$ & 312.8 & 15.1 & QXEHX,IN & FG $\mathrm{Ht}$ in & Btw/hr & N/A & N/A & & & & \\
\hline$F(E H X)$ & E FG Flow & $\operatorname{scfm}$ & 54.1 & 0.8 & $Q(F)$ & Fuel Enrg in & Btu/hr & $N / A$ & N/A & & & & \\
\hline $\mathrm{F}(\mathrm{SCA})$ & SCA Flow & $\operatorname{scfm}$ & 141.6 & 2.6 & $\alpha(F G)$ & FG Ht out & Btu/hr & 251732 & 1568.4 & & & & \\
\hline $\mathrm{F}(\mathrm{TCA})$ & TCA Flow & $\operatorname{scfm}$ & 508.6 & 13.7 & $Q(I N)$ & Tot Enrg in & Btw/hr & $N / A$ & N/A & & & & \\
\hline$F(F G, B H)$ & BH Flow & $\operatorname{scfm}$ & 503.1 & 3.5 & Q(OUT) & Tot Enrg out & Btu/hr & $N / A$ & N/A & & & & \\
\hline F(TFG) & TFG Flow & $\operatorname{scfm}$ & 503.1 & 3.5 & $\mathrm{BH} A / C$ & & & 1.92 & 0.0 & & & & \\
\hline$W(S R)$ & Recirc Rt & $\mathrm{lbs} / \mathrm{hr}$ & 8922 & 1213 & ASRATIO & & & 5.21 & 2.7 & & & & \\
\hline
\end{tabular}




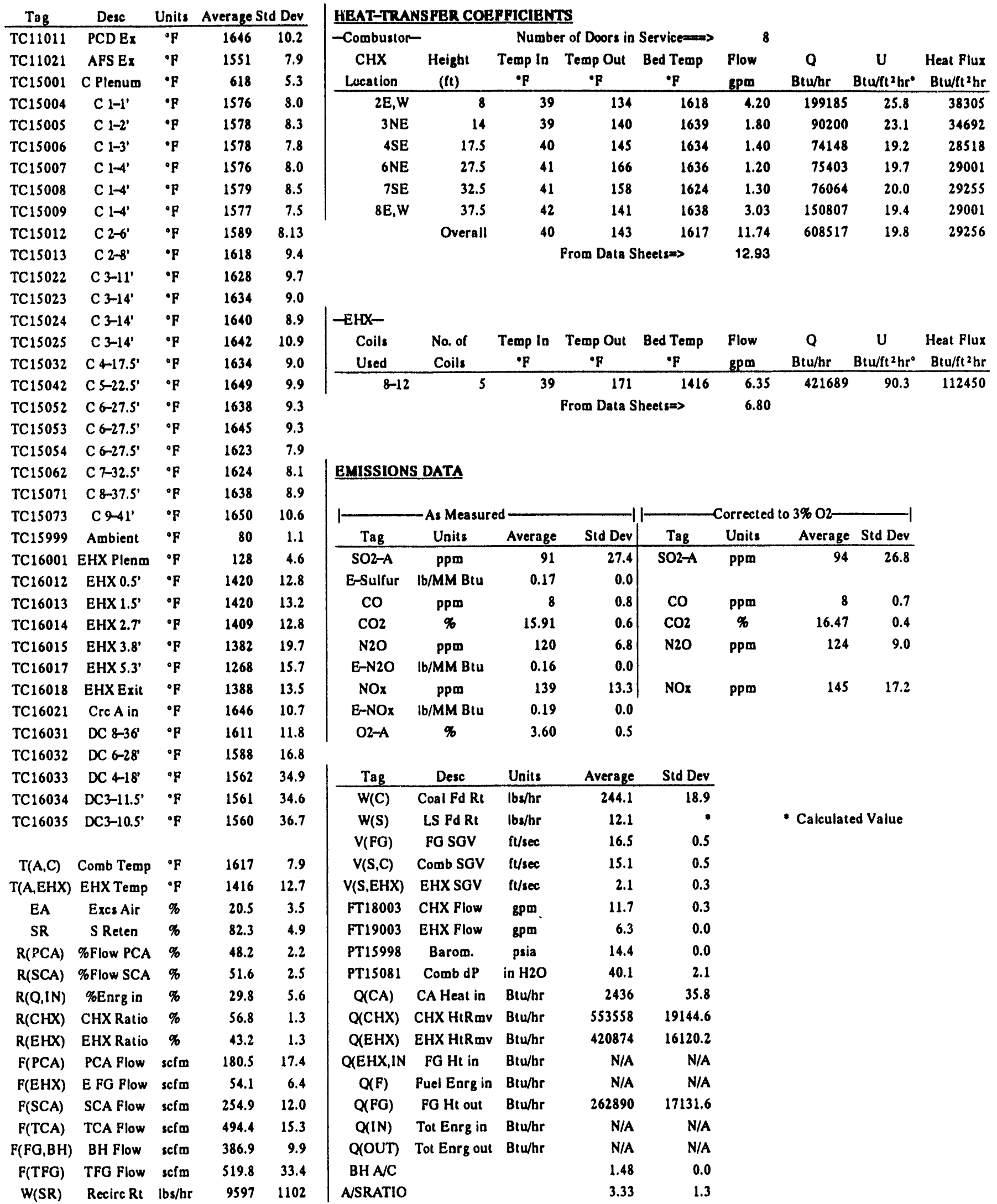




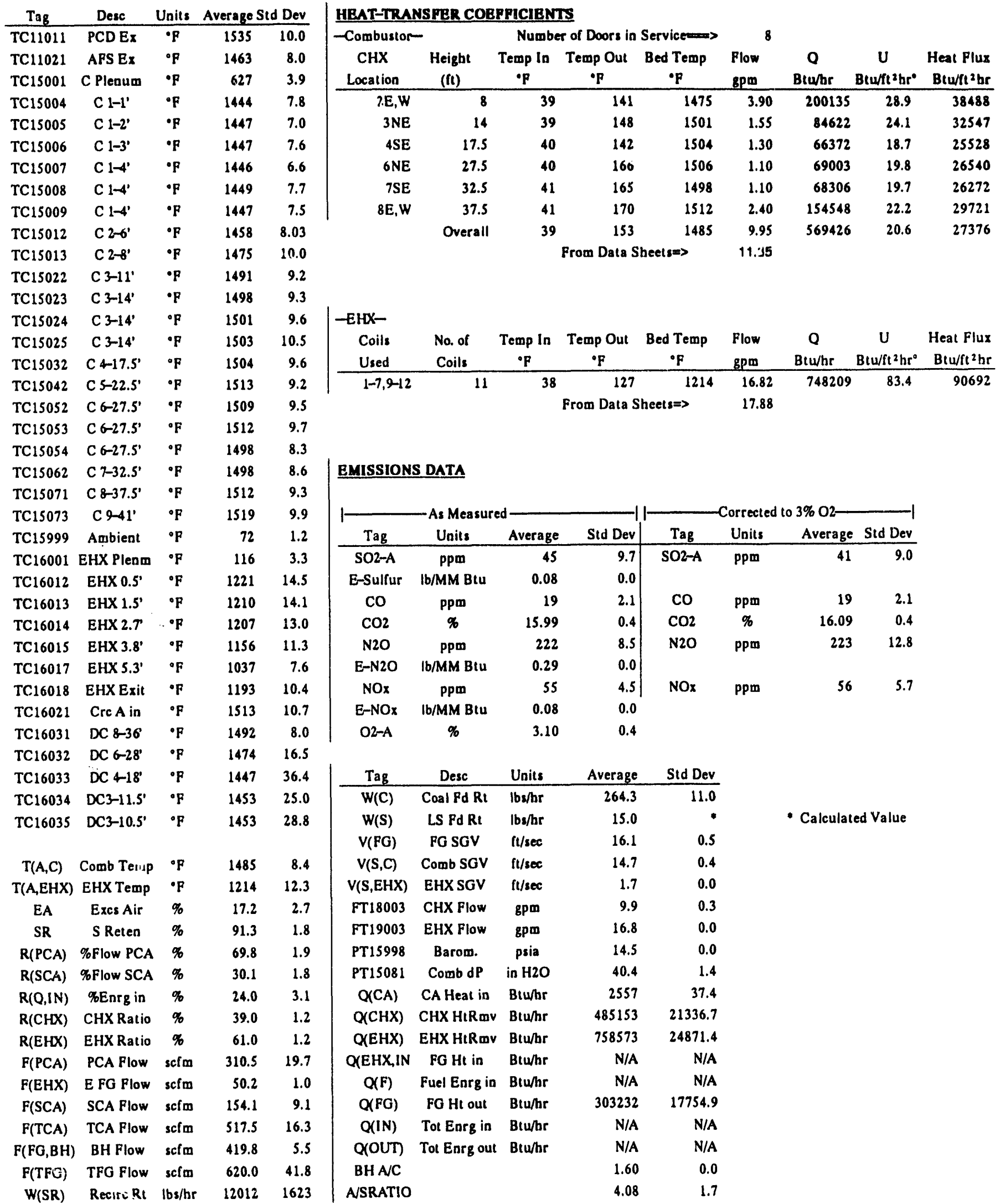




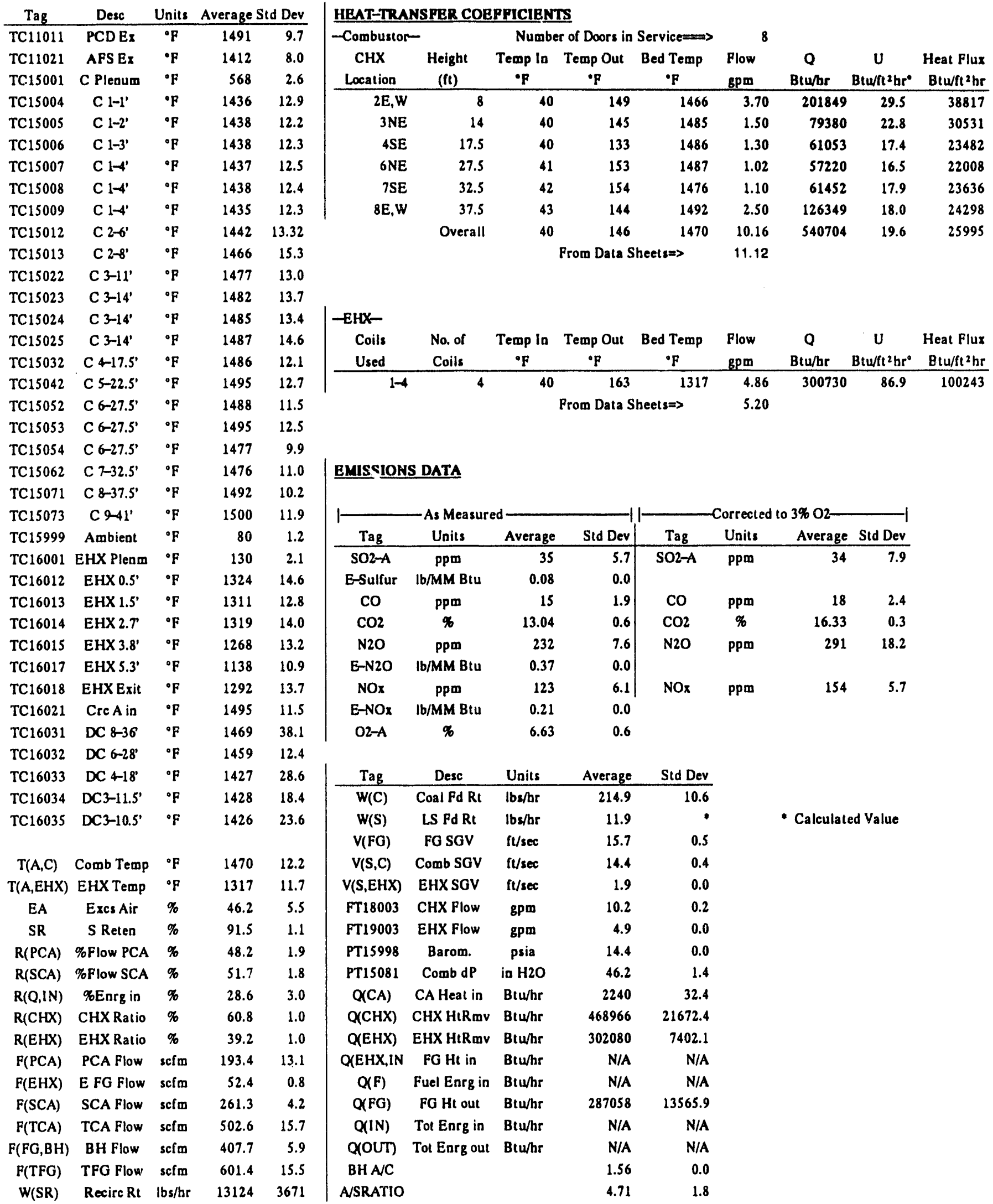


APPENDIX B

CENTER LIGNITE TEST RESULTS 


\section{TABLE OF CONTENTS}

LIST OF FIGURES

B-iii

LIST OF TABLES

B-v

TEST MATRIX

COAL AND LIMESTONE PROPERTIES

B-1

OPERATIONAL PERFORMANCE $\ldots \ldots \ldots \ldots \ldots \ldots \ldots \ldots \ldots \ldots \ldots$ B-2

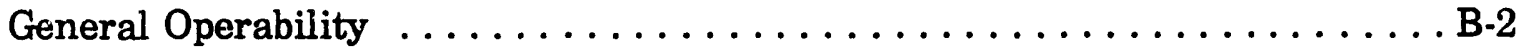

Summary of Results . . . . . . . . . . . . . . . . . . .

Recirculation Rates and Size Distributions . . . . . . . . . . . B-4

Bottom Ash/Total Ash Split . . . . . . . . . . . . . . . B-7

THERMAL PERFORMANCE $\ldots \ldots \ldots \ldots \ldots \ldots \ldots \ldots \ldots \ldots \ldots \ldots$

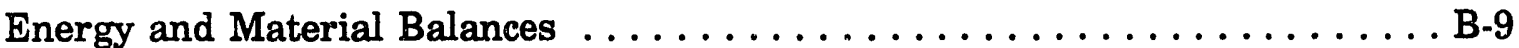

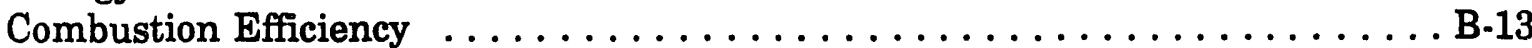

Boiler Efficiency . . . . . . . . . . . . . . . . . . . . B-13

Heat-Transfer Coefficient and Heat Flux . . . . . . . . . . . . B-13

Pressure and Temperature Profiles . . . . . . . . . . . . . . B-17

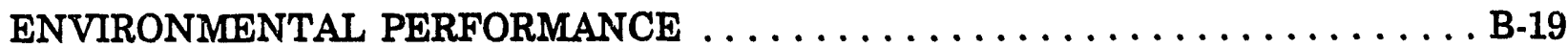

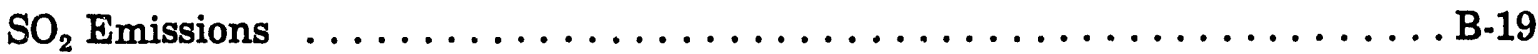

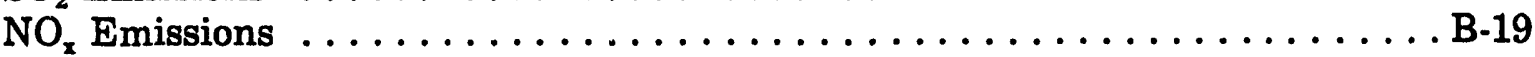

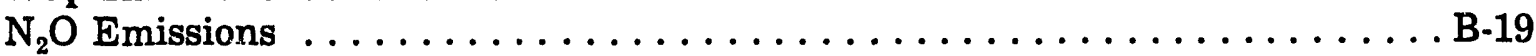

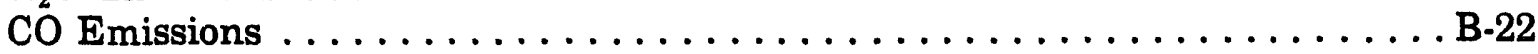

SINTERING, AGGLOMERATION, AND DEPOSIT EVALUATION . . . . . . . . B-22

SUMMARIES OF TEST DATA $\ldots \ldots \ldots \ldots \ldots \ldots \ldots \ldots \ldots \ldots \ldots \ldots \ldots$ 


\section{LIST OF FIGURES}

Figure

B-1 Size distributions of Center lignite and New Enterprise limestone $\ldots \ldots \ldots$ B-2

B-2 Size distribution of combustor bed material, downcomer, ash-fouling section ash, secondary cyclone ash, and baghouse ash . . . . . . . . B-8

B-3 Combustion efficiency as a function of temperature $\ldots \ldots \ldots \ldots \ldots \ldots$.17

B-4 Combustor pressure profiles $\ldots \ldots \ldots \ldots \ldots \ldots \ldots \ldots \ldots \ldots \ldots \ldots$ B-18

B-5 Combustor temperature profiles $\ldots \ldots \ldots \ldots \ldots \ldots \ldots \ldots \ldots \ldots \ldots \ldots$

B-6 $\mathrm{SO}_{2}$ emissions as a function of average combustor temperature. . . . . . . B-21

B-7 $\mathrm{SO}_{2}$ retention as a function of alkali-to-sulfur molar ratio $\ldots \ldots \ldots \ldots \ldots \ldots$.21

B-8 $\mathrm{NO}_{\mathrm{x}}$ emissions as a function of average combustor temperature $\ldots \ldots \ldots \ldots$ B-22

B-9 $\mathrm{N}_{2} \mathrm{O}$ emissions as a function of average combustor temperature $\ldots \ldots \ldots \ldots$ B-23

B-10 CO emissions as a function of average combustor temperature $\ldots \ldots \ldots \ldots$ B-23 


\section{LIST OF TABLES}

$\underline{\text { Table }}$

B-1 Test Matrix $\ldots \ldots \ldots \ldots \ldots \ldots \ldots \ldots \ldots \ldots \ldots \ldots \ldots \ldots \ldots \ldots \ldots$

B-2 Coal Analyses $\ldots \ldots \ldots \ldots \ldots \ldots \ldots \ldots \ldots \ldots \ldots \ldots \ldots \ldots \ldots$

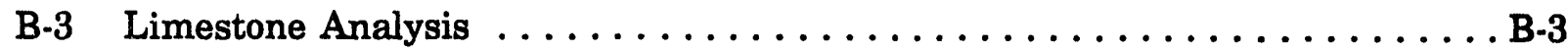

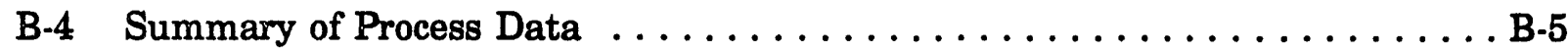

B-5 Solids Recirculation and Heat-Transfer Data $\ldots \ldots \ldots \ldots \ldots \ldots \ldots \ldots$

B-6 Ash Balance $\ldots \ldots \ldots \ldots \ldots \ldots \ldots \ldots \ldots \ldots \ldots \ldots \ldots \ldots$

B.7 Fuel Balance $\ldots \ldots \ldots \ldots \ldots \ldots \ldots \ldots \ldots \ldots \ldots \ldots \ldots \ldots \ldots$

B-8 Flue Gas Balance ............................ B-10

B-9 Energy Balance $\ldots \ldots \ldots \ldots \ldots \ldots \ldots \ldots \ldots \ldots \ldots \ldots \ldots \ldots \ldots \ldots$

B-10 Material Balance $\ldots \ldots \ldots \ldots \ldots \ldots \ldots \ldots \ldots \ldots \ldots \ldots \ldots \ldots \ldots \ldots$

B-11 Combustion Efficiency $\ldots \ldots \ldots \ldots \ldots \ldots \ldots \ldots \ldots \ldots \ldots \ldots \ldots \ldots \ldots$

B-12 Unburned Carbon $\ldots \ldots \ldots \ldots \ldots \ldots \ldots \ldots \ldots \ldots \ldots \ldots \ldots \ldots \ldots$

B-13 Boiler Efficiency $\ldots \ldots \ldots \ldots \ldots \ldots \ldots \ldots \ldots \ldots \ldots \ldots \ldots \ldots$

B-14 Individual Heat-Transfer Coefficients $\ldots \ldots \ldots \ldots \ldots \ldots \ldots \ldots$

B-15 Individual Heat Flux $\ldots \ldots \ldots \ldots \ldots \ldots \ldots \ldots \ldots \ldots \ldots \ldots$

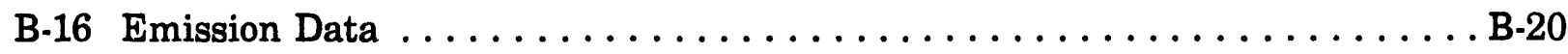




\section{TEST MATRIX}

The matrix of test parameters is shown in Table B-1. Test 0 was a baseline test to establish emission levels without limestone addition. The unit was started up using silica sand, and steady-state data were taken. Test 1 established the baseline conditions for 70\% sulfur capture. Tests 2 and 3 simulated load variances for those combustors that do not operate with an external heat exchariger. Tests 4 and 5 repeated the load conditions of Tests 2 and 3 , but were done in a manner to simulate those combustors that are designed with an external heat exchanger. The limestone feed rate was lowered for Test 6 to help generate a $\mathrm{Ca} / \mathrm{S}$ ratio versus sulfur retention curve. Tests 7 through 10 were designed to look at temperature effects on emissions; solid samples were not taken for these test periods.

\section{COAL AND LIMESTONE PROPERTIES}

The coal used for this test was supplied by BNI Coal. It was taken from their Center mine arid shipped by truck to Grand Forks, North Dakota. The sample received was stoker grade, crushed to minus 2 inches. The sorbent for the test was New Enterprise limestone. Crushing was performed with a Williams hammer-mill crusher. The material exited the crusher and was conveyed to a vibrating screen. The coal was screened to $-1 / 4$ inch. The size distribution of the as-crushed sample is shown in Figure B-1.

\section{TABLE B-1}

Test Matrix

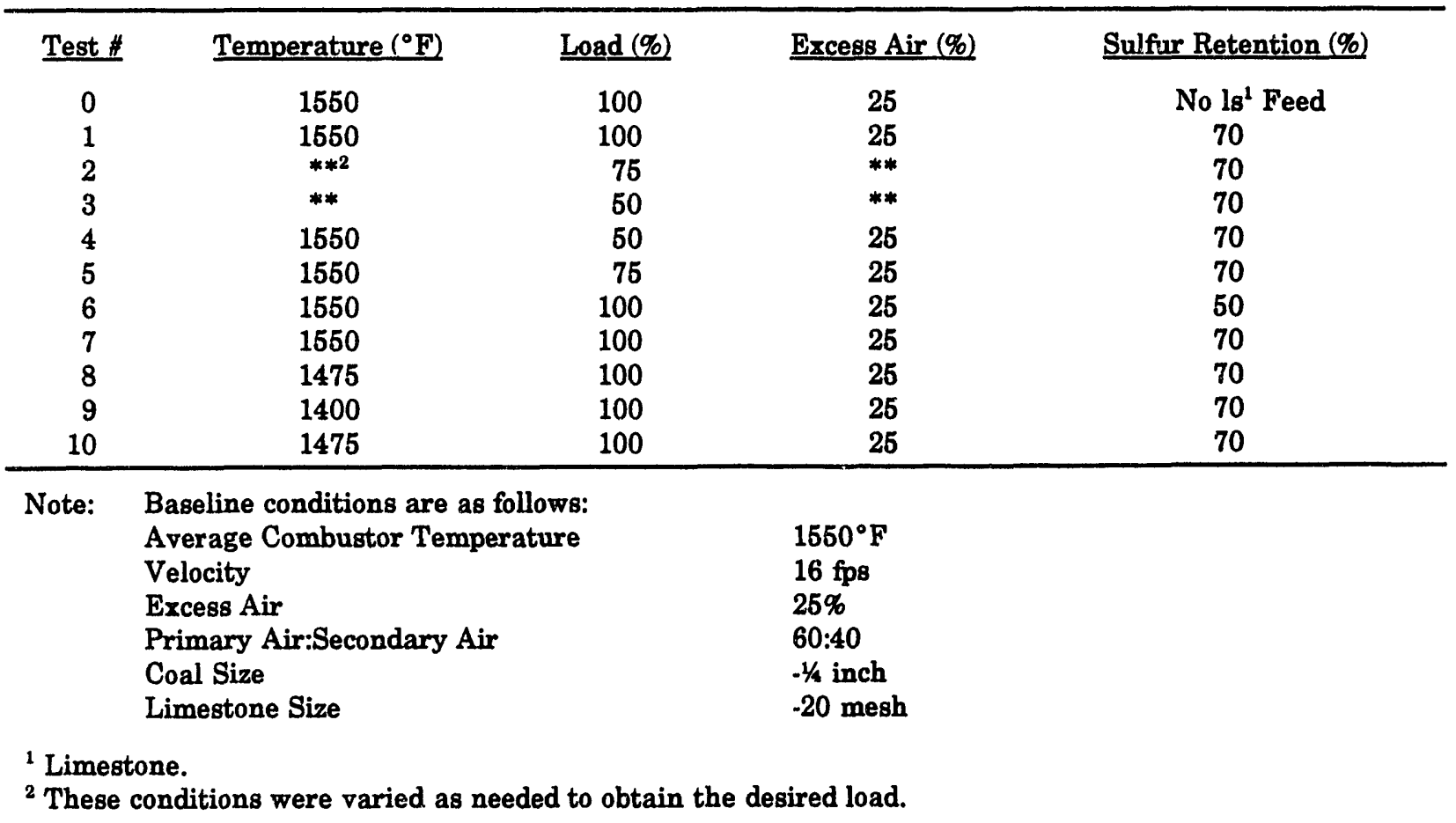




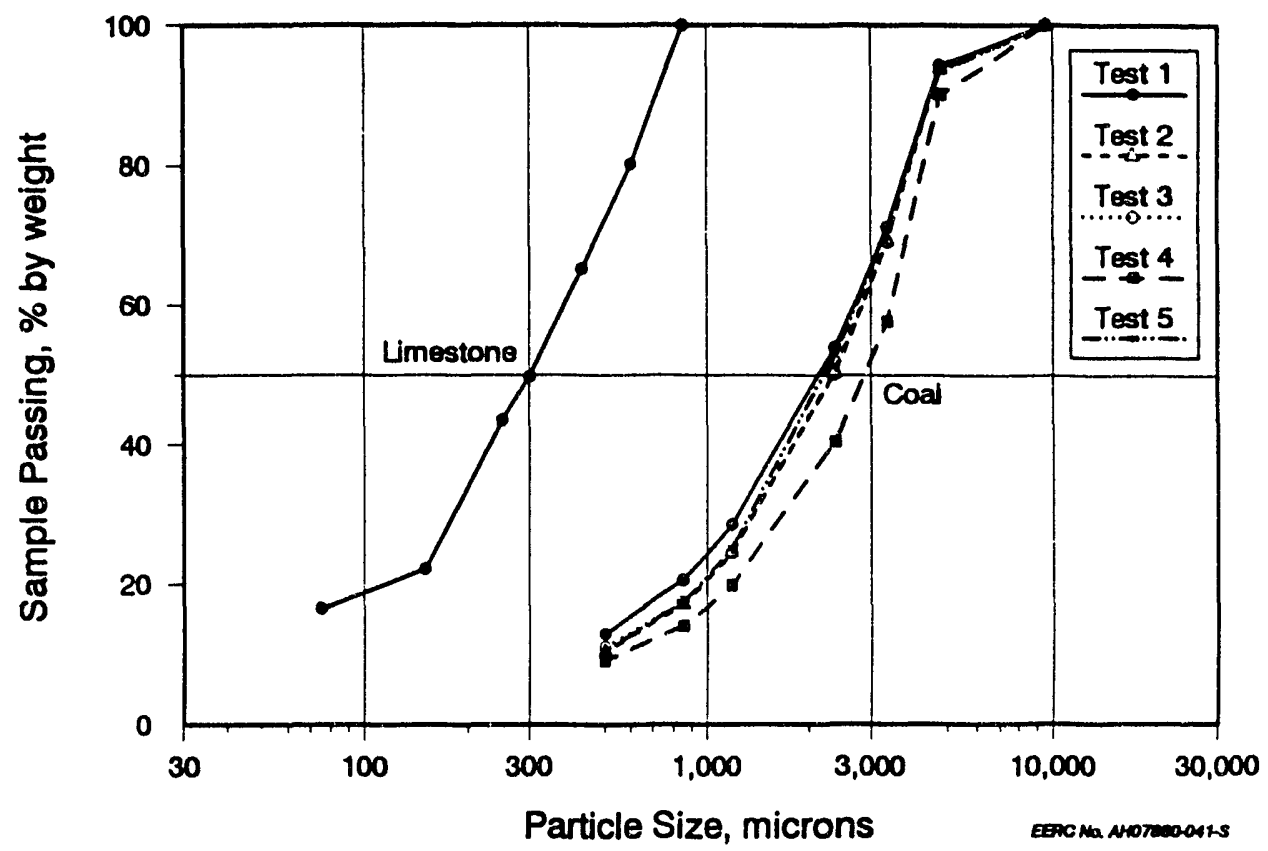

Figure B-1. Size distributions of Center lignite and New Enterprise limestone.

Limestone was crushed separately using the Williams hammer-mill crusher and screened to -20 mesh (841 microns) The limestone crushed well once-through, with only a small amount greater than 20 mesh (separated into barrels for additional crushing) and not many fines. The size distribution for an as-crushed limestone sample is shown in Figure B-1. About 18\% was less than 200 mesh (75 microns); 100\% was less than 20 mesh (841 microns), with what appears to be a good distribution. The $\mathrm{D}_{50}$ was approximately 300 microns.

The sized coal and limestone from final screening were routed into 2-ton capacity storage totes which were on standby waiting to be transferred by forklift and crane to storage hoppers having net capacities of approximately 3000 pounds and 1000 pounds for the coal and limestone, respectively.

Proximate and ultimate analyses of the coal and XRFA of the coal ash and limestone were performed. Results of the coal analyses for each test period are shown in Table B-2, and the limestone analysis is shown in Table B-3. The coal is typified by its high moisture (37\%), low ash (5\%), and low sulfur (0.6\%). The sodium content of the ash at $3.7 \%$ is midrange for a North Dakota lignite.

\section{OPERATIONAL PERFORMANCE}

\section{General Operability}

During the first week of testing with Center lignite, a couple of operational problems were encountered that increased the length of start-up. First, a leak in one of the flexible joints of the secondary air manifold had to be patched. Next, after the system 


\section{TABLE B-2}

Coal Analyses

\begin{tabular}{|c|c|c|c|c|c|c|c|c|c|c|}
\hline & Teat 0 & Test 1 & Test 2 & Test 3 & Teet 4 & Teat 6 & Toat 6 & Toots $7-10$ & Averages & $\begin{array}{l}\text { Tests } 06 \\
\text { Averago }\end{array}$ \\
\hline \multicolumn{11}{|c|}{ Proximate Analyøis, as-received, wt\% } \\
\hline Moisture & 39.2 & 37.0 & 36.9 & 36.6 & 37.1 & 37.1 & 36.9 & 22.6 & 36.29 & 37.11 \\
\hline Volatile Matter & 27.9 & 28.9 & 29.3 & 29.1 & 29.3 & 28.0 & 29.7 & 36.6 & 29.91 & 28.96 \\
\hline Fired Carbon & 29.3 & 29.0 & 28.6 & 29.4 & 28.4 & 28.7 & 28.7 & 34.7 & 29.60 & 28.87 \\
\hline Aøh & 3.7 & 6.1 & 6.2 & 4.9 & 6.3 & 6.6 & 6.7 & 6.1 & 6.19 & 6.07 \\
\hline \multicolumn{11}{|c|}{ Ultimate Analysis, ag-received, wt\% } \\
\hline Carbon & 40.96 & 40.92 & 40.94 & 41.29 & 40.99 & 40.49 & 40.71 & 43.81 & 41.26 & 40.90 \\
\hline Hydrogen & 7.02 & 7.24 & 6.80 & 6.76 & 7.26 & 7.19 & 6.95 & 6.77 & 7.00 & 7.03 \\
\hline Nitrogen & 0.49 & 0.65 & 0.67 & 0.67 & 0.54 & 0.64 & 0.64 & 0.73 & 0.67 & 0.64 \\
\hline Sulfur & 0.62 & 0.64 & 0.55 & 0.65 & 0.57 & 0.79 & 0.96 & 0.72 & 0.66 & 0.65 \\
\hline Oxygen & 47.33 & 46.56 & 46.96 & 45.93 & 46.37 & 46.34 & 46.14 & 41.81 & 46.30 & 45.80 \\
\hline Aвh & 3.66 & 6.08 & 6.17 & 4.87 & 5.25 & 6.63 & 6.69 & 6.14 & 6.19 & 5.05 \\
\hline \multicolumn{11}{|c|}{ Ash Composition, as oxides, $\%$} \\
\hline Calcium, $\mathrm{CaO}$ & 19.6 & 23.2 & 23.0 & 24.4 & 24.2 & 20.9 & NA & 21.1 & 22.80 & 22.55 \\
\hline Magnesium, MgO & 8.2 & 10.4 & 10.5 & 10.8 & 11.7 & 9.6 & NA & 7.0 & 10.01 & 10.20 \\
\hline Sodium, $\mathrm{Na}_{2} \mathrm{O}$ & 3.5 & 3.9 & 3.6 & 4.2 & 3.1 & 3.9 & NA & 9.7 & 4.73 & 3.70 \\
\hline Silica, $\mathrm{SiO}_{2}$ & 12.7 & 14.8 & 16.2 & 14.6 & 14.4 & 16.3 & NA & 16.1 & 14.90 & 14.60 \\
\hline Aluminum, $\mathrm{Al}_{2} \mathrm{O}_{3}$ & 11.6 & 9.1 & 9.5 & 9.6 & 9.6 & 9.0 & NA & 8.4 & 9.19 & 9.73 \\
\hline Ferric, $\mathrm{Fe}_{2} \mathrm{O}_{3}$ & 21.0 & 14.9 & 16.6 & 13.4 & 13.1 & 17.6 & NA & 12.3 & 14.63 & 16.08 \\
\hline Titanium, $\mathrm{TiO}_{2}$ & 0.2 & 0.4 & 0.3 & 0.4 & 0.3 & 0.3 & NA & 0.6 & 0.38 & 0.32 \\
\hline Phosphorous, $\mathrm{P}_{2} \mathrm{O}_{6}$ & 0.6 & 0.7 & 0.6 & 0.7 & 0.7 & 0.6 & NA & 1.1 & 0.74 & 0.65 \\
\hline Potassium, $\mathrm{K}_{2} \mathrm{O}$ & 0.3 & 0.4 & 0.5 & 0.4 & 0.3 & 0.6 & NA & 0.6 & 0.46 & 0.40 \\
\hline Sulfur, $\mathbf{S O}_{3}$ & 22.3 & 22.2 & 20.1 & 21.6 & 22.6 & 22.4 & NA & 24.0 & 22.15 & 21.87 \\
\hline $\begin{array}{l}\text { High Heating Value, } \\
\text { moigture-free, Btu/lb }\end{array}$ & 11,416 & 11,043 & 10,993 & 11,039 & 10,969 & 10,968 & NA & 9,633 & 10,866 & 11,071 \\
\hline $\begin{array}{l}\text { High Heating Value, } \\
\text { ag-received, Btu/lb }\end{array}$ & 6,939 & 6,955 & 6,941 & 7,002 & 6,897 & 6,901 & NA & 7,461 & 7,014 & 6,939 \\
\hline
\end{tabular}

TABLE B-3

Limestone Analysis (\%)

\begin{tabular}{lc}
\hline Component & Average \\
\hline Silica & 3.44 \\
Aluminum & 0.69 \\
Iron & 0.42 \\
Calcium & 61.32 \\
Magne日ium & 3.02 \\
Sulfur & 0.31 \\
Sodium & 0.08 \\
Potassium & 0.42 \\
\hline
\end{tabular}


had heated up and coal feed was initiated, it was discovered that the coal feed system would not feed at a rate sufficient to obtain the required operational temperatures. This was unexpected, because relatively low-speed control settings had been used during the previous test with bituminous coal, and the expected coal feed rates for the lignite testing were only slightly greater. New sprockets were installed to increase the rotational speed of the coal feed rotary valve approximately threefold, resulting in satisfactory operation. The addition of a rotary seal valve below the coal and limestone feed valves, to eliminate the backflow of flue gas into the feed system, significantly reduced coal plugs in the gravity feed line into the combustor. The only serious coal feed plug was the result of a foreign object introduced with the coal that had temporarily jammed the coal feed rotary valve.

Overall operation of the system was good, one exception being that the sulfur capture was difficult to control and was not very responsive to changes in the addition rate of limestone. Based upon temperature distribution in the combustor and downcomer, it appeared that the particle collection device was functioning well, even though postrun inspection showed that most of the chevron collectors were plugged with ash. Some small agglomerates of about one-eighth-inch diameter were noted in the combustor bed material, but did not pose any operational problem.

Because of the problem of ash buildup and chevron collector plugging, a decision was made to remove the particle collection device and install a cyclone. After the first seven tests on the Center lignite were completed, the modifications associated with the fabrication and installation of a refractory-lined cyclone were completed. Curing of the refractory was completed in two stages. Initially, a low-temperature cure up to $600^{\circ} \mathrm{F}$ was performed using the natural gas preheater. Final high-temperature curing up to $1650^{\circ} \mathrm{F}$ was completed using a Beulah North Dakota lignite.

Upon completion of curing, testing of the Center lignite was resumed. Testing proceeded smoothly and on schedule through Test 10, when operational problems were suddenly encountered. Plugging occurred either at the cyclone exit into the downcomer or elsewhere inside the downcomer. The only indication of any problem was an increase in the pressure drops measured across the upper sections of the downcomer. As a result of the plug, all but a small portion of the bed material moved out of the combustor and collected in the cone of the cyclone. A temperature excursion up to $2000^{\circ} \mathrm{F}$, indicated only by the bottom thermocouple in the combustor, occurred. A normal temperature profile existed in the remainder of the combustor even with the lack of bed material. Testing was discontinued at this time, and a final test at an average temperature of $1625^{\circ} \mathrm{F}$ was not performed.

\section{Summary of Results}

Upon completion of the run, data for each of the steady-state test periods were averaged. A summary of the process data for each test is presented in Table B-4. The ten test periods correspond to those presented in the test matrix listed in Table B-1. Summaries of the run data are presented at the end of Appendix B.

\section{Recirculation Rates and Size Distributions}

The solids recirculation rate was determined by calculating the heat balance around the external heat exchanger. The average solids recirculation rates for each test are 


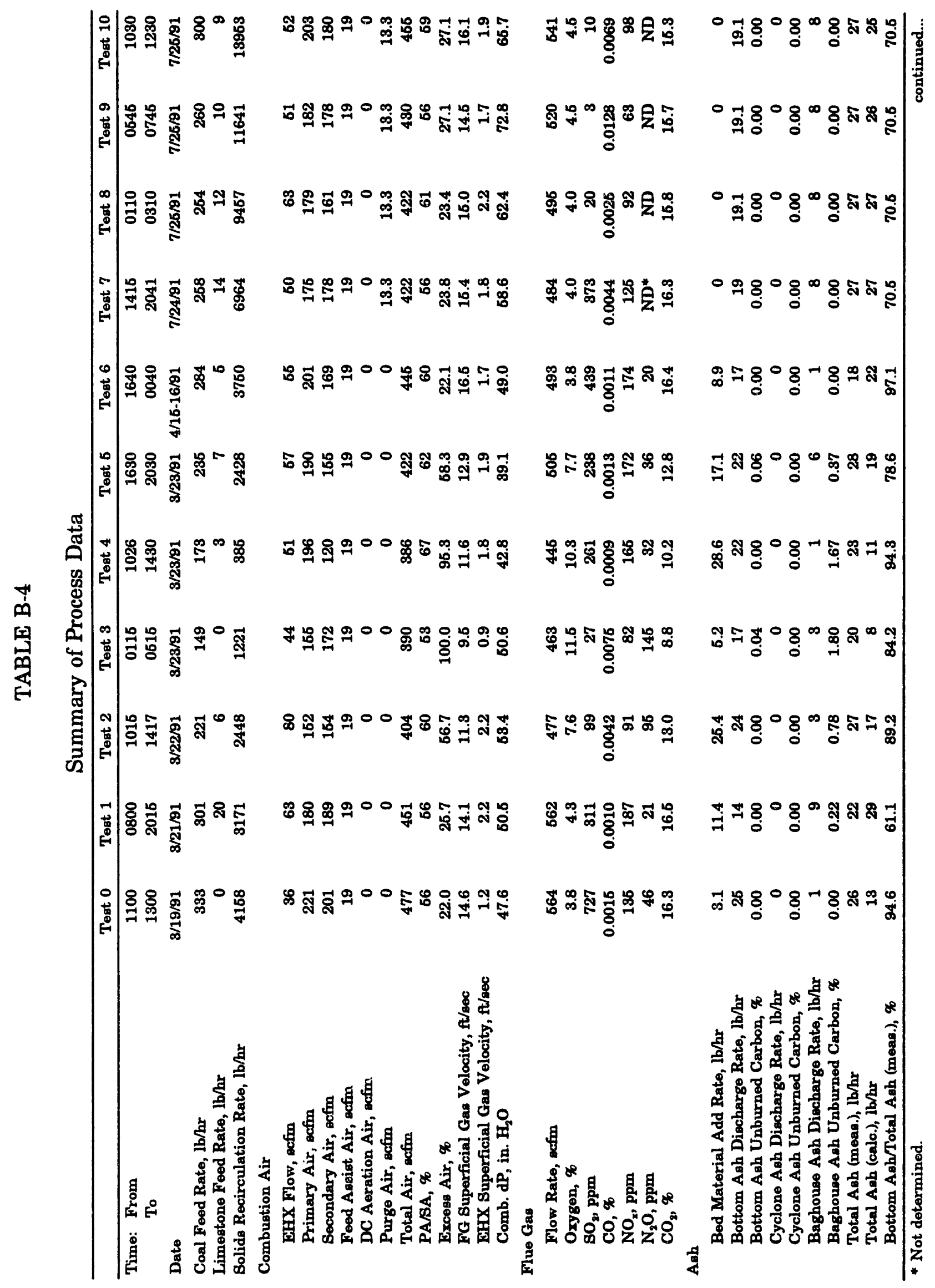




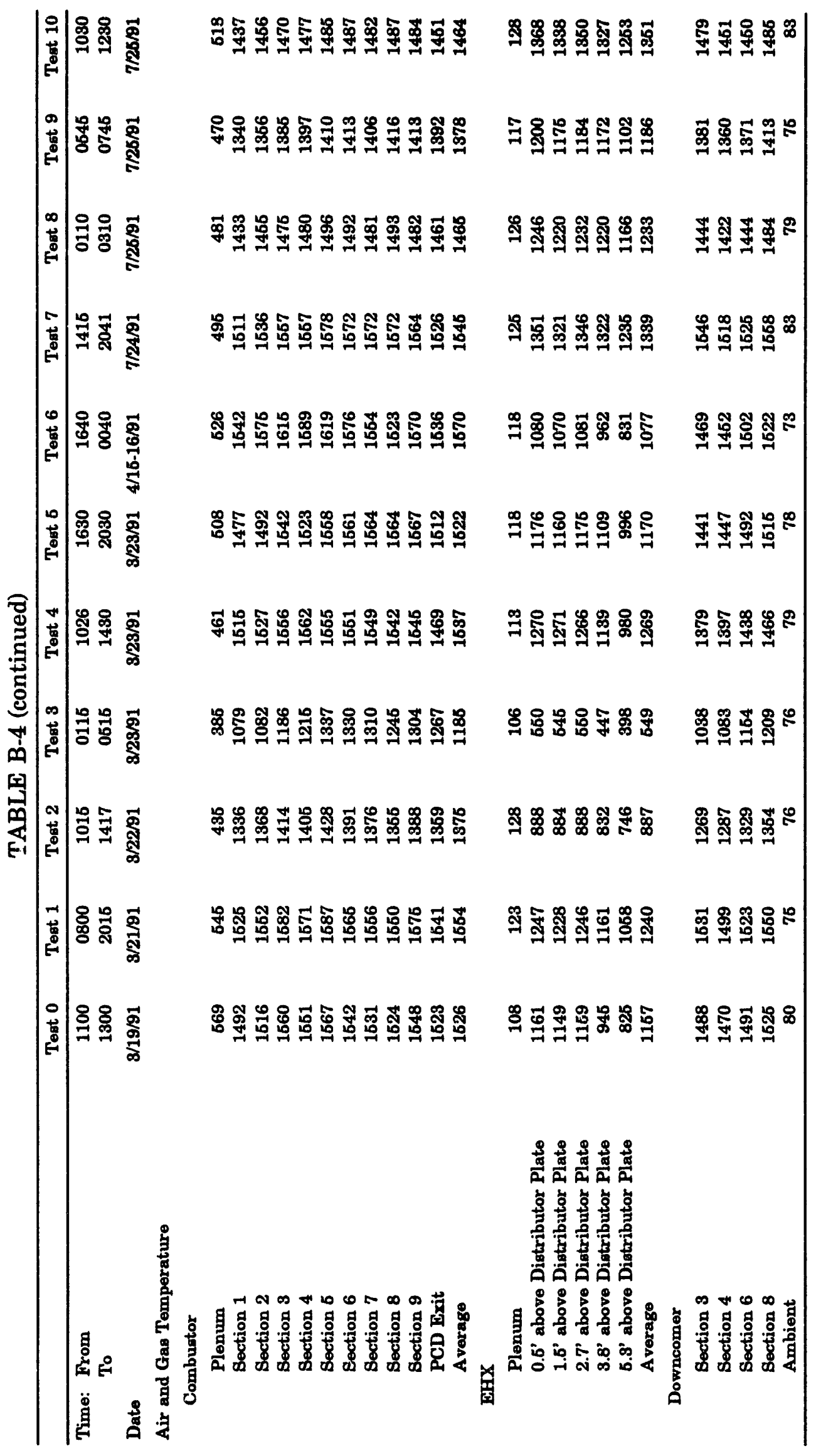


shown in Table B-5. The recirculation rates for the first seven tests (0-6) are low compared to those from the last four tests (7-10). This reflects differences in operation with the particle collection device for the first set of tests versus the cyclone for the second set of tests. It should be noted that ash from the secondary 18-inch cyclone was recycled to the downcomer for both weeks of testing. The relative recirculation rates for the tests are consistent with the operating conditions for each test. The recirculation rate decreased as the combustor velocity was decreased for the load tests. As the velocity is lowered, a smaller maximum particle size is carried out of the combustor, resulting in a lower recirculation rate. Similarly, increasing the velocity carries larger particles out of the combustor, resulting in a higher recirculation rate. The reason for the lower recirculation rate of Test 7 compared to 8 through 10 is unknown.

Primary cyclone collection efficiency is defined as one minus the ratio of fly ash collected to recirculation rate. During both weeks of testing, ash collected in the secondary 18-inch cyclone was recirculated. This resulted in an overall collection efficiency approaching $100 \%$ for all tests.

The particle-size distributions throughout the run were fairly consistent. Figure B-2 shows the particle-size distributions for the combustor bed material, downcomer material, ash-fouling section ash, and baghouse ash, respectively, for several of the tests.

\section{Bottom Ash/Total Ash Split}

The ash balance for the first eight test periods are presented in Table B-6. No balances were performed for the short duration emission tests (8, through 10). Ash input to the system was composed of calculated quantities of coal and limestone ash, based on their respective analyses and feed rates. The limestone-derived ash was further broken

TABLE B-5

Solids Recirculation and Heat-Transfer Data

\begin{tabular}{|c|c|c|c|c|c|c|c|c|c|c|}
\hline Tert & $\begin{array}{c}\text { Temperature } \\
\left({ }^{\circ} \mathrm{F}\right)\end{array}$ & $\mathrm{Ca} / \mathrm{S}$ & $\begin{array}{l}\text { Eicoss } \\
\text { Air (\%) } \\
\end{array}$ & $\begin{array}{c}\text { Primary } \\
\text { Air (\%) }\end{array}$ & $\begin{array}{c}\text { Solids } \\
\text { Rociroulation } \\
(\mathrm{b} / \mathrm{b} \mathbf{h r})\end{array}$ & $\begin{array}{c}\mathrm{DC}^{2} \\
\mathrm{~d}_{60} \\
(\mu \mathrm{m}) \\
\end{array}$ & $\mathrm{H}_{0}{ }^{2}$ & $\begin{array}{l}\text { Heat Flux } \\
\text { (Btu/hr-ft })\end{array}$ & $\begin{array}{c}\text { Cyclone } \\
\text { Efficioncy } \\
(\%)\end{array}$ & $\begin{array}{c}\begin{array}{c}\text { Rocirculation } \\
\text { Ratio }\end{array} \\
\end{array}$ \\
\hline 0 & 1,526 & 0.9 & 22.0 & 66 & 4,168 & 330 & 18.1 & 25,647 & 99.97 & 341 \\
\hline 1 & 1,654 & 4.0 & 25.7 & 56 & 3,171 & 330 & 16.5 & 23,818 & 99.73 & 90 \\
\hline 2 & 1,376 & 2.6 & 66.7 & 60 & 2,448 & 250 & 13.1 & 16,782 & 99.88 & 142 \\
\hline 3 & 1,185 & 1.2 & 100.0 & 53 & 1,221 & 300 & 10.3 & 11,398 & 99.74 & 169 \\
\hline 4 & 1,537 & 2.2 & 96.3 & 67 & $\mathrm{ND}^{8}$ & 280 & 19.0 & 26,946 & 99.66 & 32 \\
\hline 6 & 1,622 & 1.9 & 68.3 & 62 & 2,428 & ND & 17.0 & 23,768 & 99.76 & 122 \\
\hline 6 & 1,570 & 1.3 & 22.1 & 60 & 3,760 & ND & 16.6 & 23,860 & 99.99 & 179 \\
\hline 7 & 1,646 & 3.1 & 23.8 & 56 & 6,964 & ND & 19.6 & 27,362 & 99.89 & 231 \\
\hline 8 & 1,465 & 2.8 & 28.4 & 61 & 9,467 & ND & 19.0 & 25,290 & ND & ND \\
\hline 9 & 1,378 & 2.6 & 27.1 & 56 & 11,641 & ND & 20.6 & 25,621 & ND & ND \\
\hline 10 & 1,464 & 2.3 & 27.1 & 69 & 13,953 & ND & 21.8 & 28,812 & ND & ND \\
\hline
\end{tabular}

${ }^{1}$ Downcomer.

${ }^{2}$ Heat-trangfer coefficient (Btu/hr- $\left.\mathrm{tt}^{2} \cdot{ }^{\circ} \mathrm{F}\right)$.

${ }^{8}$ Not determined. 


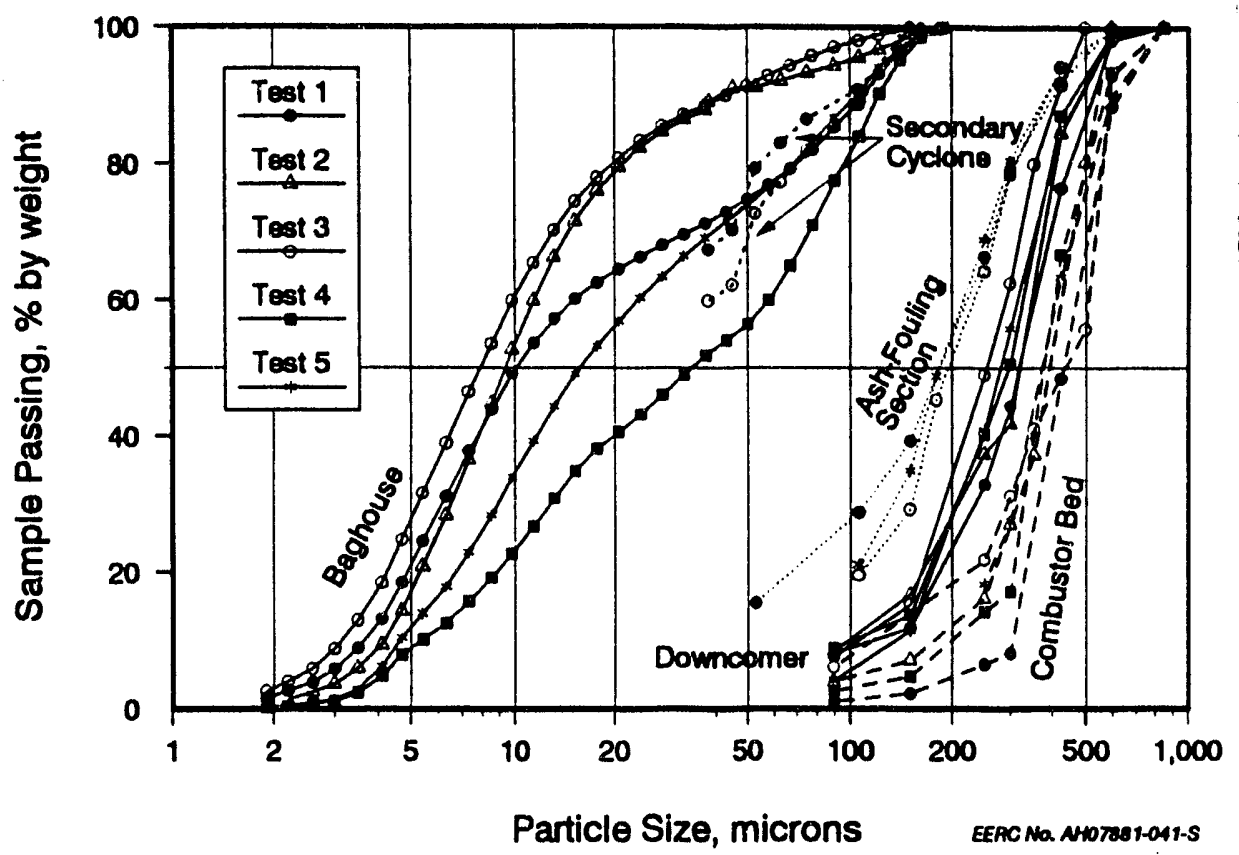

Figure B-2. Size distribution of combustor bed material, downcomer, ash-fouling section ash, secondary cyclone ash, and baghouse ash.

TABLE B-6

Ash Balance

\begin{tabular}{lrrrrrrrr}
\hline & Test 0 & Test 1 & Test 2 & Test 3 & Test 4 & Test 5 & Test 6 & Test 7 \\
\hline $\begin{array}{l}\text { Input, lb/hr } \\
\quad \text { Ash }\end{array}$ & 13 & 16 & 12 & 8 & 9 & 13 & 17 & 18 \\
$\quad$ Sorbent* & & & & & & & & \\
$\quad$ CaO & 0 & 9 & 2 & 0 & 1 & 2 & 2 & 7 \\
$\quad$ CaSO & 0 & 4 & 2 & 0 & 1 & 3 & 3 & 4 \\
Total Solids In & $\underline{13}$ & $\underline{29}$ & $\underline{17}$ & $\underline{8}$ & $\underline{11}$ & $\underline{19}$ & $\underline{21}$ & $\underline{28}$ \\
Output, lb/hr & & & & & & & & \\
$\quad$ Bed Material & 25 & 14 & 24 & 17 & 22 & 22 & 17 & 19 \\
$\quad$ Cyclone Ash & 0 & 0 & 0 & 0 & 0 & 0 & 0 & 0 \\
$\quad$ Baghouse Ash & 1 & 9 & 3 & 3 & 1 & 6 & 1 & 8 \\
Total Solids Out & $\underline{26}$ & $\underline{22}$ & $\underline{27}$ & $\underline{20}$ & $\underline{23}$ & $\underline{28}$ & $\underline{18}$ & $\underline{27}$ \\
Closure, \% & 202.9 & $\mathbf{7 5 . 0}$ & 161.9 & 265.7 & 206.4 & 148.7 & 82.2 & 98.0 \\
Bottom Ash/Total Ash, \% & 94.6 & 61.1 & 89.2 & 84.2 & 94.3 & 78.6 & 97.1 & 70.5 \\
\hline
\end{tabular}

* The $\mathrm{CaO}$ and $\mathrm{CaSO}_{4}$ mass inputs are included to express sorbent equivalent mass inputs. 
down into estimates of the sorbent which was either calcined or had undergone sulfation. The output was composed of measured quantities of bottom ash (drained from the combustor bed), fly ash removed from the secondary cyclone, and fly ash removed from the baghouse.

The ratios of bottom ash-to-total ash, as well as the percent closures, are included in Table B-6. The poor closure for some of the tests are likely due to errors in measuring small amounts of material and, possibly, from the carryover of some of the initial bed material that is not accounted for in the input stream. The bottom-to-total ash split for the tests ranged from about $61 \%$ to about $97 \%$. These high bottom-to-total ash splits are likely due to the high collection efficiency of the secondary cyclone. If a full-scale system did not reinject ash from a secondary collection device, a greater proportion of fly ash would be generated.

An alumina material balance, which had been used for determining the contributions of coal ash and limestone at each solids removal point, was not performed for the Center lignite run. Insufficient analyses were performed on the solids streams to calculate an alumina balance.

\section{THERMAL PERFORMANCE}

\section{Energy and Material Balances}

The measured and theoretical fuel and flue gas flow rates are presented in Tables B-7 and B-8, respectively. The theoretical fuel feed rate was calculated using actual fuel characteristics, measured combustion air, and measured $\mathrm{O}_{2}$ and $\mathrm{CO}_{2}$ concentrations in the flue gas. The theoretical flue gas rates were calculated using the actual coal feed rate and excess air level for each test. In most cases, the measured and theoretical rates were similar.

The energy balances for each test are presented in Table B-9 both as Btu/hr and percentages. The energy input was made up of the energy potential of the fuel, the primary and secondary combustion air, the external heat exchanger fluidizing air, and the energy released from the sulfation of the sorbent. Measurable heat loss sources were the combustor heat exchange doors, the external heat exchanger cooling coils, the flue gas, the unburned carbon in the ash removed, the heat present in the ash removed, and the energy absorbed during calcination of the sorbent. Flue gas losses include a correction for leakage. The unmeasurable heat loss due to convection and radiation is based upon a correlation developed from testing with several coals that takes into account the average operational combustor temperature.

The material balances for the eleven test periods are shown in Table B-10. Material balance inputs are the combustion air, additional air (including the external heat exchanger fluidizing air, pressure tap purges, downcomer assist air, and coal feed assist air), coal and sorbent feed rates, and bed material addition. Outputs are the measured flue gas, flue gas leaks (based on the difference between the measured and the theoretical flue gas flow rates shown in Table B-8), and measured quantities of bed material, secondary cyclone ash, and baghouse ash removed from the system. Good material balance closures were obtained for all tests and ranged from $100.1 \%$ to $101.2 \%$. 


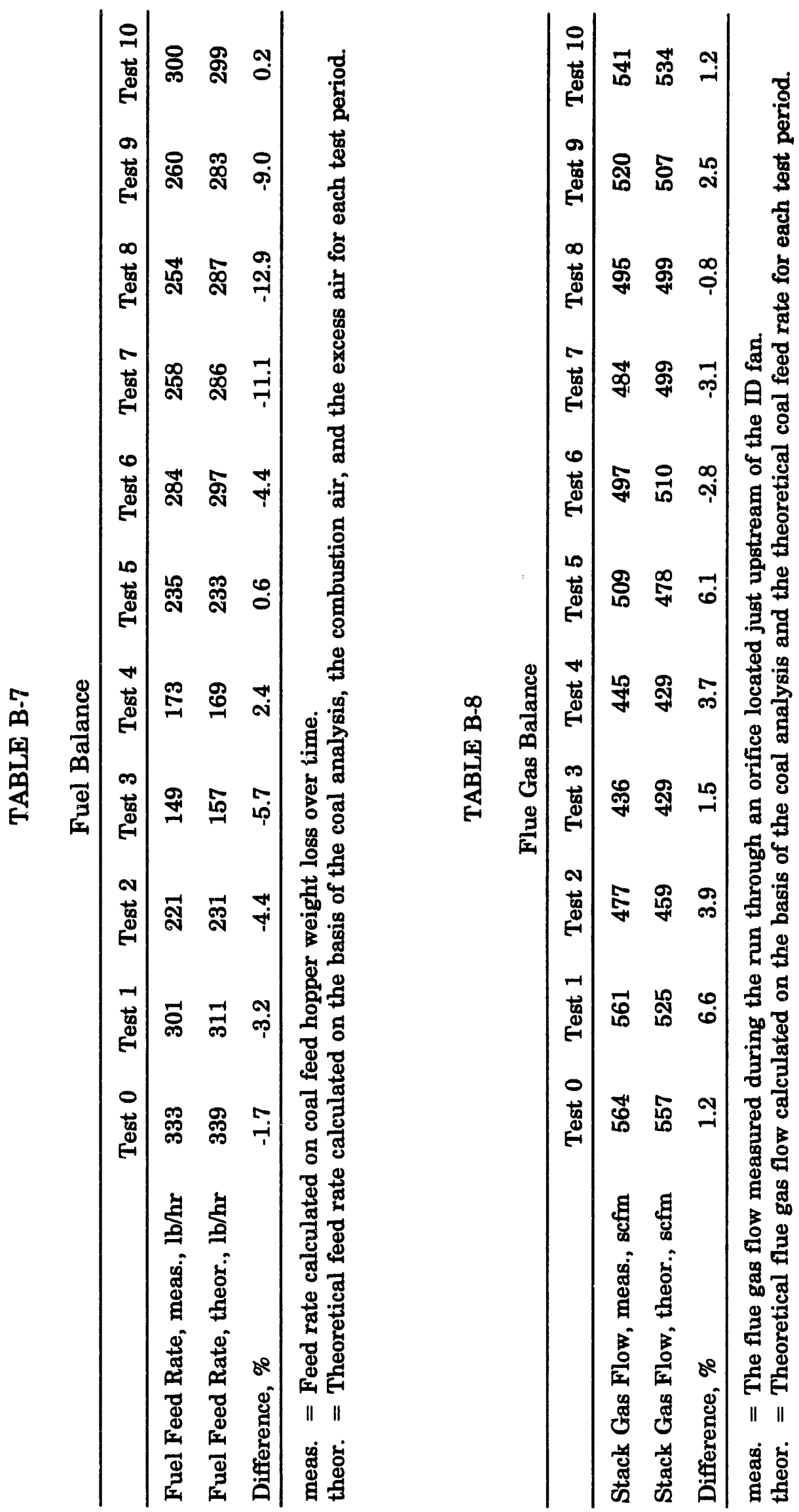




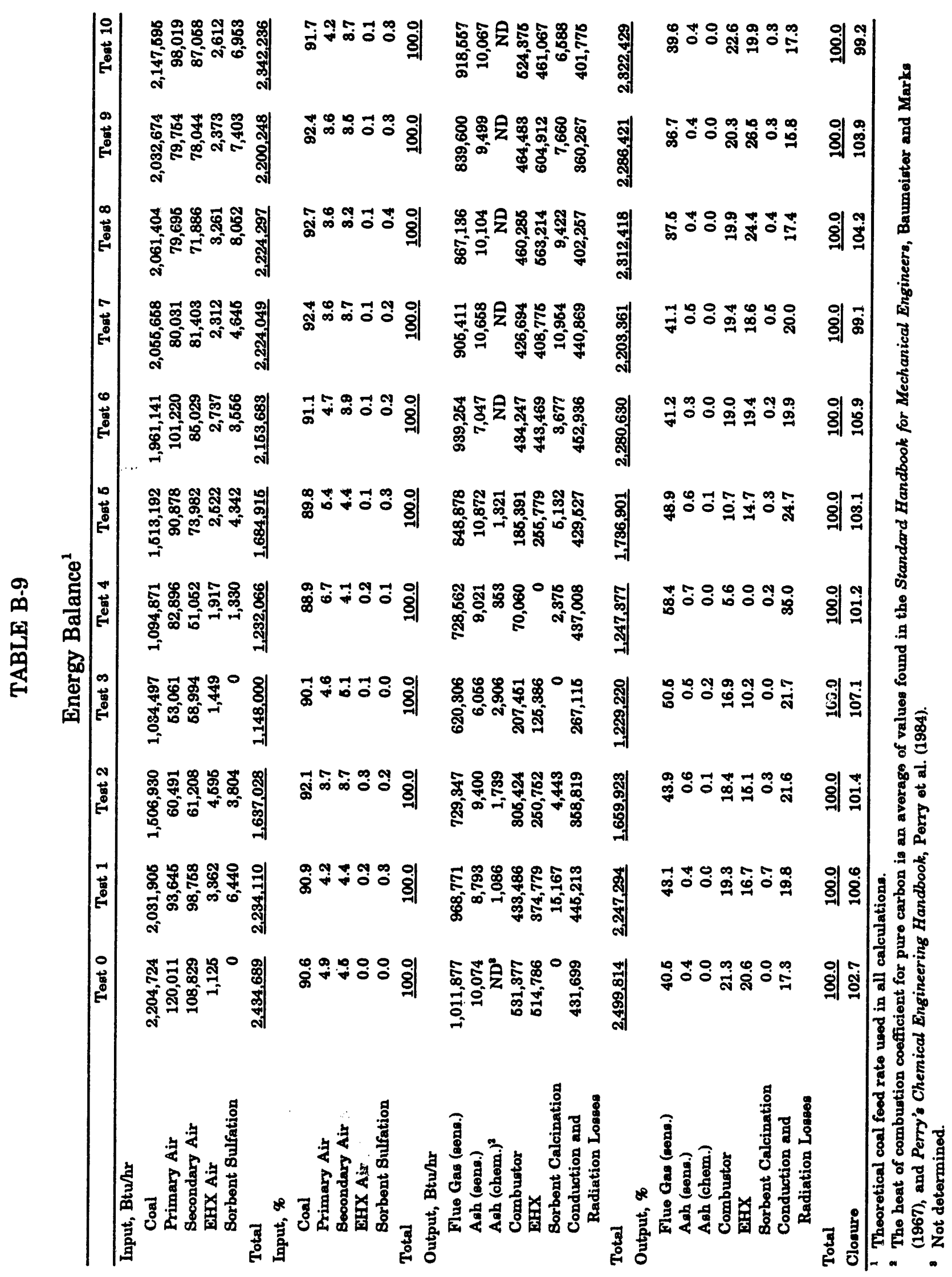




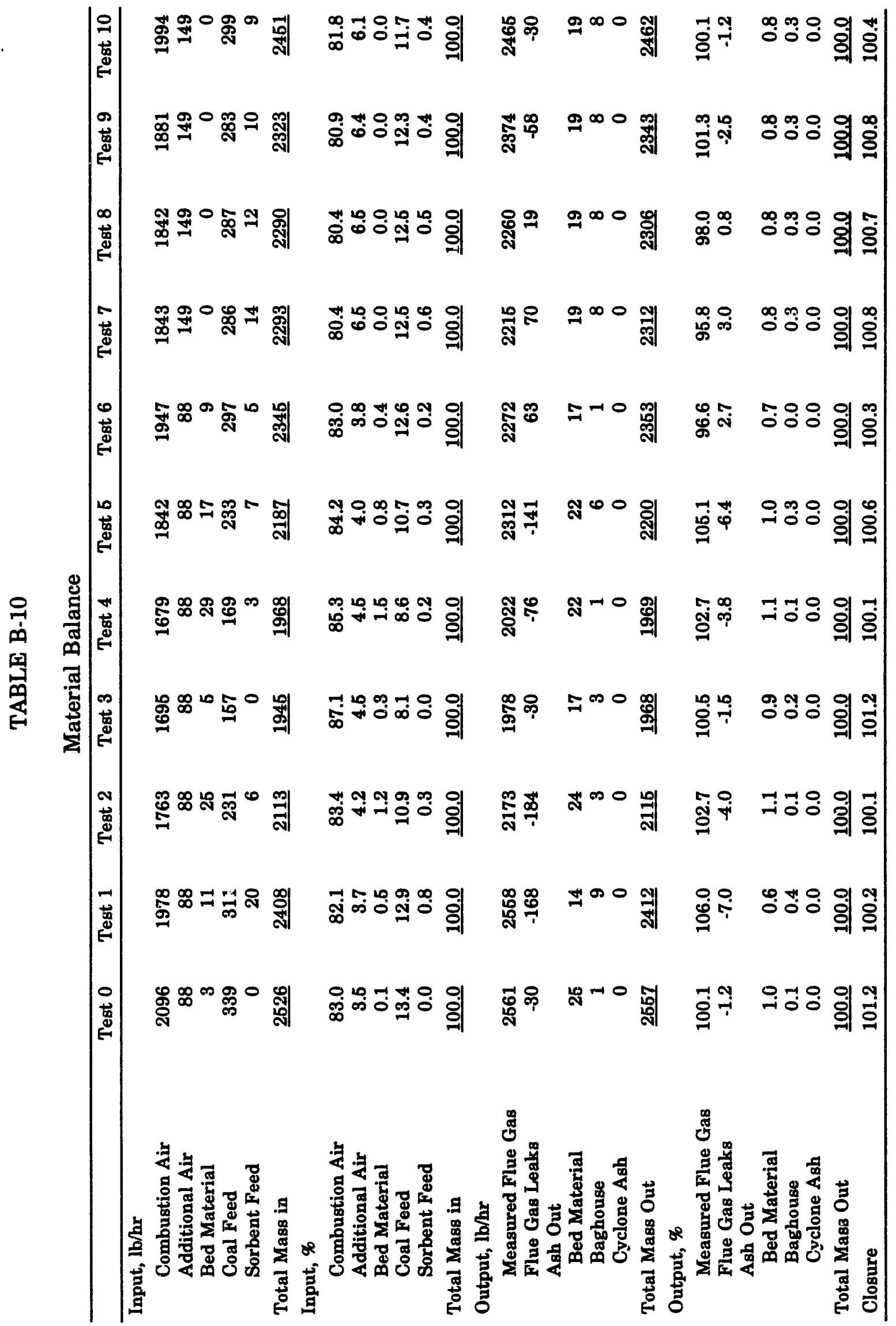




\section{Combustion Efficiency}

The combustion efficiencies for Tests 1 through 5 are presented in Table B-11 and Figure B-3. The combustion efficiencies for the five tests were very high, with very little unburned carbon in the drained bed material or baghouse ash (Table B-12). Insufficient samples were taken during Tests 0,6 , and 7 for combustion efficiency to be calculated. Solid samples were not taken for the emission tests ( 8 through 10 ).

\section{Boiler Efficiency}

Boiler efficiencies were calculated for each test period using a modified version of ASME PTC 4.1. The modifications to the PTC 4.1 are those recommended in EPRI's "Atmospheric Fluidized-Bed Combustion Performance Guidelines." The basic modification made to PTC 4.1 is a method to account for the heat losses and gains associated with calcination and sulfation of the limestone.

Table B-13 summarizes the results of boiler efficiency calculations for the Center lignite tests. In performing these calculations, boiler radiation and convective losses were assumed to be $0.4 \%$. Although these losses were much higher for our pilot plant, $0.4 \%$ was chosen as a number that is representative of a full-scale system. Vendors may quote slightly different radiation and convective losses. The boiler efficiency numbers presented here also do not include unaccounted losses and manufacturing margins that are typically specified by the vendor. An exit gas temperature of $300^{\circ} \mathrm{F}$ was used in the efficiency calculations.

For full-load operation, the boiler efficiency was approximately $86.5 \%$. As the load was reduced, the boiler efficiency decreased at a rate of $1 / 2$ percentage point for each $10 \%$ increase in excess air. The moisture and hydrogen accounted for about $6.8 \%$ of the losses and is constant for all tests. The loss due to solids removal increased as the limestone feed rate was increased due to the generation of more solids. Contributions due to sorbent calcination and sulfation are also a function of sorbent feed rate. The major change between tests is the dry flue gas losses, which are directly related to excess air level.

\section{Heat-Transfer Coefficient and Heat Flux}

During testing, the combustor heat exchange surfaces used for heat removal were in Sections 2, 3, 4, 6, 7, and 8. Flow rates and temperatures of the cooling water in the combustor heat exchangers were monitored to allow calculation of heat-transfer coefficients and heat fluxes as a function of position in the combustor. Heat transfer and heat flux within the EHX were also calculated based upon the total flow and overall temperature difference of the cooling water from the EHX heat exchange coils. The average values of heat-transfer coefficient and heat flux for each combustor section which contains one or more heat exchangers, as well as from the EHX, are presented in Tables B-14 and B-15. The combustor heat-transfer data are also summarized in Table B-5 to facilitate comparison to test conditions.

The combustor heat flux calculated for this run ranged from $11,398 \mathrm{Btu} / \mathrm{hr}^{-\mathrm{ft}^{2}}$ for Test 3 to $28,812 \mathrm{Btu} / \mathrm{hr}$ - $\mathrm{ft}^{2}$ for Test 10 . Similarly, the EHX heat flux ranged from $27,864 \mathrm{Btu} / \mathrm{hr}$ - $\mathrm{ft}^{2}$ to $122,951 \mathrm{Btu} / \mathrm{hr}-\mathrm{ft}^{2}$ for Tests 3 and 10 , respectively. The low heat fluxes observed during Tests 2 and 3 were the result of reduced load while operating with 

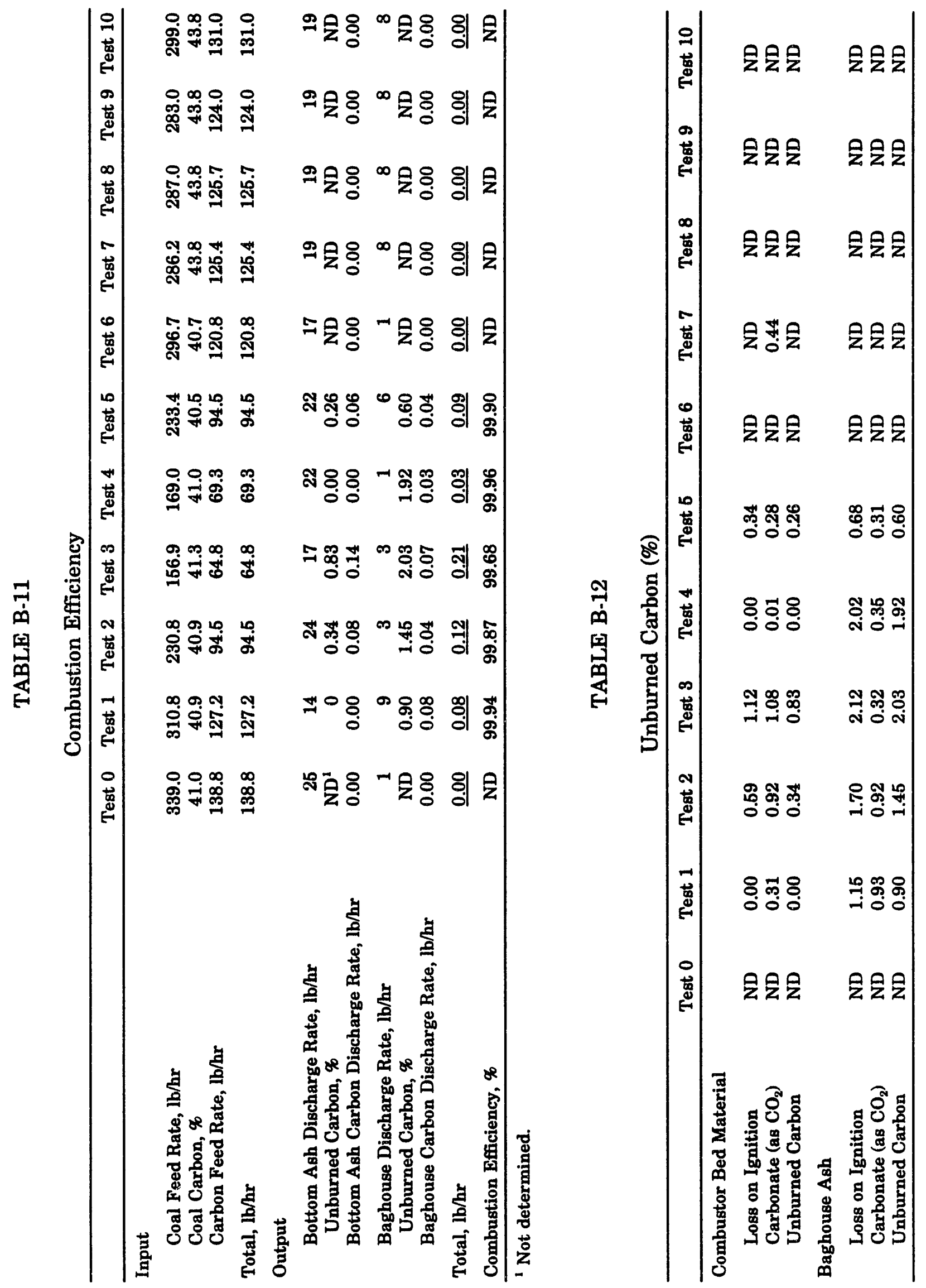


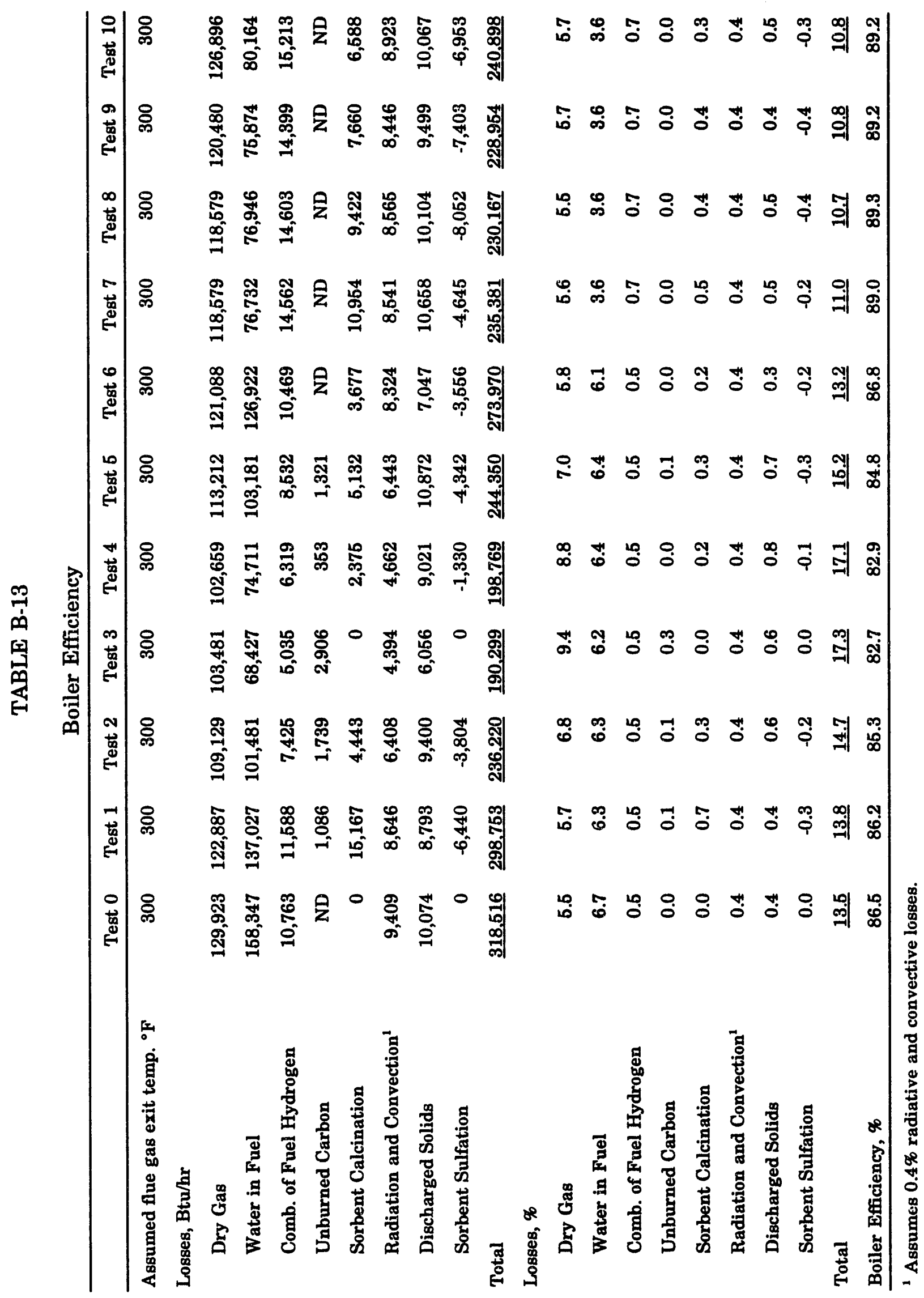




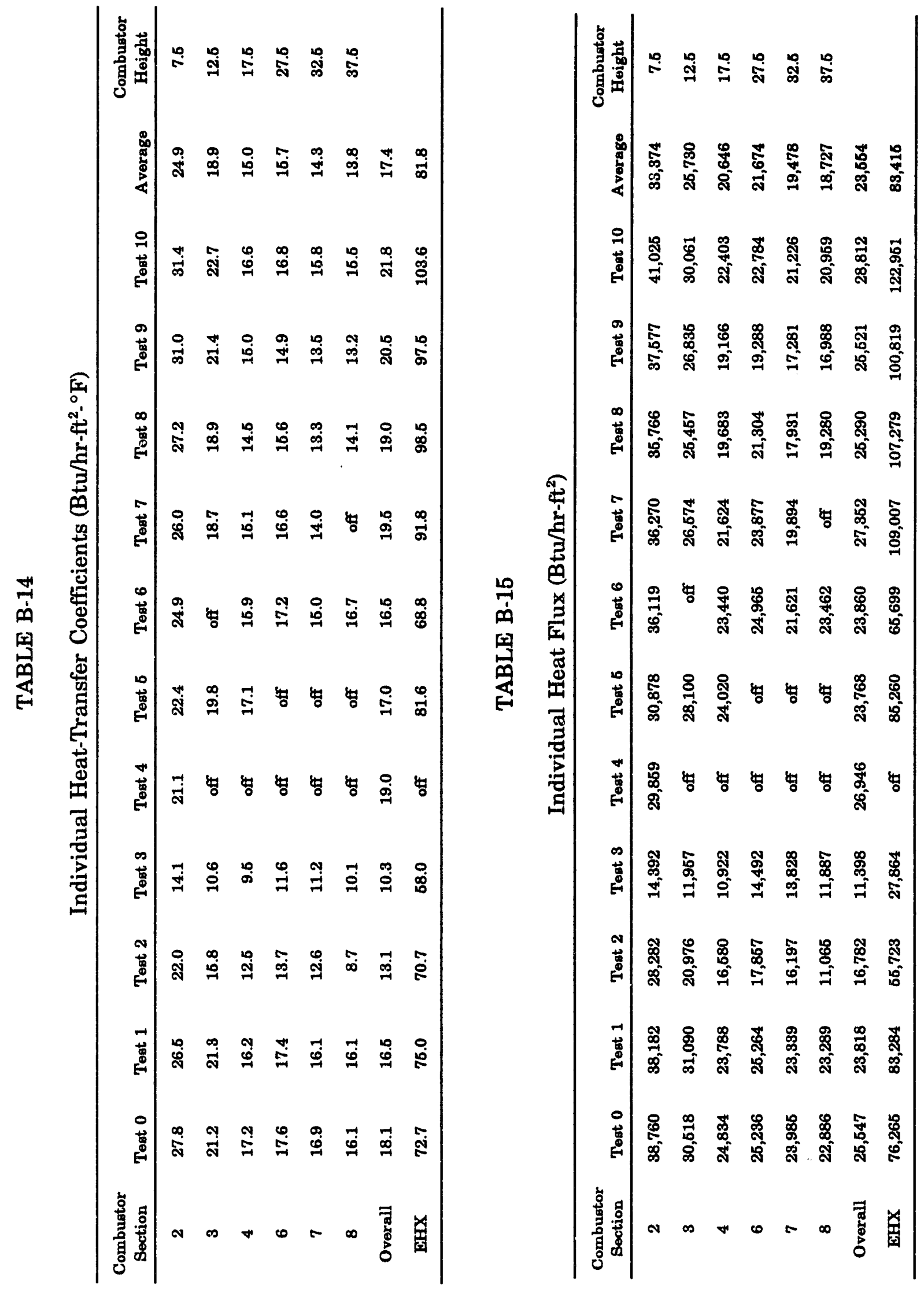




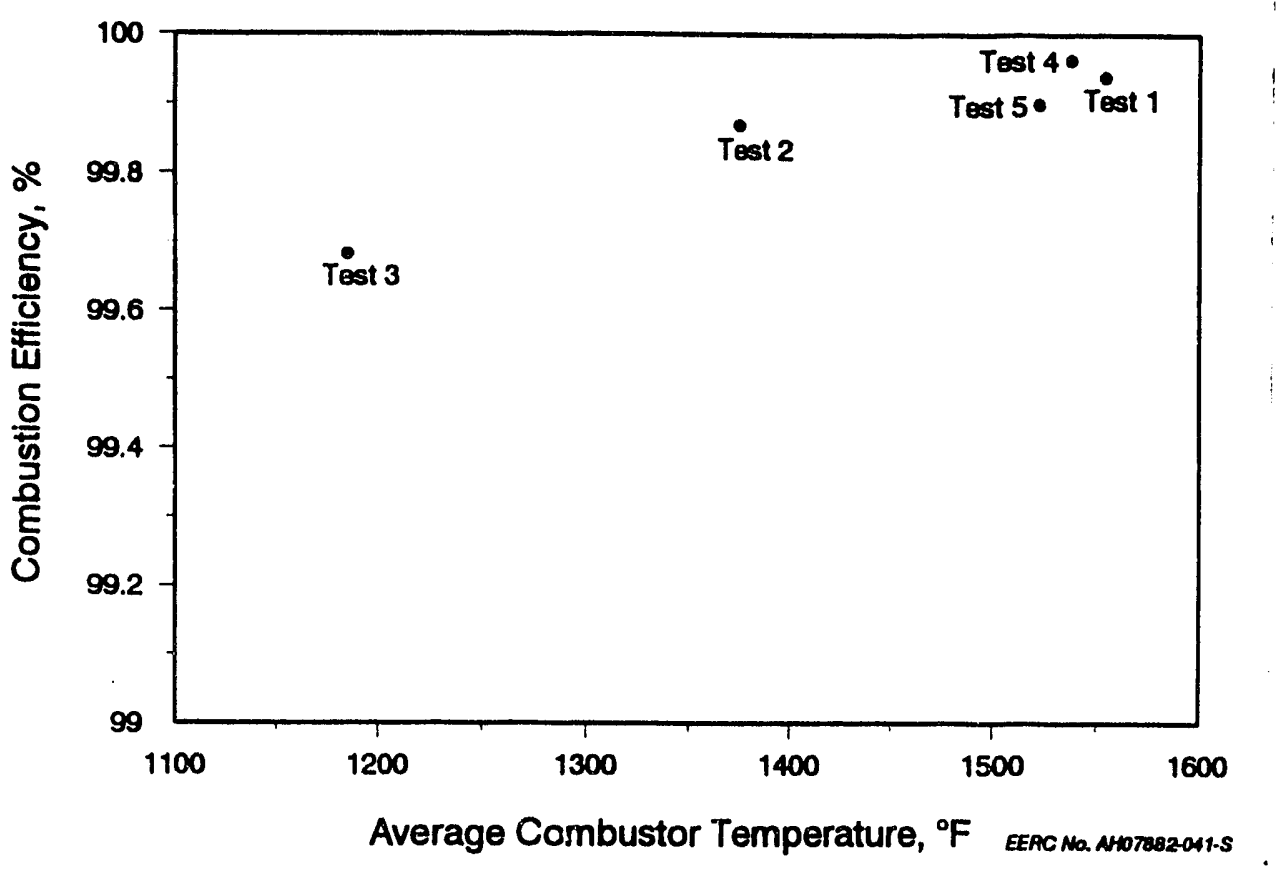

Figure B-3. Combustion efficiency as a function of temperature.

constant heat-transfer surface. During constant heat-transfer load reduction, the total amount of heat-transfer surface kept in service is equivalent to that used during the fullload baseline test with sorbent addition. By reducing load under constant heat-transfer conditions, operational temperatures and velocity are reduced, lowering the solids recirculation rate, thereby decreasing heat transfer. For Tests 4 and 5 , which utilized a constant temperature load reduction technique, heat-transfer surface was taken out of service, and combustor temperatures and velocity were maintained near full-load levels. Therefore, heat-transfer performance was affected to a lesser degree.

The heat flux measured for the full-load tests is similar to the 24,500 to $35,800 \mathrm{Btu} / \mathrm{hr}-\mathrm{ft}^{2}$ observed in previous runs on this unit and on full-scale units. There was limited variability in heat flux between the full-load tests. Similar trends were seen with the heat-transfer coefficients.

\section{Pressure and Temperature Profiles}

The pressure profiles for Tests 7 through 10 are presented in Figure B-4, and the temperature profiles for Tests 0 through 10 are presented in Figure B-5. The pressure profiles for Tests 0 through 6 were not plotted because the pressure taps quickly plugged with ash during those tests. Following Test 6 , a continuous air purge system was added to keep the pressure taps clear. The temperature profile for the full-load tests are quite uniform; areas of lower temperature are caused by heat-transfer doors in those sections of the combustor. The low-load tests ( 2 and 3 ) which correspond to those systems without an external heat exchanger have a much lower temperature in the bottom of the combustor than the top. 


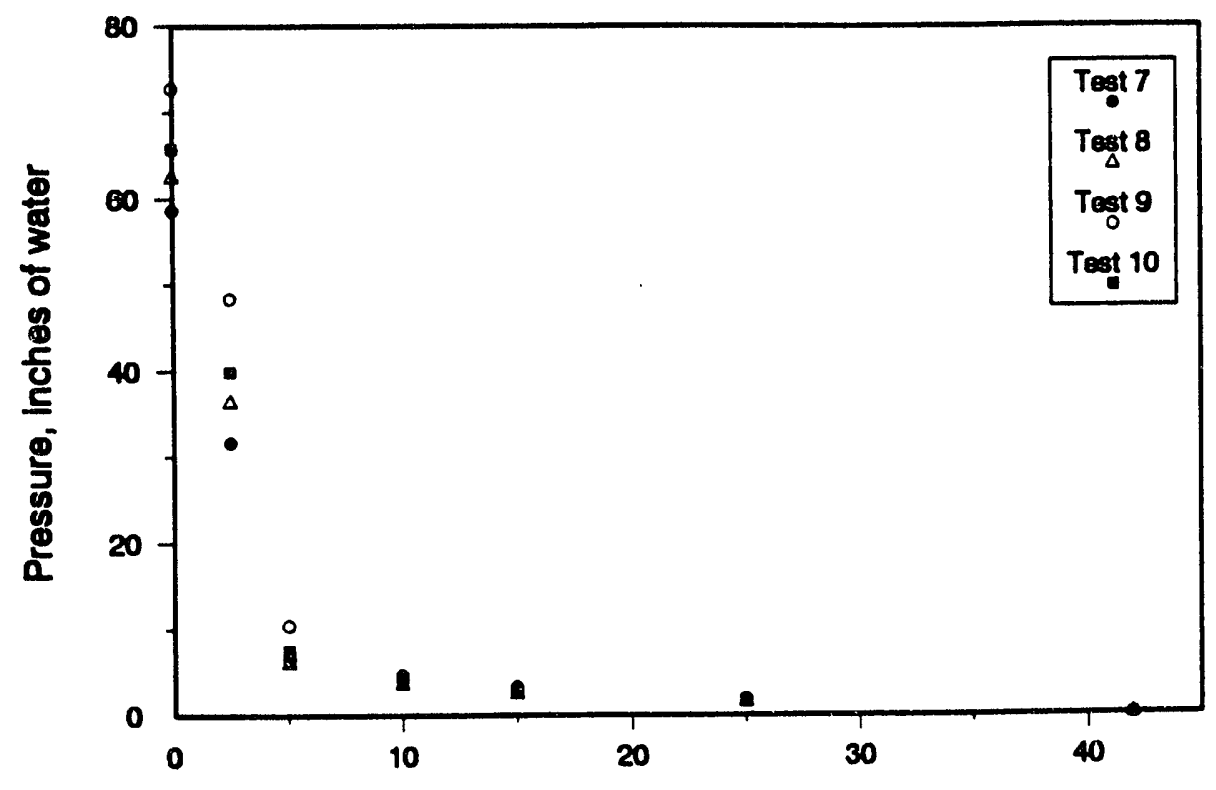

Height above Distributor Plate, ft enc na notreasurs

Figure B-4. Combustor pressure profiles.

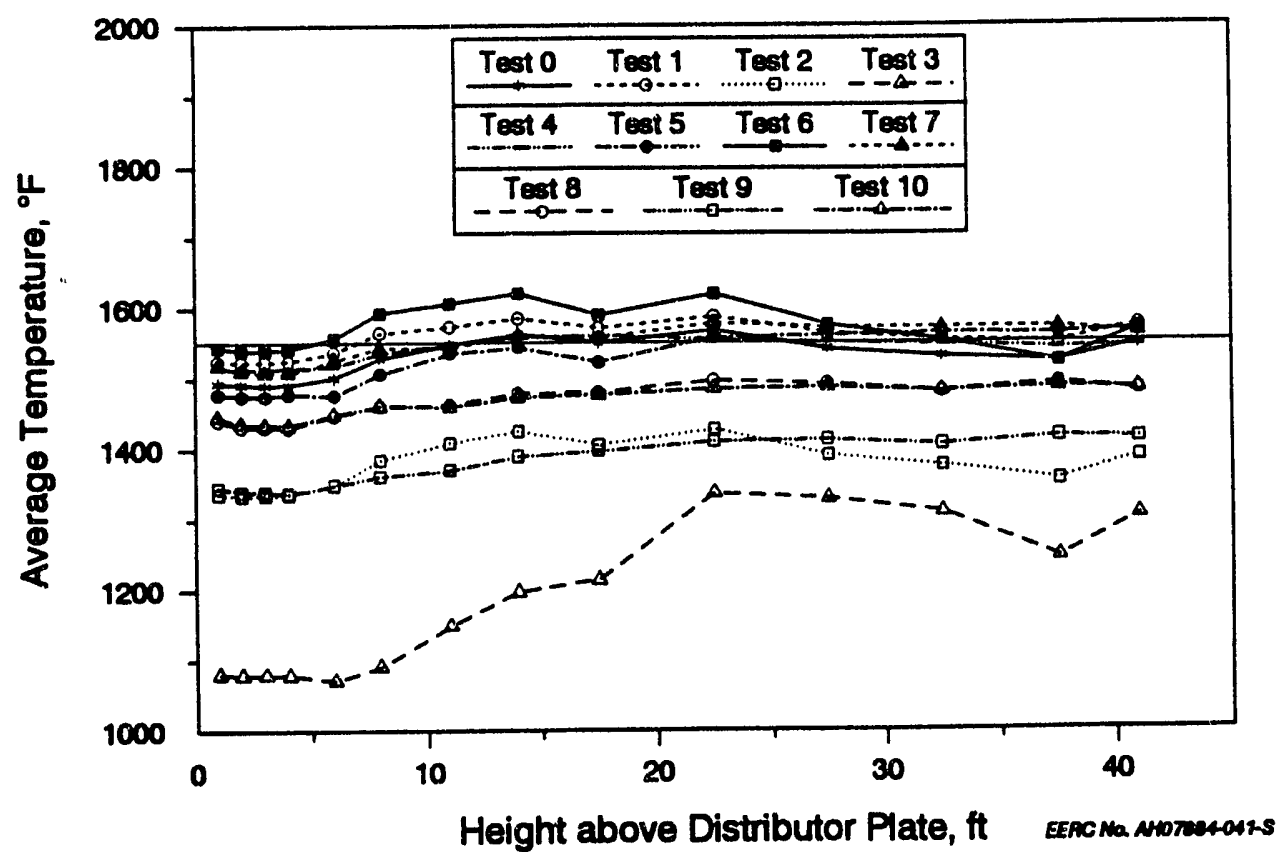

Figure B-5. Combustor temperature profiles. 


\section{ENVIRONMENTAL PERFORMANCE}

Average flue gas emissions for each of the steady-state test periods are presented in Table B-16 and discussed in the following sections. All of the emissions are represented graphically in relation to average combustor temperature. The trends noted in all cases were the same as expected based on previous experience.

\section{$\mathrm{SO}_{2}$ Emissions}

Uncontrolled sulfur emissions for the Center lignite, corrected to 3\% oxygen, were $760 \mathrm{ppm}(1.406 \mathrm{lb} / \mathrm{MM} \mathrm{Btu})$. For those tests with limestone addition, the average concentration of $\mathrm{SO}_{2}$ in the flue gas varied from 3 to $459 \mathrm{ppm}(0.006$ to $0.839 \mathrm{lb} / \mathrm{MMM} \mathrm{Btu})$, depending upon the operating temperature and ratio of calcium to sulfur in the system. Figure B-6 shows that the lowest $\mathrm{SO}_{2}$ emissions occurred under Test 8,9 , and 10 conditions, during which the average combustor temperature ranged from $1375^{\circ}$ to $1475^{\circ} \mathrm{F}$. These data indicate that the optimum temperature for sulfur capture using the Center lignite is approximately $1400^{\circ}$ to $1450^{\circ} \mathrm{F}$. This is lower than is reported for other coals; however, it is consistent with tests using North Dakota lignites in bubbling beds where the optimum sulfur capture was obtained at approximately $1425^{\circ} \mathrm{F} .^{1}$

Figure B-7 is a plot of the measured sulfur retention versus total alkali-to-sulfur $(\mathrm{Ca} / \mathrm{S})$ ratio expressed on a molar basis. The data can be separated into two sets: those at $1545^{\circ} \mathrm{F}$ and those at lower temperatures. At equivalent $\mathrm{Ca} / \mathrm{S}$ ratios, the sulfur retention was approximately $30 \%$ more for the low-temperature tests as compared to those at $1545^{\circ} \mathrm{F}$, indicating that low-temperature operation is preferred for this coal in terms of sulfur capture. Overall, a Ca/S ratio of approximately 2 (1.0 from limestone plus 1.0 inherent with coal) is needed to achieve an $\mathrm{SO}_{2}$ retention of $90 \%$ for combustor temperatures between $1400^{\circ}$ and $1450^{\circ} \mathrm{F}$. As shown in Figure B-7, the alkali inherent in the coal ash was sufficient to achieve $23 \% \mathrm{SO}_{2}$ retention at $1550^{\circ} \mathrm{F}$.

\section{NO Emissions}

Flue gas emissions of $\mathrm{NO}_{\mathrm{x}}$ (corrected to $3 \% \mathrm{O}_{2}$ ) ranged from 69 to $278 \mathrm{ppm}(0.090$ to $0.368 \mathrm{lb} / \mathrm{MM} \mathrm{Btu}$ ). The effect of temperature on $\mathrm{NO}_{\mathrm{z}}$ emissions is shown in Figure $\mathrm{B}-8$, with $\mathrm{NO}_{\mathrm{x}}$ increasing with increasing temperature. $\mathrm{NO}_{\mathrm{x}}$ emissions were high during Tests 2 through 5 due to the excess air levels required for these load tests. The low $\mathrm{NO}_{\mathrm{x}}$ values for Tests 2 and 3 (122 and 156 ppm) relative to Tests 4 and 5 (278 and $232 \mathrm{ppm}$ ) indicate that $\mathrm{NO}_{\mathrm{x}}$ emissions will be lower at low load for those combustion systems operating without an external heat exchanger. This is due to the corresponding lower combustor temperatures.

\section{$\mathrm{N}_{2} \mathrm{O}$ Emissions}

Although emissions of nitrous oxide $\left(\mathrm{N}_{2} \mathrm{O}\right)$ are currently unregulated, relatively high values have been measured from $\mathrm{FBC}$ systems. Because $\mathrm{N}_{2} \mathrm{O}$ is both a greenhouse gas and an ozone destroyer, it may become regulated sometime in the future. The $\mathrm{N}_{2} \mathrm{O}$

1 Mann, M.D.; Zobeck, B.J.; Hajicek, D.R. "Comparison of FBC Performance as a Function of Coal Rank," 88-JPGC/FACT-3. 


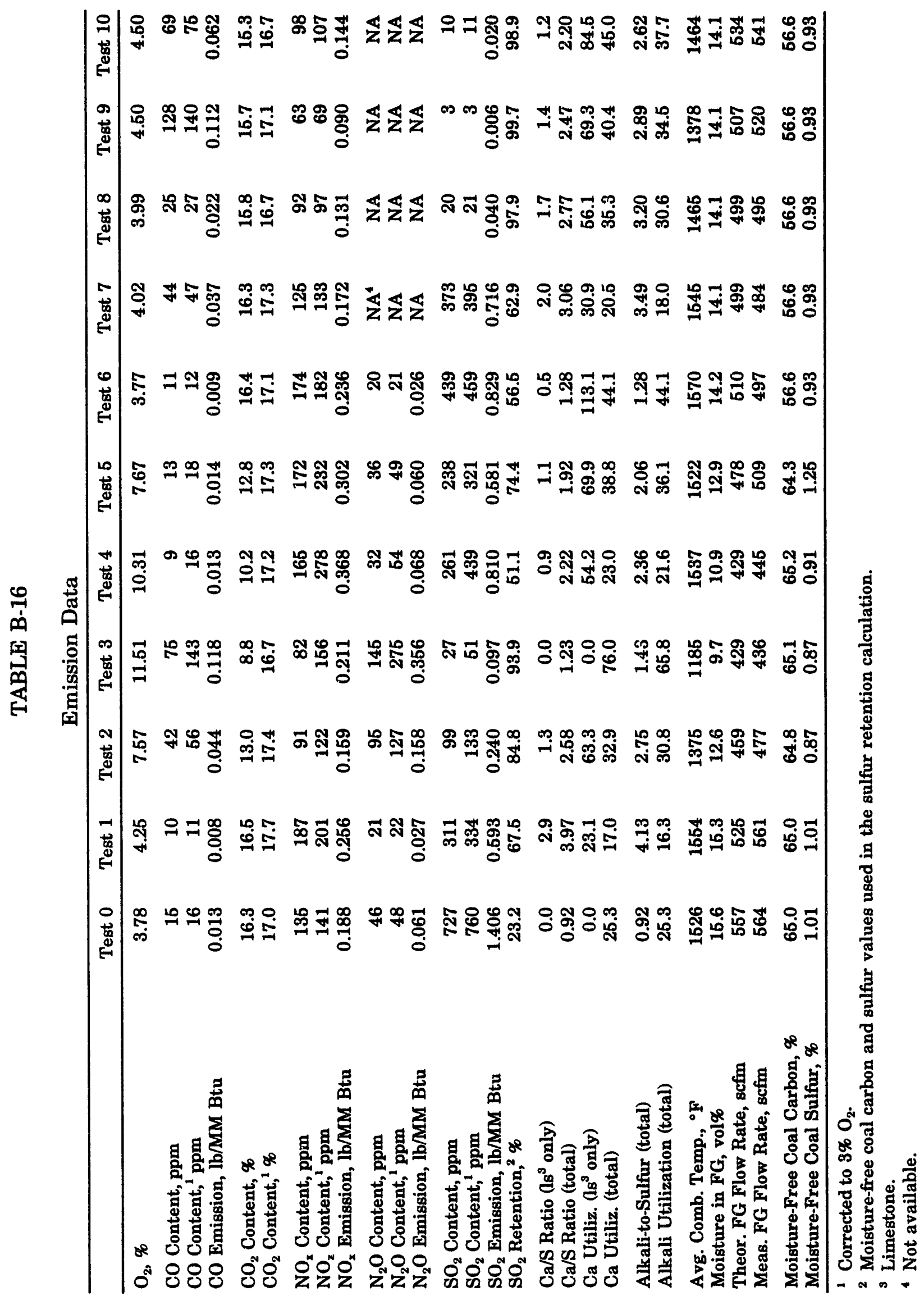




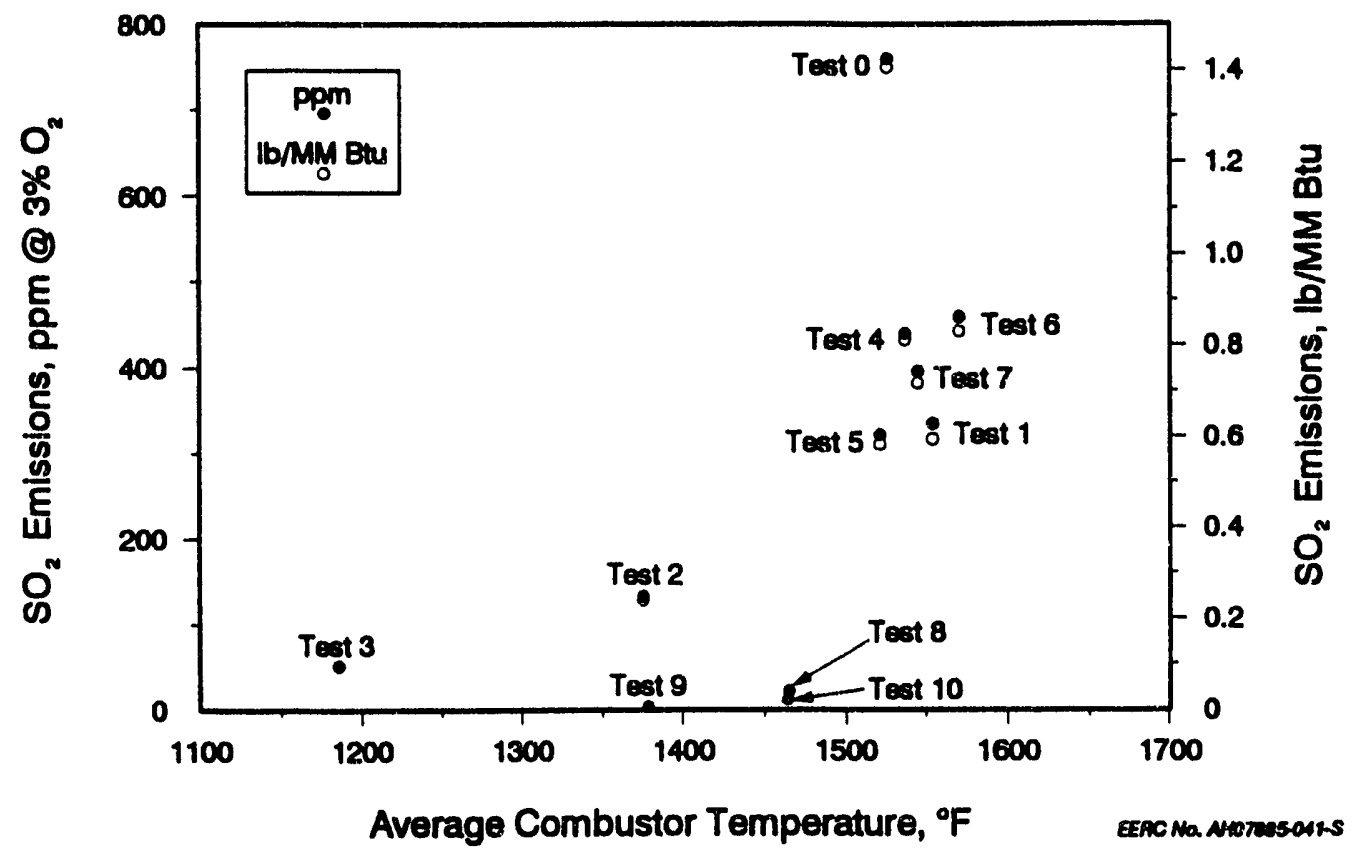

Figure B-6. $\mathrm{SO}_{2}$ emissions as a function of average combustor temperature.

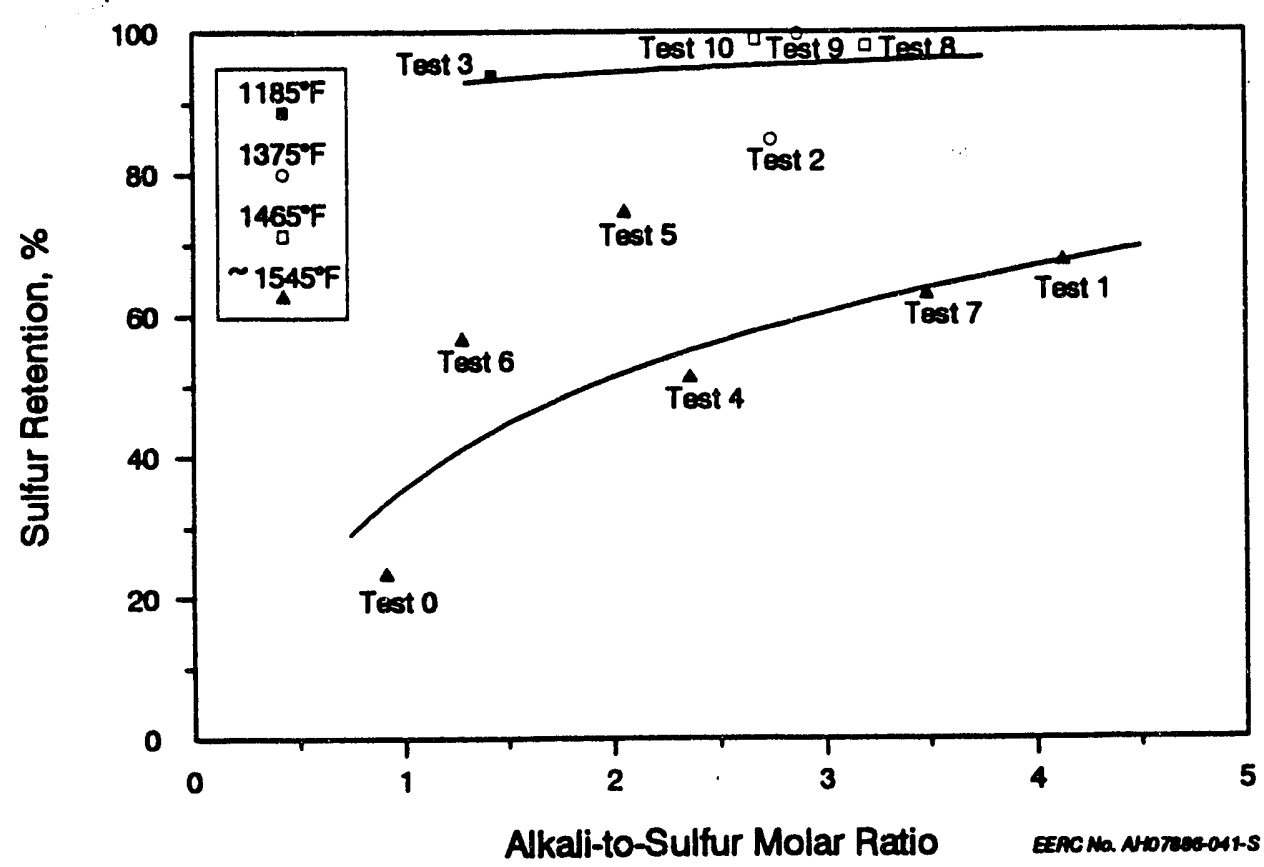

Figure B-7. $\mathrm{SO}_{2}$ retention as a function of alkali-to-sulfur molar ratio. 


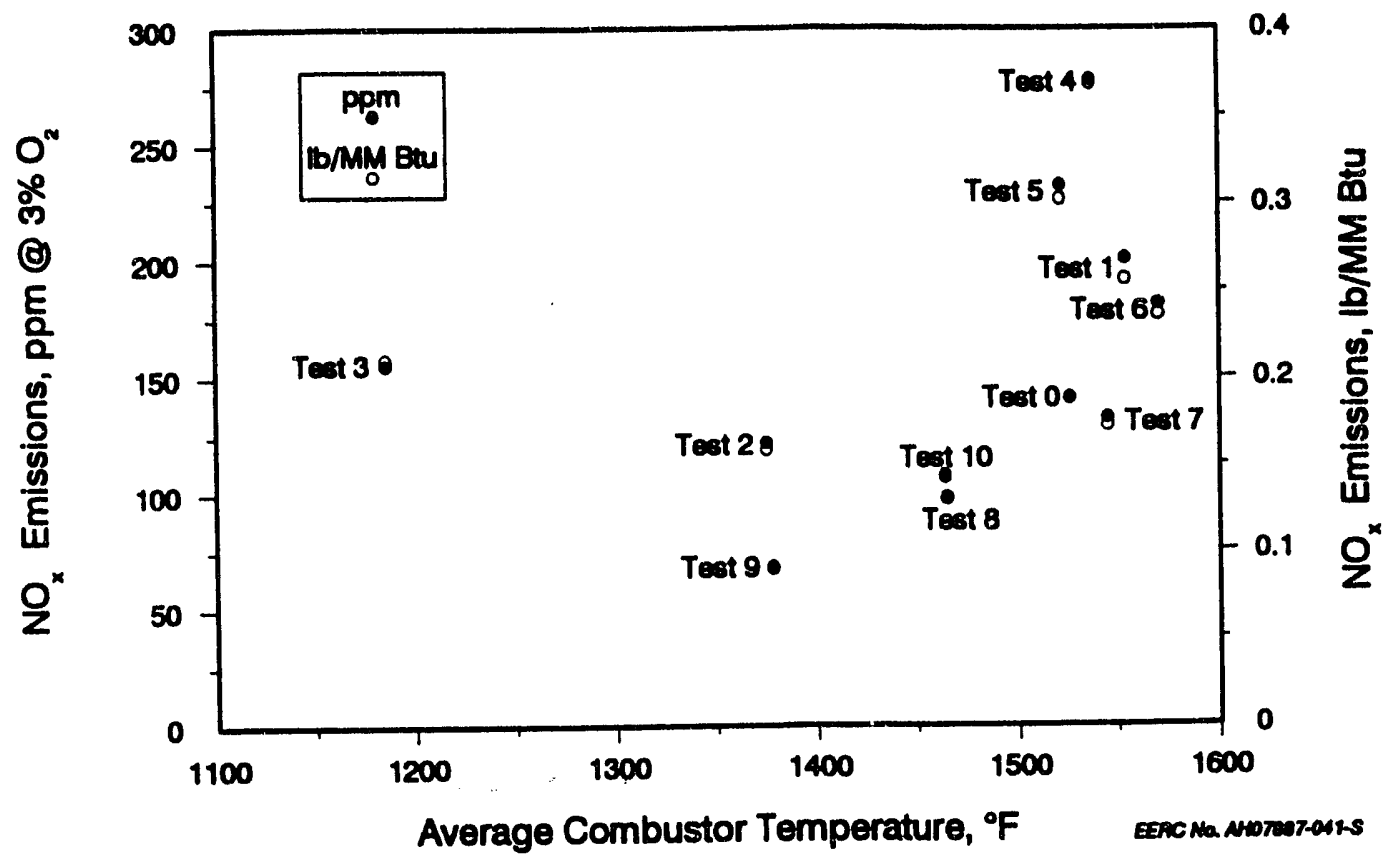

Figure B-8. $\mathrm{NO}_{\mathrm{x}}$ emissions as a function of average combustor temperature.

emissions from the Center lignite test burn ranged from 21 to $275 \mathrm{ppm}$ (corrected to $3 \%$ $\mathrm{O}_{2}$ ), as shown in Figure B-9. $\mathrm{N}_{2} \mathrm{O}$ is linearly dependent upon temperature and increases as temperature is decreased. This is the opposite trend of $\mathrm{NO}_{\mathbf{x}}$. For low-load conditions obtained without using the external heat exchanger, high $\mathrm{N}_{2} \mathrm{O}$ emissions were measured, due to the low temperatures. When varying load by taking heat-transfer surface out of service (simulating use of an external heat exchanger), $\mathrm{N}_{2} \mathrm{O}$ emissions were approximately 50 ppm. No significant differences in $\mathrm{N}_{2} \mathrm{O}$ emissions were seen for testing with and without limestone. For comparison purposes, the $\mathrm{N}_{2} \mathrm{O}$ emissions from the test burn with Salt Creek bituminous coal ranged from 115 to $430 \mathrm{ppm}$ over a temperature range of $1350^{\circ}$ to $1625^{\circ} \mathrm{F}$.

\section{CO Emissions}

The measured emissions of $\mathrm{CO}$ varied from 11 to $143 \mathrm{ppm}$ (corrected to $3 \% \mathrm{O}_{2}$ ), as shown in Figure B-10. The CO concentrations decreased as the average operating temperature increased.

\section{SINTERING, AGGLOMERATION, AND DEPOSIT EVALUATION}

Although FBCs typically operate at relatively low temperatures, evidence from pilot, industrial, and utility boilers indicates that certain ash components can cause ash-related problems. These ash-related problems can manifest themselves as agglomeration and sintering of bed material, or as deposition on the heat exchange tube surfaces and refractory walls. These ash-related phenomena have been shown to cause a loss in steam 


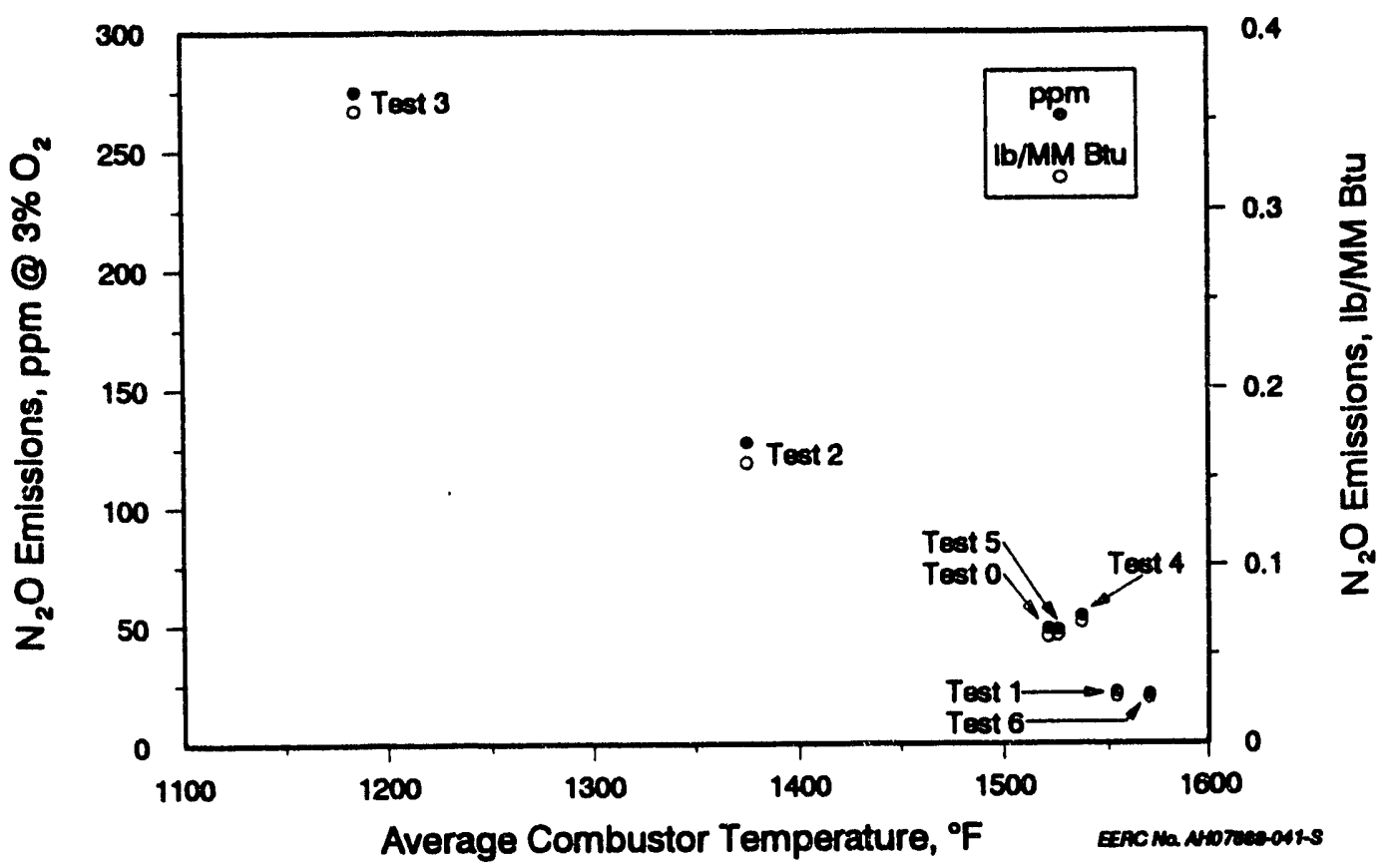

Figure B-9. $\mathrm{N}_{2} \mathrm{O}$ emissions as a function of average combustor temperature.

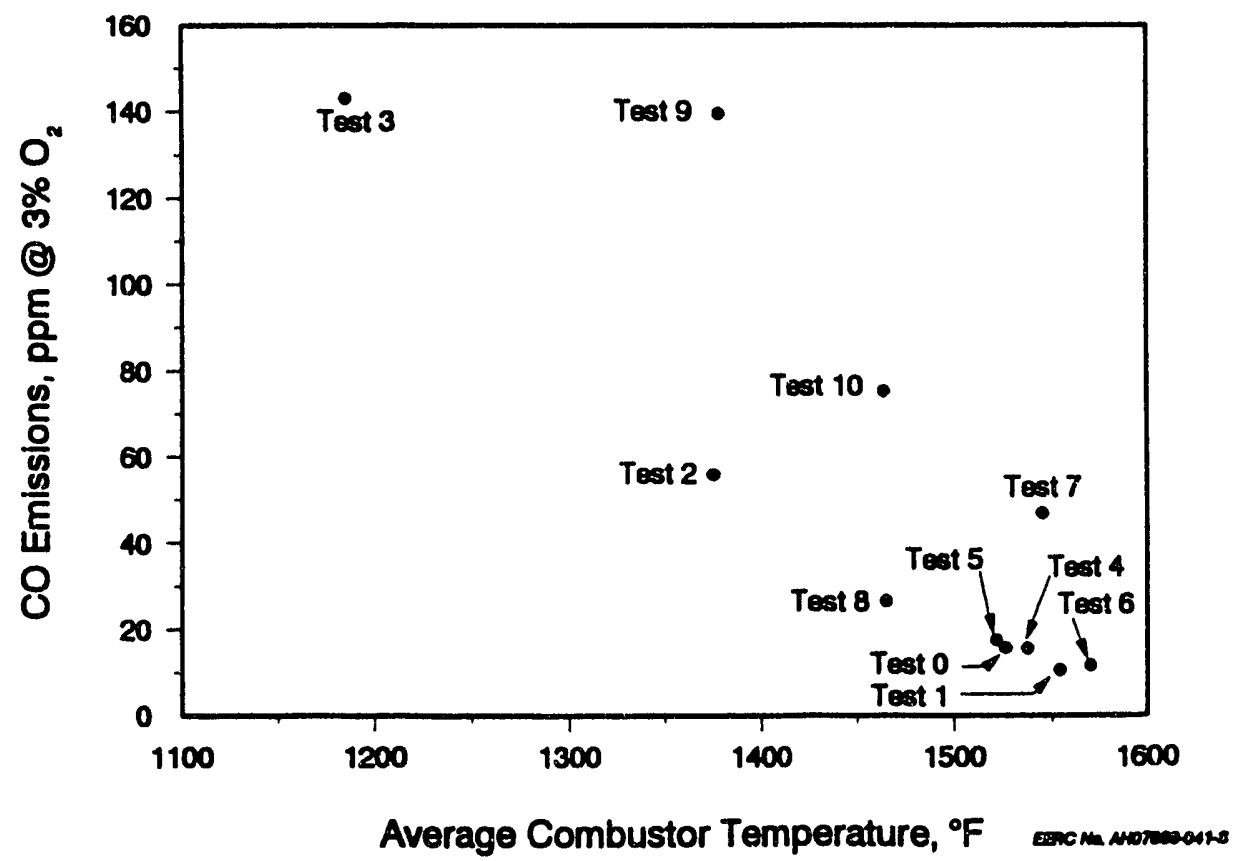

Figure B-10. CO emissions as a function of average combustor temperature. 
temperature; operating difficulties; and, in some cases, unplanned shutdowns. Experience at the EERC has shown fuels with high sodium and potassium levels to be the most troublesome, particularly with bed agglomeration. Large agglomerates have been reported at the MDU Heskett bubbling FBC using a high-sodium (up to $12 \% \mathrm{NaO}$ in the ash) Beulah North Dakota lignite, although the agglomeration is typically controlled on this unit by using a high bed turnover rate. High calcium and sulfur in the fuel have also been demonstrated to produce ash-related problems. Because of the nature of the ash from North Dakota lignites and experience burning this fuel in pc-fired systems, an important goal of this study was to determine the nature of any ash-related problems.

After the first week of testing, some small agglomerates of about one-eighth-inch diameter were noted in the combustor bed material, but did not pose any operational problems. Postrun visual inspection of the system after the last week of testing showed the formation of high-temperature agglomerates in the bottom of the combustor. This was likely an artifact of the plugging in the downcomer and a consequence of the temperature excursion. Bed material agglomerates slightly larger than one-inch diameter and one-half inch thick were found in the drained bed material. These were quite friable. The material that collected and plugged the cyclone and downcomer appeared to be extremely cohesive, but was relatively easy to clean out of the cyclone cone and downcomer. The material forming the plug could be broken with finger pressure. Some slightly larger and harder agglomerates, along with some ash deposits, were found in the material removed from the downcomer and external heat exchanger.

Two air-cooled probes located at the exit of the cyclone are used to investigate the degree of ash deposition or slagging that could be expected at the leading edge of the convective pass region of a circulating fluidized-bed boiler. Air flow to the probes was controlled to maintain a probe surface temperature of approximately $1000^{\circ} \mathrm{F}$. Only a thin layer of deposit less than one millimeter thick was present on the probes after the last, week of testing. This contrasts to a much thicker deposit that formed during the first week of testing using Center lignite when the probes installed in the ash-fouling section were uncooled. Ash deposition would not likely be a problem in the convective pass region of a CFB boiler firing this coal. Some soot-blowing potential would be recommended, however.

Postrun inspection of system components revealed several hard deposits had formed on the walls of the refractory and on some of the uncooled surfaces. The deposits were not very thick and were composed of a very fine-grained matrix, with most of the particles less than one micron. A few larger particles (1-10 microns) were found intermixed in the fine-grained matrix. The elemental analyses show that the deposit was primarily composed of calcium and sulfur. XRD identified the major phases as $\mathrm{CaSO}_{4}$ and $\mathrm{Ca}_{5}\left(\mathrm{PO}_{4}\right)_{3} \mathrm{OH}$ with minor amounts of $\mathrm{MgO}$. This composition differs from both the coal and the limestone analyses, showing an enrichment in the calcium and sulfur. The most likely mechanism for the formation of this deposit is deposition of fine-grained calcium oxide. Sulfation of the calcium oxide and subsequent sintering of the particles produce a very hard, tenacious deposit. Some of the ash particles appear to have stuck to the deposit; however, it is unlikely that any of the constituents in these ash particles caused the deposit to form or gave it strength. 
A similar phenomenon has been noted in pc-fired boilers firing high-calcium western United States subbituminous coals. In these systems, calcium sulfate-based deposits are found primarily in the reheat section of the boiler where flue gas temperatures range from $1650^{\circ}$ to $1200^{\circ} \mathrm{F}$. These deposits are very tenacious and difficult to remove using conventional soot blowers if they are allowed to build up and develop strength over time. It is recommended for any FBC built to burn North Dakota lignite that a conservative design be used in the back pass ensuring adequate soot-blowing coverage to prevent buildup of calcium sulfate-based deposits.

\section{SUMMARIES OF TEST DATA}

This section contains the summaries of test data for each test period, including averages and standard deviations of many of the data points recorded by the computerized data acquisition system. 


\begin{tabular}{|c|c|c|c|c|c|c|c|c|c|c|c|c|c|}
\hline \multirow{3}{*}{$\frac{\mathrm{Tag}}{\mathrm{TC} 11011}$} & \multirow{2}{*}{$\frac{\text { Desc }}{\text { PCDEX }}$} & \multirow{2}{*}{$\frac{\text { Units }}{\cdot p}$} & \multicolumn{2}{|c|}{ Average Sid Dev } & \multicolumn{5}{|c|}{ HEAT-TRANS PER COEPPICIENTS } & \multirow{2}{*}{\multicolumn{2}{|c|}{8}} & \multirow[b]{3}{*}{ U } & \multirow[b]{3}{*}{ Heat Plux } \\
\hline & & & 1523 & $\overrightarrow{4.1}$ & \multicolumn{2}{|c|}{ - Combustor } & \multicolumn{3}{|c|}{ Number of Doors in Service $\Longrightarrow$} & & & & \\
\hline & AFS Ex & ${ }^{\bullet} \mathbf{F}$ & 1420 & 4.8 & CHX & Height & Temp lo & Temp Out & Bed Temp & Plow & $\mathbf{Q}$ & & \\
\hline TC15001 & C Plenum & $\bullet \mathbf{F}$ & 569 & 5.5 & Location & (ft) & • $\mathbf{F}$ & $\bullet \mathbf{F}$ & ${ }^{\circ} \mathbf{F}$ & gpm & Btu/hr & Btu/ft ${ }^{2} \mathrm{hr}^{*} \mathrm{~F}$ & Btw/tt ${ }^{2} \mathrm{hr}$ \\
\hline TC15004 & C 1-1' & $\cdot \mathbf{F}$ & 1494 & 7.1 & $2 E, W$ & 8 & 38 & 136 & 1529 & 4.10 & 201551 & 27.8 & 38760 \\
\hline TC15005 & C 1-2' & $\bullet \mathbf{F}$ & 1493 & 6.2 & $3 N E$ & 14 & 38 & 126 & 1563 & 1.80 & 79346 & 21.2 & 30518 \\
\hline TC15006 & C 1-3' & ${ }^{\circ} \mathbf{P}$ & 1491 & 6.9 & 4SE & 17.5 & 38 & 109 & 1551 & 1.80 & 64569 & 17.2 & 24834 \\
\hline TC15007 & C $1-4^{\prime}$ & ${ }^{\circ} \mathbf{P}$ & 1488 & 6.8 & 6NE & 27.5 & 39 & 112 & 1542 & 1.80 & 65614 & 17.6 & 25236 \\
\hline TC15008 & $\mathrm{C}_{1-4}$ & ${ }^{\circ} \mathbf{F}$ & 1494 & 6.4 & 7SE & 32.5 & 39 & 112 & 1531 & $1 . \%$ & 62360 & 16.9 & 23985 \\
\hline TC15009 & C $1-4^{\prime}$ & ${ }^{\circ} \mathbf{F}$ & 1492 & 7.6 & $8 E, W$ & 37.5 & 40 & 106 & 1524 & 3.60 & 119006 & 16.1 & 22886 \\
\hline TC15012 & C 2-6' & ${ }^{\circ} \mathbf{F}$ & 1502 & 6.3 & & Overall & 37 & 119 & 1526 & 12.98 & 531377 & 18.1 & 25547 \\
\hline TC15013 & C 2-8' & ${ }^{\circ} \mathbf{F}$ & 1529 & 5.6 & & & \multicolumn{3}{|c|}{ From Data Sheets $=>$} & 14.80 & & & \\
\hline TC15022 & C 3-11' & $\bullet \mathbf{F}$ & 1549 & 6.8 & & & & & & & & & \\
\hline TC15023 & C 3-14' & ${ }^{\circ} \mathrm{F}$ & 1559 & 6.4 & -EHX- & & \multirow{3}{*}{$\begin{array}{c}\text { Temp In } \\
\cdot F\end{array}$} & & & & & & \\
\hline TC15024 & C 3-14' & ${ }^{\circ} \mathbf{F}$ & 1565 & 5.5 & Coils & No. of & & Temp Out & Bed Temp & Flow & $\mathbf{Q}$ & U & Heat Plux \\
\hline TC15025 & C 3-14' & ${ }^{\circ} \mathbf{F}$ & 1565 & 6.0 & Used & Coils & & $\bullet \mathbf{F}$ & ${ }^{\circ} \mathbf{F}$ & gpm & Btu/hr & Btu/ft ${ }^{2} \mathrm{hr}^{\circ} \mathrm{F}$ & $\mathrm{Btu} / \mathrm{ft}^{2} \mathrm{hr}$ \\
\hline TC15032 & C 4-17.5' & ${ }^{\circ} \mathrm{F}$ & 1551 & 6.9 & \multirow{2}{*}{\multicolumn{5}{|c|}{ From Data Sheet $s \Rightarrow$}} & 14.76 & 514786 & 72.7 & 76265 \\
\hline TC15042 & C 5-22.5' & ${ }^{\circ} \mathrm{P}$ & 1567 & 5.1 & & & & & & 15.80 & & & \\
\hline TC15052 & C 6-27.5' & ${ }^{\circ} \mathbf{F}$ & 1544 & 4.3 & & & & & & & & & \\
\hline TC15053 & C 6-27.5' & $\bullet \mathbf{P}$ & 1554 & 5.2 & \multicolumn{5}{|c|}{ EMISSIONS DATA } & & & & \\
\hline $\mathrm{TC} 15054$ & C 6-27.5' & ${ }^{\circ} \mathbf{F}$ & 1527 & 4.5 & \multirow{2}{*}{\multicolumn{4}{|c|}{ 1—As Measured - }} & \multirow{2}{*}{\multicolumn{3}{|c|}{ - Corrected to $3 \%$ O2- }} & & \\
\hline TC15062 & C 7-32.5' & ${ }^{\circ} \mathbf{F}$ & 1531 & 4.6 & & & & & & & & 1 & \\
\hline TC15071 & C 8-37.5' & ${ }^{\circ} \mathrm{p}$ & 1524 & 4.8 & $\mathrm{Tag}$ & Units & Averages & Std Dev & Tag & Units & Averages & Std Dev & \\
\hline TC15073 & C $9-41^{\prime}$ & ${ }^{\circ} \mathrm{F}$ & 1548 & 5.2 & SO2-A & ppm & 727 & 37.46 & SO2-A & ppm & 760 & 36.79 & \\
\hline TC15999 & Ambient & ${ }^{\circ} \mathbf{F}$ & 80 & 1.1 & SO2-AE & $\mathrm{Ib} / \mathrm{MM} \mathrm{Blu}$ & 1.46 & 0.07 & & & & & \\
\hline TC16001 & EHX Plenm & $\circ p$ & 108 & 3.7 & co & ppm & 15 & 2.57 & Co & ppm & 16 & 2.55 & \\
\hline TC16012 & EHX $0.5^{\prime}$ & ${ }^{\circ} \mathbf{F}$ & 1161 & 20.7 & $\mathrm{CO} 2$ & $\%$ & 16.26 & 0.45 & $\mathrm{CO} 2$ & $\%$ & 17.00 & 0.23 & \\
\hline TC16013 & EHX $1.5^{\prime}$ & ${ }^{\circ} \mathrm{F}$ & 1149 & 18.7 & $\mathrm{~N} 2 \mathrm{O}$ & ppm & 46 & 3.15 & $\mathrm{~N} 2 \mathrm{O}$ & ppm & 48 & 3.85 & \\
\hline TC16014 & EHX 2.7' & ${ }^{\circ} \mathrm{p}$ & 1159 & 18.4 & N2OE & Ib/MM Btu & 0.06 & 0.01 & & & & & \\
\hline TC16015 & EHX 3.8' & ${ }^{\circ} \mathbf{F}$ & 945 & 19.4 & NOx & ppm & 135 & 8.50 & NOx & ppm & 141 & 10.58 & \\
\hline TC16017 & EHX 5.3' & ${ }^{\circ} \mathbf{F}$ & 825 & 24.3 & NOxE & $\mathrm{Ib} / \mathrm{MM}$ Btu & 0.19 & 0.02 & & & & & \\
\hline TC16018 & EHXExit & ${ }^{\circ} \mathbf{F}$ & 1038 & 20.4 & O2-A & $\%$ & 3.78 & 0.48 & & & & & \\
\hline TC16021 & $\operatorname{Crc} A$ in & ${ }^{\circ} \mathrm{F}$ & 1539 & 3.9 & & & & & & & & & \\
\hline TC16031 & DC \&-36 & ${ }^{\circ} \mathrm{F}$ & 1525 & 5.9 & & & & & & & & & \\
\hline TC16032 & DC 6-28 & ${ }^{\circ} \mathbf{F}$ & 1491 & 20.2 & Tag & Desc & Units & Average & Std Der & & & & \\
\hline TC16033 & $D C 4-18^{\prime}$ & ${ }^{\circ} \mathbf{F}$ & 1470 & 23.8 & $W(C)$ & Coal Fd Rt & $\mathrm{lb} / \mathrm{hr}$ & 333.4 & 13.1 & & & & \\
\hline TC16034 & DC3-11.5' & ${ }^{\circ} \mathbf{F}$ & 1482 & 21.4 & $W(S)$ & LS Fd Rt & $\mathrm{lbs} / \mathrm{hr}$ & 0.1 & 0.2 & & & & \\
\hline TC16035 & DC3-10.5' & ${ }^{\circ} \mathbf{F}$ & 1493 & 24.4 & $V(F G)$ & FG SGV & $\mathrm{ft} / \mathrm{sec}$ & 14.6 & 0.6 & & & & \\
\hline & & & & & $V(S, C)$ & Comb SGV & $\mathrm{ft} / \mathrm{sec}$ & 13.4 & 0.5 & & & & \\
\hline $\mathrm{T}(\mathrm{A}, \mathrm{C})$ & Comb Temp & ${ }^{\circ} \mathbf{F}$ & 1526 & 4.9 & $V(S, E H X)$ & EHX SGV & $\mathrm{ft} / \mathrm{sec}$ & 1.2 & 0.1 & & & & \\
\hline$T(A, E H X)$ & EHX Temp & ${ }^{\circ} \mathbf{F}$ & 1157 & 19.0 & FT 18003 & CHX Flow in & $g p m$ & 13.0 & 0.0 & & & & \\
\hline EA & Excess Air & $\%$ & 22.0 & 3.6 & FT19003 & EHX Flow in & gpm & 14.8 & 0.1 & & & & \\
\hline SR & S Reten & $\%$ & 6.2 & 4.3 & PT15998 & Barometric & psia & 14.4 & 0.0 & & & & \\
\hline$R(P C A)$ & \%Flow PCA & $\%$ & 55.8 & 2.1 & PT15081 & Comb dP & in. $\mathrm{H} 2 \mathrm{O}$ & 47.6 & 3.5 & & & & \\
\hline $\mathbf{R}(\mathrm{SCA})$ & \%Flow SCA & $\%$ & 43.9 & 1.7 & $U(\mathrm{CA})$ & CA Heat in & $\mathrm{KBtw} / \mathrm{hr}$ & 104.8 & 4.3 & & & & \\
\hline$R(Q, I N)$ & \%Enrg in & $\%$ & 116.7 & 5.0 & (сннX) & CHX HIRmv & $\mathrm{KBt} / \mathrm{h} / \mathrm{hr}$ & 500.3 & 16.6 & & & & \\
\hline $\mathrm{R}(\mathrm{CHX})$ & CHX Ratio & $\%$ & 49.1 & 1.4 & Q(EHX) & EHX HIRmv & $\mathrm{KBtu} / \mathrm{hr}$ & 519.2 & 19.3 & & & & \\
\hline$R(E H X)$ & EHX Ratio & $\%$ & 50.9 & 1.4 & $Q(F)$ & Fuel Enrg in & $\mathrm{KB}(\mathrm{u} / \mathrm{br}$ & 1275.0 & 50.9 & & & & \\
\hline$F(P C A)$ & PCA Flow & SCFM & 221.1 & 16.1 & $\alpha(F G)$ & FG Enrg out & $\mathrm{KB} t \mathrm{u} / \mathrm{hr}$ & 277.1 & 9.4 & & & & \\
\hline $\mathbf{F}(\mathbf{S C A})$ & SCA Flow & SCFM & 200.5 & 4.3 & $\alpha(I N)$ & Tot Enrg in & $\mathrm{KBt}(\mathrm{w} / \mathrm{hr}$ & 1380.6 & 51.4 & & & & \\
\hline$F(F G, B H)$ & BH Flow & SCFM & 555.5 & 8.0 & QOIT) & Tot Enrg out & KBtu/hr & 1596.6 & 21.5 & & & & \\
\hline F(TFG) & TFG Plow & SCFM & 563.5 & 18.9 & BH ACC & & & 2.1 & 0.0 & & & & \\
\hline$W(S R)$ & Recire $R_{t}$ & $\mathrm{~b} b \mathrm{~s} / \mathrm{hr}$ & 4158 & 427.3 & ASSRATIO & & & 1.63 & 0.6 & & & & \\
\hline
\end{tabular}




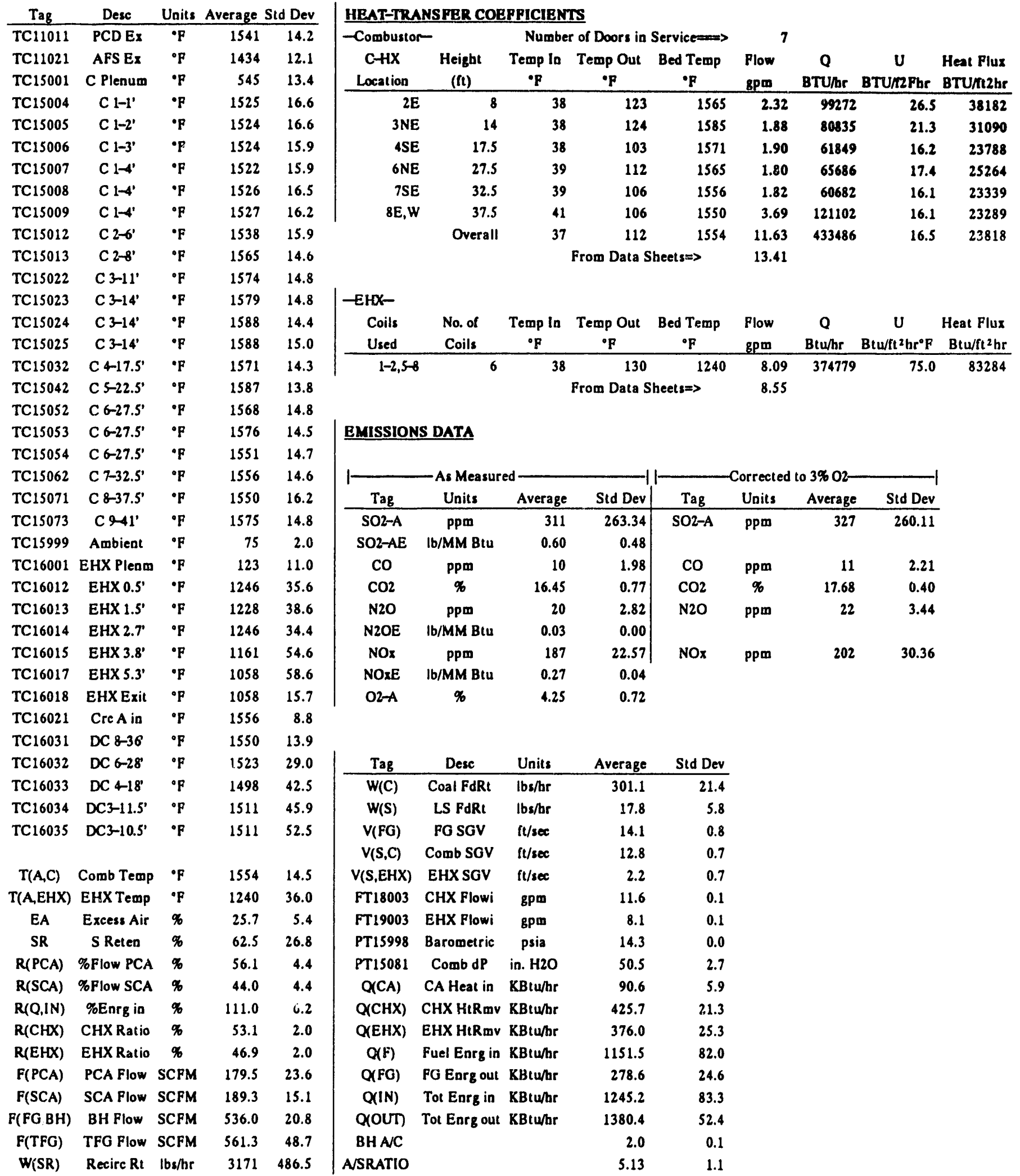




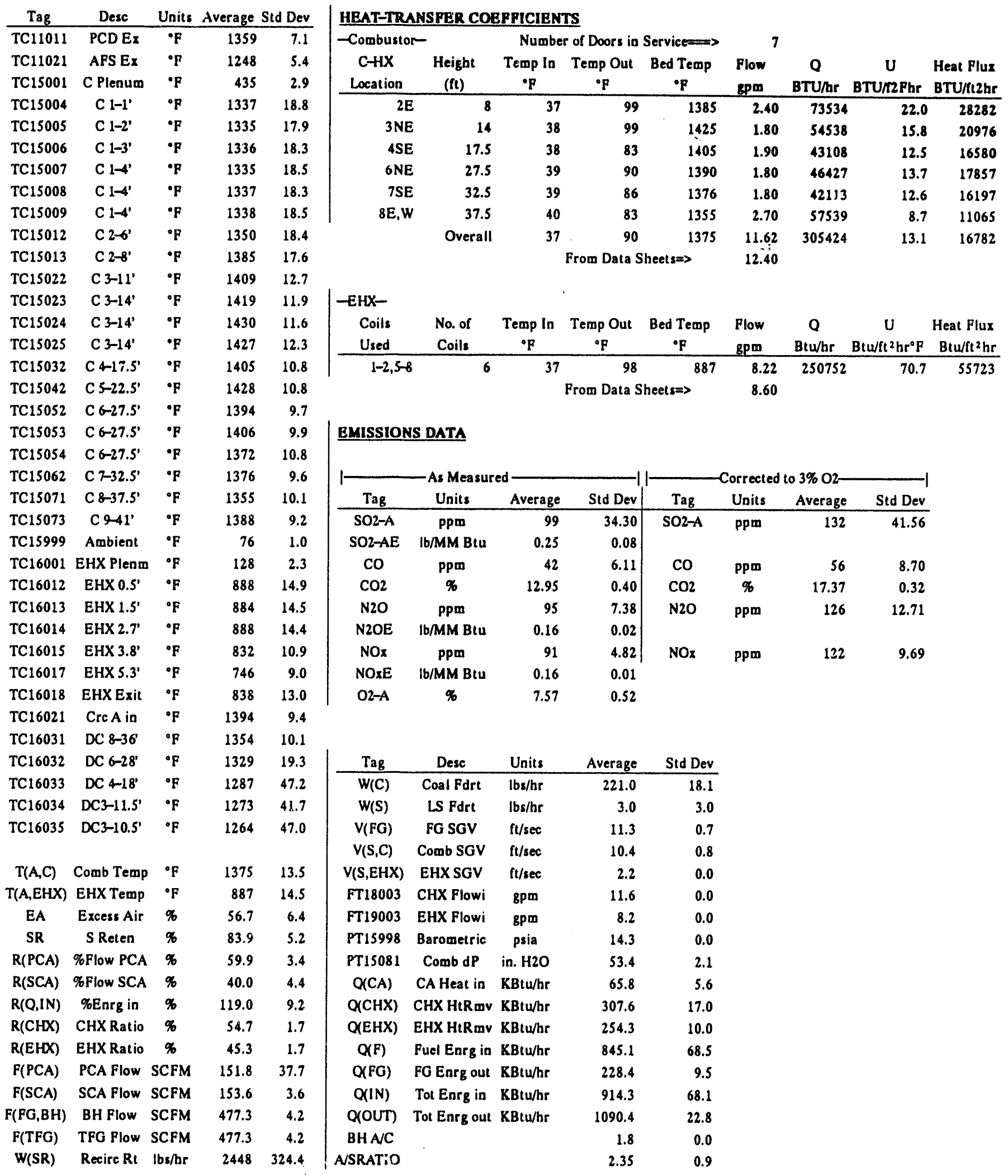




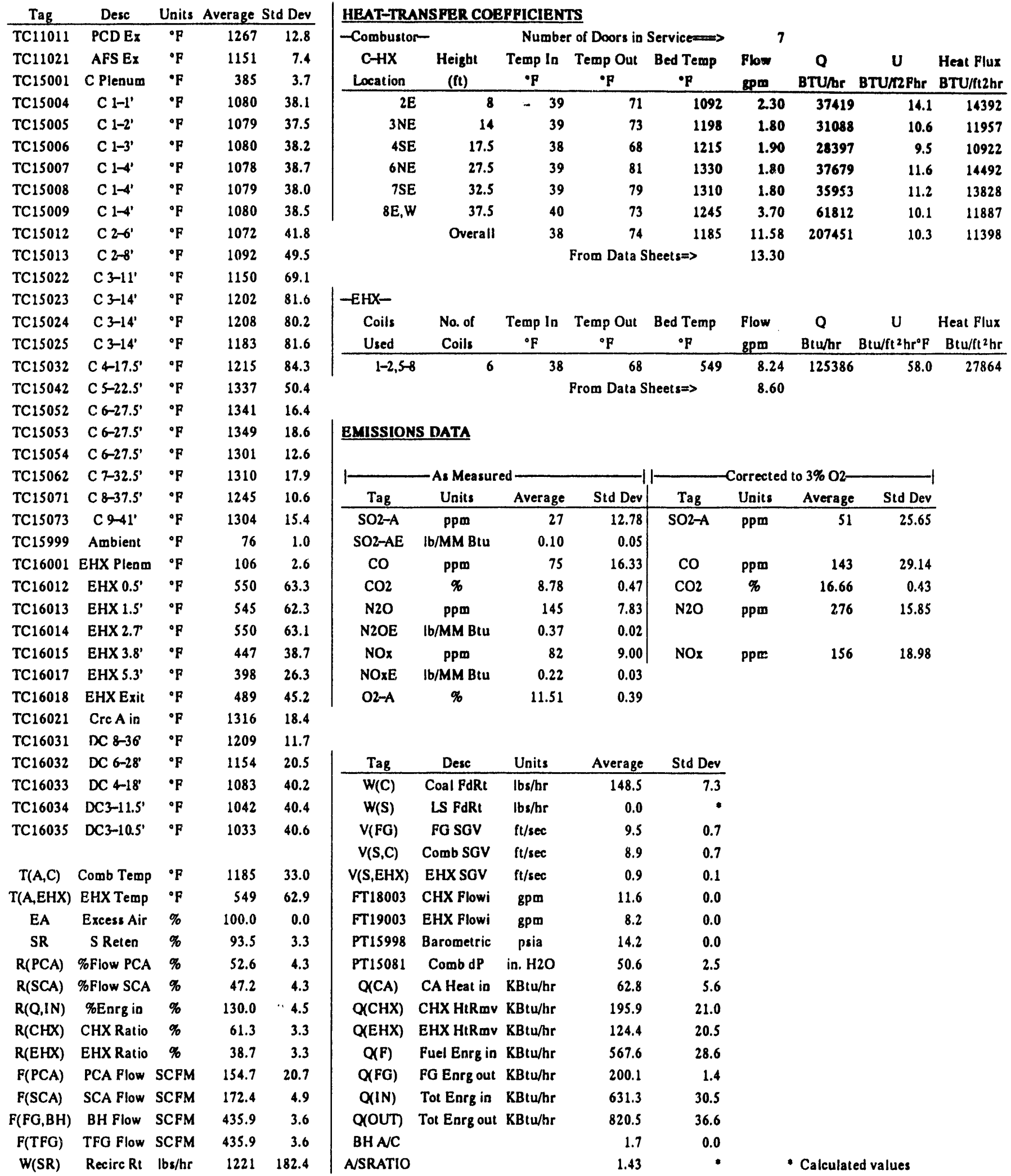




\begin{tabular}{|c|c|c|c|c|c|c|c|c|c|c|c|c|c|}
\hline \multirow{2}{*}{$\frac{\text { Tag }}{\text { TC11011 }}$} & \multirow{2}{*}{$\frac{\text { Desc }}{\text { PCD Ex }}$} & \multirow{2}{*}{$\frac{\text { Units }}{{ }^{\circ} \mathbf{F}}$} & \multicolumn{2}{|c|}{ Average Std Dev } & \multicolumn{9}{|c|}{ HEAT-TRANSPER COEPPICIENTS } \\
\hline & & & 1469 & 8.2 & \multicolumn{2}{|c|}{-Combustor } & \multicolumn{3}{|c|}{ Number of Doors in Service $\Longrightarrow$} & \multicolumn{2}{|l|}{1} & & \multirow{3}{*}{$\begin{array}{l}\text { Heat Flux } \\
\text { BTU/Rt2br }\end{array}$} \\
\hline & AFS Ex & $\bullet \mathbf{F}$ & 1328 & 13.6 & $c-+1 x$ & Height & Temp In & Temp Out & Bed Temp & Flow & $\mathbf{Q}$ & $\mathbf{u}$ & \\
\hline TC15001 & C Pleaum & ${ }^{\bullet} \mathbf{F}$ & 461 & 12.4 & Location & (ft) & ${ }^{\circ} \mathbf{P}$ & $\bullet \mathbf{p}$ & $\cdot \mathbf{F}$ & gpm & BTU/hr & BTU/R2 Fhr & \\
\hline TC15004 & C 1-1' & ${ }^{\bullet} \mathbf{F}$ & 1516 & 13.5 & $2 \mathrm{E}$ & 8 & 44 & 122 & 1535 & 2.00 & 77634 & 21.1 & 29859 \\
\hline TC15005 & C $1-2$ & ${ }^{\circ} \mathbf{F}$ & 1514 & 13.3 & 3 & 14 & 125 & 178 & 1557 & 0.00 & 0 & 0.0 & 0 \\
\hline $\mathrm{TC} 15006$ & C $1-3$ & ${ }^{\circ} \mathbf{F}$ & 1514 & 13.1 & 4 & 17.5 & 121 & 167 & 1562 & 0.00 & 0 & 0.0 & 0 \\
\hline TC15007 & C 1-4 & ${ }^{\circ} \mathbf{F}$ & 1512 & 13.1 & 6 & 27.5 & 127 & 199 & 1551 & 0.00 & 0 & 0.0 & 0 \\
\hline TC15008 & C $1-4^{\prime}$ & ${ }^{\circ} \mathbf{F}$ & 1518 & 13.1 & 7 & 32.5 & 128 & 190 & 1549 & 0.00 & $\mathbf{0}$ & 0.0 & 0 \\
\hline TC15009 & C $1-4^{\prime}$ & ${ }^{\circ} \mathbf{F}$ & 1516 & 13.3 & 8 & 37.5 & 128 & 171 & 1542 & 0.00 & 0 & 0.0 & 0 \\
\hline TC15012 & C 2-6' & ${ }^{\circ} \mathbf{F}$ & 1518 & 13.7 & & Overall & 44 & 122 & 1537 & 1.79 & 70060 & 19.0 & 26946 \\
\hline TC15013 & C 2-8' & ${ }^{\circ} \mathbf{F}$ & 1535 & 12.9 & & & \multicolumn{3}{|c|}{ From Data Sheet $s=>$} & 2.00 & & & \\
\hline TC15022 & C 3-11' & ${ }^{\circ} \mathbf{F}$ & 1550 & 11.3 & & & & & & & & & \\
\hline $\mathrm{TC} 15023$ & C 3-14' & ${ }^{\text {"F }} \mathbf{F}$ & 1557 & 10.2 & -EHX- & & & & & & & & \\
\hline TC15024 & C 3-14' & ${ }^{\circ} \mathbf{F}$ & 1555 & 10.5 & Coils & No. of & Temp ln & Temp Out & Bed Temp & Flow & Q & $u$ & Heat Flux \\
\hline TC15025 & C 3-14' & ${ }^{\circ} \mathbf{F}$ & 1560 & 10.7 & Used & Coils & ${ }^{\circ} \mathbf{F}$ & ${ }^{\circ} \mathrm{F}$ & • $F$ & $\mathrm{gpm}$ & Btu/hr & Btu/ft ${ }^{2} \mathrm{hr}^{\circ} \mathrm{F}$ & $\mathrm{Btu} / \mathrm{ft}^{2} \mathrm{hr}$ \\
\hline TC15032 & C 4-17.5' & ${ }^{\circ} \mathbf{F}$ & 1562 & 10.4 & \multirow{2}{*}{\multicolumn{5}{|c|}{$72 \underset{\text { From Data Sheets }=>}{1269}$}} & 0.04 & 13 & 0.0 & 0 \\
\hline TC15042 & C 5-22.5 & ${ }^{\circ} \mathbf{F}$ & 1555 & 8.1 & & & & & & 0.00 & & & \\
\hline TC15052 & C 6-27.5' & ${ }^{\circ} \mathbf{F}$ & 1551 & 6.5 & & & & & & & & & \\
\hline TC15053 & C 6-27.5' & ${ }^{\circ} \mathbf{P}$ & 1555 & 7.1 & \multicolumn{5}{|c|}{ EMISSIONS DATA } & & & & \\
\hline TC15054 & C 6-27.5' & ${ }^{\circ} \mathbf{F}$ & 1548 & 7.0 & \multirow{2}{*}{\multicolumn{4}{|c|}{ As Measured - }} & \multirow{2}{*}{\multicolumn{4}{|c|}{-Corrected to $3 \% \mathrm{O} 2$}} & \\
\hline TC15062 & C 7-32.5' & ${ }^{\circ} \mathbf{p}$ & 1549 & 6.2 & & & & & & & & & \\
\hline $\mathrm{TC} 15071$ & C 8-37.5' & ${ }^{\circ} \mathrm{F}$ & 1542 & 5.7 & Tag & Units & Average & Std Dev & Tag & Units & Average & Std Dev & \\
\hline TC15073 & C $9-41$ & ${ }^{\circ} \mathrm{F}$ & 1545 & 6.4 & SO2-A & ppm & 261 & 103.78 & SO2-A & $\mathrm{ppm}$ & 438 & 168.76 & \\
\hline TC15999 & Ambient & ${ }^{\circ} \mathrm{F}$ & 79 & 0.8 & $\mathrm{SO} 2-\mathrm{AE}$ & $\mathrm{Ib} / \mathrm{MM} \mathrm{B} t \mathrm{u}$ & 0.83 & 0.33 & & & & & \\
\hline $\mathrm{TC} 16001$ & EHX Plenm & ${ }^{\circ} \mathrm{F}$ & 113 & 5.2 & $\mathrm{co}$ & ppm & 9 & 3.52 & $\mathrm{CO}$ & ppm & 16 & 5.91 & \\
\hline TC16012 & EHX 0.5 & ${ }^{\circ} \mathbf{F}$ & 1270 & 25.4 & $\mathrm{CO} 2$ & $\%$ & 10.21 & 0.46 & $\mathrm{CO} 2$ & $\%$ & 17.19 & 0.46 & \\
\hline $\mathrm{TC} 16013$ & EHX 1.5' & ${ }^{\circ} \mathrm{F}$ & 1271 & 25.7 & $\mathrm{~N} 2 \mathrm{O}$ & ppm & 32 & 2.33 & $\mathrm{~N} 2 \mathrm{O}$ & ppm & 54 & 5.07 & \\
\hline TC16014 & EHX 2.7 & ${ }^{\circ} \mathbf{P}$ & 1266 & 26.4 & $\mathrm{~N} 2 \mathrm{OE}$ & Ib/MM Btu & 0.07 & 0.01 & & & & & \\
\hline TC16015 & EHX 3.8' & ${ }^{\circ} \mathrm{F}$ & 1139 & 59.6 & NOx & ppm & 165 & 7.87 & NOx & ppm & 278 & 13.21 & \\
\hline TC16017 & EHX 5.3' & ${ }^{\circ} \mathbf{p}$ & 980 & 72.1 & NOxE & lb/MM Btu & 0.38 & 0.02 & & & & & \\
\hline TC16018 & EHX Exit & ${ }^{\circ} \mathbf{F}$ & 1059 & 21.7 & $02-A$ & $\%$ & 10.31 & 0.36 & & & & & \\
\hline $\mathrm{TC} 16021$ & $\operatorname{Crc} A$ in & ${ }^{\circ} \mathbf{P}$ & 1537 & 5.1 & & & & & & & & & \\
\hline $\mathrm{TC} 16031$ & DC 8-36' & ${ }^{\circ} \mathbf{F}$ & 1466 & 12.1 & & & & & & & & & \\
\hline TC16032 & DC 6-28 & ${ }^{\circ} \mathbf{F}$ & 1438 & 22.6 & Tag & Desc & Units & Average & Std Dev & & & & \\
\hline $\mathrm{TC} 16033$ & $D C 4-18^{\prime}$ & ${ }^{\circ} \mathrm{F}$ & 1397 & 38.7 & $W(C)$ & Coal FdRt & $\mathrm{lbs} / \mathrm{hr}$ & 173.1 & 11.5 & & & & \\
\hline $\mathrm{TC} 16034$ & DC3-11.5' & ${ }^{\circ} \mathrm{F}$ & 1383 & 40.7 & $W(S)$ & LS FdRt & $\mathrm{lbs} / \mathrm{hr}$ & 3.1 & $\cdot$ & & & & \\
\hline TC16035 & DC3-10.5' & ${ }^{\circ} \mathbf{F}$ & 1374 & 41.7 & $V(F G)$ & FG SGV & $\mathrm{ft} / \mathrm{sec}$ & 11.6 & 0.6 & & & & \\
\hline & & & & & $V(S, C)$ & Comb SGV & $\mathrm{ft} / \mathrm{sec}$ & 10.7 & 0.6 & & & & \\
\hline $\mathrm{T}(\mathrm{A}, \mathrm{C})$ & Comb Temp & ${ }^{\circ} \mathrm{P}$ & 1537 & 9.6 & $\mathrm{~V}(\mathrm{~S}, \mathrm{EHX})$ & EHX SGV & $f t / s e c$ & 1.8 & 0.3 & & & & \\
\hline$T(A, E H X)$ & EHX Temp & ${ }^{\circ} \mathrm{F}$ & 1269 & 25.7 & FT 18003 & CHX Flowi & $\mathrm{gpm}$ & 1.8 & 0.0 & & & & \\
\hline EA & Excess Air & $\%$ & 95.3 & 4.3 & FT19003 & EHX Flowi & gpm & 0.0 & 0.0 & & & & \\
\hline SR & S Reten & $\%$ & 47.2 & 17.8 & PT15998 & Barometric & psia & 14.2 & 0.0 & & & & \\
\hline $\mathrm{R}(\mathrm{PCA})$ & \%Flow PCA & $\%$ & 66.7 & 4.7 & PT15081 & Comb dP & in. $\mathrm{H} 2 \mathrm{O}$ & 42.8 & 1.8 & & & & \\
\hline $\mathrm{R}(\mathrm{SCA})$ & \%Flow SCA & $\%$ & 33.0 & 5.1 & $Q(C A)$ & CA Heat in & $\mathrm{KBtu} / \mathrm{hr}$ & 69.7 & 4.4 & & & & \\
\hline$R(Q, I N)$ & \%Enrg in & $\%$ & 79.6 & 4.9 & $Q(\mathrm{CHX})$ & CHX HtRmv & $\mathrm{KBt} / \mathrm{h} / \mathrm{hr}$ & 63.8 & 2.8 & & & & \\
\hline $\mathrm{R}(\mathrm{CHX})$ & CHX Ratio & $\%$ & 100.0 & 0.0 & $Q(E H X)$ & EHX HIRmv & $\mathrm{KBtu} / \mathrm{hr}$ & 0.0 & 0.0 & & & & \\
\hline$R(E H X)$ & EHX Ratio & $\%$ & 0.0 & 0.0 & $Q(F)$ & Fuel Enrg in & KBtu/hr & 661.9 & 44.7 & & & & \\
\hline $\mathrm{F}(\mathrm{PCA})$ & PCA Flow & SCFM & 195.5 & 20.9 & $Q(F G)$ & FG Enrg out & $\mathrm{KBtu} / \mathrm{hr}$ & 217.7 & 8.5 & & & & \\
\hline $\mathrm{F}(\mathrm{SCA})$ & SCA Flow & SCPM & 120.4 & 21.6 & $Q(I N)$ & Tol Enrg in & KBtu/hr & 733.1 & 47.0 & & & & \\
\hline $\mathrm{F}(\mathrm{FG}, \mathrm{BH})$ & BH Flow & SCFM & 441.6 & 16.8 & Q(OUT) & Tot Enrg out & $\mathrm{KBtu} / \mathrm{hr}$ & 581.5 & 8.2 & & & & \\
\hline $\mathrm{F}$ (TFG) & TFG Flow & SCFM & 445.4 & 26.7 & BH AVC & & & 1.7 & 0.1 & & & & \\
\hline $\mathrm{W}(\mathrm{SR})$ & Recirc Rt & lbs/hr & 385 & 69.6 & A/SRATIO & & & 2.32 & • & & Calculate & ed values & \\
\hline
\end{tabular}




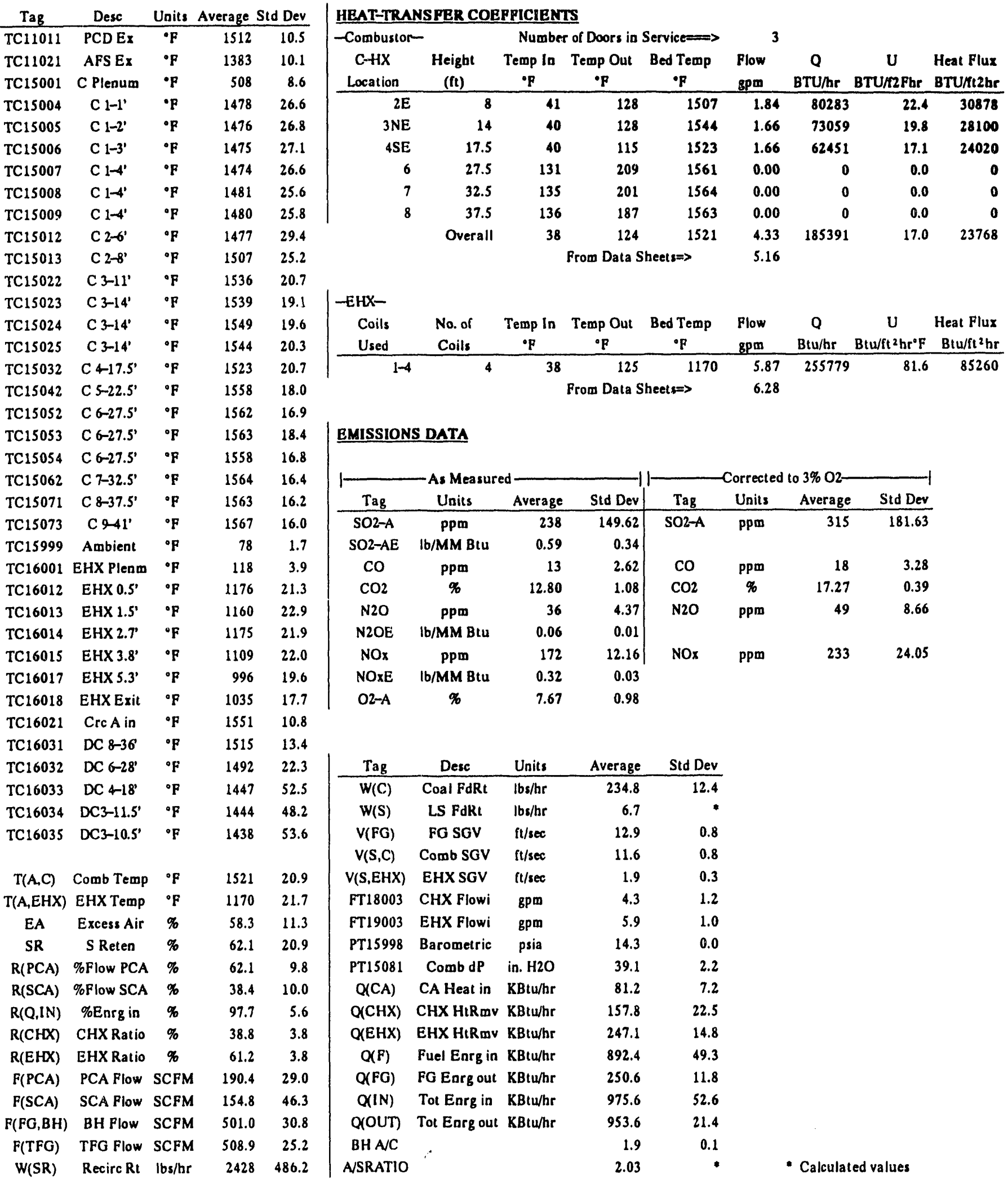




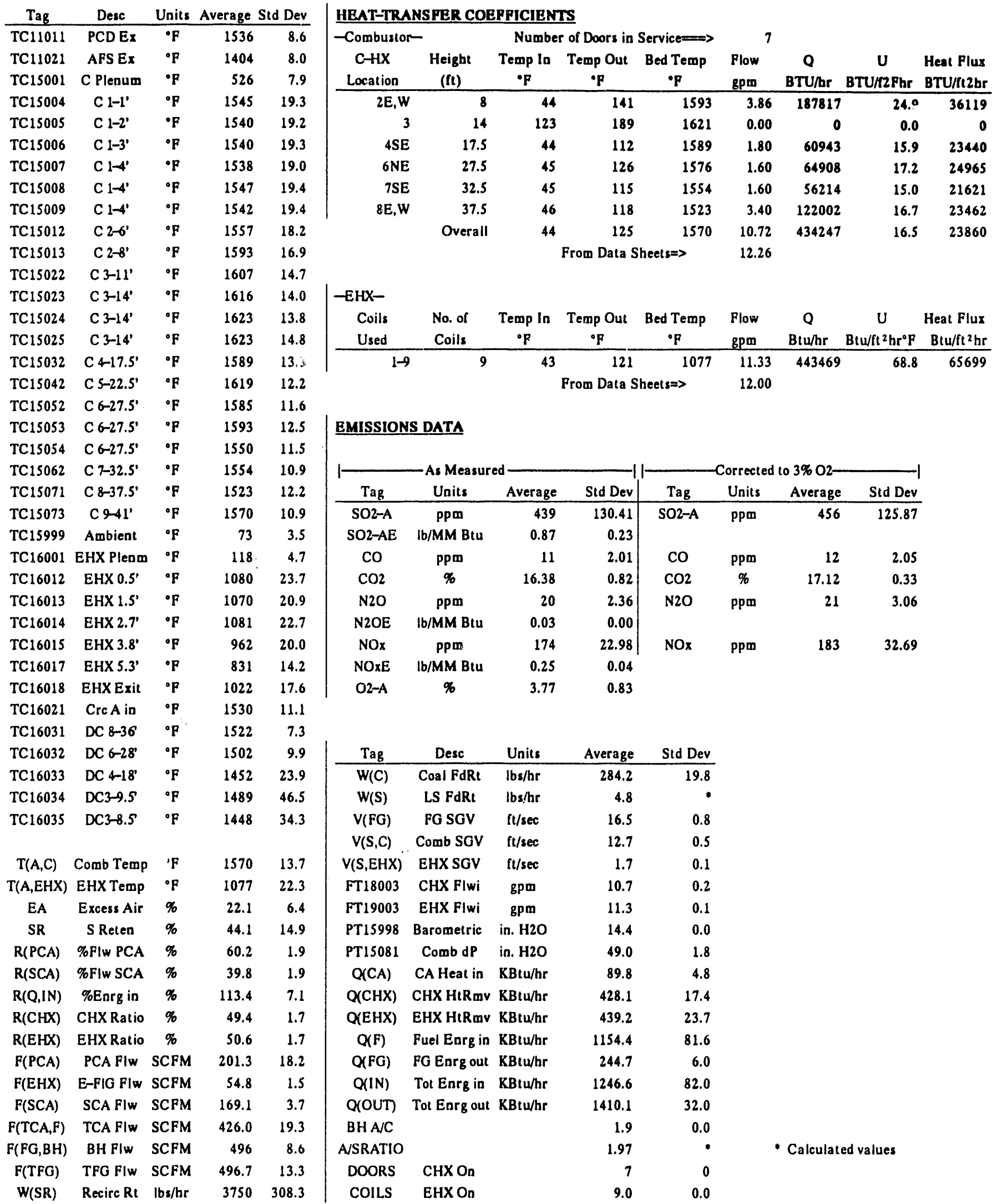




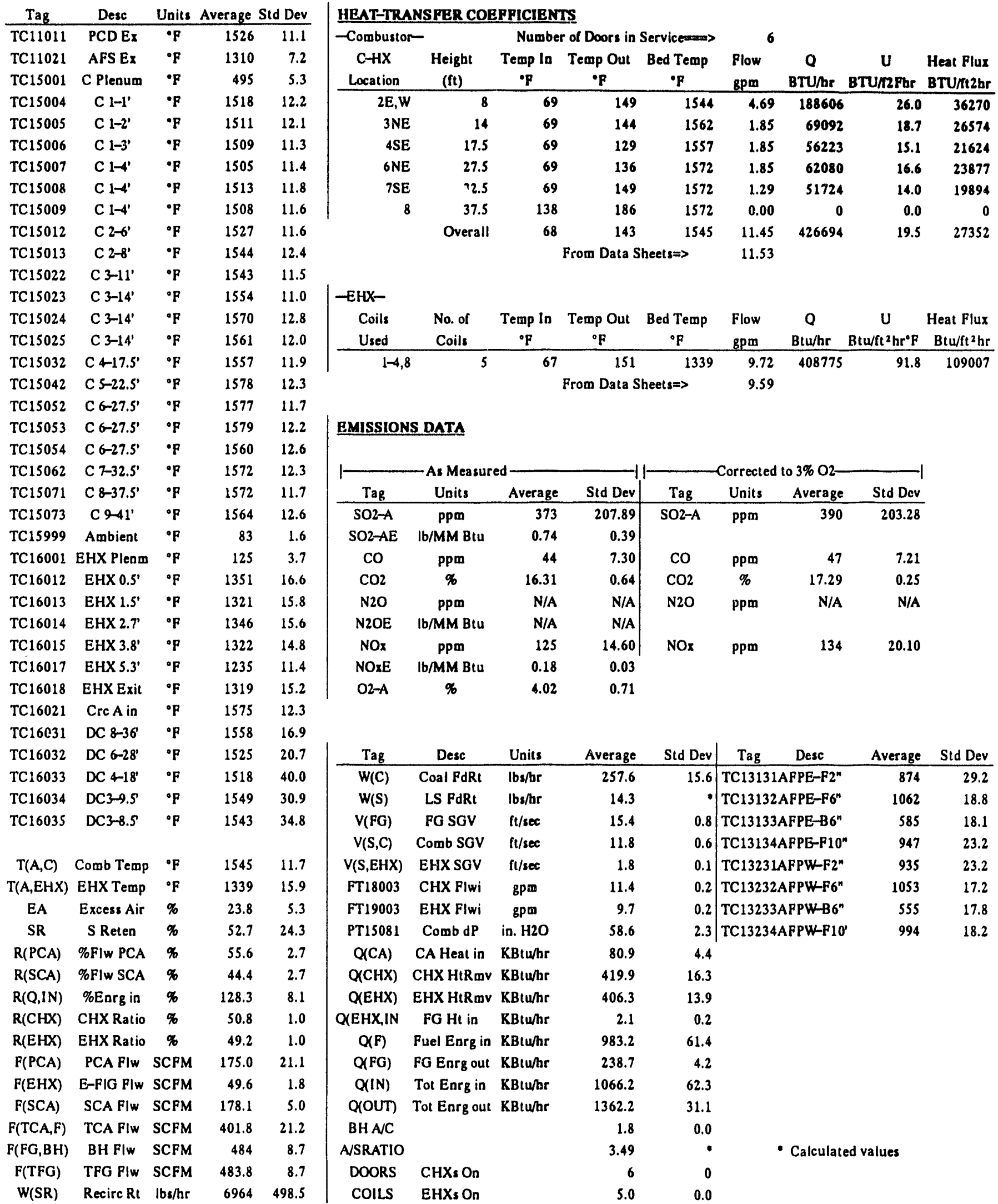




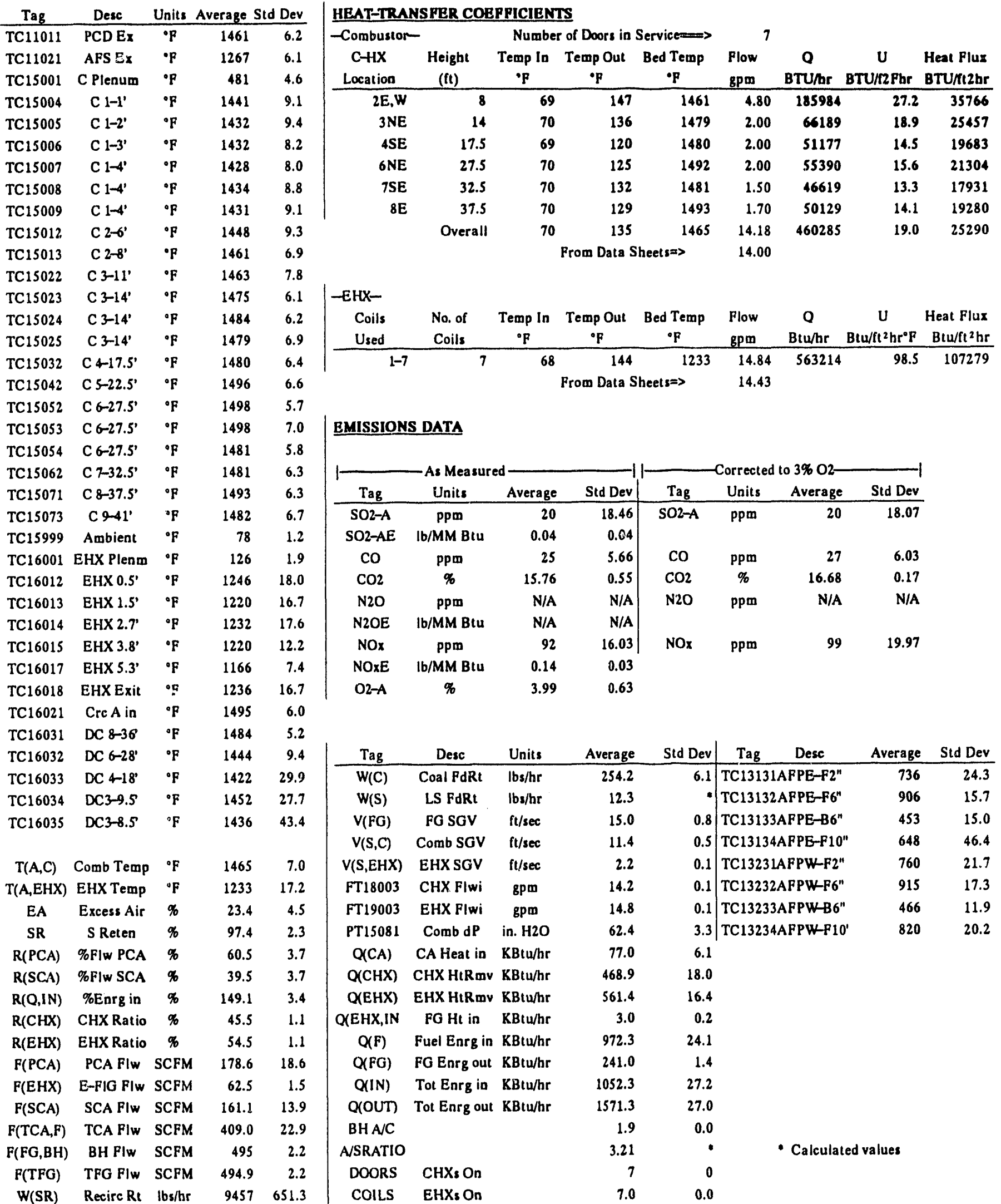




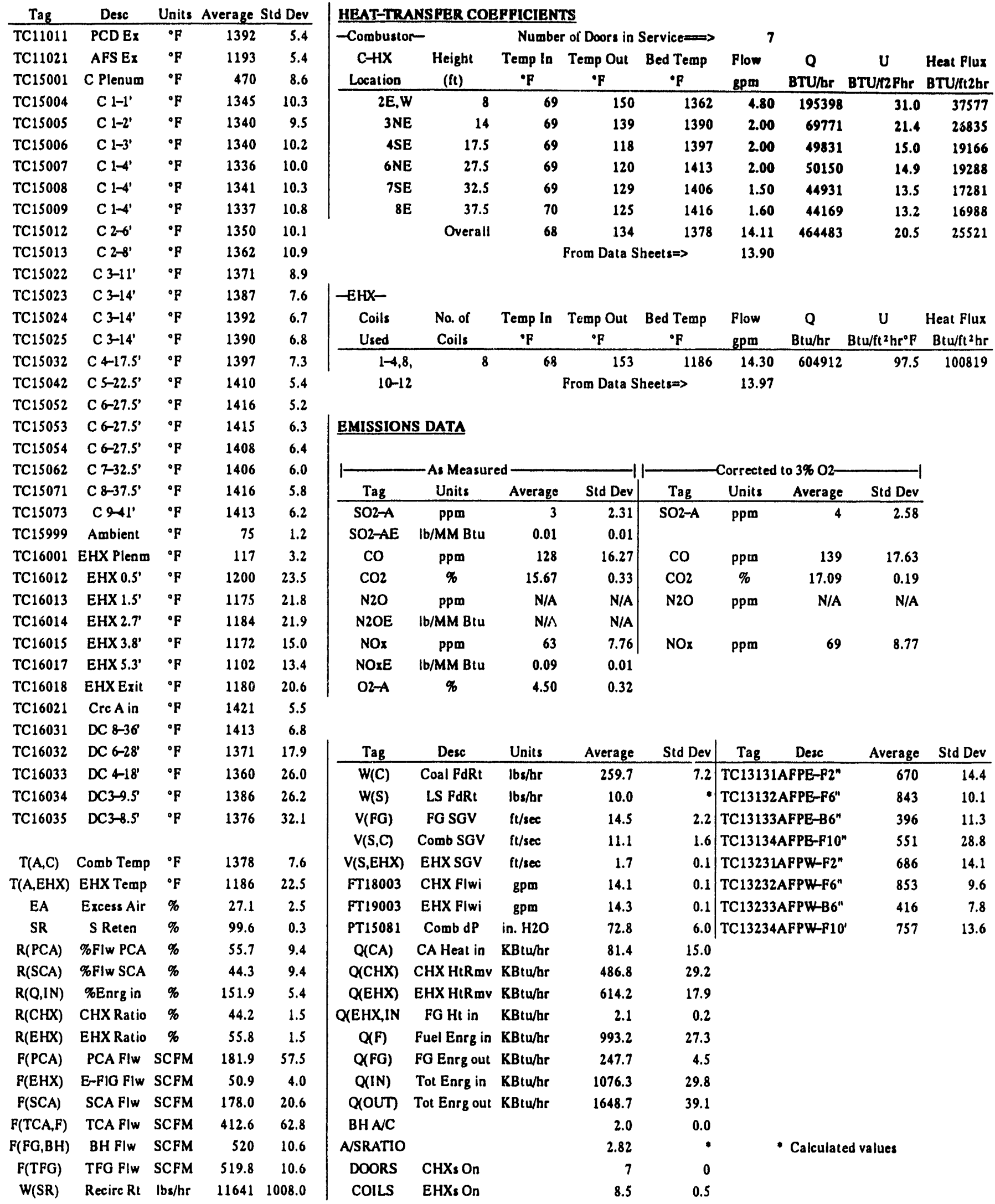




\begin{tabular}{|c|c|c|c|c|c|c|c|c|c|c|c|c|c|}
\hline \multirow{3}{*}{$\frac{\mathrm{Tag}}{\mathrm{TC} 11011}$} & \multirow{2}{*}{$\frac{\text { Desc }}{\text { PCD EX }}$} & \multirow{2}{*}{$\frac{\text { Units }}{\cdot F}$} & \multicolumn{2}{|c|}{ Average Std Dev } & \multicolumn{9}{|c|}{ HEAT-TRANSFBR COEPPICIENTS } \\
\hline & & & 1451 & 5.0 & \multicolumn{2}{|c|}{ - Combustor- } & \multicolumn{3}{|c|}{ Number of Doors in Servic $\Longrightarrow$} & \multicolumn{2}{|l|}{7} & \multirow{3}{*}{$\begin{array}{c}\text { U } \\
\text { BTU/2 } \mathrm{Fbr}\end{array}$} & \multirow{3}{*}{$\begin{array}{l}\text { Heat Flux } \\
\text { BTU/tt2br }\end{array}$} \\
\hline & AFS Ex & ${ }^{\circ} \mathrm{F}$ & 1248 & 4.3 & C-HX & Height & Temp In & Temp Out & Bed Temp & Flow & $\mathbf{Q}$ & & \\
\hline TC15001 & C Plenum & ${ }^{\circ} \mathbf{F}$ & 518 & 5.2 & Location & $(f t)$ & $\bullet \mathbf{p}$ & $\cdot \mathbf{p}$ & $\bullet \mathbf{P}$ & gpm & BTU/ar E & & \\
\hline TC15004 & C 1-1' & ${ }^{\circ} \mathbf{F}$ & 1446 & 12.8 & $2 E, W$ & 8 & 69 & 156 & 1461 & 4.93 & 213332 & 31.4 & 41025 \\
\hline TC15005 & C 1-2' & ${ }^{\circ} \mathbf{F}$ & 1436 & 12.2 & 3NE & 14 & 69 & 147 & 1473 & 2.00 & 78159 & 22.7 & 30061 \\
\hline TC15006 & C 1-3' & ${ }^{\circ} \mathbf{F}$ & 1435 & 12.3 & 4SE & 17.5 & 69 & 127 & 1477 & 2.00 & 58248 & 16.6 & 22403 \\
\hline TC15007 & C $1-4^{\prime}$ & ${ }^{\circ} \mathbf{P}$ & 1431 & 11.4 & 6NE & 27.5 & 69 & 128 & 1487 & 2.00 & 59238 & 16.8 & 22784 \\
\hline TC15008 & C $1-4^{\prime}$ & $\cdot \mathbf{F}$ & 1438 & 12.5 & 7SE & 32.5 & 69 & 142 & 1482 & 1.50 & 55187 & 15.8 & 21226 \\
\hline TC15009 & C 1-4' & ${ }^{\circ} \mathbf{F}$ & 1433 & 11.5 & $8 \mathrm{E}$ & 37.5 & 69 & 138 & 1487 & 1.60 & 54493 & 15.5 & 20959 \\
\hline TC15012 & C 2-6' & ${ }^{\circ} \mathbf{F}$ & 1450 & 12.5 & & Overall & 69 & 143 & 1464 & 14.14 & 524375 & 21.8 & 28812 \\
\hline TC15013 & C 2-8' & $\bullet \mathbf{F}$ & 1461 & 11.6 & & & \multicolumn{3}{|c|}{ From Data Sheets $\Rightarrow$} & 14.03 & & & \\
\hline TC15022 & C 3-11' & ${ }^{\circ} \mathbf{F}$ & 1460 & 9.4 & & & & & & & & & \\
\hline TC15023 & C 3-14' & ${ }^{\circ} \mathbf{F}$ & 1470 & 9.5 & -EHX- & & & & & & & & \\
\hline TC15024 & C 3-14' & ${ }^{\circ} \mathbf{F}$ & 1476 & 10.3 & Coils & No. of & Temp In & Temp Out & Bed Temp & Flow & $\mathbf{Q}$ & $u$ & Heat Flux \\
\hline TC15025 & C 3-14' & ${ }^{\circ} \mathbf{F}$ & 1474 & 9.7 & Used & Coils & ${ }^{\circ} \mathbf{p}$ & ${ }^{\circ} \mathbf{F}$ & •F & gpm & Btu/hr B & Btu/ft ${ }^{2} r^{\circ} F$ & $\mathrm{Btu} / \mathrm{ft}^{2} \mathrm{hr}$ \\
\hline TC15032 & $C 4-17.5^{\prime}$ & ${ }^{\circ} \mathrm{F}$ & 1477 & 8.0 & $1-2,10-12$ & 5 & 68 & 164 & 1351 & 9.62 & 461067 & 103.6 & 122951 \\
\hline TC15042. & C 5-22.5 & ${ }^{\circ} \mathrm{F}$ & 1485 & 8.7 & & & \multicolumn{3}{|c|}{ From Data Sheets $\Rightarrow>$} & 9.50 & & & \\
\hline $\mathrm{TC} 15052$ & C 6-27.5' & ${ }^{\circ} \mathbf{F}$ & 1489 & 8.9 & & & & & & & & & \\
\hline $\mathrm{TC} 15053$ & C 6-27.5' & ${ }^{\circ} \mathbf{F}$ & 1490 & 9.4 & \multicolumn{5}{|c|}{ EMISSIONS DATA } & & & & \\
\hline TC15054 & C 6-27.5' & ${ }^{\circ} \mathbf{F}$ & 1482 & 7.9 & & & & & & & & & \\
\hline TC15062 & C 7-32.5' & ${ }^{\circ} \mathbf{F}$ & 1482 & 8.1 & \multicolumn{4}{|c|}{ As Measured - } & \multicolumn{4}{|c|}{-Corrected to $3 \%$ O2 } & \\
\hline TC15071 & C 8-37.5' & ${ }^{\circ} \mathbf{F}$ & 1487 & 8.5 & Tag & Units & Average & Std Dev & $\mathrm{Tag}$ & Units & Average & Std Dev & \\
\hline TC15073 & C $9-41^{\prime}$ & ${ }^{\circ} \mathbf{F}$ & 1484 & 9.4 & SO2-A & $\mathrm{ppm}$ & 10 & 13.35 & SO2-A & ppm & 10 & $\overline{14.02}$ & \\
\hline TC15999 & Ambient & ${ }^{\circ} \mathbf{F}$ & 83 & 1.1 & $\mathrm{SO} 2 \mathrm{AE}$ & $\mathrm{lb} / \mathrm{MM} \mathrm{Btu}$ & 0.02 & 0.03 & & & & & \\
\hline TC16001 & EHX Plenm & ${ }^{\circ} \mathbf{F}$ & 128 & 3.0 & co & ppm & 69 & 12.35 & $\mathrm{Co}$ & ppm & 76 & 13.86 & \\
\hline $\mathrm{TC} 16012$ & EHX 0.5' & ${ }^{\circ} \mathbf{F}$ & 1368 & 13.8 & $\mathrm{CO} 2$ & $\%$ & 15.31 & 0.54 & $\mathrm{CO} 2$ & $\%$ & 16.70 & 0.35 & \\
\hline TC16013 & EHX $1.5^{\prime}$ & ${ }^{\circ} \mathbf{p}$ & 1338 & 13.2 & $\mathrm{~N} 2 \mathrm{O}$ & ppm & $N / A$ & N/A & $\mathrm{N} 2 \mathrm{O}$ & ppm & N/A & N/A & \\
\hline $\mathrm{TCl} 16014$ & EHX 2.7' & ${ }^{\circ} \mathrm{F}$ & 1350 & 11.8 & N2OE & Ib/MM Btu & $N / A$ & N/A & & & & & \\
\hline TC16015 & EHX 3.8' & ${ }^{\circ} \mathbf{F}$ & 1327 & 7.0 & NOx & ppm & 98 & 13.63 & NOx & ppm & 108 & 17.82 & \\
\hline TC16017 & EHX 5.3' & ${ }^{\circ} \mathbf{F}$ & 1253 & 6.0 & NOxE & $\mathrm{lb} / \mathrm{MM}$ Btu & 0.15 & 0.03 & & & & & \\
\hline TC16018 & EHXExit & ${ }^{\circ} \mathbf{F}$ & 1345 & 10.3 & O2-A & $\%$ & 4.50 & 0.50 & & & & & \\
\hline TC16021 & $\operatorname{CrcA}$ in & ${ }^{\circ} \mathrm{F}$ & 1493 & 7.4 & & & & & & & & & \\
\hline TC16031 & DC \&-36 & ${ }^{\circ} \mathbf{F}$ & 1485 & 6.7 & & & & & & & & & \\
\hline TC16032 & $D C$ 6-28' & ${ }^{\circ} \mathrm{F}$ & 1450 & 5.9 & Tag & Desc & Units & Average & Std Dev & $\mathrm{Tag}$ & Desc & Average & Sid Dev \\
\hline $\mathrm{TC} 16033$ & $D C 4-18^{\prime}$ & ${ }^{\circ} \mathrm{F}$ & 1451 & 7.1 & $W(C)$ & Coal FdRt & $\mathrm{lbs} / \mathrm{hr}$ & 299.6 & 13.0 & TC13131 & AFPE-P2n & 789 & 21.0 \\
\hline TC16034 & DC3-9.5 & ${ }^{\circ} \mathrm{F}$ & 1484 & 10.7 & $W(S)$ & LS FdRt & $\mathrm{lbs} / \mathrm{br}$ & 8.6 & - & TC13132 & AFPE-F $6^{n}$ & 939 & 15.4 \\
\hline $\mathrm{TC} 16035$ & $D C 3-8.5$ & ${ }^{\circ} \mathrm{F}$ & 1474 & 11.2 & $V(F G)$ & FG SGV & $\mathrm{ft} / \mathrm{sec}$ & 16.1 & 0.8 & TC13133 & AFPE-B6" & 491 & 16.9 \\
\hline & & & & & $V(S, C)$ & Comb SGV & $\mathrm{ft} / \mathrm{sec}$ & 12.3 & 0.6 & TC13134 & AFPE-F10" & 725 & 40.3 \\
\hline $\mathrm{T}(\mathrm{A}, \mathrm{C})$ & Comb Temp & ${ }^{\circ} \mathbf{F}$ & 1464 & 9.9 & V(S,EHX) & EHX SGV & $\mathrm{ft} / \mathrm{sec}$ & 1.9 & 0.1 & TC13231 & AFPW-F2" & 803 & 18.3 \\
\hline $\mathrm{T}(\mathrm{A}, \mathrm{EHX})$ & EHX Temp & ${ }^{\circ} \mathrm{F}$ & 1351 & 12.9 & FT 18003 & CHX Flwi & gpm & 14.1 & 0.0 & TC13232 & AFPW-F6" & 947 & 13.2 \\
\hline$E A$ & Excess Air & $\%$ & 27.1 & 3.9 & FT19003 & EHX Flwi & $\mathrm{gpm}$ & 9.6 & 0.1 & $\mathrm{TC} 13233$ & AFPW-B6" & 502 & 13.6 \\
\hline SR & S Reten & $\%$ & 98.7 & 1.8 & PT15081 & Comb dP & in. $\mathrm{H} 2 \mathrm{O}$ & 65.7 & 2.8 & TC13234 & AFPWF $10^{\prime}$ & 862 & 17.8 \\
\hline$R(P C A)$ & $\%$ FIw PCA & $\%$ & 58.8 & 3.8 & $Q(C A)$ & CA Heat in & KBtu/hr & 91.8 & 4.5 & & & & \\
\hline $\mathrm{R}(\mathrm{SCA})$ & $\%$ FIW SCA & $\%$ & 41.2 & 3.8 & Q(CHX) & CHX HtRmv & $\mathrm{KBt} / \mathrm{h} \mathrm{br}$ & 525.3 & 21.4 & & & & \\
\hline$R(Q, I N)$ & \%Enrg in & $\%$ & 124.8 & 5.9 & QEHX) & EHX HtRmv & $\mathrm{KBt} / \mathrm{h} / \mathrm{hr}$ & 461.4 & 9.5 & & & & \\
\hline $\mathrm{R}(\mathrm{CHX})$ & CHX Ratio & $\%$ & 53.2 & 1.0 & Q(EHX,IN & FG $\mathrm{Ht}$ in & $\mathrm{KBtu} / \mathrm{hr}$ & 2.4 & 0.2 & & & & \\
\hline$R(E H X)$ & EHX Ratio & $\%$ & 46.8 & 1.0 & $\alpha(F)$ & Fuel Enrg in & $\mathrm{KB}$ tu/hr & 1151.4 & 45.1 & & & & \\
\hline$F(P C A)$ & PCA Flw & SCFM & 203.0 & 27.9 & $\alpha(F G)$ & FG Enrg out & $\mathrm{KBt} / \mathrm{hr}$ & 262.1 & 1.5 & & & & \\
\hline$F(E H X)$ & E-FIG Fiw & SCFM & 52.3 & 1.4 & $Q(I N)$ & Tot Enrg in & $\mathrm{KBt} / \mathrm{h} / \mathrm{hr}$ & 1246.3 & 46.4 & & & & \\
\hline $\mathrm{F}(\mathrm{SCA})$ & SCA FIw & SCFM & 180.3 & 12.4 & QOUT) & Tot Enrg out & $\mathrm{KBtu} / \mathrm{hr}$ & 1548.8 & 26.1 & & & & \\
\hline$F(T C A, F)$ & TCA Fiw & SCFM & 439.0 & 21.2 & BH AVC & & & 2.1 & 0.0 & & & & \\
\hline$F(F G, B H)$ & BH FIw & SCFM & 541 & 2.5 & A/SRATIO & & & 2.43 & - & & - Calculated & d values & \\
\hline F(TFG) & TFG FIw & SCPM & 540.6 & 2.5 & DOORS & $\mathrm{CHXs}$ On & & 7 & 0 & & & & \\
\hline W(SR) & Recirc Rt & $\mathrm{lbs} / \mathrm{hr}$ & 13953 & 505.8 & colls & EHXs On & & 5.0 & 0.0 & & & & \\
\hline
\end{tabular}




\section{APPENDIX C}

\section{BLACKSVILLE BITUMINOUS COAL TEST RESULTS}




\section{TABLE OF CONTENTS}

Page

LIST OF FIGURES $\ldots \ldots \ldots \ldots \ldots \ldots \ldots \ldots \ldots \ldots \ldots \ldots \ldots$ C-iii

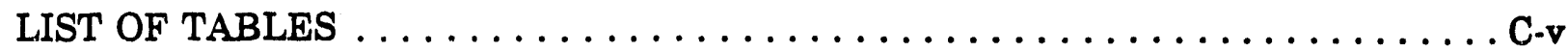

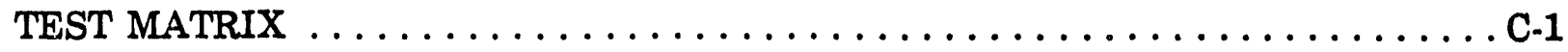

COAL AND LIMESTONE PROPERTIES $\ldots \ldots \ldots \ldots \ldots \ldots \ldots \ldots \ldots \ldots \ldots$ C-2

OPERATIONAL PERFORMANCE $\ldots \ldots \ldots \ldots \ldots \ldots \ldots \ldots \ldots \ldots \ldots, \ldots \ldots \ldots, 2$

General Operability $\ldots \ldots \ldots \ldots \ldots \ldots \ldots \ldots \ldots \ldots \ldots \ldots \ldots, \mathrm{C}-2$

Summary of Results .........................

Recirculation Rates and Size Distributions .................. C-5

Fly Ash/Bottom Ash Splits $\ldots \ldots \ldots \ldots \ldots \ldots \ldots \ldots \ldots \ldots \ldots \ldots$ C-11

Coal Ash/Limestone Split $\ldots \ldots \ldots \ldots \ldots \ldots \ldots \ldots \ldots \ldots \ldots \ldots \ldots \ldots \ldots \ldots \ldots \ldots, 13$

THERMAL PERFORMANCE $\ldots \ldots \ldots \ldots \ldots \ldots \ldots \ldots \ldots \ldots \ldots \ldots \ldots, \ldots \ldots \ldots$

Energy and Material Balances $\ldots \ldots \ldots \ldots \ldots \ldots \ldots \ldots \ldots \ldots \ldots$, C-14

Combustion Efficiency $\ldots \ldots \ldots \ldots \ldots \ldots \ldots \ldots \ldots \ldots \ldots \ldots \ldots \ldots \ldots, \mathrm{C}-20$

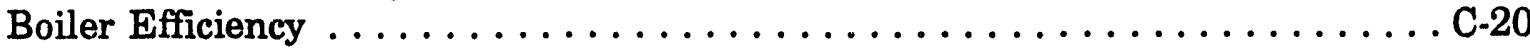

Heat-Transfer Coefficient and Heat Flux $\ldots \ldots \ldots \ldots \ldots \ldots \ldots \ldots \ldots \ldots$ C-20

Pressure and Temperature Profiles $\ldots \ldots \ldots \ldots \ldots \ldots \ldots \ldots \ldots \ldots \ldots, \mathrm{C}-26$

ENVIRONMENTAL PERFORMANCE $\ldots \ldots \ldots \ldots \ldots \ldots \ldots \ldots \ldots \ldots \ldots$ C-30

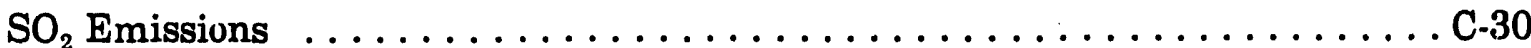

$\mathrm{NO}_{\mathrm{x}}$ Emissions $\ldots \ldots \ldots \ldots \ldots \ldots \ldots \ldots \ldots \ldots \ldots \ldots \ldots \ldots \ldots \ldots \ldots \ldots, \mathrm{C}-35$

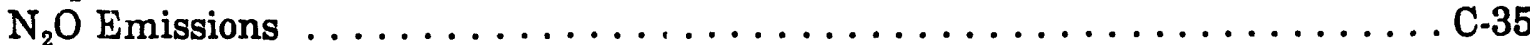

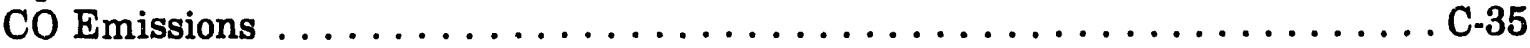

LIMESTONE PERFORMANCE $\ldots \ldots \ldots \ldots \ldots \ldots \ldots \ldots \ldots \ldots \ldots \ldots \ldots$

SUMMARIES OF TEST DATA $\ldots \ldots \ldots \ldots \ldots \ldots \ldots \ldots \ldots \ldots \ldots \ldots$ C-39 


\section{LIST OF FIGURES}

Figure

C-1 Particle-size distribution of coal $\ldots \ldots \ldots \ldots \ldots \ldots \ldots \ldots \ldots \ldots \ldots$

C-2 Particle-size distribution of limestone $\ldots \ldots \ldots \ldots \ldots \ldots \ldots \ldots \ldots \ldots$

C-3 Particle-size distributions of the combustor bed material, downcomer, secondary cyclone ash, and baghouse ash $\ldots \ldots \ldots \ldots \ldots$ C-11

C-4 Particle-size distributions of the combustor bed material, downcomer, secondary cyclone ash, and baghouse ash . . . . . . . . C-12

C-5 Particle-size distributions of the combustor bed material, downcomer, secondary cyclone ash, and baghouse ash . . . . . . . C-12

C-6 Combustion efficiency as a function of superficial gas velocity $\ldots \ldots \ldots \ldots$ C-25

C-7 Effect of average combustor temperature $\ldots \ldots \ldots \ldots \ldots \ldots \ldots \ldots$

C-8 Pressure profiles of Tests 1 through $6 \ldots \ldots \ldots \ldots \ldots \ldots \ldots \ldots$

C-9 Pressure profiles of Tests 7 through $12 \ldots \ldots \ldots \ldots \ldots \ldots \ldots \ldots$

C-10 Pressure profiles of Tests 13 through $18 \ldots \ldots \ldots \ldots \ldots \ldots \ldots \ldots$

C-11 Temperature profiles of Tests 1 through $6 \ldots \ldots \ldots \ldots \ldots \ldots$ C-31

C-12 Temperature profiles of Tests 7 through $12 \ldots \ldots \ldots \ldots \ldots \ldots$ C-31

C-13 Temperature profiles of Tests 13 through $18 \ldots \ldots \ldots \ldots \ldots \ldots \ldots$

C-14 Relationship between temperature and flue gas $\mathrm{SO}_{2}$ emissions $\ldots \ldots \ldots$ C-32

C-15 Effect of alkali-to-sulfur ratio on $\mathrm{SO}_{2}$ emissions $\ldots \ldots \ldots \ldots \ldots \ldots$

C-16 Effect of solids recirculation rate on $\mathrm{SO}_{2}$ emissions $\ldots \ldots \ldots \ldots \ldots$

C-17 $\mathrm{NO}_{\mathrm{z}}$ emissions as a function of average combustor temperature $\ldots \ldots \ldots$ C-37

$\mathrm{C}-18 \mathrm{NO}_{\mathrm{z}}$ emissions as a function of excess air $\ldots \ldots \ldots \ldots \ldots \ldots \ldots \ldots$

C-19 $\mathrm{N}_{2} \mathrm{O}$ emissions as a function of average combustor temperature $\ldots \ldots \ldots \ldots$ C-38

$\mathrm{C}-20 \mathrm{CO}$ emissions as a function of average combustor temperature $\ldots \ldots \ldots . \mathrm{C}-38$

C-21 Effect of limestone type, size, and source $\ldots \ldots \ldots \ldots \ldots \ldots \ldots \ldots$ 


\section{LIST OF TABLES}

Table

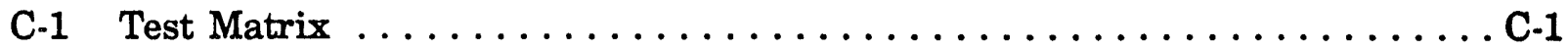

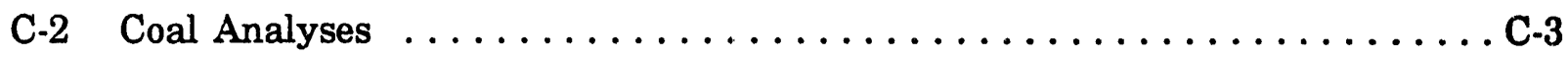

C-3 Average Limestone Analysis $\ldots \ldots \ldots \ldots \ldots \ldots \ldots \ldots \ldots \ldots \ldots$

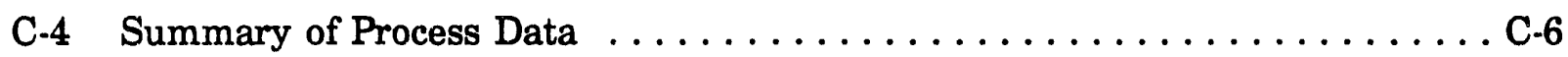

C-5 Solids Recirculation and Heat-Transfer Data . . . . . . . . . . . . . C-10

C-6 Ash Balance . . . . . . . . . . . . . . . . . . . . . C-13

C-7 Material Derived from Coal Ash and Limestone Based on Aluminum Material Balance .......................... C-15

C-8 Aluminum Material Balance $\ldots \ldots \ldots \ldots \ldots \ldots \ldots \ldots \ldots \ldots \ldots \ldots$

C-9 Fuel Balance $\ldots \ldots \ldots \ldots \ldots \ldots \ldots \ldots \ldots \ldots \ldots \ldots \ldots \ldots \ldots \ldots$

C-10 Flue Gas Balance $\ldots \ldots \ldots \ldots \ldots \ldots \ldots \ldots \ldots \ldots \ldots \ldots \ldots \ldots \ldots$

C-11 Energy Balance $\ldots \ldots \ldots \ldots \ldots \ldots \ldots \ldots \ldots \ldots \ldots \ldots \ldots \ldots \ldots \ldots \ldots$

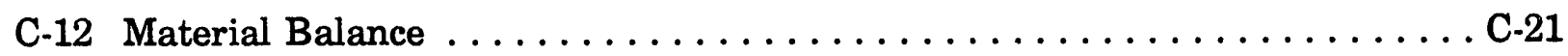

C-13 Combustion Efficiency $\ldots \ldots \ldots \ldots \ldots \ldots \ldots \ldots \ldots \ldots \ldots \ldots \ldots$

C-14 Unburned Carbon $\ldots \ldots \ldots \ldots \ldots \ldots \ldots \ldots \ldots \ldots \ldots \ldots \ldots \ldots$

C-15 Boiler Efficiency $\ldots \ldots \ldots \ldots \ldots \ldots \ldots \ldots \ldots \ldots \ldots \ldots \ldots \ldots$

C-16 Individual Heat-Transfer Coefficients $\ldots \ldots \ldots \ldots \ldots \ldots \ldots \ldots \ldots$ C-28

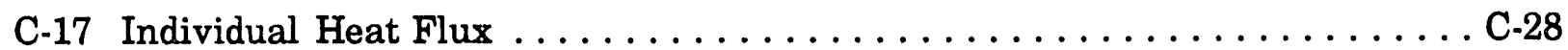

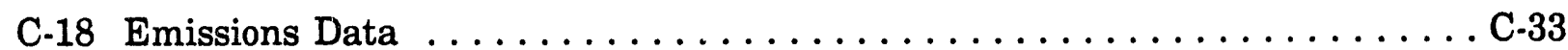




\section{TEST MATRIX}

Table C-1 shows the test matrix that was used for the Blacksville bituminous coal. Test duration was 231 hours of continuous testing, resulting in the successful completion of 18 scheduled test periods plus one additional test within the scheduled time. Each of the scheduled tests were conducted over a 6 -hour test period.

Test 1 was a baseline test without limestone feed to determine the maximum sulfur emissions generated by this coal. Test 2 served as a baseline with limestone feed to establish the nominal calcium-to-sulfur ratio for $90 \%$ sulfur capture to be used in the latter test periods. Tests 6 and 3 were high- and low-temperature tests, respectively. Test 14 was operated at the same conditions as Test 13, except that secondary air addition was through Section 3 (10.5 feet above distributor plate level) of the combustor instead of Section 2 (5.75 feet above distributor plate level). Tests 9 through 12 were load tests performed at approximately $50 \%$ and $75 \%$ of full load established in Test 2 . Turndown

\section{TABLE C-1}

Test Matrix

\begin{tabular}{cccccccc}
\hline Test \# & $\begin{array}{c}\text { Temp. } \\
\left({ }^{\circ} \mathrm{F}\right)\end{array}$ & $\begin{array}{c}\text { Load } \\
(\%)\end{array}$ & $\begin{array}{c}\text { Sulfur Ret. (\%) or } \\
\text { Ca/S ratio }\end{array}$ & $\begin{array}{c}\text { PA/SA } \\
\text { Split }\end{array}$ & $\begin{array}{c}\text { SGV } \\
(\mathrm{ft} / \mathrm{sec})\end{array}$ & $\begin{array}{c}\text { Excess } \\
\text { Air }(\%)\end{array}$ & $\begin{array}{c}\text { Sec. Air } \\
\text { Port }\end{array}$ \\
\hline 1 & 1550 & 100 & No ls & $60: 40$ & 16 & 25 & 2 \\
2 & 1550 & 100 & $90 \%$ & $60: 40$ & 16 & 25 & 2 \\
3 & 1425 & 100 & same Ca/S as 2 & $60: 40$ & $15^{2}$ & 25 & 2 \\
4 & 1550 & 100 & same Ca/S as 2 & $70: 30$ & 19 & 15 & 2 \\
5 & 1550 & 100 & same Ca/S as 2 & $50: 50$ & 19 & 45 & 2 \\
6 & 1675 & 100 & same Ca/S as 2 & $60: 40$ & $17^{2}$ & 25 & 2 \\
7 & 1550 & 100 & same Ca/S as 2 & $50: 50$ & 13 & 15 & 2 \\
8 & 1550 & 100 & same Ca/S as 2 & $70: 30$ & 13 & 45 & 2 \\
9 & 1550 & 75 & same Ca/S as 2 & $80: 20$ & $12^{2}$ & 25 & 2 \\
10 & 1550 & 50 & same Ca/S as 2 & $90: 10$ & $8^{2}$ & 25 & 2 \\
11 & 1000 & 50 & same Ca/S as 2 & $90: 10$ & $10^{2}$ & $100^{2}$ & 2 \\
12 & 1400 & 75 & same Ca/S as 2 & $90: 10$ & $12^{2}$ & $50^{2}$ & 2 \\
$12 a$ & 1400 & 75 & same Ca/S as 2 & $60: 40$ & $12^{2}$ & $50^{2}$ & 2 \\
13 & 1550 & 100 & $95 \%$ & $60: 40$ & 16 & 25 & 2 \\
14 & 1550 & 100 & $95 \%$ & $60: 40$ & 16 & 25 & 3 \\
15 & 1550 & 100 & $70 \%$ & $60: 40$ & 16 & 25 & 2 \\
16 & 1550 & 100 & same Ca/S as 2 & $60: 40$ & 16 & 25 & 2 \\
17 & 1550 & 100 & same Ca/S as 2 & $60: 40$ & 16 & 25 & 2 \\
18 & 1550 & 100 & No ls & $60: 40$ & 16 & 25 & 2 \\
\hline
\end{tabular}

${ }^{1}$ Limestone.

${ }^{2}$ Estimated values. 
philosophies that would be used for CFB boilers with and without external heat exchangers were investigated. The addition of Test 12a provided more emission data for different primary/secondary combustion air splits. During Tests 13 and 15 , the $\mathrm{Ca} / \mathrm{S}$ ratio was adjusted to obtain $95 \%$ and $70 \%$ sulfur capture, respectively. Tests $4,5,7$, and 8 were $\mathrm{N}_{2} \mathrm{O}$ tests. Operational conditions that were varied included the primary/secondary air split, velocity, and excess air to determine the effects of these variables specifically on $\mathrm{N}_{2} \mathrm{O}$ as well as ocher emissions. Tests 16 and 17 were at baseline operating conditions, using fine New Enterprise limestone for Test 16 and fine Colorado Ute limestone for Test 17. Test 18 was without limestone feed, operating with a bed of limestone and coal ash.

\section{COAL AND LIMESTONE PROPERTIES}

The coal and limestone used for this test were supplied by the Empire State Electric Energy Research Corporation (ESEERCO). Two railcars of the Blacksville coal, a bituminous coal from the Pittuburgh \#8 seam, along with one railcar of the New Enterprise limestone were received at the EERC. Proximate and ultimate analyses of the coal and $x$-ray fluorescence analysis of the coal ash and limestone were performed. Coal samples from Tests $1,5,9,13,17$, and 18 were analyzed, and the averages of these analyses are shown in Table C-2. Limestone samples from Tests 2 through 15 were composited; the results of the analysis on the composite, as well as the analysis of the Colorado Ute limestone, are shown in Table C-3. Size distributions of the coal and limestones are shown in Figures C-1 and C-2, respectively.

\section{OPERATIONAL PERFORMANCE}

\section{General Operability}

Overall operation for this test was very good. There were occasional hang-ups of coal in either the coal weigh hopper or in the rotary feed valve used for controlling the coal feed rate. This was the result of an accumulation of surface moisture on coal that had been processed and stored in movable sealed storage hoppers. The coal feed rate when using freshly processed coal from the storage silos did fluctuate slightly, but did not present any significant feed problems. The smaller-sized New Enterprise limestone used in Test 16 and the Colorado Ute limestone used in Test 17, which also had a fine consistency, were both difficult to feed steadily into the combustion system. It tended to "rathole" and "bridge" in the weigh hopper and was even difficult to feed out of the movable storage hoppers. The use of a vibrator had little effect on producing uniform feed rates, and, as a result, frequent pounding on hoppers and rotary valves was necessary to maintain limestone feed.

For this test, it was decided to use recirculation from the 25-inch refractory-lined primary cyclone only. Ash from the secondary stainless steel cyclone was routed to a collection barrel. Recirculation rates tended to be relatively low compared to tests conducted with other fuels when secondary cyclone ash was recirculated. Even with low recirculation rates, reasonable heat transfer to heat exchange surfaces in the combustor and external heat exchanger were obtained. 
TABLE C-2

Coal Analyses

Average of 'Tests 1, 5, 9, 13, 17, and 18

\begin{tabular}{|c|c|}
\hline \multicolumn{2}{|l|}{ Proximate Analysis, as-received, wt\% } \\
\hline $\begin{array}{l}\text { Moisture } \\
\text { Volatile Matter } \\
\text { Fixed Carbon } \\
\text { Ash }\end{array}$ & $\begin{array}{r}2.9 \\
35.1 \\
53.8 \\
8.2\end{array}$ \\
\hline \multicolumn{2}{|l|}{ Ultimate Analysis, \% as-received, wt\% } \\
\hline $\begin{array}{l}\text { Carbon } \\
\text { Hydrogen } \\
\text { Nitrogen } \\
\text { Sulfur } \\
\text { Oxygen } \\
\text { Ash }\end{array}$ & $\begin{array}{r}74.4 \\
5.3 \\
1.3 \\
2.4 \\
8.4 \\
8.2\end{array}$ \\
\hline \multicolumn{2}{|l|}{ Ash Composition, as oxides, wt\% } \\
\hline $\begin{array}{l}\text { Calcium, } \mathrm{CaO} \\
\text { Magnesium, } \mathrm{MgO} \\
\text { Sodium, } \mathrm{Na}_{2} \mathrm{O} \\
\text { Silica, } \mathrm{SiO}_{2} \\
\text { Aluminum, } \mathrm{Al}_{2} \mathrm{O}_{3} \\
\text { Ferric, } \mathrm{Fe}_{2} \mathrm{O}_{3} \\
\text { Titanium, } \mathrm{TiO}_{2} \\
\text { Phosphorous, } \mathrm{P}_{2} \mathrm{O}_{5} \\
\text { Potassium, } \mathrm{K}_{2} \mathrm{O} \\
\text { Sulfur, } \mathrm{SO}_{3}\end{array}$ & $\begin{array}{r}5.6 \\
1.2 \\
0.7 \\
43.6 \\
22.7 \\
16.6 \\
0.7 \\
0.4 \\
1.7 \\
6.8\end{array}$ \\
\hline High Heating Value (as-received), Btu/lb & 13,274 \\
\hline
\end{tabular}

TABLE C-3

Average Limestone Analysis (\% as oxide)

\begin{tabular}{lccc}
\hline Component & $\begin{array}{c}\text { New Enterprise } \\
\text { (Coarse) }\end{array}$ & $\begin{array}{c}\text { New Enterprise } \\
\text { (Fine) }\end{array}$ & $\begin{array}{c}\text { Colorado Ute } \\
\text { (Fine) }\end{array}$ \\
\hline Silica & 2.96 & 2.66 & 2.81 \\
Aluminum & 0.78 & 0.59 & 0.48 \\
Iron & 0.42 & 0.44 & 0.26 \\
Titanium & 0.03 & 0.01 & 0.00 \\
Calcium & 51.77 & 51.77 & 54.19 \\
Magnesium & 2.77 & 3.23 & 0.95 \\
Sulfur & 0.21 & 0.22 & 0.30 \\
Sodium & 0.06 & 0.36 & 0.04 \\
Potassium & 0.32 & 0.06 & 0.29 \\
\hline
\end{tabular}




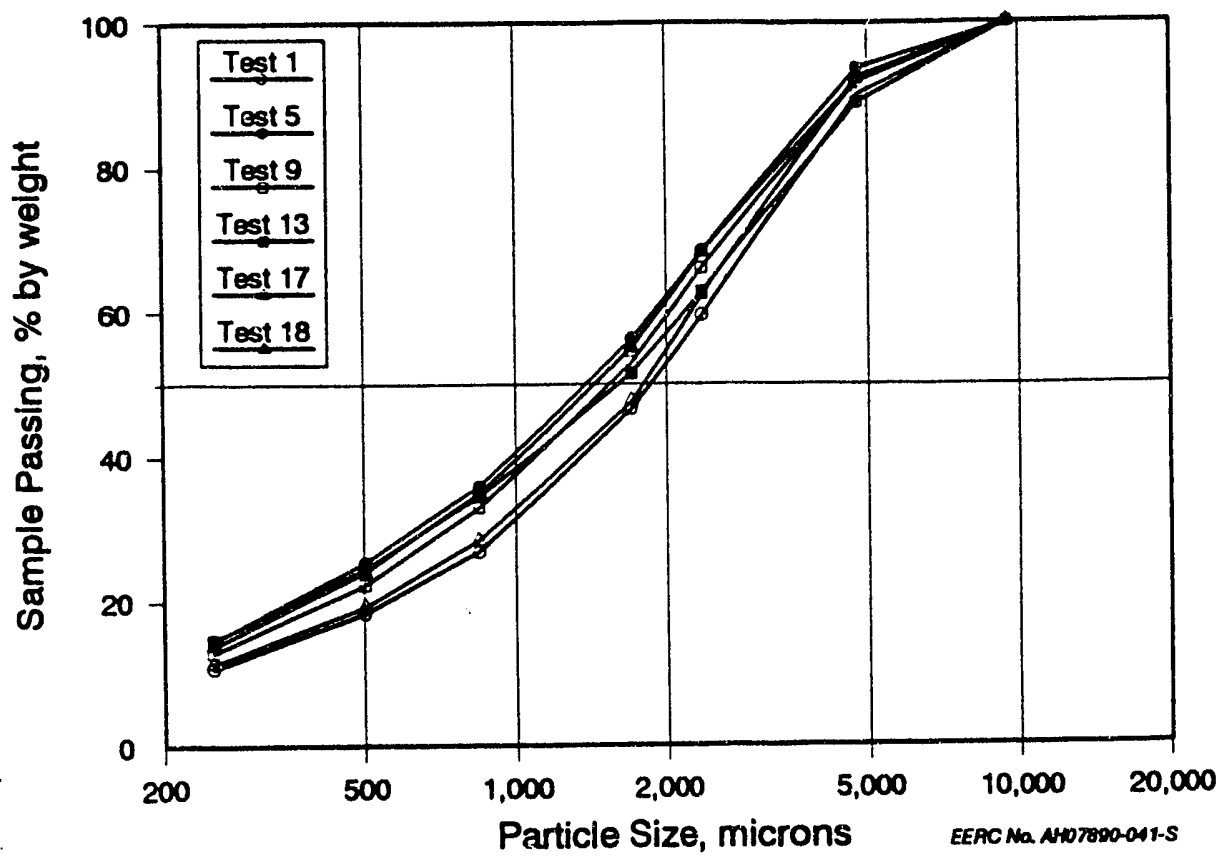

Figure C-1. Particle-size distribution of coal.

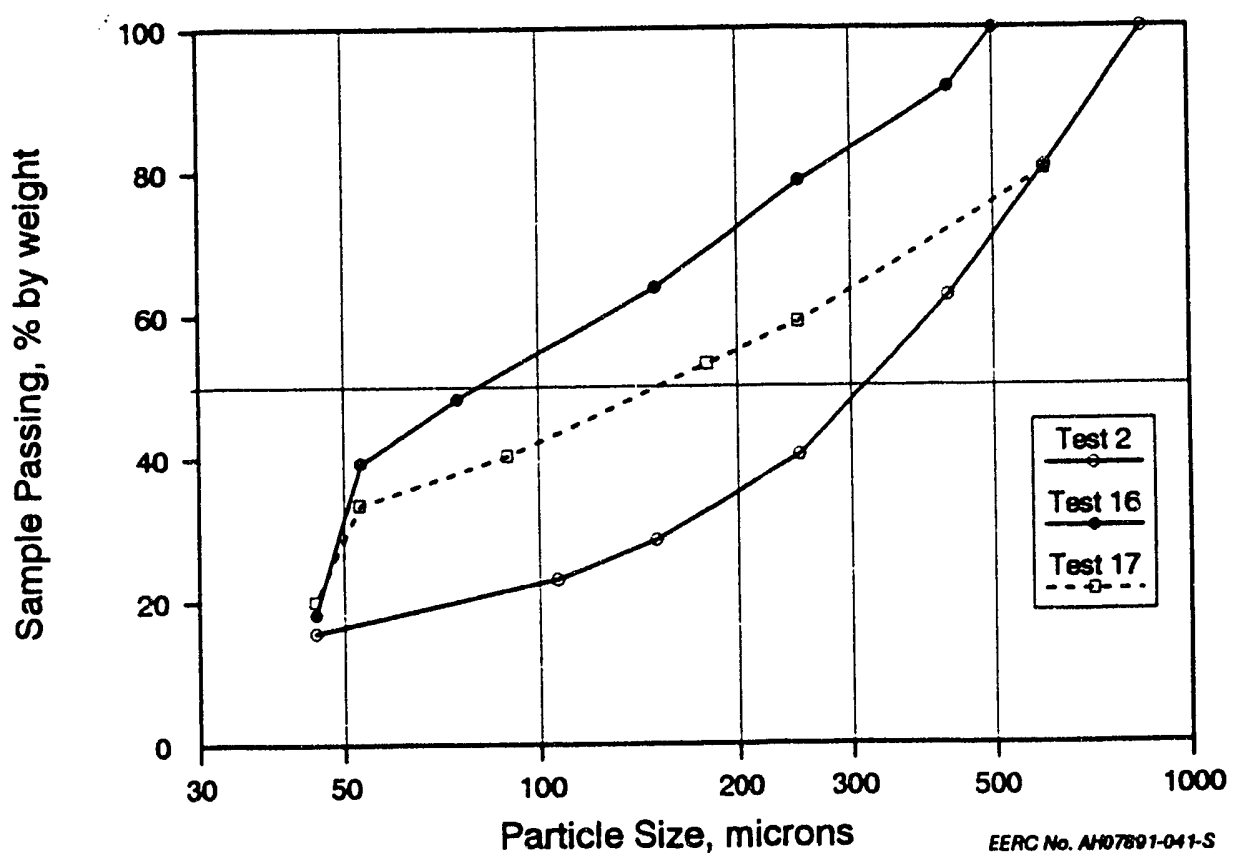

Figure C-2. Particle-size distribution of limestone. 
This was the first test in which proportional, integral, and differential (PID) control loops were incorporated for controlling the combustor velocity, the velocity through the external heat exchanger, and the primary/secondary combustion air (PA/SA) split. These control loops were very successful, reducing the amount of interaction required to maintain steady state conditions. The most obvious difference in data obtained using automatic control compared to the previous manual control method is in how much more concisely we can control the EHX velocity and the PASA split. Obtaining precise velocity through the combustor can still be challenging at some of the extreme conditions even with automatic control.

\section{Summary of Results}

Upon completion of the run, the data from the data acquisition system and operator's log sheets were averaged over each of the nineteen test periods. Certain data points were deleted before the averages were calculated, such as emissions data from time periods when the gas analyzers were calibrated or the sample conditioner was purged, and baghouse pressure drop when the baghouse was bypassed. A summary of the process data for the 19 tests conducted is presented in Table C.4. The 19 test periods correspond to those presented in the test matrix listed in Table C-1. Summaries of the run data, showing averages and standard deviations for most of the data collected by the data acquisition system, are included at the end of this appendix.

\section{Recirculation Rates and Size Distributions}

The average solids recirculation rates, determined by a heat balance around the external heat exchanger, are shown in Table C-5. Recirculation rates were, on the average, lower during this test compared to previously conducted tests with other coals. This was primarily due to not recirculating the fly ash collected from the secondary cyclone back into the downcomer. The Blacksville coal has a high sulfur content that requires a significant limestone feed rate. Thus a large amount of solids are being steadily fed into the system, making it less critical to have an overall high collection efficiency to retain sufficient solids for recirculation. Additionally, when solids recirculation is too high, it can cause operational problems in the shell-and-tube combustion air heater and result in high temperatures downstream in the baghouse. As the recirculation rate increases, it appears that particulate loading increases as well, and the water-jacketed flue gas heat exchangers cannot keep up, resulting in high inlet temperatures into the baghouse. In a full-scale system, this could correspond to higher heat-transfer rates in the convective pass region along with greater erosion potential. The advantages of recirculating additional fines include potentially higher limestone utilization and combustion efficiency.

All of the low velocity tests ( 7 through 12 ) had low recirculation rates. The lowest recirculation rates encountered were for the $50 \%$ load tests (10 and 11) conducted at the lowest velocities ( 10.6 and $9.1 \mathrm{ft} / \mathrm{sec}$, respectively). Switching over to secondary air addition through Section 3 at a level of 10.5 feet above the distributor plate also resulted in a low recirculation rate. Normally, secondary air addition is through Section 2 at 5.75 feet above the distributor plate. Section 1 of the combustor, as described earlier, is tapered, starting at a 14-inch inside diameter, increasing to the 20-inch inside diameter over its 5 -foot length. This allows sufficient velocity in this section to keep the solids fluidized. Then secondary air is introduced at the Section 2 level, resulting in full 


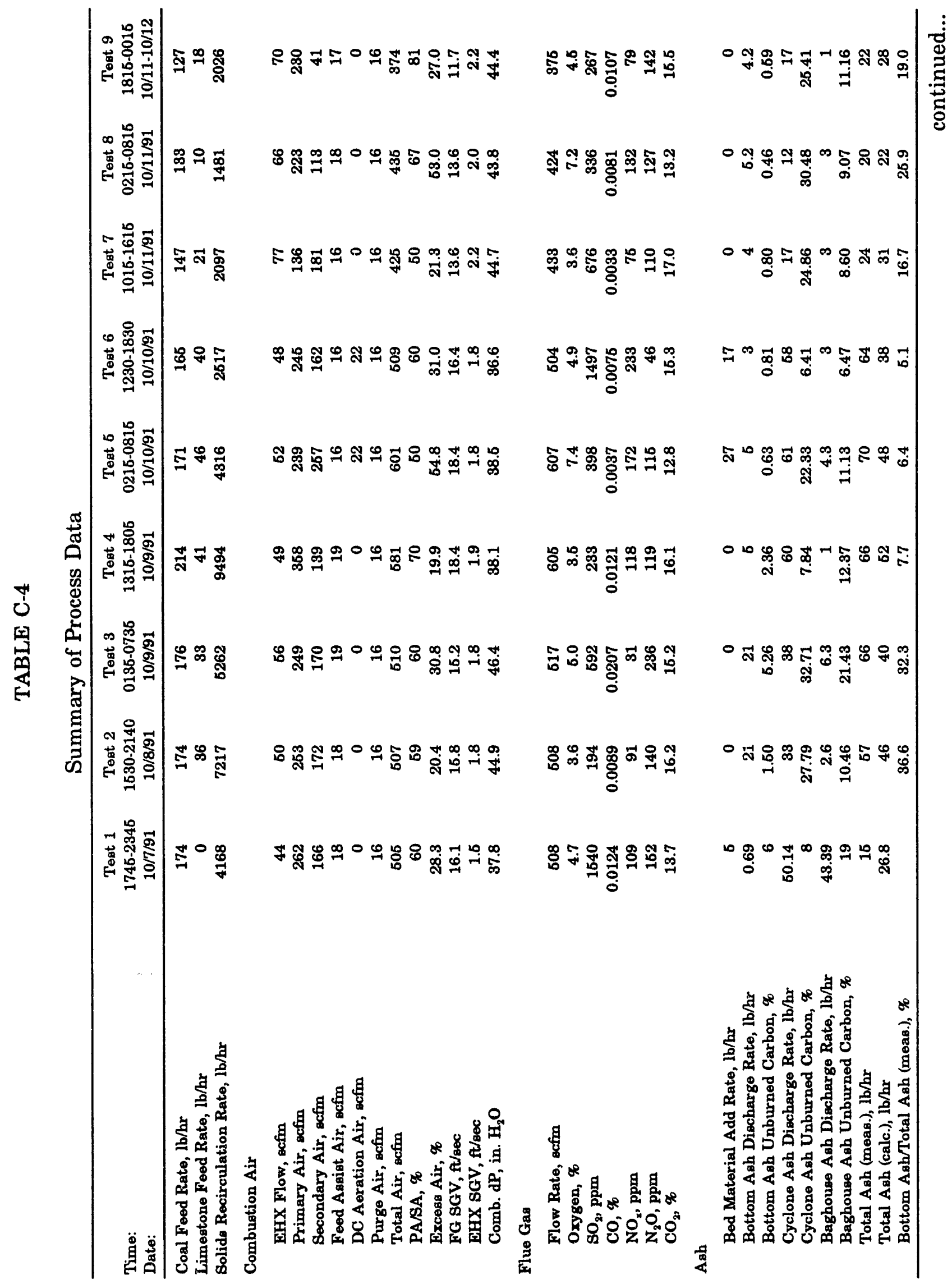




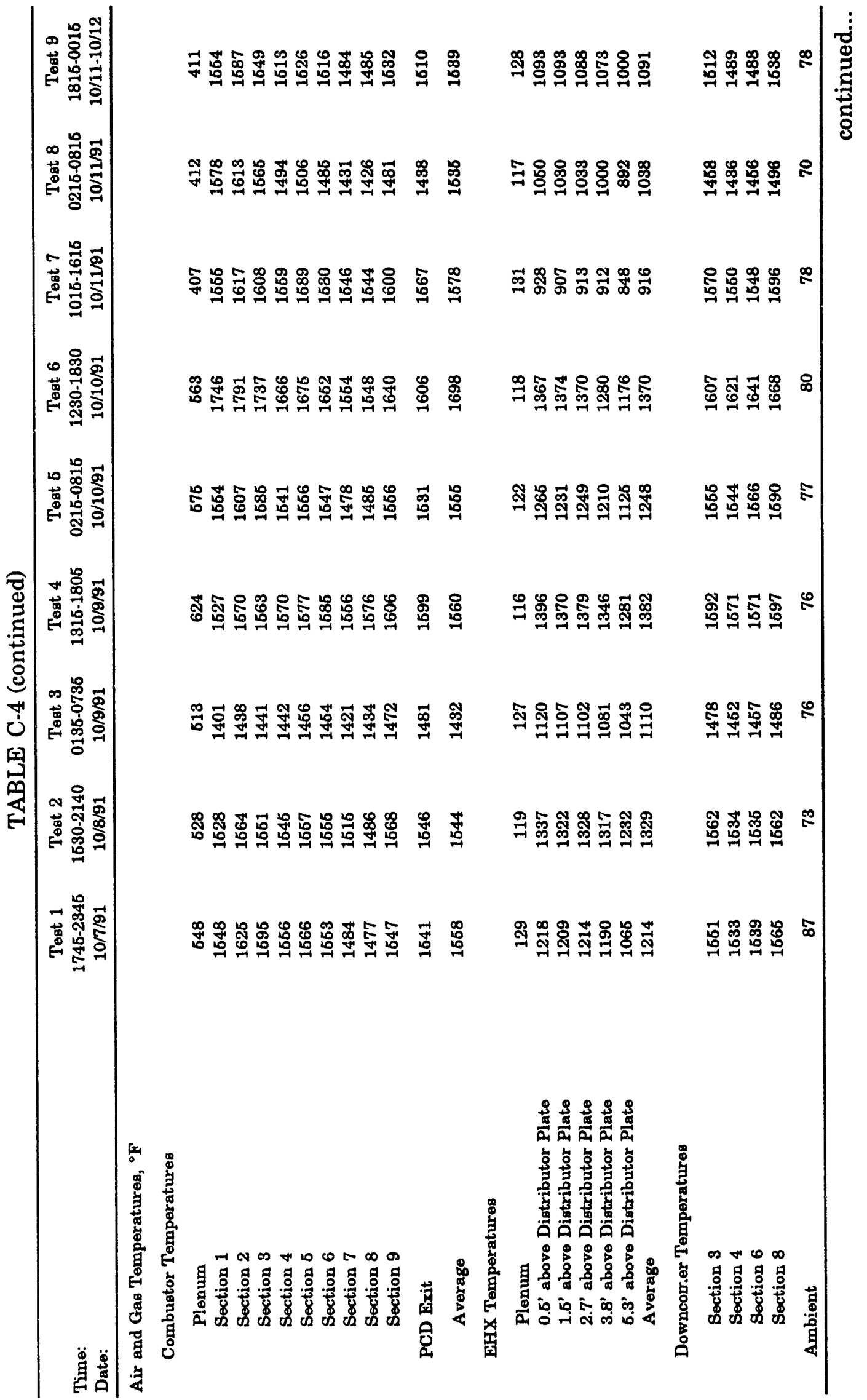




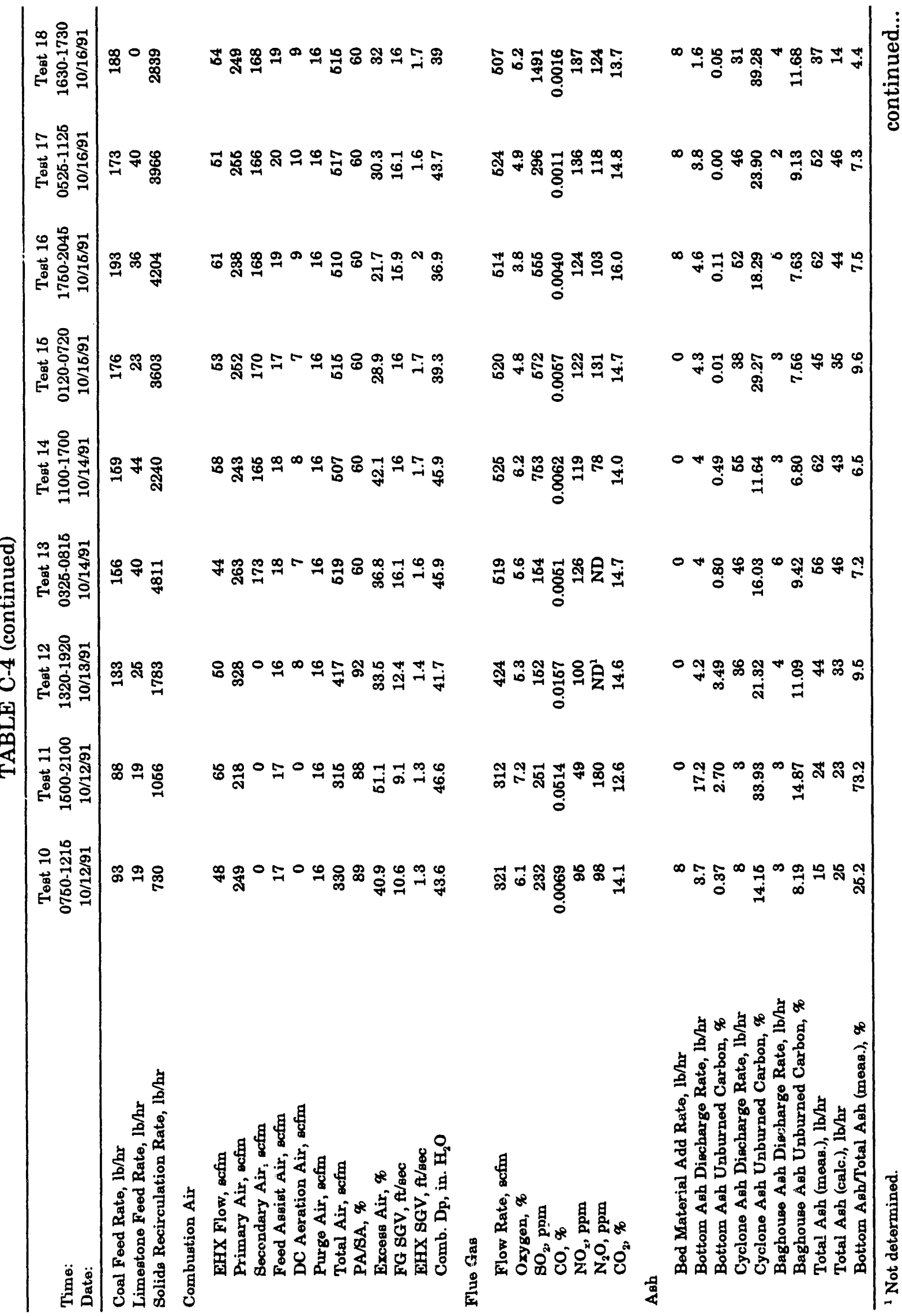




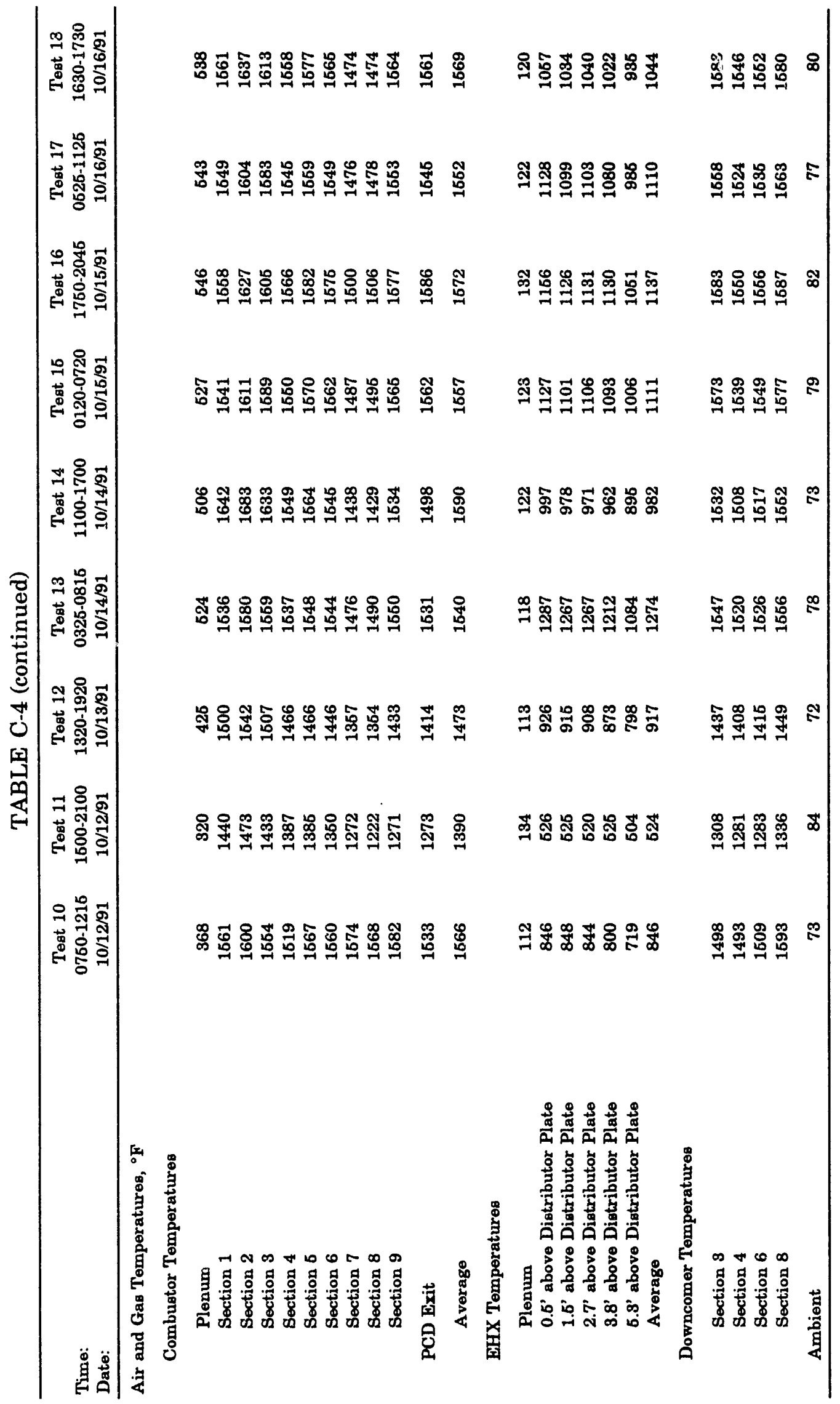




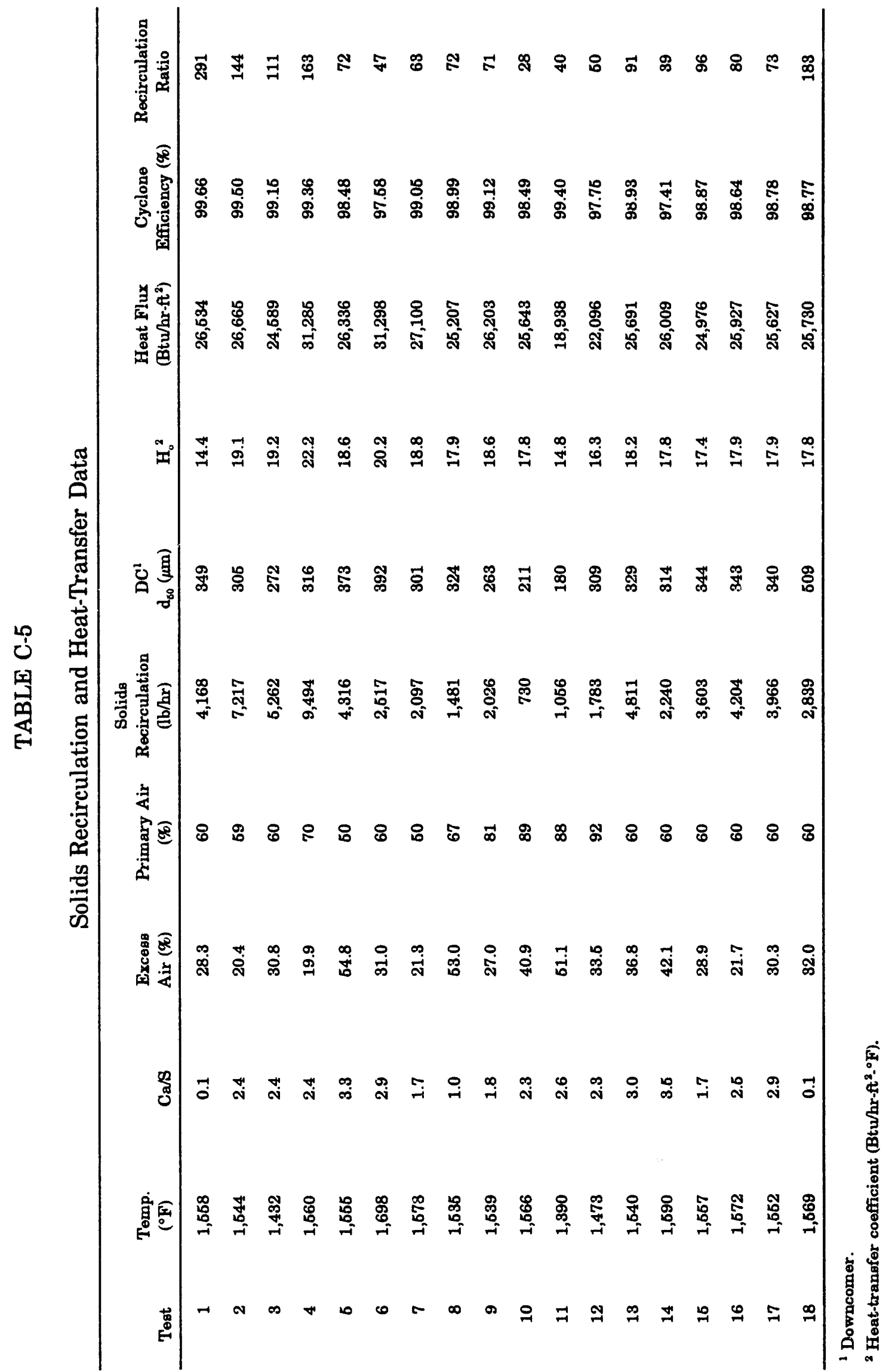


operational velocity up the remaining combustor sections, which have a uniform 20-inch inside diameter. Section 3 secondary air addition ereates a low-velocity region in Section 2, causing less solids to be blown upward to the full velocity region where they can be conveyed up and out of the combustor into the primary cyclone.

Recirculation rates for Tests 16 and 17, conducted with two difference types of finesized limestone, were each lower than for Test 2 . Test 2 was run at the same type of conditions and with the same limestone as Test 16, but with a larger particle size. The finer-sized limestone does not seem to stay in the system long enough to sulfate and is carried more readily to the baghouse.

Cyclone efficiency is defined as one minus the ratio of total fly ash collected (including both baghouse and secondary cyclone ash) to the recirculation rate. The lowest cyclone efficiency, 97.4\%, was calculated for Test 14, while Test 1 had the highest, 99.7\%.

The particle-size distributions of the combustor bed material, downcomer, secondary cyclone ash, and baghouse ash are shown in Figures C-3 through C-5.

\section{Fly Ash/Bottom Ash Splits}

The ash balance for all of the test periods is shown in Table C.6 and includes ratios of bottom ash-to-total ash and percent closure. The bottom ash-to-total ash ratio was generally in the range of $5 \%$ to $35 \%$. In most instances, more material was being removed than was being added during the test periods. Tests 3,10 , and 18 had the poorest closures. Test 3 had high material removal rates from the combustor bed,

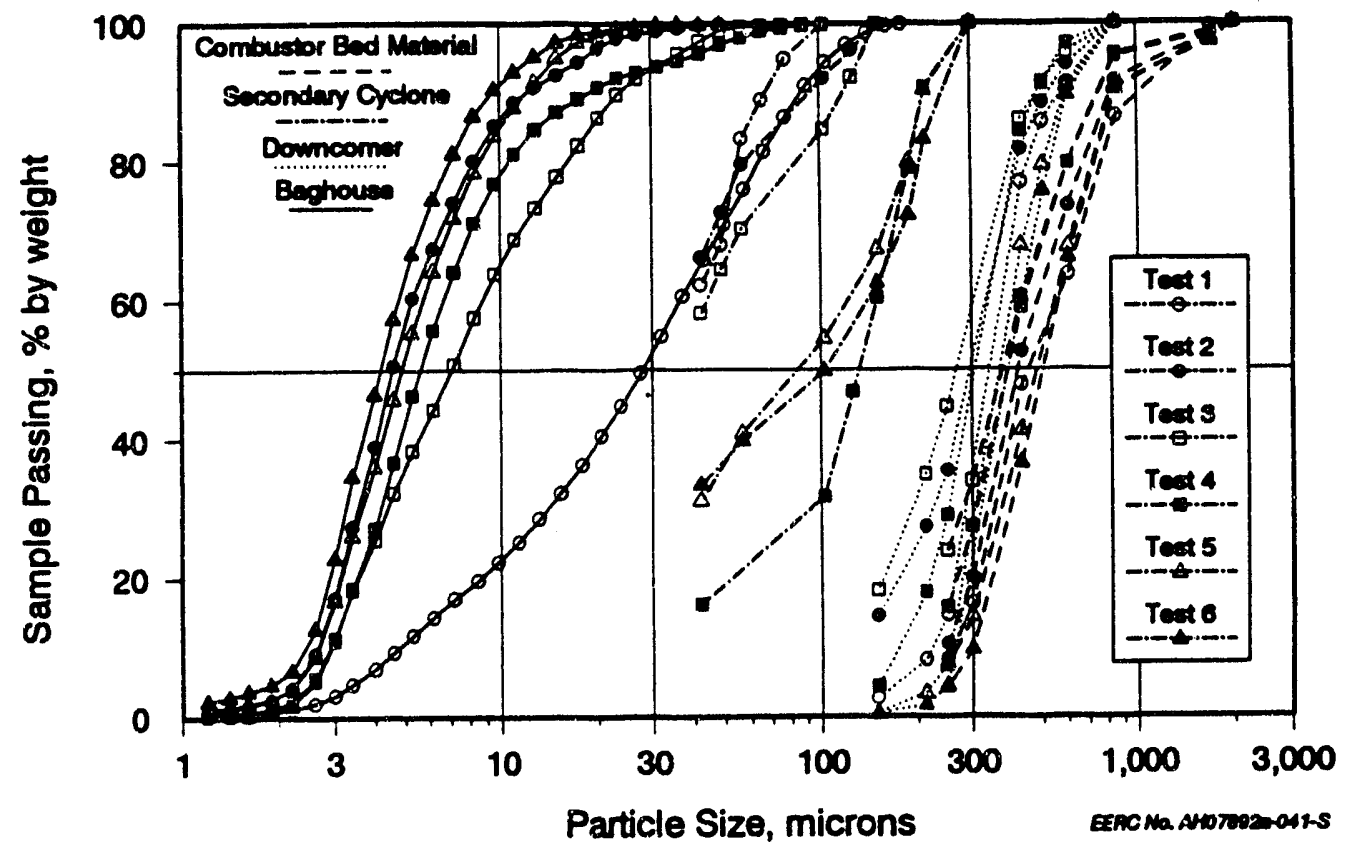

Figure C-3. Particle-size distributions of the combustor bed material, downcomer, secondary cyclone ash, and baghouse ash. 


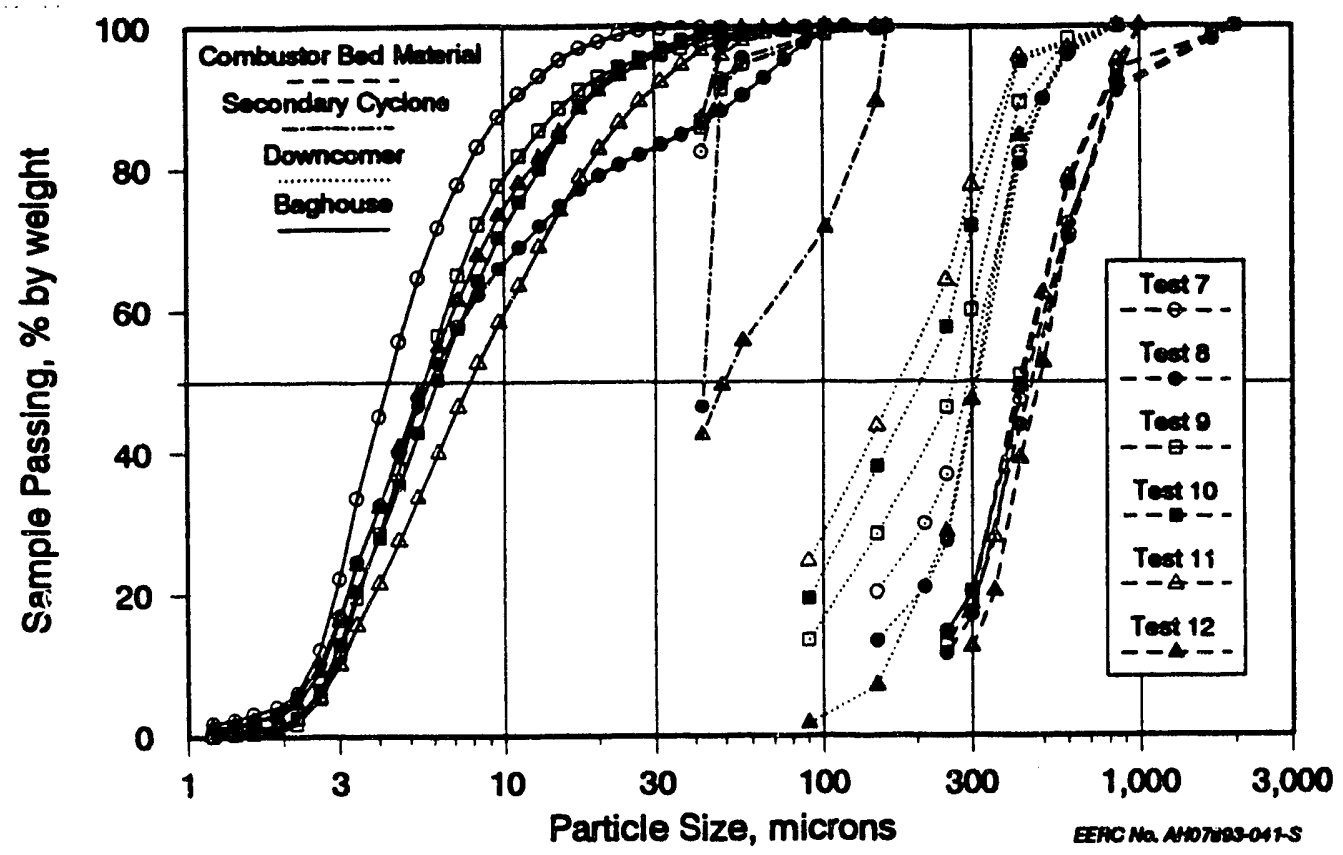

Figure C-4. Particle-size distributions of the combustor bed material, downcomer, secondary cyclone ash, and baghouse ash.

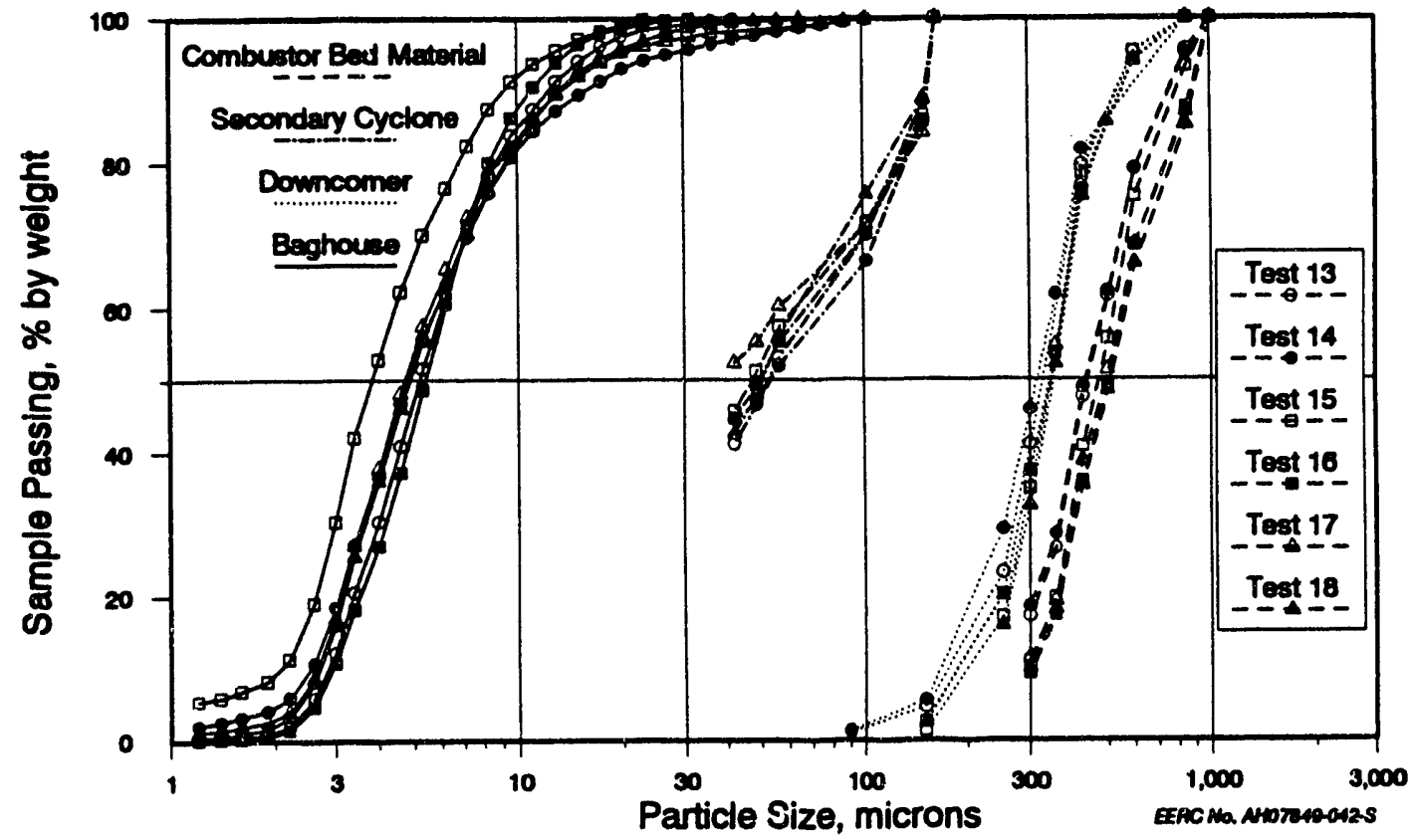

Figure C-5. Particle-size distributions of the combustor bed material, downcomer, secondary cyclone ash, and baghouse ash. 


\section{TABLE C-6}

Ash Balance

\begin{tabular}{|c|c|c|c|c|c|c|c|c|c|}
\hline & Test 1 & Teat 2 & Teat 3 & Toot 4 & Toot 5 & Toet 6 & Toot 7 & Teut 8 & Tont 9 \\
\hline \multicolumn{10}{|l|}{ Input $(\mathrm{lb} / \mathrm{hr})$} \\
\hline Ash & 16 & 16 & 14 & 18 & 16 & 14 & 13 & 11 & 11 \\
\hline \multicolumn{10}{|l|}{ Sorbent* } \\
\hline $\mathrm{CaO}$ & 0 & 13 & 13 & 15 & 20 & 21 & 7 & 1 & 6 \\
\hline $\mathrm{CaSO}_{4}$ & 0 & 18 & 12 & 20 & 14 & 3 & 11 & 10 & 12 \\
\hline Bod Material & 0 & 0 & 0 & 0 & 27 & 17 & 0 & $\mathbf{0}$ & 0 \\
\hline Total Solids In & 16 & 46 & $\underline{40}$ & $\underline{63}$ & $\underline{75}$ & $\underline{66}$ & $\underline{31}$ & $\underline{22}$ & $\underline{28}$ \\
\hline \multicolumn{10}{|l|}{ Output (lb/hr) } \\
\hline Bed Material & 5 & 21 & 21 & 5 & 5 & 3 & 4 & 5 & 4 \\
\hline Cyclone Ash & 6 & 33 & 38 & 60 & 61 & 68 & 17 & 12 & 17 \\
\hline Baghouse Ash & 8 & 3 & 6 & 1 & 4 & 3 & 3 & 3 & 1 \\
\hline Total Solids Out & $\underline{19}$ & $\underline{67}$ & $\underline{66}$ & $\underline{66}$ & $\underline{70}$ & $\underline{64}$ & $\underline{24}$ & $\underline{20}$ & $\underline{22}$ \\
\hline Closure (\%) & 132.0 & 122.9 & 163.8 & 125.3 & 93.2 & 115.5 & 76.6 & 91.9 & 79.0 \\
\hline \multirow[t]{2}{*}{ Bottom Asb/Total Ash (\%) } & 26.8 & 36.6 & 32.3 & 7.7 & 6.4 & 6.1 & 16.7 & 25.9 & 19.0 \\
\hline & Tect 10 & Teet 11 & Tent 12 & Tent 13 & Test 14 & Test 15 & Teat 16 & Test 17 & Test 18 \\
\hline \multicolumn{10}{|l|}{ Input $(\mathrm{lb} / \mathrm{hr})$} \\
\hline Ash & 9 & 8 & 12 & 14 & 13 & 16 & 16 & 16 & 14 \\
\hline \multicolumn{10}{|l|}{ Sorbent* } \\
\hline $\mathrm{CaO}$ & 7 & 7 & 8 & 14 & 17 & 11 & 12 & 16 & 0 \\
\hline $\mathrm{CaSO}_{4}$ & 10 & 8 & 13 & 20 & 18 & 5 & 20 & 16 & 0 \\
\hline Bed Material & 8 & 0 & 0 & 0 & 0 & 0 & 8 & 8 & 8 \\
\hline Total Solide In & $\underline{33}$ & $\underline{23}$ & $\underline{33}$ & $\underline{48}$ & $\underline{49}$ & $\underline{31}$ & $\underline{56}$ & $\underline{55}$ & $\underline{23}$ \\
\hline \multicolumn{10}{|l|}{ Output $(\mathrm{lb} / \mathrm{hr})$} \\
\hline Bed Material & 4 & 17 & 4 & 4 & 4 & 4 & 5 & 4 & 2 \\
\hline Cyclone Ash & 8 & 3 & 36 & 46 & 65 & 38 & 62 & 46 & 31 \\
\hline Baghouse Aah & 3 & 3 & 4 & 6 & 3 & 3 & 5 & 2 & 4 \\
\hline Total Solids Out & $\underline{15}$ & $\underline{24}$ & $\underline{44}$ & $\underline{66}$ & $\underline{62}$ & $\underline{45}$ & $\underline{62}$ & $\underline{52}$ & $\underline{37}$ \\
\hline Closure (\%) & 44.4 & 101.4 & 133.1 & 116.2 & 127.6 & 146.5 & 110.5 & 96.2 & 160.4 \\
\hline Bottom Asb/Total Ash (\%) & 25.2 & 73.2 & 9.5 & 7.2 & 6.6 & 9.6 & 7.5 & 7.3 & 4.4 \\
\hline
\end{tabular}

* The $\mathrm{CaO}$ and $\mathrm{CaSO}_{4}$ mase inputs are included to express sorbent equivalent mass inputs.

secondary cyclone, and baghouse. Test 10 was a low-load, low-velocity test with very little material removed from the secondary cyclone. Test 18 had no limestone addition and a much higher secondary cyclone ash removal rate than Test 1 , which also had no limestone addition. The combined output of secondary cyclone and baghouse ash in most instances very closely matches the total input of the limestone and coal ash. It appears that operation would be possible without much bottom ash removal.

\section{Coal Ash/Limestone Split}

An aluminum balance was performed to determine the composition of each ash stream. $\mathrm{Al}_{2} \mathrm{O}_{3}$ was used as a tracer, since it is prevalent in the coal ash and almost nonexistent in the limestone. The percentage of each ash stream that came from the coal, as well as the proportions of coal and limestone as inputs for each test, are shown in 
Table C-7. The percentage of limestone in the ash is determined by difference. For several tests, such as Test 5, bed material was added during the test; for these tests, the sum of the coal and limestone input does not total 100\%, and the percentages of ash from both the coal and limestone are artificially high, since the aluminum in the added bed material is not accounted for. Test 18 shows a greater than $100 \%$ contribution of coal ash to the baghouse ash because the percentage of aluminum in the baghouse ash was greater than that in the coal; this is probably due to the aluminum in the bed material added during that test. Table C-8 shows the aluminum balance for each test. The closure in this table and in Table C-7 is based on the coal ash only.

The baghouse material typically was made up of over $80 \%$ fly ash. This indicates the limestone is not degrading to any great extent and producing fines. Recycle from the baghouse would do little to improve sulfur capture for this coal. The material collected in the secondary cyclone, however, contained 40-78\% limestone. Recycle of this stream could potentially increase sulfur capture and improve the utilization of the limestone. The bed drain contained $82 \%-86 \%$ limestone, indicating that most of the ash in the coal is being removed as fly ash.

\section{THERMAL PERFORMANCE}

\section{Energy and Material Balances}

The measured and theoretical fuel and flue gas flow rates are shown in Tables C-9 and C-10, respectively. The theoretical coal feed rate is calculated using the coal analysis and the actual air flow rates and flue gas emissions for each test period. The measured coal feed rate is determined by calculating the weight loss over time of the coal weigh hopper. The fuel balance for most of the tests was fairly good; the largest difference between measured and theoretical was for Test 10, which was a $50 \%$ load test and, consequently, had a very low coal feed rate. Fourteen of the eighteen tests had a negative difference; that is, the theoretical feed rate was greater than the measured. Other tests have shown the same trend.

The theoretical flue gas rates were calculated using the coal analysis and theoretical coal feed rates for each test. The actual air and flue gas flow rates were measured with orifice plates. In all cases, the measured flue gas flow rate was less than the theoretical, with the greatest difference observed for Test 10.

The energy balances for the eighteen tests are shown in Table C-11, both as Btu/hr and as percentages. The energy input is made up of the energy potential of the fuel, the primary and secondary combustion air, the external heat exchanger fluidizing air, the carbon present in the added bed material, and the energy released from the sulfation of the sorbent. Measurable heat loss sources consist of the combustor heat exchange doors, the external heat exchanger cooling coils, the heat of the flue gas (including a correction for leakage), the heat of the solids removed from the system, the unburned carbon in the ash removed, and the energy absorbed during calcination of the sorbent. The unmeasurable heat loss due to convection and radiation is estimated using a correlation, which relates heat loss to average combustor temperature, that was developed from the data generated from testing with all five coals. The energy balances for all eighteen tests were generally quite good, ranging from $90.6 \%$ closure for Test 10 to $108.2 \%$ closure for Test 11. 
TABLE C-7

Material Derived from Coal Ash and Limestone Based on Aluminum Material Balance (\%)

\begin{tabular}{|c|c|c|c|c|c|c|}
\hline & Coal & $\mathrm{ls}^{1}$ & Coal & ls & Coal & ls \\
\hline & \multicolumn{2}{|c|}{ Test 1} & \multicolumn{2}{|c|}{ Test 2} & \multicolumn{2}{|c|}{ Test 3} \\
\hline $\begin{array}{l}\text { Solids Input } \\
\text { Bed Drain } \\
\text { Cyclone Catch } \\
\text { Baghouse Catch }\end{array}$ & $\begin{array}{r}100.00 \\
19.78 \\
74.89 \\
95.59\end{array}$ & $\begin{array}{l}0.00 \\
0.00 \\
0.00 \\
0.00\end{array}$ & $\begin{array}{l}34.30 \\
17.67 \\
50.22 \\
86.78\end{array}$ & $\begin{array}{l}65.70 \\
82.33 \\
49.78 \\
13.22\end{array}$ & $\begin{array}{l}35.75 \\
16.65 \\
39.52 \\
84.58\end{array}$ & $\begin{array}{l}64.25 \\
83.35 \\
60.48 \\
15.42\end{array}$ \\
\hline \multirow[t]{2}{*}{ Aluminum Balance Closure } & \multicolumn{2}{|c|}{90.32} & \multicolumn{2}{|c|}{144.94} & \multicolumn{2}{|c|}{165.94} \\
\hline & \multicolumn{2}{|c|}{ Test 4} & \multicolumn{2}{|c|}{ Test 5} & \multicolumn{2}{|c|}{ Test 6} \\
\hline $\begin{array}{l}\text { Solids Input } \\
\text { Bed Drain } \\
\text { Cyclone Catch } \\
\text { Baghouse Catch }\end{array}$ & $\begin{array}{l}34.02 \\
15.64 \\
21.81 \\
81.50\end{array}$ & $\begin{array}{l}65.98 \\
84.36 \\
78.19 \\
18.50\end{array}$ & $\begin{array}{l}19.22 \\
14.18 \\
32.54 \\
81.03\end{array}$ & $\begin{array}{l}45.03 \\
85.82 \\
67.46 \\
18.97\end{array}$ & $\begin{array}{l}25.30 \\
17.16 \\
23.53 \\
83.62\end{array}$ & $\begin{array}{l}45.49 \\
82.84 \\
76.47 \\
16.38\end{array}$ \\
\hline \multirow[t]{2}{*}{ Aluminum Balance Closure } & \multicolumn{2}{|c|}{81.44} & \multicolumn{2}{|c|}{165.89} & \multicolumn{2}{|c|}{114.41} \\
\hline & \multicolumn{2}{|c|}{ Test 7} & \multicolumn{2}{|c|}{ Test 8} & \multicolumn{2}{|c|}{ Test 9} \\
\hline $\begin{array}{l}\text { Solids Input } \\
\text { Bed Drain } \\
\text { Cyclone Catch } \\
\text { Baghouse Catch }\end{array}$ & $\begin{array}{l}43.54 \\
15.09 \\
55.60 \\
92.67\end{array}$ & $\begin{array}{r}56.46 \\
84.61 \\
44.40 \\
7.33\end{array}$ & $\begin{array}{l}49.16 \\
15.22 \\
67.24 \\
93.97\end{array}$ & \begin{tabular}{r|}
50.84 \\
84.78 \\
32.76 \\
6.03
\end{tabular} & $\begin{array}{l}40.61 \\
17.15 \\
56.14 \\
87.72\end{array}$ & $\begin{array}{l}59.39 \\
82.85 \\
43.86 \\
12.28\end{array}$ \\
\hline \multirow[t]{2}{*}{ Aluminum Balance Closure } & \multicolumn{2}{|c|}{98.85} & \multicolumn{2}{|c|}{109.66} & \multicolumn{2}{|c|}{100.44} \\
\hline & \multicolumn{2}{|c|}{ Test 10} & \multicolumn{2}{|c|}{ Test 11} & \multicolumn{2}{|c|}{ Test 12} \\
\hline $\begin{array}{l}\text { Solids Input } \\
\text { Bed Drain } \\
\text { Cyclone Catch } \\
\text { Baghouse Catch }\end{array}$ & $\begin{array}{l}28.11 \\
16.27 \\
55.26 \\
82.02\end{array}$ & $\begin{array}{l}45.14 \\
83.73 \\
44.74 \\
17.98\end{array}$ & $\begin{array}{l}34.01 \\
15.31 \\
61.84 \\
86.40\end{array}$ & $\begin{array}{l}65.99 \\
84.69 \\
38.16 \\
13.60\end{array}$ & $\begin{array}{l}34.54 \\
13.51 \\
36.62 \\
85.96\end{array}$ & $\begin{array}{l}65.46 \\
86.49 \\
63.38 \\
14.04\end{array}$ \\
\hline \multirow[t]{2}{*}{ Aluminum Balance Closure } & \multicolumn{2}{|c|}{84.92} & \multicolumn{2}{|c|}{94.00} & \multicolumn{2}{|c|}{149.54} \\
\hline & \multicolumn{2}{|c|}{ Test 13} & \multicolumn{2}{|c|}{ Test 14} & \multicolumn{2}{|c|}{ Test 15} \\
\hline $\begin{array}{l}\text { Solids Input } \\
\text { Bed Drain } \\
\text { Cyclone Catch } \\
\text { Baghouse Catch }\end{array}$ & $\begin{array}{l}31.39 \\
13.20 \\
28.95 \\
78.95\end{array}$ & $\begin{array}{l}68.61 \\
86.80 \\
71.05 \\
21.05\end{array}$ & $\begin{array}{l}30.74 \\
13.88 \\
27.27 \\
75.77\end{array}$ & $\begin{array}{l}69.26 \\
86.12 \\
72.73 \\
24.23\end{array}$ & $\begin{array}{l}41.39 \\
12.47 \\
47.58 \\
98.68\end{array}$ & $\begin{array}{r}58.61 \\
87.53 \\
52.42 \\
1.32\end{array}$ \\
\hline Aluminum Balance Closure & 129.35 & 16 & & 17 & $\mathrm{Te}$ & \\
\hline $\begin{array}{l}\text { Solids Input } \\
\text { Bed Drain } \\
\text { Cyclone Catch } \\
\text { Baghouse Catch }\end{array}$ & $\begin{array}{l}29.39 \\
15.24 \\
27.00 \\
68.28\end{array}$ & $\begin{array}{l}54.90 \\
84.76 \\
73.00 \\
31.72\end{array}$ & $\begin{array}{l}27.87 \\
16.83 \\
38.72 \\
75.33\end{array}$ & $\begin{array}{l}56.50 \\
83.17 \\
61.28 \\
24.67\end{array}$ & $\begin{array}{r}63.52 \\
12.87 \\
54.71 \\
105.38\end{array}$ & $\begin{array}{r}0.00 \\
87.13 \\
45.29 \\
-5.38\end{array}$ \\
\hline Aluminum Balance Closure & & .96 & & & & \\
\hline
\end{tabular}

Timestone. 


\section{TABLE C-8}

Aluminum Material Balance

\begin{tabular}{|c|c|c|c|c|c|c|c|c|c|}
\hline & Tert 1 & Test 2 & Test 3 & Toet 4 & Test 5 & Test 6 & Toat 7 & Toot 8 & Toet 9 \\
\hline $\begin{array}{l}\text { Coal Ash Feod Rate, lb/hr } \\
\mathrm{Al}_{2} \mathrm{O}_{3} \text { in Coal Ash, } \%\end{array}$ & $\begin{array}{l}14.70 \\
22.70\end{array}$ & $\begin{array}{l}15.66 \\
22.70\end{array}$ & $\begin{array}{l}14.47 \\
22.70\end{array}$ & $\begin{array}{l}18.05 \\
22.70\end{array}$ & $\begin{array}{l}14.51 \\
23.20\end{array}$ & $\begin{array}{l}14.46 \\
23.20\end{array}$ & $\begin{array}{l}13.11 \\
23.20\end{array}$ & $\begin{array}{l}10.64 \\
23.20\end{array}$ & $\begin{array}{l}10.94 \\
22.80\end{array}$ \\
\hline Secondary Cyclone Ash Out, lb/hr & 6.40 & 33.40 & 38.30 & 60.00 & 61.30 & 68.30 & 16.70 & 11.70 & 17.20 \\
\hline $\mathrm{Al}_{2} \mathrm{O}_{3}$ in Secondary Cyclone Ash, $\%$ & 17.00 & 11.40 & 8.97 & 4.96 & 7.65 & 5.46 & 12.90 & 16.60 & 12.80 \\
\hline $\begin{array}{l}\text { Ash from Coal, } \% \\
\text { Ash from Coal, lb/hr }\end{array}$ & $\begin{array}{r}74.89 \\
4.79\end{array}$ & $\begin{array}{l}50.22 \\
16.77\end{array}$ & $\begin{array}{l}39.62 \\
16.13\end{array}$ & $\begin{array}{l}21.81 \\
13.08\end{array}$ & $\begin{array}{l}32.54 \\
19.96\end{array}$ & $\begin{array}{l}23.53 \\
13.72\end{array}$ & $\begin{array}{r}65.60 \\
9.29\end{array}$ & $\begin{array}{r}67.24 \\
7.87\end{array}$ & $\begin{array}{r}66.14 \\
9.66\end{array}$ \\
\hline Baghouse Ash Out, lb/hr & 7.80 & 2.60 & 6.30 & 1.00 & 4.30 & 2.70 & 3.30 & 3.20 & 0.70 \\
\hline $\mathrm{Al}_{2} \mathrm{O}_{3}$ in Baghouse Ash, $\%$ & 21.70 & 19.70 & 19.20 & 18.60 & 18.80 & 19.40 & 21.50 & 21.80 & 20.00 \\
\hline $\begin{array}{l}\text { Ash from Coal, } \% \\
\text { Ash from Coal, } \mathrm{lb} / \mathrm{hr}\end{array}$ & $\begin{array}{r}96.59 \\
7.46\end{array}$ & $\begin{array}{r}86.78 \\
2.26\end{array}$ & $\begin{array}{r}84.58 \\
6.33\end{array}$ & $\begin{array}{r}81.60 \\
0.81\end{array}$ & $\begin{array}{r}81.03 \\
3.48\end{array}$ & $\begin{array}{r}83.62 \\
2.26\end{array}$ & $\begin{array}{r}92.67 \\
3.06\end{array}$ & $\begin{array}{r}93.97 \\
3.01\end{array}$ & $\begin{array}{r}87.72 \\
0.61\end{array}$ \\
\hline Bed Material Out, lb/hx & 5.20 & 20.80 & 21.30 & 6.10 & 4.60 & 3.30 & 4.00 & 6.20 & 4.20 \\
\hline $\mathrm{Al}_{2} \mathrm{O}_{8}$ in Bed Material, $\%$ & 4.49 & 4.01 & 3.78 & 3.56 & 3.29 & 3.98 & 3.57 & 3.63 & 3.91 \\
\hline $\begin{array}{l}\text { Ash from Coal, } \% \\
\text { Ash from Coal, lb/hr }\end{array}$ & $\begin{array}{r}19.78 \\
1.03\end{array}$ & $\begin{array}{r}17.67 \\
3.67\end{array}$ & $\begin{array}{r}16.65 \\
3.65\end{array}$ & $\begin{array}{r}16.64 \\
0.80\end{array}$ & $\begin{array}{r}14.18 \\
0.64\end{array}$ & $\begin{array}{r}17.16 \\
0.67\end{array}$ & $\begin{array}{r}16.39 \\
0.62\end{array}$ & $\begin{array}{r}16.22 \\
0.79\end{array}$ & $\begin{array}{r}17.15 \\
0.72\end{array}$ \\
\hline Total Ash from Coal, $\mathrm{lb} / \mathrm{hr}$ & $\underline{13.28}$ & 22.70 & $\underline{24.01}$ & $\underline{14.70}$ & $\underline{24.07}$ & $\underline{16.64}$ & $\underline{12.96}$ & $\underline{11.67}$ & $\underline{10.99}$ \\
\hline \multirow[t]{2}{*}{ Closure, $\%$} & 90.32 & 144.94 & 165.94 & 81.44 & 165.89 & 114.41 & 98.85 & 109.66 & 100.44 \\
\hline & Test 10 & Test 11 & Test 12 & Test 13 & Test 14 & Test 16 & Teot 16 & Teat 17 & Test 18 \\
\hline $\begin{array}{l}\text { Coal Ash Feed Rate, } \mathrm{lb} / \mathrm{hr} \\
\mathrm{Al}_{2} \mathrm{O}_{3} \text { in Coal Ash, } \%\end{array}$ & $\begin{array}{r}8.72 \\
22.80\end{array}$ & $\begin{array}{r}7.73 \\
22.80\end{array}$ & $\begin{array}{l}11.61 \\
22.80\end{array}$ & $\begin{array}{l}14.18 \\
22.80\end{array}$ & $\begin{array}{l}13.32 \\
22.70\end{array}$ & $\begin{array}{l}14.83 \\
22.70\end{array}$ & $\begin{array}{l}16.62 \\
22.70\end{array}$ & $\begin{array}{l}14.80 \\
22.70\end{array}$ & $\begin{array}{l}14.45 \\
22.30\end{array}$ \\
\hline Secondary Cyclone Ash Out, lb/hr & 8.30 & 3.30 & 36.00 & 46.00 & 65.00 & 37.80 & 62.00 & 46.20 & 31.10 \\
\hline $\mathrm{Al}_{2} \mathrm{O}_{3}$ in Secondary Cyclone Ash, $\%$ & 12.60 & 14.10 & 8.35 & 6.60 & 6.19 & 10.80 & 6.13 & 8.79 & 12.20 \\
\hline $\begin{array}{l}\text { Ash from Coal, } \% \\
\text { Ash from Coal, lb/hr }\end{array}$ & $\begin{array}{r}55.26 \\
4.69\end{array}$ & $\begin{array}{r}61.84 \\
2.04\end{array}$ & $\begin{array}{l}36.62 \\
13.18\end{array}$ & $\begin{array}{l}28.95 \\
13.32\end{array}$ & $\begin{array}{l}27.27 \\
15.00\end{array}$ & $\begin{array}{l}47.58 \\
17.98\end{array}$ & $\begin{array}{l}27.00 \\
14.04\end{array}$ & $\begin{array}{l}38.72 \\
17.89\end{array}$ & $\begin{array}{l}54.71 \\
17.02\end{array}$ \\
\hline Baghouse Ash Out, lb/hr & 2.70 & 3.00 & 4.20 & 6.70 & 3.00 & 2.80 & 6.00 & 2.30 & 3.80 \\
\hline $\mathrm{Al}_{2} \mathrm{O}_{3}$ in Baghouse Ash, $\%$ & 18.70 & 19.70 & 19.60 & 18.00 & 17.20 & 22.40 & 15.60 & 17.10 & 23.50 \\
\hline $\begin{array}{l}\text { Ash from Coal, } \% \\
\text { Ash from Coal, lb/hr }\end{array}$ & $\begin{array}{r}82.02 \\
2.21\end{array}$ & $\begin{array}{r}86.40 \\
2.59\end{array}$ & $\begin{array}{r}85.96 \\
3.61\end{array}$ & $\begin{array}{r}78.95 \\
4.50\end{array}$ & $\begin{array}{r}75.77 \\
2.27\end{array}$ & $\begin{array}{r}98.68 \\
2.76\end{array}$ & $\begin{array}{r}68.28 \\
3.41\end{array}$ & $\begin{array}{r}75.33 \\
1.73\end{array}$ & $\begin{array}{r}105.38 \\
4.00\end{array}$ \\
\hline Bed Material Out, lb/hr & 3.70 & 17.20 & 4.20 & 4.00 & 4.00 & 4.30 & 4.60 & 3.80 & 1.60 \\
\hline $\mathrm{Al}_{2} \mathrm{O}_{3}$ in Bed Material, $\%$ & 3.71 & 3.49 & 3.08 & 3.01 & 3.15 & 2.83 & 3.46 & 3.82 & 2.87 \\
\hline $\begin{array}{l}\text { Ash from Coal, } \% \\
\text { Ash from Coal, lb/hr }\end{array}$ & $\begin{array}{r}16.27 \\
0.60\end{array}$ & $\begin{array}{r}15.31 \\
2.63\end{array}$ & $\begin{array}{r}13.51 \\
0.57\end{array}$ & $\begin{array}{r}13.20 \\
0.63\end{array}$ & $\begin{array}{r}13.88 \\
0.56\end{array}$ & $\begin{array}{r}12.47 \\
0.64\end{array}$ & $\begin{array}{r}15.24 \\
0.70\end{array}$ & $\begin{array}{r}16.83 \\
0.64\end{array}$ & $\begin{array}{r}12.87 \\
0.21\end{array}$ \\
\hline Total Ash from Coal, $\mathrm{lb} / \mathrm{hr}$ & $\underline{7.40}$ & $\underline{7.27}$ & $\underline{17.36}$ & $\underline{18.34}$ & $\underline{17.83}$ & $\underline{21.28}$ & $\underline{18.16}$ & $\underline{20.26}$ & $\underline{21.22}$ \\
\hline Closure, $\%$ & 84.92 & 94.00 & 149.64 & 129.36 & 133.87 & 143.60 & 116.96 & 136.91 & 146.85 \\
\hline
\end{tabular}



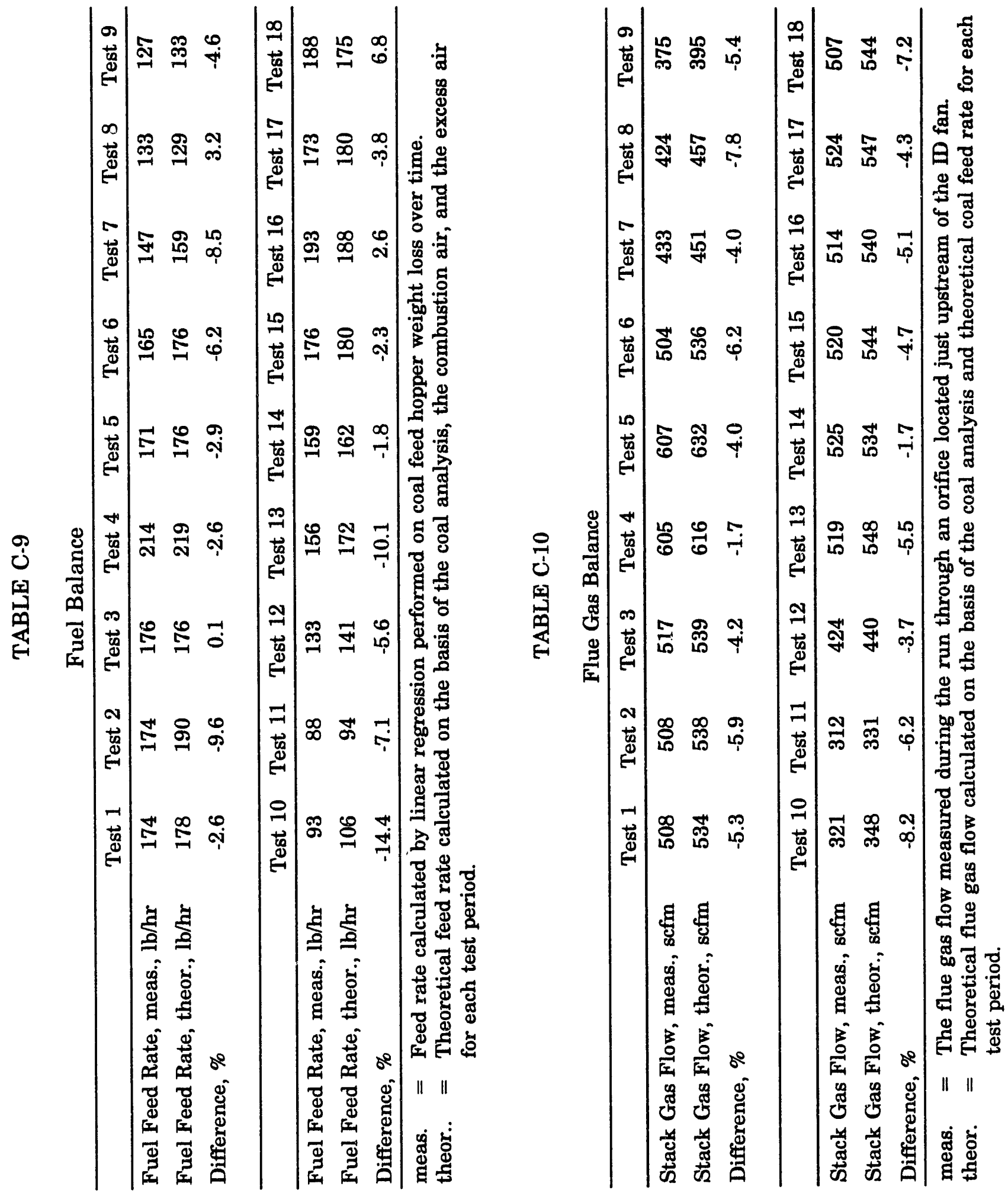


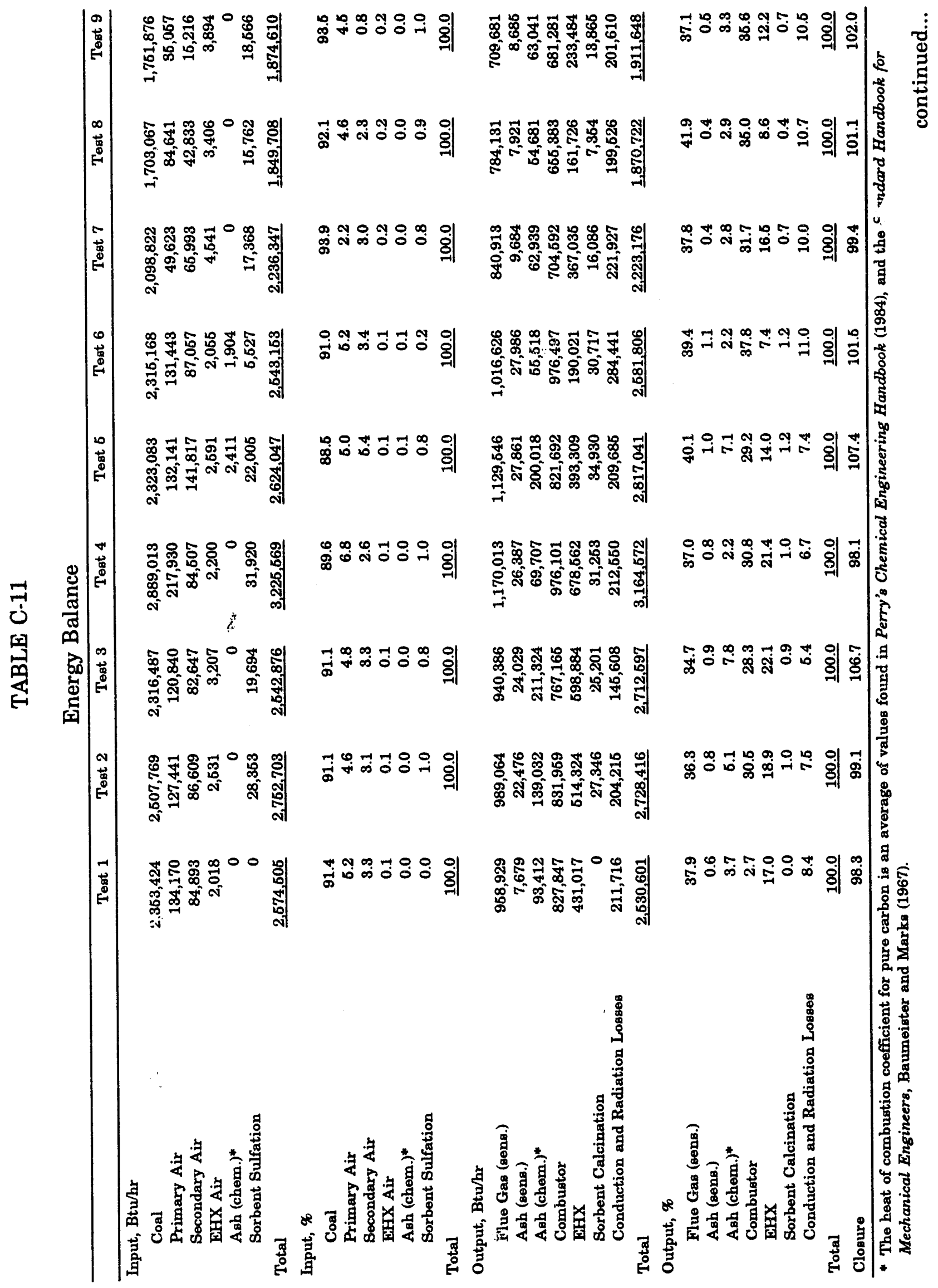




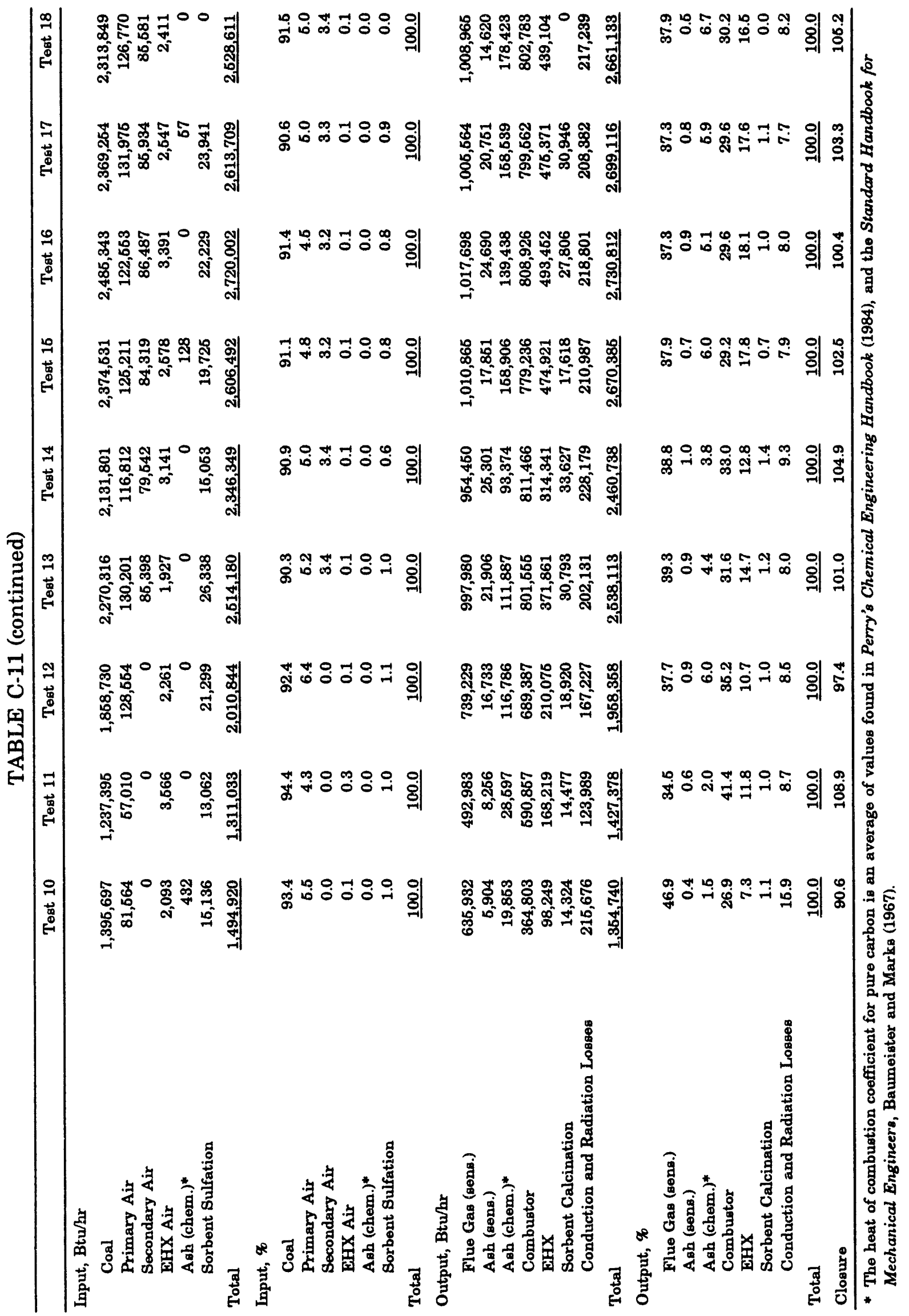


The material balances, which ranged from $99.9 \%$ closure for Test 10 to $102.0 \%$ for Test 3, are presented in Table C-12. The inputs are the combustion air, additional air (composed of external heat exchanger fluidizing air, pressure tap purges, downcomer assist air, and coal feed assist air), coal and limestone feeds, and bed material addition. Outputs consist of measured flue gas, flue gas leaks (based on the theoretical flue gas flow rate shown in Table C-10), and measured quantities of bed material, secondary cyclone ash, and baghouse ash removed from the system.

\section{Combustion Efficiency}

The combustion efficiencies, shown in Table C-13, ranged from a low of $89.4 \%$ for Test 5, a high-velocity, high excess air test, to $98.3 \%$ for Test 10, a low-load, low-velocity test. In both cases, superficial gas velocity plays a key role: as velocity increases, particle residence time and, hence, carbon burnout decrease. The combustion efficiencies for several tests, conducted at the same temperature, are plotted as a function of superficial gas velocity in Figure C-6. The effect of combustor temperature is shown in Figure C-7. The tests shown in this figure were all conducted at similar velocities. The percentage of unburned carbon in each ash stream was calculated as the difference between the loss on ignition (LOI) and the carbonate content (as $\left.\mathrm{CO}_{2}\right)$. These values are shown in Table C-14.

\section{Boiler Efficiency}

Boiler efficiencies were calculated for each test period using ASME PTC 4.1, modified according to the recommendations in EPRI's "Atmospheric Fluidized-Bed Combustion Performance Guidelines" to account for the heat losses and gains associated with calcination and sulfation of the limestone.

Table C-15 summarizes the results of the boiler efficiency calculations for this run. Boiler radiation and convective losses were assumed to be $0.4 \%$; although the actual losses at the pilot scale are much greater, $0.4 \%$ was chosen to be representative of a full-scale system. The exit gas temperature was assumed to be $300^{\circ} \mathrm{F}$. The boiler efficiency ranged from $81.4 \%$ to $90.2 \%$. An increase in unburned carbon losses at low temperatures, low velocity, and low loads had the greatest impacts on boiler efficiency.

\section{Heat-Transfer Coefficient and Heat Flux}

The heat-transfer coefficient and the heat flux for each of the combustor sections containing heat exchange panels, as well as for the EHX, are shown in Tables C-16 and C-17, respectively. The overall values for each test are also presented in Table C-5, to facilitate comparison with operating conditions. The values for each combustor section are based on the average temperature in the section; the overall values for each test are based on the average combustor temperature. The combustor heat fluxes ranged from $18,938 \mathrm{Btu} / \mathrm{hr}$ - $\mathrm{ft}^{2}$ for Test 11 , a low-temperature, low-load test, to about $31,300 \mathrm{Btu} / \mathrm{hr}-\mathrm{ft}^{2}$ for the Tests 4 and 6 . Test 4 was a high-velocity $(18.4 \mathrm{ft} / \mathrm{sec})$ test with a resulting high recirculation rate; Test 6 was high-temperature $\left(1698^{\circ} \mathrm{F}\right)$ test. The heat flux within the EHX ranged from $32,040 \mathrm{Btu} / \mathrm{hr}-\mathrm{ft}^{2}$ to $97,966 \mathrm{Btu} / \mathrm{hr}^{-\mathrm{ft}^{2}}$ for Tests 11 and 2, respectively. 


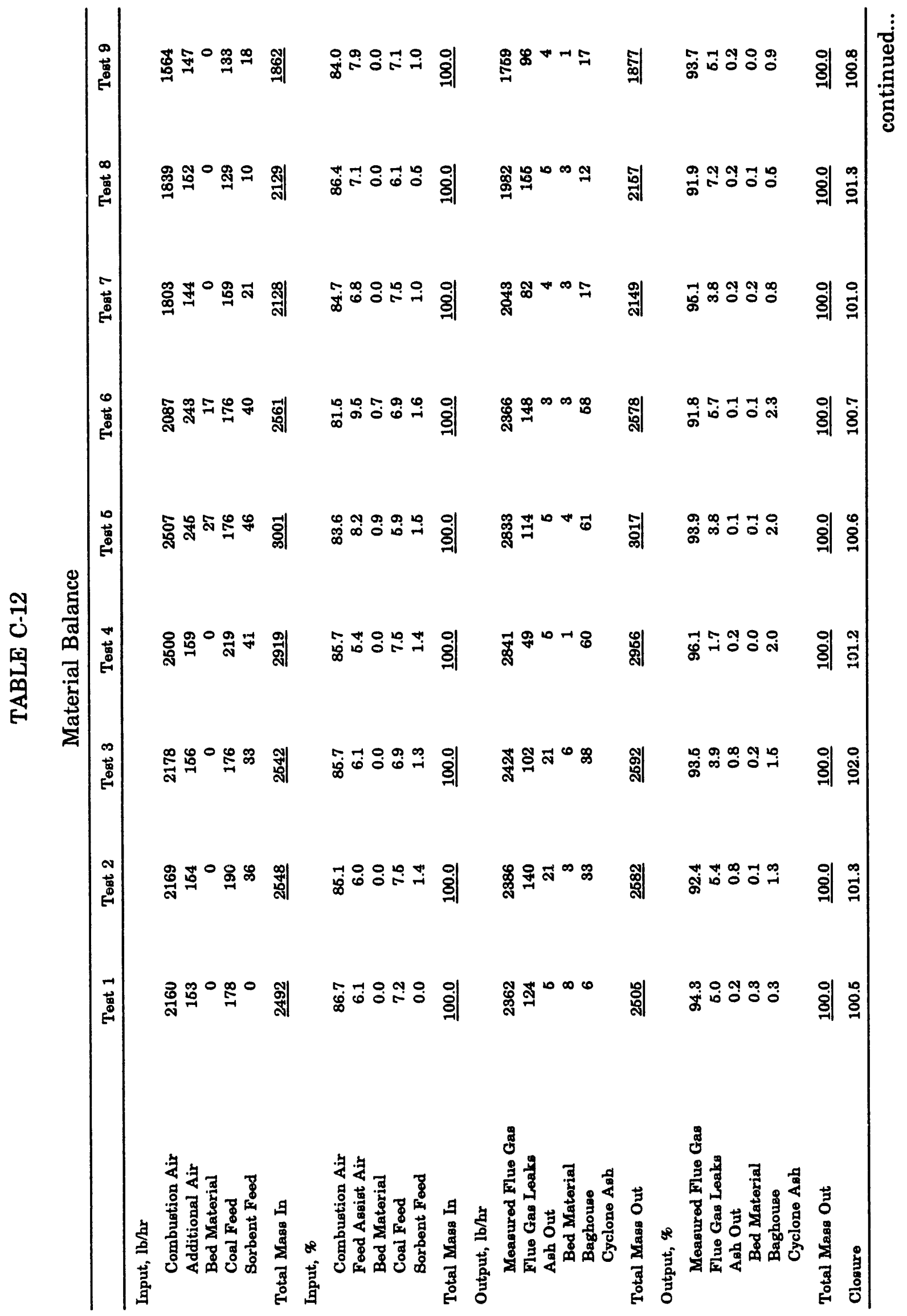




\begin{tabular}{|c|c|c|c|c|c|c|c|c|}
\hline 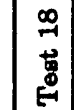 & 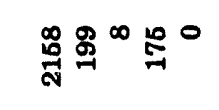 & 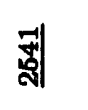 & 㑒 & 월 & 芯 & ฆั้ํำ & 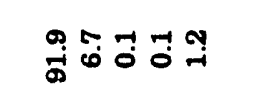 & 월 \\
\hline 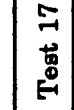 & 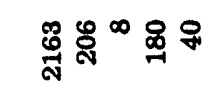 & 善 & 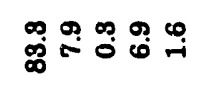 & 웜 & 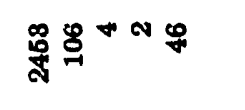 & 웡 & 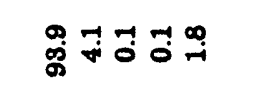 & 워 웡 \\
\hline 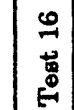 & 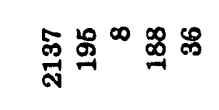 & : ํํำ & 串 & 웜 & 可哭 & 竒 & 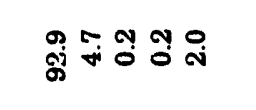 & 웡 \\
\hline 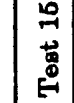 & 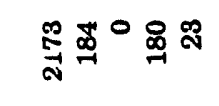 & : ํํㅇ & 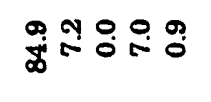 & 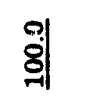 & 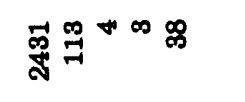 & 总 & ஜ̂̀ & 웡 \\
\hline $\begin{array}{l}\overrightarrow{7} \\
\overrightarrow{\mathrm{D}} \\
\mathrm{E}\end{array}$ & 怘怘○哭 & ㅊํํ & 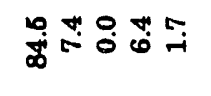 & 웜 & 战 & 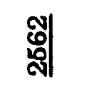 & 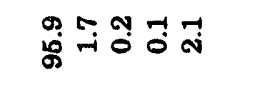 & 웡 홈 \\
\hline 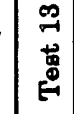 & 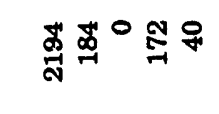 & 旁 & 可 & : & 总嵒 & ఫ్త్రి & 茴 & 월 \\
\hline 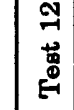 & 赵品 & ક્ષิ & 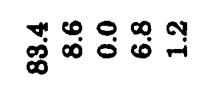 & 윙 & 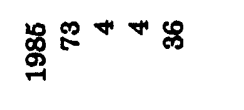 & ㅎํ & 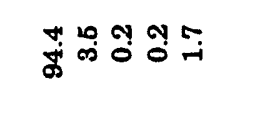 & 월 \\
\hline 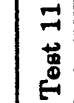 & 沀 & 哭 & 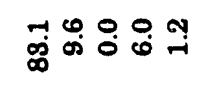 & : & 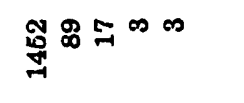 & 营| & 号 & 웡 형 \\
\hline 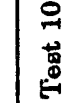 & 茐 & 暍 & 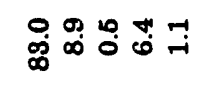 & 월 & 总 & ज్뷔 & 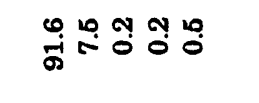 & 웡 \\
\hline & 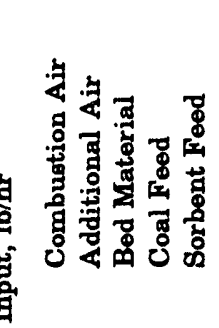 & 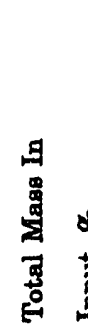 & 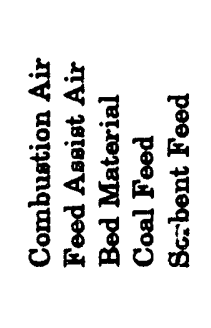 & 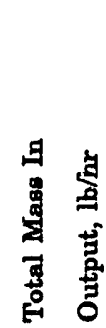 & 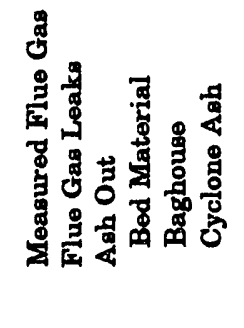 & 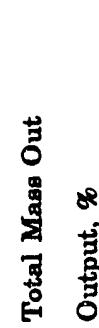 & 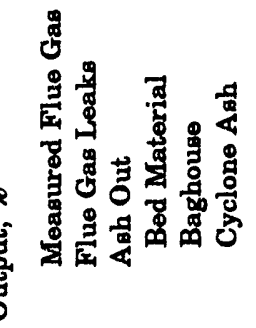 & 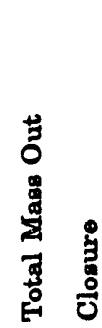 \\
\hline
\end{tabular}




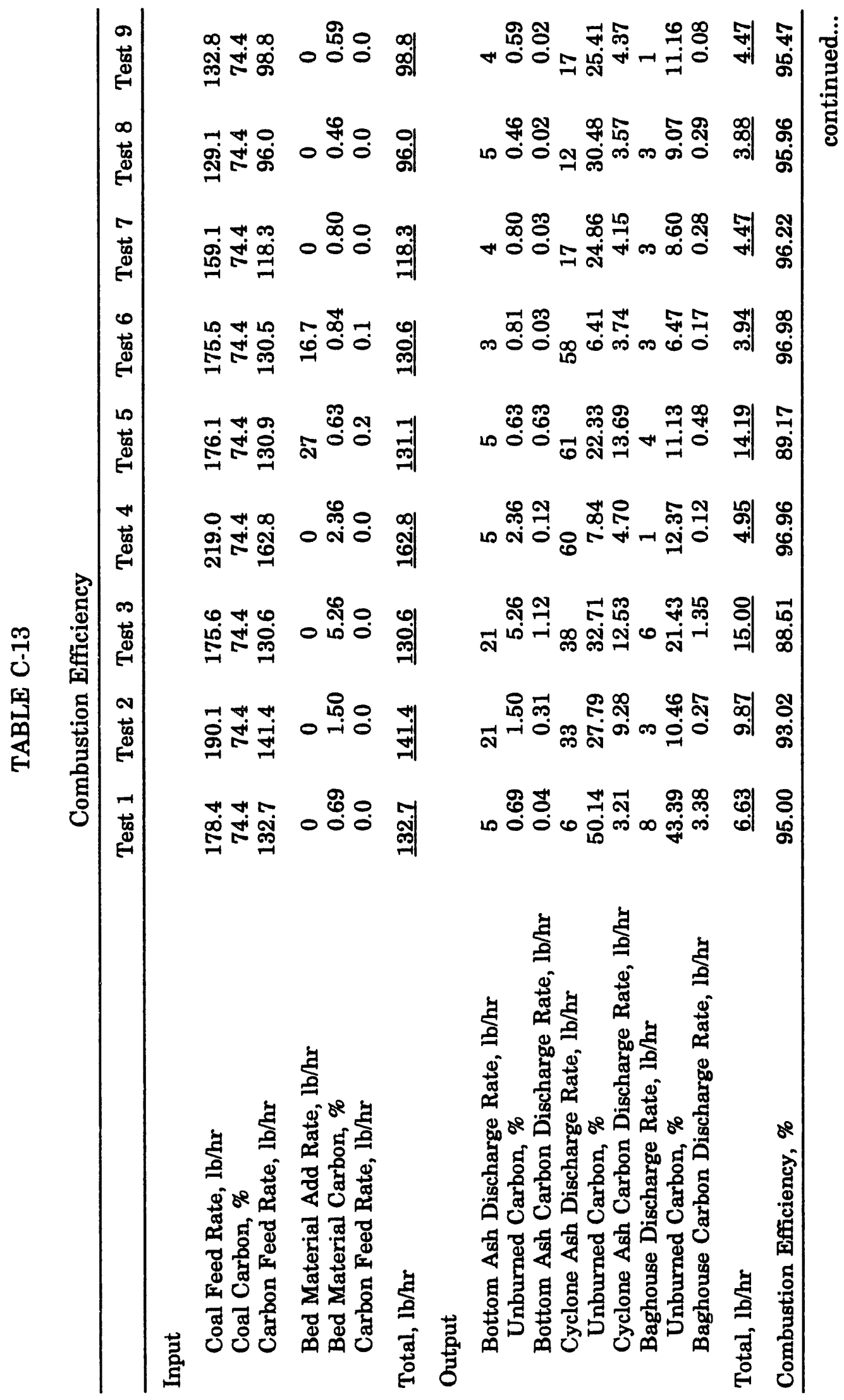




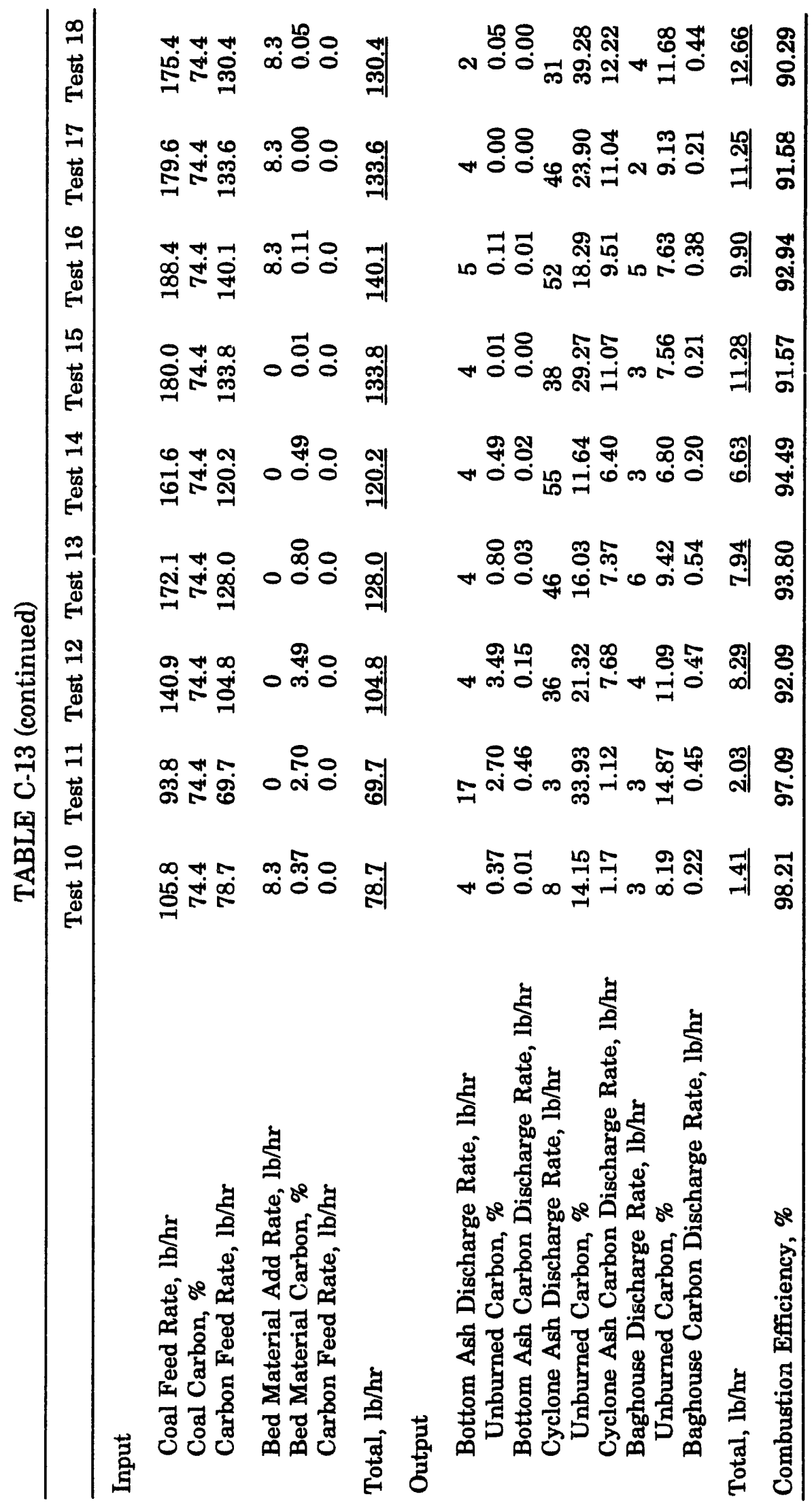




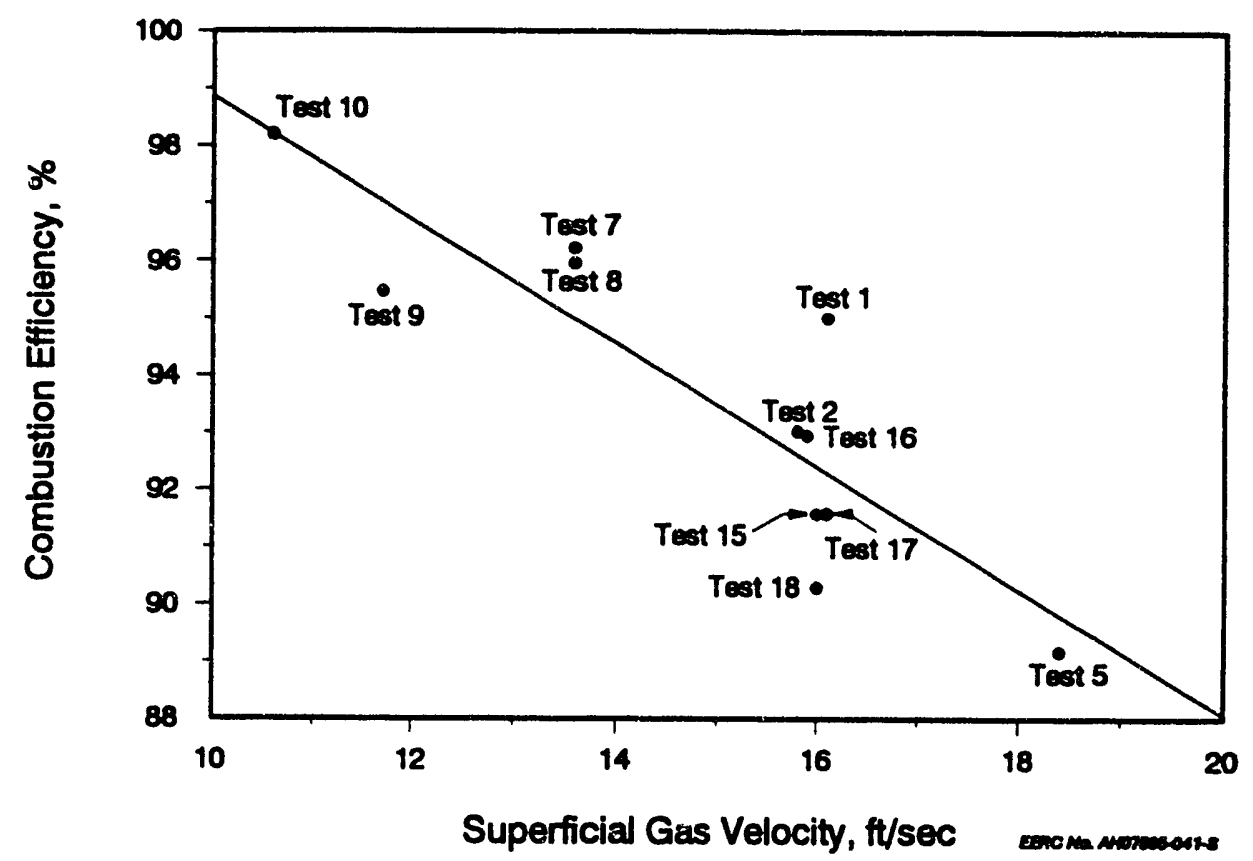

Figure C-6. Combustion efficiercy as a function of superficial gas velocity.

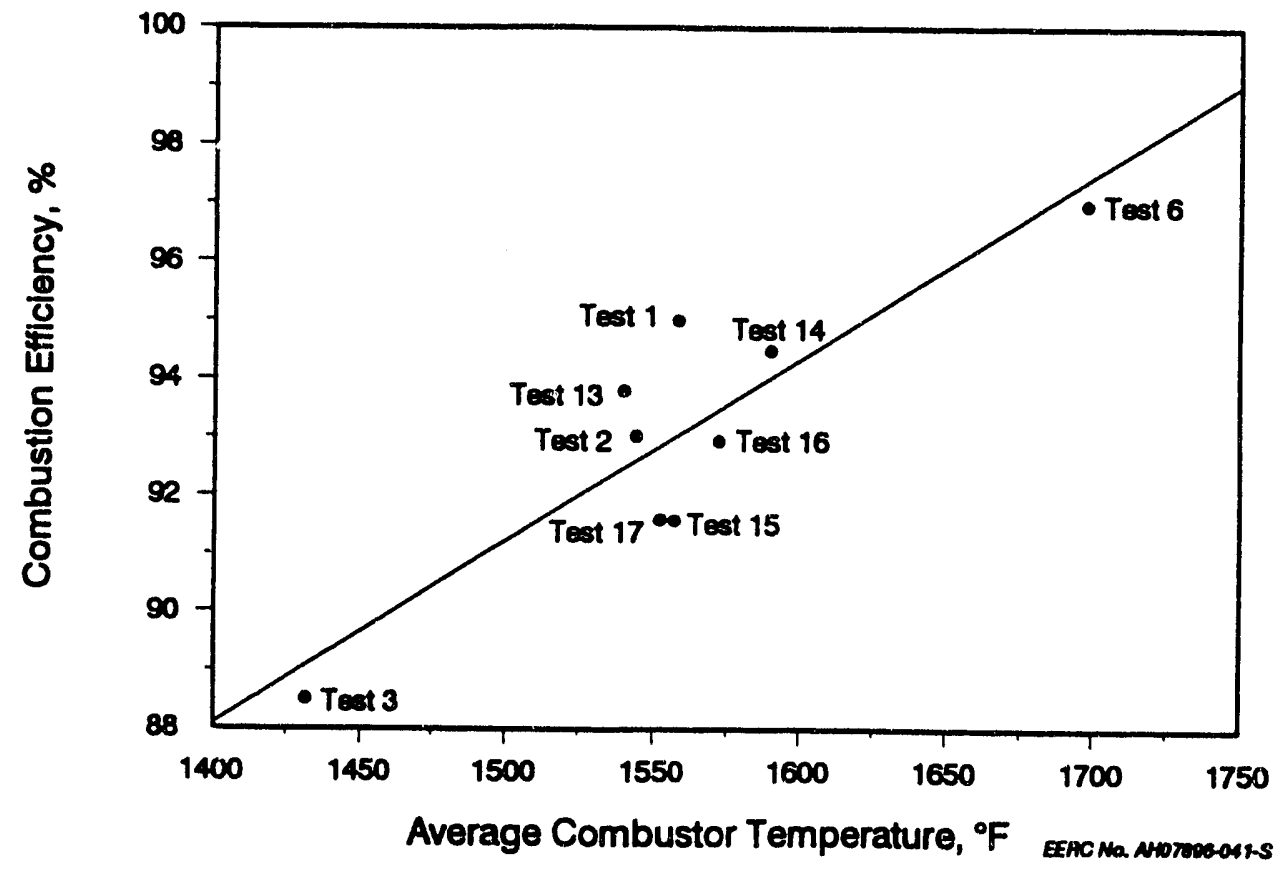

Figure C-7. Effect of average combustor temperature. 


\section{TABLE C-14}

\section{Unburned Carbon (\%)}

\begin{tabular}{|c|c|c|c|c|c|c|c|c|c|}
\hline & Tont 1 & Toot 2 & Test 3 & Teat 4 & Toet 6 & Toet 6 & Tent 7 & Toet 8 & Tout 9 \\
\hline \multicolumn{10}{|l|}{ Combustor Bod Matorial } \\
\hline $\begin{array}{l}\text { Loss on Ignition } \\
\text { Carbonate (as } \mathrm{CO}_{2} \text { ) } \\
\text { Unburned Coal Carbon* }\end{array}$ & $\begin{array}{l}0.72 \\
0.11 \\
0.69\end{array}$ & $\begin{array}{l}1.67 \\
0.63 \\
1.60\end{array}$ & $\begin{array}{l}6.87 \\
6.90 \\
6.26\end{array}$ & $\begin{array}{l}2.98 \\
2.28 \\
2.36\end{array}$ & $\begin{array}{l}0.83 \\
0.72 \\
0.63\end{array}$ & $\begin{array}{l}1.03 \\
0.81 \\
0.81\end{array}$ & $\begin{array}{l}1.03 \\
0.84 \\
0.80\end{array}$ & $\begin{array}{l}0.63 \\
0.61 \\
0.46\end{array}$ & $\begin{array}{l}0.70 \\
0.42 \\
0.69\end{array}$ \\
\hline \multicolumn{10}{|l|}{ Secondary Cyclone Ash } \\
\hline $\begin{array}{l}\text { Loss on Ignition } \\
\text { Carbonate (as } \mathrm{CO}_{2} \text { ) } \\
\text { Unburned Coal Carbon* }\end{array}$ & $\begin{array}{r}50.24 \\
0.35 \\
50.14\end{array}$ & $\begin{array}{r}28.02 \\
0.83 \\
27.79\end{array}$ & $\begin{array}{r}34.32 \\
5.92 \\
32.71\end{array}$ & $\begin{array}{l}8.04 \\
0.74 \\
7.84\end{array}$ & $\begin{array}{r}22.49 \\
0.69 \\
22.33\end{array}$ & $\begin{array}{l}6.63 \\
0.43 \\
6.41\end{array}$ & $\begin{array}{r}24.94 \\
0.31 \\
24.86\end{array}$ & $\begin{array}{r}30.62 \\
0.61 \\
30.48\end{array}$ & $\begin{array}{r}25.49 \\
0.28 \\
25.41\end{array}$ \\
\hline \multicolumn{10}{|l|}{ Baghouse Ash } \\
\hline $\begin{array}{l}\text { Loss on Ignition } \\
\text { Carbonate (as } \mathrm{CO}_{2} \text { ) } \\
\text { Unburned Coal Carbon* }\end{array}$ & $\begin{array}{r}43.47 \\
0.31 \\
43.39\end{array}$ & $\begin{array}{r}10.66 \\
0.36 \\
10.46\end{array}$ & $\begin{array}{r}21.78 \\
1.27 \\
21.43\end{array}$ & $\begin{array}{r}12.60 \\
0.83 \\
12.37 \\
\end{array}$ & $\begin{array}{r}11.21 \\
0.30 \\
11.13\end{array}$ & $\begin{array}{l}6.62 \\
0.19 \\
6.47\end{array}$ & $\begin{array}{l}8.64 \\
0.16 \\
8.60\end{array}$ & $\begin{array}{l}9.10 \\
0.12 \\
9.07\end{array}$ & $\begin{array}{r}11.24 \\
0.29 \\
11.16 \\
\end{array}$ \\
\hline & Teat 10 & Test 11 & Test 12 & Test 13 & Tost 14 & Teat 15 & Test 16 & Test 17 & Test 18 \\
\hline \multicolumn{10}{|l|}{ Combustor Bed Material } \\
\hline $\begin{array}{l}\text { Loss on Ignition } \\
\text { Carbonate (as } \mathrm{CO}_{2} \text { ) } \\
\text { Unburned Coal Carbon* }\end{array}$ & $\begin{array}{l}0.63 \\
0.69 \\
0.37\end{array}$ & $\begin{array}{r}3.74 \\
3.83 \\
2.70\end{array}$ & $\begin{array}{l}4.90 \\
5.18 \\
3.49\end{array}$ & $\begin{array}{l}1.12 \\
1.18 \\
0.80\end{array}$ & $\begin{array}{l}0.86 \\
1.33 \\
0.49\end{array}$ & $\begin{array}{l}0.14 \\
0.48 \\
0.01\end{array}$ & $\begin{array}{l}0.21 \\
0.37 \\
0.11\end{array}$ & $\begin{array}{l}0.00 \\
0.69 \\
0.00\end{array}$ & $\begin{array}{l}0.09 \\
0.15 \\
0.05\end{array}$ \\
\hline \multicolumn{10}{|l|}{ Secondary Cyclone Ash } \\
\hline $\begin{array}{l}\text { Loss on Ignition } \\
\text { Carbonate (as } \mathrm{CO}_{2} \text { ) } \\
\text { Unburned Coal Carbon* }\end{array}$ & $\begin{array}{r}14.42 \\
1.00 \\
14.15\end{array}$ & $\begin{array}{r}34.86 \\
3.42 \\
33.93\end{array}$ & $\begin{array}{r}21.66 \\
1.24 \\
21.32\end{array}$ & $\begin{array}{r}16.38 \\
1.30 \\
16.03\end{array}$ & $\begin{array}{r}11.83 \\
0.69 \\
11.64\end{array}$ & $\begin{array}{r}29.36 \\
0.32 \\
29.27\end{array}$ & $\begin{array}{r}18.84 \\
2.03 \\
18.29\end{array}$ & $\begin{array}{r}24.13 \\
0.86 \\
23.90\end{array}$ & $\begin{array}{r}39.32 \\
0.13 \\
39.28\end{array}$ \\
\hline \multicolumn{10}{|l|}{ Baghouse Ash } \\
\hline $\begin{array}{l}\text { Loss on Ignition } \\
\text { Carbonate (as } \mathrm{CO}_{2} \text { ) } \\
\text { Unburned Coal Carbon* }\end{array}$ & $\begin{array}{l}8.26 \\
0.27 \\
8.19\end{array}$ & $\begin{array}{r}16.22 \\
1.27 \\
14.87\end{array}$ & $\begin{array}{r}11.30 \\
0.78 \\
11.09\end{array}$ & $\begin{array}{l}9.56 \\
0.63 \\
9.42\end{array}$ & $\begin{array}{l}6.97 \\
0.62 \\
6.80\end{array}$ & $\begin{array}{l}7.69 \\
0.11 \\
7.56\end{array}$ & $\begin{array}{l}7.90 \\
0.98 \\
7.63\end{array}$ & $\begin{array}{l}9.32 \\
0.68 \\
9.13\end{array}$ & $\begin{array}{r}11.71 \\
0.10 \\
11.68\end{array}$ \\
\hline
\end{tabular}

* Unburned Coal Carbon = Lose on ignition (LON) - carbonate $\left(\mathrm{as}_{2} \mathrm{CO}_{2}\right)$

The low combustor heat fluxes observed during Tests 11 and 12 were the result of reduced load while operating with constant heat-transfer surface. During constant heattransfer load reduction, the total amount of heat-transfer surface kept in service is equivalent to that used during the full-load baseline test with sorbent addition. By reducing load under constant heat-transfer conditions, operational temperatures and velocity are reduced, lowering the solids recirculation rate, thereby decreasing heat transfer. Tests 9 and 10 were run under constant temperature load reduction conditions. During constant temperature load reduction, heat-transfer surface was taken off-line, and combustor temperatures and velocity were maintained near full-load levels. Therefore, heat-transfer performance was affected to a lesser degree.

\section{Pressure and Temperature Profiles}

The pressure profiles for the run are shown in Figures C-8 through C-10 and are typical of a circulating fluidized-bed combustor. The figures show a dense phase in the lower portion of the combustor, similar to a bubbling bed, and a dilute phase in the rest of the combustor. Variations in pressure profiles are due to differences in bed inventory and combustor velocity. 


\section{TABLE C-15}

Boiler Efficiency

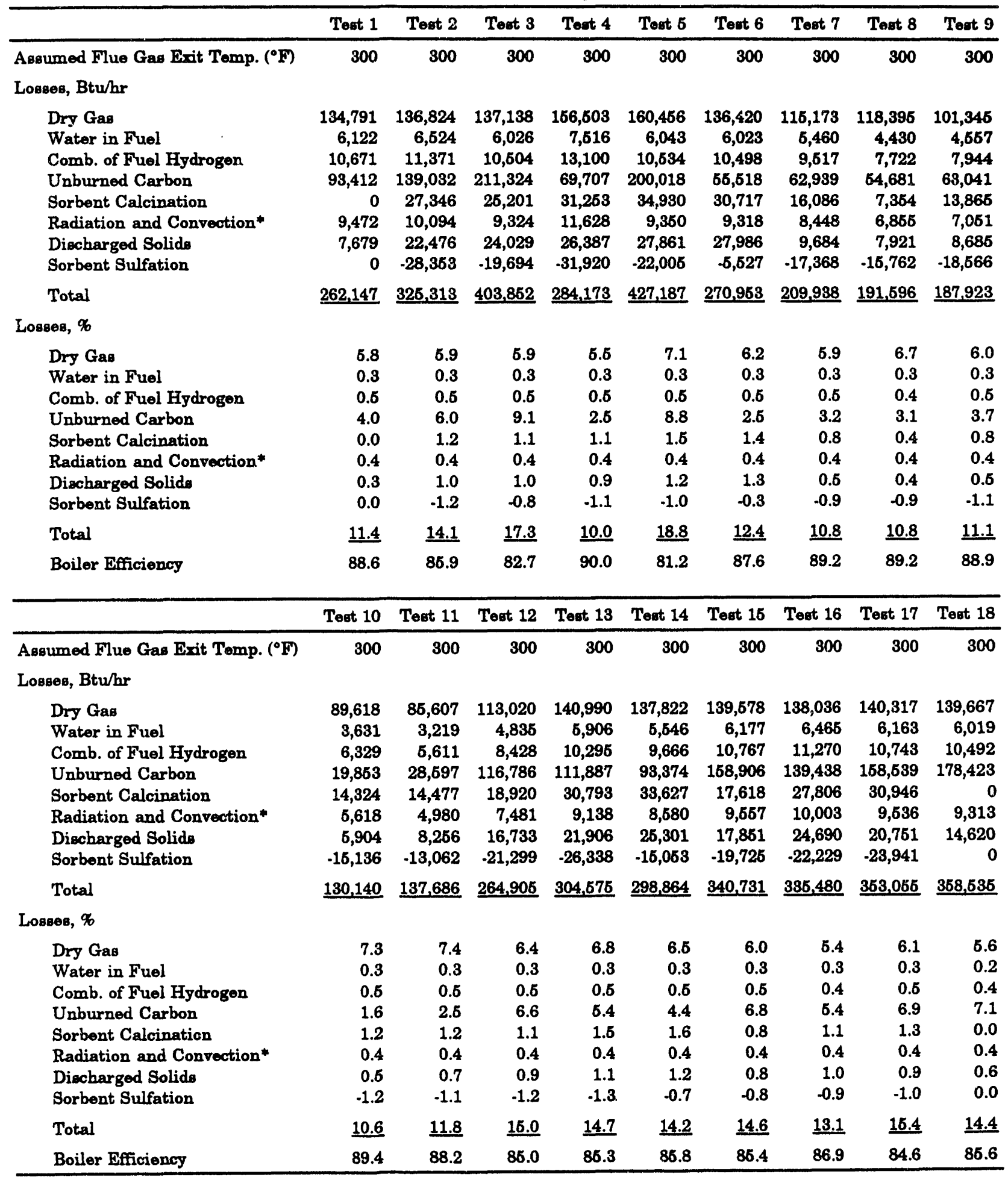

* Assumes 0.4\% radiative and convective losses. 
TABLE C-16

Individual Heat-Transfer Coefficients (Btu/hr- $\left.\mathrm{ft}^{2}-^{\circ} \mathrm{F}\right)$

\begin{tabular}{|c|c|c|c|c|c|c|c|c|c|c|}
\hline $\begin{array}{l}\text { Combustor } \\
\text { Section }\end{array}$ & Tont 1 & Tost 2 & Toot 3 & Tost 4 & Test 5 & Test 6 & Tost 7 & Tout 8 & Toat 9 & Toet 10 \\
\hline 2 & 17.5 & 22.2 & 21.0 & 21.3 & 18.0 & 21.0 & 18.0 & 18.4 & $\overline{19.4}$ & 19.3 \\
\hline 3 & 21.1 & 21.1 & 24.3 & 25.3 & 20.9 & 23.7 & 20.4 & 19.8 & 20.6 & 19.1 \\
\hline 4 & 23.2 & 21.7 & 22.9 & 28.5 & 23.6 & 27.0 & 23.0 & 22.5 & 22.6 & 17.6 \\
\hline 5 & 23.2 & 24.7 & 22.5 & 28.4 & 22.7 & 25.5 & 21.3 & 19.4 & 19.9 & off \\
\hline 6 & 16.6 & 18.0 & 26.4 & 18.1 & 16.7 & 16.8 & 15.2 & 13.4 & 14.4 & 6.8 \\
\hline 7 & 14.4 & 12.9 & 14.6 & 21.1 & 16.6 & 17.6 & 18.7 & 16.9 & 17.7 & off \\
\hline 8 & 14.4 & 17.6 & 15.0 & 19.0 & 15.1 & 16.8 & 16.6 & 16.8 & 16.5 & off \\
\hline Overall & 18.6 & 19.1 & 19.2 & 22.2 & 18.6 & 20.2 & 18.8 & 17.9 & 18.6 & 17.8 \\
\hline EHXX & 77.4 & 84.2 & 67.9 & 65.1 & 78.2 & 67.8 & 66.6 & 77.8 & 79.8 & 58.6 \\
\hline $\begin{array}{c}\text { Combustor } \\
\text { Section }\end{array}$ & Test 11 & Test 12 & Teet 13 & Test 14 & Teat 16 & Test 16 & Test 17 & Test 18 & Averago & $\begin{array}{c}\text { Combustor } \\
\text { Height }\end{array}$ \\
\hline 2 & 18.4 & 20.9 & 21.2 & 23.1 & 17.6 & 17.4 & 18.8 & 16.7 & 19.6 & 7.5 \\
\hline 3 & 17.9 & 19.6 & 20.8 & 22.6 & 19.9 & 20.3 & 20.1 & 19.6 & 20.9 & 12.5 \\
\hline 4 & 19.1 & 20.2 & 22.2 & 21.7 & 22.4 & 23.6 & 23.0 & 22.9 & 22.6 & 17.5 \\
\hline 5 & 19.0 & 21.0 & 23.8 & 23.9 & 23.5 & 24.2 & 23.1 & 24.6 & 23.0 & 22.5 \\
\hline 6 & 11.8 & 13.4 & 15.6 & 15.0 & 16.8 & 16.0 & 16.8 & 16.9 & 15.6 & 27.5 \\
\hline 7 & 11.4 & 13.2 & 15.6 & 14.2 & 16.5 & 15.8 & 15.0 & 15.2 & 16.7 & 32.5 \\
\hline 8 & 10.6 & 12.0 & 13.7 & 12.4 & 13.9 & 13.8 & 13.7 & 13.7 & 14.7 & 37.6 \\
\hline Overall & 14.8 & 16.3 & 18.2 & 17.8 & 17.4 & 17.9 & 17.9 & 17.8 & 18.3 & \\
\hline EHXX & 75.4 & 67.7 & 73.4 & 80.4 & 70.4 & 71.4 & 70.6 & 69.4 & 71.8 & \\
\hline
\end{tabular}

TABLE C-17

Individual Heat Flux (Btu/hr-ft'

\begin{tabular}{|c|c|c|c|c|c|c|c|c|c|c|}
\hline $\begin{array}{c}\text { Combustor } \\
\text { Section }\end{array}$ & Test 1 & Teat 2 & Test 3 & Teat 4 & Test 5 & Test 6 & Test 7 & Iest 8 & Test 9 & Test 10 \\
\hline 2 & 26,666 & 31,574 & 27,263 & 30,679 & 27,029 & 34,687 & 27,311 & 27,638 & 28,273 & 28,352 \\
\hline 3 & 30,775 & 29,670 & 31,051 & 35,727 & 20,169 & 37,297 & 30,100 & 28,270 & 28,997 & 27,212 \\
\hline 4 & 32,908 & 30,341 & 29,250 & 39,972 & 32,865 & 40,674 & 32,654 & 30,691 & 31,015 & 24,489 \\
\hline 5 & 33,068 & 34,368 & 29,156 & 39,914 & 31,839 & 38,613 & 30,997 & 26,840 & 27,756 & off \\
\hline 6 & 23,244 & 25,151 & 33,763 & 26,236 & 22,099 & 25,289 & 21,992 & 18,256 & 20,021 & 9,763 \\
\hline 7 & 19,672 & 17,956 & 18,936 & 29,664 & 22,384 & 24,916 & 26,480 & 22,234 & 24,098 & off \\
\hline 8 & 19,644 & 24,176 & 19,626 & 26,947 & 20,433 & 22,297 & 23,126 & 20,380 & 22,140 & off \\
\hline Overall & 26,534 & 26,665 & 24,689 & 31,285 & 26,336 & 31,298 & 27,100 & 25,207 & 26,203 & 25,643 \\
\hline EHX & 82,098 & 97,966 & 66,643 & 82,250 & 87,402 & 84,464 & 54,376 & 71,878 & 77,828 & 43,666 \\
\hline $\begin{array}{l}\text { Combustor } \\
\text { Section }\end{array}$ & Test 11 & Test 12 & Tent 13 & Tent 14 & Teat 15 & Test 16 & Test 17 & Test 18 & Average & $\begin{array}{c}\text { Combustor } \\
\text { Height }\end{array}$ \\
\hline 2 & 24,812 & 29,569 & 30,886 & 35,670 & 26,676 & 26,644 & 28,117 & 25,891 & 28,757 & 7.5 \\
\hline 3 & 23,305 & 27,041 & 29,692 & 33,444 & 28,348 & 29,849 & 29,212 & 29,146 & 29,434 & 12.5 \\
\hline 4 & 24,022 & 27,009 & 31,021 & 30,711 & 31,609 & 33,412 & 32,306 & 32,488 & 31,619 & 17.5 \\
\hline 5 & 23,962 & 28,062 & 33,462 & 33,946 & 33,658 & 34,763 & 32,676 & 35,277 & 32,243 & 22.5 \\
\hline 6 & 14,653 & 17,692 & 22,007 & 21,252 & 22,673 & 23,026 & 22,320 & 22,685 & 21,773 & 27.5 \\
\hline 7 & 13,417 & 16,567 & 21,082 & 18,886 & 21,350 & 21,878 & 20,476 & 20,818 & 21,224 & 32.5 \\
\hline 8 & 11,851 & 16,064 & 18,873 & 16,464 & 19,341 & 19,343 & 18,854 & 18,701 & 19,833 & 37.5 \\
\hline Overall & 18,938 & 22,096 & 25,691 & 26,009 & 24,976 & 25,927 & 25,627 & 25,730 & 26,881 & \\
\hline BHXX & 32,042 & 46,683 & 82,636 & 69,854 & 70,359 & 73,104 & 70,425 & 65,053 & 69,923 & \\
\hline
\end{tabular}




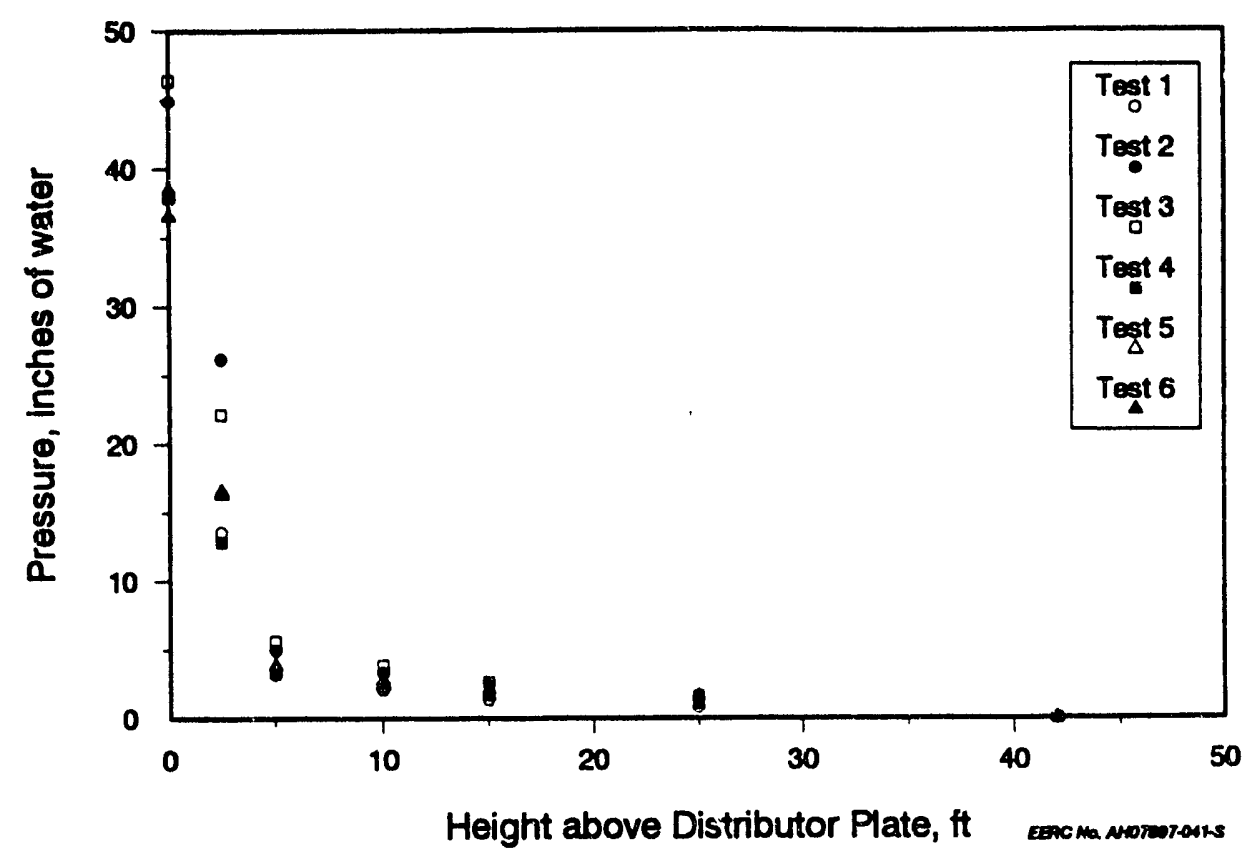

Figure C-8. Pressure profiles of Tests 1 through 6 .

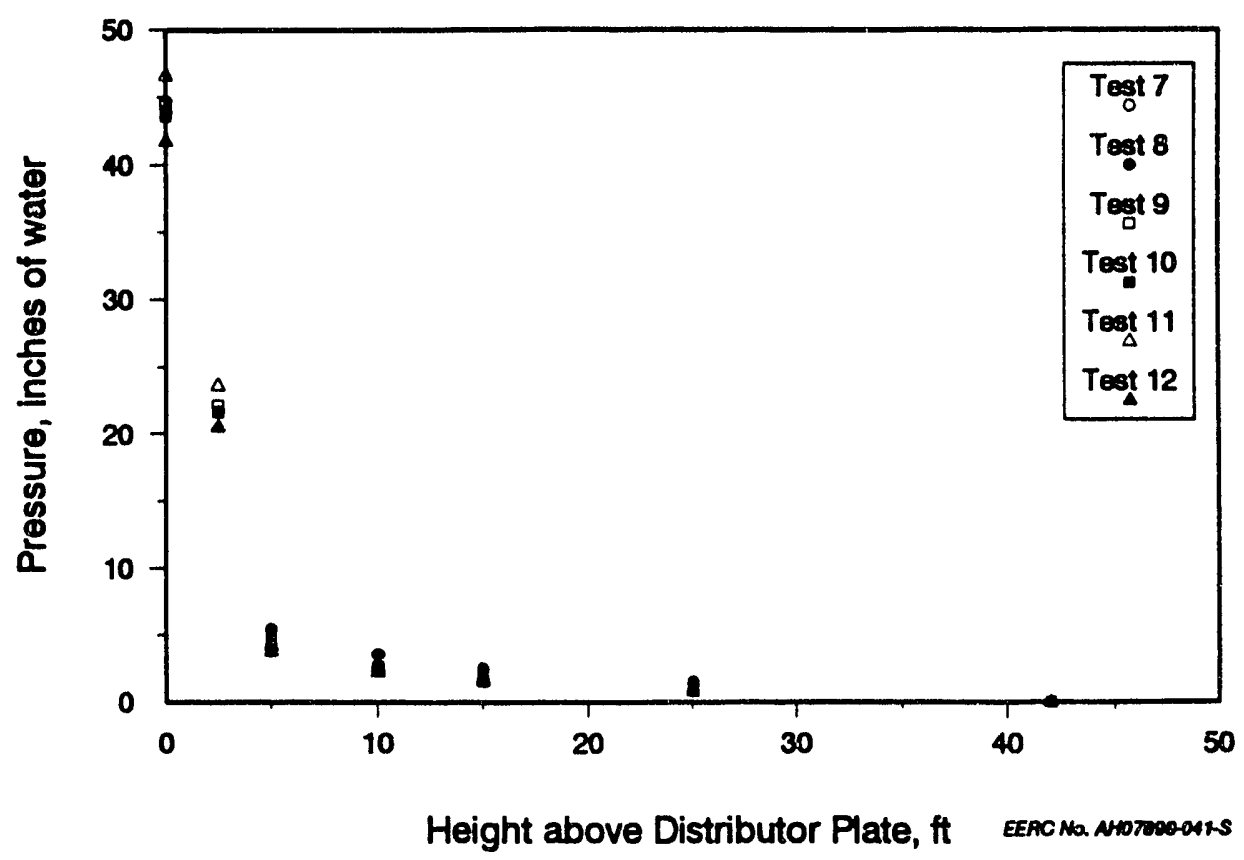

Figure C-9. Pressure profiles of Tests 7 through 12. 


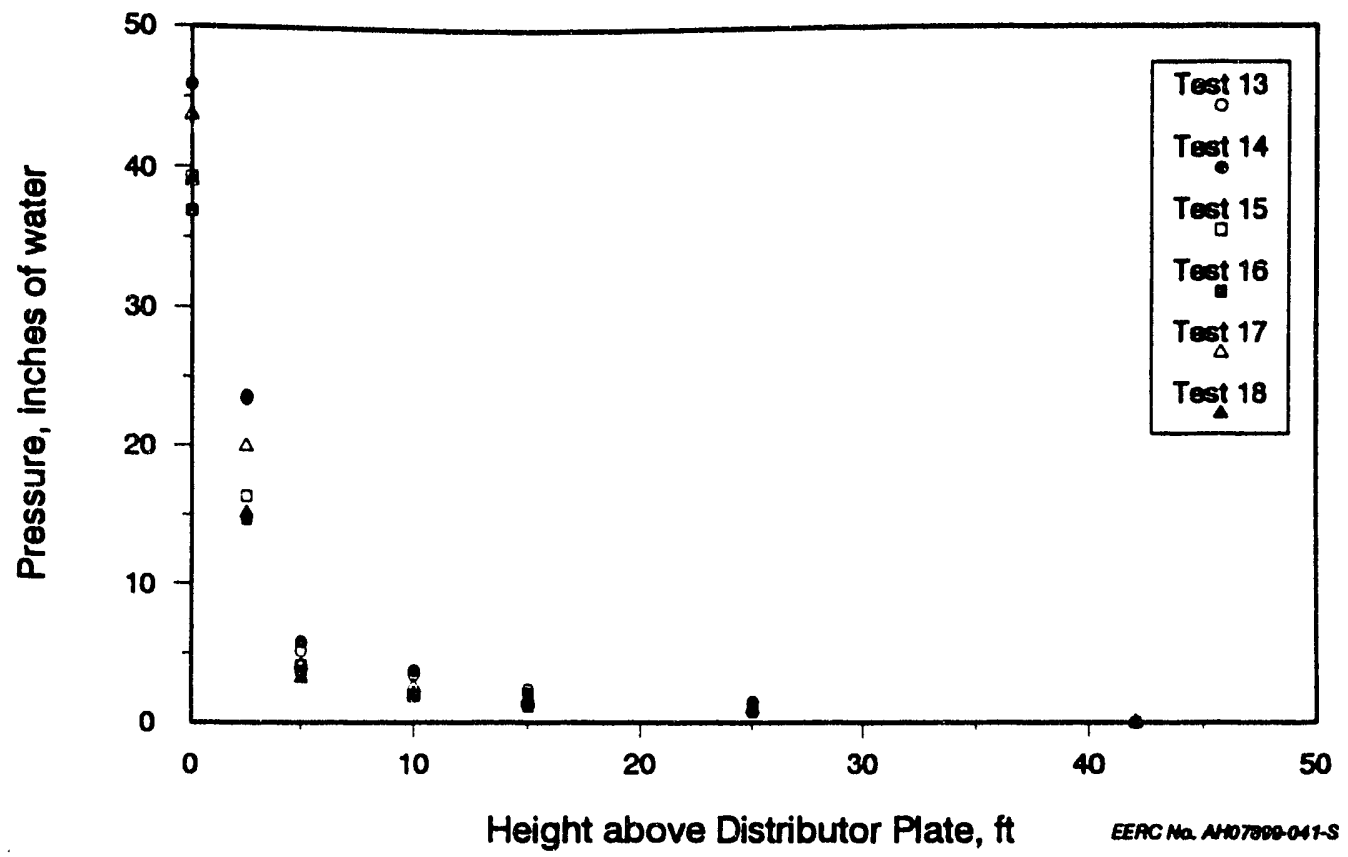

Figure C-10. Pressure profiles of Tests 13 through 18.

The temperature profiles for the run are shown in Figures C-11 through C-13. In general, the temperature distributions were fairly uniform throughout the combustor. The high-temperature test (Test 6) and a low-temperature, low-load test (Tests 11) had the greatest variations. Because of the relatively low solids recirculation rates throughout most of the tests, the external heat exchanger did not remove much heat from the system. Most of the heat removal occurred in the combustor. These two factors accounted for the nonuniform temperature distribution in the combustor, with a higher temperature at the bottom than the top. Starting with Test 10, the temperature reading located 3 feet above the distributor plate was about $30^{\circ}$ lower than those located at 2 and 4 feet. An attempt was made to replace the thermocouple, but it could not be removed from the combustor. Postrun inspection revealed that the thermocouple had melted, and it had to be cut away before it could be replaced.

\section{ENVIRONMENTAL PERFORMANCE}

Average flue gas emissions for each of the steady-state test periods are shown in Table C-18. Emissions of individual flue gas constituents are discussed in detail in the following sections.

\section{$\mathrm{SO}_{2}$ Emissions}

The relationship between temperature and flue gas $\mathrm{SO}_{2}$ emissions is shown in Figure C-14. Sulfur retention is greatest at temperatures between $1475^{\circ}$ and $1550^{\circ} \mathrm{F}$ and decreases at higher and lower temperatures. Test $6\left(1698^{\circ} \mathrm{F}\right)$ had virtually the same alkali-to-sulfur ratio as Test $13\left(1540^{\circ} \mathrm{F}\right)$, but their respective sulfur retentions were $19 \%$ and $91 \%$. Tests 5, 6, 13, and 14 had alkali-to-sulfur ratios near 3, while the alkali-tosulfur ratios for the remaining tests shown in Figure C-14 were about 2.3. Obviously, temperature control is a very critical operating parameter with this coal. 


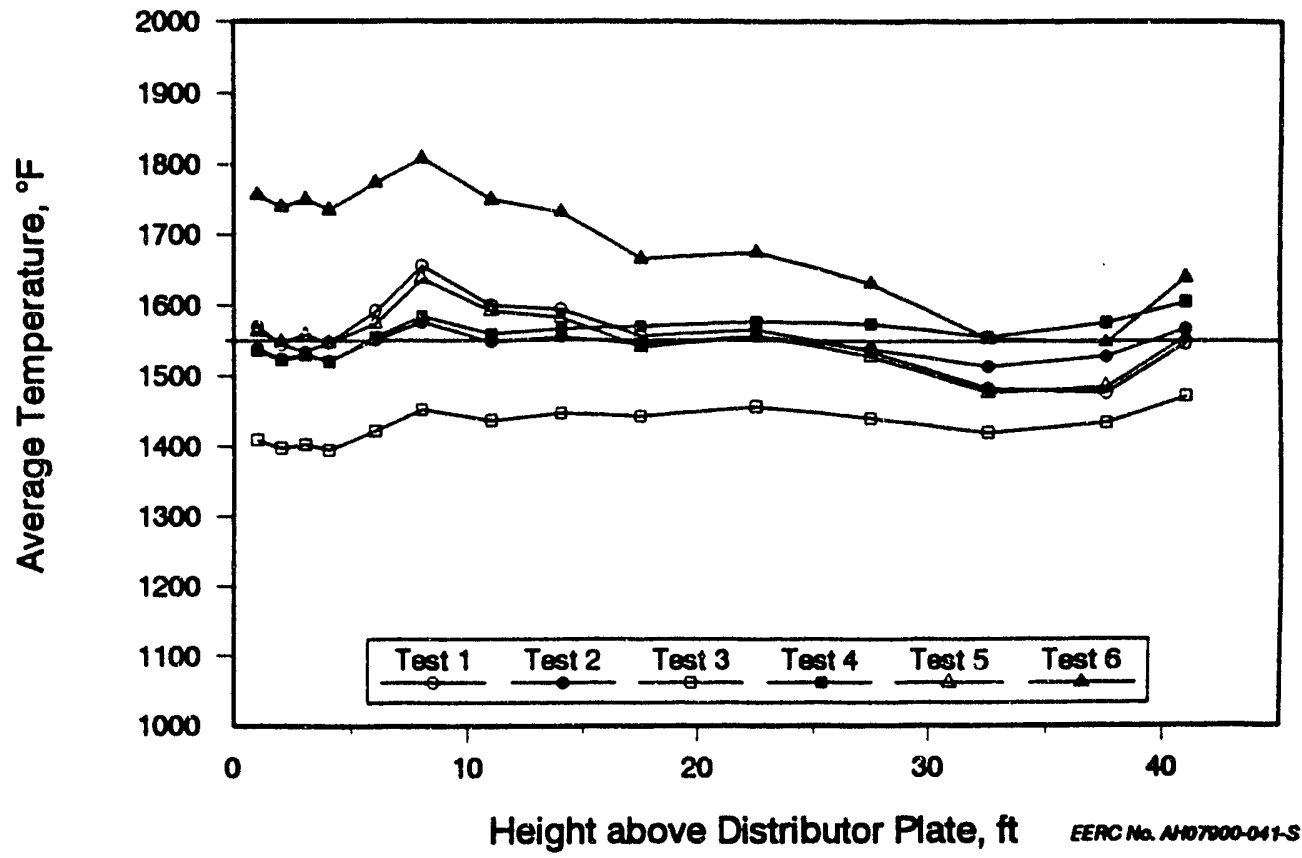

Figure C-11. Temperature profiles of Tests 1 through 6.

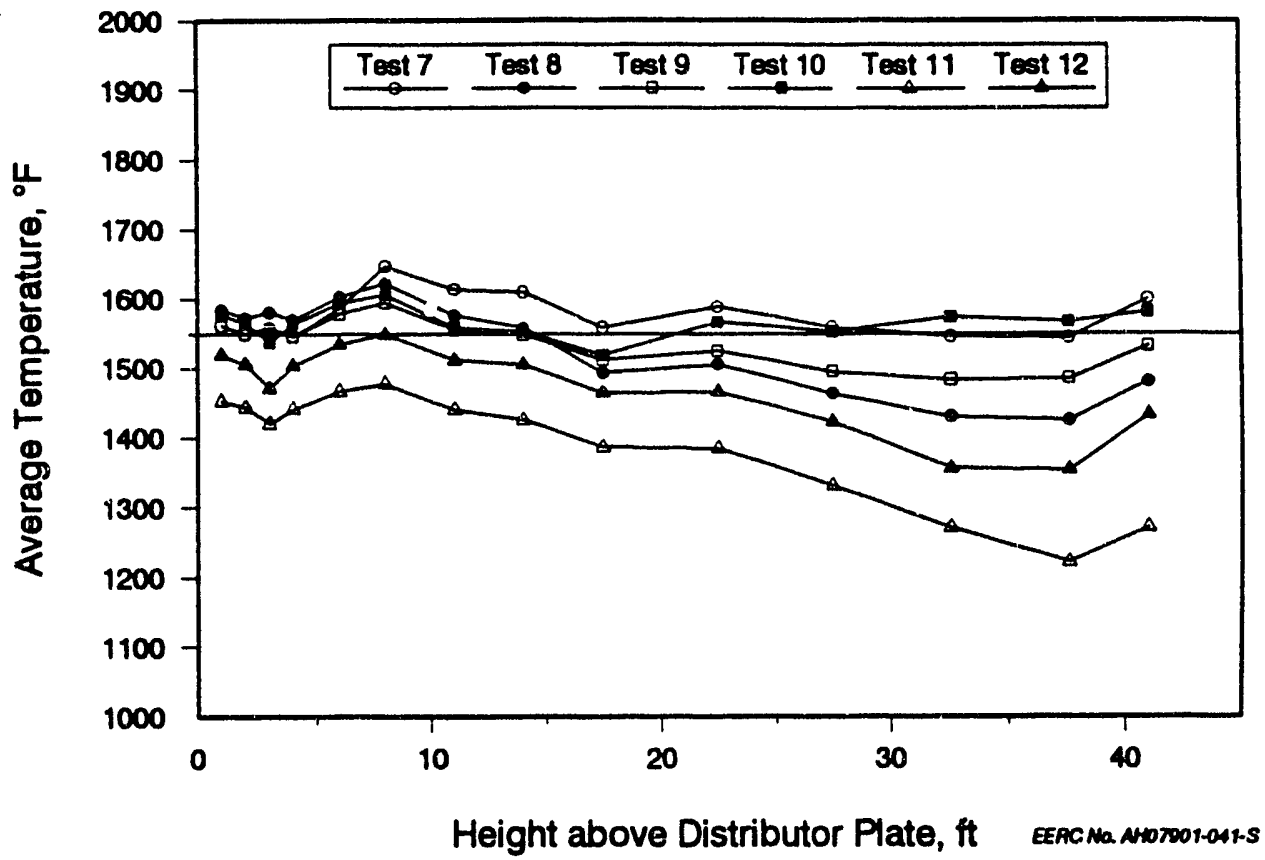

Figure C-12. Temperature profiles of Tests 7 through 12. 


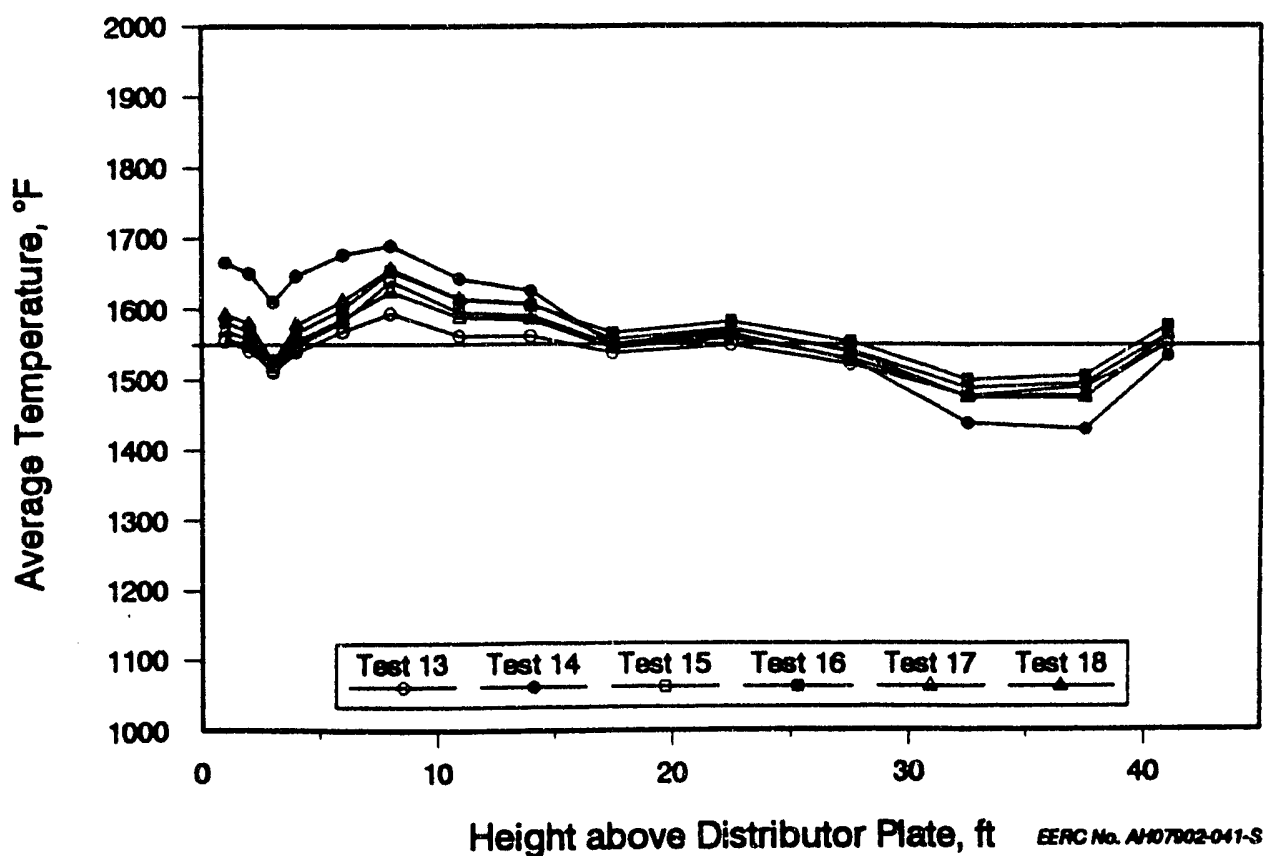

Figure C-13. Temperature profiles of Tests 13 through 18.

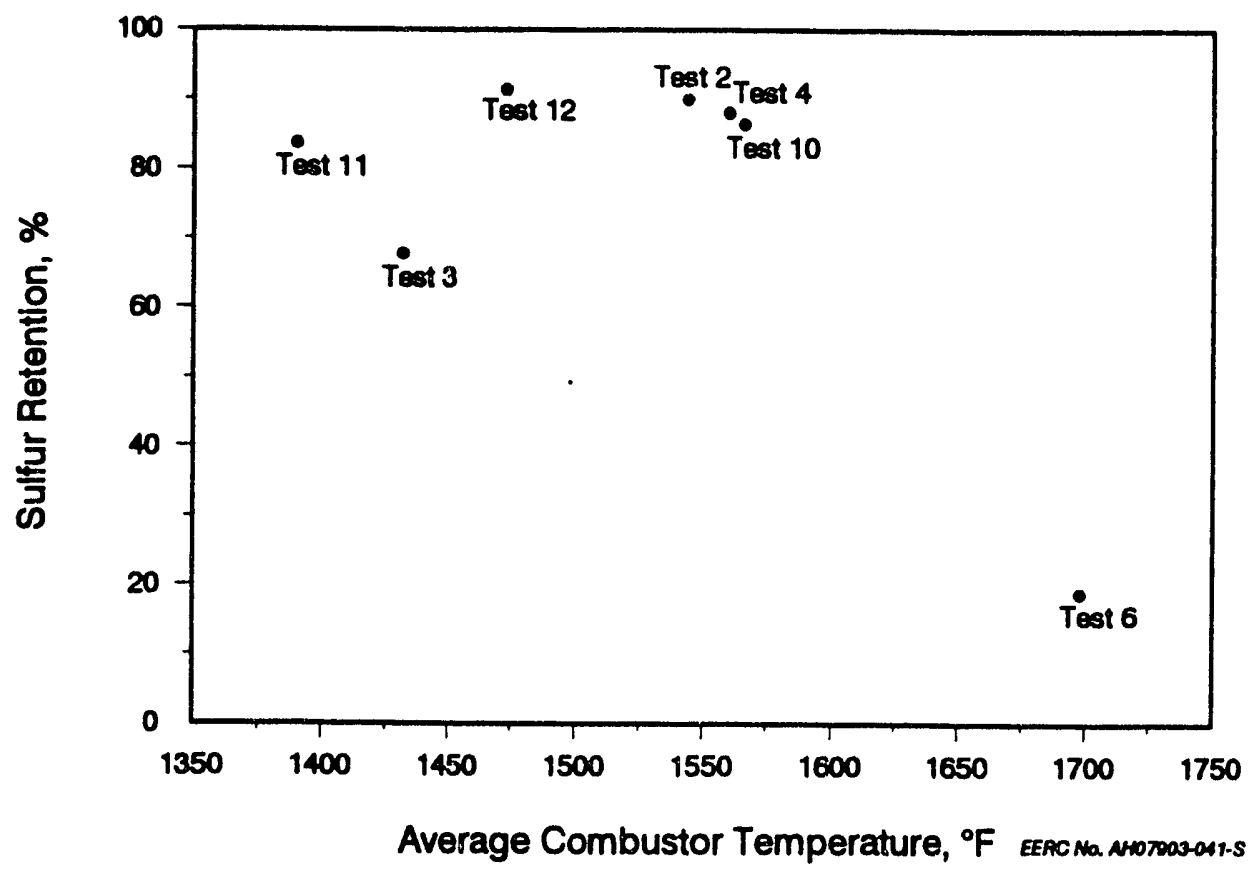

Figure C-14. Relationship between temperature and flue gas $\mathrm{SO}_{2}$ emissions. 


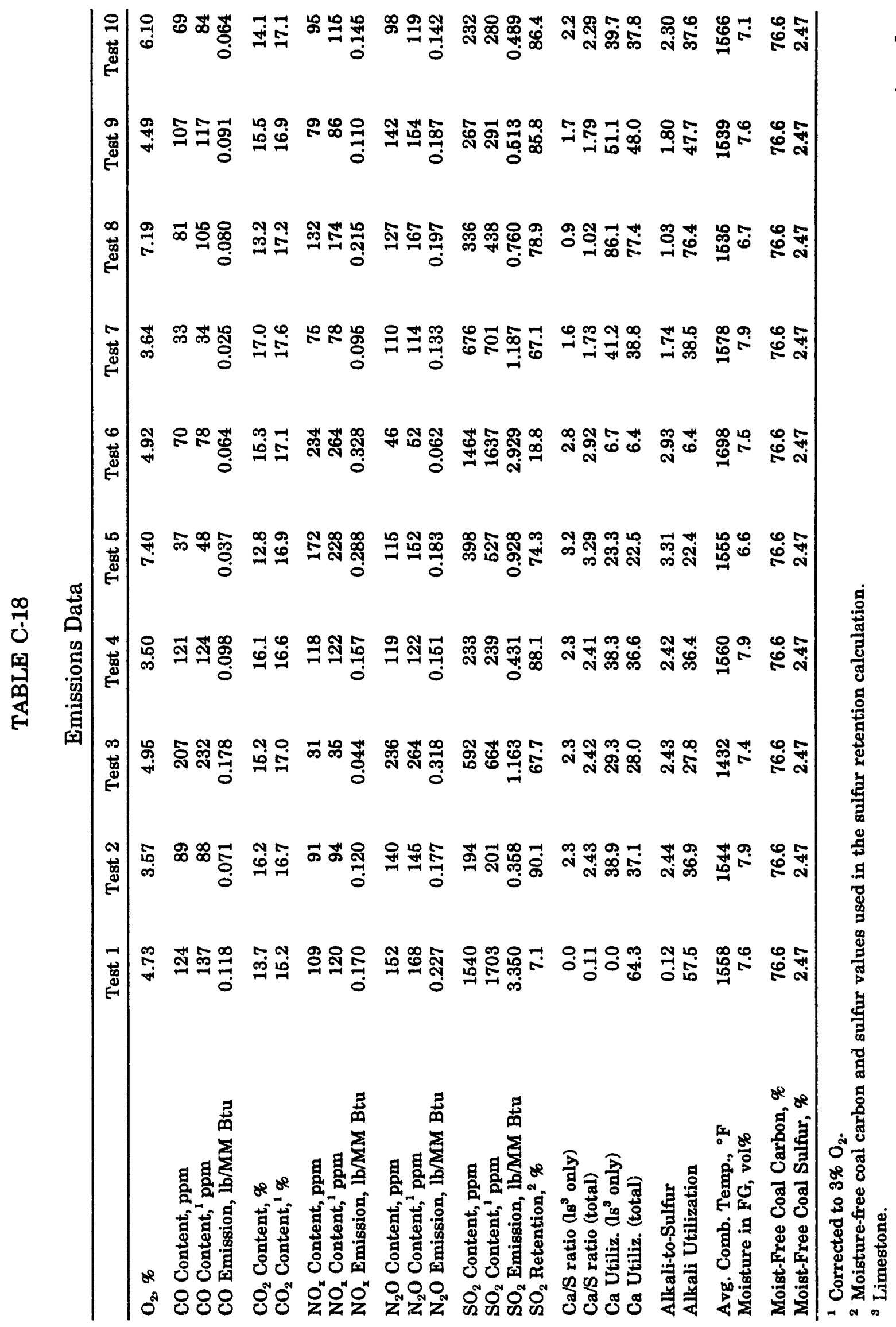




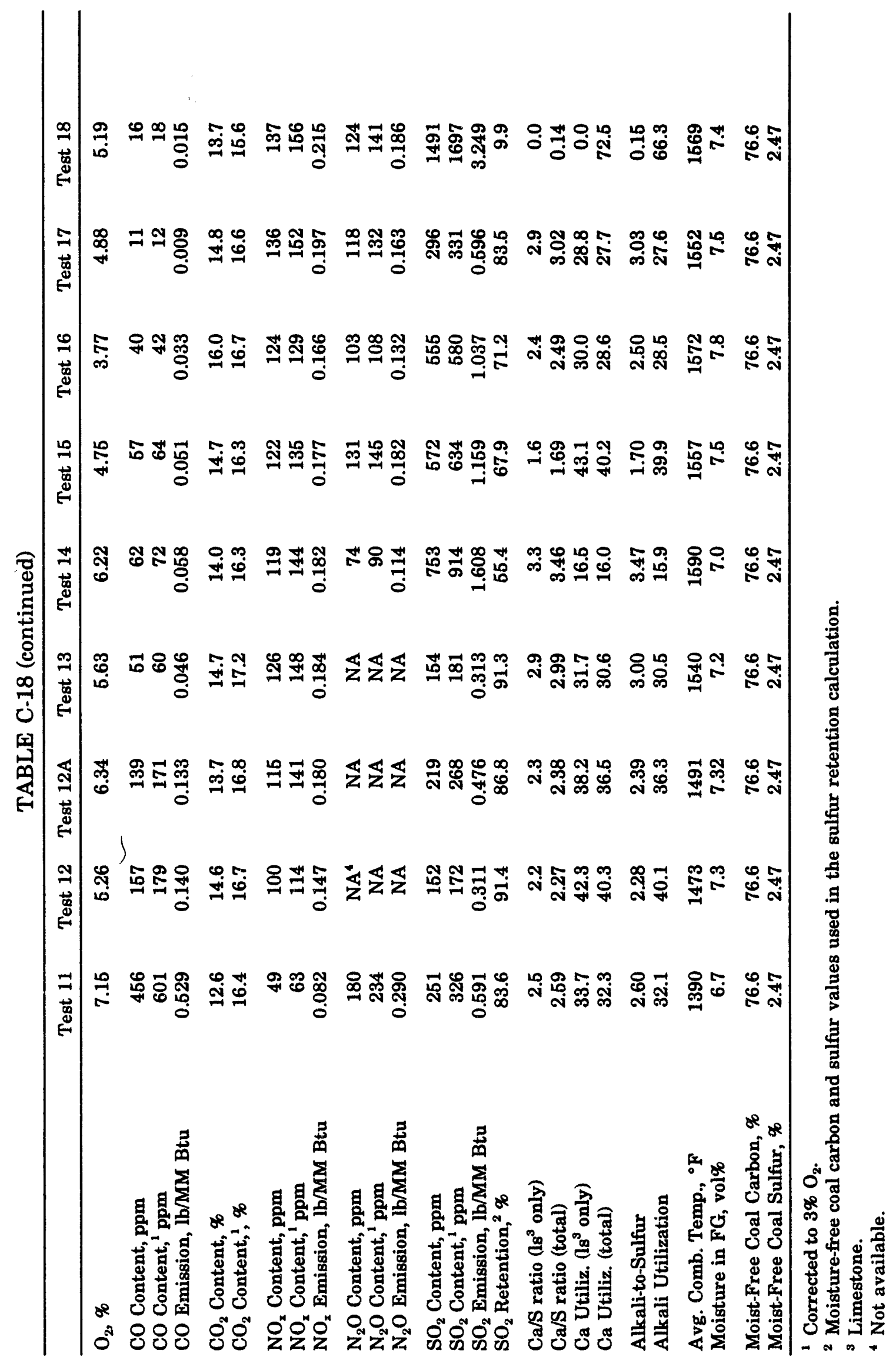


Figure C-15 shows the effect of alkali-to-sulfur ratio on $\mathrm{SO}_{2}$ emissions. The total alkali content includes the calcium in the limestone and both the calcium and sodium in the coal ash. The tests shown were operated at temperatures ranging from $1539^{\circ}$ to $1578^{\circ} \mathrm{F}$, with an average temperature of $1555^{\circ} \mathrm{F}$. The sulfur emission levels for Tests 1 and 18, with no limestone feed, were 1703 and $1697 \mathrm{ppm}$ (corrected to $3 \% \mathrm{O}_{2}$ ), respectively; this corresponds to 3.35 and $3.25 \mathrm{lb} / \mathrm{MM}$ Btu for Tests 1 and 18, respectively, and sulfur retentions of $7 \%$ and $10 \%$.

Sulfur emissions are also affected by the solids recirculation rate. Figure C-16 shows that, as recirculation rate increases, sulfur emissions decrease. With a higher recirculation rate, limestone stays in the system longer and has more time to react with the sulfur.

\section{NO Emissions}

The $\mathrm{NO}_{\mathrm{x}}$ emissions for this run ranged from $35 \mathrm{ppm}$ (corrected to $3 \% \mathrm{O}_{2}$ ) for Test 3 to $261 \mathrm{ppm}$ (corrected to $3 \% \mathrm{O}_{2}$ ) for Test 6 . Figure C-17 shows that $\mathrm{NO}_{\mathrm{x}}$ emissions increase with increasing temperature. These tests were operated at similar conditions of velocity, excess air, and alkali-to-sulfur ratio.

The $\mathrm{NO}_{\mathrm{x}}$ emissions for several $1550^{\circ} \mathrm{F}$ tests are shown as a function of excess air in Figure C-18. As expected, the $\mathrm{NO}_{\mathrm{x}}$ emissions increased with increasing excess air. A decrease in $\mathrm{NO}_{\mathrm{x}}$ with increasing $\mathrm{Ca} / \mathrm{S}$ ratio was also observed.

\section{$\mathrm{N}_{2} \mathrm{O}$ Emissions}

The relationship between $\mathrm{N}_{2} \mathrm{O}$ emissions and combustor temperature is shown in Figure C.19. $\mathrm{N}_{2} \mathrm{O}$ emissions data from all of the tests, except Tests 12 and 13, during which the $\mathrm{N}_{2} \mathrm{O}$ analyzer was not functioning, are shown in this figure. As expected, $\mathrm{N}_{2} \mathrm{O}$ emissions decrease with increasing temperature. $\mathrm{N}_{2} \mathrm{O}$ emissions also increased with increasing excess air, and decreased with increasing $\mathrm{Ca} / \mathrm{S}$ ratio.

\section{CO Emissions}

The $\mathrm{CO}$ emissions as a function of average combustor temperature are shown in Figure C-20. While there is a tendency for $\mathrm{CO}$ emissions to decrease with increasing temperature, this trend is not consistent for all tests. Other factors such as excess air and primary air split, also have a small effect on CO emissions. Test 11, the 50\% load, lowtemperature test had the highest $\mathrm{CO}$ emissions at $668 \mathrm{ppm}$ (corrected to $3 \% \mathrm{O}_{2}$ ). The next highest, 232 ppm, was measured for Test 3, also a low-temperature test.

\section{LIMESTONE PERFORMANCE}

Tests 15, 16, and 17 were limestone tests. Test 15 used the same sized New Enterprise limestone used in Tests 2 through 14; Test 16 used a finer size of the same limestone, and Test 17 used a fine-sized Colorado Ute limestone. All three tests were run at the same velocity $(16 \mathrm{ft} / \mathrm{sec})$. Tests 15 and 17 had the same temperature $\left(1555^{\circ} \mathrm{F}\right)$, while Test 16 was slightly higher $\left(1572^{\circ} \mathrm{F}\right)$. Test 16 was also operated at a lower excess air (22\%) compared to Tests 15 and 17 (29\% and 30\%, respectively). The test matrix called 


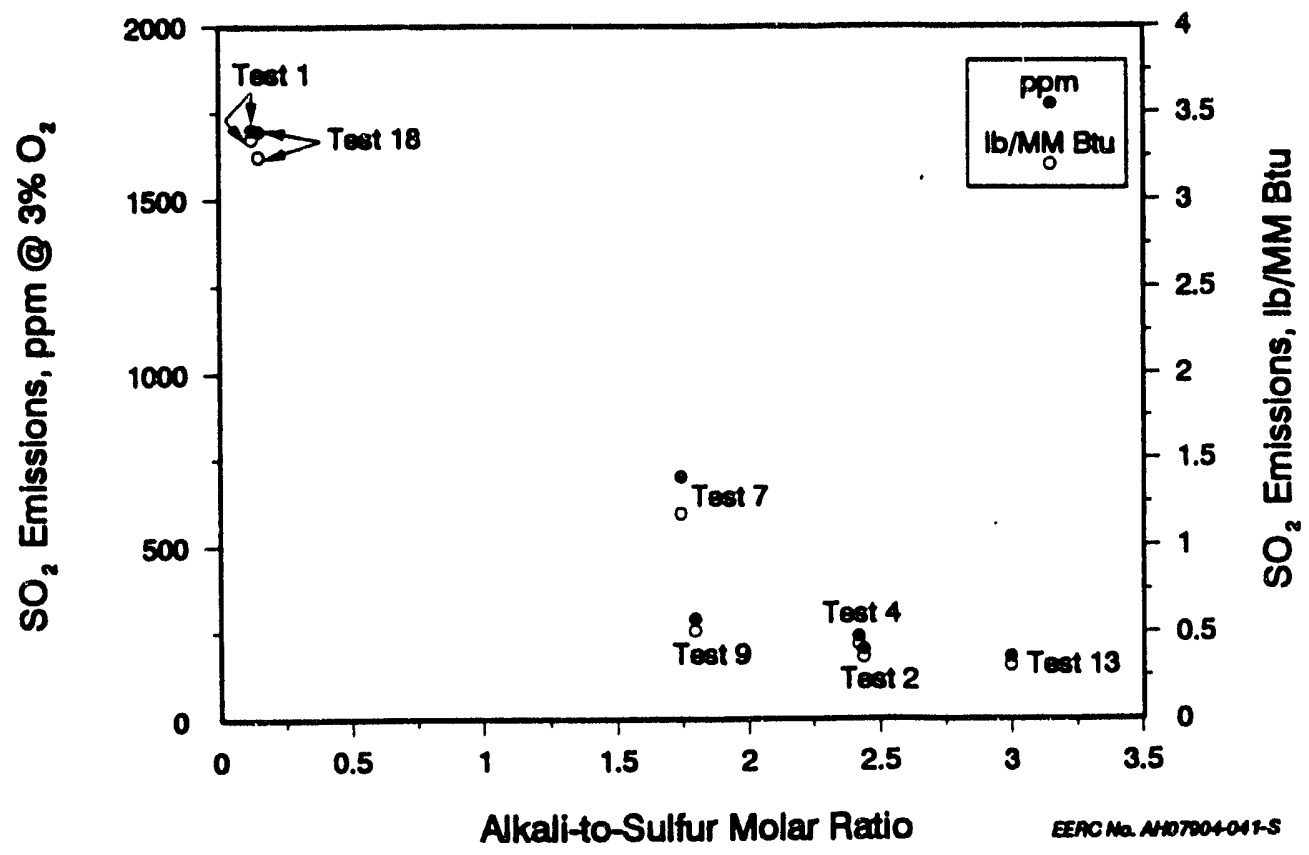

Figure C-15. Effect of alkali-to-sulfur ratio on $\mathrm{SO}_{2}$ emissions.

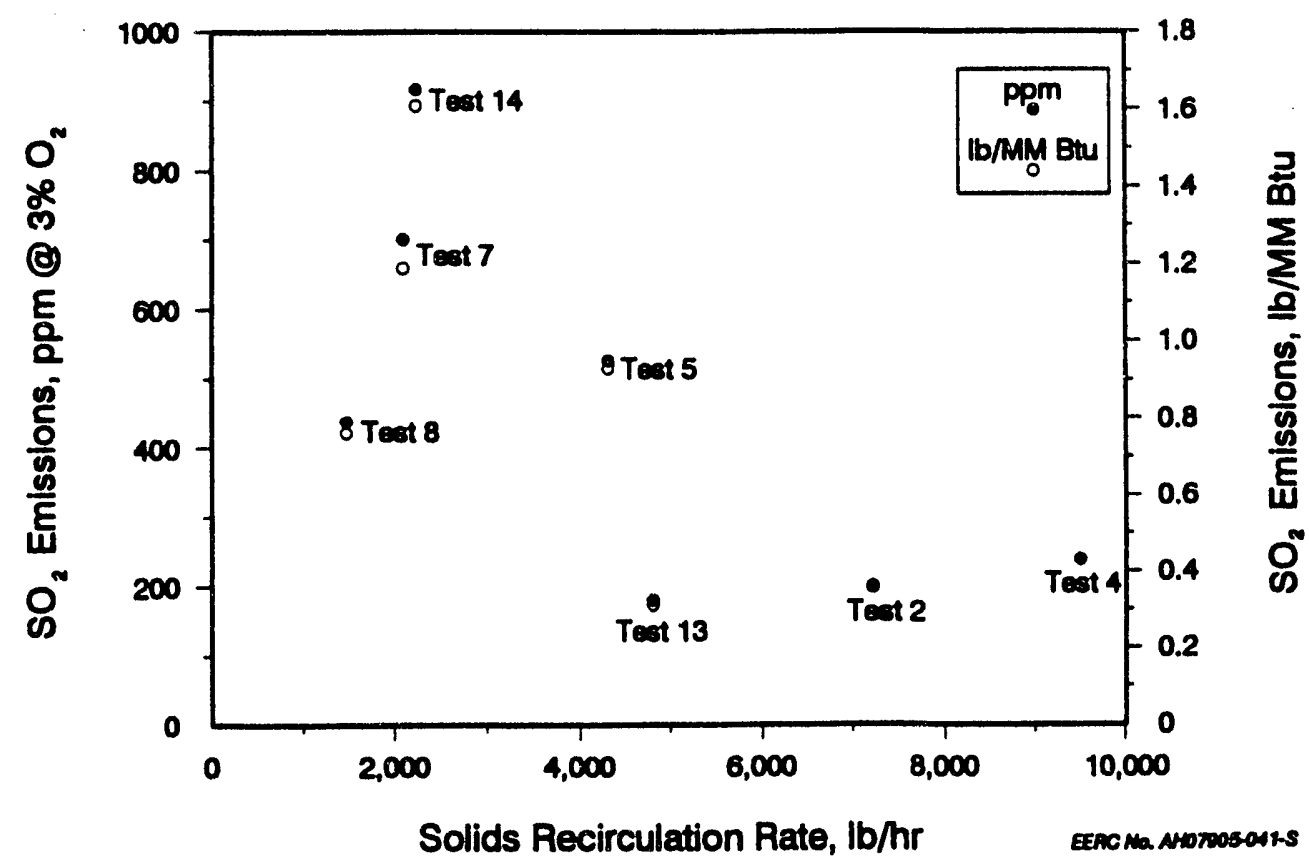

Figure C-16. Effect of solids recirculation rate on $\mathrm{SO}_{2}$ emissions. 


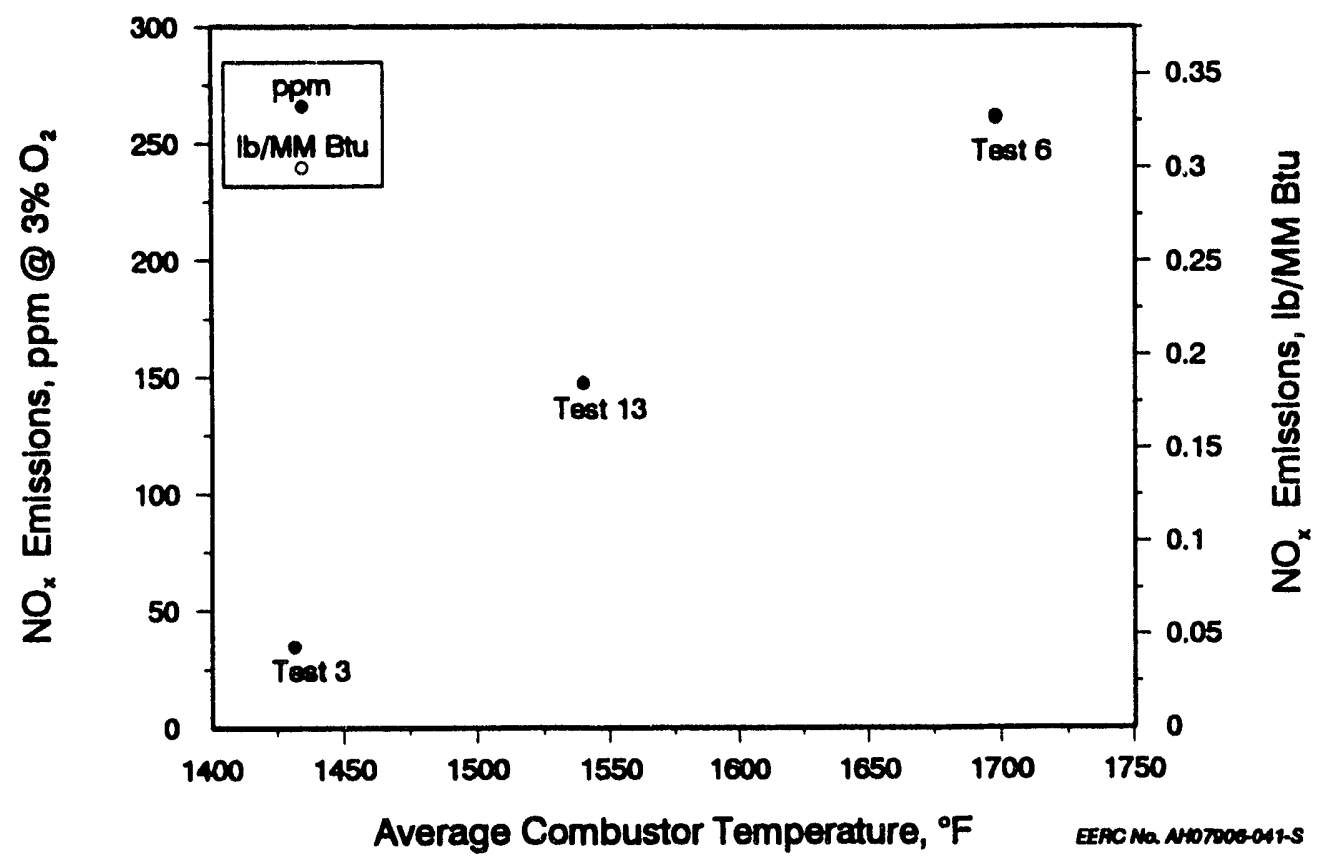

Figure C-17. $\mathrm{NO}_{\mathrm{z}}$ emissions as a function of average combustor temperature.

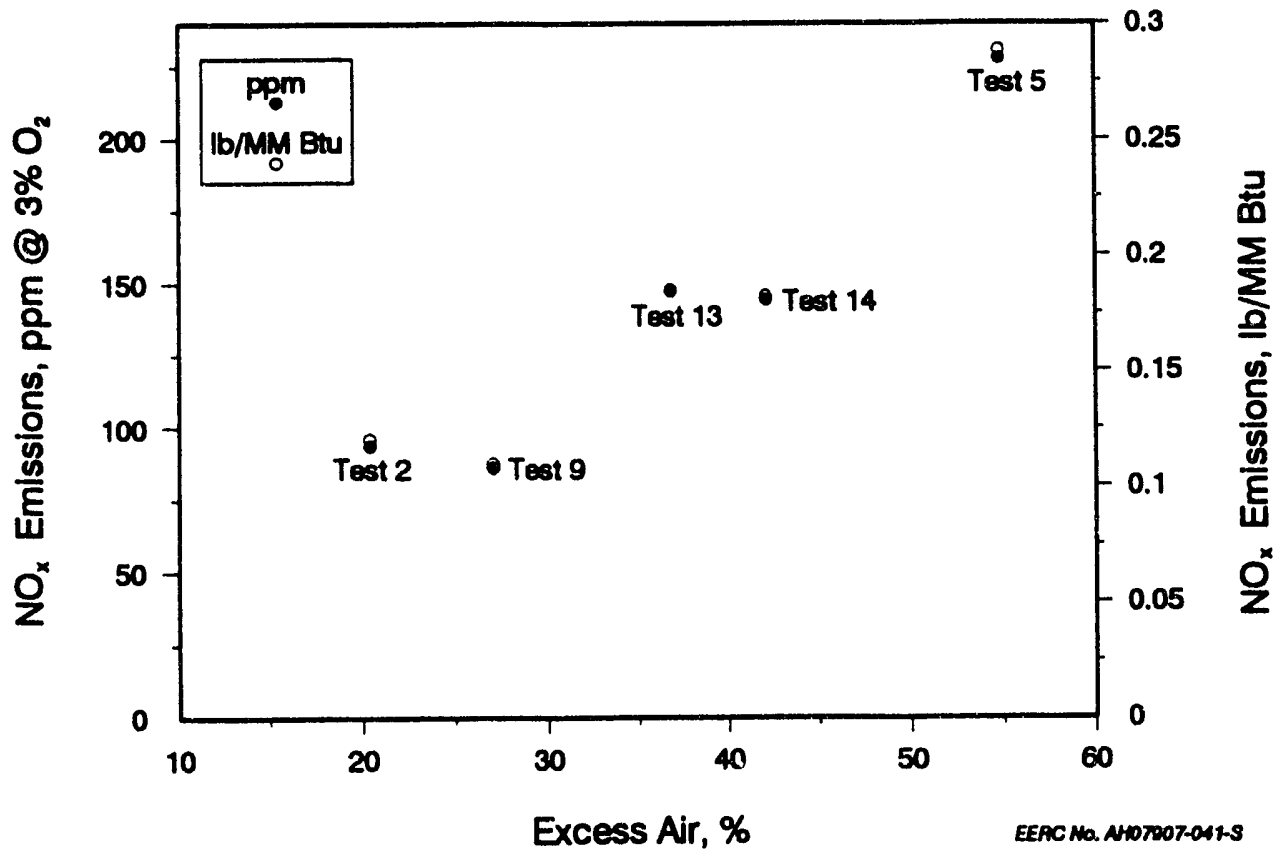

Figure C-18. $\mathrm{NO}_{\mathbf{x}}$ emissions as a function of excess air. 


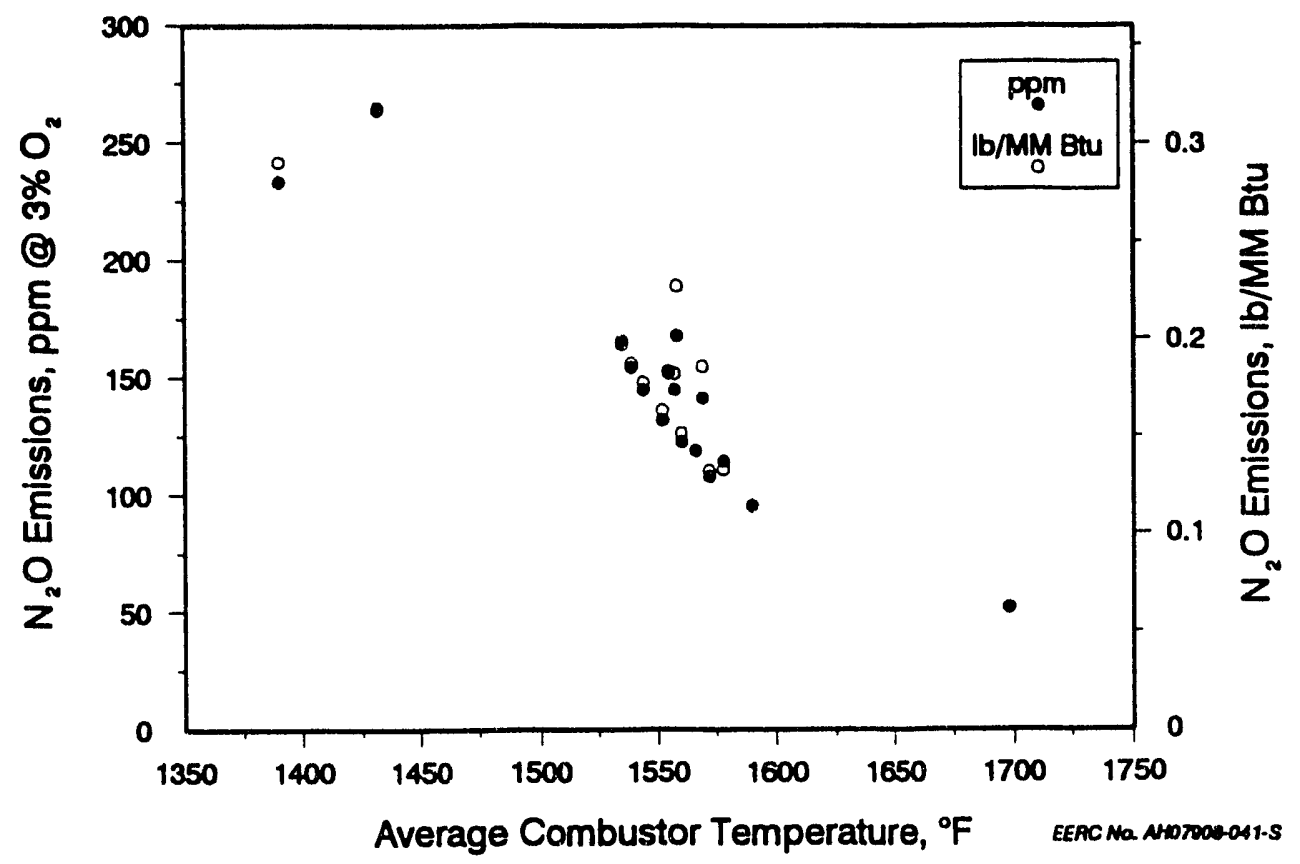

Figure C-19. $\mathrm{N}_{2} \mathrm{O}$ emissions as a function of average combustor temperature.

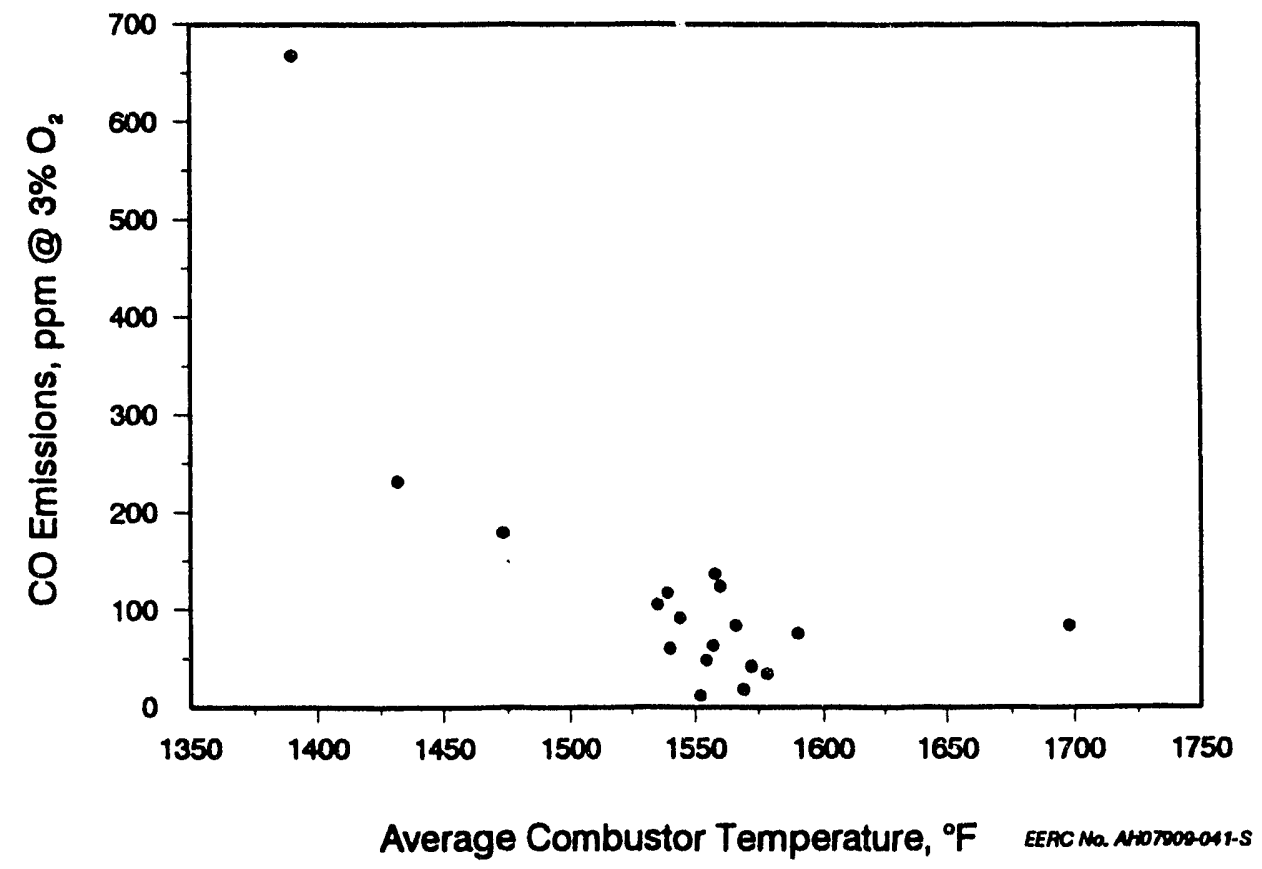

Figure C-20. CO emissions as a function of average combustor temperature. 
for all three tests to be run at an alkali-to-sulfur ratio to achieve $70 \%$ sulfur retention; the actual retentions for Tests 15,16 , and 17 were $70 \%, 71 \%$, and $84 \%$, respectively. The alkali-to-sulfur ratios required to achieve these levels of sulfur retention were 1.6, 2.4, and 2.8.

Figure C-21 shows the effect of limestone type and size on several parameters. Alkali utilization and heat-transfer coefficient are both more sensitive to limestone particle size than type. This indicates the reactivities of these two limestones are similar. The poorer utilization and higher alkali-to-sulfur ratio required for $70 \%$ sulfur retention for the finer limestones is due to a shorter residence time in the combustor, either because the larger particles stayed in the bed until attrition made them small enough to be carried out of the combustor, or because the smaller particles were not captured by the primary cyclone and recirculated back to the combustor.

The $\mathrm{NO}_{x}, \mathrm{~N}_{2} \mathrm{O}$, and $\mathrm{CO}$ emissions shown in Figure $\mathrm{C}-21$ reveal the interactions of several operating parameters. The relative $\mathrm{NO}_{\mathrm{x}}$ emissions for the three tests may result from an excess air effect (see Figure C-18), since the excess air for Test 16 was lower than the other two, as well as a limestone source effect. The lower $\mathrm{N}_{2} \mathrm{O}$ emissions for Test 16 may have been influenced by the higher temperature for that test (see Figure.C-19), as well as limestone differences. While both limestone size and source appear to have an effect on $\mathrm{CO}$ emissions, Figure C-20 suggests that these differences may be random.

\section{SUMMARIES OF TEST DATA}

This section contains the summaries of test data for each test period, including averages and standard deviations of many of the data points recorded by the computerized data acquisition system.

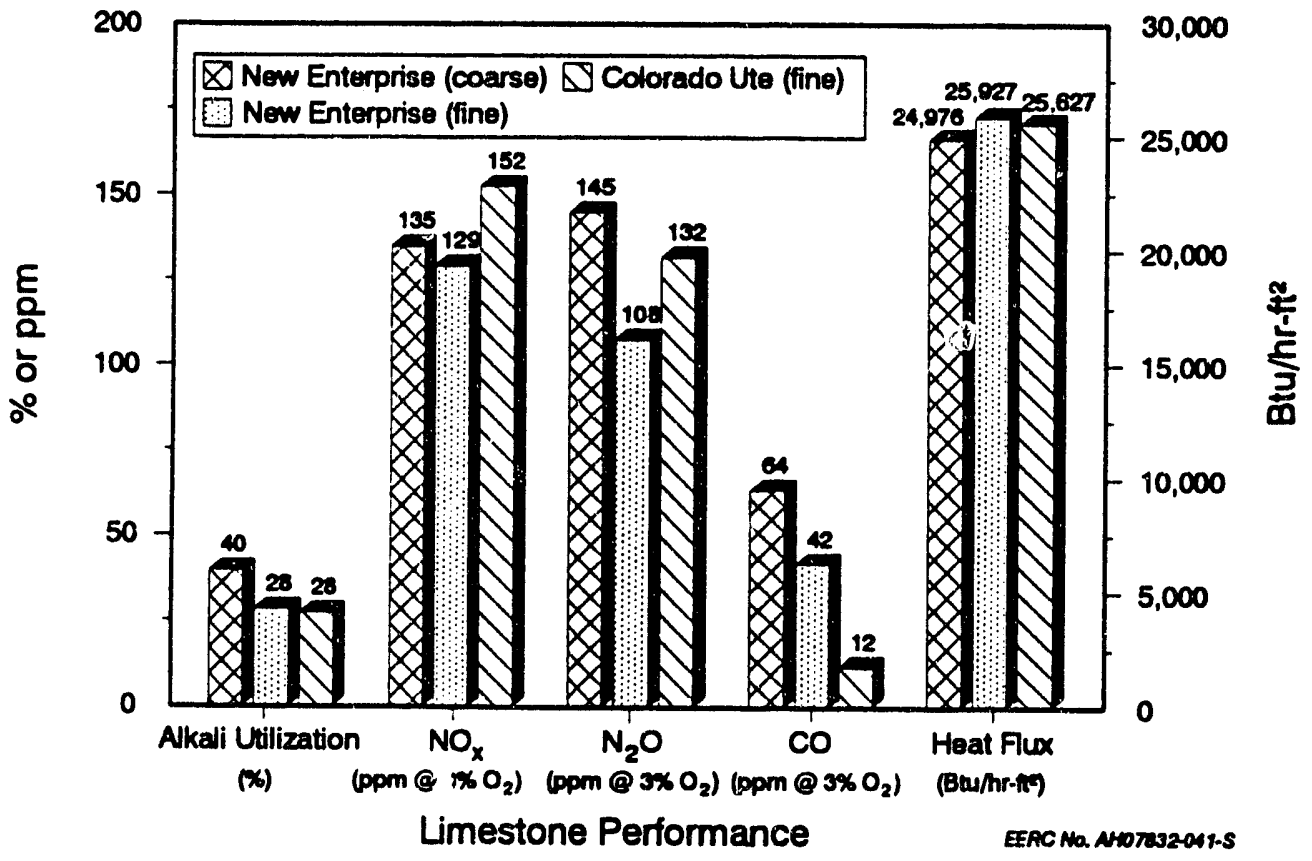

Figure C-21. Effect of limestone type, size, and source. 
07-Oct-91

$$
\text { CFB-BVH-0791 - TEST } 1
$$

$(1745-2345)$

\begin{tabular}{|c|c|c|c|c|c|c|c|c|c|c|c|c|c|}
\hline \multirow{3}{*}{$\frac{\text { Tag }}{\text { TC11011 }}$} & \multirow{2}{*}{$\frac{\text { Dese }}{\text { PCD Ex }}$} & \multirow{2}{*}{$\frac{\text { Units }}{{ }^{\circ} \mathrm{F}}$} & \multicolumn{2}{|c|}{ Average Std Dev } & \multicolumn{9}{|c|}{ HEAT-TRANSFER COEPFICIENTS } \\
\hline & & & 1541 & 6.4 & \multicolumn{2}{|l|}{-Combustor } & \multicolumn{3}{|c|}{ Number of Doors in Service } & \multicolumn{2}{|l|}{12} & & \multirow[b]{2}{*}{ Heat Flux } \\
\hline & AFS Ex & ${ }^{\circ} \mathbf{F}$ & 1301 & 4.8 & CHX & Height & Temp In & Temp Out & Bed Temp & Plow & $\mathbf{Q}$ & $\mathbf{U}$ & \\
\hline TC1500I & C Plenum & ${ }^{\circ} \mathbf{F}$ & 548 & 4.5 & Location & (fi) & $\bullet \mathbf{p}$ & ${ }^{\bullet} \mathbf{F}$ & $\cdot \mathbf{P}$ & gPm & Btu/br & Btuftt ${ }^{2} h r^{\circ} \mathrm{F}$ & $B t w / t^{2} h r$ \\
\hline TC15004 & C 1-1' & $\bullet \mathbf{P}$ & 1570 & 10.1 & $2 \mathrm{E}, \mathrm{W}$ & 8 & 57 & 130 & 1657 & 3.78 & 138664 & 17.5 & 26666 \\
\hline TC15005 & C 1-2' & ${ }^{\bullet} \mathbf{F}$ & 1545 & 10.7 & 3NE,SW & 14 & 56 & 137 & 1594 & 3.97 & 160029 & 21.1 & 30775 \\
\hline TC15006 & C 1-3' & $\cdot \mathbf{p}$ & 1534 & 9.6 & 4SE,NW & 17.5 & 57 & 136 & 1556 & 4.33 & 171120 & 23.2 & 32908 \\
\hline TC15007 & $C_{1-4}$ & ${ }^{\circ} \mathrm{F}$ & 1543 & 9.4 & $5 E$ & 22.5 & 57 & 141 & 1566 & 2.05 & 85976 & 23.2 & 33068 \\
\hline TC15008 & C 1-4' & ${ }^{\circ} \mathbf{p}$ & 1557 & 9.8 & 6NE & 27.5 & 57 & 124 & 1536 & 1.80 & 60434 & 16.5 & 23244 \\
\hline TC15009 & C 1-4' & ${ }^{\circ} \mathbf{F}$ & 1543 & 10.4 & 7SE,NW & 32.5 & 58 & 121 & 1484 & 3.23 & 102294 & 14.4 & 19672 \\
\hline TC15012 & C 2-6' & ${ }^{\circ} \mathbf{F}$ & 1593 & 10.9 & $8 \mathrm{E}, \mathrm{W}$ & 37.5 & 58 & 113 & 1477 & 3.70 & 102149 & 14.4 & 19644 \\
\hline TC15013 & C 2-8' & ${ }^{\bullet} \mathbf{P}$ & 1657 & 14.0 & & Overall & 57 & 129 & 1558 & 22.89 & 827847 & 18.6 & 26534 \\
\hline TC15022 & C 3-11' & ${ }^{\circ} \mathbf{P}$ & 1600 & 10.7 & & & \multicolumn{3}{|c|}{ From Data Sheets $\Rightarrow$} & 22.86 & & & \\
\hline TC15023 & c 3-14' & ${ }^{\circ} \mathrm{F}$ & 1591 & 9.2 & & & & & & & & & \\
\hline TC15024 & C 3-14' & $\bullet F$ & 1582 & 8.4 & -EHX- & & \multirow[b]{2}{*}{ Temp In } & & \multirow[b]{2}{*}{ Bed Temp } & & & & \multirow[b]{2}{*}{ Heat Flux } \\
\hline TC15025 & C 3-14' & ${ }^{\circ} \mathrm{F}$ & 1610 & 10.1 & Coils & No. of & & Temp Out & & Flow & $\mathbf{Q}$ & $\mathbf{u}$ & \\
\hline TC15032 & $C 4-17.5$ & ${ }^{\circ} \mathrm{F}$ & 1556 & 8.4 & Used & Coils & ${ }^{\circ} \mathbf{F}$ & ${ }^{\circ} \mathrm{F}$ & $\cdot \mathbf{P}$ & gpm & Btu/hr & Btu/ft ${ }^{2} b r^{\circ} \mathrm{F}$ & $\mathrm{Btu} / \mathrm{ft}^{2} \mathrm{hr}$ \\
\hline TC15042 & C $5-22.5^{\prime}$ & ${ }^{\circ} \mathrm{F}$ & 1566 & 6.2 & $1-4,10-12$ & 7 & 55 & 153 & 1214 & 8.79 & 431017 & 77.4 & 82098 \\
\hline TC15052 & C 6-27.5' & ${ }^{\circ} \mathrm{F}$ & 1553 & 6.6 & & & \multicolumn{3}{|c|}{ From Data Sheet $\Rightarrow$} & 9.18 & & & \\
\hline TC15053 & C G-27.5 & ${ }^{\circ} \mathbf{F}$ & 1562 & 8.0 & & & & & & & & & \\
\hline TC15054 & $C 6-27.5^{\prime}$ & $\bullet \mathbf{P}$ & 1492 & 5.4 & \multicolumn{2}{|c|}{ EMISSIONS DATA } & & & & & & & \\
\hline TC15062 & C 7-32.5' & ${ }^{\bullet} \mathbf{F}$ & 1484 & 5.9 & & & & & & & & & \\
\hline TC15071 & C 8-37.5' & ${ }^{\circ} \mathbf{F}$ & 1477 & 6.3 & & As Measure & ed & 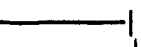 & - & -Corrected to & $103 \% 02-$ & & \\
\hline TC15073 & C $941^{\prime}$ & ${ }^{\circ} \mathbf{P}$ & 1547 & 5.5 & $\mathrm{Tag}$ & Units & Average & Std Dev & $\mathrm{Tag}$ & Units & Average & Std Dev & \\
\hline TC15999 & Ambient & ${ }^{\circ} \mathbf{F}$ & 87 & 1.8 & $\mathrm{SO} 2-\mathrm{A}$ & ppm & 1540 & 87.8 & $\mathrm{SO} 2-\mathrm{A}$ & ppm & 1703 & 76.2 & \\
\hline TC16001 & EHX Plenm & $\cdot F$ & 129 & 3.9 & SO2-AE & $\mathrm{Ib} / \mathrm{MM} \mathrm{Btu}$ & 3.02 & 0.1 & & & & & \\
\hline TC16012 & EHX 0.5' & $\cdot \mathbf{F}$ & 1218 & 13.9 & $\mathrm{SO} 2-\mathrm{B}$ & ppm & 1554 & 61.6 & $\mathrm{SO} 2-\mathrm{B}$ & ppm & 1696 & 33,4 & \\
\hline TC16013 & EHX 1.5' & ${ }^{\circ} \mathbf{F}$ & 1209 & 13.5 & $\mathrm{SO}-\mathrm{BE}$ & $\mathrm{Ib} / \mathrm{MM}$ Btu & 3.05 & 0.1 & & & & & \\
\hline TC16014 & EHX 2.7 & ${ }^{\circ} \mathrm{F}$ & 1214 & 13.3 & co & ppm & 124 & 16.4 & co & ppm & 137 & 19.6 & \\
\hline TC16015 & EHX 3.8' & ${ }^{\circ} \mathbf{F}$ & 1190 & 12.1 & $\mathrm{CO} 2$ & $\%$ & 13.71 & 0.6 & $\mathrm{CO} 2$ & $\%$ & 15.17 & 0.5 & \\
\hline TC16017 & EHX 5.3' & ${ }^{\circ} \mathbf{P}$ & 1065 & 6.7 & $\mathrm{~N} 2 \mathrm{O}$ & ppm & 152 & 5.8 & N2n & ppm & 168 & 9.2 & \\
\hline TC16018 & EHXExit & ${ }^{\circ} \mathrm{P}$ & 1126 & 13.6 & N2OE & $\mathrm{Ib} / \mathrm{MM} \mathrm{Btu}$ & 0.21 & 0.0 & & & & & \\
\hline TC16021 & $\operatorname{CrcA}$ in & ${ }^{\circ} \mathrm{F}$ & 1531 & 4.8 & NOx & ppm & 109 & 10.6 & NOx & ppm & 121 & 14.2 & \\
\hline TC16031 & DC \&-36 & ${ }^{\circ} \mathrm{F}$ & 1565 & 4.6 & NOxE & $\mathrm{lb} / \mathrm{MM} \mathrm{Btu}$ & 0.15 & 0.0 & & & & & \\
\hline TC16032 & DC 6-28' & ${ }^{\circ} \mathbf{F}$ & 1539 & 4.1 & $\mathrm{O}-\mathrm{A}$ & $\%$ & 4.73 & 0.5 & & & & & \\
\hline TC16033 & $D C 4-18^{\prime}$ & ${ }^{\circ} \mathrm{F}$ & 1533 & 5.6 & O2-B & $\%$ & 4.52 & 0.4 & & & & & \\
\hline TC16034 & DC3-9.5 & $\bullet p$ & 1553 & 3.6 & & & & & & & & & \\
\hline TC16035 & DC3-8.5 & ${ }^{\circ} \mathbf{F}$ & 1550 & 4.7 & Tag & Desc & Units & Average & Std Dev & $\mathrm{Tag}$ & Desc & Average & Std Dev \\
\hline & & & & & $W(C)$ & Coal Fd Rt & $\mathrm{Ibs} / \mathrm{hr}$ & 173.8 & 11.9 & TC13131 & AFPE-F2" & 1113 & 22.2 \\
\hline$T(A, C)$ & Comb Temp & ${ }^{\circ} \mathrm{F}$ & 1558 & 6.8 & W(S) & LS Fd Rt & $\mathrm{lbs} / \mathrm{hr}$ & 0.0 & 0.1 & TC13132 & AFPE-F $6^{n}$ & 1198 & 15.6 \\
\hline $\mathrm{T}(\mathrm{A}, \mathrm{EHX})$ & EHX Temp & $\cdot \mathrm{P}$ & 1214 & 13.4 & $V(F G)$ & FG SGV & $\mathrm{ft} / \mathrm{sec}$ & 16.1 & 1.1 & TC13133 & AFPE-B6" & 886 & 31.0 \\
\hline EA & Excess Air & $\%$ & 28.3 & 4.0 & $V(S, C)$ & Comb SGV & $\mathrm{ft} / \mathrm{sec}$ & 15.0 & 1.1 & TC13134 & AFPE-F10 & 1168 & 20.8 \\
\hline SR & S Reten & $\%$ & 13.7 & 2.4 & $V(S, E H X)$ & EHX SGV & $\mathrm{ft} / \mathrm{sec}$ & 1.5 & 0.1 & TC13231 & APPW-F2" & 1064 & 30.8 \\
\hline$R(P C A)$ & \%FIw PCA & $\%$ & 60.3 & 4.2 & FT18003 & CHX Flow & gpm & 22.9 & 0.3 & TC13232 & AFPW-F6" & 1160 & 30.1 \\
\hline $\mathrm{R}(\mathrm{SCA})$ & \%FIW SCA & $\%$ & 39.7 & 4.2 & FT19003 & EHX Flow & gpm & 8.8 & 0.1 & TC13233 & APPW-B6n & 837 & 49.6 \\
\hline$R(Q, I N)$ & \% Enrg in & $\%$ & 78.0 & 5.0 & PT15081 & Comb dP & in. $\mathrm{H} 12 \mathrm{O}$ & 37.8 & 4.0 & TC13234 & AFPW-F10 & 1130 & 32.9 \\
\hline $\mathrm{R}(\mathrm{CHX})$ & CHX Ratio & $\%$ & 62.4 & 1.6 & $O(C A)$ & CA Heat in & $\mathrm{KBtu} / \mathrm{hr}$ & 102.5 & 9.0 & DOORS & $\mathrm{CHX}$ s On & 12 & 0 \\
\hline$R(E H X)$ & EHX Ratio & $\%$ & 37.6 & 1.6 & $Q(\mathrm{CHX})$ & CHX HtRmv & $\mathrm{KBtw} / \mathrm{hr}$ & 715.7 & 42.7 & COILS & EHXs On & 7 & 0 \\
\hline $\mathbf{F}(\mathrm{PCA})$ & PCA F/w & SCFM & 262.2 & 40.6 & $Q(E H X)$ & EHX HIRmv & $\mathrm{KBtu} / \mathrm{hr}$ & 431.0 & 13.4 & BH A/C & & 1.9 & 0.0 \\
\hline $\mathbf{F}(\mathrm{EHX})$ & EHX F/w & SCFM & 43.7 & 1.8 & Q'EHX,IN & FG Enrg in & KBtw/hr & 1.8 & 0.2 & A/SRATIO & & 0.1 & 0.1 \\
\hline F(TPA) & TPCA FIw & SCFM & 307.9 & 37.8 & $Q(F)$ & Fuel Enrg in & $\mathbf{K B t u} / \mathbf{h r}$ & 2319.1 & 158.9 & Feed Air & scfm & 18.0 & \\
\hline $\mathbf{F}(\mathrm{SCA})$ & SCA Flw & SCFM & 165.9 & 18.2 & $Q(F G)$ & FG Enrg out & $\mathrm{KBtu} / \mathrm{hr}$ & 245.6 & 4.7 & DC Air & sefm & 0.0 & \\
\hline $\mathrm{F}(\mathrm{TCA}, \mathrm{F})$ & TCA Flw & SCFM & 508.9 & 36.4 & $Q(I N)$ & Tot Enrg in & $\mathrm{KBt} / \mathrm{h} \mathbf{h r}$ & 2423.4 & 160.4 & Purge Air & scfm & 15.5 & \\
\hline $\mathrm{F}(\mathrm{FG}, \mathrm{BH})$ & BH Flw & SCFM & 503.0 & 9.5 & QOUT) & Tot Enrg out & $\mathrm{KBtu} / \mathrm{hr}$ & 1887.5 & $47.6^{\circ}$ & & & & \\
\hline$F(T F G)$ & TFG FIw & SCFM & 503.0 & 9.5 & $W(S R)$ & Recirc Rt & $\mathrm{lb} / \mathrm{hr}$ & 4168 & 217.9 & & & & \\
\hline
\end{tabular}




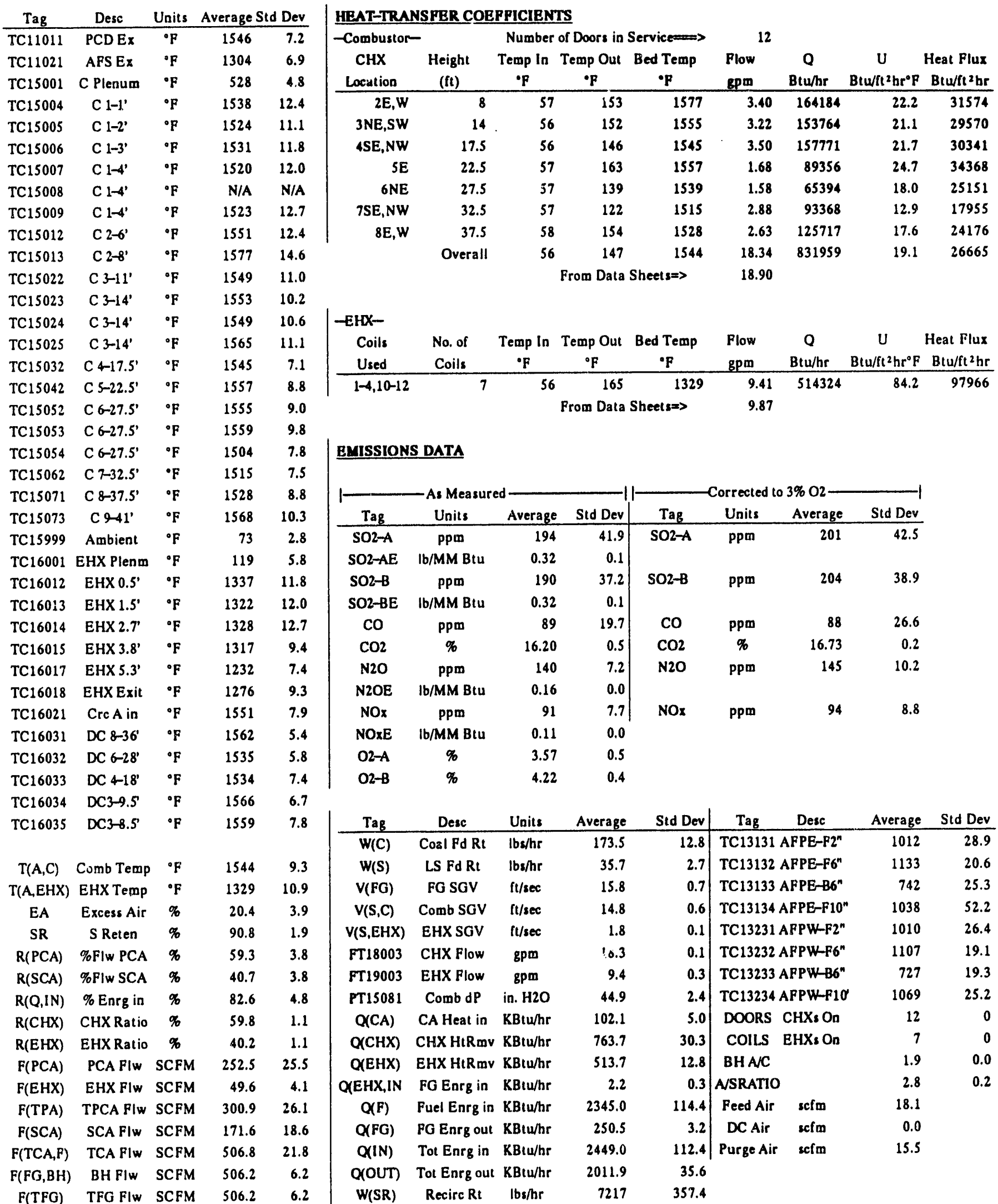




\begin{tabular}{|c|c|c|c|c|}
\hline Tag & Desc & Units & Average & d Dev \\
\hline TC11011 & PCDEX & ${ }^{\circ} \mathbf{F}$ & 1481 & 8.8 \\
\hline TC11021 & AFS Ex & ${ }^{\circ} \mathbf{F}$ & 1253 & 8.4 \\
\hline TC15001 & C Plenum & ${ }^{\circ} \mathrm{F}$ & 513 & 7.8 \\
\hline TC15004 & C 1-1' & ${ }^{\circ} \mathbf{F}$ & 1410 & 20.2 \\
\hline TC15005 & C 1-2' & ${ }^{\circ} \mathrm{F}$ & 1398 & 20.3 \\
\hline TC15006 & C 1-3' & ${ }^{\circ} \mathbf{F}$ & 1403 & 19.0 \\
\hline TC15007 & C 1-4' & ${ }^{\circ} \mathbf{F}$ & 1395 & 17.5 \\
\hline TC15008 & C 1-4' & ${ }^{\circ} \mathbf{P}$ & N/A & N/A \\
\hline TC15009 & C 1-4' & ${ }^{\circ} \mathrm{F}$ & 1397 & 19.7 \\
\hline TC15012 & C 2-6' & ${ }^{\circ} \mathrm{F}$ & 1423 & 21.3 \\
\hline TC15013 & C 2-8' & ${ }^{\circ} \mathbf{F}$ & 1452 & 19.8 \\
\hline TC15022 & C 3-11' & ${ }^{\circ} \mathrm{F}$ & 1437 & 16.3 \\
\hline TC15023 & C 3-14' & ${ }^{\circ} \mathrm{F}$ & 1444 & 17.1 \\
\hline TC15024 & C 3-14' & ${ }^{\circ} \mathbf{F}$ & 1441 & 16.2 \\
\hline TC15025 & C 3-14' & ${ }^{\circ} \mathrm{F}$ & 1454 & 16.7 \\
\hline TC15032 & C 4-17.5' & ${ }^{\circ} \mathrm{F}$ & 1442 & 17.4 \\
\hline TC15042 & C 5-22.5' & ${ }^{\circ} \mathbf{F}$ & 1456 & 15.2 \\
\hline TC15052 & C 6-27.5' & ${ }^{\circ} \mathrm{F}$ & 1454 & 14.6 \\
\hline $\mathrm{TC} 15053$ & $C 6-27.5^{\prime}$ & ${ }^{\circ} \mathbf{F}$ & 1457 & 15.4 \\
\hline TC15054 & C 6-27.5' & ${ }^{\circ} \mathbf{F}$ & 1411 & 15.1 \\
\hline TC15062 & C 7-32.5' & ${ }^{\circ} \mathrm{F}$ & 1421 & 15.4 \\
\hline TC15071 & C 8-37.5' & ${ }^{\circ} \mathrm{F}$ & 1434 & 14.1 \\
\hline TC15073 & C 9-41' & ${ }^{\circ} \mathbf{F}$ & 1472 & 14.6 \\
\hline TC15999 & Ambient & ${ }^{\circ} \mathbf{F}$ & 76 & 3.6 \\
\hline TC16001 & EHX Plenm & ${ }^{\circ} \mathbf{F}$ & 127 & 4.6 \\
\hline TC16012 & EHX 0.5' & ${ }^{\circ} \mathrm{F}$ & 1120 & 29.0 \\
\hline TC16013 & EHX 1.5' & ${ }^{\circ} \mathbf{F}$ & 1107 & 29.3 \\
\hline TC16014 & EHX 2.T & ${ }^{\circ} \mathbf{F}$ & 1102 & 29.8 \\
\hline TC16015 & EHX 3.8' & ${ }^{\circ} \mathbf{F}$ & 1081 & 28.1 \\
\hline TC16017 & EHX 5.3' & ${ }^{\circ} \mathbf{F}$ & 1043 & 23.6 \\
\hline TC16018 & EHX Exit & ${ }^{\circ} \mathbf{F}$ & 1051 & 24.7 \\
\hline TC16021 & $\operatorname{Crc} A$ in & ${ }^{\circ} \mathbf{F}$ & 1458 & 14.0 \\
\hline $\mathrm{TC} 16031$ & DC \&-36 & ${ }^{\circ} \mathbf{F}$ & 1486 & 8.0 \\
\hline TC16032 & DC 6-28' & ${ }^{\circ} \mathbf{F}$ & 1457 & 7.6 \\
\hline TC16033 & DC 4-18' & ${ }^{\circ} \mathbf{F}$ & 1452 & 10.5 \\
\hline TC16034 & DC3-9.5 & ${ }^{\circ} \mathbf{F}$ & 1479 & 11.0 \\
\hline TC16035 & DC3-8.5 & ${ }^{\circ} \mathbf{P}$ & 1477 & 10.1 \\
\hline$T(A, C)$ & Comb Temp & ${ }^{\circ} \mathrm{F}$ & 1431 & 17.2 \\
\hline $\mathrm{T}(\mathrm{A}, \mathrm{EHX})$ & EHX Temp & ${ }^{\circ} \mathbf{F}$ & 1110 & 28.3 \\
\hline EA & Excess Air & $\%$ & 30.8 & 5.9 \\
\hline SR & S Reten & $\%$ & 69.9 & 4.3 \\
\hline $\mathrm{R}(\mathrm{PCA})$ & $\% F \mid w$ PCA & $\%$ & 59.9 & 5.2 \\
\hline $\mathrm{R}(\mathrm{SCA})$ & \%FIw SCA & $\%$ & 40.1 & 5.2 \\
\hline$R(Q, I N)$ & \% Enrg in & $\%$ & 78.3 & 7.5 \\
\hline $\mathrm{R}(\mathrm{CHX})$ & CHX Ratio & $\%$ & 51.9 & 1.6 \\
\hline$R(E H X)$ & EHX Ratio & $\%$ & 48.1 & 1.6 \\
\hline$F(P C A)$ & PCA FIw & SCFM & 249.0 & 31.9 \\
\hline $\mathrm{F}(\mathrm{EHX})$ & EHX Fiw & SCFM & 56.4 & 3.6 \\
\hline$F(T P A)$ & TPCA Flw & SCFM & 304.7 & 30.8 \\
\hline $\mathrm{F}(\mathrm{SCA})$ & SCA F/w & SCFM & 170.3 & 26.7 \\
\hline$F(T C A, F)$ & TCA FIw & SCFM & 508.9 & 21.7 \\
\hline$F(F G, B H)$ & BH Flw & SCFM & 511.8 & 17.2 \\
\hline $\mathrm{F}(\mathrm{TFG})$ & TFG F/W & SCFM & 511.8 & 17.2 \\
\hline
\end{tabular}

HEAT-TRANSPER COEPPICIENTS

\begin{tabular}{|c|c|c|c|c|c|c|c|c|}
\hline \multirow{2}{*}{$\begin{array}{c}- \text { Combustor- } \\
\text { CHX } \\
\text { Location }\end{array}$} & \multirow{2}{*}{$\begin{array}{c}\text { Height } \\
\text { (ft) }\end{array}$} & \multicolumn{3}{|c|}{ Number of Doors in Service $\Longrightarrow$} & \multicolumn{2}{|l|}{12} & \multirow[b]{2}{*}{$\begin{array}{c}U \\
B\left(u / f t^{2} b r \cdot P\right.\end{array}$} & \multirow[b]{2}{*}{$\begin{array}{l}\text { Heat Flux } \\
\text { Btw/t }{ }^{2} h\end{array}$} \\
\hline & & $\begin{array}{c}\text { Temp lo } \\
\cdot \mathbf{p}\end{array}$ & $\begin{array}{c}\text { Temp Out } \\
\bullet p \\
\end{array}$ & $\begin{array}{c}\text { Bed Temp } \\
\cdot F \\
\end{array}$ & $\begin{array}{l}\text { Flow } \\
\text { gpm }\end{array}$ & $\begin{array}{c}\mathbf{Q} \\
\text { Btu/hr }\end{array}$ & & \\
\hline $2 E, W$ & 8 & 57 & 158 & 1452 & 2.82 & 141765 & 21.1 & 27263 \\
\hline $3 N E, S W$ & 14 & 56 & 169 & 1447 & 2.85 & 161466 & 24.3 & 31051 \\
\hline 4SE,NW & 17.5 & 59 & 164 & 1442 & 2.90 & 152099 & 22.9 & 29250 \\
\hline SE & 22.5 & 56 & 159 & 1456 & 1.47 & 75803 & 22.5 & 29155 \\
\hline 6NE & 27.5 & 60 & 163 & 1441 & 1.70 & 87784 & 26.4 & 33763 \\
\hline 7SE,NW & 32.5 & 60 & 120 & 1421 & 3.27 & 98468 & 14.6 & 18936 \\
\hline \multirow[t]{3}{*}{$8 \mathrm{E}, \mathrm{W}$} & 37.5 & 59 & 132 & 1434 & 2.77 & 101534 & 15.0 & 19526 \\
\hline & Overall & 55 & 150 & 1431 & 16.16 & 767165 & 19.2 & 24589 \\
\hline & \multicolumn{4}{|c|}{ From Data Sheets $\Rightarrow$} & 17.78 & & & \\
\hline
\end{tabular}

\begin{tabular}{|c|c|c|c|c|c|c|c|c|}
\hline $\begin{array}{r}\text { EHX- } \\
\text { Coils } \\
\text { Used }\end{array}$ & $\begin{array}{l}\text { No. of } \\
\text { Coils }\end{array}$ & $\begin{array}{c}\text { Temp ln } \\
\cdot F\end{array}$ & $\begin{array}{c}\text { Temp Out } \\
{ }^{\circ} \mathbf{F} \\
\end{array}$ & $\begin{array}{c}\text { Bed Temp } \\
{ }^{\circ} \mathbf{F} \\
\end{array}$ & $\begin{array}{l}\text { Flow } \\
\text { spm }\end{array}$ & $\begin{array}{c}Q \\
\text { Btu/hr }\end{array}$ & $\begin{array}{c}U \\
\text { Btu/ft }{ }^{2} h r^{\circ} \mathrm{F}\end{array}$ & $\begin{array}{l}\text { Heat Flux } \\
\text { Btu/ft }{ }^{2} \mathrm{hr}\end{array}$ \\
\hline $1-7,9$ & & 55 & 129 & 1110 & 16.09 & 598884 & 67.9 & 66543 \\
\hline $13-16$ & \multicolumn{4}{|c|}{ From Data Sheet $s=>$} & 16.82 & & & \\
\hline
\end{tabular}

EMISSIONS DATA

\begin{tabular}{|c|c|c|c|c|c|c|c|}
\hline \multirow{2}{*}{$\mathrm{Tag}$} & \multicolumn{3}{|l|}{ Meas } & \multicolumn{4}{|c|}{$3 \%$} \\
\hline & Units & Average & Std Dev & Tag & Units & Average & Std Dev \\
\hline SO2-A & ppm & 592 & 75.3 & $\mathrm{SO} 2-\mathrm{A}$ & ppm & 666 & 98.4 \\
\hline SO2-AE & $\mathrm{lb} / \mathrm{MM} \mathrm{Blu}$ & 1.05 & 0.1 & & & & \\
\hline SO2-B & ppm & 579 & 74.6 & SO2-B & ppm & 662 & 93.4 \\
\hline $\mathrm{SO}-\mathrm{BE}$ & $\mathrm{lb} / \mathrm{MM}$ Btu & 1.03 & 0.1 & & & & \\
\hline $\mathrm{CO}$ & ppm & 207 & 50.4 & $\mathrm{CO}$ & ppm & 233 & 62.2 \\
\hline $\mathrm{CO} 2$ & $\%$ & 15.17 & 0.6 & $\mathrm{CO} 2$ & $\%$ & 17.02 & 0.6 \\
\hline $\mathrm{N} 2 \mathrm{O}$ & ppm & 236 & 11.7 & $\mathrm{~N} 2 \mathrm{O}$ & ppm & 265 & 22.9 \\
\hline $\mathrm{N} 2 \mathrm{OE}$ & $\mathrm{lb} / \mathrm{MM}$ Btu & 0.29 & 0.0 & & & & \\
\hline NOx & ppm & 31 & 4.1 & NOx & ppm & 35 & 4.7 \\
\hline NOxE & $\mathrm{Ib} / \mathrm{MM}$ Btu & 0.04 & 0.0 & & & & \\
\hline O2-A & $\%$ & 4.95 & 0.7 & & & & \\
\hline $\mathrm{O} 2-\mathrm{B}$ & $\%$ & 5.21 & 0.6 & & & & \\
\hline
\end{tabular}

$\begin{array}{llll}\mathrm{O}-\mathrm{B} & \% & 5.21 & 0.6\end{array}$

\begin{tabular}{|c|c|c|c|c|c|c|c|c|}
\hline Tag & Desc & Units & Average & Sid Dev & Tag & Desc & Average & Std Dev \\
\hline$W(C)$ & Coal Fd Rt & $\mathrm{lb} / \mathrm{hr}$ & 175.7 & 16.1 & $\mathrm{TC} 13131$ & AFPE-F2 $2^{n}$ & 888 & 25. \\
\hline $\mathbf{W}(\mathbf{S})$ & LS Fd Rt & $\mathrm{lb} / \mathrm{hr}$ & 32.9 & 5.1 & TC13132 & AFPE-F 6" & 1032 & 18 \\
\hline$V(F G)$ & FG SGV & $\mathrm{ft} / \mathrm{sec}$ & 15.2 & 0.8 & $\mathrm{TC} 13133$ & AFPE-B6" & 653 & 18 \\
\hline$V(S, C)$ & Comb SGV & $\mathrm{ft} / \mathrm{sec}$ & 14.3 & 0.6 & TC13134 & AFPE-F10" & 867 & 41 \\
\hline V(S,EHX) & EHX SGV & $\mathrm{ft} / \mathrm{sec}$ & 1.8 & 0.1 & TC13231 & AFPW-F2" & 899 & 22 \\
\hline FT18003 & CHX Flow & gpm & 16.2 & 0.2 & TC13232 & AFPW-F $6^{n}$ & 1014 & 18 \\
\hline FT 19003 & EHX Flow & gpm & 16.1 & 0.2 & TC13233 & AFPW-B6" & 654 & 17. \\
\hline PT15081 & Comb dP & in. $\mathrm{H}_{2} \mathrm{O}$ & 46.4 & 3.1 & TC13234 & AFPW-F10 & 961 & 22. \\
\hline$Q(C A)$ & CA Heat in & KBtu/hr & 98.9 & 6.0 & DOORS & $\mathrm{CHX}_{s} \mathrm{On}$ & 12 & \\
\hline$Q(\mathrm{CHX})$ & CHX HtRmv & KBtu/hr & 642.0 & 37.2 & COILS & EHXs On & 12 & \\
\hline$Q(E H X)$ & EHX HtRmv & $\mathrm{KBt} / \mathrm{hr}$ & 595.4 & 31.3 & $\mathrm{BH} A / C$ & & 1.9 & \\
\hline Q(EHX,IN & FG Enrg in & KBtw/hr & 2.8 & 0.3 & A/SRATIO & & 2.7 & \\
\hline$Q(F)$ & Fuel Enrg in & $\mathbf{K B t u} / \mathrm{hr}$ & 2338.4 & 214.8 & Feed Air & $\operatorname{sefm}$ & 18.6 & \\
\hline$Q(F G)$ & FG Enrg out & $\mathrm{KBtu} / \mathrm{hr}$ & 246.8 & 9.0 & DC Air & scfm & 0.0 & \\
\hline$Q(I N)$ & Tot Enrg in & KBtu/hr & 2440.0 & 217.4 & Purge Air & scfm & 15.5 & \\
\hline QOUT) & Tot Enrg out & $\mathrm{KB} t \mathrm{u} / \mathrm{hr}$ & 1889.3 & 68.6 & & & & \\
\hline$W(S R)$ & Recirc Rt & $\mathrm{lbs} / \mathrm{hr}$ & 5262 & 676.0 & & & & \\
\hline
\end{tabular}




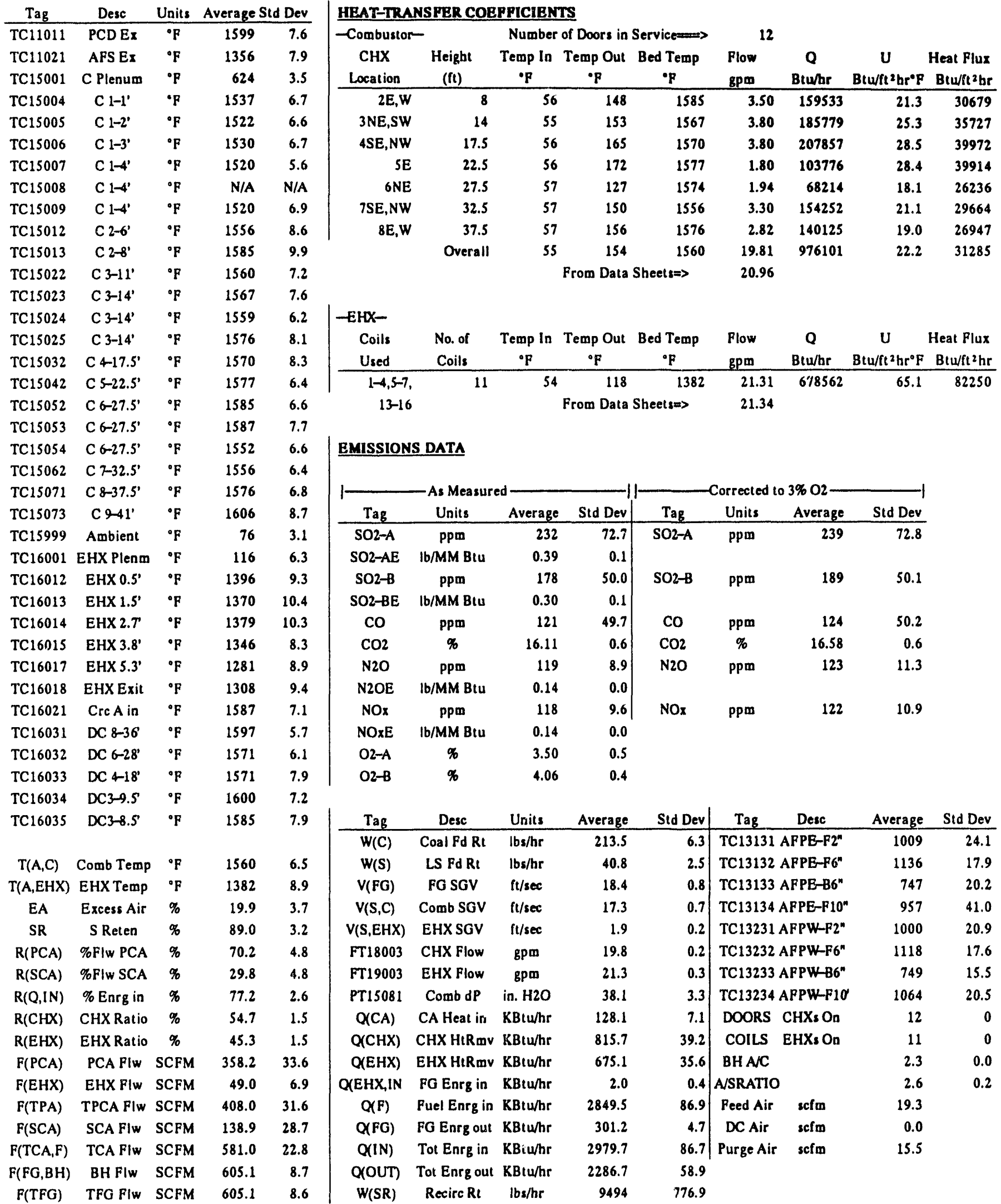




\begin{tabular}{|c|c|c|c|c|c|c|c|c|c|c|c|c|c|}
\hline \multirow{3}{*}{ 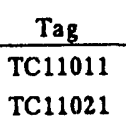 } & \multirow{2}{*}{$\frac{\text { Desc }}{\text { PCD EX }}$} & \multirow{2}{*}{$\frac{\text { Units }}{{ }^{\circ} \mathbf{F}}$} & \multicolumn{2}{|c|}{ Average Std Dev } & \multicolumn{9}{|c|}{ HEAT-TRANSPER COEPPICIENTS } \\
\hline & & & 1531 & 17.7 & \multicolumn{2}{|c|}{-Combustor- } & \multicolumn{3}{|c|}{ Number of Doors in Service } & \multicolumn{2}{|l|}{12} & & \multirow{3}{*}{$\begin{array}{l}\text { Heat Plux } \\
\mathrm{Btu} / \mathrm{tt}^{2} \mathrm{hr}\end{array}$} \\
\hline & AFS Ex & $\cdot \mathbf{P}$ & 1311 & 16.3 & $\mathrm{CHX}$ & Height & Temp In & Temp Out & Bed Teinp & Flow & $\mathbf{Q}$ & $\mathbf{U}$ & \\
\hline TC15001 & C Plenum & $\circ p$ & 575 & 4.9 & Location & (ft) & $\bullet \mathbf{F}$ & F & $\cdot \mathbf{P}$ & gpm & Btu/hr & Btu/ft ${ }^{2} \mathrm{hr} \cdot \mathrm{P}$ & \\
\hline TC15004 & $C_{1-1}^{\prime}$ & ${ }^{\circ} \mathbf{F}$ & 1564 & 36.7 & $2 E, W$ & 8 & 56 & 138 & 1639 & 3.43 & 140551 & 18.0 & 27029 \\
\hline TC15005 & C 1-2' & ${ }^{\circ} \mathbf{F}$ & 1548 & 34.6 & $3 N E, S W$ & 14 & 56 & 139 & 1583 & 3.80 & 156881 & 20.9 & 30169 \\
\hline TC15006 & C $1-3$ & $\bullet^{\bullet} \mathbf{F}$ & 1558 & 35.9 & 4SE,NW & 17.5 & 57 & 147 & 1541 & 3.80 & 170899 & 23.6 & 32865 \\
\hline TC15007 & C $1-4^{\prime}$ & ${ }^{\circ} \mathrm{p}$ & 1547 & 33.4 & $5 \mathrm{E}$ & 22.5 & 57 & 154 & 1556 & 1.70 & 82782 & 22.7 & 31839 \\
\hline $\mathrm{TC} 15008$ & C 1-4' & ${ }^{\circ} \mathbf{F}$ & $N / A$ & N/A & 6NE & 27.5 & 57 & 117 & 1528 & 1.90 & 57457 & 15.7 & 22099 \\
\hline TC15009 & C $1-4^{\prime}$ & ${ }^{\circ} \mathbf{p}$ & 1548 & 34.7 & 7SE,NW & 32.5 & 58 & 128 & 1478 & 3.33 & 116399 & 16.6 & 22384 \\
\hline TC15012 & C 2-6' & ${ }^{\circ} \mathrm{P}$ & 1575 & 34.1 & $8 \mathrm{E}, \mathrm{W}$ & 37.5 & 58 & 134 & 1485 & 2.80 & 106253 & 15.1 & 20433 \\
\hline TC15013 & C 2-8' & ${ }^{\circ} \mathrm{F}$ & 1639 & 41.9 & & Overall & 55 & 137 & 1555 & 20.14 & 821692 & 18.6 & 26336 \\
\hline TC15022 & C. $3-11^{\prime}$ & ${ }^{\circ} \mathrm{F}$ & 1593 & 35.9 & & & \multicolumn{3}{|c|}{ From Data Sheets=> } & 20.76 & & & \\
\hline TC15023 & C 3-14' & ${ }^{\circ} \mathbf{p}$ & 1577 & 30.5 & & & & & & & & & \\
\hline $\mathrm{TC} 15024$ & C 3-14' & $\bullet \mathbf{F}$ & 1577 & 29.0 & EHX- & & \multirow{3}{*}{$\begin{array}{c}\text { Temp In } \\
{ }^{\circ} \mathrm{F} \\
\end{array}$} & & & & & & \\
\hline TC15025 & C $3-14^{\prime}$ & ${ }^{\circ} \mathbf{F}$ & 1594 & 32.7 & Coils & No. of & & Temp Out & Bed Temp & Flow & 0 & u & Heat Flux \\
\hline $\mathrm{TC} 15032$ & $C+17.5^{\prime}$ & ${ }^{\circ} \mathbf{F}$ & 1541 & 24.5 & Used & Coils & & ${ }^{\circ} \mathrm{F}$ & ${ }^{\circ} \mathrm{F}$ & gpm & Btu/hr & $\mathrm{Btu} / \mathrm{ft}{ }^{2} \mathrm{hr}^{0} \mathrm{~F}$ & $\mathrm{Btu} / \mathrm{ft}^{2} \mathrm{hr}$ \\
\hline $\mathrm{TC} 15042$ & C 5-22.5' & ${ }^{\circ} \mathbf{F}$ & 1556 & 24.2 & $1-4,8,9$ & 6 & 56 & 130 & 1248 & 10.59 & 393309 & 78.2 & 87402 \\
\hline $\mathrm{TC} 15052$ & C 6-27.5' & ${ }^{\circ} \mathrm{F}$ & 1547 & 23.1 & & & \multicolumn{3}{|c|}{ From Data Sheets $=>$} & 11.13 & & & \\
\hline $\mathrm{TC} 15053$ & C 6-27.5' & ${ }^{\circ} \mathrm{F}$ & 1551 & 24.5 & & & & & & & & & \\
\hline $\mathrm{TC} 15054$ & C 6-27.5 & ${ }^{\circ} \mathbf{F}$ & 1487 & 20.4 & \multicolumn{2}{|c|}{ EMISSIONS DATA } & & & & & & & \\
\hline TC15062 & C 7-32.5' & ${ }^{\circ} \mathbf{F}$ & 1478 & 18.9 & & & & & & & & & \\
\hline TC15071 & C 8-37.5' & ${ }^{\circ} \mathbf{F}$ & 1485 & 18.8 & \multicolumn{4}{|c|}{ As Measured- } & \multicolumn{4}{|c|}{- Corrected to $3 \% 02$} & \\
\hline $\mathrm{TC} 15073$ & C $9-41^{\prime}$ & ${ }^{\circ} \mathbf{F}$ & 1556 & 23.2 & Tag & Units & Average & Std Dev & Tag & Units & Average & Std Dev & \\
\hline TC15999 & Ambient & ${ }^{\circ} \mathbf{F}$ & 77 & 2.0 & SO2-A & ppm & 398 & 183.9 & SO2-A & ppm & 526 & $\overline{230.1}$ & \\
\hline TC16001 & EHX Plenm & ${ }^{\circ} \mathbf{F}$ & 122 & 5.6 & SO2-AE & $\mathrm{Ib} / \mathrm{MM}$ Btu & 0.83 & 0.3 & & & & & \\
\hline TC16012 & EHX 0.5 & ${ }^{\mathrm{a}} \mathbf{F}$ & 1265 & 28.4 & $\mathrm{SO} 2-\mathrm{B}$ & ppm & 354 & 137.8 & $\mathrm{SO} 2-\mathrm{B}$ & ppm & 495 & 182.4 & \\
\hline TC16013 & EHX 1.5' & ${ }^{\circ} \mathbf{F}$ & 1231 & 27.0 & $\mathrm{SO} 2-\mathrm{BE}$ & $\mathrm{Ib} / \mathrm{MM}$ Btu & 0.75 & 0.3 & & & & & \\
\hline TC16014 & EHX 2.7 & $\bullet \mathbf{F}$ & 1249 & 26.8 & co & ppm & 37 & 26.6 & co & ppm & 49 & 36.1 & \\
\hline TC16015 & EHX 3.8' & ${ }^{\circ} \mathbf{F}$ & 1210 & 15.8 & $\mathrm{CO} 2$ & $\%$ & 12.80 & 1.0 & $\mathrm{CO} 2$ & $\%$ & 16.95 & 0.8 & \\
\hline TC16017 & EHX 5.3' & ${ }^{\circ} \mathrm{F}$ & 1125 & 12.2 & $\mathrm{~N} 2 \mathrm{O}$ & ppm & 114 & 15.6 & $\mathrm{~N} 2 \mathrm{O}$ & ppm & 153 & 27.2 & \\
\hline $\mathrm{TC} 16018$ & EHX Exit & ${ }^{\circ} \mathrm{F}$ & 1173 & 18.0 & $\mathrm{~N} 2 \mathrm{OE}$ & $\mathrm{Ib} / \mathrm{MM}$ Biu & 0.17 & 0.0 & & & & & \\
\hline $\mathrm{TC} 16021$ & $\operatorname{CrcA} \mathrm{A}$ in & ${ }^{\circ} \mathbf{F}$ & 1536 & 20.5 & NOx & ppm & 172 & 15.6 & NOx & ppm & 228 & 20.9 & \\
\hline TC16031 & DC \&-36 & ${ }^{\circ} \mathbf{F}$ & 1590 & 17.1 & NOXE & $\mathrm{Ib} / \mathrm{MM} \mathrm{Btu}$ & 0.26 & 0.0 & & & & & \\
\hline TC16032 & DC 6-28' & ${ }^{\circ} \mathbf{F}$ & 1566 & 16.1 & O2-A & $\%$ & 7.40 & 0.9 & & & & & \\
\hline TC16033 & $D C 4-18^{\prime}$ & ${ }^{\circ} \mathbf{F}$ & 1544 & 19.2 & O2-B & $\%$ & 8.17 & 0.9 & & & & & \\
\hline TC16034 & DC3-9.5 & $\cdot \mathbf{F}$ & 1562 & 23.6 & & & & & & & & & \\
\hline TC16035 & DC3-8.5' & ${ }^{\circ} \mathrm{F}$ & 1547 & 25.7 & Tag & Desc & Units & Average & Std Dev & Tag & Desc & Average & Std Dev \\
\hline & & & & & $W(C)$ & Coal Fd Rt & $\mathrm{lbs} / \mathrm{hr}$ & 171.1 & 20.1 & TC13131 & AFPE-F2" & 979 & 30.3 \\
\hline$T(A, C)$ & Comb Temp & ${ }^{\circ} \mathrm{F}$ & 1555 & 28.5 & $W(S)$ & LS Fd Rt & lbs/he & 45.6 & 7.3 & TC13132 & APPE-F $6^{n}$ & 1092 & 23.4 \\
\hline$T(A, E H X)$ & EHX Temp & ${ }^{\circ} \mathrm{F}$ & 1248 & 27.3 & $V(F G)$ & FG SGV & $\mathrm{ft} / \mathrm{sec}$ & 18.4 & 0.7 & TC13133 & AFPE-B6" & 801 & 23.0 \\
\hline EA & Excess Air & $\%$ & 54.8 & 10.3 & $v(S, C)$ & Comb SGV & $\mathrm{ft} / \mathrm{sec}$ & 17.3 & 0.7 & TC13134 & AFPE-F10" & 946 & 44.9 \\
\hline $\mathrm{SR}$ & S Reten & $\%$ & 76.3 & 10.0 & $V(S, E H X)$ & EHX SGV & $\mathrm{fl} / \mathrm{sec}$ & 1.8 & 0.3 & TC13231 & AFPW-F2" & 962 & 25.5 \\
\hline$R(P C A)$ & \%Flw PCA & $\%$ & 50.0 & 2.7 & FT18003 & CHX Flow & gpm & 20.1 & 0.1 & TC13232 & $A F P W-F 6^{n}$ & 1078 & 23.2 \\
\hline$R(S C A)$ & \%FIw SCA & $\%$ & 50.0 & 2.7 & FT19003 & EHX Flow & $\mathrm{gpm}$ & 10.6 & 0.1 & TC13233 & AFPW-B6" & 776 & 21.3 \\
\hline$R(Q, I N)$ & \% Enrg in & $\%$ & 78.7 & 8.5 & PT15081 & Comb dP & in. $\mathrm{H} 2 \mathrm{O}$ & 38.5 & 4.4 & TC13234 & AFPW-F10 & 1030 & 26.7 \\
\hline $\mathbf{R}(\mathrm{CHX})$ & CHX Ratio & $\%$ & 63.7 & 3.2 & $Q(C A)$ & CA Heat in & $\mathrm{KB} t \mathrm{u} / \mathrm{hr}$ & 123.9 & 5.6 & DOORS & $\mathrm{CHXs}$ On & 12 & 0 \\
\hline$R(E H X)$ & EHX Ratio & $\%$ & 36.3 & 3.2 & $Q(\mathrm{CHX})$ & CHX HIRmv & $\mathrm{KBt} t \mathrm{hr}$ & 690.6 & 41.2 & COILS & EHXs On & 6 & 0 \\
\hline$F(P C A)$ & PCA FIw & SCFM & 239.0 & 26.7 & Q(EHX) & EHX HIRmv & KBtw/hr & 394.8 & 38.8 & ВH AVC & & 2.2 & 0.2 \\
\hline $\mathrm{F}(\mathrm{EHX})$ & EHX Flw & SCFM & 52.1 & 7.9 & $Q(E H X, I N$ & FG Enrg in & $\mathrm{KBt} t \mathrm{hr}$ & 2.3 & 0.5 & A/SRATIO & & 3.7 & 0.7 \\
\hline$F(T P A)$ & TPCA Flw & SCFM & 292.1 & 23.9 & $Q(F)$ & Fuel Enrg in & KBtw/hr & 2282.4 & 267.4 & Feed Air & $\operatorname{sefm}$ & 16.1 & \\
\hline $\mathrm{F}(\mathrm{SCA})$ & SCA FIw & SCFM & 256.5 & 15.7 & $Q(F G)$ & FG Enrg out & $\mathrm{KBt} / \mathrm{hr}$ & 294.7 & 6.7 & DC Air & scfm & 22.0 & \\
\hline $\mathrm{F}(\mathrm{TCA}, \mathrm{F})$ & TCA Flw & SCFM & 583.9 & 25.3 & $Q(I N)$ & Tot Enrg in & $\mathrm{KBt} t \mathrm{hr}$ & 2408.6 & 267.4 & Purge Air & sefm & 15.5 & \\
\hline $\mathrm{F}(\mathrm{FG}, \mathrm{BH})$ & BH Flw & SCFM & 599.4 & 13.4 & Q(OUT) & Tot Enrg out & KBtw/hr & 1873.7 & 62.4 & & & & \\
\hline$F(T F G)$ & TFG FIw & SCFM & 599.4 & 13.4 & $W(S R)$ & Recirc Rt & $\mathrm{lbs} / \mathrm{hr}$ & 4359 & 354.7 & & & & \\
\hline
\end{tabular}




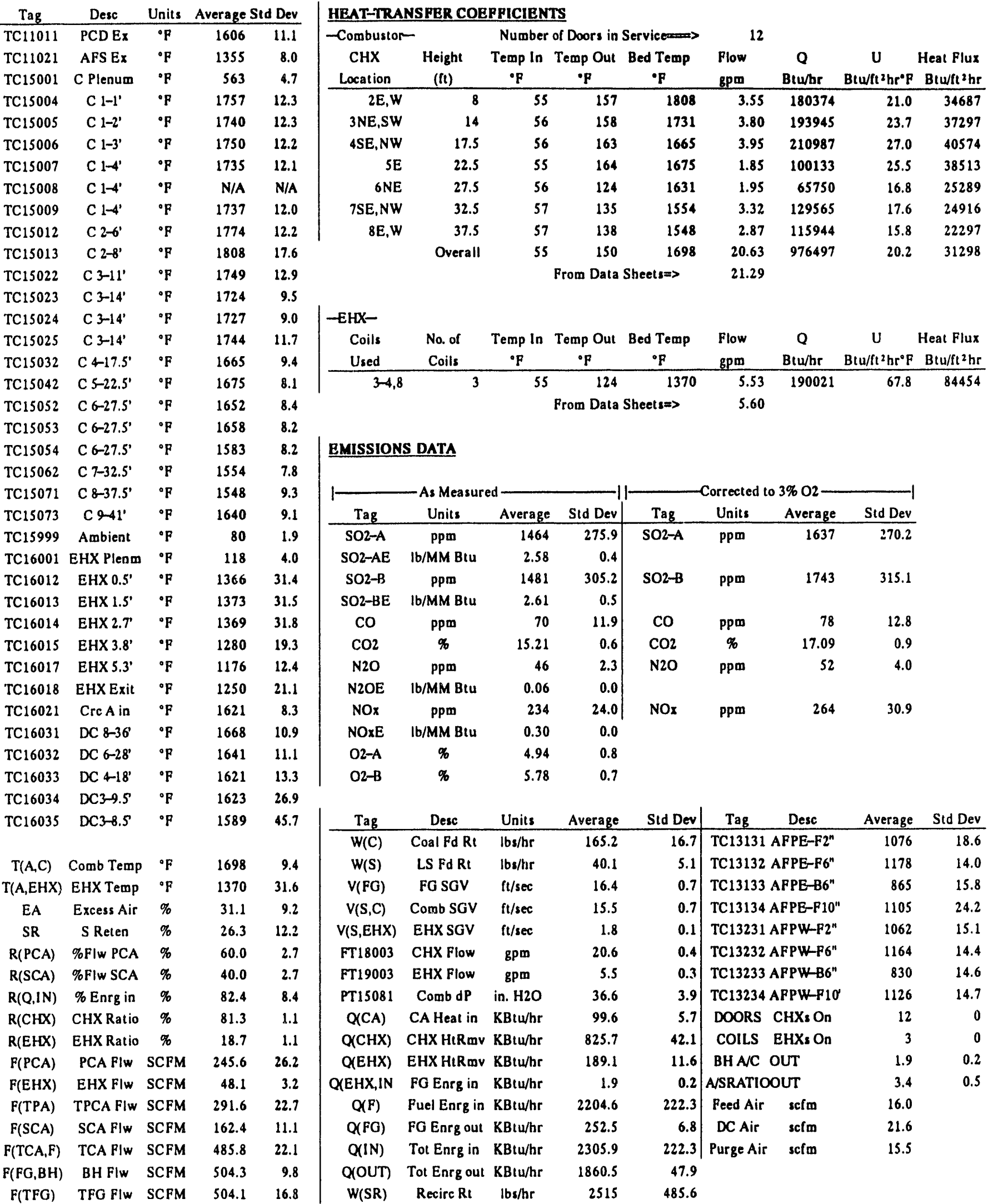




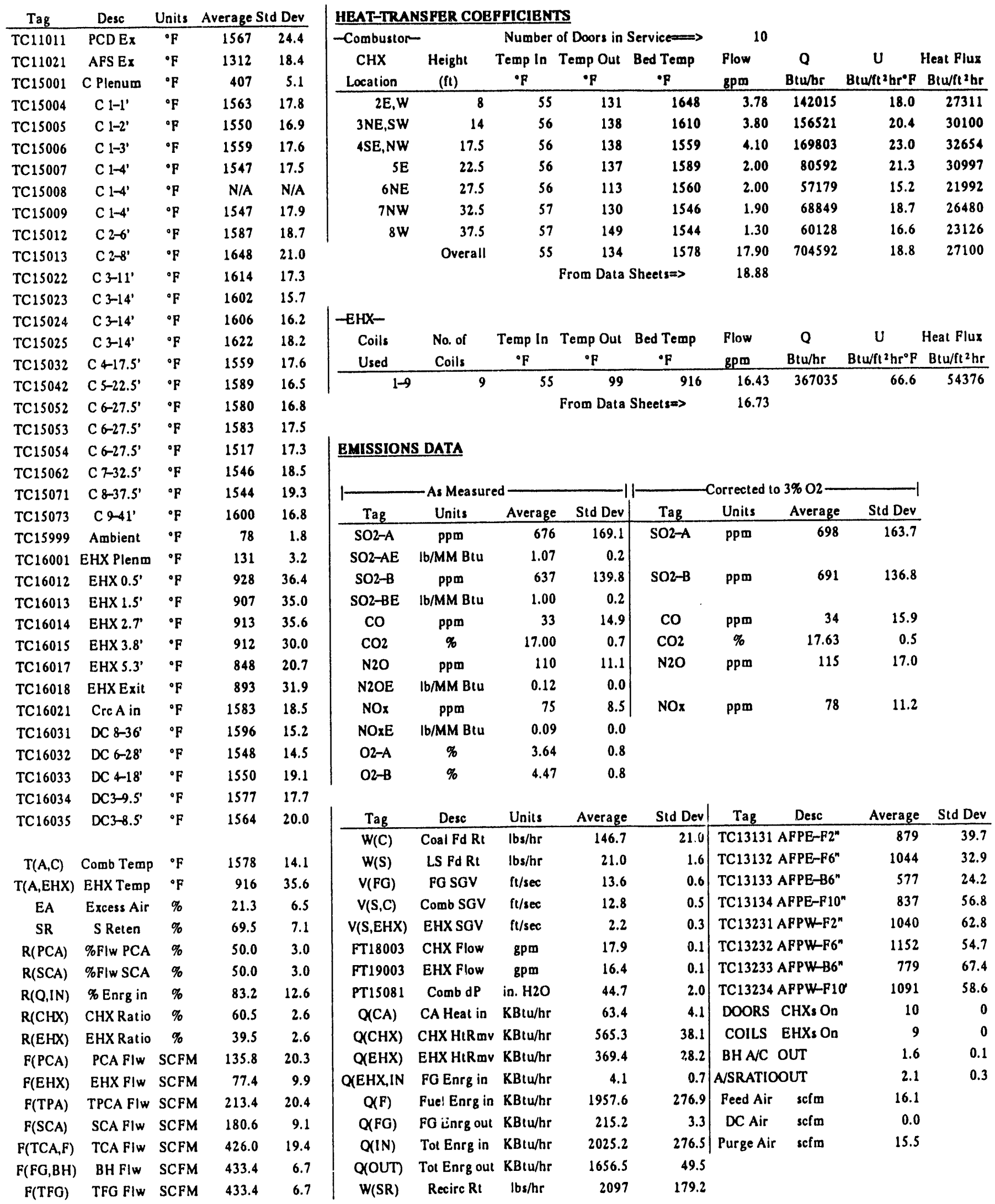




\begin{tabular}{|c|c|c|c|c|c|c|c|c|c|c|c|c|c|}
\hline \multirow{3}{*}{$\frac{\mathrm{Tag}}{\mathrm{TC} 11011}$} & \multirow{2}{*}{$\frac{\text { Desc }}{\text { PCD Ex }}$} & \multirow{2}{*}{$\frac{\text { Units }}{{ }^{\circ} p}$} & \multicolumn{2}{|c|}{ Average Std Dev } & \multicolumn{9}{|c|}{ HEAT-TRANSPER COEPPICIENTS } \\
\hline & & & 1438 & 15.2 & \multicolumn{2}{|c|}{-Combustor- } & \multicolumn{3}{|c|}{ Number of Doors in Servicem } & \multicolumn{2}{|l|}{10} & & \multirow{3}{*}{$\begin{array}{l}\text { Heat Plux } \\
\text { Btw/tt }{ }^{2} \mathrm{hr}\end{array}$} \\
\hline & AFS Ex & ${ }^{\circ} \mathrm{F}$ & 1201 & 12.3 & $\mathrm{CHX}$ & Height & Temp ln & Temp Out & Bed Temp & Plow & $\mathbf{Q}$ & $\mathbf{u}$ & \\
\hline TC15001 & C Plenum & ${ }^{\circ} \mathbf{F}$ & 412 & 6.6 & Location & (ft) & & $\bullet p$ & $\bullet \mathbf{p}$ & $\mathrm{gpm}$ & Btwhr & Btu/ht ${ }^{2} \mathrm{hr} \cdot \mathrm{P}$ & \\
\hline TC15004 & C $1-1$ & ${ }^{\circ} \mathbf{p}$ & 1584 & 35.8 & $2 E, W$ & 8 & 55 & 130 & 1623 & 3.80 & 143197 & 18.4 & 27538 \\
\hline TC1500S & C $1-2$ & ${ }^{\circ} \mathrm{F}$ & 1573 & 33.9 & 3NE,SW & 14 & 56 & 133 & 1559 & 3.80 & 147001 & 19.8 & 28270 \\
\hline TC15006 & $C 1-31$ & $\bullet \mathbf{p}$ & 1581 & 34.6 & 4SE,NW & 17.5 & 55 & 130 & 1494 & 4.30 & 159593 & 22.5 & 30691 \\
\hline TC15007 & C 1-4' & $\cdot \mathbf{p}$ & 1572 & 33.6 & SE & 22.5 & 56 & 126 & 1506 & 2.00 & 69784 & 19.4 & 26840 \\
\hline TC15008 & C 1-4' & ${ }^{\circ} \mathbf{F}$ & N/A & N/A & 6NE & 27.5 & 55 & 103 & 1465 & 2.00 & 47466 & 13.4 & 18256 \\
\hline TC15009 & C $1-4^{\prime}$ & $\cdot p$ & 1570 & 34.0 & $7 \mathrm{NW}$ & 32.5 & 57 & 115 & 1431 & 2.00 & 57809 & 16.9 & 22234 \\
\hline TC15012 & C 2-6' & ${ }^{\circ} \mathbf{p}$ & 1603 & 36.9 & $8 W$ & 37.5 & 57 & 133 & 1426 & 1.40 & 52987 & 15.8 & 20380 \\
\hline TC15013 & C 2-8' & ${ }^{\circ} \mathbf{F}$ & 1623 & 37.8 & & Overall & 55 & 126 & 1535 & 18.54 & 655383 & 17.9 & 25207 \\
\hline TC15022 & C 3-11' & ${ }^{\circ} \mathrm{F}$ & 1577 & 32.6 & & & \multicolumn{3}{|c|}{ From Data Sheets $=>$} & 19.30 & & & \\
\hline TC15023 & C 3-14' & ${ }^{\circ} \mathbf{F}$ & 1553 & 30.4 & & & & & & & & & \\
\hline TC15024 & C 3-14' & ${ }^{\circ} \mathrm{F}$ & 1555 & 31.7 & EHX- & & & & & & & & \\
\hline TC15025 & C 3-14' & ${ }^{\circ} \mathrm{F}$ & 1569 & 32.0 & Coils & No. of & Temp In & Temp Out & Bed Temp & Flow & $\mathbf{Q}$ & $\mathrm{U}$ & Heat Flux \\
\hline $\mathrm{TC} 15032$ & $C 4-17.5^{\prime}$ & ${ }^{\circ} \mathbf{F}$ & 1494 & 28.8 & Used & Coils & $\bullet^{\circ} \mathbf{F}$ & ${ }^{\circ} \mathbf{F}$ & ${ }^{\circ} \mathbf{F}$ & $\mathrm{gpm}$ & Btu/hr & Btu/ft ${ }^{2} \mathrm{hr}^{\circ} \mathrm{F}$ & $\mathrm{Btu} / \mathrm{ft}{ }^{2} \mathrm{hr}$ \\
\hline $\mathrm{TC} 15042$ & C S $-22.5^{\prime}$ & ${ }^{\circ} \mathrm{p}$ & 1506 & 24.9 & \multirow{2}{*}{\multicolumn{5}{|c|}{$55 \underset{ }{114} \quad 1037$}} & 5.51 & 161726 & 77.8 & 71878 \\
\hline TC15052 & C 6-27.5' & ${ }^{\circ} \mathbf{p}$ & 1485 & 22.5 & & & & & & 5.72 & & & \\
\hline TC15053 & C 6-27.5' & ${ }^{\circ} \mathbf{P}$ & 1490 & 24.0 & & & & & & & & & \\
\hline TC15054 & C 6-27.5' & ${ }^{\circ} \mathbf{p}$ & 1419 & 21.0 & \multicolumn{2}{|c|}{ EMISSIONS DATA } & & & & & & & \\
\hline TC15062 & C 7-32.5' & ${ }^{\circ} \mathbf{F}$ & 1431 & 20.8 & & & & & & & & & \\
\hline TC15071 & C \&-37.5' & ${ }^{\circ} \mathbf{F}$ & 1426 & 21.8 & \multicolumn{4}{|c|}{ W As Measured - } & \multicolumn{4}{|c|}{ Corrected to $3 \% 02$} & \\
\hline TC15073 & C $9-41^{\prime}$ & ${ }^{\circ} \mathbf{F}$ & 1481 & 20.5 & Tag & Units & Average & Std Dev & Tag & Units & Average & Std Dev & \\
\hline TC15999 & Ambient & ${ }^{\circ} \mathrm{F}$ & 70 & 2.7 & $\mathrm{SO} 2-\mathrm{A}$ & $\mathrm{ppm}$ & 336 & 91.1 & SO2-A & ppm & 436 & 102.7 & \\
\hline TC16001 & EHX Plenm & ${ }^{\circ} \mathbf{P}$ & 117 & 4.8 & $\mathrm{SO} 2-\mathrm{AE}$ & $\mathrm{lb} / \mathrm{MM} \mathrm{Blu}$ & 0.68 & 0.2 & & & & & \\
\hline $\mathrm{TC} 16012$ & EHX $0.5^{\prime}$ & ${ }^{\circ} \mathrm{F}$ & 1050 & 35.6 & $\mathrm{SO} 2-\mathrm{B}$ & ppm & 331 & 94.8 & $\mathrm{SO} 2-\mathrm{B}$ & ppm & 437 & 109.2 & \\
\hline TC16013 & EHX 1.5' & ${ }^{\circ} \mathrm{F}$ & 1030 & 35.2 & $\mathrm{SO} 2-\mathrm{BE}$ & $\mathrm{tb} / \mathrm{MM} \mathrm{Btu}$ & 0.67 & 0.2 & & & & & \\
\hline TC16014 & EHX 2.7' & ${ }^{\circ} \mathbf{F}$ & 1033 & 38.4 & $\mathrm{Co}$ & ppm & 81 & 22.9 & $\mathrm{CO}$ & ppm & 106 & 31.6 & \\
\hline TC16015 & EHX 3.8' & ${ }^{\circ} \mathbf{F}$ & 1000 & 39.7 & $\mathrm{CO} 2$ & $\%$ & 13.21 & 1.2 & $\mathrm{CO} 2$ & $\%$ & 17.23 & 1.1 & \\
\hline TC16017 & EHX 5.3' & ${ }^{\circ} \mathbf{F}$ & 892 & 38.6 & $\mathrm{~N} 2 \mathrm{O}$ & ppm & 127 & 15.8 & $\mathrm{~N} 2 \mathrm{O}$ & ppm & 167 & 26.4 & \\
\hline TC16018 & EHX Exit & ${ }^{\circ} \mathrm{F}$ & 995 & 40.5 & N2OE & $\mathrm{lb} / \mathrm{MM} \mathrm{Btu}$ & 0.18 & 0.0 & & & & & \\
\hline $\mathrm{TC} 16021$ & $\operatorname{Crc} A$ in & ${ }^{\circ} \mathrm{F}$ & 1465 & 18.5 & NOx & ppm & 132 & 20.9 & NOx & ppm & 174 & 32.6 & \\
\hline TC16031 & DC \&-36 & ${ }^{\circ} \mathrm{F}$ & 1496 & 11.9 & NOxE & $\mathrm{Ib} / \mathrm{MM}$ Btu & 0.20 & 0.0 & & & & & \\
\hline TC16032 & DC 6-28' & ${ }^{\circ} \mathbf{F}$ & 1456 & 10.9 & O2-A & $\%$ & 7.19 & 1.1 & & & & & \\
\hline $\mathrm{TC} 16033$ & DC 4-18' & ${ }^{\circ} \mathbf{F}$ & 1436 & 12.9 & O2-B & $\%$ & 7.46 & 0.8 & & & & & \\
\hline TC16034 & $D C 3-9.5$ & ${ }^{\circ} \mathbf{p}$ & 1464 & 12.3 & & & & & & & & & \\
\hline \multirow[t]{2}{*}{ TC16035 } & DC3-8.5 & ${ }^{\circ p}$ & 1452 & 12.9 & $\mathrm{Tag}$ & Desc & Units & Average & Std Dev & $\mathrm{Tag}$ & Desc & Average & Std Dev \\
\hline & & & & & $w(C)$ & Coal Fd Rt & $\mathrm{lbs} / \mathrm{hr}$ & 133.4 & 16.7 & TC13131 & AFPE-F2" & 712 & 35.1 \\
\hline$T(A, C)$ & Comb Temp & ${ }^{\circ} \mathbf{F}$ & 1535 & 28.5 & $\mathbf{W}(\mathbf{S})$ & LS Fd Rt & $\mathrm{lbs} / \mathrm{hr}$ & 9.6 & 0.9 & TC13132 & AFPE-F $6^{n}$ & 896 & 25.2 \\
\hline$T(A, E H X)$ & EHX Temp & ${ }^{\circ} \mathbf{F}$ & 1037 & 36.2 & $V(\mathbf{F G})$ & FG SGV & $\mathrm{ft} / \mathrm{sec}$ & 13.6 & 0.7 & TC13133 & APPE-B6" & 500 & 40.1 \\
\hline EA & Excess Air & $\%$ & 53.0 & 12.4 & $V(S, C)$ & Comb SGV & $\mathrm{ft} / \mathrm{sec}$ & 12.7 & 0.7 & TC13134 & AFPE-F10" & 648 & 65.4 \\
\hline SR & S Reten & $\%$ & 80.5 & 4.5 & $V(S, E H X)$ & EHXSGV & $\mathrm{ft} / \mathrm{sec}$ & 2.0 & 0.2 & TC13231 & AFPW-F2" & 736 & 32.5 \\
\hline$R(P C A)$ & $\%$ FIw PCA & $\%$ & 66.8 & 7.6 & FT18003 & CHX Flow & gpm & 18.5 & 0.2 & TC13232 & AFPW-P6" & 895 & 22.8 \\
\hline$R(S C A)$ & $\%$ F/w SCA & $\%$ & 33.2 & 7.6 & FT19003 & EHX Flow & $\mathrm{gpm}$ & 5.5 & 0.1 & TC13233 & AFPW-B6" & 515 & 32.5 \\
\hline$R(Q, I N)$ & \% Enrg in & $\%$ & 76.6 & 7.8 & PT15081 & Comb dP & in. $\mathrm{H} 2 \mathrm{O}$ & 43.8 & 1.6 & TC13234 & AFPW-F10 & 817 & 31.0 \\
\hline $\mathrm{R}(\mathrm{CHX})$ & CHX Ratio & $\%$ & 77.1 & 1.8 & $Q(C A)$ & CA Heal in & $\mathrm{KBtu} / \mathrm{hr}$ & 69.8 & 5.0 & DOORS & $\mathrm{CHX}_{s} \mathrm{On}$ & 10 & 0 \\
\hline$R(E H X)$ & EHX Ratio & $\%$ & 22.9 & 1.8 & Q(CHX) & CHX HIRmv & $\mathrm{KBt} / \mathrm{h} \mathbf{h r}$ & 549.8 & 43.2 & COILS & EHXs On & 3 & 0 \\
\hline$F(P C A)$ & PCA FIW & SCFM & 223.1 & 40.1 & Q(EHX) & EHX HIRmv & $\mathrm{KBt} / \mathrm{hr}$ & 162.5 & 11.5 & BH AVC & & 1.6 & 0.0 \\
\hline$F(E H X)$ & EHX Flw & SCFM & 65.6 & 4.6 & Q(EHX,IN & FG Enrg in & KBtu/hr & 3.1 & 0.4 & AVSRATIO & & 1.0 & 0.4 \\
\hline$F(T P A)$ & TPCA Flw & SCFM & 290.5 & 34.4 & $\alpha(F)$ & Fuel Enrg in & KBtu/hr & 1765.5 & 237.6 & Feed Air & scfm & 17.7 & \\
\hline$F(S C A)$ & SCA FIW & SCFM & 112.9 & 33.2 & $Q(F G)$ & FG Enrg out & $\mathrm{KBtu} / \mathrm{hr}$ & 205.9 & 8.2 & DC Air & $\operatorname{scfm}$ & 0.0 & \\
\hline $\mathrm{F}(\mathrm{TCA}, \mathrm{F})$ & TCA FIw & SCFM & 435.0 & 21.8 & $Q(I N)$ & Tot Enrg in & $\mathrm{KBtu} / \mathrm{hr}$ & 1850.3 & 221.3 & Purge Air & scfm & 15.5 & \\
\hline $\mathrm{F}(\mathrm{FG}, \mathrm{BH})$ & BH Flw & SCFM & 421.5 & 7.1 & QOUT) & Tot Enrg out & $K B(u / h r$ & 1394.6 & $64.7^{\prime}$ & & & & \\
\hline $\mathrm{F}(\mathrm{TFG})$ & TFG Flw & SCFM & 423.5 & 11.2 & $W(\mathbf{S R})$ & Recirc Rt & lbs/hr & 1481 & 180.0 & & & & \\
\hline
\end{tabular}




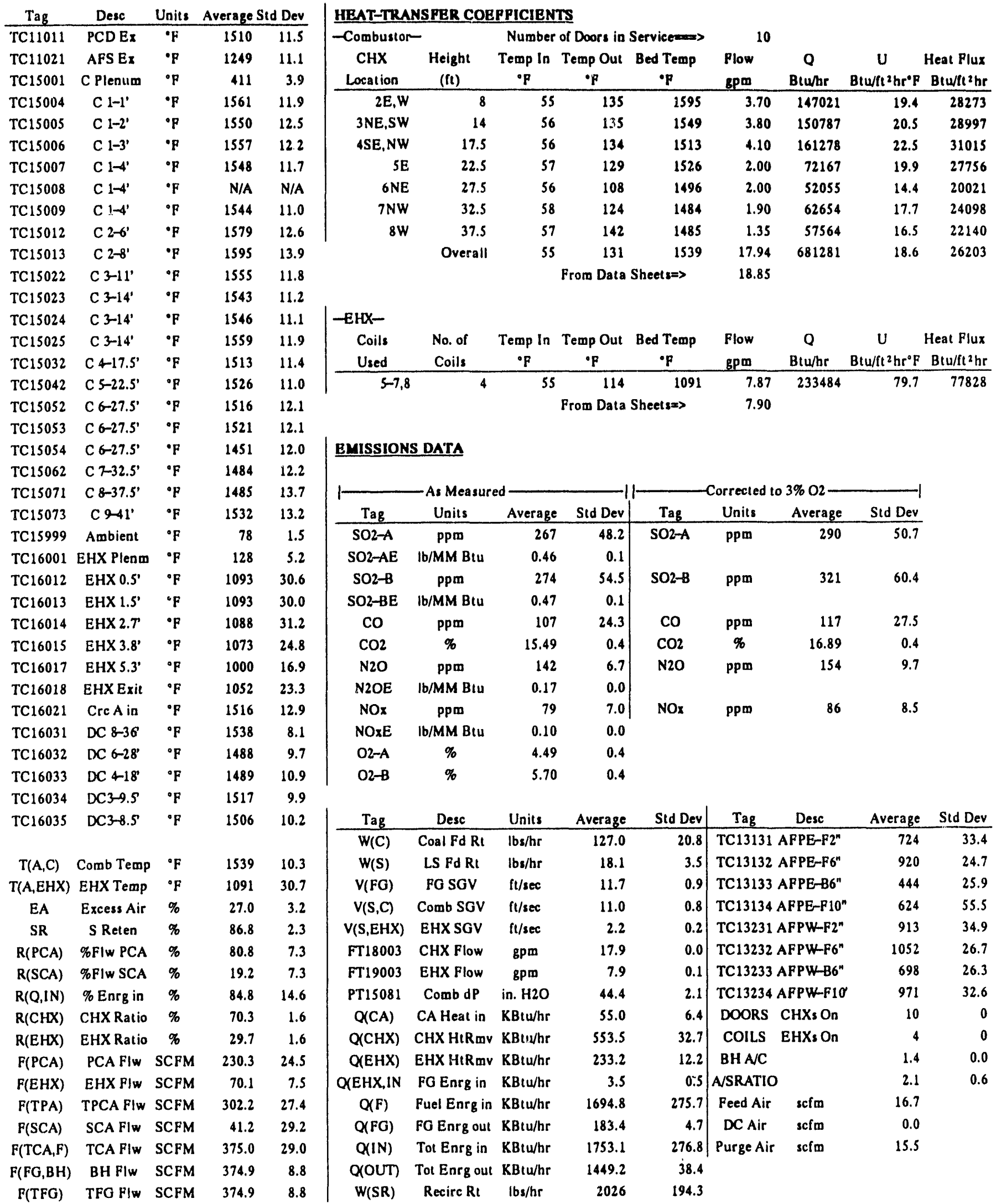




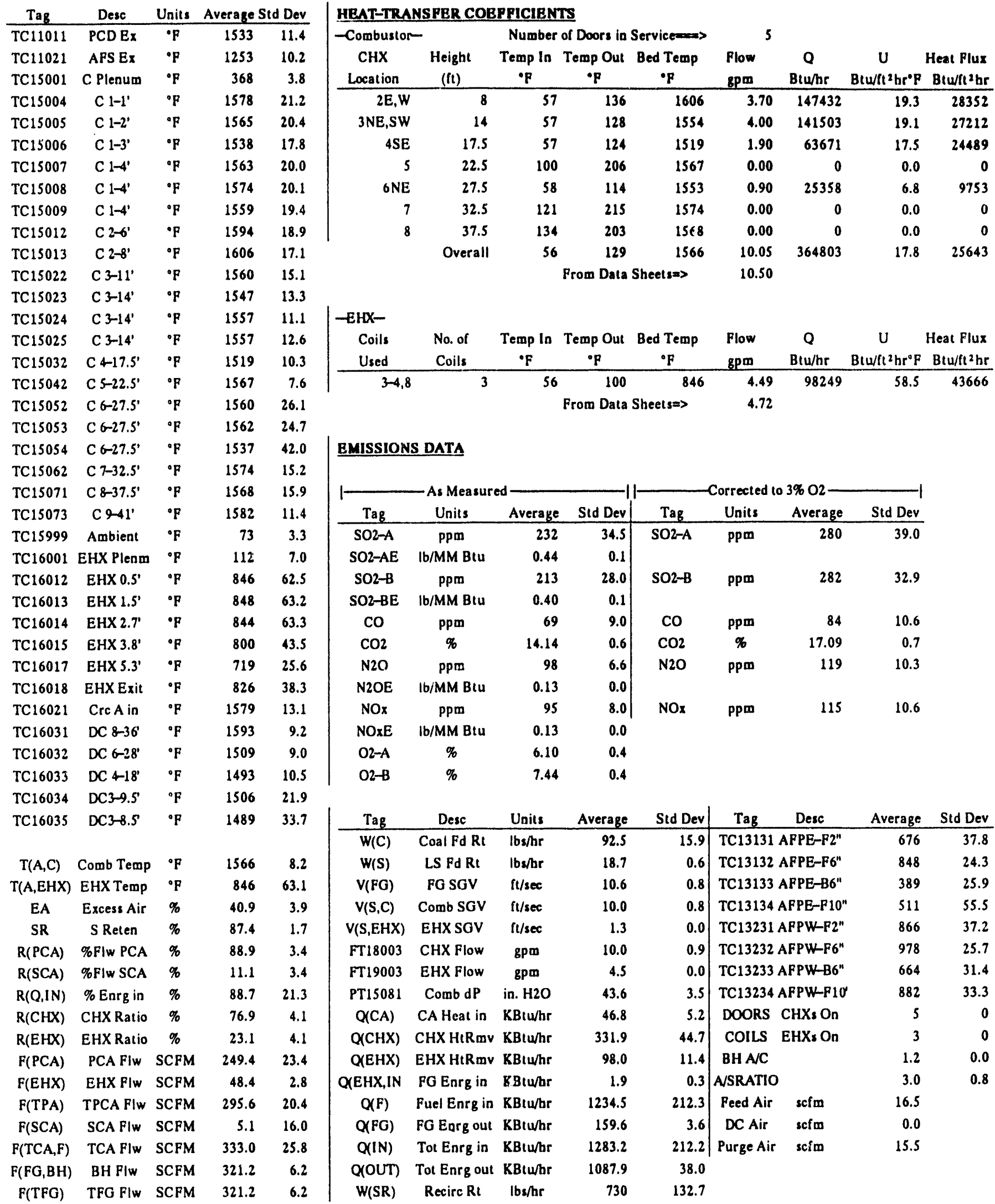




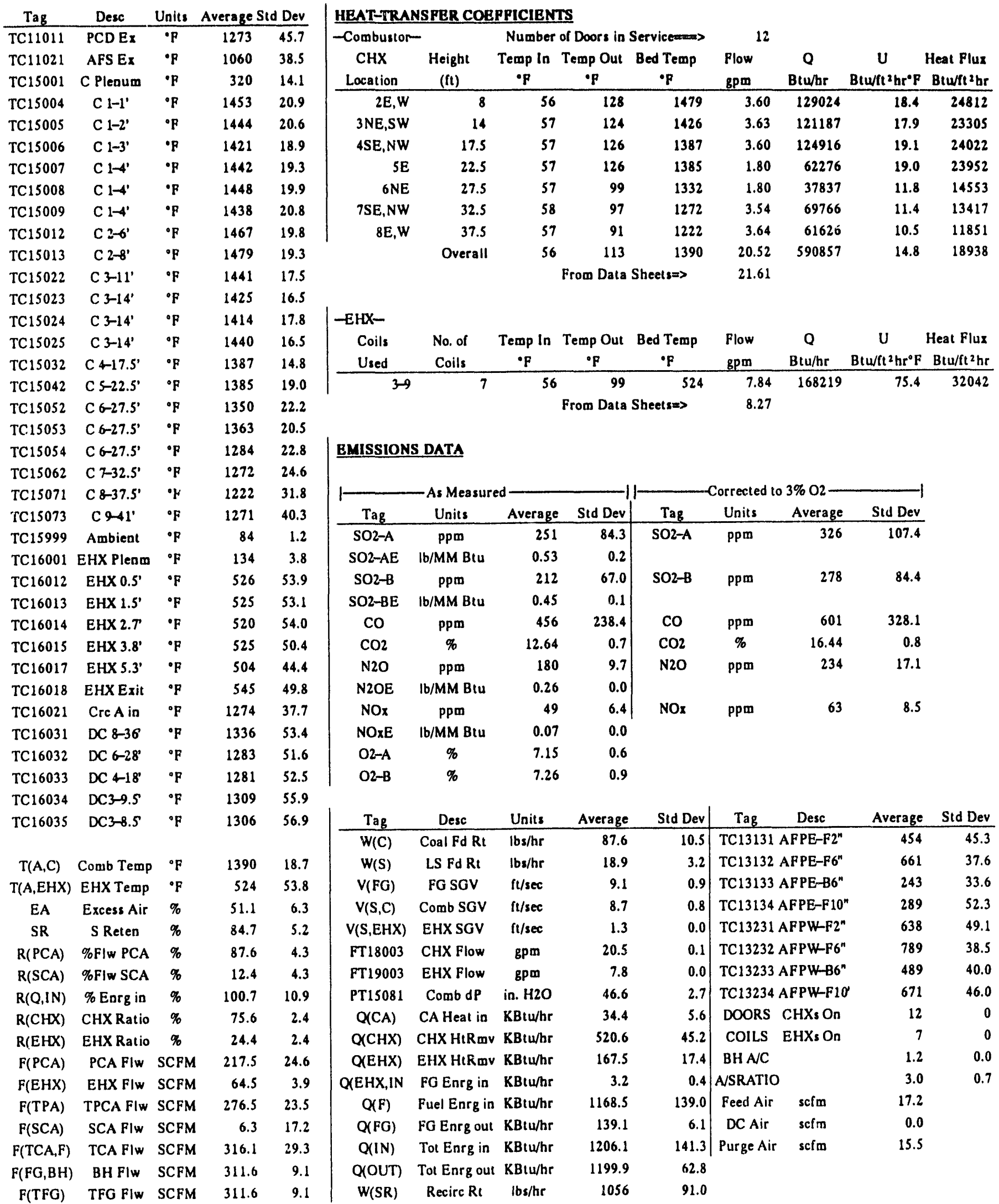




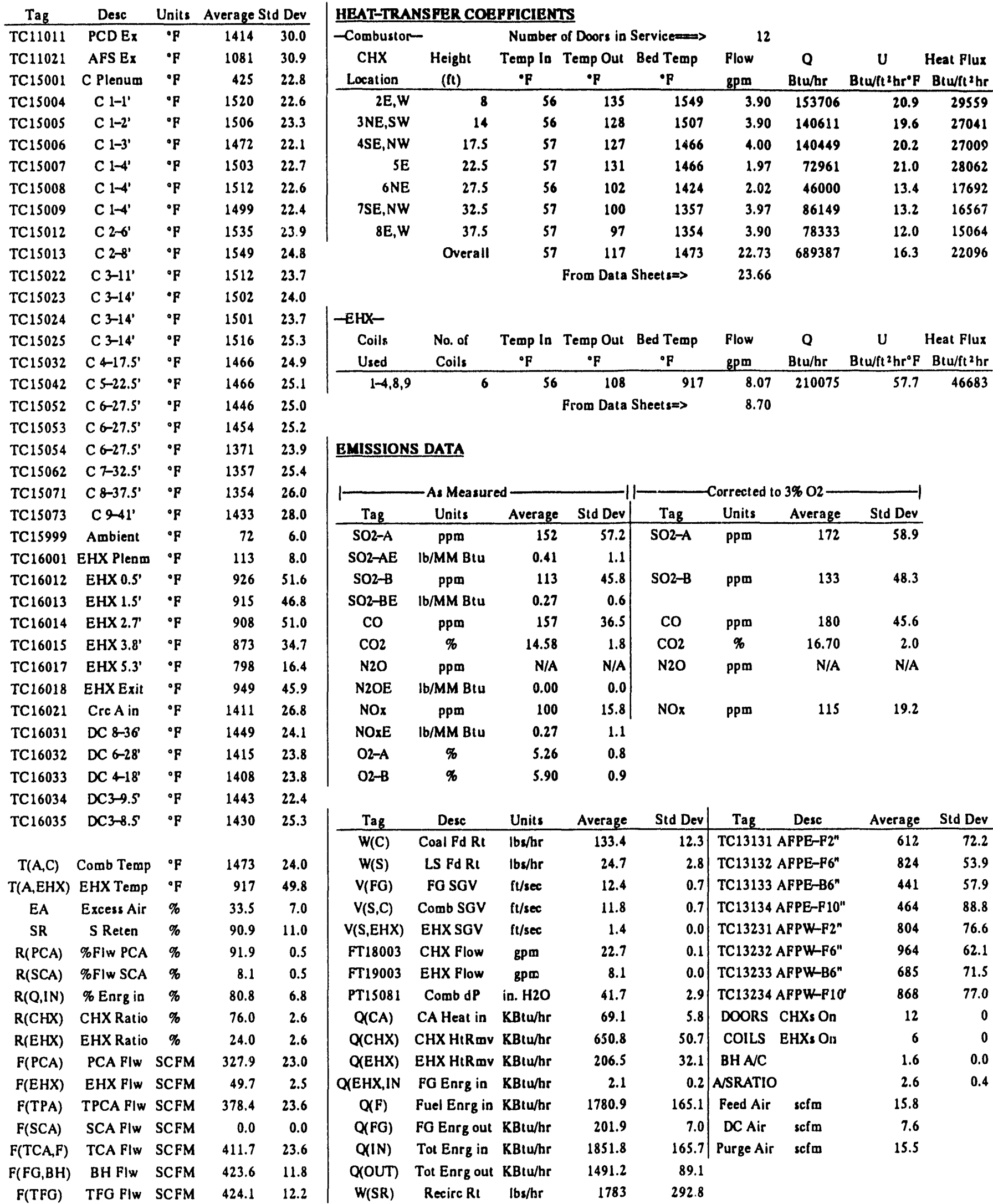




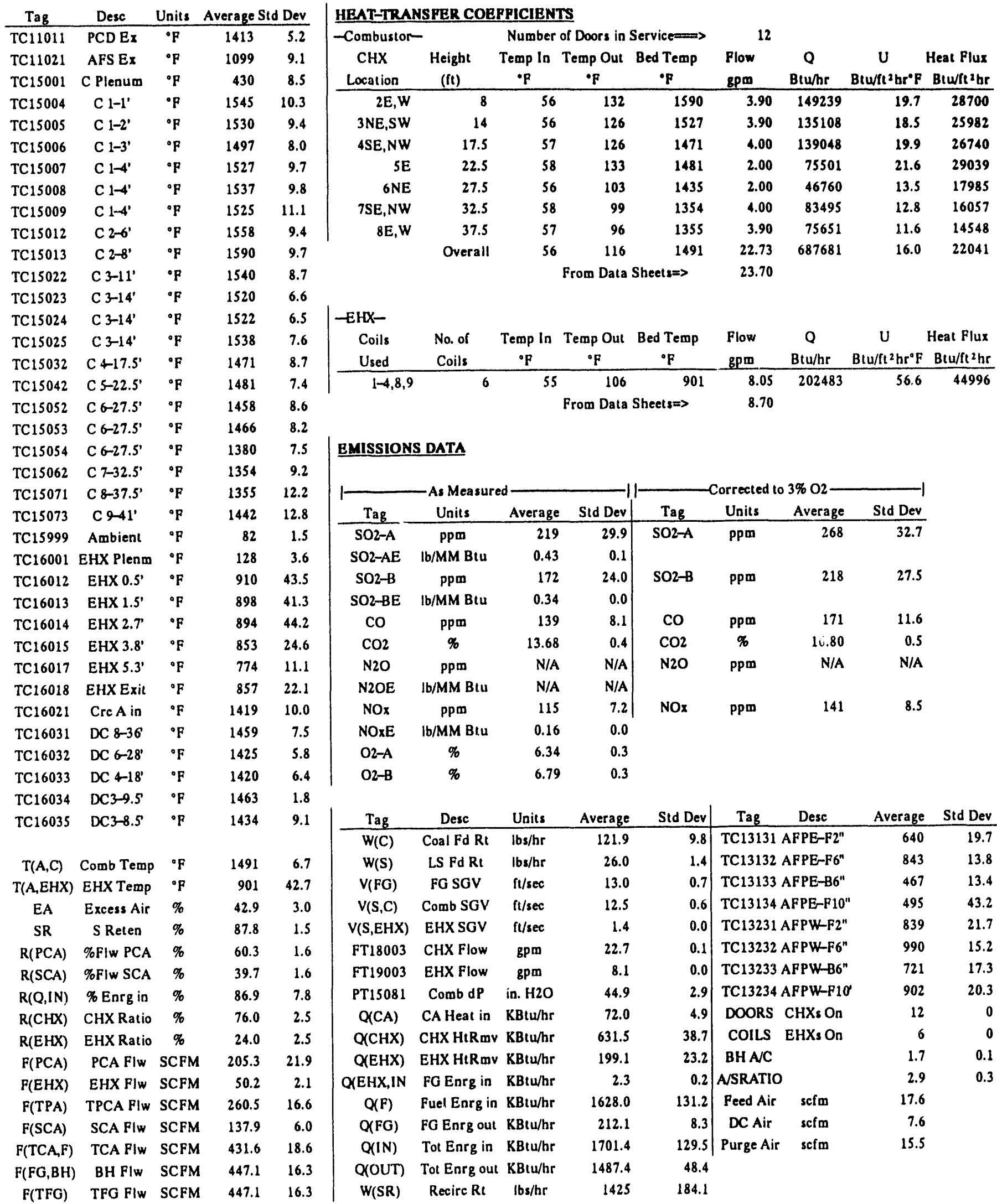




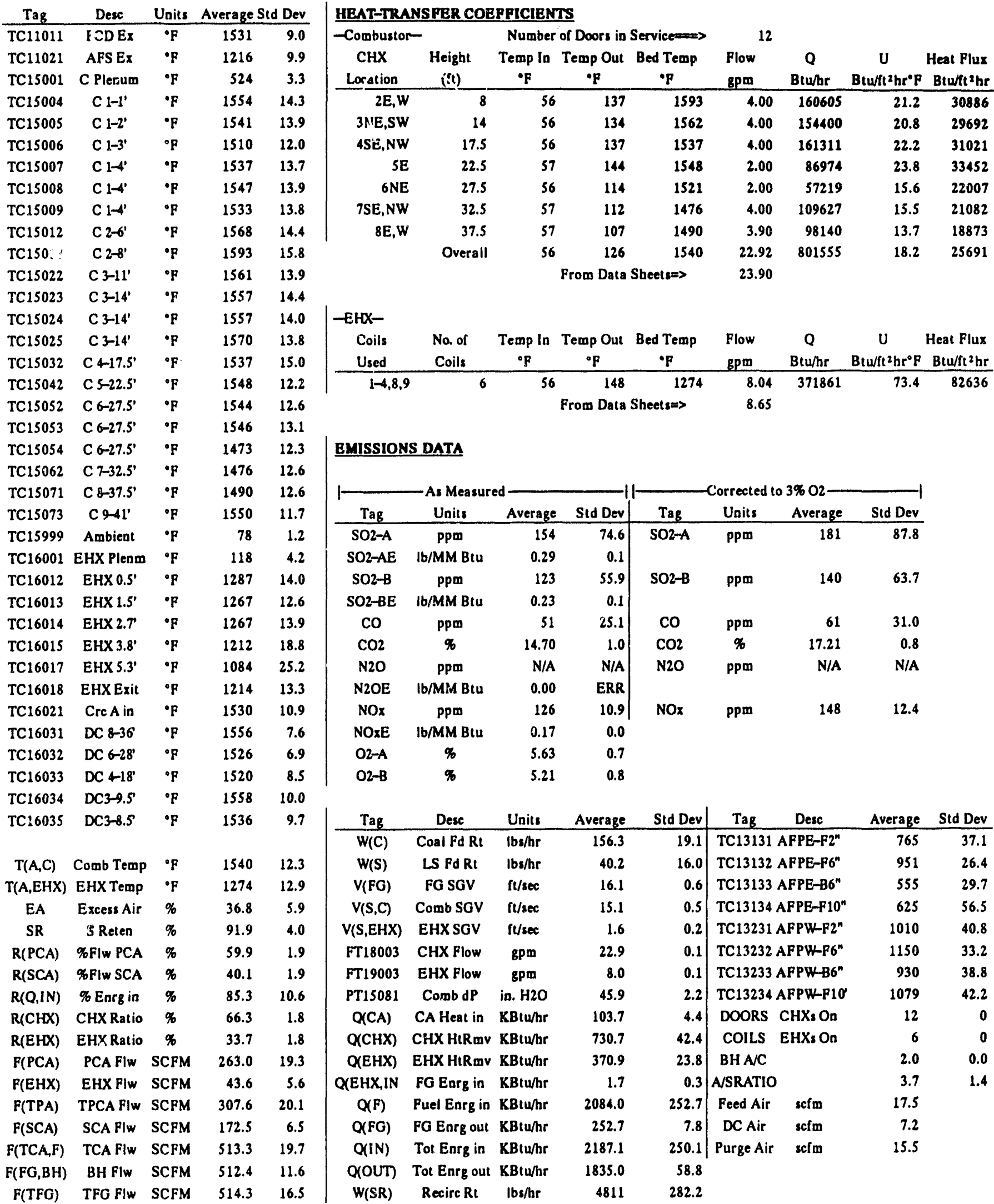




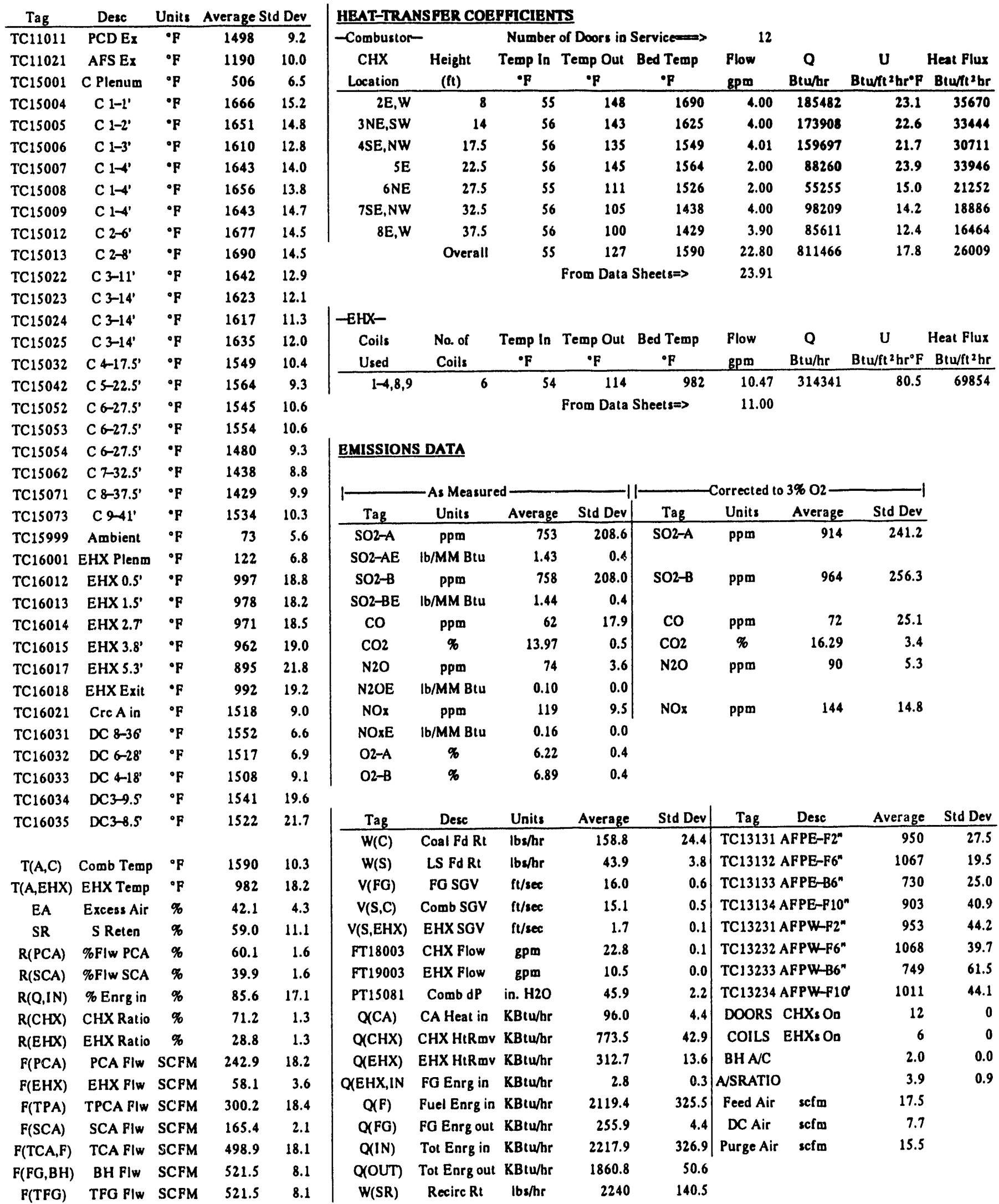




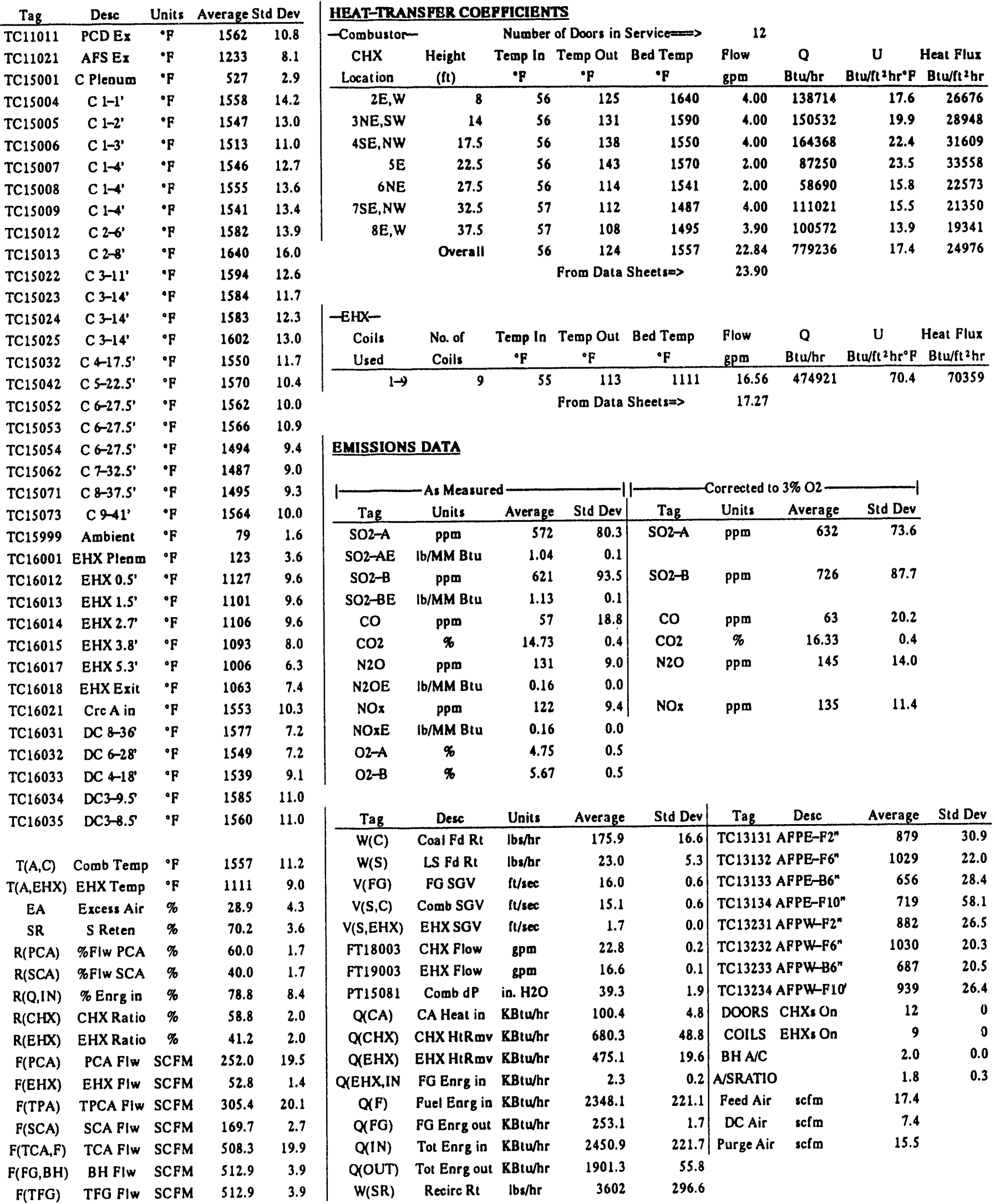




\begin{tabular}{|c|c|c|c|c|c|c|c|c|c|c|c|c|c|}
\hline \multirow{3}{*}{$\begin{array}{c}\text { Tag } \\
\text { TC11011 } \\
\text { TC11021 }\end{array}$} & \multirow{2}{*}{$\frac{\text { Desc }}{\text { PCD Ex }}$} & \multirow{2}{*}{$\frac{\text { Units }}{{ }^{\circ} \mathrm{F}}$} & \multicolumn{2}{|c|}{ Average Std Dev } & \multicolumn{9}{|c|}{ HEAT-TRANS PER COEPPICIENTS } \\
\hline & & & 1586 & 9.3 & \multicolumn{2}{|c|}{-Combustor- } & \multicolumn{3}{|c|}{ Number of Doors in Service $\Longrightarrow$} & \multicolumn{2}{|l|}{12} & \multirow{3}{*}{$\underset{\text { Btwftt }}{\mathbf{U} b r^{0} \mathrm{~F}}$} & \multirow{3}{*}{$\begin{array}{l}\text { Heat Flux } \\
\text { Bturt } t^{2} \mathrm{hr}\end{array}$} \\
\hline & AFS Ex & ${ }^{\bullet} \mathbf{F}$ & 1251 & 8.0 & $\mathrm{CHX}$ & Height & Temp in & Temp Out & Bed Temp & Flow & $\mathbf{Q}$ & & \\
\hline TC15001 & C Plenum & ${ }^{\bullet} \mathbf{F}$ & 546 & 6.0 & Location & (ft) & $\cdot \mathbf{p}$ & $\cdot p$ & $\cdot \mathbf{p}$ & $\mathrm{gpm}$ & Btw/hr & & \\
\hline TC15004 & C $1-1^{\prime}$ & ${ }^{\circ} \mathrm{F}$ & 1582 & 23.1 & $2 \mathrm{E}, \mathrm{W}$ & 8 & 55 & 124 & 1653 & 4.00 & 138550 & 17.4 & 26644 \\
\hline TC1500S & C $1-21$ & ${ }^{\circ} \mathrm{F}$ & 1567 & 22.3 & 3NE,SW & 14 & 55 & 132 & 1605 & 4.00 & 155216 & 20.3 & 29849 \\
\hline TC15006 & C $1-3$ & ${ }^{\circ} \mathrm{F}$ & 1521 & 19.0 & 4SE,NW & 17.5 & 55 & 142 & 1566 & 4.00 & 173740 & 23.5 & 33412 \\
\hline TC15007 & C 1-4' & ${ }^{\circ p}$ & 1562 & 21.7 & SE & 22.5 & 57 & 147 & 1582 & 2.00 & 90384 & 24.2 & 34763 \\
\hline TC15008 & C 1-4' & ${ }^{\circ} \mathrm{F}$ & 1576 & 20.7 & 6NE & 27.5 & 56 & 115 & 1554 & 2.00 & 59867 & 16.0 & 23026 \\
\hline TC15009 & C 1-4' & ${ }^{\circ} \mathrm{F}$ & 1560 & 21.3 & 7SE,NW & 32.5 & 56 & 112 & 1500 & 4.07 & 113768 & 15.8 & 21878 \\
\hline $\mathrm{TC} 15012$ & C 2-6' & ${ }^{\circ} \mathbf{P}$ & 1600 & 21.6 & $8 E, W$ & 37.5 & 56 & 109 & 1506 & 3.80 & 100586 & 13.8 & 19343 \\
\hline TC15013 & C 2-8' & ${ }^{\circ} \mathrm{p}$ & 1653 & 22.2 & & Overall & 54 & 125 & 1572 & 22.86 & 808926 & 17.9 & 25927 \\
\hline TC15022 & C 3-11' & $\cdot p$ & 1612 & 16.1 & & & & From Data & Sheets $\Rightarrow$ & 23.87 & & & \\
\hline TC15023 & C 3-14' & ${ }^{\circ} \mathrm{p}$ & 1599 & 13.1 & & & & & & & & & \\
\hline TC15024 & C 3-14' & ${ }^{\circ} \mathbf{p}$ & 1598 & 12.3 & -EHX- & & & & & & & & \\
\hline TC15025 & C 3-14' & ${ }^{\circ} \mathrm{F}$ & 1619 & 15.1 & Coils & No. of & Temp In & Temp Out & Bed Temp & Flow & $Q$ & $\mathrm{u}$ & Heat Flux \\
\hline $\mathrm{TC} 15032$ & $C 4-17.5^{\prime}$ & ${ }^{\circ} \mathrm{F}$ & 1566 & 10.3 & Used & Coils & ${ }^{\circ} \mathbf{F}$ & ${ }^{\circ} \mathrm{F}$ & ${ }^{\circ} \mathrm{F}$ & gpm & Btu/hr & $B t u / f t^{2} h r^{\circ} \mathrm{P}$ & Btu/ft ${ }^{2} \mathrm{hr}$ \\
\hline rC15042 & C 5-22.5' & ${ }^{\circ} \mathbf{F}$ & 1582 & 8.6 & $1-9$ & 9 & 54 & 114 & 1137 & 16.33 & 493452 & 71.4 & 73104 \\
\hline $\mathrm{TC} 15052$ & $C 6-27.5^{\circ}$ & ${ }^{\circ} \mathrm{F}$ & 1575 & 7.6 & & & & From Data & Sheets $\Rightarrow$ & 17.10 & & & \\
\hline TC15053 & C 6-27.5' & ${ }^{\circ} \mathrm{F}$ & 1582 & 9.0 & & & & & & & & & \\
\hline TC15054 & C 6-27.5 & ${ }^{\circ} \mathrm{p}$ & 1504 & 7.6 & EMISSION & S DATA & & & & & & & \\
\hline TC15062 & C 7-32.5' & ${ }^{\circ} \mathbf{F}$ & 1500 & 6.3 & & & & & & & & & \\
\hline TC15071 & C \&-37.5' & ${ }^{\circ} \mathbf{F}$ & 1506 & 5.5 & & As Measure & ed - & -1 & - & -Corrected $t$ & $03 \% 02$ & -1 & \\
\hline TC15073 & $C 9-41^{\prime}$ & ${ }^{\circ} \mathbf{F}$ & 1577 & 8.3 & $\mathrm{Tag}$ & Units & Average & Std Dev & Tag & Units & Average & Std Dev & \\
\hline TC15999 & Ambient & $\cdot \mathbf{P}$ & 82 & 1.9 & SO2-A & ppm & 555 & 277.9 & SO2-A & ppm & 574 & 277.1 & \\
\hline TC16001 & EHX Plenm & ${ }^{\circ} \mathrm{F}$ & 132 & 4.1 & $S O 2-A E$ & $\mathrm{Ib} / \mathrm{MM}$ Blu & 0.93 & 0.5 & & & & & \\
\hline $\mathrm{TC} 16012$ & EHX 0.5' & ${ }^{\circ} \mathbf{F}$ & 1156 & 20.2 & SO2-B & ppm & 524 & 219.2 & SO2-B & ppm & 580 & 224.3 & \\
\hline TC16013 & EHX 1.5' & ${ }^{\circ} \mathrm{F}$ & 1126 & 20.6 & $\mathrm{SO} 2-\mathrm{BE}$ & $\mathrm{Ib} / \mathrm{MM} \mathrm{Btu}$ & 0.87 & 0.3 & & & & & \\
\hline TC16014 & EHX 2.7' & ${ }^{\circ} \mathrm{F}$ & 1131 & 23.6 & $\mathrm{Co}$ & ppm & 40 & 17.5 & Co & ppm & 42 & 18.3 & \\
\hline TC16015 & EHX 3.8' & ${ }^{\circ} \mathbf{F}$ & 1130 & 15.7 & $\mathrm{CO} 2$ & $\%$ & 15.97 & 0.7 & $\mathrm{CO} 2$ & $\%$ & 16.68 & 0.3 & \\
\hline TC16017 & EHX 5.3' & ${ }^{\circ} \mathbf{F}$ & 1051 & 8.2 & $\mathrm{~N} 2 \mathrm{O}$ & ppm & 103 & 7.0 & $\mathrm{~N} 20$ & ppm & 108 & 9.7 & \\
\hline TC16018 & EHX Exit & ${ }^{\circ} \mathbf{F}$ & 1090 & 17.6 & $\mathrm{~N} 2 \mathrm{OE}$ & $\mathrm{Ib} / \mathrm{MM} \mathrm{Btu}$ & 0.12 & 0.0 & & & & & \\
\hline TC16021 & $\operatorname{CrcA}$ in & ${ }^{\bullet} \mathrm{F}$ & 1565 & 6.4 & NOx & ppm & 124 & 15.7 & NOx & ppm & 130 & 19.7 & \\
\hline TC16031 & DC 8-36 & ${ }^{\circ} \mathrm{F}$ & 1587 & 6.3 & NOXE & Ib/MM Btu & 0.15 & 0.0 & & & & & \\
\hline TC16032 & DC 6-28' & ${ }^{\circ} \mathrm{F}$ & 1556 & 6.6 & O2-A & $\%$ & 3.77 & 0.6 & & & & & \\
\hline TC16033 & $D C 4-18^{\prime}$ & ${ }^{\circ} \mathbf{F}$ & 1550 & 6.1 & O2-B & $\%$ & 4.92 & 0.7 & & & & & \\
\hline TC16034 & DC3-9.5 & ${ }^{\circ} \mathrm{F}$ & 1601 & 7.7 & & & & & & & & & \\
\hline $\mathrm{TC} 16035$ & DC3-8.5' & ${ }^{\circ} \mathrm{F}$ & 1565 & 11.3 & Tag & Desc & Units & Average & Std Dev & Tag & Desc & Average & Std Dev \\
\hline & & & & & $W(C)$ & Coal Fd Rt & $\mathrm{lbs} / \mathrm{hr}$ & 193.4 & 19.5 & $\mathrm{TC} 13131$ & AFPE-F2" & 1076 & 29.2 \\
\hline $\mathrm{T}(\mathrm{A}, \mathrm{C})$ & Comb Temp & ${ }^{\circ} \mathrm{F}$ & 1572 & 12.9 & $\mathbf{W}(\mathbf{S})$ & LS Fd Rt & Ibs/hr & 36.3 & 10.2 & TC13132 & AFPE-F $6^{\prime \prime}$ & 1201 & 20.7 \\
\hline$T(A, E H X)$ & EHX Temp & ${ }^{\circ} \mathbf{F}$ & 1137 & 20.8 & $V(F G)$ & FG SGV & $\mathrm{ft} / \mathrm{sec}$ & 15.9 & 0.7 & TC13133 & AFPE-B6" & 936 & 25.9 \\
\hline $\mathrm{EA}$ & Excess Air & $\%$ & 21.7 & 4.5 & $V(S, C)$ & Comb SGV & $\mathrm{ft} / \mathrm{sec}$ & 14.9 & 0.6 & TC13134 & AFPE-F10" & 919 & 51.9 \\
\hline SR & S Reten & $\%$ & 73.5 & 13.0 & $\mathrm{~V}(\mathrm{~S}, \mathrm{EHX})$ & EHXSGV & $\mathrm{ft} / \mathrm{sec}$ & 2.0 & 0.4 & TC13231 & AFPW-F2" & 1058 & 31.5 \\
\hline$R(P C A)$ & \%Flw PCA & $\%$ & 59.7 & 5.9 & FT18003 & CHX Flow & gpm & 22.9 & 0.2 & $\mathrm{TC} 13232$ & AFPW-F6" & 1189 & 23.8 \\
\hline $\mathrm{R}(\mathrm{SCA})$ & \%FIw SCA & $\%$ & 40.3 & 5.9 & FT19003 & EHX Flow & gpm & 16.3 & 0.0 & $\mathrm{TC} 13233$ & AFPW-B6" & 925 & 24.1 \\
\hline$R(Q, I N)$ & $\%$ Enrg in & $\%$ & 72.9 & 7.5 & PT15081 & Comb $d P$ & in. $\mathrm{H} 2 \mathrm{O}$ & 36.9 & 2.9 & $\mathrm{TC} 13234$ & AFPW-F10 & 1115 & 26.0 \\
\hline $\mathrm{R}(\mathrm{CHX})$ & CHX Ratio & $\%$ & 58.4 & 1.7 & $Q(C A)$ & CA Heat in & $\mathrm{KBtu} / \mathrm{hr}$ & 98.5 & 6.4 & DOORS & CHXs On & 12 & 0 \\
\hline$R(E H X)$ & EHX Ratio & $\%$ & 41.6 & 1.7 & $\alpha(\mathrm{CHX})$ & CHX HtRmv & KBtu/hr & 687.3 & 37.5 & colls & EHXs On & 9 & 0 \\
\hline $\mathbf{P}(\mathrm{PCA})$ & PCA FIW & SCFM & 238.2 & 38.4 & Q(EHX) & EHX HtRmV & $\mathrm{KB} t \mathrm{w} / \mathrm{hr}$ & 488.3 & 23.2 & BH AVC & & 2.0 & 0.4 \\
\hline $\mathbf{F}(\mathbf{E H X})$ & EHX Flw & SCFM & 60.5 & 13.3 & Q(EHX,IN & FG Enrg in & KBtu/hr & 3.0 & 0.8 & A/SRATIO & & 2.7 & 0.8 \\
\hline$F(T P A)$ & TPCA Flw & SCFM & 301.4 & 33.2 & $Q(F)$ & Fuel Enrg in & $\mathrm{KB} t u / \mathrm{hr}$ & 2579.9 & 259.6 & Feed Air & scfm & 18.5 & \\
\hline $\mathrm{F}(\mathrm{SCA})$ & SCA Flw & SCFM & 168.1 & 30.8 & $\alpha F G)$ & FG Enrg out & $\mathrm{KBt} / \mathrm{hr} \mathrm{hr}$ & 254.3 & 40.9 & DC Air & sefm & 8.7 & \\
\hline$F(T C A, F)$ & TCA Flw & SCFM & 504.6 & 22.5 & $Q(I N)$ & Tot Enrg in & KBtu/hr & 2681.3 & 258.7 & Purge Air & $\operatorname{scfm}$ & 15.5 & \\
\hline $\mathrm{F}(\mathrm{FG}, \mathrm{BH})$ & BH FIW & SCFM & 513.5 & 86.9 & Qoun & Tot Enrg out & KBtuhr & 1932.7 & 62.9 & & & & \\
\hline$F(T F G)$ & TFG F/W & SCFM & 513.5 & 86.9 & $W(S R)$ & Recirc Rt & $\mathrm{lbs} / \mathrm{hr}$ & 4204 & 416.9 & & & & \\
\hline
\end{tabular}




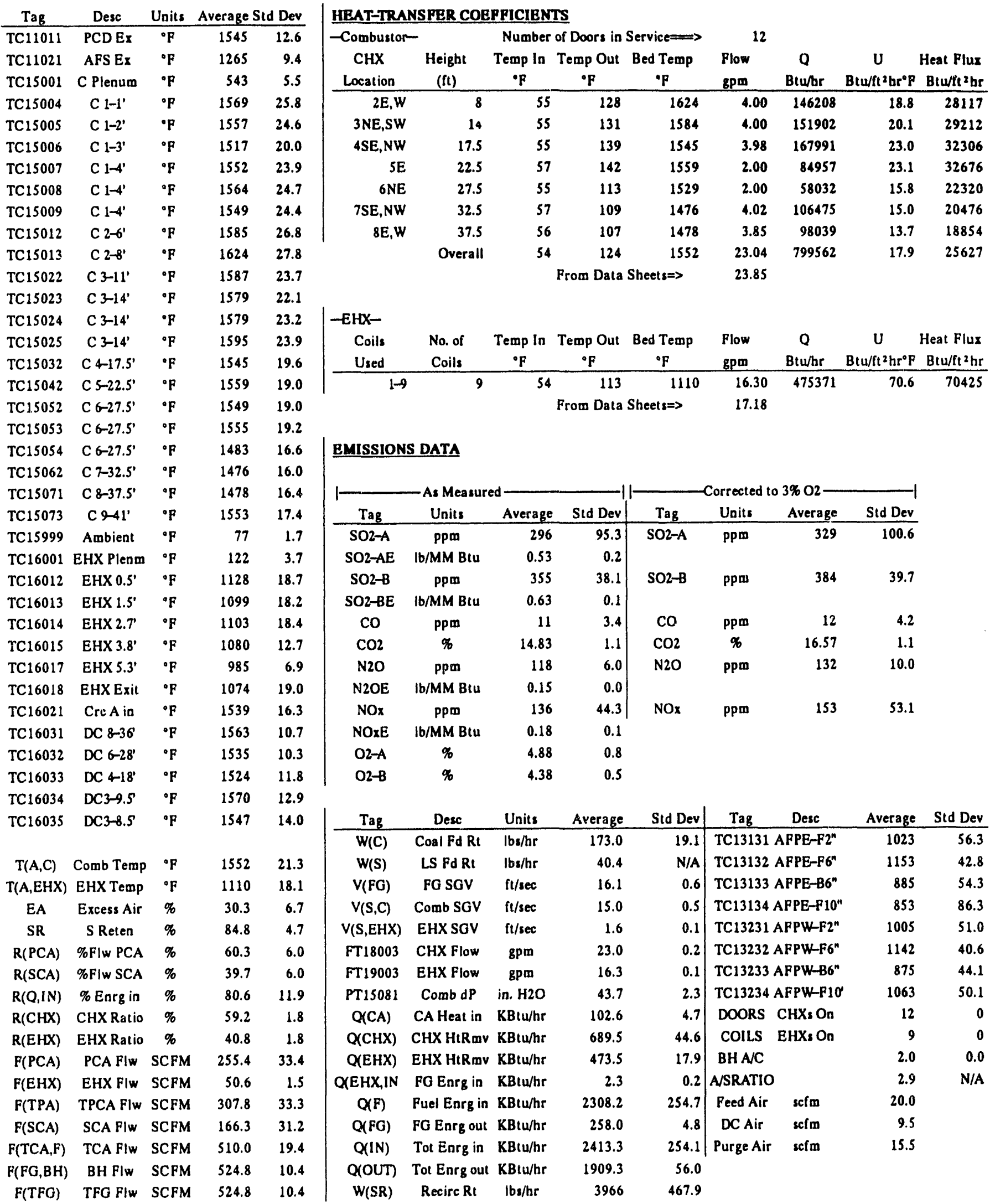




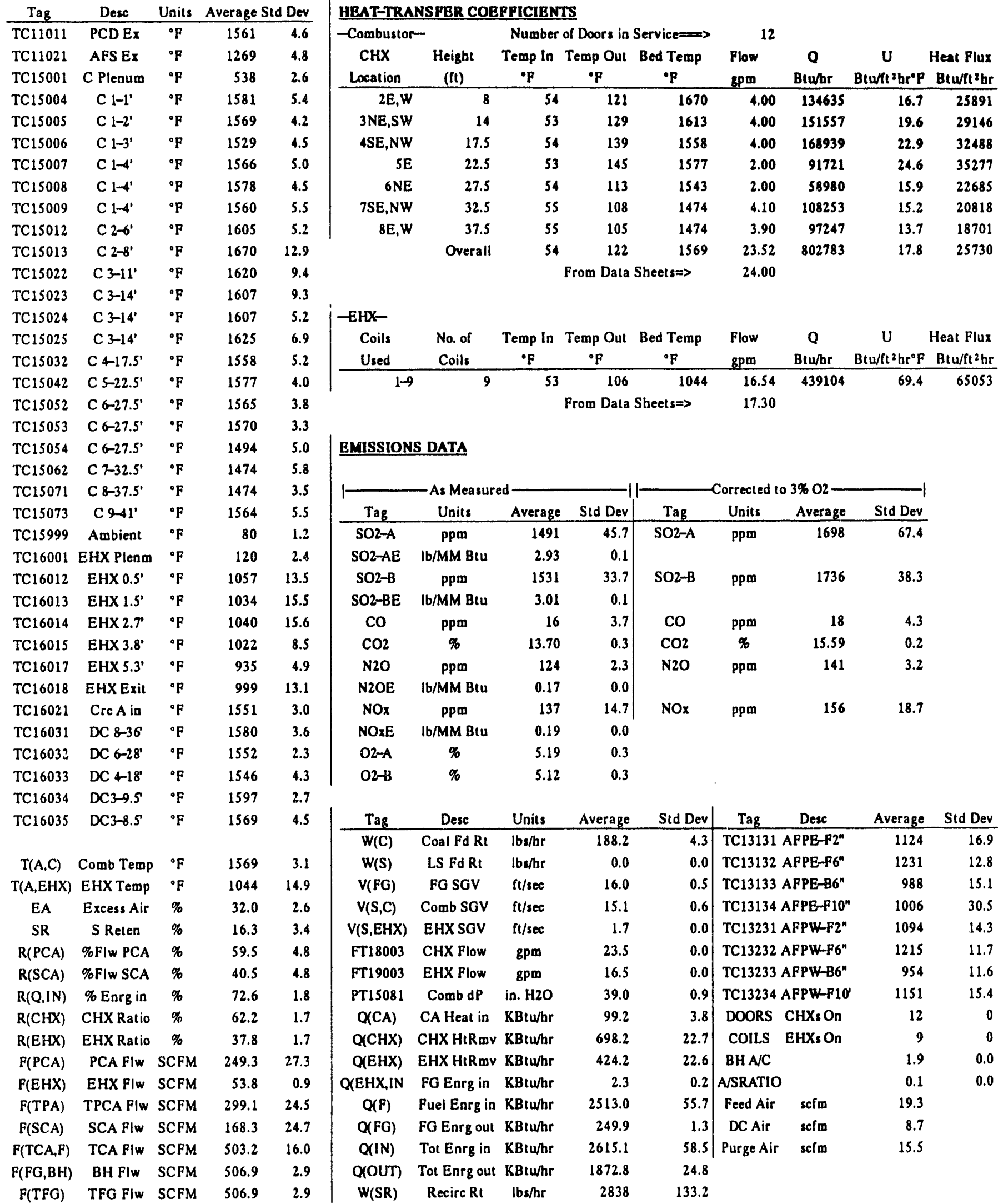


APPENDIX D

BLACK THUNDER SUBBITUMINOUS COAL TEST RESULTS 


\section{TABLE OF CONTENTS}

$\underline{\text { Page }}$

LIST OF FIGURES $\ldots \ldots \ldots \ldots \ldots \ldots \ldots \ldots \ldots \ldots \ldots \ldots \ldots \ldots \ldots$

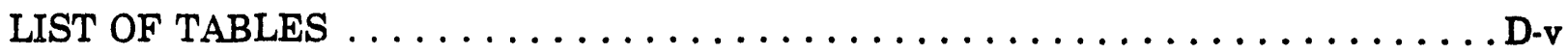

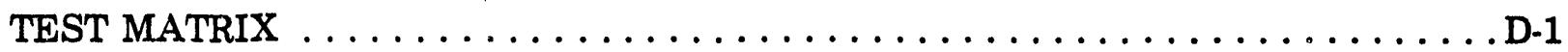

COAL AND LIMESTONE PROPERTIES $\ldots \ldots \ldots \ldots \ldots \ldots \ldots \ldots \ldots \ldots$

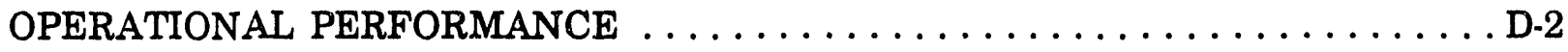

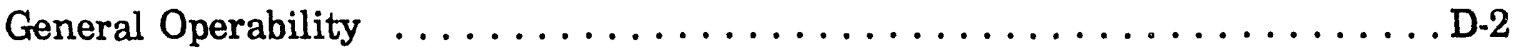

Summary of Results . . . . . . . . . . . . . . . . . . D -4

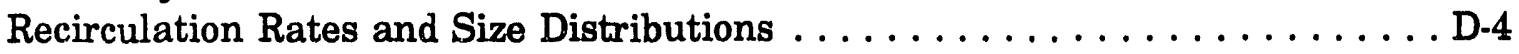

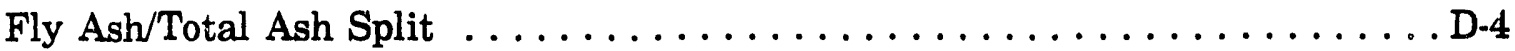

Coal Ash/Limestone Split . . . . . . . . . . . . . . . . . D-8

THERMAL PERFORMANCE $\ldots \ldots \ldots \ldots \ldots \ldots \ldots \ldots \ldots \ldots \ldots \ldots$

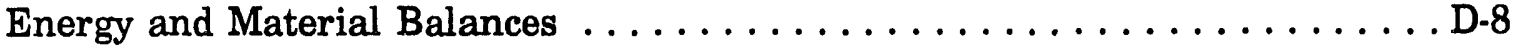

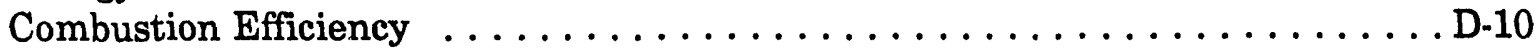

Boiler Efficiency . . . . . . . . . . . . . . . . . . . . D-11

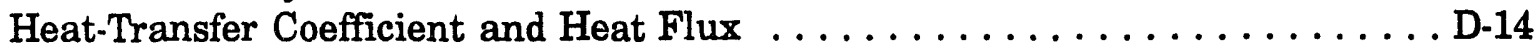

Pressure and Temperature Profiles . . . . . . . . . . . . . . . D-15

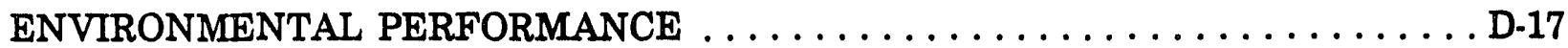

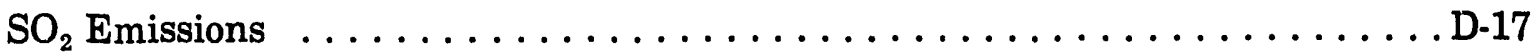

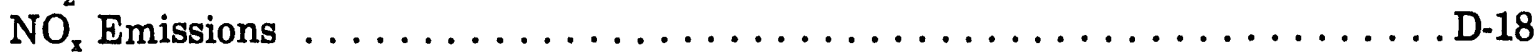

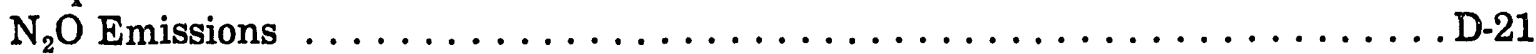

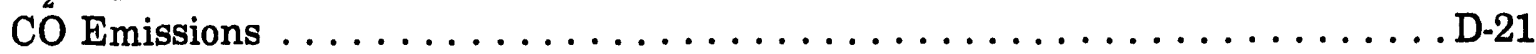

SUMMARIES OF TEST DATA $\ldots \ldots \ldots \ldots \ldots \ldots \ldots \ldots \ldots \ldots \ldots \ldots \ldots$ 


\section{LIST OF FIGURES}

Figure

Page

D-1 Coal and limestone particle-size distribution $\ldots \ldots \ldots \ldots \ldots \ldots \ldots \ldots$

D-2 Baghouse, secondary cyclone, downcomer, and bed material particle-size distributions $\ldots \ldots \ldots \ldots \ldots \ldots \ldots \ldots \ldots \ldots$. . . . . . . . .

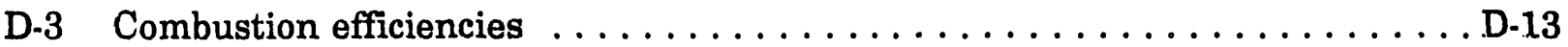

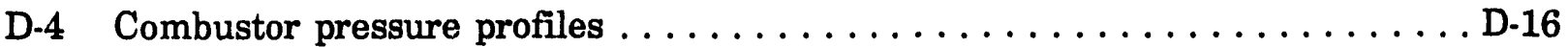

D-5 Combustor temperature profiles $\ldots \ldots \ldots \ldots \ldots \ldots \ldots \ldots \ldots \ldots \ldots \ldots$

D-6 Sulfur retention as a function of average combustor temperature $\ldots \ldots \ldots$ D-18

D-7 $\mathrm{SO}_{2}$ emissions as a function of excess air $\ldots \ldots \ldots \ldots \ldots \ldots \ldots \ldots \ldots$

D-8 $\mathrm{SO}_{2}$ emissions as a function of alkali-to-sulfur ratio $\ldots \ldots \ldots \ldots \ldots \ldots \ldots \ldots$ D-19

D-9 $\mathrm{NO}_{\mathrm{x}}$ emissions as a function of average combustor temperature $\ldots \ldots \ldots \ldots \mathrm{D} \cdot 20$

D-10 Relationship between $\mathrm{NO}_{\mathrm{x}}$ emissions and added calcium-to-sulfur ratio . . . . D-20

D.11 $\mathrm{NO}_{\mathrm{z}}$ emissions as a function of excess air $\ldots \ldots \ldots \ldots \ldots \ldots \ldots \ldots \ldots \ldots \ldots$

D-12 $\mathrm{N}_{2} \mathrm{O}$ emissions as a function of average combustor temperature $\ldots \ldots \ldots \ldots$ D-22

D-13 CO emissions as a function of average combustor temperature $\ldots \ldots \ldots \ldots$ D-22 


\section{LIST OF TABLES}

Table

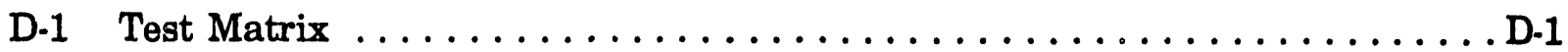

D-2 Coal Analyses $\ldots \ldots \ldots \ldots \ldots \ldots \ldots \ldots \ldots \ldots \ldots \ldots \ldots \ldots \ldots$

D-3 Average Limestone Analysis $\ldots \ldots \ldots \ldots \ldots \ldots \ldots \ldots \ldots \ldots \ldots$

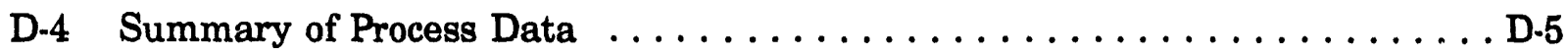

D-5 Solids Recirculation and Heat-Transfer Data . . . . . . . . . . . . D-7

D-6 Ash Balance $\ldots \ldots \ldots \ldots \ldots \ldots \ldots \ldots \ldots \ldots \ldots \ldots \ldots \ldots$

D-7 Material Derived from Coal Ash and Limestone Based on Aluminum Material Balance ........................... D-9

D-8 Aluminum Material Balance $\ldots \ldots \ldots \ldots \ldots \ldots \ldots \ldots \ldots \ldots$

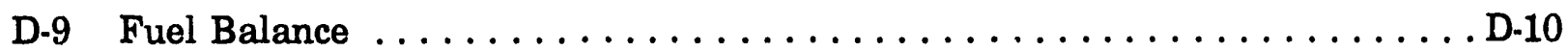

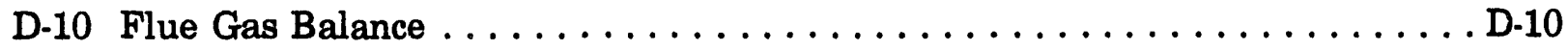

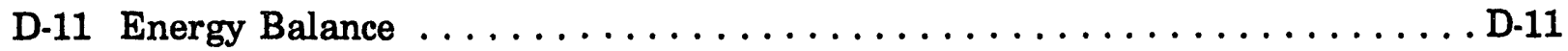

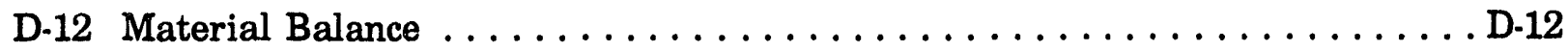

D-13 Combustion Efficiency $\ldots \ldots \ldots \ldots \ldots \ldots \ldots \ldots \ldots \ldots \ldots \ldots \ldots \ldots \ldots \ldots \ldots$

D-14 Unburned Carbon $\ldots \ldots \ldots \ldots \ldots \ldots \ldots \ldots \ldots \ldots \ldots \ldots \ldots \ldots$

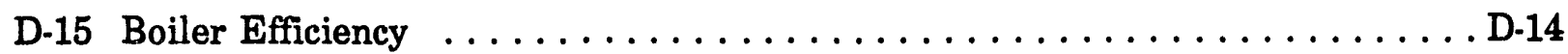

D-16 Individual Heat-Transfer Coefficients $\ldots \ldots \ldots \ldots \ldots \ldots \ldots \ldots \ldots$

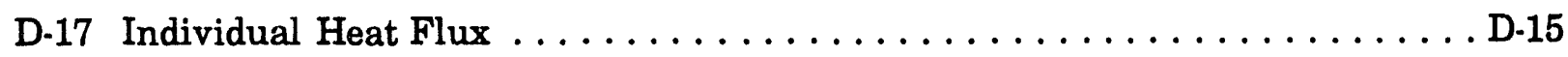

D-18 Emission Data $\ldots \ldots \ldots \ldots \ldots \ldots \ldots \ldots \ldots \ldots \ldots \ldots \ldots \ldots$ 


\section{TEST MATRIX}

The matrix of test parameters is shown in Table D-1. Test 1 was a baseline test at nominal conditions of $1550^{\circ} \mathrm{F}$, primary-to-secordary air split of $60: 40$, flue gas superficial gas velocity of $16.0 \mathrm{ft} / \mathrm{sec}$, and $25 \%$ excess air. No limestone was fed during this test. Test 2 maintained the same operating conditions as Test 1 , with the addition of limestone. In order to turn the bed over from the start-up sand to a limestone/coal ash bed more quickly, bed material was drained from the combustor and replaced with end-of-run bed material from the Blacksville run. This operation was performed in four 200-pound increments. Tests 3 and 9 were low- and high-temperature tests, respectively; Tests 4 and 8 were run at low and high excess air, respectively. Test 5 was a low-sulfur-capture test. Tests 6 and 7 were low-load tests; in Test 6, the heat-transfer configuration was to be the same as in Test 5, allowing temperature to drift. In Test 7, heat-transfer surface was to be removed to increase the average combustor temperature to $1550^{\circ} \mathrm{F}$. However, Test 7 was run first, and the heat-transfer configuration was almost identical to that of Test 5; since Test 6 would then have been essentially a repeat of Test 7, with the addition of a single heat-transfer coil, it was deleted from the matrix.

\section{COAL AND LIMESTONE PROPERTIES}

The coal used for this test was supplied by ARCO Coal Company. The limestone used was New Enterprise. Coal and limestone preparation was as described earlier. The coal was screened to $-1 / 4 "$. The size distributions of the coal and limestone are shown in Figure D-1.

The sized coal was stored in 2-ton capacity coal totes until it was needed, at which time it was transferred by forklift and crane to storage hoppers having net capacities of 3500 pounds. The prepared limestone was placed directly into 1000-pound capacity storage hoppers.

TABLE D-1

Test Matrix

\begin{tabular}{cccccc}
\hline Test No. & $\begin{array}{c}\text { Average } \\
\text { Temperature, }{ }^{\circ} \mathrm{F}\end{array}$ & $\begin{array}{c}\text { Sulfur Retention or } \\
\mathrm{Ca} / \mathrm{S}\end{array}$ & PA/SA & $\begin{array}{c}\text { Superficial Gas } \\
\text { Velocity, ft/sec }\end{array}$ & $\begin{array}{c}\text { Excess } \\
\text { Air, } \%\end{array}$ \\
\hline 1 & 1550 & No $1 \mathbf{s}^{1}$ & $60: 40$ & 16.0 & 25 \\
2 & 1550 & $90 \%$ & $60: 40$ & 16.0 & 25 \\
3 & 1450 & Same $\mathrm{Ca} / \mathrm{S}$ as 2 & $60: 40$ & 15.2 & 25 \\
4 & 1550 & Same $\mathrm{Ca} / \mathrm{S}$ as 2 & $60: 40$ & 16.0 & 5 \\
5 & 1550 & $70 \%$ & $60: 40$ & 16.0 & 25 \\
6 & $* 2$ & Same $\mathrm{Ca} / \mathrm{S}$ as 2 & $80: 20$ & 12.0 & 25 \\
7 & 1550 & Same Ca/S as 2 & $80: 20$ & 12.0 & 25 \\
8 & 1550 & Same Ca/S as 2 & $60: 40$ & 16.0 & 45 \\
9 & 1650 & Same Ca/S as 2 & $60: 40$ & 16.8 & 25 \\
\hline
\end{tabular}

${ }^{1}$ Limestone.

${ }^{2}$ Not specified-dependent on operating conditions. 


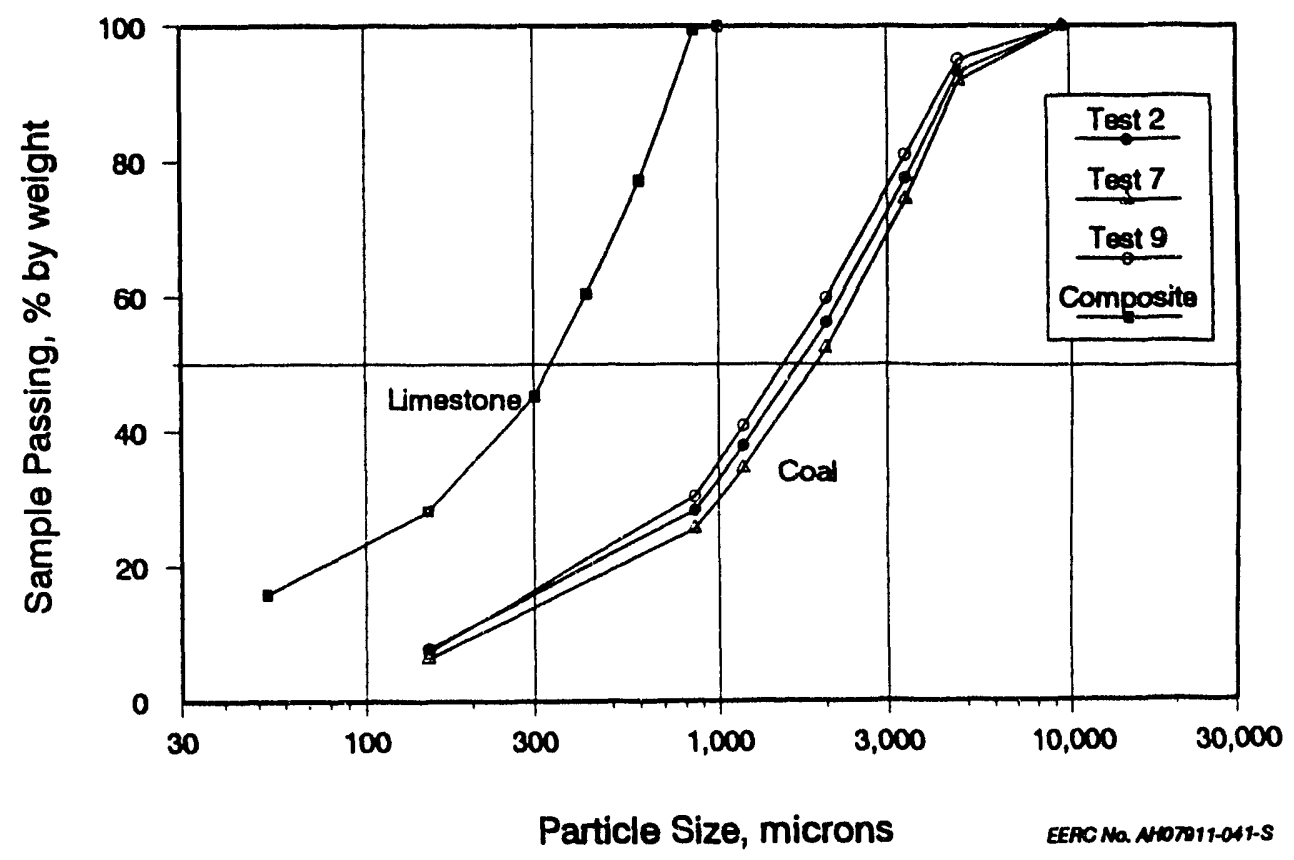

Figure D-1. Coal and limestone particle-size distribution.

Proximate and ultimate analyses of the coal and XRFA of the coal ash from Tests 2, 7 , and 9 were performed. The coal samples from the three tests showed little variability, so the average of the three was used for all tests. If there had been much variability, particularly in the sulfur analysis, samples from all the tests would have been analyzed. The results of the coal analyses are shown in Table D-2. XRFA was performed on a sample of limestone that was composited from all the tests. The limestone analysis is shown in Table D-3.

\section{OPERATIONAL PERFORMANCE}

\section{General Operability}

While overall operability of the system was good, several problems were encountered during testing with the Black Thunder coal. The coal was difficult to feed, hanging up in the transition section between the coal hopper and the rotary feed valve. For the first day after coal feed was initiated, the speed of the rotary feed valve had to be increased to maintain a constant coal feed rate, until the speed controller setting was at a maximum. The pockets in the rotary feeder apparently filled up with coal, requiring increasingly faster rotation. A hole was drilled just below the rotary feeder, and a compressed air line was attached, connected to manual control valve located in the control room. The rotary valve could then be periodically blown clean to help maintain a consistent coal feed rate.

Limestone feed also proved problematic. Because of the relatively low limestone feed rates required for this run, an Accurate limestone feeder was again utilized as during a portion of the Blacksville coal testing. Some of the limestone was wet and sticky; this tended to pack into the feed screw, halting its operation. A larger sleeve was installed around the screw, and the wettest limestone was mixed with drier material to help alleviate the feed problems. 
TABLE D-2

Coal Analyses (Average of Tests 2, 7, and 9)

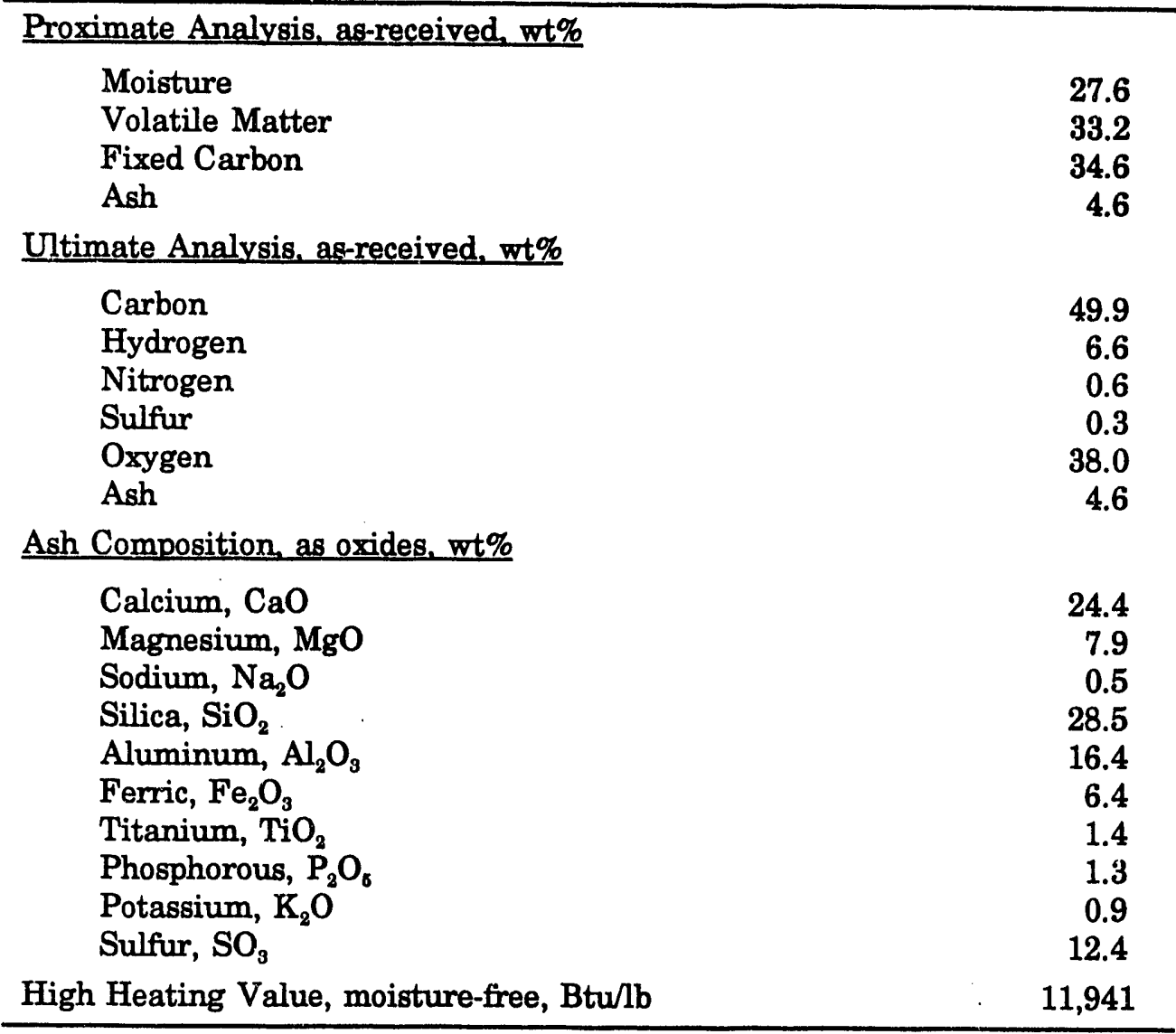

\section{TABLE D-3}

Average Limestone Analysis

\begin{tabular}{cc}
\hline Component, as oxide, $\%$ & Average \\
\hline Silica & 2.96 \\
Aluminum & 0.62 \\
Titanium & 0.38 \\
Iron & 0.02 \\
Calcium & 51.76 \\
Magnesium & 2.93 \\
Sulfur & 0.26 \\
Sodium & 0.06 \\
Potassium & 0.33 \\
\hline
\end{tabular}

Because of the low limestone feed rate and the low ash content of the coal, it would have taken a number of days to displace the sand bed used at start-up with a limestone/coal ash bed. To facilitate bed turnover at the end of Test 1 , when limestone feed was initiated, bed material was drained and replaced with bed material remaining from the Blacksville run. The low-sulfur content of the coal resulted in a very slow response time in terms of sulfur capture when operating conditions were changed. 
In addition to the feed problems, material tended to hang up in the downcomer. This was evidenced by large fluctuations in the downcomer pressure drops. The ability to inject compressed air into several sections of the downcomer was incorporated into the pilot system as a result of problems encountered during CFB testing with the Center lignite; this air was used to keep the downcomer clear.

The secondary cyclone catch was recycled back into the system after Test 1 to maintain solids inventory and increase the solids recirculation rate. The cyclone catch was collected in a barrel for short periods (usually one-half hour) when bed inventory was high, indicated by an increase in the solids recirculation rate (near $20,000 \mathrm{lb} / \mathrm{hr}$ ), or when there was too much sorbent built up in the bed, indicated by very low $\mathrm{SO}_{2}$ emissions (less than $10 \mathrm{ppm}$ ).

\section{Summary of Results}

Upon completion of the run, data for each of the steady-state test periods were averaged. A summary of the process data for each test period is presented in Table D-4. The eight test periods correspond to the tests outlined in the test matrix in Table D-1. They are presented in the order used in Table D-1, even though they were actually run in the order $1,5,2,3,4,9,8,7$, to accommodate the slow system response times. Summaries of the run data are included at the end of this appendix.

\section{Recirculation Rates and Size Distributions}

The solids recirculation rate for each test was determined by calculating a heat balance around the external heat exchanger. The average solids recirculation rates for each test are shown in Table D-5. The recirculation rate for Test 1 was very low, 2245 $\mathrm{lb} / \mathrm{hr}$, because the ash captured by the secondary cyclone was collected in a barrel. For the remainder of the run, the secondary cyclone catch was recycled back into the unit, except for brief periods when the ash was diverted to a barrel to control bed inventory or sulfur emissions. Tests 2 through 4 had recirculation rates typical for full load tests on this unit. The solids recirculation for Test 9 may have been higher due to the higher velocity in the combustor during this test. The lowest recirculation rate observed after the reinjection of secondary cyclone ash was initiated occurred in Test 7, the low-load test. This is due in part to the low superficial gas velocity in the combustor, the decreased solids input, and the use of secondary cyclone ash drain for sulfur control prior to the test. Secondary cyclone ash drain before Test 8 also contributed to the low recirculation rate in that test.

The particle-size distributions are shown in Figure D-2. The combustor bed material in Test 1 was relatively large, since the system was operating with a predominantly sand bed at that time. Test 1 was also the only test during which secondary cyclone ash was collected rather than recycled back into the system.

\section{Fly Ash/Total Ash Split}

The ash balance for each test period is presented in Table D-6. Ash input to the system was composed of calculated quantities of coal and limestone ash, based on their respective analyses and feed rates. The limestone-derived ash was further broken down into estimates of the sorbent which was either calcined or had undergone sulfation. The output consisted of the measured quantities of bottom ash (drained from the combustor bed), fly ash collected from the secondary cyclone, and fly ash removed from the baghouse. 


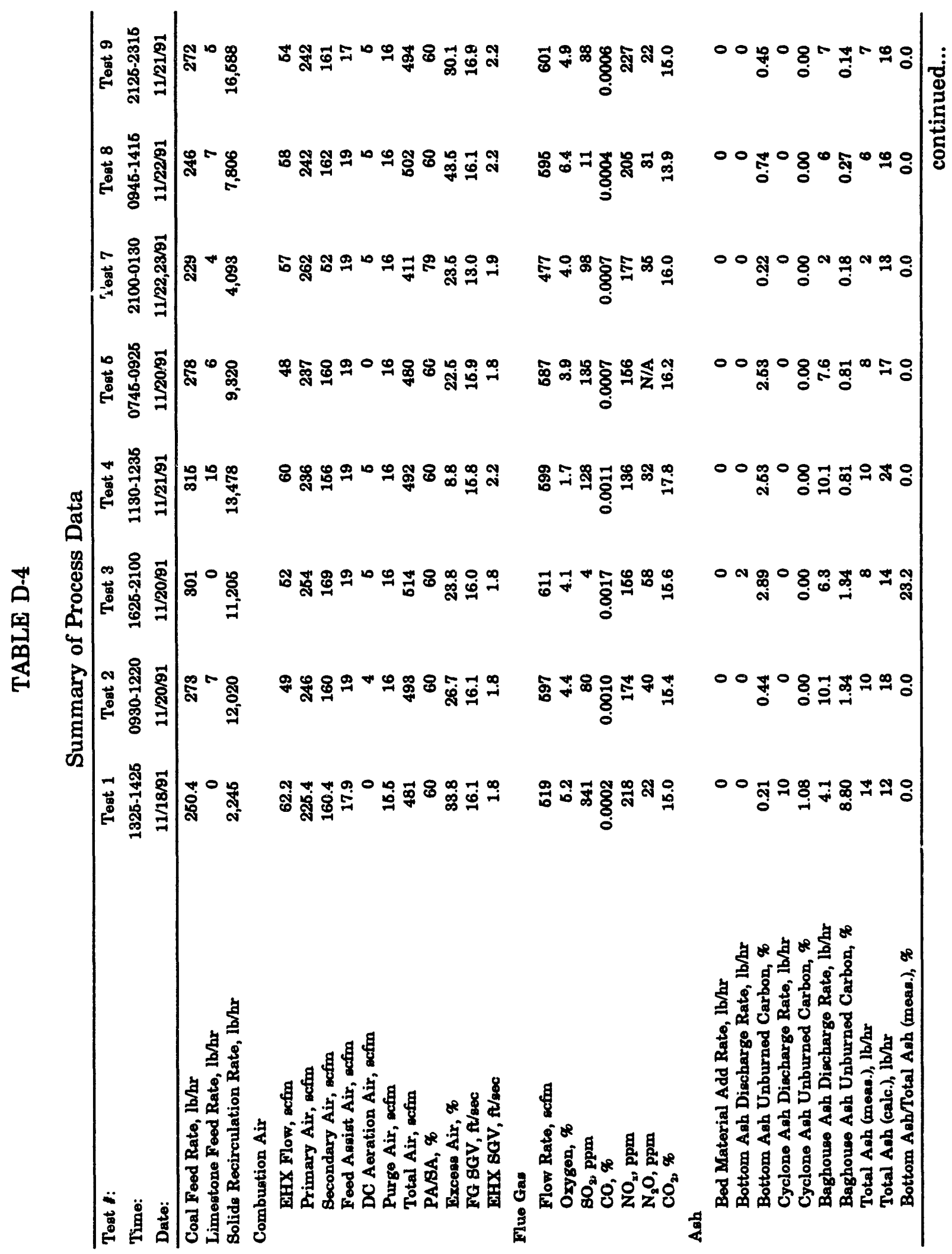




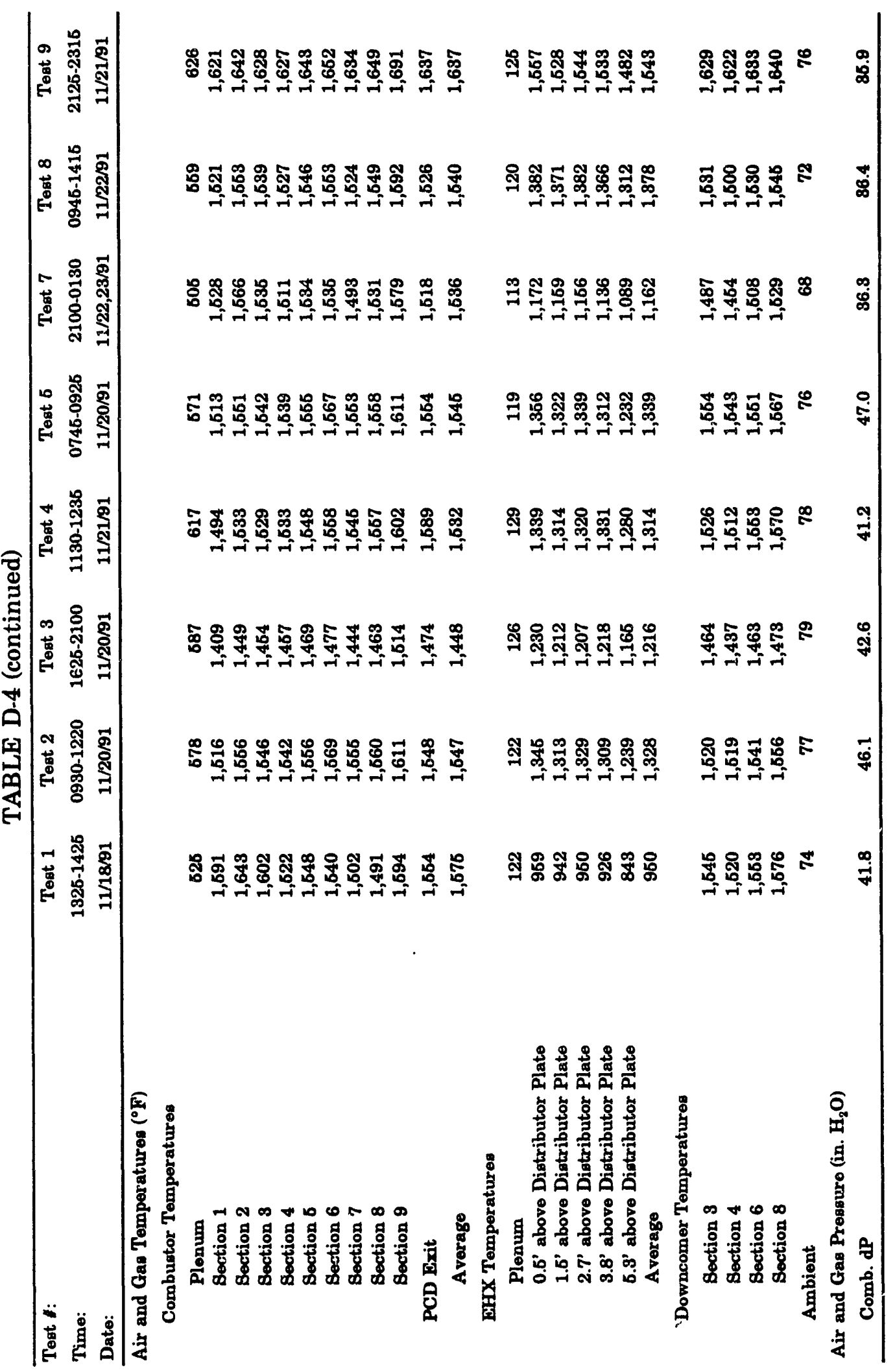




\section{TABLE D-5}

Solids Recirculation and Heat-Transfer Data

\begin{tabular}{|c|c|c|c|c|c|c|c|c|c|c|}
\hline Test & $\begin{array}{c}\text { Temperaturo } \\
\left({ }^{\circ} \mathrm{F}\right)\end{array}$ & $\begin{array}{l}\text { Total } \\
\text { Ca/s }\end{array}$ & $\begin{array}{l}\text { Froess } \\
\text { Air (9) }\end{array}$ & $\begin{array}{l}\text { Primary } \\
\text { Air (\%) }\end{array}$ & $\begin{array}{c}\text { Bolids } \\
\text { Recirculation } \\
\text { (lb/hr) }\end{array}$ & $\begin{array}{c}D C^{1} \\
d_{60}(\operatorname{mon})\end{array}$ & $\mathbf{H}_{0}{ }^{2}$ & $\begin{array}{l}\text { Heat Flux } \\
\text { (Btw/hr-ft') }\end{array}$ & $\begin{array}{l}\text { Cyclono } \\
\text { Efificionoy } \\
\text { (\%) }\end{array}$ & $\begin{array}{l}\text { Recirculation } \\
\text { Ratio }\end{array}$ \\
\hline 1 & 1,576 & 2.1 & 33.8 & 60 & 2,246 & 376 & 16.8 & 28,628 & 99.38 & 198 \\
\hline 2 & 1,647 & 4.6 & 26.7 & 60 & 12,020 & 376 & 23.4 & 32,929 & 99.92 & 608 \\
\hline 3 & 1,448 & 2.1 & 28.8 & 60 & 11,205 & 309 & 20.0 & 26,339 & 99.94 & 806 \\
\hline 4 & 1,632 & 6.4 & 8.8 & 60 & 13,478 & 317 & 20.6 & 28,796 & 99.98 & 466 \\
\hline 6 & 1,646 & 4.1 & 22.6 & 60 & 9,320 & $\mathrm{ND}^{2}$ & 23.6 & 33,076 & 99.92 & 496 \\
\hline 7 & 1,536 & 3.6 & 29.6 & 79 & 4,098 & 314 & 19.0 & 26,919 & 99.95 & 292 \\
\hline 8 & 1,540 & 4.7 & 43.6 & 60 & 7,806 & 331 & 20.2 & 28,670 & 99.98 & 432 \\
\hline 9 & 1,637 & 4.0 & 30.1 & 60 & 16,688 & 328 & 22.8 & 34,009 & 99.96 & 927 \\
\hline
\end{tabular}

1 Downcomar.

2 Heat-tranufor coefficient (Btu/hr-ft' ${ }^{\circ} \mathrm{F}$ ).

Not determined.

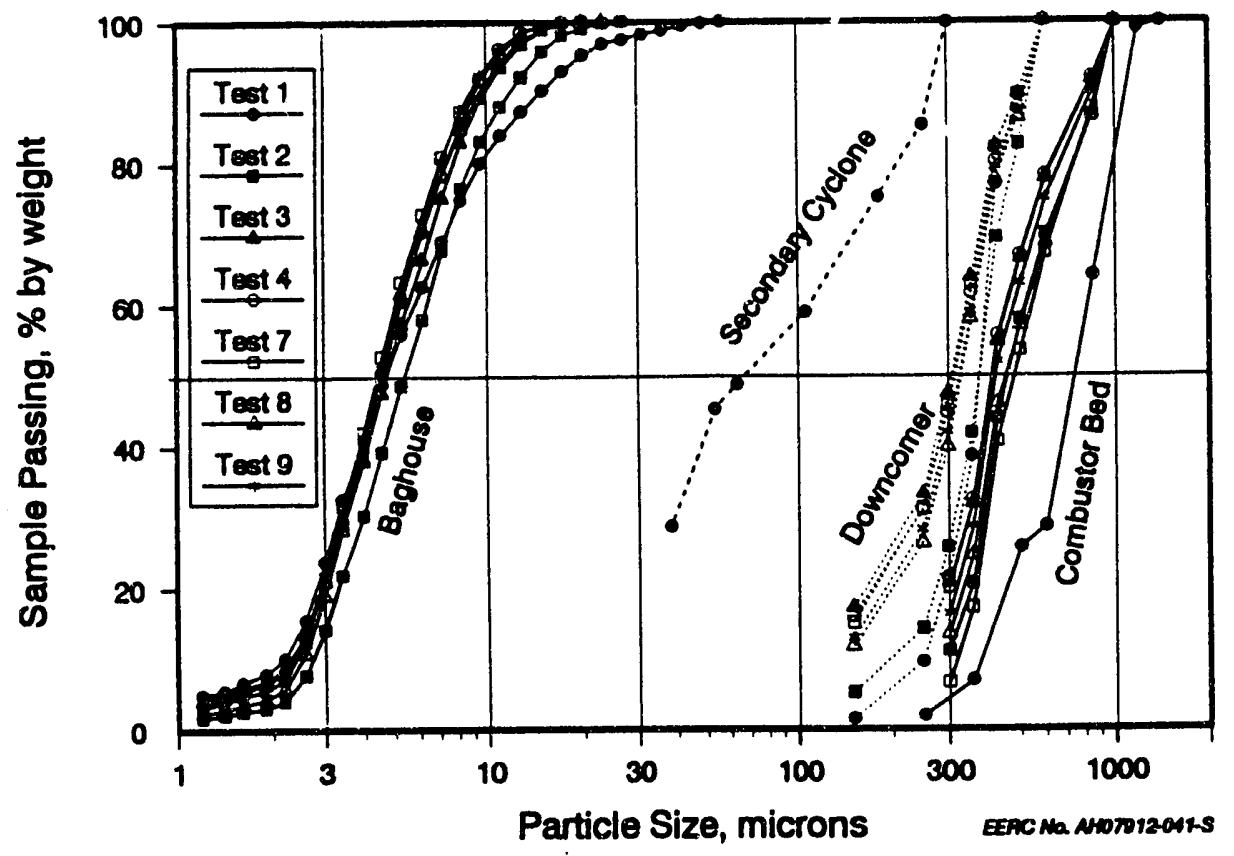

Figure D-2. Baghouse, secondary cyclone, downcomer, and bed material particle-size distributions.

The ratios of bottom ash to total ash, as well as the ash closure for each test, are also shown in Table D-6. Since bed inventory, measured by pressure drop across the combustor, was uniform for most of the run, bed material drain was minimal; hence the bottom ash-to-total ash split for all tests except Test 3 was zero. The average closure for the eight tests was poor, about $41 \%$. The reason for the poor closure was the intermittent use of secondary cyclone ash collection to control both bed inventory and sulfur retention; cyclone ash was collected between tests, rather than during them. Tests 7 and 8 were both preceded by periods of cyclone ash drain. Even the best closure, $60.5 \%$ for Test 3, was poor. The small quantities of ash input provide for a very large margin of error; a one-pound difference in the amount of ash collected could be a $5 \%$ to $10 \%$ difference in the closure. 


\section{TABLE D-6}

Ash Balance

\begin{tabular}{|c|c|c|c|c|c|c|c|c|}
\hline & Test 1 & Test 2 & Teat 3 & Test 4 & Test 5 & Teet 7 & Test 8 & Tost 9 \\
\hline \multicolumn{9}{|l|}{ Input, $\mathrm{lb} / \mathrm{hr}$} \\
\hline $\begin{array}{l}\text { Ash } \\
\text { Sorbent * }\end{array}$ & 12 & 13 & 14 & 16 & 13 & 11 & 11 & 12 \\
\hline $\mathrm{CaO}$ & 0 & 3 & 0 & 7 & 3 & 2 & 3 & 2 \\
\hline $\mathrm{CaSO}_{4}$ & 0 & 2 & 0 & 2 & 1 & 1 & 2 & 2 \\
\hline Total Solids In & 12 & 18 & 14 & 24 & 18 & 13 & 16 & 16 \\
\hline \multicolumn{9}{|l|}{ Output, lb/hr } \\
\hline $\begin{array}{l}\text { Bed Material } \\
\text { Cyclone Ash } \\
\text { Baghouse Ash }\end{array}$ & $\begin{array}{r}0 \\
10 \\
4\end{array}$ & $\begin{array}{r}0 \\
0 \\
10\end{array}$ & $\begin{array}{l}2 \\
0 \\
6\end{array}$ & $\begin{array}{r}0 \\
0 \\
10\end{array}$ & $\begin{array}{l}0 \\
0 \\
8\end{array}$ & $\begin{array}{l}0 \\
0 \\
2\end{array}$ & $\begin{array}{l}0 \\
0 \\
6\end{array}$ & $\begin{array}{l}0 \\
0 \\
7\end{array}$ \\
\hline Total Solida Out & 14 & 10 & 8 & 10 & 8 & 2 & 6 & 7 \\
\hline Closure, \% & 116.8 & 66.4 & 60.1 & 41.8 & 44.7 & 16.4 & 33.6 & 44.5 \\
\hline Bottom Ash/Total Ash, \% & 0.0 & 0.0 & 23.2 & 0.0 & 0.0 & 0.0 & 0.0 & 0.0 \\
\hline
\end{tabular}

* The $\mathrm{CaO}$ and $\mathrm{CaSO}_{4}$ mass inputs are included to express sorbent equivalent mass inputs.

\section{Coal Ash/Limestone Split}

An aluminum balance was performed to determine the composition of each ash stream. $\mathrm{Al}_{2} \mathrm{O}_{3}$ was used as a tracer. While there was a small percentage of $\mathrm{Al}_{2} \mathrm{O}_{3}$ in the limestone $(0.62 \%)$, it was generally less than $2 \%$ of the total $\mathrm{Al}_{2} \mathrm{O}_{3}$ fed; therefore, only the aluminum in the coal ash was considered in the aluminum balance. The proportions of coal and limestone as solid inputs for each test, as well as the percentage of each ash stream that came from the coal, are shown in Table D-7. The percentage of limestone in each ash stream is determined by difference. No aluminum balance was performed for Test 5 because solids samples were not taken during that test. Every test except 4 and 9 shows a greater than $100 \%$ contribution of coal ash to the baghouse ash because the percentage of aluminum in the baghouse ash was greater than that in the coal. Table D-8 shows the aluminum balance for each test. The closure in this table and in Table D-7 is based on the coal ash only.

\section{THERMAL PERFORMANCE}

\section{Energy and Material Balances}

The measured and theoretical fuel and flue gas flow rates are shown in Tables D-9 and D-10, respectively. Theoretical coal feed rate is calculated using the coal analysis and the actual air flow rates and flue gas emissions. The measured coal feed rate is determined by calculating the weight loss over time of the coal weigh hopper. The fuel balances for this run were fairly close for all eight tests, with the greatest difference between measured and theoretical, $-3.8 \%$, occurring during Test 7 .

The theoretical flue gas rates were calculated using the coal analyses and theoretical fuel feed rates for each test. The actual air and flue gas flow rates were measured with orifice plates. With the exception of Test 1 , the measured flue gas volume was greater than the theoretical. 


\section{TABLE D-7}

Material Derived from Coal Ash and Limestone Based on Aluminum Material Balance (\%)

\begin{tabular}{|c|c|c|c|c|c|c|c|c|}
\hline & Coal & $1 \mathrm{~s}^{1}$ & Coal & ls & Coal & ls & Coal & lo \\
\hline & \multicolumn{2}{|c|}{ Teat 1} & \multicolumn{2}{|c|}{ Tost 2} & \multicolumn{2}{|c|}{ Teat 3} & \multicolumn{2}{|c|}{ Tost 4} \\
\hline $\begin{array}{l}\text { Solids Input } \\
\text { Bed. Drain } \\
\text { Cyclone Catch } \\
\text { Baghouse Catch }\end{array}$ & $\begin{array}{r}100.00 \\
10.98 \\
78.06 \\
107.93 \\
\end{array}$ & $\begin{array}{l}0.00 \\
0.00 \\
0.00 \\
0.00\end{array}$ & $\begin{array}{r}71.87 \\
29.45 \\
\mathrm{NA}^{2} \\
101.22\end{array}$ & $\begin{array}{r}28.13 \\
70.66 \\
\text { NA } \\
0.00\end{array}$ & $\begin{array}{r}100.00 \\
24.09 \\
\text { NA } \\
114.02\end{array}$ & $\begin{array}{r}0.00 \\
76.91 \\
\text { NA } \\
0.00\end{array}$ & $\begin{array}{r}62.18 \\
24.51 \\
\text { NA } \\
79.27\end{array}$ & $\begin{array}{r}37.82 \\
75.49 \\
\text { NA } \\
0.00\end{array}$ \\
\hline Aluminum Bal. Closure & \multicolumn{2}{|c|}{101.48} & Teat 8 & & Tost 9 & & & \\
\hline $\begin{array}{l}\text { Solids Input } \\
\text { Bed Drain } \\
\text { Cyclone Catch } \\
\text { Baghouse Catch }\end{array}$ & $\begin{array}{r}84.49 \\
25.37 \\
\text { NA } \\
109.15\end{array}$ & $\begin{array}{r}15.61 \\
74.63 \\
\text { NA } \\
0.00\end{array}$ & $\begin{array}{r}69.67 \\
27.87 \\
\text { NA } \\
101.83\end{array}$ & $\begin{array}{r}30.43 \\
72.13 \\
\text { NA } \\
0.00\end{array}$ & $\begin{array}{r}75.63 \\
27.87 \\
\text { NA } \\
75.61\end{array}$ & $\begin{array}{r}24.37 \\
72.13 \\
\text { NA } \\
0.00\end{array}$ & & \\
\hline
\end{tabular}

${ }^{1}$ Limestone.

${ }^{2}$ Not applicable.

\section{TABLE D-8}

Aluminum Material Balance

\begin{tabular}{|c|c|c|c|c|c|c|c|c|}
\hline & Test 1 & Test 2 & Test 3 & Test 4 & Test 5 & Test 7 & Test 8 & Test 9 \\
\hline Coal Aah, lb/hr & 11.90 & 12.77 & 13.66 & 14.80 & 12.82 & 10.89 & 11.43 & 12.42 \\
\hline $\mathrm{Al}_{2} \mathrm{O}_{3}$ in coal ash, $\%$ & 16.40 & 16.40 & 16.40 & 16.40 & 16.40 & 16.40 & 16.40 & 16.40 \\
\hline Bed Material Drain, lb/hr & 0.00 & 0.00 & 1.90 & 0.00 & 0.00 & 0.00 & 0.00 & 0.00 \\
\hline $\mathrm{Al}_{2} \mathrm{O}_{3}$ in Bod Material, $\%$ & 1.80 & 4.83 & 3.95 & 4.02 & $\mathrm{ND}^{1}$ & 4.16 & 4.67 & 4.57 \\
\hline $\begin{array}{l}\text { Ash from Coal, } \% \\
\text { Ash from Coal, lb/hr }\end{array}$ & $\begin{array}{r}10.98 \\
0.00\end{array}$ & $\begin{array}{r}29.45 \\
0.00\end{array}$ & $\begin{array}{r}24.09 \\
0.46\end{array}$ & $\begin{array}{r}24.51 \\
0.00\end{array}$ & $\begin{array}{l}0.00 \\
0.00\end{array}$ & $\begin{array}{r}25.37 \\
0.00\end{array}$ & $\begin{array}{r}27.87 \\
0.00\end{array}$ & $\begin{array}{r}27.87 \\
0.00\end{array}$ \\
\hline Baghouse Drain, lb/hr & 4.10 & 10.10 & 6.30 & 10.10 & 7.60 & 2.20 & 5.60 & 7.30 \\
\hline $\mathrm{Al}_{2} \mathrm{O}_{3}$ in Baghouse A.h, $\%$ & 17.70 & 16.60 & 18.70 & 13.00 & ND & 17.90 & 16.70 & 12.40 \\
\hline $\begin{array}{l}\text { Ash from Coal, } \% \\
\text { Ash from Coal, lb/hr }\end{array}$ & $\begin{array}{r}107.98 \\
4.43\end{array}$ & $\begin{array}{r}101.22 \\
10.22\end{array}$ & $\begin{array}{r}114.02 \\
7.18\end{array}$ & $\begin{array}{r}79.27 \\
8.01\end{array}$ & $\begin{array}{l}0.00 \\
0.00\end{array}$ & $\begin{array}{r}109.15 \\
2.40\end{array}$ & $\begin{array}{r}101.83 \\
5.60\end{array}$ & $\begin{array}{r}75.61 \\
5.62\end{array}$ \\
\hline Secondary Cyclone Drain, $\mathrm{lb} / \mathrm{hr}$ & 9.80 & 0.00 & 0.00 & 0.00 & 0.00 & 0.00 & 0.00 & 0.00 \\
\hline $\mathrm{Al}_{2} \mathrm{O}_{3}$ in Cyclone Ash, $\%$ & 12.8 & $\mathbf{N A}^{2}$ & NA & NA & NA & NA & NA & NA \\
\hline $\begin{array}{l}\text { Ash from Coal, } \% \\
\text { Ash from Coal, lb/hr }\end{array}$ & $\begin{array}{r}78.05 \\
7.65\end{array}$ & $\begin{array}{l}0.00 \\
0.00\end{array}$ & $\begin{array}{l}0.00 \\
0.00\end{array}$ & $\begin{array}{l}0.00 \\
0.00\end{array}$ & $\begin{array}{l}0.00 \\
0.00\end{array}$ & $\begin{array}{l}0.00 \\
0.00\end{array}$ & $\begin{array}{l}0.00 \\
0.00\end{array}$ & $\begin{array}{l}0.00 \\
0.00\end{array}$ \\
\hline Total Ash from Coal, lb/hr & 12.07 & 10.22 & 7.64 & 8.01 & 0.00 & 2.40 & 5.60 & 6.52 \\
\hline Closure & 101.48 & 80.03 & 56.36 & 64.10 & 0.00 & 22.05 & 49.00 & 44.46 \\
\hline
\end{tabular}

1 Not determined.

${ }^{2}$ Not applicable. 
TABLE D-9

Fuel Balance

\begin{tabular}{lcccccccc}
\hline & Test 1 & Test 2 & Test 3 & Test 4 & Test 5 & Test 7 & Test 8 & Test 9 \\
\hline Fuel Feed Rate, meas., lb/hr & 250 & 273 & 301 & 315 & 278 & 229 & 246 & 272 \\
Fuel Feed Rate, theor., lb/hr & 259 & 278 & 295 & 322 & 279 & 237 & 249 & 271 \\
Difference, \% & -3.5 & -2.1 & 1.8 & -2.3 & -0.7 & -3.8 & -1.3 & 0.6 \\
\hline
\end{tabular}

meas. $=$ Feed rate determined by weight loss of the coal feed hopper over time.

theor. = Theoretical feed rate calculated on the basis of the coal analysis, the combustion air, and the excess air for each test period.

TABLE D-10

Flue Gas Balance

\begin{tabular}{lcccccccc}
\hline & Test 1 & Test 2 & Test 3 & Test 4 & Test 5 & Test 7 & Test 8 & Test 9 \\
\hline Fuel Feed Rate, meas., scfm & 519 & 597 & 611 & 599 & 587 & 477 & 595 & 601 \\
Fuel Feed Rate, theor., scfm & 538 & 554 & 578 & 560 & 540 & 462 & 558 & 553 \\
Difference, \% & -3.7 & 7.2 & 5.3 & 6.4 & 8.0 & 3.0 & 6.2 & 7.9 \\
\hline
\end{tabular}

meas. = The flue gas flow measured during the run through an orifice located just upstream of the ID fan.

theor. = Theoretical flue gas flow calculated on the basis of the coal analysis and the theoretical coal feed rate for each test period..

The energy balances for the eight tests are shown in Table D-11, both as Btu/hr and as percentages. The energy input is made up of the energy potential of the fuel, the primary and secondary combustion air, the external heat exchanger fluidizing air, and the energy released from the sulfation of the sorbent. Measurable heat loss sources are the combustor heat exchange doors, the external heat exchange cooling coils, the heat of the flue gas (including a correction for leakage), the heat of the ash removed, the unburned carbon in the ash removed, and the energy absorbed during calcination of the sorbent. The unmeasurable heat loss due to convection and radiation is estimated using a correlation developed from the data generated during testing with all five coals. The correlation relates heat loss to average combustor temperature. The energy balances for all eight tests were very good. The material balances are presented in Table D-12. Closure was near $100 \%$ for all eight tests.

\section{Combustion Efficiency}

The combustion efficiencies, shown in Table D-13 and Figure D-3, were greater than 99\% for all eight tests, and greater than $99.9 \%$ for all but Test 1 . The percentage of unburned carbon in each ash stream was calculated as the difference between the loss on ignition (LOI) and the carbonate content (as $\mathrm{CO}_{2}$ ). These values are shown in Table D-14. The highest percentage of unburned carbon in the baghouse was seen in Test 1 ; however, because of the low baghouse ash drain rate during this test, the combustion efficiency was still high. 
TABLE D-11

Energy Balance

\begin{tabular}{|c|c|c|c|c|c|c|c|c|}
\hline & Tost 1 & Test 2 & Teat 3 & Test 4 & Tont 5 & Test 7 & Toot 8 & Teat 9 \\
\hline \multicolumn{9}{|l|}{ Input, Btu/hr } \\
\hline Coal & $2,158,285$ & $2,317,325$ & $2,469,712$ & $2,684,533$ & $2,326,485$ & $1,975,930$ & $2,073,362$ & $2,262,377$ \\
\hline Primary Air & 112,830 & 136,619 & 142,961 & 141,033 & 130,238 & 126,960 & 130,936 & 147,795 \\
\hline Secondary Air & 80,293 & 88,616 & 96,213 & 93,463 & 87,942 & 24,963 & 87,742 & 98,651 \\
\hline EHX Air & 3,262 & 2,435 & 2,639 & 3,468 & 2,267 & 2,900 & 3,144 & 2,898 \\
\hline Sorbent Sulfation & 0 & 2,662 & 100 & 3,375 & 2,014 & 1,582 & 3,003 & 2,678 \\
\hline Total & $\underline{2,354,670}$ & $\underline{2,547,658}$ & $2,700,624$ & $\underline{2.925,873}$ & $2,548,946$ & $\underline{2,132,325}$ & $\underline{2,298,177}$ & $\underline{2,504,199}$ \\
\hline \multicolumn{9}{|l|}{ Input, \% } \\
\hline Coal & 91.7 & 91.0 & 91.1 & 91.8 & 91.3 & 92.7 & 90.2 & 89.9 \\
\hline Primary Air & 4.8 & 5.4 & 6.3 & 4.8 & 5.1 & 6.0 & 6.7 & 5.9 \\
\hline Secondary Air & 3.4 & 3.6 & 3.5 & 3.2 & 3.5 & 1.2 & 3.8 & 3.9 \\
\hline EHAX Air & 0.1 & 0.1 & 0.1 & 0.1 & 0.1 & 0.1 & 0.1 & 0.1 \\
\hline Sorbent Sulfation & 0.0 & 0.1 & 0.0 & 0.1 & 0.1 & 0.1 & 0.1 & 0.1 \\
\hline Total & 100.0 & 100.0 & 100.0 & $\underline{100.0}$ & 100.0 & 100.0 & $\underline{100.0}$ & 100.0 \\
\hline \multicolumn{9}{|l|}{ Output, Btw/hr } \\
\hline Flue Gas (sens.) & 993,676 & $1,017,893$ & $1,008,625$ & $1,070,294$ & $1,001,269$ & 840,465 & $1,016,557$ & $1,082,646$ \\
\hline Ash (sens.) & 6,611 & 3,994 & 3,018 & 3,951 & 3,002 & 869 & 2,172 & 3,066 \\
\hline Ash (chem.) * & 6,577 & 1,914 & 1,969 & 1,165 & 869 & 56 & 213 & 146 \\
\hline Combustor & 744,325 & 856,163 & 821,767 & 748,664 & 859,971 & 699,893 & 742,817 & 884,241 \\
\hline EHXX & 371,307 & 680,504 & 759,244 & 790,674 & 680,405 & 367,686 & 362,426 & 333,608 \\
\hline $\begin{array}{l}\text { Sorbent Calcination } \\
\text { Conduction and }\end{array}$ & 0 & 5,668 & 77 & 11,107 & 4,673 & 2,681 & 5,209 & 4,136 \\
\hline Radiation Losses & 220,260 & 205,882 & 163,943 & 197,807 & 204,475 & 199,839 & 202,079 & 252,716 \\
\hline Total & $\underline{2,341,756}$ & $\underline{2,672,008}$ & $\underline{2,748,642}$ & $\underline{2,823,652}$ & $2,654,664$ & $\underline{2,101,486}$ & $\underline{2,331,472}$ & $2,560,357$ \\
\hline \multicolumn{9}{|l|}{ Output, $\%$} \\
\hline Flue Gas (sens.) & 42.4 & 38.1 & 36.7 & 37.9 & 37.7 & 40.0 & 43.6 & 42.3 \\
\hline Ash (веns.) & 0.2 & 0.1 & 0.1 & 0.1 & 0.1 & 0.0 & 0.1 & 0.1 \\
\hline Ash (chem.) * & 0.3 & 0.1 & 0.1 & 0.0 & 0.0 & 0.0 & 0.0 & 0.0 \\
\hline Combustor & 31.8 & 32.0 & 29.9 & 26.6 & 32.4 & 33.3 & 31.9 & 34.5 \\
\hline EHX & 15.9 & 21.7 & 27.6 & 28.0 & 21.9 & 17.0 & 16.6 & 13.0 \\
\hline $\begin{array}{l}\text { Sorbent Calcination } \\
\text { Conduction and }\end{array}$ & 0.0 & 0.2 & 0.0 & 0.4 & 0.2 & 0.1 & 0.2 & 0.2 \\
\hline Radiation Losses & 9.4 & 7.7 & 6.6 & 7.0 & 7.7 & 9.5 & 8.7 & 9.9 \\
\hline Total & $\underline{99.5}$ & 100.0 & 101.8 & 100.0 & 100.0 & 100.0 & $\underline{100.0}$ & 100.0 \\
\hline Closure & 99.4 & 104.9 & 101.7 & 96.5 & 104.1 & 98.6 & 101.4 & 102.2 \\
\hline
\end{tabular}

* The heat of comburtion coefficient for pure carbon is an average of values found in Perry's Chemical Engineering Handbook Perry et al. (1984) and the Standord Handbook for Mechanical Engineers, Baumeister and Marko (1967).

\section{Boiler Efficiency}

Boiler efficiencies were calculated for each test period using ASME PTC 4.1, modified according to the recommendations in EPRI's "Atmospheric Fluidized-Bed Combustion Performance Guidelines" to account for the heat losses and gains associated with calcination and sulfation of the limestone. 


\section{TABLE D-12}

Material Balance

\begin{tabular}{|c|c|c|c|c|c|c|c|c|}
\hline & Test 1 & Tost 2 & Test 3 & Teat 4 & Tont 5 & Teat 7 & Teet 8 & Test 9 \\
\hline \multicolumn{9}{|l|}{ Total Mass Balance } \\
\hline \multicolumn{9}{|l|}{ Input, $\mathrm{lb} / \mathrm{hr}$} \\
\hline Comburtion Air & 2061 & 2082 & 2173 & 2070 & 2040 & 1697 & 2117 & 2092 \\
\hline Additional Air & 163 & 175 & 180 & 181 & 166 & 183 & 183 & 170 \\
\hline Bed Material & 0 & 0 & 0 & 0 & 0 & 0 & 0 & $\mathbf{0}$ \\
\hline Coal Foed & 259 & 278 & 295 & 322 & 279 & 237 & 249 & 271 \\
\hline Sorbent Feed & 0 & 7 & 0 & 16 & 6 & 4 & 7 & 5 \\
\hline Total Mass In & $\underline{2463}$ & $\underline{2543}$ & $\underline{2649}$ & 2589 & 2481 & $\underline{2121}$ & $\underline{2565}$ & $\underline{2538}$ \\
\hline \multicolumn{9}{|l|}{ Input, \% } \\
\hline Comburtion Air & 83.3 & 81.9 & 82.0 & 80.0 & 82.2 & 80.0 & 82.8 & 82.4 \\
\hline Foed Argiat Air & 6.2 & 6.9 & 6.8 & 7.0 & 6.3 & 8.6 & 7.2 & 6.7 \\
\hline Bed Material & 0.0 & 0.0 & 0.0 & 0.0 & 0.0 & 0.0 & 0.0 & 0.0 \\
\hline Coal Food & 10.6 & 10.9 & 11.2 & 12.6 & 11.3 & 11.2 & 9.7 & 10.7 \\
\hline Sorbent Feed & 0.0 & 0.3 & 0.0 & 0.6 & 0.2 & 0.2 & 0.3 & 0.2 \\
\hline Total Mase In & $\underline{100.0}$ & 100.0 & 100.0 & 100.0 & 100.0 & 100.0 & 100.0 & 100.0 \\
\hline \multicolumn{9}{|l|}{ Output, lb/hr } \\
\hline Measured Flue Gas & 2390 & 2747 & 2809 & 2761 & 2706 & 2196 & 2736 & 2765 \\
\hline Flue Gas Leaks & 89 & -198 & .149 & -177 & .216 & -65 & .169 & .219 \\
\hline \multicolumn{9}{|l|}{ Ash Out } \\
\hline Bed Material & 0 & 0 & 2 & 0 & 0 & 0 & 0 & 0 \\
\hline Baghouse & 4 & 10 & 6 & 10 & 8 & 2 & 6 & 7 \\
\hline Cyclone Ash & 10 & 0 & 0 & 0 & 0 & 0 & 0 & 0 \\
\hline Total Mass Out & $\underline{2493}$ & $\underline{2568}$ & $\underline{2668}$ & $\underline{2594}$ & $\underline{2498}$ & $\underline{2133}$ & $\underline{2573}$ & $\underline{2553}$ \\
\hline \multicolumn{9}{|l|}{ Output, $\%$} \\
\hline Measured Flue Gas & 95.9 & 107.4 & 105.3 & 106.4 & 108.3 & 102.9 & 106.4 & 108.3 \\
\hline Flue Gas Leaks & 3.6 & -7.8 & -6.6 & -6.8 & -8.6 & -3.0 & -6.6 & -8.6 \\
\hline Ash out & 0.0 & 0.0 & 0.1 & 0.0 & 0.0 & 0.0 & 0.0 & 0.0 \\
\hline Bed Material & 0.2 & 0.4 & 0.2 & 0.4 & 0.3 & 0.1 & 0.2 & 0.3 \\
\hline Baghouse & 0.4 & 0.0 & 0.0 & 0.0 & 0.0 & 0.0 & 0.0 & 0.0 \\
\hline Cyclone Ash & & & & & & & & \\
\hline Total Mass Out & 100.0 & 100.0 & $\underline{100.0}$ & 100.0 & 100.0 & 100.0 & $\underline{100.0}$ & 100.0 \\
\hline Closure & $\overline{101.2}$ & $\overline{100.6}$ & $\overline{100.7}$ & $\overline{100.2}$ & $\overline{100.7}$ & $\overline{100.5}$ & 100.7 & 100.6 \\
\hline
\end{tabular}

\section{TABLE D-13}

Combustion Efficiency

\begin{tabular}{|c|c|c|c|c|c|c|c|c|}
\hline & Test 1 & Test 2 & Test 3 & Test 4 & Test 5 & Test 7 & Test 8 & Test 9 \\
\hline \multicolumn{9}{|l|}{ Input } \\
\hline Coal Feed Rate, lb/hr & 259.20 & 278.30 & 296.40 & 322.40 & 279.40 & 237.30 & 249.00 & 270.60 \\
\hline Coal Carbon, $\%$ & 49.90 & 49.90 & 49.90 & 49.90 & 49.90 & 49.90 & 49.90 & 49.90 \\
\hline Total, $\mathrm{lb} / \mathrm{hr}$ & $\underline{129.20}$ & $\underline{138.70}$ & $\underline{147.30}$ & $\underline{160.70}$ & $\underline{139.30}$ & $\underline{118.30}$ & $\underline{124.10}$ & $\underline{134.80}$ \\
\hline \multicolumn{9}{|l|}{ Output } \\
\hline $\begin{array}{l}\text { Bottom Ash Discharge Rate, lb/hr } \\
\text { Unburned Carbon, \% }\end{array}$ & $\begin{array}{l}0.00 \\
0.21\end{array}$ & $\begin{array}{l}0.00 \\
0.44\end{array}$ & $\begin{array}{l}2.00 \\
2.89\end{array}$ & $\begin{array}{l}0.00 \\
2.53\end{array}$ & $\begin{array}{l}0.00 \\
2.53\end{array}$ & $\begin{array}{l}0.00 \\
0.22\end{array}$ & $\begin{array}{l}0.00 \\
0.74\end{array}$ & $\begin{array}{l}0.00 \\
0.45\end{array}$ \\
\hline Bottom Ash Carbon Discharge Rate, lb/hr & 0.00 & 0.00 & 0.05 & 0.00 & 0.00 & 0.00 & 0.00 & 0.00 \\
\hline $\begin{array}{l}\text { Cyclone Discharge Rate, lb/hr } \\
\text { Unburned Carbon, } \%\end{array}$ & $\begin{array}{l}9.80 \\
1.08\end{array}$ & $\begin{array}{l}0.00 \\
0.00\end{array}$ & $\begin{array}{l}0.00 \\
0.00\end{array}$ & $\begin{array}{l}0.00 \\
0.00\end{array}$ & $\begin{array}{l}0.00 \\
0.00\end{array}$ & $\begin{array}{l}0.00 \\
0.00\end{array}$ & $\begin{array}{l}0.00 \\
0.00\end{array}$ & $\begin{array}{l}0.00 \\
0.00\end{array}$ \\
\hline Cyclone Carbon Discharge Rate, lb/hr & 0.11 & 0.00 & 0.00 & 0.00 & 0.00 & 0.00 & 0.00 & 0.00 \\
\hline $\begin{array}{l}\text { Baghouse Discharge Rate, lb/hr } \\
\text { Unburned Carbon, } \%\end{array}$ & $\begin{array}{l}4.00 \\
8.80\end{array}$ & $\begin{array}{r}10.00 \\
1.34\end{array}$ & $\begin{array}{l}6.00 \\
1.34\end{array}$ & $\begin{array}{r}10.00 \\
0.81\end{array}$ & $\begin{array}{l}8.00 \\
0.81\end{array}$ & $\begin{array}{l}2.00 \\
0.18\end{array}$ & $\begin{array}{l}6.00 \\
0.27\end{array}$ & $\begin{array}{l}7.00 \\
0.14\end{array}$ \\
\hline Baghouse Carbon Discharge Rate, lb/hr & 0.36 & 0.14 & 0.08 & 0.08 & 0.06 & 0.00 & 0.02 & 0.01 \\
\hline Total, $\mathrm{lb} / \mathrm{hr}$ & $\underline{0.47}$ & $\underline{0.14}$ & $\underline{0.14}$ & $\underline{0.08}$ & $\underline{0.06}$ & $\underline{0.00}$ & $\underline{0.02}$ & $\underline{0.01}$ \\
\hline Combuation Efficiency, $\%$ & 99.64 & 99.90 & 99.91 & 99.96 & 99.96 & 100.00 & 99.99 & 99.99 \\
\hline
\end{tabular}




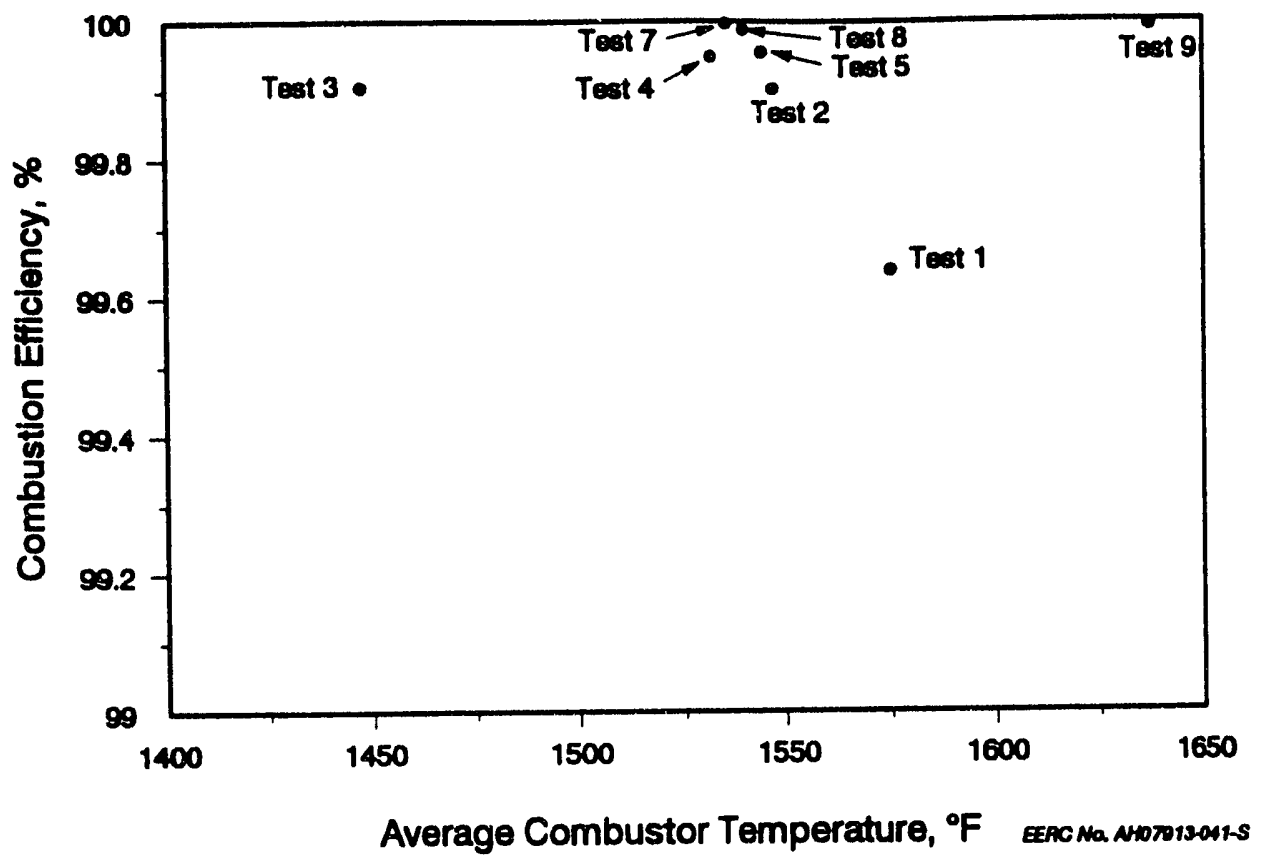

Figure D-3. Combustion efficiencies.

TABLE D-14

Unburned Carbon (\%)

\begin{tabular}{|c|c|c|c|c|c|c|c|c|}
\hline & Test 1 & Test 2 & Test 3 & Test 4 & Test 5 & Test 7 & Test 8 & Test 9 \\
\hline \multicolumn{9}{|l|}{ Combustor Bed Material } \\
\hline $\begin{array}{l}\text { Loss on Ignition } \\
\text { Carbonate (as } \mathrm{CO}_{2} \text { ) } \\
\text { Unburned Carbon }\end{array}$ & $\begin{array}{l}0.24 \\
0.11 \\
0.21\end{array}$ & $\begin{array}{l}0.56 \\
0.44 \\
0.44\end{array}$ & $\begin{array}{l}4.01 \\
4.09 \\
2.89\end{array}$ & $\begin{array}{l}3.41 \\
3.22 \\
2.53\end{array}$ & $\begin{array}{l}3.41 \\
3.22 \\
2.53\end{array}$ & $\begin{array}{l}0.37 \\
0.56 \\
0.22\end{array}$ & $\begin{array}{l}0.94 \\
0.75 \\
0.74\end{array}$ & $\begin{array}{l}0.62 \\
0.64 \\
0.45\end{array}$ \\
\hline \multicolumn{9}{|l|}{ Secondary Cyclone Ash } \\
\hline $\begin{array}{l}\text { Loss on Ignition } \\
\left.\text { Carbonate (as } \mathrm{CO}_{2}\right) \\
\text { Unburned Carbon }\end{array}$ & $\begin{array}{l}1.19 \\
0.4 \\
1.08\end{array}$ & $\begin{array}{l}\mathrm{NA}^{1} \\
\mathrm{NA} \\
0.00\end{array}$ & $\begin{array}{c}\text { NA } \\
\text { NA } \\
0.00\end{array}$ & $\begin{array}{c}\text { NA } \\
\text { NA } \\
0.00\end{array}$ & $\begin{array}{c}\text { NA } \\
\text { NA } \\
0.00\end{array}$ & $\begin{array}{l}\text { NA } \\
\text { NA } \\
0.00\end{array}$ & $\begin{array}{l}\text { NA } \\
\text { NA } \\
0.00\end{array}$ & $\begin{array}{r}\text { NA } \\
\text { NA } \\
0.00\end{array}$ \\
\hline \multicolumn{9}{|l|}{ Baghouse Ash } \\
\hline $\begin{array}{l}\text { Loss on Ignition } \\
\left.\text { Carbonate (as } \mathrm{CO}_{2}\right) \\
\text { Unburned Carbon }\end{array}$ & $\begin{array}{l}8.94 \\
0.51 \\
8.80\end{array}$ & $\begin{array}{l}1.47 \\
0.46 \\
1.34\end{array}$ & $\begin{array}{l}1.56 \\
0.79 \\
1.34\end{array}$ & $\begin{array}{l}0.97 \\
0.58 \\
0.81\end{array}$ & $\begin{array}{l}0.97 \\
0.58 \\
0.81\end{array}$ & $\begin{array}{l}0.27 \\
0.34 \\
0.18 \\
\end{array}$ & $\begin{array}{l}0.4 \\
0.46 \\
0.27\end{array}$ & $\begin{array}{l}0.28 \\
0.51 \\
0.14\end{array}$ \\
\hline
\end{tabular}

${ }^{1}$ Not applicable.

Table D-15 summarizes the results of the boiler efficiency calculations for this run. Boiler radiation and convective losses were assumed to be $0.4 \%$; although the actual losses at the pilot scale are much greater, $0.4 \%$ was chosen to be representative of a full-scale system. The exit gas temperature was assumed to be $300^{\circ} \mathrm{F}$. 


\section{TABLE D-15}

\section{Boiler Efficiency}

\begin{tabular}{|c|c|c|c|c|c|c|c|c|}
\hline & Test 1 & Test 2 & Test 3 & Toet 4 & Tost 6 & Teat 7 & Toat 8 & Test 9 \\
\hline Assumed Flue Gas Exit Temp., ${ }^{\circ} F$ & 300 & 300 & 300 & 300 & 300 & 300 & 300 & 300 \\
\hline \multicolumn{9}{|l|}{ Losses, Btu/hr } \\
\hline Dry Gas & 130,817 & 134,137 & 139,894 & 134,977 & 130,910 & 112,041 & 137,204 & 134,839 \\
\hline Water in Fuel & 86,162 & 91,427 & 97,044 & 106,914 & 91,788 & 77,957 & 81,801 & 88,864 \\
\hline Comb. of Fuel Hydrogen & 10,964 & 11,761 & 12,484 & 13,625 & 11,808 & 10,029 & 10,623 & 11,432 \\
\hline Unburned Carbon & 6,677 & 1,914 & 1,969 & 1,166 & 869 & 66 & 213 & 145 \\
\hline Sorbent Calcination & 0 & 5,668 & 77 & 11,107 & 4,673 & 2,681 & 5,209 & 4,136 \\
\hline Radiation and Convection * & 8,969 & $\mathbf{9 , 6 3 0}$ & 10,221 & 11,166 & 9,668 & 8,211 & 8,616 & 9,360 \\
\hline Discharged Solids & 5,611 & 3,994 & 3,018 & 3,961 & 3,002 & 869 & 2,172 & 3,066 \\
\hline Sorbent Sulfation & $\mathbf{0}$ & $-2,662$ & -100 & $-3,376$ & $-2,014$ & $-1,582$ & $-3,003$ & $-2,5,78$ \\
\hline Total & $\underline{248,079}$ & $\underline{255,867}$ & $\underline{264,607}$ & $\underline{278,059}$ & $\underline{250,703}$ & $\underline{210,260}$ & $\underline{242,735}$ & $\underline{249,263}$ \\
\hline \multicolumn{9}{|l|}{ Losses, \% } \\
\hline Dry Gas & 6.0 & 6.7 & 6.4 & 5.0 & 5.6 & 5.7 & 6.5 & 6.7 \\
\hline Water in Fuel & 3.9 & 3.9 & 3.7 & 3.9 & 3.8 & 3.9 & 3.8 & 3.8 \\
\hline Comb. of Fuel Hydrogen & 0.5 & 0.6 & 0.6 & 0.5 & 0.5 & 0.5 & 0.5 & 0.5 \\
\hline Unburned Carbon & 0.3 & 0.1 & 0.1 & 0.0 & 0.0 & 0.0 & 0.0 & 0.0 \\
\hline Sorbent Calcination & 0.0 & 0.2 & 0.0 & 0.4 & 0.2 & 0.1 & 0.2 & 0.2 \\
\hline Radiation and Convection * & 0.4 & 0.4 & 0.4 & 0.4 & 0.4 & 0.4 & 0.4 & 0.4 \\
\hline Discharged Solids & 0.3 & 0.2 & 0.1 & 0.1 & 0.1 & 0.0 & 0.1 & 0.1 \\
\hline Sorbent Sulfation & 0.0 & -0.1 & 0.0 & -0.1 & .0 .1 & -0.1 & -0.1 & .0 .1 \\
\hline Total & $\underline{11.5}$ & $\underline{10.8}$ & $\underline{10.2}$ & $\underline{10.2}$ & 10.4 & $\underline{10.6}$ & $\underline{11.4}$ & $\underline{10.6}$ \\
\hline Boilex Efficiency & 88.6 & 89.2 & 89.8 & 89.8 & 89.6 & 89.4 & 88.6 & 89.4 \\
\hline
\end{tabular}

* Assumes $0.4 \%$ radiative and convective losses.

Boiler efficiencies for this run ranged from $88.6 \%$ to $89.9 \%$. The moisture and hydrogen in the fuel accounted for about $4.3 \%$ of the losses in all tests. The difference in boiler efficiencies between the eight tests is due to differences in the loss from the dry flue gas; this was greatest $(6.5 \%)$ for Test 8 , the high excess air test, and lowest (5.0\%) for Test 4, the low excess air test.

\section{Heat-Transfer Coefficient and Heat Flux}

The heat-transfer coefficients and heat flux for each of the combustor sections containing heat exchange surface, as well as the EHX, are shown in Tables D-16 and D17, respectively. The overall values for each test are also presented in Table D-5 to facilitate comparison with test conditions. The combustor heat fluxes for this run ranged from 26,339 Btu/hr- $\mathrm{ft}^{2}$ for Test 3, the low-temperature test, to $34,009 \mathrm{Btu} / \mathrm{hr}$ - $\mathrm{ft}^{2}$ for Test 9, the high-temperature, high-velocity test. Test 7, the low-load test which was conducted at low velocity and an intermediate operating temperature, also had a low average heat flux of $26,919 \mathrm{Btu} / \mathrm{hr}-\mathrm{ft}^{2}$. Inspection of the data in Table D-5 shows that for those tests in which secondary cyclone ash was recycled back into the system the solids recirculation rate was highest for Test 9 and lowest for Test 7 . Therefore, both the average combustor temperature and the solids recirculation rate had a significant effect on heat flux for the Black Thunder subbituminous coal. 
Table D-16

Individual Heat-Transfer Coefficients, Btu/hr- $\mathrm{ft}^{2}{ }^{\circ} \mathrm{F}$

\begin{tabular}{cccccccccrr}
\hline $\begin{array}{c}\text { Combustor } \\
\text { Section }\end{array}$ & Test 1 & Test 2 & Test 3 & Test 4 & Test 5 & Test 7 & Test 8 & Tost 9 & Average & $\begin{array}{c}\text { Combustor } \\
\text { Height }\end{array}$ \\
\hline 2 & 20.2 & 21.9 & 20.8 & 20.9 & 21.9 & 19.0 & 19.1 & 21.5 & 20.7 & 7.6 \\
3 & 24.6 & 23.6 & 22.8 & 23.0 & 22.8 & 21.2 & 21.7 & 24.4 & 28.0 & 12.5 \\
4 & 25.3 & 39.4 & 30.7 & 26.9 & 39.5 & 27.3 & 28.5 & 32.6 & 31.3 & 17.5 \\
5 & 26.5 & 28.3 & 27.2 & 27.7 & 26.7 & 23.9 & 25.3 & 29.1 & 26.8 & 22.5 \\
6 & 19.9 & 18.1 & 16.7 & 18.0 & 18.1 & 15.7 & 17.7 & 20.4 & 18.1 & 27.5 \\
7 & 14.5 & 21.0 & 17.4 & 18.3 & 10.5 & 16.2 & 17.8 & 21.2 & 17.1 & 32.6 \\
8 & 16.8 & 16.8 & 17.1 & off & 8.8 & off & off & off & 14.9 & 37.5 \\
Overall & 20.0 & 23.4 & 20.0 & 20.5 & 23.6 & 19.0 & 20.2 & 22.8 & 21.2 & \\
EHXX & 66.3 & 82.6 & 78.9 & 82.0 & 81.9 & 66.1 & 78.0 & 79.6 & 75.7 & \\
\hline
\end{tabular}

TABLE D-17

Individual Heat Flux, Btu/hr-ft ${ }^{2}$

\begin{tabular}{|c|c|c|c|c|c|c|c|c|c|c|}
\hline $\begin{array}{c}\text { Combustor } \\
\text { Section }\end{array}$ & Test 1 & Test 2 & Test 3 & Test 4 & Teat 5 & Test 7 & Test 8 & Test 9 & Average & $\begin{array}{c}\text { Combustor } \\
\text { Hoight }\end{array}$ \\
\hline 2 & 30,796 & 31,699 & 28,048 & 29,811 & 31,653 & 27,739 & 27,793 & 32,679 & 30,015 & 7.5 \\
\hline 3 & 35,394 & 33,301 & 30,196 & 32,300 & 32,178 & 29,896 & 30,688 & 36,182 & 32,504 & 12.5 \\
\hline 4 & 34,599 & 64,093 & 40,357 & 37,430 & 64,121 & 37,610 & 39,474 & 47,775 & 43,182 & 17.5 \\
\hline 5 & 36,624 & 39,658 & 36,700 & 38,541 & 37,456 & 33,667 & 35,703 & 43,284 & 37,654 & 22.6 \\
\hline 6 & 27,581 & 26,052 & 22,565 & 25,856 & 25,997 & 22,186 & 25,120 & 30,749 & 25,763 & 27.5 \\
\hline 7 & 20,153 & 29,946 & 22,994 & 26,164 & 14,903 & 22,471 & 25,154 & 31,912 & 24,212 & 32.6 \\
\hline 8 & 23,096 & 24,278 & 22,913 & off & 12,712 & off & off & off & 20,750 & 37.6 \\
\hline Overall & 28,628 & 32,929 & 26,339 & 28,796 & 33,076 & 26,919 & 28,570 & 34,009 & 29,908 & \\
\hline EHXX & 65,008 & 96,761 & 84,360 & 95,839 & 96,734 & 69,614 & 96,647 & 111,169 & 87,015 & \\
\hline
\end{tabular}

Heat flux in the EHX ranged from $55,008 \mathrm{Btu} / \mathrm{hr}-\mathrm{ft}^{2}$ to $111,169 \mathrm{Btu} / \mathrm{hr}-\mathrm{ft}^{2}$ for Tests 1 and 9, respectively. The EHX heat flux for Test 7 was only slightly higher than during Test 1 at $59,614 \mathrm{Btu} / \mathrm{hr}$ - $\mathrm{ft}^{2}$ and reflects the change in the size distribution of the bed material in the EHX, as well as the increase in solids recirculation rate with secondary cyclone recycle after Test 1.

\section{Pressure and Temperature Profiles}

The pressure profiles for this run are shown in Figure D-4 and are typical of a CFB, with a dense phase in the lower portion of the combustor, similar to a bubbling bed, and a dilute phase in the rest of the combustor. The pressure profiles for all eight tests are quite uniform, with some variation due to differences in bed inventory and superficial gas velocity in the combustor.

Figure D-5 shows the temperature profiles for each test. The lower temperature at the bottom of the combustor is the result of cooler solids flowing into combustor Section 1 from the external heat exchanger. The temperature distribution in Test 1, with a much higher temperature in the bottom than at the top, is a function of the low solids recirculation rate $(2245 \mathrm{lb} / \mathrm{hr})$ resulting from the removal of secondary cyclone ash from the system. 


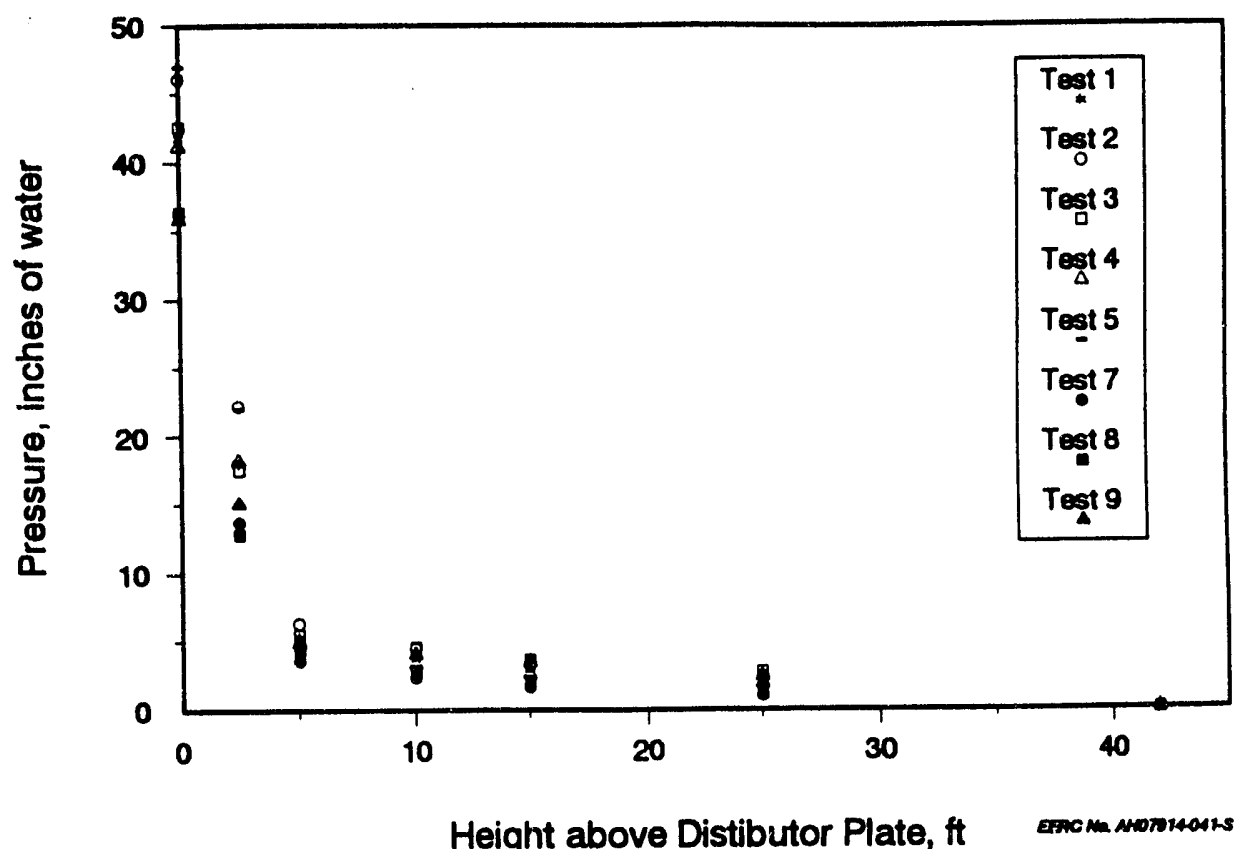

Figure D-4. Combustor pressure profiles.

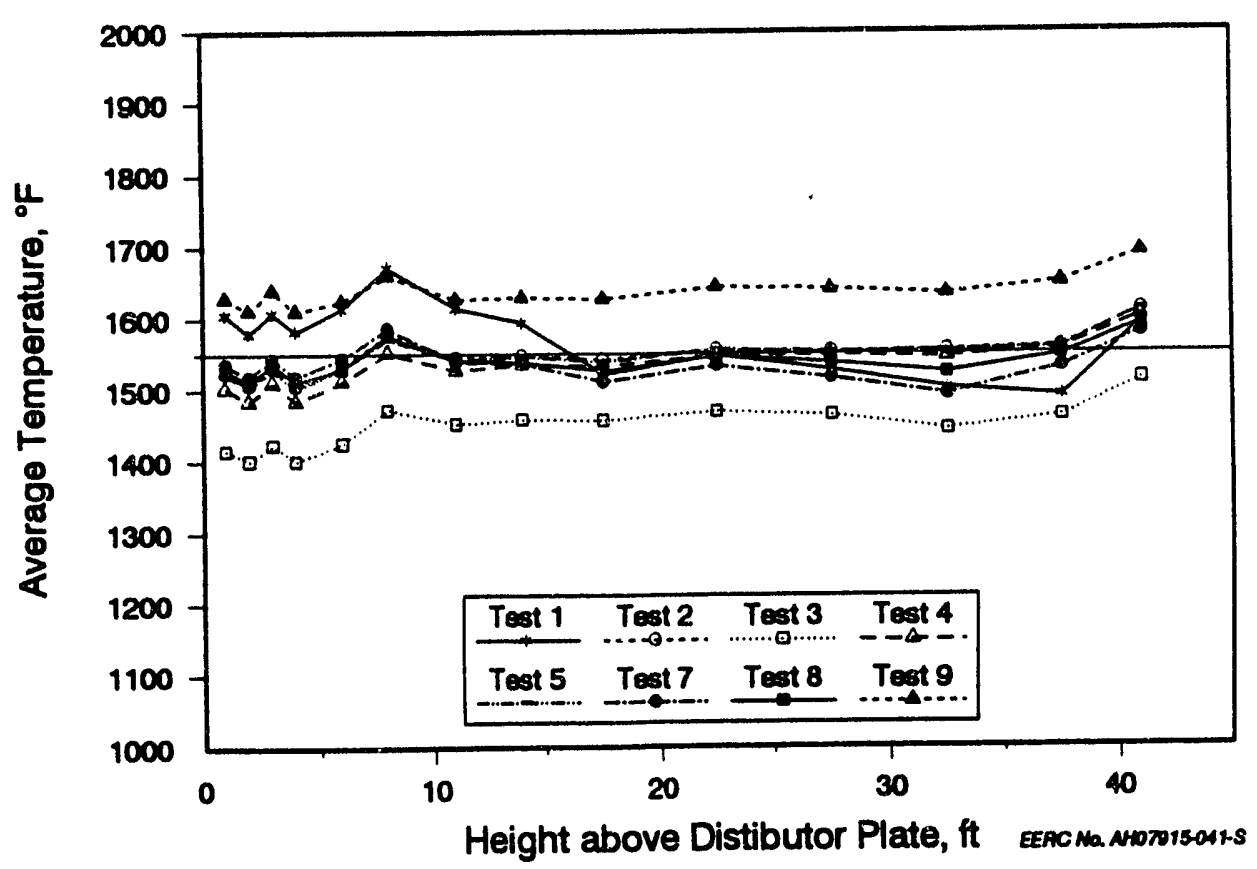

Figure D-5. Combustor temperature profiles. 


\section{ENVIRONMENTAL PERFORMANCE}

Average flue gas emissions for each of the steady-state test periods are presented in Table D-18 and discussed in the following sections.

\section{$\mathrm{SO}_{2}$ Emissions}

The sulfur retention for the low-, medium-, and high-temperature tests (Tests 3, 2, and 9, respectively) are shown as a function of temperature in Figure D-6. The expected trend is optimum sulfur capture at a particular temperature or temperature range, with less sulfur capture at lower and higher temperatures. For the Black Thunder subbituminous coal, optimum sulfur capture appears to occur at or near $1450^{\circ} \mathrm{F}$. Test 9 had much higher sulfur retention than expected; this is due to the relatively large amount of limestone added to the system prior to this test. The high recirculation rate $(>16,000 \mathrm{lb} / \mathrm{hr}$ ) indicated that most of the limestone stayed in the system, rather than being removed in the secondary cyclone drain.

TABLE D-18

Emission Data

\begin{tabular}{|c|c|c|c|c|c|c|c|c|}
\hline & Tost 1 & Test 2 & Test 3 & Test 4 & Test 5 & Test 7 & Test 8 & Test 9 \\
\hline $\mathrm{O}_{2}, \%$ & 6.15 & 4.44 & 4.06 & 1.72 & 3.85 & 4.00 & 6.38 & 4.88 \\
\hline $\begin{array}{l}\text { CO Content, ppm } \\
\text { CO Content, }{ }^{1} \mathrm{ppm} \\
\text { CO Emission, lb/MM Btu }\end{array}$ & $\begin{array}{r}2 \\
3 \\
0.002\end{array}$ & $\begin{array}{r}10 \\
11 \\
0.009\end{array}$ & $\begin{array}{r}17 \\
18 \\
0.016\end{array}$ & $\begin{array}{r}11 \\
10 \\
0.008\end{array}$ & $\begin{array}{r}7 \\
8 \\
0.006\end{array}$ & $\begin{array}{r}7 \\
7 \\
0.006\end{array}$ & $\begin{array}{r}4 \\
6 \\
0.004\end{array}$ & $\begin{array}{r}6 \\
6 \\
0.005\end{array}$ \\
\hline $\begin{array}{l}\mathrm{CO}_{2} \text { Content, } \% \\
\mathrm{CO}_{2} \text { Content, }{ }^{1} \%\end{array}$ & $\begin{array}{l}16.0 \\
17.1\end{array}$ & $\begin{array}{l}16.4 \\
16.8\end{array}$ & $\begin{array}{l}15.6 \\
16.6\end{array}$ & $\begin{array}{l}17.8 \\
16.6\end{array}$ & $\begin{array}{l}16.2 \\
17.0\end{array}$ & $\begin{array}{l}16.0 \\
16.9\end{array}$ & $\begin{array}{l}13.9 \\
17.2\end{array}$ & $\begin{array}{l}16.0 \\
16.7\end{array}$ \\
\hline $\begin{array}{l}\mathrm{NO}_{\mathrm{x}} \text { Conteint, ppm } \\
\mathrm{NO}_{\mathrm{x}} \text { Content, }{ }^{1} \mathrm{ppm} \\
\mathrm{NO}_{\mathrm{z}} \text { Emissi } \mathrm{pm}, \mathrm{lb} / \mathrm{MM} \text { Btu }\end{array}$ & $\begin{array}{r}218 \\
248 \\
0.321\end{array}$ & $\begin{array}{r}174 \\
189 \\
0.249\end{array}$ & $\begin{array}{r}156 \\
166 \\
0.221\end{array}$ & $\begin{array}{r}136 \\
127 \\
0.169\end{array}$ & $\begin{array}{r}166 \\
164 \\
0.213\end{array}$ & $\begin{array}{r}177 \\
188 \\
0.245\end{array}$ & $\begin{array}{r}205 \\
252 \\
0.324\end{array}$ & $\begin{array}{r}227 \\
253 \\
0.334\end{array}$ \\
\hline $\begin{array}{l}\mathrm{N}_{2} \mathrm{O} \text { Content, ppm } \\
\mathrm{N}_{2} \mathrm{O} \text { Content, }{ }^{1} \text { ppm } \\
\mathrm{N}_{2} \mathrm{O} \text { Emission, lb/MM Btu }\end{array}$ & $\begin{array}{r}22 \\
26 \\
0.031\end{array}$ & $\begin{array}{r}40 \\
44 \\
0.055\end{array}$ & $\begin{array}{r}58 \\
62 \\
0.079\end{array}$ & $\begin{array}{r}32 \\
30 \\
0.038\end{array}$ & $\begin{array}{r}N / A^{2} \\
0 \\
0.000\end{array}$ & $\begin{array}{r}35 \\
37 \\
0.046\end{array}$ & $\begin{array}{r}31 \\
38 \\
0.046\end{array}$ & $\begin{array}{r}22 \\
24 \\
0.031\end{array}$ \\
\hline $\begin{array}{l}\mathrm{SO}_{2} \text { Content, }{ }^{3} \mathrm{ppm} \\
\mathrm{SO}_{2} \text { Content, }{ }^{1} \mathrm{ppm} \\
\mathrm{SO}_{3} \text { Emisgion, } \mathrm{lb} / \mathrm{MM} \text { Btu } \\
\mathrm{SO}_{2} \text { Retention, }{ }^{9} \%\end{array}$ & $\begin{array}{r}341 \\
388 \\
0.698 \\
2.9\end{array}$ & $\begin{array}{r}80 \\
87 \\
0.160 \\
77.7\end{array}$ & $\begin{array}{r}4 \\
4 \\
0.007 \\
99.0\end{array}$ & $\begin{array}{r}128 \\
120 \\
0.221 \\
69.3\end{array}$ & $\begin{array}{r}136 \\
142 \\
0.256 \\
64.3\end{array}$ & $\begin{array}{r}98 \\
108 \\
0.188 \\
73.9\end{array}$ & $\begin{array}{r}11 \\
13 \\
0.023 \\
96.8\end{array}$ & $\begin{array}{r}38 \\
43 \\
0.079 \\
89.1\end{array}$ \\
\hline $\begin{array}{l}\mathrm{Ca} / \mathrm{S} \text { ratio }\left(\mathrm{a}^{4} \text { only) }\right. \\
\mathrm{Ca} / \mathrm{S} \text { ratio (total) } \\
\mathrm{Ca} \text { Utiliz. (la only) } \\
\mathrm{Ca} \text { Utiliz. (total) }\end{array}$ & $\begin{array}{r}0.0 \\
2.06 \\
0.0 \\
1.4\end{array}$ & $\begin{array}{r}2.5 \\
4.60 \\
30.6 \\
16.9\end{array}$ & $\begin{array}{r}0.0 \\
2.10 \\
0.0 \\
47.2\end{array}$ & $\begin{array}{r}4.3 \\
6.36 \\
16.1 \\
10.9\end{array}$ & $\begin{array}{r}2.1 \\
4.15 \\
30.9 \\
16.5\end{array}$ & $\begin{array}{r}1.4 \\
3.47 \\
62.5 \\
21.3\end{array}$ & $\begin{array}{r}2.6 \\
4.67 \\
37.1 \\
20.7\end{array}$ & $\begin{array}{r}1.9 \\
3.97 \\
46.8 \\
22.4\end{array}$ \\
\hline $\begin{array}{l}\text { Alkali-to-Sulfur (total) } \\
\text { Alkali Utilization }\end{array}$ & $\begin{array}{r}2.11 \\
1.4\end{array}$ & $\begin{array}{l}4.64 \\
16.7\end{array}$ & $\begin{array}{l}2.14 \\
46.3\end{array}$ & $\begin{array}{l}6.40 \\
10.8\end{array}$ & $\begin{array}{l}4.19 \\
16.4\end{array}$ & $\begin{array}{l}3.51 \\
21.0\end{array}$ & $\begin{array}{l}4.71 \\
20.6\end{array}$ & $\begin{array}{l}4.01 \\
22.2\end{array}$ \\
\hline $\begin{array}{l}\text { Avg. Comb. Temp., }{ }^{\circ} \\
\text { Moisture in FG, } \% \\
\text { Moiøt-Free Coal Carbon, } \% \\
\text { Moist-Free Coal Sulfur, } \%\end{array}$ & $\begin{array}{r}1575 \\
11.6 \\
68.8 \\
0.4 \\
\end{array}$ & $\begin{array}{r}1547 \\
12.0 \\
68.8 \\
0.4 \\
\end{array}$ & $\begin{array}{r}1448 \\
12.2 \\
68.8 \\
0.4 \\
\end{array}$ & $\begin{array}{r}1632 \\
13.4 \\
68.8 \\
0.4 \\
\end{array}$ & $\begin{array}{r}1545 \\
12.3 \\
68.8 \\
0.4 \\
\end{array}$ & $\begin{array}{r}1636 \\
12.2 \\
68.8 \\
0.4 \\
\end{array}$ & $\begin{array}{r}1640 \\
10.9 \\
68.8 \\
0.4 \\
\end{array}$ & $\begin{array}{r}1637 \\
11.7 \\
68.8 \\
0.4 \\
\end{array}$ \\
\hline
\end{tabular}

1 Corrected to $3 \% \mathrm{O}_{2}$.

2 Not available.

8 Moisture-free coal carbon and sulfur values used in the sulfur retention calculation.

4 Limestone. 


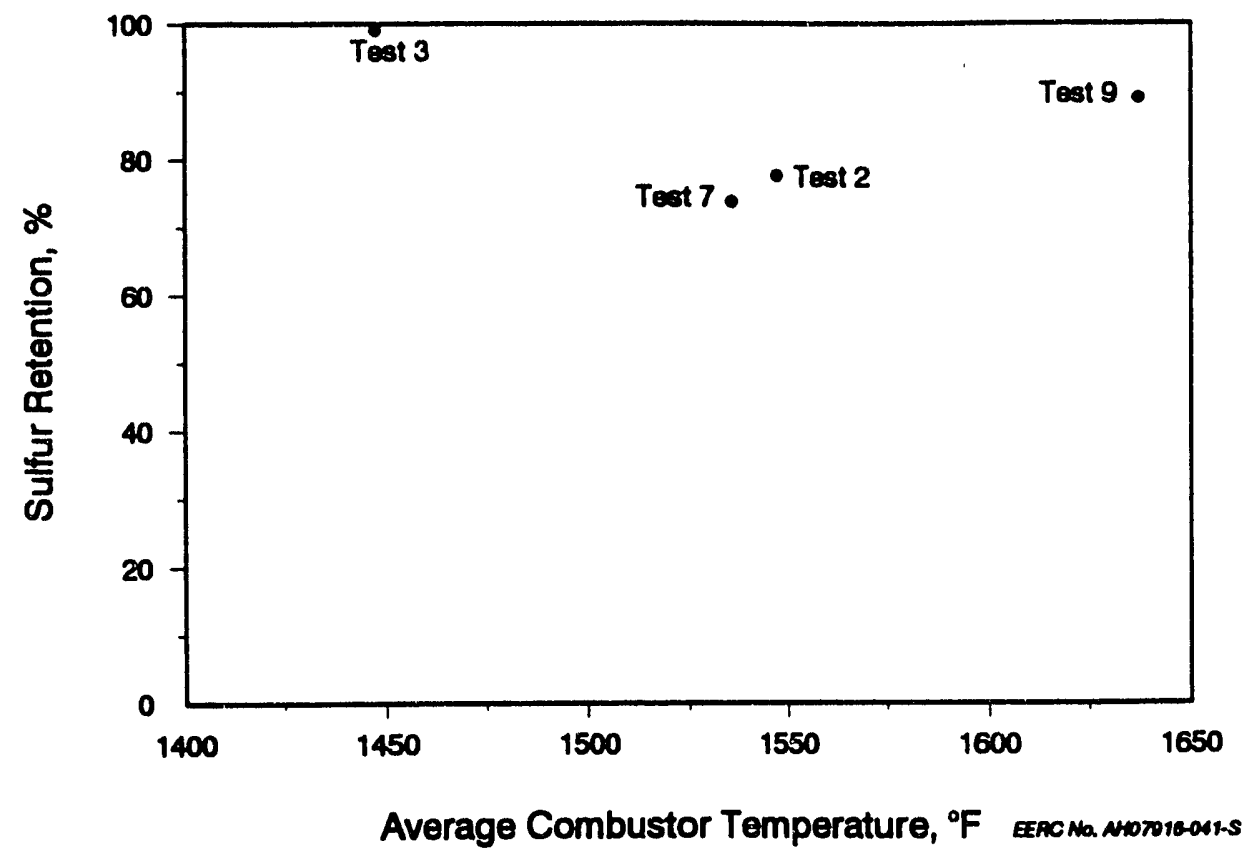

Figure D-6. Sulfur retention as a function of average combustor temperature.

Figure D-7 shows the effect of excess air on sulfur emissions for three tests with similar temperatures: Tests 2, 4, and 8 . As expected, the high excess air test had the lowest sulfur emissions.

Finally, the effect of alkali-to-sulfur ratio on sulfur retention is shown in Figure D-8. Tests 1, 2, and 5 were operated at similar temperature and excess air. Test 1, with no limestone feed, served as the baseline for sulfur emissions. Sulfur retention increases with increasing alkali-to-sulfur ratio.

\section{$\mathrm{NO}_{\mathbf{x}}$ Emissions}

$\mathrm{NO}_{\mathrm{z}}$ emissions for this coal ranged from $127 \mathrm{ppm}$ (corrected to $3 \% \mathrm{O}_{2}$ ) for Test 4 , to $253 \mathrm{ppm}$ (corrected to $3 \% \mathrm{O}_{2}$ ) for Test 9 . Figure D-9 shows the $\mathrm{NO}_{\mathrm{x}}$ emissions 's a function of temperature for Tests $2,3,7$, and 9 . There appears to be a slight relationship between temperature and $\mathrm{NO}_{\mathrm{x}}$ emissions for Tests 3,7 , and 2 ; the higher $\mathrm{NO}_{\mathrm{x}}$ for Test 9 shows the additional effects of higher excess air and calcium in the bed.

Typically, there is a positive relationship between $\mathrm{NO}_{\mathrm{x}}$ emissions and limestone addition; however, this coal produced the opposite effect, as shown in Figure D-10. Tests 2,5 , and 7 had similar temperatures $\left(1545^{\circ}, 1541^{\circ}\right.$, and $1532^{\circ} \mathrm{F}$, respectively) and excess air levels $(26.7 \%, 22.5 \%$, and $23.5 \%$, respectively); Test 1 had both higher temperature $\left(1573^{\circ} \mathrm{F}\right)$ and higher excess air $(33.8 \%)$, which may account for some of the difference.

Figure D-11 shows the $\mathrm{NO}_{2}$ emissions as a function of excess air for Tests 2, 4, and 8. These tests had similar temperatures ( $1529^{\circ}$ to $\left.1545^{\circ} \mathrm{F}\right)$; Tests 2 and 8 had added calcium-to-sulfur ratios of about 2.5; Test 4 had an added calcium-to-sulfur ratio of 4.3 . There is a strong positive correlation between excess air and $\mathrm{NO}_{\mathbf{z}}$ emissions for these three tests. 


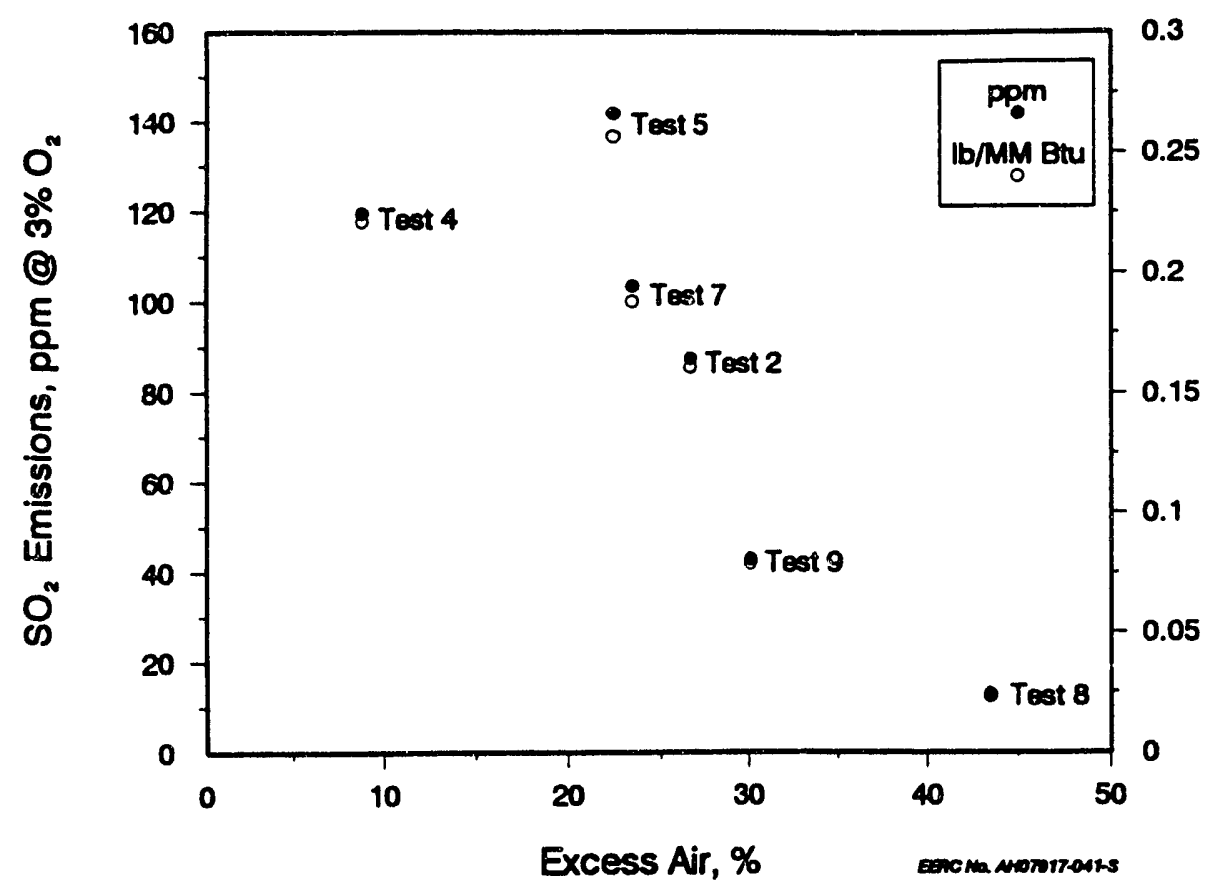

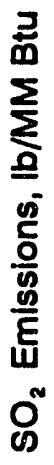

Figure D-7. $\mathrm{SO}_{2}$ emissions as a function of excess air.

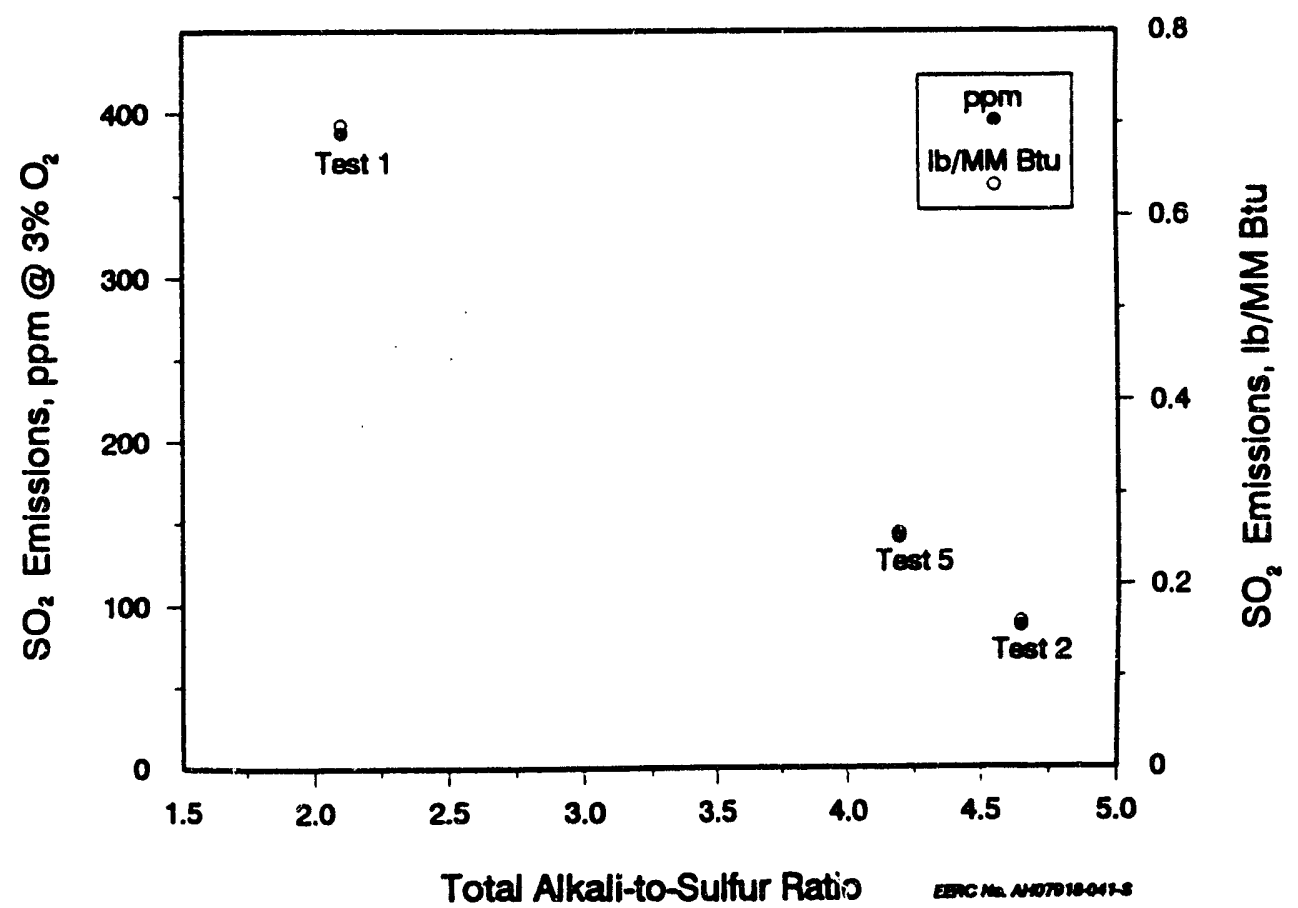

Figure D-8. $\mathrm{SO}_{2}$ emissions as a function of alkali-to-sulfur ratio. 


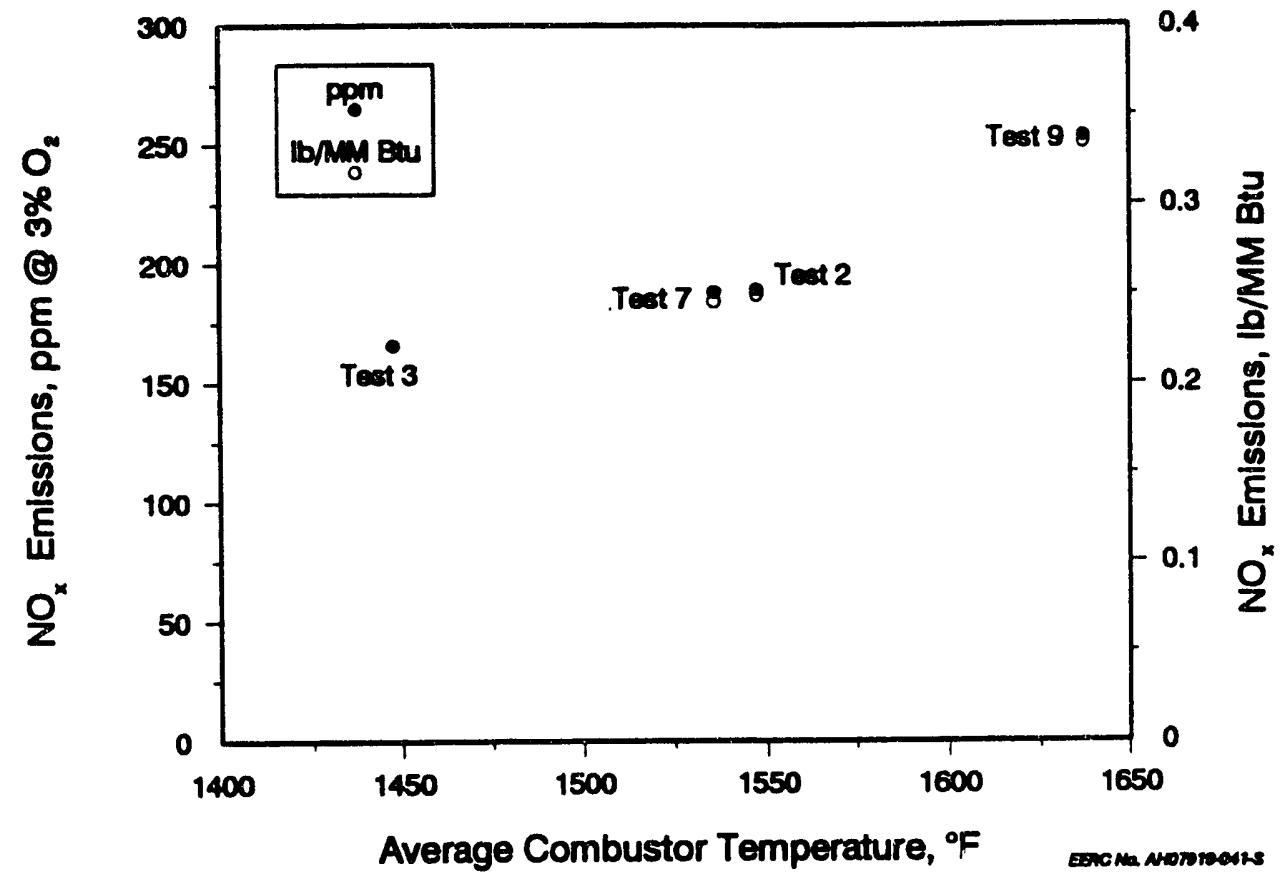

Figure D-9. $\mathrm{NO}_{\mathrm{z}}$ emissions as a function of average combustor temperature.

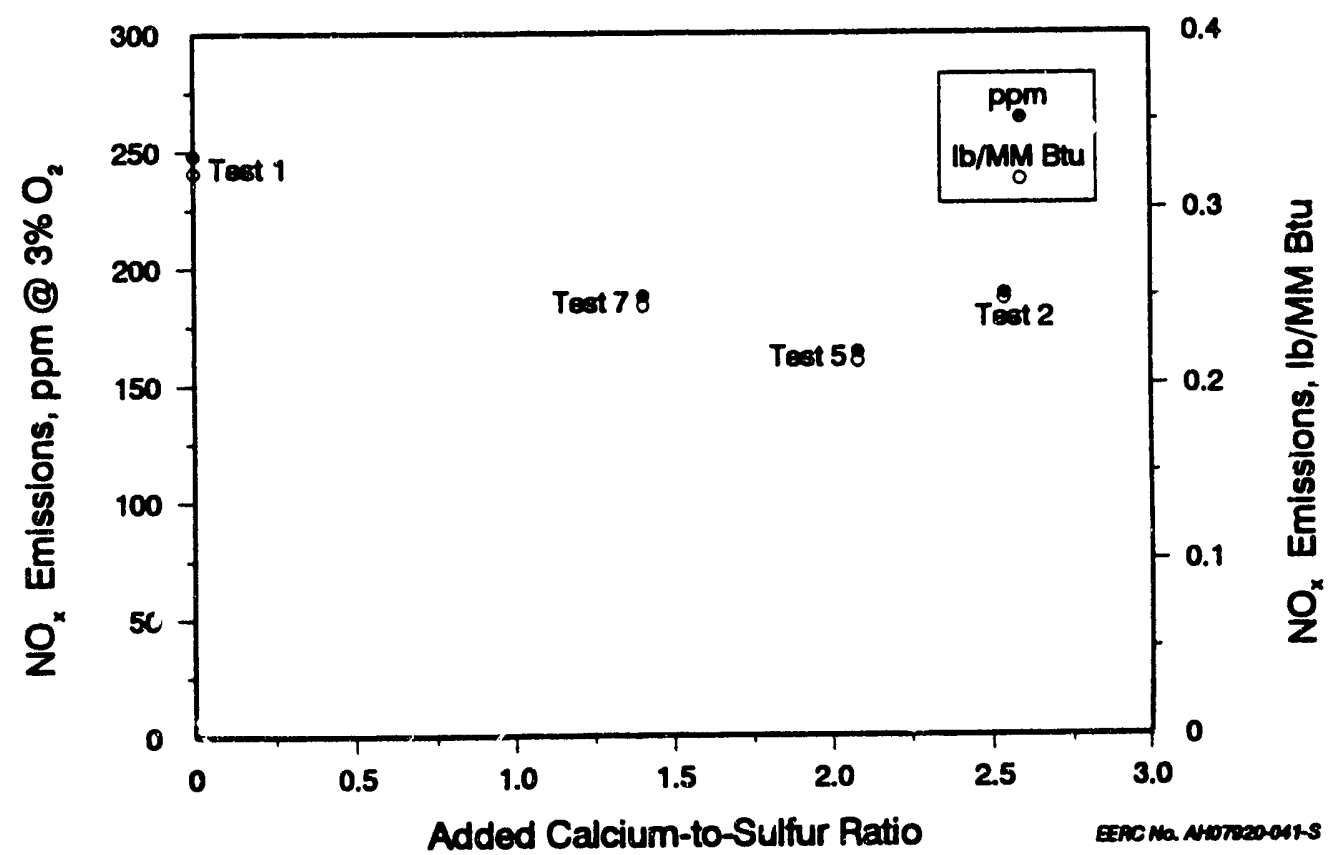

Figure D-10. Relationship between $\mathrm{NO}_{\mathbf{x}}$ emissions and added calcium-to-sulfur ratio. 


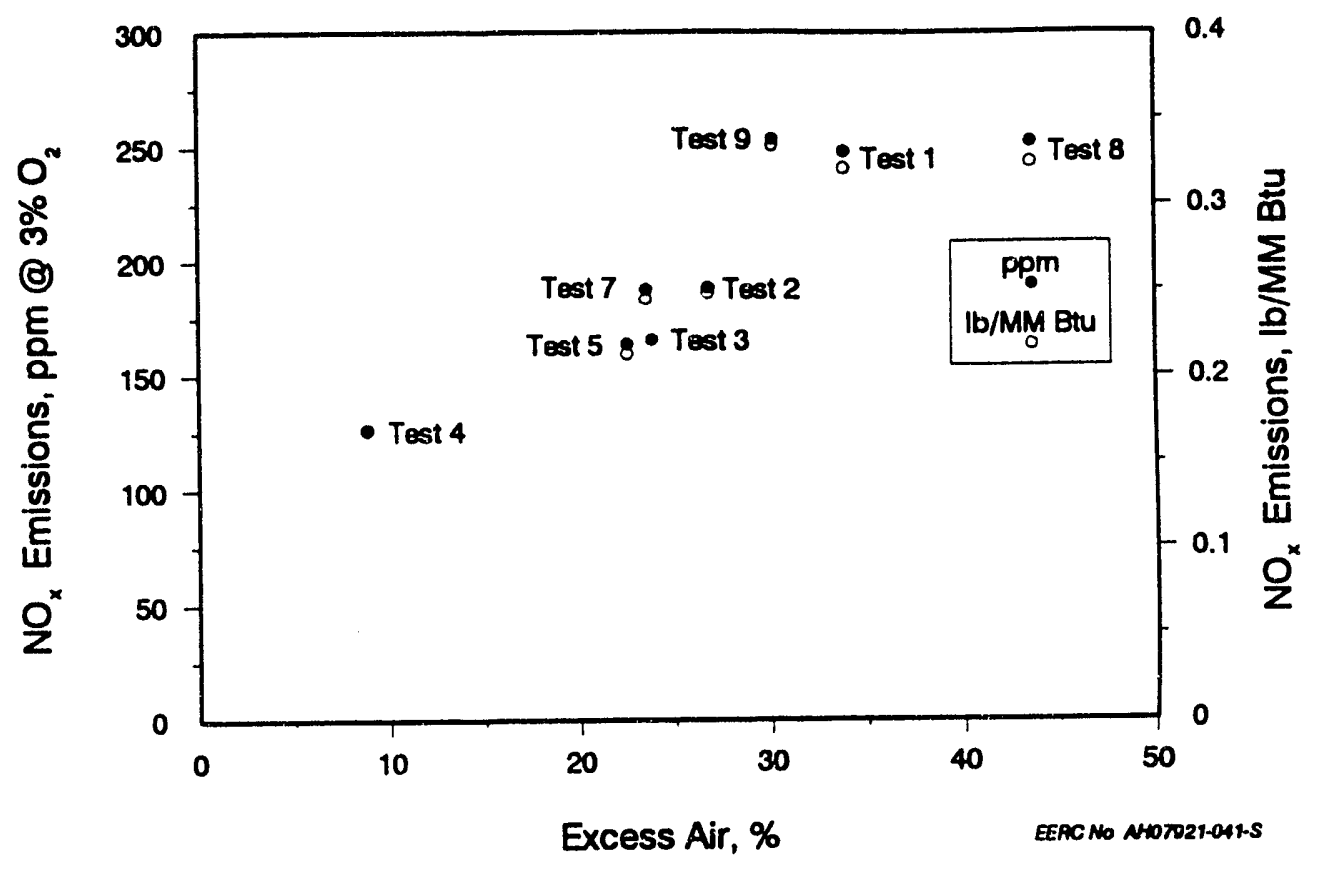

Figure D-11. $\mathrm{NO}_{\mathrm{x}}$ emissions as a function of excess air.

\section{$\mathrm{N}_{2} \mathrm{O}$ Emissions}

The $\mathrm{N}_{2} \mathrm{O}$ emissions for all 7 tests (no $\mathrm{N}_{2} \mathrm{O}$ measurements were made during Test 5) were quite low; Test 3 had the highest $\mathrm{N}_{2} \mathrm{O}$ emissions at $62 \mathrm{ppm}$ (corrected to $3 \% \mathrm{O}_{2}$ ). The $\mathrm{N}_{2} \mathrm{O}$ emissions as a function of average combustor temperature are shown in Figure D-12. As expected, levels of $\mathrm{N}_{2} \mathrm{O}$ decreased as combustor temperature increased. However, $\mathrm{N}_{2} \mathrm{O}$ emissions, like $\mathrm{NO}_{\mathbf{x}}$, showed an unexpected relationship with alkali-to-sulfur ratio.

All three tests were operated at approximately the same temperature (from $1529^{\circ} \mathrm{F}$ for Test 4 to $1545^{\circ} \mathrm{F}$ for Test 2), and Tests 2 and 8 had the same calcium-to-sulfur ratio (2.5), while Test 4 had a higher calcium-io-sulfur ratio (4.3). At this ternperature, there is no specific effect of excess air on $\mathrm{N}_{2} \mathrm{O}$.

\section{CO Emissions}

CO emissions for the entire run were very low, with a high of $18 \mathrm{ppm}$ (corrected to $3 \% \mathrm{O}_{2}$ ) for Test 3 . Figure D-13 shows a decrease in CO emissions as average combustor temperature increases.

\section{SUMIMARIES OF TEST DATA}

This section contains the summaries of test data for each test period, including averages and standard deviations of many of the data points recorded by the computerized data acquisition system. 


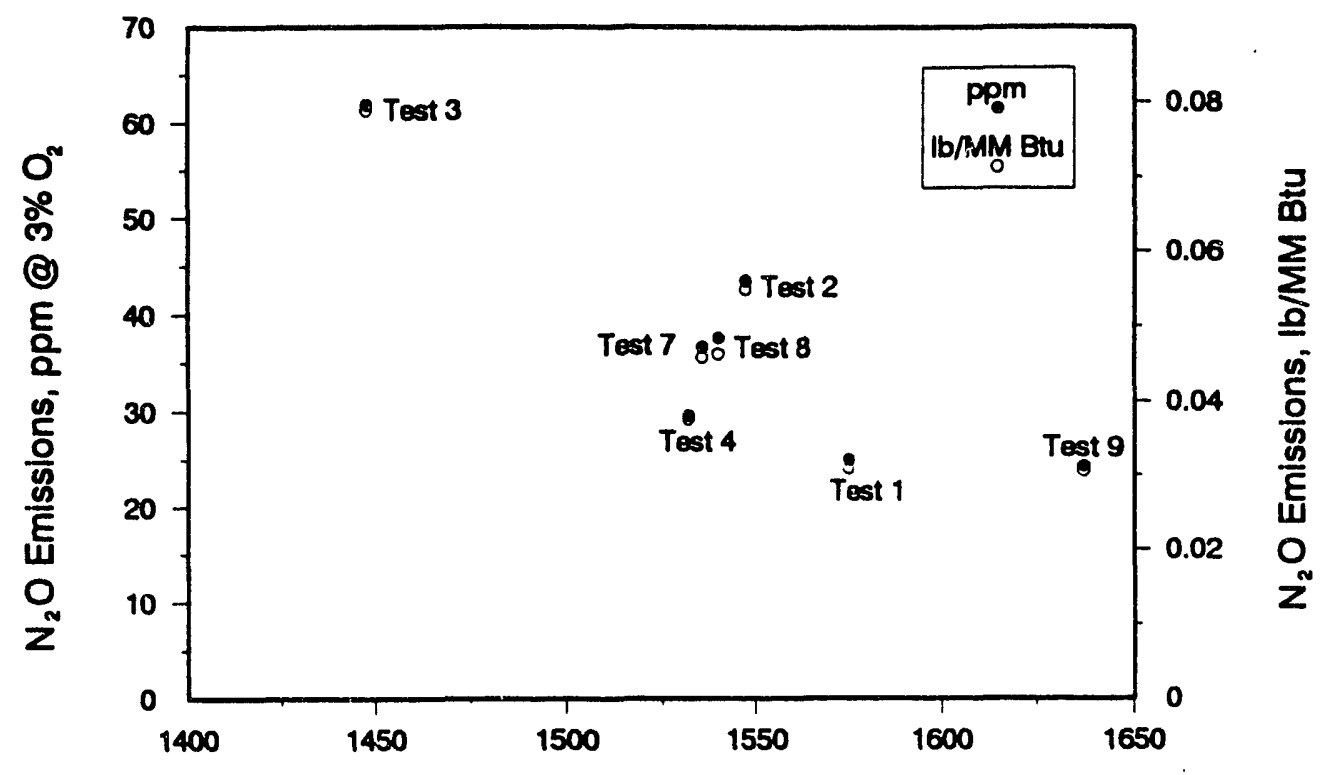

Average Combustor Temperature, ${ }^{\circ} \mathrm{F} \quad$ EEACNa NHotiz2orrs

Figure D-12. $\mathrm{N}_{2} \mathrm{O}$ emissions as a function of average combustor temperature.

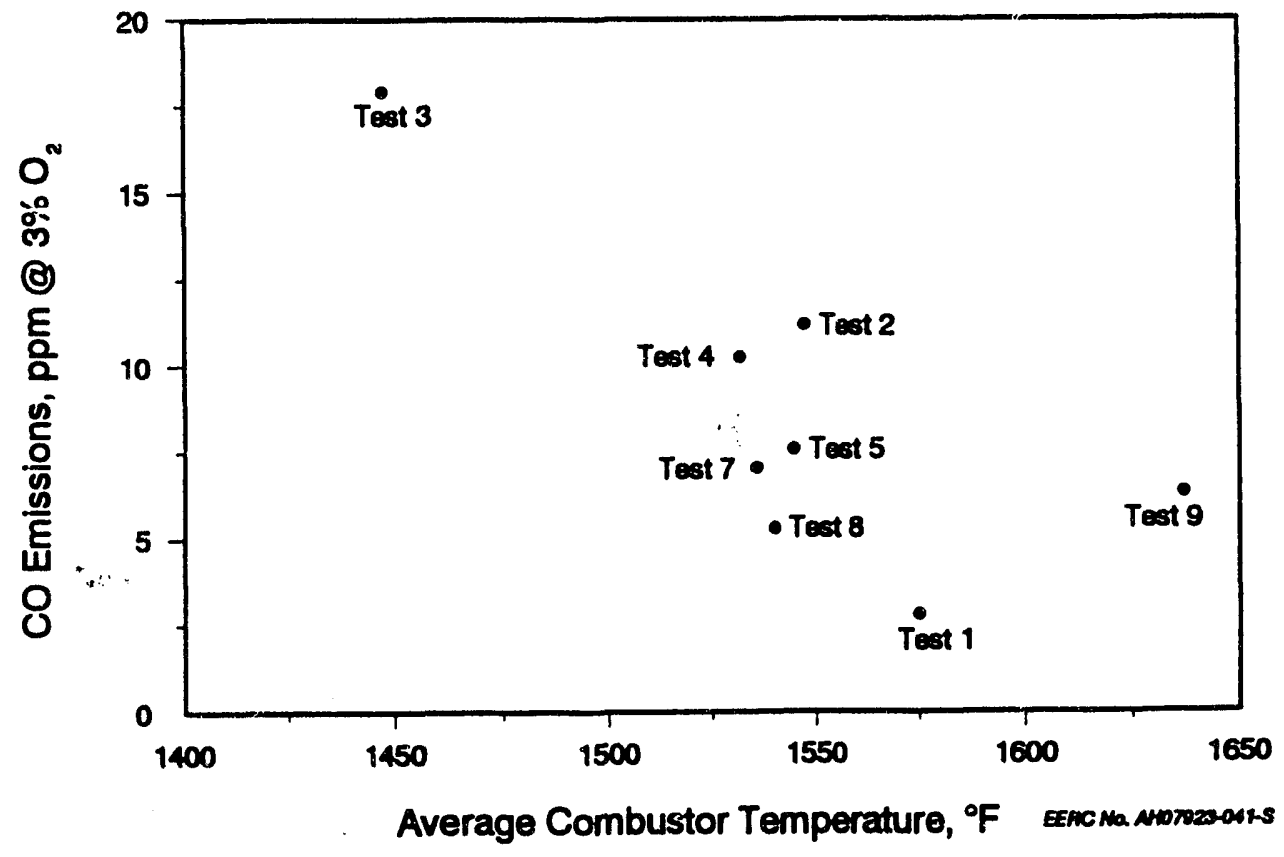

Figure D-13. CO emissions as a function of average combustor temperature. 


\begin{tabular}{|c|c|c|c|c|c|c|c|c|c|c|c|c|c|}
\hline \multirow{3}{*}{$\frac{\mathrm{Tag}}{\mathrm{TC} 11011}$} & \multirow{2}{*}{$\frac{\text { Desc }}{\text { PCD Ex }}$} & \multirow{2}{*}{$\frac{\text { Units }}{{ }^{\circ} \mathbf{F}}$} & \multicolumn{2}{|c|}{ Average Std Dev } & \multicolumn{9}{|c|}{ HEAT-TRANSPER COEPPICIENTS } \\
\hline & & & 1554 & $\overline{22.4}$ & -Combustor & & Number & of Doors in & Service & 10 & & & \\
\hline & AFS Ex & ${ }^{\circ} \mathbf{F}$ & 432 & 5.3 & $\mathrm{CHX}$ & Height & Temp In & Temp Out & Bed Temp & Flow & $\mathbf{Q}$ & u & Heat Flux \\
\hline TC15001 & C Plenum & ${ }^{\circ} \mathbf{F}$ & 525 & 5.3 & Location & (fi) & ${ }^{\circ} \mathbf{F}$ & ${ }^{\circ} \mathbf{F}$ & ${ }^{\circ} \mathbf{F}$ & gpm & Btu/hr & Btu/ft ${ }^{2} \mathrm{hr}^{\circ} \mathrm{P}$ & Btu/ft ${ }^{2} \mathrm{hr}$ \\
\hline TC15004 & C 1-1' & ${ }^{\circ} \mathbf{F}$ & 1605 & 14.0 & 2E,W & 8 & 45 & 148 & 1672 & 3.10 & 160140 & 20.2 & 30796 \\
\hline TC15005 & C $1-2$ & ${ }^{\circ} \mathbf{F}$ & 1580 & 14.5 & 3NE,SW & 14 & 44 & 155 & 1594 & 3.30 & 184046 & 24.6 & 35394 \\
\hline TC15006 & C 1-3' & ${ }^{\circ} \mathbf{F}$ & 1608 & 14.6 & 4SE,NW & 17.5 & 44 & 153 & 1522 & 3.30 & 179916 & 25.3 & 34599 \\
\hline TC15007 & C 1-4' & ${ }^{\circ} \mathbf{F}$ & 1571 & 14.1 & $5 \mathrm{E}$ & 22.5 & 44 & 171 & 1548 & 1.50 & 94963 & 26.5 & 36524 \\
\hline TC15008 & C 1-4' & ${ }^{\circ} \mathbf{F}$ & 1598 & 14.7 & 6NE & 27.5 & 46 & 141 & 1528 & 1.50 & 71710 & 19.9 & 27581 \\
\hline TC15009 & C 1-4' & ${ }^{\circ} \mathbf{F}$ & 1578 & 16.4 & 7SE & 32.5 & 44 & 109 & 1502 & 1.60 & 52397 & 14.5 & 20153 \\
\hline TC15012 & C 2-6' & ${ }^{\circ} \mathbf{F}$ & 1614 & 14.2 & $8 W$ & 37.5 & 47 & 117 & 1491 & 1.70 & 60048 & 16.8 & 23095 \\
\hline TC15013 & C 2-8' & ${ }^{\circ} \mathbf{F}$ & 1672 & 12.6 & & Overall & 44 & 145 & 1575 & 14.68 & 744325 & 20.0 & 28628 \\
\hline TC15022 & C 3-11' & ${ }^{\circ} \mathbf{F}$ & 1614 & 13.9 & & & & From Data & Sheets $\Rightarrow$ & 16.00 & & & \\
\hline TC15023 & C 3-14' & ${ }^{\circ} \mathbf{F}$ & 1590 & 10.8 & -EHX- & & & & & & & & \\
\hline TC15024 & C 3-14' & ${ }^{\circ} \mathbf{F}$ & 1583 & 11.8 & Coils & No. of & Temp In & Temp Out & Bed Temp & Flow & $\mathbf{Q}$ & $\mathrm{u}$ & Heat Flux \\
\hline TC15025 & C 3-14' & ${ }^{\circ} \mathbf{F}$ & 1608 & 13.2 & Used & Coils & $\cdot \mathbf{F}$ & ${ }^{\circ} \mathrm{F}$ & ${ }^{\circ} \mathbf{F}$ & gpm & Btu/hr & Btu/ft ${ }^{2} h r^{2} F$ & Btu/ft ${ }^{2} \mathrm{hr}$ \\
\hline $\mathrm{TC} 15032$ & $c 4-17.5^{\prime}$ & ${ }^{\circ} \mathbf{p}$ & 1522 & 10.5 & $1-9$ & 9 & 43 & 120 & 950 & 9.62 & 371307 & 66.3 & 55008 \\
\hline TC15042 & C 5-22.5' & ${ }^{\circ} \mathrm{F}$ & 1548 & 10.7 & & & & From Data & Sheet $s=>$ & 10.60 & & & \\
\hline $\mathrm{TC} 15052$ & $C 6-27.5^{\prime}$ & ${ }^{\circ} \mathbf{F}$ & 1540 & 11.9 & & & & & & & & & \\
\hline TC15053 & C 6-27.5 & ${ }^{\circ} \mathrm{F}$ & 1553 & 12.7 & EMISSION & IS DATA & & & & & & & \\
\hline TC15054 & C 6-27.5' & $\bullet \mathbf{F}$ & 1490 & 14.2 & & & & & & & & & \\
\hline TC15062 & C 7-32.5' & ${ }^{\circ} \mathrm{F}$ & 1502 & 21.8 & & As Measure & ed & -1 & $\longrightarrow$ & Corrected to & to $3 \% 02-$ & & \\
\hline TC15071 & C 8-37.5' & ${ }^{\circ} \mathrm{F}$ & 1491 & 14.5 & Tag & Units & Ayerage & Std Dev & Tag & Units & Average & Std Dev & \\
\hline TC15073 & C $9-41$ & op & 1594 & 19.6 & SO2-A & ppm & 341 & 105.0 & SO2-A & ppm & 372 & 79.2 & \\
\hline TC15999 & Ambient & ${ }^{\circ} \mathrm{F}$ & . 74 & 0.8 & SO2-AE & Ib/MM Btu & 0.68 & 0.2 & & & & & \\
\hline TC16001 & EHX Plenm & ${ }^{\circ} \mathbf{F}$ & 122 & 1.6 & SO2-B & ppm & 351 & 103.0 & SO2-B & ppm & 301 & 88.3 & \\
\hline TC16012 & EHX 0.5' & $\cdot P$ & 959 & 36.3 & SO2-BE & $\mathrm{Ib} / \mathrm{MM} \mathrm{Btu}$ & 0.70 & 0.2 & & & & & \\
\hline TC16013 & EHX 1.5' & $\cdot F$ & 942 & 32.3 & $\mathrm{Co}$ & ppm & 2 & 0.5 & $\mathrm{Co}$ & ppm & 3 & 0.7 & \\
\hline TCl 6014 & EHX 2.7 & ${ }^{\circ} \mathrm{F}$ & 950 & 35.0 & $\mathrm{CO} 2$ & $\%$ & 15.02 & 1.3 & $\mathrm{CO} 2$ & $\%$ & 16.70 & 0.7 & \\
\hline TC16015 & EHX 3.8' & ${ }^{\circ} \mathbf{F}$ & 926 & 25.2 & $\mathrm{~N} 2 \mathrm{O}$ & ppm & 22 & 2.0 & $\mathrm{~N} 2 \mathrm{O}$ & ppm & 25 & 4.1 & \\
\hline TC16017 & EHX 5.3' & ${ }^{\circ} \mathrm{F}$ & 843 & 15.2 & N2OE & lb/Mm Btu & 0.03 & 0.0 & & & & & \\
\hline TC16018 & EHX Exit & ${ }^{\circ} \mathrm{F}$ & 900 & 28.4 & NOx & ppm & 218 & 18.5 & NOx & ppm & 246 & 42.2 & \\
\hline TC16021 & $\operatorname{CrcA}$ in & ${ }^{\circ} \mathbf{p}$ & 1582 & 17.6 & NOxE & $\mathrm{lb} / \mathrm{Mm}$ Btu & 0.32 & 0.1 & & & & & \\
\hline TC16031 & DC $8-36$ & ${ }^{\circ} \mathrm{F}$ & 1576 & 17.6 & O2-A & $\%$ & 5.15 & 1.5 & & & & & \\
\hline TC16032 & DC 6-28' & ${ }^{\circ} \mathbf{F}$ & 1553 & 18.6 & O2-B & $\%$ & 4.78 & 1.6 & & & & & \\
\hline TC16033 & DC $4-18^{\prime}$ & ${ }^{\circ} \mathbf{F}$ & 1520 & 12.6 & & & & & & & & & \\
\hline TC16034 & DC3-9.5 & ${ }^{\circ} \mathbf{F}$ & 1552 & 13.7 & & & & & & & & & \\
\hline TC16035 & DC3-8.5 & ${ }^{\circ} \mathrm{F}$ & 1539 & 11.9 & & & & & & & & & \\
\hline $\mathrm{T}(\mathrm{A}, \mathrm{C})$ & Comb Temp & ${ }^{\circ} \mathbf{F}$ & 1575 & 11.5 & Tag & Desc & Units & verage & Std Dev & $\mathrm{Tag}$ & Desc & Average & Std Dev \\
\hline$T(A, E H X)$ & EHX Temp & ${ }^{\circ} \mathrm{F}$ & 950 & 34.9 & $W(C)$ & Coal Fd Rt & $\mathrm{lbs} / \mathrm{br}$ & 250 & 23.2 & TC13131 & AFPE-F2" & 888 & 40.0 \\
\hline $\mathrm{EA}$ & Excess Air & $\%$ & 33.8 & 13.0 & W(S) & LS Fd Rt & $\mathrm{lbs} / \mathrm{hr}$ & 0 & 0.0 & TC13132 & AFPE-F $6^{n}$ & 1046 & 30.5 \\
\hline SR & S Reten & $\%$ & 15.2 & 12.1 & $V(F G)$ & FG SGV & $\mathrm{ft} / \mathrm{sec}$ & 16.1 & 0.4 & TC13133 & AFPE $B 6^{n}$ & 926 & 46.4 \\
\hline$R(P C A)$ & \% Flw PCA & $\%$ & 59.6 & 2.0 & $V(S, C)$ & Comb SGV & $\mathrm{t} t / \mathrm{sec}$ & 14.5 & 0.6 & TC13134 & AFPE-F10" & 577 & 59.7 \\
\hline $\mathrm{R}(\mathrm{SCA})$ & $\%$ Flw SCA & $\%$ & 40.4 & 2.0 & $V(S, E H X)$ & EHX SGV & $\mathrm{ft} / \mathrm{sec}$ & 1.8 & 0.1 & TC13231 & APPW-P2n & 911 & 35.9 \\
\hline$R(Q, I N)$ & $\%$ Enrg in & $\%$ & 76.0 & 5.1 & FT18003 & CHX Flow & $\mathrm{gpm}$ & 14.7 & 0.4 & TC13232 & APPW-P6" & 1035 & 27.5 \\
\hline $\mathrm{R}(\mathrm{CHX})$ & CHX Ratio & $\%$ & 62.4 & 2.2 & FT19003 & EHX Flow & gpm & 9.6 & 0.2 & TC13233 & APPW-B6" & 812 & 27.6 \\
\hline$R(E H X)$ & EHX Ratio & $\%$ & 37.6 & 2.2 & PT15081 & Comb dP & in. $\mathrm{H} 2 \mathrm{O}$ & 41.8 & 1.5 & TC13234 & AFPW-F10 & 953 & 33.3 \\
\hline $\mathrm{F}(\mathrm{PCA})$ & PCA FIw & scfu & 225.4 & 20.5 & $Q(C A)$ & CA Heat in & $\mathrm{KBt} / \mathrm{h} / \mathrm{hr}$ & 92.9 & 4.5 & DOORS & $\mathrm{CHX}$, On & 10 & 0 \\
\hline$F(E H X)$ & EHX Flw & scfm & 62.2 & 2.5 & $Q(\mathrm{CHX})$ & CHX HIRmv & $\mathrm{KBt} / \mathrm{h} / \mathrm{hr}$ & 619.2 & 36.8 & COILS & EHXs On & 9 & 0 \\
\hline$F(T P A)$ & TPCA FIW & sefm & 290.0 & 19.9 & Q(EHX) & EHX HIRmv & $\mathrm{KBtu} / \mathrm{hr}$ & 372.6 & 19.4 & BH A/C & & 2.0 & 0.0 \\
\hline $\mathrm{F}(\mathrm{SCA})$ & SCA Fiw & sefm & 160.4 & 4.5 & QEHX,IN & $\mathrm{EFG} \mathrm{Ht}$ in & $\mathrm{KBtu} / \mathrm{hr}$ & 2.8 & 0.4 & A/SRATIO & & 1.8 & 0.0 \\
\hline F(TAIR) & TCA Fiw & sefm & 485.7 & 18.8 & $Q(F)$ & Fuel Earg in & $\mathrm{KB}$ tu/hr & 2227.3 & 206.1 & Feed Air & scfm & 17.9 & \\
\hline $\mathrm{F}(\mathrm{FG}, \mathrm{BH})$ & BH FIw & scfø & 518.9 & 5.2 & $Q(F G)$ & FG Enrg out & $\mathrm{KB}$ tu/hr & 258.2 & 2.0 & DC Air & scfm & 0.0 & \\
\hline$F(T F G)$ & TFG Flw & scim & 518.9 & 5.2 & $\alpha(N)$ & Tot Enrg in & $\mathrm{KB} t u / \mathrm{hr}$ & 2322.9 & 204.8 & Purge Air & scfm & 15.5 & \\
\hline W(SR) & Recirc RI & $\mathrm{lbs} / \mathrm{hr}$ & 2245 & 150.4 & QYOUT) & Tot Enrg out & $\mathrm{KB}(\mathrm{w} / \mathrm{hr}$ & 1755.1 & 34.1 & & & & \\
\hline
\end{tabular}




\begin{tabular}{|c|c|c|c|c|c|c|c|c|c|c|c|c|c|}
\hline \multirow{2}{*}{$\frac{\mathrm{Tag}}{\mathrm{TC} 11011}$} & \multirow{2}{*}{$\frac{\text { Desc }}{\text { PCD Ex }}$} & \multirow{2}{*}{$\frac{\text { Units }}{\cdot \mathrm{P}}$} & \multicolumn{2}{|c|}{ Average Std Dev } & \multicolumn{9}{|c|}{ HEAT-TRANSPER COEPPICIENTS } \\
\hline & & & 1548 & 5.8 & \multicolumn{2}{|l|}{-Combustor- } & \multicolumn{3}{|c|}{ Number of Doors in Service } & \multicolumn{2}{|l|}{10} & & \\
\hline & AFS Ex & ${ }^{\circ} \mathrm{F}$ & 1417 & 8.7 & $c-H x$ & Height & Temp In & Temp Out & Bed Temp & Plow & $\mathbf{Q}$ & $\mathbf{U}$ & Heat Flux \\
\hline TC15001 & C Plenum & ${ }^{\circ} \mathrm{P}$ & 578 & 7.0 & Location & (ft) & $\cdot \mathbf{P}$ & $\bullet \mathbf{p}$ & $\bullet \mathbf{F}$ & $\mathrm{gpm}$ & Blu/hr B & Btu/ft ${ }^{2} \mathrm{br}^{\circ} \mathrm{P}$ & $\mathrm{Btu} / \mathrm{ft}{ }^{2} \mathrm{hr}$ \\
\hline TC15004 & C 1-1' & ${ }^{\circ} \mathrm{F}$ & 1524 & 7.9 & $2 \mathrm{E}, \mathrm{W}$ & 8 & 44 & 133 & 1578 & 3.70 & 164833 & 21.9 & 31699 \\
\hline TC15005 & C 1-2' & ${ }^{\circ} \mathrm{F}$ & 1507 & 7.3 & 3NE,SW & 14 & 44 & 137 & 1549 & 3.73 & 173165 & 23.6 & 33301 \\
\hline $\mathrm{TC} 15006$ & C 1-3' & ${ }^{\circ} \mathrm{F}$ & 1532 & 7.6 & 4SE,NW & 17.5 & 43 & 170 & 1542 & 4.43 & 281281 & 39.4 & 54093 \\
\hline TC15007 & C 1-4' & ${ }^{\bullet P}$ & 1501 & 7.2 & $5 \mathrm{E}$ & 22.5 & 44 & 154 & 1556 & 1.87 & 103110 & 28.3 & 39658 \\
\hline TC15008 & C 1-4' & $\bullet p$ & 1513 & 7.5 & $6 \mathrm{NE}$ & 27.5 & 44 & 118 & 1554 & 1.83 & 67736 & 18.1 & 26052 \\
\hline TC15009 & C $1-4^{\prime}$ & $\cdot \mathbf{F}$ & 1500 & 7.2 & $7 \mathrm{NW}$ & 32.5 & 46 & 131 & 1555 & 1.83 & 77859 & 21.0 & 29946 \\
\hline $\mathrm{TC} 15012$ & C 2-6' & ${ }^{\circ} \mathrm{F}$ & 1534 & 7.0 & $8 W$ & 37.5 & 45 & 114 & 1560 & 1.83 & 63122 & 16.8 & 24278 \\
\hline TC15013 & C 2-8' & $\cdot \mathbf{P}$ & 1578 & 7.3 & & Overall & 44 & 141 & 1547 & 17.60 & 856153 & 23.4 & 32929 \\
\hline $\mathrm{TC} 15022$ & C 3-11' & $\cdot \mathrm{P}$ & 1546 & 5.5 & & & & From Data & Sheets $=>$ & 19.22 & & & \\
\hline TC15023 & C 3-14' & ${ }^{\circ} \mathrm{F}$ & 1547 & 5.7 & EHX- & & & & & & & & \\
\hline TC15024 & C 3-14' & ${ }^{\circ} \mathrm{F}$ & 1539 & 4.7 & Coils & No. of & Temp In & Temp Out & Bed Temp & Flow & $\mathbf{Q}$ & U & Heat Flux \\
\hline TC15025 & C 3-14' & ${ }^{\circ} \mathrm{F}$ & 1561 & 6.6 & Used & Coils & ${ }^{\circ} \mathbf{F}$ & ${ }^{\circ} \mathrm{F}$ & ${ }^{\circ} \mathbf{F}$ & $\mathrm{gpm}$ & Btu/hr & Btu/ft ${ }^{2} h r^{\circ} \mathrm{F}$ & $\mathrm{Btu} / \mathrm{ft} \cdot \mathrm{hr}$ \\
\hline TC15032 & C 4-17.5' & ${ }^{\circ} \mathrm{F}$ & 1542 & 4.8 & $1-2,5-7$ & 8 & 42 & 158 & 1328 & 10.07 & 580504 & 82.6 & 96751 \\
\hline TC15042 & C 5-22.5' & ${ }^{\circ} \mathrm{F}$ & 1556 & 4.3 & $10-12$ & & & From Data & Sheets $\Rightarrow>$ & 10.87 & & & \\
\hline TC15052 & C 6-27.5' & ${ }^{\circ} \mathrm{F}$ & 1569 & 4.5 & & & & & & & & & \\
\hline TC15053 & C 6-27.5' & ${ }^{\circ} \mathrm{F}$ & 1569 & 5.6 & EMISSIO & ONS DATA & & & & & & & \\
\hline TC15054 & C 6-27.5' & ${ }^{\circ} \mathbf{F}$ & 1523 & 6.1 & & & & & & & & & \\
\hline TC15062 & C 7-32.5' & ${ }^{\circ} \mathbf{p}$ & 1555 & 4.1 & & As Measured & ed & 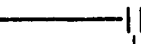 & - & Corrected to & $03 \% 02-$ & -1 & \\
\hline TC15071 & C 8-37.5' & ${ }^{\circ} \mathbf{F}$ & 1560 & 4.6 & Tag & Units & Average & Std Dev & Tag & Units & Average & Std Dev & \\
\hline TC15073 & C $9-41^{\prime}$ & ${ }^{\circ} \mathbf{P}$ & 1611 & 6.1 & SO2-A & ppm & 80 & 34.1 & SO2-A & ppm & 84 & 33.6 & \\
\hline TC15999 & Ambient & ${ }^{\circ} \mathbf{F}$ & 77 & 1.4 & SO2-AE & Ib/MM Btu & 0.16 & 0.1 & & & & & \\
\hline $\mathrm{TC} 16001$ & EHX Plenm & ${ }^{\circ} \mathrm{F}$ & 122 & 3.0 & $\mathrm{SO} 2-\mathrm{B}$ & $\mathrm{ppm}$ & 91 & 44.4 & $\mathrm{SO} 2-\mathrm{B}$ & ppm & 78 & 38.0 & \\
\hline TC16012 & EHX $0.5^{\prime}$ & ${ }^{\circ} \mathbf{P}$ & 1345 & 11.0 & $\mathrm{SO} 2-\mathrm{BE}$ & $\mathrm{Ib} / \mathrm{MM}$ Btu & 0.18 & 0.1 & & & & & \\
\hline TC16013 & EHX $1.5^{\circ}$ & ${ }^{\circ} \mathbf{F}$ & 1313 & 10.6 & $\mathrm{co}$ & ppm & 10 & 14.0 & Co & ppm & 11 & 13.2 & \\
\hline TC16014 & EHX 2.7 & ${ }^{\circ} \mathbf{F}$ & 1329 & 10.6 & $\mathrm{CO} 2$ & $\%$ & 15.41 & 0.5 & $\mathrm{CO} 2$ & $\%$ & 16.20 & 0.4 & \\
\hline $\mathrm{TC} 16015$ & EHX 3.8' & ${ }^{\circ} \mathrm{p}$ & 1309 & 8.3 & $\mathrm{~N} 2 \mathrm{O}$ & ppm & 40 & 1.3 & $\mathrm{~N} 2 \mathrm{O}$ & ppm & 43 & 2.3 & \\
\hline TC16017 & EHX 5.3' & ${ }^{\circ} \mathrm{F}$ & 1239 & 6.5 & N2OE & $\mathrm{Ib} / \mathrm{Mm} \mathrm{Btu}$ & 0.06 & 0.0 & & & & & \\
\hline TC16018 & EHX Exit & ${ }^{\circ} \mathrm{F}$ & 1301 & 12.1 & NOx & $\mathrm{ppm}$ & 174 & 14.0 & NOx & ppm & 183 & 21.9 & \\
\hline TC16021 & Cre $A$ in & ${ }^{\circ} \mathbf{F}$ & 1570 & 5.4 & NOxE & lb/Mm Btu & 0.25 & 0.0 & & & & & \\
\hline $\mathrm{TC} 16031$ & DC $8-36$ & ${ }^{\circ} \mathrm{F}$ & 1556 & 11.0 & O2-A & $\%$ & 4.44 & 0.5 & & & & & \\
\hline $\mathrm{TC} 16032$ & DC $6-28^{\prime}$ & ${ }^{\circ} \mathrm{F}$ & 1541 & 10.0 & $\mathrm{O}-\mathrm{B}$ & $\%$ & 3.87 & 0.7 & & & & & \\
\hline TC16033 & $D C 4-18^{\prime}$ & ${ }^{\circ} \mathrm{P}$ & 1519 & 29.2 & & & & & & & & & \\
\hline $\mathrm{TC} 16034$ & DC3-9.5 & ${ }^{\circ} \mathrm{F}$ & 1544 & 32.9 & & & & & & & & & \\
\hline TC16035 & $D C 3-8.5^{\circ}$ & ${ }^{\circ} \mathrm{P}$ & 1496 & 41.5 & & & & & & & & & \\
\hline $\mathrm{T}(\mathrm{A}, \mathrm{C})$ & Comb Temp & ${ }^{\circ} \mathrm{P}$ & 1547 & 4.5 & Tag & Desc & Units & Average & Std Dev & Tag & Desc & Average & Std Dev \\
\hline $\mathrm{T}(\mathrm{A}, \mathrm{EHX})$ & EHX Temp & ${ }^{\circ} \mathrm{F}$ & 1328 & 10.7 & $w(C)$ & Coal Fd Rt & $\mathrm{lbs} / \mathrm{hr}$ & 273 & 13.2 & TC13131 & AFPE-F2 $2^{n}$ & 758 & 40.3 \\
\hline EA & Excess Air & $\%$ & 26.7 & 4.1 & $W(S)$ & LS Fd Rt & lbs/hr & 7 & 1.2 & TC13132 & AFPE-F $6^{\prime \prime}$ & 962 & 31.4 \\
\hline SR & S Reten & $\%$ & 80.9 & 7.7 & $V(F G)$ & FG SGV & $\mathrm{ft} / \mathrm{sec}$ & 16.1 & 0.7 & TC13133 & AFPE- $B 6^{n}$ & 765 & 47.2 \\
\hline$R(P C A)$ & $\%$ FIw PCA & $\%$ & 60.0 & 4.7 & $v(S, C)$ & Comb SGV & $\mathrm{ft} / \mathrm{sec}$ & 14.2 & 0.6 & TC13134 & AFPE-F10" & 374 & 58.0 \\
\hline $\mathrm{R}(\mathrm{SCA})$ & $\%$ FIw SCA & $\%$ & 40.0 & 4.7 & V(S,EHX) & EHXSGV & $\mathrm{ft} / \mathrm{sec}$ & 1.8 & 0.1 & TC13231 & AFPW-F2" & 788 & 32.0 \\
\hline$R(Q, I N)$ & \% Enrg in & $\%$ & 78.8 & 4.3 & FT18003 & CHX Flow & $\mathrm{gpm}$ & 17.6 & 0.3 & TC13232 & APPW-F $6^{n}$ & 954 & 24.6 \\
\hline $\mathrm{R}(\mathrm{CHX})$ & CHX Ratio & $\%$ & 52.1 & 1.4 & FT19003 & EHX Flow & $\mathrm{gpm}$ & 10.1 & 0.1 & $\mathrm{TC} 13233$ & AFPW-B6" & 660 & 30.2 \\
\hline$R(E H X)$ & EHX Ratio & $\%$ & 47.9 & 1.4 & PT15081 & Comb dP & in. $\mathrm{H} 2 \mathrm{O}$ & 46.1 & 2.3 & TC13234 & APPW +10 & 832 & 36.3 \\
\hline $\mathrm{P}(\mathrm{PCA})$ & PCA FIw & scfm & 245.9 & 26.5 & $\alpha(\mathrm{CA})$ & CA Heat in & KBtu/hr & 100.1 & 5.2 & DOORS & $\mathrm{CHX}$ s On & 10 & 0 \\
\hline $\mathrm{F}(\mathrm{EHX})$ & EHX F/W & scfm & 49.4 & 1.2 & $\alpha(C H X)$ & CHX HIRmv & $\mathrm{KB} t \mathrm{u} / \mathrm{hr}$ & 632.5 & 31.2 & COILS & EHXs On & 8 & 0 \\
\hline $\mathrm{F}(\mathrm{TPA})$ & TPCA FIw & scfm & 291.1 & 24.3 & Q(EHX) & EHX HtRmv & $\mathrm{KBtu} / \mathrm{hr}$ & 581.3 & 18.9 & BH ACC & & 2.3 & 0.0 \\
\hline $\mathrm{P}(\mathrm{SCA})$ & SCA FIw & scfm & 159.5 & 25.3 & QEHX,IN & E FO $\mathrm{Ht}$ in & $\mathrm{KBt} t \mathrm{u} / \mathrm{hr}$ & 2.2 & 0.2 & A/SRATIO & & 3.9 & 0.5 \\
\hline $\mathrm{F}(\mathrm{TAIR})$ & TCA Flw & sefm & 485.2 & 19.8 & $Q(F)$ & Fuel Enrg in & $\mathrm{KBtu} / \mathrm{hr}$ & 2418.9 & 130.4 & Feed Air & scfm & 18.5 & \\
\hline $\mathrm{F}(\mathrm{FG}, \mathrm{BH})$ & BH FIw & $\operatorname{scfm}$ & 596.8 & 12.6 & $Q(F G)$ & FG Enrg out & $\mathrm{KBtu} / \mathrm{hr}$ & 296.0 & 6.2 & DC Air & sefm & 4.2 & \\
\hline $\mathrm{F}(\mathrm{TFG})$ & TFG Flw & scfm & 596.8 & 12.6 & $Q(I N)$ & Tot Enrg in & $\mathrm{KBt} / \mathrm{hr}$ & 2518.6 & 128.6 & Purge Air & $\operatorname{scfm}$ & 15.5 & \\
\hline $\mathrm{W}(\mathrm{SR})$ & Recirc Rt & $\mathrm{lbs} / \mathrm{hr}$ & 10274 & 1222.9 & QOUT) & Tot Enrg out & $\mathrm{KBt}$ /hr & 1992.6 & 39.6 & & & & \\
\hline
\end{tabular}




\begin{tabular}{|c|c|c|c|c|c|c|c|c|c|c|c|c|c|}
\hline \multirow{3}{*}{$\frac{\mathrm{Tag}}{\mathrm{TC} 11011}$} & \multirow{2}{*}{$\frac{\text { Desc }}{\text { PCD Ex }}$} & \multirow{2}{*}{$\frac{\text { Units }}{{ }^{\circ} \mathbf{F}}$} & \multicolumn{2}{|c|}{ Average Std Dev } & \multicolumn{9}{|c|}{ HEAT-TRANSPER COEPPICIENTS } \\
\hline & & & 1474 & 8.7 & -Combustor & & Number & of Doors in & Service & 12 & & & \\
\hline & AFS Ex & ${ }^{\circ} \mathbf{F}$ & 1366 & 8.9 & $\mathrm{C}-\mathrm{HX}$ & Height & Temp In & Temp Out & Bed Temp & Flow & $\mathbf{Q}$ & $U$ & Heat Plux \\
\hline TC15001 & C Plenum & ${ }^{\circ} \mathbf{P}$ & 587 & 5.6 & Location & $(\mathrm{ft})$ & $\bullet \mathbf{p}$ & 'P & 'P & gpm & $\mathrm{Btu} / \mathrm{hr}$ & Btw/tt $h r^{\circ} \mathrm{F}$ & Btu/ft ${ }^{2} \mathrm{br}$ \\
\hline TC15004 & C 1-1' & ${ }^{\circ} \mathbf{F}$ & 1416 & 17.5 & $2 E, W$ & 8 & 43 & 126 & 1473 & 3.48 & 145847 & 20.8 & 28048 \\
\hline $\mathrm{TC} 15005$ & C 1-2' & ${ }^{\circ} \mathbf{F}$ & 1402 & 16.8 & 3NE,SW & 14 & 43 & 135 & 1459 & 3.38 & 157019 & 22.8 & 30196 \\
\hline TC15006 & C 1-3' & ${ }^{\circ} \mathbf{P}$ & 1423 & 16.9 & 4SE,NW & 17.5 & 44 & 144 & 1457 & 4.18 & 209856 & 30.7 & 40357 \\
\hline TC15007 & C 1-4' & ${ }^{\circ} \mathbf{F}$ & 1397 & 15.9 & $5 E$ & 22.5 & 43 & 158 & 1469 & 1.62 & 92820 & 27.2 & 35700 \\
\hline TC15008 & C $1-4^{\prime}$ & ${ }^{\mathrm{a}} \mathrm{F}$ & 1410 & 16.7 & 6NE & 27.5 & 44 & 116 & 1464 & 1.62 & 58668 & 16.7 & 22565 \\
\hline TC15009 & C 1-4' & ${ }^{\circ} \mathrm{F}$ & 1397 & 16.4 & 7SE,NW & 32.5 & 45 & 120 & 1444 & 3.20 & 119568 & 17.4 & 22994 \\
\hline TC15012 & C 2-6' & ${ }^{\circ} \mathrm{F}$ & 1425 & 17.2 & $8 \mathrm{E}, \mathrm{W}$ & 37.5 & 44 & 121 & 1463 & 3.10 & 119148 & 17.1 & 22913 \\
\hline TC15013 & C 2-8' & $\bullet \mathbf{F}$ & 1473 & 17.6 & & Overall & 43 & 131 & 1448 & 18.52 & 821767 & 20.0 & 26339 \\
\hline TC15022 & C 3-11' & ${ }^{\circ} \mathbf{P}$ & 1453 & 13.5 & & & & From Data & Sheets $\Rightarrow$ & 20.58 & & & \\
\hline TC15023 & C 3-14' & ${ }^{\circ} \mathbf{F}$ & 1456 & 11.4 & -EHX- & & & & & & & & \\
\hline TC15024 & C 3-14' & ${ }^{\circ} \mathbf{F}$ & 1448 & 12.7 & Coils & No. of & Temp In & Temp Out & Bed Temp & Plow & $\mathbf{Q}$ & U & Heat Flux \\
\hline $\mathrm{TC} 15025$ & C 3-14' & ${ }^{\circ} \mathrm{F}$ & 1472 & 13.4 & Used & Coils & op & ${ }^{\circ} \mathbf{F}$ & ${ }^{\circ} \mathbf{P}$ & gpm & Btu/br & Btu/ft ${ }^{2} \mathrm{hr}^{\circ} \mathrm{F}$ & $\mathrm{Btu} / \mathrm{ft}^{2} \mathrm{hr}$ \\
\hline TC15032 & C 4-17.5' & ${ }^{\circ} \mathrm{F}$ & 1457 & 10.7 & $1-12$ & 12 & 41 & 147 & 1216 & 14.39 & 759244 & 78.9 & 84360 \\
\hline TC15042 & C 5-22.5' & ${ }^{\circ} \mathbf{F}$ & 1469 & 10.4 & & & & From Data & Sheet $\Leftrightarrow$ & 16.00 & & & \\
\hline $\mathrm{TC} 15052$ & C 6-27.5' & ${ }^{\circ} \mathrm{P}$ & 1477 & 10.4 & & & & & & & & & \\
\hline TC15053 & C 6-27.5' & ${ }^{\circ} \mathbf{F}$ & 1479 & 11.1 & EMISSI & ONS DATA & & & & & & & \\
\hline $\mathrm{TC} 15054$ & C 6-27.5' & ${ }^{\circ} \mathbf{F}$ & 1437 & 8.1 & & & & & & & & & \\
\hline TC15062 & $c 7-32.5$ & ${ }^{\circ} \mathbf{F}$ & 1444 & 8.3 & & -As Measure & $e d-$ & - & 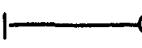 & Corrected to & $103 \%$ O2 - & -1 & \\
\hline TC15071 & C 8-37.5' & ${ }^{\circ} \mathbf{F}$ & 1463 & 7.8 & $\mathrm{Tag}$ & Units & Average & Std Dev & Tag & Units & Average & Std Dev & \\
\hline TC15073 & $C 9-41^{\prime}$ & ${ }^{\circ} \mathbf{P}$ & 1514 & 10.9 & SO2-A & ppm & 4 & 2.8 & SO2-A & ppm & 4 & $\overline{3.0}$ & \\
\hline TC15999 & Ambient & ${ }^{\circ} \mathbf{F}$ & 79 & 1.4 & SO2-AE & $\mathrm{Ib} / \mathrm{MM} \mathrm{Btu}$ & 0.01 & 0.0 & & & & & \\
\hline $\mathrm{TC} 16001$ & EHX Plenm & ${ }^{\circ} \mathbf{F}$ & 125 & 4.7 & $\mathrm{SO} 2-\mathrm{B}$ & ppm & 1 & 0.6 & $\mathrm{SO} 2-\mathrm{B}$ & ppm & 1 & 0.7 & \\
\hline $\mathrm{TC} 16012$ & EHX 0.5' & ${ }^{\circ} \mathbf{P}$ & 1230 & 25.4 & SO2-BE & $\mathrm{lb} / \mathrm{MM} \mathrm{Btu}$ & 0.00 & 0.0 & & & & & \\
\hline TC16013 & EHX 1.5' & ${ }^{\circ} \mathbf{F}$ & 1212 & 25.5 & $\mathrm{co}$ & ppm & 17 & 4.0 & $\mathrm{CO}$ & ppm & 18 & 4.4 & \\
\hline $\mathrm{TCl} 16014$ & EHX 2.7 & ${ }^{\circ} \mathbf{F}$ & 1207 & 24.4 & $\mathrm{CO} 2$ & $\%$ & 15.58 & 0.6 & $\mathrm{CO} 2$ & $\%$ & 16.55 & 0.3 & \\
\hline TC16015 & EHX 3.8' & ${ }^{\circ} \mathbf{F}$ & 1218 & 17.5 & $\mathrm{~N} 2 \mathrm{O}$ & ppm & 58 & 2.5 & $\mathrm{~N} 2 \mathrm{O}$ & ppm & 62 & 3.7 & \\
\hline TC16017 & EHX 5.3' & ${ }^{\circ} \mathbf{F}$ & 1165 & 12.3 & N2OE & $\mathrm{Ib} / \mathrm{Mm}$ Btu & 0.08 & 0.0 & & & & & \\
\hline $\mathrm{TC} 16018$ & EHX Exit & ${ }^{\circ} \mathbf{F}$ & 1200 & 21.4 & NOx & ppm & 156 & 10.9 & Nox & ppm & 166 & 15.9 & \\
\hline $\mathrm{TC} 16021$ & Crc $A$ in & ${ }^{\circ} \mathbf{F}$ & 1487 & 10.9 & NOxE & lb/Mm Btu & 0.22 & 0.0 & & & & & \\
\hline $\mathrm{TC} 16031$ & DC \&-36 & ${ }^{\circ} \mathbf{p}$ & 1473 & 8.1 & $\mathrm{O} 2-\mathrm{A}$ & $\%$ & 4.06 & 0.5 & & & & & \\
\hline TC16032 & DC 6-28' & ${ }^{\circ} \mathrm{F}$ & 1463 & 8.6 & $\mathrm{O} 2-\mathrm{B}$ & $\%$ & 3.71 & 0.5 & & & & & \\
\hline $\mathrm{TC} 16033$ & DC 4-18' & ${ }^{\circ} \mathbf{P}$ & 1437 & 34.8 & & & & & & & & & \\
\hline $\mathrm{TC} 16034$ & DC3-9.5 & ${ }^{\circ} \mathbf{F}$ & 1464 & 37.7 & & & & & & & & & \\
\hline $\mathrm{TCl} 16035$ & DC3-8.5 & ${ }^{\circ} \mathbf{P}$ & 1463 & 20.6 & & & & & & & & & \\
\hline $\mathrm{T}(\mathrm{A}, \mathrm{C})$ & Comb Temp & ${ }^{\circ} \mathbf{F}$ & 1448 & 12.5 & $\mathrm{Tag}$ & Desc & Units & Average & Std Dev & $\mathrm{Tag}$ & Desc & Average & Std Dev \\
\hline $\mathrm{T}(\mathbf{A}, \mathrm{EHX})$ & EHX Temp & ${ }^{\circ} \mathbf{F}$ & 1216 & 24.1 & $W(C)$ & Coal Fd Rt & lbs/hr & 301 & 10.6 & $\mathrm{TC} 13131$ & AFPE-F2" & 697 & 42.6 \\
\hline EA & Excess Air & $\%$ & 23.8 & 3.4 & $W(S)$ & LS Fd Rt & Ibs/hr & 0 & 0.0 & $\mathrm{TC} 13132$ & APPE-F $6^{\prime \prime}$ & 907 & 33.7 \\
\hline SR & S Reten & $\%$ & 99.2 & 0.7 & $V(F G)$ & FG SGV & $\mathrm{ft} / \mathrm{sec}$ & 16.0 & 0.7 & TC13133 & AFPE-B6" & 699 & 50.8 \\
\hline$R(P C A)$ & $\%$ Flw PCA & $\%$ & 60.1 & 4.1 & $V(S, C)$ & Comb SGV & $\mathrm{ft} / \mathrm{sec}$ & 14.3 & 0.6 & TC13134 & AFPE-F10" & 338 & 56.8 \\
\hline $\mathrm{R}(\mathrm{SCA})$ & $\%$ Flw SCA & $\%$ & 39.9 & 4.1 & $V(S, E H X)$ & EHXSGV & $\mathrm{ft} / \mathrm{sec}$ & 1.8 & 0.4 & $\mathrm{TC} 13231$ & APPW-F2" & 730 & 37.5 \\
\hline$R(Q, I N)$ & $\%$ Enrg in & $\%$ & 75.2 & 4.3 & FT18003 & CHX Flow & gpm & 18.5 & 0.5 & TC13232 & APPW-F6" & 902 & 27.1 \\
\hline $\mathbf{R}(\mathrm{CHX})$ & CHX Ratio & $\%$ & 46.1 & 3.8 & FT19003 & EHX Flow & gpm & 14.4 & 0.3 & TC13233 & $A F P W-B 6^{n}$ & 635 & 32.1 \\
\hline$R(E H X)$ & EHX Ratio & $\%$ & 53.9 & 3.8 & PT15081 & Comb dP & in. $\mathrm{H} 2 \mathrm{O}$ & 42.6 & 3.6 & TC13234 & AFPW-P10 & 779 & 39.2 \\
\hline $\mathrm{F}(\mathrm{PCA})$ & PCA FIw & $\operatorname{scfm}$ & 253.9 & 31.3 & $\alpha(C A)$ & CA Heat in & KBtwhr & 106.7 & 6.9 & DOORS & $\mathrm{CHXs} \mathrm{O}$ & 12 & 0 \\
\hline$F(E H X)$ & EHX Flw & $\operatorname{scfm}$ & 51.5 & 10.7 & $Q(\mathrm{CHX})$ & CHX HtRmv & KBtw/hr & 638.4 & 33.7 & colls & EHXs On & 12 & 0 \\
\hline F(TPA) & TPCA FIw & scfm & 306.9 & 28.0 & $Q(E H X)$ & EHX HtRmv & KBtu/hr & 752.2 & 75.8 & BH AVC & & 2.3 & 0.0 \\
\hline $\mathrm{F}(\mathrm{SCA})$ & SCA FIw & scfm & 169.1 & 20.5 & Q(EHX,IN & E FG $\mathrm{Ht}$ in & KBtu/hr & 2.5 & 0.7 & AVSRATIO & & 1.7 & 0.0 \\
\hline F(TAIR) & TCA FIw & $\operatorname{scfm}$ & 510.5 & 25.6 & $Q(F)$ & Fuel Enrg in & KBtu/hr & 2670.9 & 99.9 & Feed Air & $\operatorname{scfm}$ & 18.9 & \\
\hline$F(F G, B H)$ & BH Flw & scfm & 610.6 & 4.1 & $Q(F G)$ & FG Enrg out & KBtu/hr & 296.2 & 2.2 & DC Air & $\operatorname{scfm}$ & 5.1 & \\
\hline$F(T F G)$ & TFG FIw & $\operatorname{scfm}$ & 610.6 & 4.1 & $Q(I N)$ & Tot Enrg in & KBtu/hr & 2779.7 & 100.9 & Purge Air & sctm & 15.5 & \\
\hline W(SR) & Recirc Rt & $\mathrm{Ibs} / \mathrm{hr}$ & 11205 & 1416.7 & Q(OUT) & Tot Enrg out & KBtw/hr & 2100.8 & 84.7 & & & & \\
\hline
\end{tabular}




\begin{tabular}{|c|c|c|c|c|c|c|c|c|c|c|c|c|c|}
\hline \multirow{2}{*}{$\frac{\text { Tag }}{\text { TC11011 }}$} & \multirow{2}{*}{$\frac{\text { Desc }}{\text { PCD EX }}$} & \multirow{2}{*}{$\frac{\text { Units }}{{ }^{\circ} \mathbf{P}}$} & \multicolumn{2}{|c|}{ Average Std Dev } & \multicolumn{9}{|c|}{ HEAT-TRANSPER COEPPICIENTS } \\
\hline & & & 1589 & 5.7 & -Combustor- & & Number & r of Doors in & Servicem & 10 & & & \\
\hline & AFS Ex & $\bullet \mathbf{F}$ & 1469 & 6.1 & $c+1 x$ & Height & Temp In & Temp Out & Bed Temp & Plow & $\mathbf{Q}$ & $\mathbf{U}$ & Heat Plux \\
\hline TC15001 & C Plenum & ${ }^{\circ} \mathbf{F}$ & 617 & 5.0 & Location & (fi) & & $\bullet \mathbf{p}$ & $\bullet \mathbf{p}$ & gpm & Btu/br & Btw/ft ${ }^{2} \mathrm{br}^{\circ} \mathrm{p}$ & Btu/ft $2 \mathrm{br}$ \\
\hline TC15004 & C $1-1$ & ${ }^{\circ} \mathbf{F}$ & 1503 & 7.9 & $2 \mathrm{E}, \mathrm{W}$ & 8 & 42 & 126 & 1553 & 3.70 & 155018 & 20.9 & 29811 \\
\hline TC15005 & C $1-2$ & ${ }^{\circ} \mathbf{p}$ & 1485 & 9.2 & 3NE,SW & 14 & 42 & 133 & 1535 & 3.70 & 167958 & 23.0 & 32300 \\
\hline TC15006 & C 1-3' & ${ }^{\circ} \mathbf{F}$ & 1511 & 6.8 & 4SE,NW & 17.5 & 44 & 141 & 1533 & 4.00 & 194635 & 26.9 & 37430 \\
\hline TC15007 & C 1-4' & ${ }^{\circ} \mathbf{F}$ & 1479 & 7.0 & $S E$ & 22.5 & 44 & 155 & 1548 & 1.80 & 100208 & 27.7 & 38541 \\
\hline TC15008 & C $1-4^{\prime}$ & ${ }^{\circ} \mathbf{P}$ & 1494 & 7.5 & $6 \mathrm{NE}$ & 27.5 & 44 & 115 & 1549 & 1.90 & 67227 & 18.0 & 25856 \\
\hline TC15009 & $C 1-4$ & ${ }^{\circ} \mathrm{F}$ & 1480 & 7.1 & 7SE,NW & 32.5 & 44 & 114 & 1545 & 3.90 & 136052 & 18.3 & 26164 \\
\hline $\mathrm{TC} 15012$ & C 2-6' & ${ }^{\circ} \mathbf{p}$ & 1513 & 6.9 & 8 & 37.5 & 144 & 413 & 1557 & 0.00 & 0 & 0.0 & 0 \\
\hline TC15013 & C 2-8' & ${ }^{\circ} \mathrm{F}$ & 1553 & 6.5 & & Overall & 44 & 130 & 1532 & 17.54 & 748664 & 20.5 & 28795 \\
\hline TC15022 & C 3-11' & ${ }^{\circ} \mathrm{F}$ & 1528 & 5.4 & & & & From Data & Sheets $\Rightarrow$ & 19.00 & & & \\
\hline TC15023 & C 3-14' & ${ }^{\circ} \mathrm{F}$ & 1531 & 5.0 & -EHX- & & & & & & & & \\
\hline TC15024 & C 3-14' & ${ }^{\circ} \mathbf{F}$ & 1527 & 4.7 & Coils & No. of & Temp In & Temp Out & Bed Temp & Flow & $\mathbf{Q}$ & u & Heat Flux \\
\hline TC15025 & C 3-14' & ${ }^{\circ} \mathrm{F}$ & 1548 & 4.5 & Used & Coils & ${ }^{\circ} \mathrm{F}$ & ${ }^{\circ} \mathrm{F}$ & $\bullet \mathrm{F}$ & gpm & Btu/hr & Btu/ft ${ }^{2} h r^{\circ} \mathrm{F}$ & $\mathrm{Btu} / \mathrm{ft}^{2} \mathrm{hr}$ \\
\hline TC15032 & $C 4-17.5^{\prime}$ & ${ }^{\circ} \mathrm{F}$ & 1533 & 4.5 & $1-7,9-12$ & 11 & 41 & 156 & 1324 & 13.79 & 790674 & 82.0 & 95839 \\
\hline TC15042 & C 5-22.5' & ${ }^{\circ} \mathrm{F}$ & 1548 & 3.7 & & & & From Data & Sheets $\Rightarrow>$ & 15.20 & & & \\
\hline TC15052 & C 6-27.5' & ${ }^{\circ} \mathrm{F}$ & 1558 & 3.3 & & & & & & & & & \\
\hline TC15053 & C 6-27.5' & ${ }^{\circ} \mathrm{p}$ & 1559 & 3.4 & EMISSIO & ONS DATA & & & & & & & \\
\hline $\mathrm{TC} 15054$ & C 6-27.5 & ${ }^{\circ} \mathrm{F}$ & 1529 & 3.6 & & & & & & & & & \\
\hline TC15062 & C 7-32.5' & ${ }^{\circ} \mathrm{F}$ & 1545 & 3.5 & & As Measured & ed - & 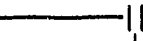 & 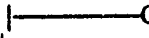 & Corrected to & o $3 \% \mathrm{O2}$ - & & \\
\hline TC15071 & C 8-37.5' & ${ }^{\circ} \mathrm{F}$ & 1557 & 3.4 & Tag & Units & Average & Std Dev & $\mathrm{Tag}$ & Units & Average & Std Dev & \\
\hline $\mathrm{TC} 15073$ & C $9-41^{\prime}$ & ${ }^{\circ} \mathrm{F}$ & 1602 & 3.7 & SO2-A & $\mathrm{ppm}$ & 128 & 59.3 & SO2-A & $\mathrm{ppm}$ & 119 & 53.1 & \\
\hline TC15999 & Ambient & ${ }^{\circ} \mathrm{F}$ & 78 & 1.0 & $\mathrm{SO} 2 \mathrm{AE}$ & Ib/MM Btu & 0.22 & 0.1 & & & & & \\
\hline TC16001 & EHX Plenm & ${ }^{\circ} \mathbf{P}$ & 129 & 4.0 & $\mathrm{SO} 2-\mathrm{B}$ & ppm & 123 & 51.2 & $\mathrm{SO} 2-\mathrm{B}$ & ppm & 105 & 43.8 & \\
\hline $\mathrm{TC} 16012$ & EHX 0.5' & ${ }^{\circ} \mathrm{F}$ & 1339 & 15.5 & $\mathrm{SO} 2 \mathrm{BE}$ & $\mathrm{Ib} / \mathrm{MM} \mathrm{Btu}$ & 0.21 & 0.1 & & & & & \\
\hline TC16013 & EHX 1.5' & ${ }^{\circ} \mathrm{F}$ & 1314 & 15.9 & $\mathrm{Co}$ & ppm & 11 & 7.6 & $\mathrm{CO}$ & ppm & 10 & 7.0 & \\
\hline TC16014 & EHX 2.7 & ${ }^{\circ} \mathrm{F}$ & 1320 & 17.0 & $\mathrm{CO} 2$ & $\%$ & 17.80 & 0.3 & $\mathrm{CO} 2$ & $\%$ & 16.69 & 0.1 & \\
\hline TC16015 & EHX 3.8' & ${ }^{\circ} \mathrm{F}$ & 1331 & 9.7 & $\mathrm{~N} 2 \mathrm{O}$ & ppm & 32 & 4.2 & $\mathrm{~N} 2 \mathrm{O}$ & ppm & 30 & 3.9 & \\
\hline TC16017 & EHX 5.3' & ${ }^{\circ} \mathrm{F}$ & 1280 & 6.6 & $\mathrm{~N} 2 \mathrm{OE}$ & $\mathrm{lb} / \mathrm{Mm}$ Btu & 0.04 & 0.0 & & & & & \\
\hline TC16018 & EHX Exit & ${ }^{\circ} \mathbf{P}$ & 1314 & 7.7 & NOx & $\mathrm{ppm}$ & 136 & 9.9 & Nox & ppm & 128 & 11.6 & \\
\hline $\mathrm{TC} 16021$ & $\operatorname{Crc} A$ in & ${ }^{\circ} \mathrm{F}$ & 1573 & 5.2 & NOxE & $\mathrm{lb} / \mathrm{Mm} \mathrm{Btu}$ & 0.17 & 0.0 & & & & & \\
\hline $\mathrm{TC} 16031$ & DC 8-36 & ${ }^{\circ} \mathbf{p}$ & 1570 & 7.4 & O2-A & $\%$ & 1.72 & 0.4 & & & & & \\
\hline TC16032 & DC 6-28' & ${ }^{\circ} \mathrm{F}$ & 1553 & 7.7 & $\mathrm{O}-\mathrm{B}$ & $\%$ & 1.80 & 0.4 & & & & & \\
\hline $\mathrm{TC} 16033$ & DC 4-18' & ${ }^{\circ} \mathrm{F}$ & 1512 & 29.3 & & & & & & & & & \\
\hline $\mathrm{TC} 16034$ & DC3-9.5 & ${ }^{\circ} \mathrm{F}$ & 1540 & 29.0 & & & & & & & & & \\
\hline $\mathrm{TC} 16035$ & DC3-8.5 & ${ }^{\circ} \mathbf{P}$ & 1513 & 31.9 & & & & & & & & & \\
\hline $\mathrm{T}(\mathrm{A}, \mathrm{C})$ & Comb Temp & ${ }^{\circ} \mathrm{F}$ & 1532 & 4.7 & Tag & Desc & Units & Average & Std Dev & Tag & Desc & Average & Std Dev \\
\hline $\mathrm{T}(\mathrm{A}, \mathrm{EHX})$ & EHX Temp & ${ }^{\circ} \mathrm{p}$ & 1324 & 16.0 & $W(C)$ & Coal Fd Rt & $\mathrm{lbs} / \mathrm{hr}$ & 315 & 11.7 & TC13131 & AFPE-F2" & 793 & 41.3 \\
\hline EA & Excess Air & $\%$ & 8.8 & 2.1 & W(S) & LS Fd Rt & $\mathrm{lbs} / \mathrm{hr}$ & 15 & 0.0 & TC13132 & AFPE-F6" & 998 & 27.8 \\
\hline SR & S Reten & $\%$ & 73.7 & 11.8 & $V(F G)$ & PG SGV & $\mathrm{ft} / \mathrm{sec}$ & 15.8 & 0.5 & TC13133 & AFPE-B6" & 804 & 36.8 \\
\hline$R(P C A)$ & $\%$ F $\mid w$ PCA & $\%$ & 60.4 & 1.7 & $V(S, C)$ & Comb SGV & $\mathrm{ft} / \mathrm{sec}$ & 14.1 & 0.5 & TC13134 & AFPE-F10 & 418 & 66.8 \\
\hline $\mathrm{R}(\mathrm{SCA})$ & $\%$ F $\mid w$ SCA & $\%$ & 39.6 & 1.7 & $V(S, E H X)$ & EHXSGV & $\mathrm{ft} / \mathrm{sec}$ & 2.2 & 0.0 & $\mathrm{TC} 13231$ & AFPW-F2" & 821 & 32.1 \\
\hline$R(Q, I N)$ & $\%$ Enrg in & $\%$ & 74.4 & 2.3 & FT18003 & CHX Flow & $\mathrm{gpm}$ & 17.5 & 0.1 & TC13232 & AFPW-F6" & 1000 & 26.0 \\
\hline $\mathrm{R}(\mathrm{CHX})$ & CHX Ratio & $\%$ & 43.1 & 1.1 & FT 19003 & EHX Flow & $\mathrm{gpm}$ & 13.8 & 0.0 & TC13233 & AFPW-B6" & 721 & 29.2 \\
\hline$R(E H X)$ & EHX Ratio & $\%$ & 56.9 & 1.1 & PT15081 & Comb dP & in. $\mathrm{H} 20$ & 41.2 & 2.0 & $\mathrm{TC} 13234$ & APPW-P10 & 879 & 34.4 \\
\hline $\mathrm{P}(\mathrm{PCA})$ & PCA F/w & scfm & 235.7 & 18.3 & $Q(C A)$ & CA Heat in & $\mathrm{KBtu} / \mathrm{hr}$ & 100.1 & 4.8 & DOORS & $\mathrm{CHX}$ s On & 10 & 0 \\
\hline$F(E H X)$ & EHX Flw & scfm & 60.3 & 0.9 & Q(CHX) & CHX HIRmv & KBtu/hr & 600.0 & 34.2 & COILS & EHXs On & 11 & 0 \\
\hline$F(T P A)$ & TPCA FIw & scfm & 291.5 & 16.8 & Q(EHX) & EHX HIRmv & $\mathrm{KBtu} / \mathrm{hr}$ & 790.7 & 21.0 & BH A/C & & 2.2 & 0.4 \\
\hline $\mathrm{F}(\mathrm{SCA})$ & SCA FIW & scfm & 156.2 & 5.2 & Q(EHX,IN & $\mathrm{E} \mathrm{FG} \mathrm{Ht} \mathrm{in}$ & $\mathrm{KBtu} / \mathrm{hr}$ & 3.1 & 0.2 & A/SRATIO & & 5.5 & 0.1 \\
\hline F(TAIR) & TCA Fiw & scfm & 482.2 & 16.2 & $\alpha(F)$ & Fuel Enrg in & $\mathrm{KBt} t \mathrm{~h} / \mathrm{hr}$ & 2801.6 & 104.0 & Peed Air & scfm & 19.1 & \\
\hline $\mathrm{F}(\mathrm{FG}, \mathrm{BH})$ & BH F/W & scfm & 598.8 & 9.9 & $Q(F G)$ & FG Enrg out & KBtw/hr & 296.7 & 4.7 & DC Air & $\operatorname{scfm}$ & 5.1 & \\
\hline $\mathrm{F}(\mathrm{TFG})$ & TFG $F / w$ & sefm & 598.8 & 9.9 & $Q(I N)$ & Tot Enrg in & $\mathrm{KBlu} / \mathrm{hr}$ & 2904.8 & 102.5 & Purge Air & scfm & 15.5 & \\
\hline$W(S R)$ & Recirc Rt & $\mathrm{lbs} / \mathrm{hr}$ & 13478 & 938.1 & Q(OUT) & Tot Enrg out & $\mathrm{KBt} t \mathrm{~h} / \mathrm{hr}$ & 2164.2 & 50.9 & & & & \\
\hline
\end{tabular}




\begin{tabular}{|c|c|c|c|c|c|c|c|c|c|c|c|c|c|}
\hline Tag & Desc & Units & Average $S$ & Dev & HEAT-TRAN & VSPER COEP & PPICIENI & & & & & & \\
\hline TC11011 & PCDEX & ${ }^{\circ} \mathbf{F}$ & 1554 & 6.6 & -Combustor- & & Number & of Doors in & Service & 10 & & & \\
\hline TC11021 & AFS Ex & ${ }^{\circ} \mathbf{F}$ & 1421 & 7.8 & $C-H X$ & Height & Temp In & Temp Out & Bed Temp & Plow & $\mathbf{Q}$ & $\mathbf{U}$ & Heat Flux \\
\hline TC15001 & C Plenum & ${ }^{\prime} \mathbf{F}$ & 571 & 5.4 & Location & (ft) & •F & $\cdot \boldsymbol{P}$ & • $\mathbf{P}$ & $\mathrm{gpm}$ & Btu/hr & Btu/ft ${ }^{2} h r^{\circ} \mathrm{p}$ & Btu/ft ${ }^{2} \mathrm{br}$ \\
\hline TC15004 & C $1-1^{\prime}$ & ${ }^{\circ} \mathbf{p}$ & 1522 & 8.9 & $2 \mathrm{E}, \mathrm{W}$ & 8 & 42 & 133 & 1572 & 3.60 & 164078 & 21.9 & 31553 \\
\hline TC15005 & C $1-2^{\prime}$ & ${ }^{\circ} \mathrm{P}$ & 1505 & 8.8 & 3NE,SW & 14 & 43 & 135 & 1547 & 3.65 & 167326 & 22.8 & 32178 \\
\hline TC15006 & C 1-3' & ${ }^{\circ} \mathbf{F}$ & 1529 & 9.0 & 4SE,NW & 17.5 & 43 & 169 & 1539 & 4.45 & 281428 & 39.5 & 54121 \\
\hline TC15007 & C $1-4^{\prime}$ & ${ }^{\circ} \mathrm{p}$ & 1497 & 7.8 & $5 \mathrm{E}$ & 22.5 & 45 & 153 & 1555 & 1.80 & 97385 & 26.7 & 37456 \\
\hline TC15008 & C $1-4^{\prime}$ & ${ }^{\circ} \mathbf{F}$ & 1511 & 8.8 & 6NE & 27.5 & 43 & 118 & 1552 & 1.80 & 67591 & 18.1 & 25997 \\
\hline TC15009 & $C 1^{-4}$ & ${ }^{\circ} \mathbf{F}$ & 1497 & 9.0 & 7SE,NW & 32.5 & 45 & 131 & 1553 & 1.80 & 77498 & 10.5 & 14903 \\
\hline TC15012 & C 2-6' & ${ }^{\circ} \mathrm{F}$ & 1531 & 7.8 & $8 \mathrm{E}, \mathrm{W}$ & 37.5 & 45 & 115 & 1558 & 1.90 & 66105 & 8.8 & 12712 \\
\hline TC15013 & C 2-8' & ${ }^{\circ} \mathrm{F}$ & 1572 & 6.3 & & Overall & 42 & 140 & 1545 & 17.56 & 859971 & 23.6 & 33076 \\
\hline TC15022 & C 3-11' & ${ }^{\circ} \mathrm{F}$ & 1540 & 5.1 & & & & From Data & Sheets $\Rightarrow$ & 19.00 & & & \\
\hline TC15023 & C 3-14' & ${ }^{\circ} \mathrm{F}$ & 1544 & 6.1 & -EHX- & & & & & & & & \\
\hline TC15024 & C 3-14' & ${ }^{\circ} \mathrm{P}$ & 1539 & 5.1 & Coils & No. of & Temp In & Temp Out & Bed Temp & Flow & $\mathbf{Q}$ & $\mathbf{U}$ & Heat Flux \\
\hline TC15025 & C 3-14' & ${ }^{\circ} \mathrm{F}$ & 1558 & 4.0 & Used & Coils & ${ }^{\circ} \mathbf{F}$ & ${ }^{\circ} \mathbf{p}$ & & gpm & Btu/hr & $\mathrm{Btu} / \mathrm{ft}^{2} \mathrm{hr} r^{\circ} \mathrm{P}$ & Btu/ft ${ }^{2} \mathrm{hr}$ \\
\hline TC15032 & C 4-17.5' & ${ }^{\circ} \mathrm{F}$ & 1539 & 5.2 & $1-2,5-7$ & 8 & 42 & 157 & 1339 & 10.07 & 580405 & 81.9 & 96734 \\
\hline TC15042 & C 5-22.5' & ${ }^{\circ} \mathrm{P}$ & 1555 & 3.4 & $10-12$ & & & From Data & Sheets $\Rightarrow$ & 11.00 & & & \\
\hline TC15052 & C 6-27.5' & $\cdot \mathbf{p}$ & 1567 & 3.6 & & & & & & & & & \\
\hline TC15053 & C 6-27.5' & ${ }^{\circ} \mathbf{p}$ & 1568 & 3.9 & EMISSIO & ONS DATA & & & & & & & \\
\hline TC15054 & C 6-27.5 & ${ }^{\circ} \mathbf{F}$ & 1521 & 4.9 & & & & & & & & & \\
\hline TC15062 & C 7-32.5' & ${ }^{\circ} \mathrm{F}$ & 1553 & 3.3 & & As Measured & ed- & 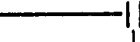 & & Corrected to & $3 \% 02-$ & & \\
\hline TC15071 & C 8-37.5' & ${ }^{\circ} \mathrm{F}$ & 1558 & 3.2 & Tag & Units & Average & Std Dev & Tag & Units & Average & Std Dev & \\
\hline TC15073 & C $9-41^{\prime}$ & ${ }^{\circ} \mathrm{p}$ & 1611 & 4.8 & SO2-A & ppm & 135 & 60.0 & SO2-A & $\mathrm{ppm}$ & 135 & 55.4 & \\
\hline TC15999 & Ambient & ${ }^{\circ} \mathrm{F}$ & 76 & 1.8 & SO2-AE & Ib/MM Btu & 0.25 & 0.1 & & & & & \\
\hline TC16001 & EHX Plenm & ${ }^{\circ} \mathbf{F}$ & 119 & 3.1 & SO2-B & ppm & 119 & 54.8 & SO2-B & ppm & 102 & 47.0 & \\
\hline TC16012 & EHX 0.5' & $\cdot \mathbf{p}$ & 1356 & 12.3 & SO2-BE & lb/MM Btu & 0.22 & 0.1 & & & & & \\
\hline TC16013 & EHX 1.5' & ${ }^{\circ} \mathrm{F}$ & 1322 & 10.2 & CO & ppm & 7 & 2.6 & CO & ppm & 7 & 2.6 & \\
\hline TC16014 & EHX 2.7' & ${ }^{\circ} \mathbf{F}$ & 1339 & 11.8 & $\mathrm{CO} 2$ & $\%$ & 16.19 & 0.5 & $\mathrm{CO} 2$ & $\%$ & 16.39 & 0.2 & \\
\hline TC16015 & EHX 3.8' & $\cdot \mathbf{F}$ & 1312 & 10.3 & $\mathrm{~N} 2 \mathrm{O}$ & ppm & N/A & $\mathrm{N} / \mathrm{A}$ & $\mathrm{N} 2 \mathrm{O}$ & ppm & N/A & N/A & \\
\hline TC16017 & EHX 5.3' & ${ }^{\circ} \mathrm{F}$ & 1232 & 7.1 & N2OE & $\mathrm{lb} / \mathrm{Mm} \mathrm{Btu}$ & N/A & N/A & & & & & \\
\hline TC16018 & EHX Exit & ${ }^{\circ} \mathbf{P}$ & 1301 & 10.5 & NOx & ppm & 156 & 13.0 & NOx & ppm & 159 & 18.7 & \\
\hline TC16021 & Crc $A$ in & ${ }^{\circ} \mathrm{F}$ & 1573 & 5.1 & NOxE & $\mathrm{lb} / \mathrm{Mm} \mathrm{Btu}$ & 0.21 & 0.0 & & & & & \\
\hline TC16031 & DC $8-36^{\prime}$ & ${ }^{\circ} \mathrm{F}$ & 1567 & 4.2 & O2-A & $\%$ & 3.85 & 0.6 & & & & & \\
\hline TC16032 & DC 6-28' & ${ }^{\circ} \mathrm{F}$ & 1551 & 4.0 & O2-B & $\%$ & 3.22 & 0.7 & & & & & \\
\hline TC16033 & DC 4-18' & ${ }^{\circ} \mathrm{F}$ & 1543 & 4.9 & & & & & & & & & \\
\hline TC16034 & $D C 3-9.5$ & ${ }^{\circ} \mathrm{F}$ & 1574 & 3.2 & & & & & & & & & \\
\hline TC16035 & $D C 3-8.5$ & ${ }^{\circ} \mathrm{F}$ & 1534 & 27.4 & & & & & & & & & \\
\hline$T(A, C)$ & romb Temp & ${ }^{\circ} \mathrm{F}$ & 1545 & 5.2 & Tag & Desc & Units & Average & Std Dev & $\mathrm{Tag}$ & Desc & Average & Std Dev \\
\hline $\mathrm{T}(\mathrm{A}, \mathrm{EHX})$ & EHX Temp & ${ }^{\circ} \mathbf{F}$ & 1339 & 11.6 & $W(C)$ & Coal Fd Rt & $\mathrm{lbs} / \mathrm{hr}$ & 277 & 6.9 & TC13131 & AFPE-F2n & 739 & 41.1 \\
\hline EA & Excess Air & $\%$ & 22.5 & 4.5 & $W(S)$ & LS Fd Rt & lbs/br & 6 & 1.2 & TC13132 & AFPE-F $6^{n}$ & 947 & 31.2 \\
\hline SR & S Reten & $\%$ & 69.6 & 12.5 & $V(F G)$ & FG SGV & $\mathrm{ft} / \mathrm{sec}$ & 15.9 & 0.6 & $\mathrm{TC} 13133$ & AFPE-B6" & 740 & 34.5 \\
\hline $\mathrm{R}(\mathrm{PCA})$ & $\%$ FIw PCA & $\%$ & 60.0 & 5.6 & $v(S, C)$ & Comb SGV & $\mathrm{ft} / \mathrm{sec}$ & 14.2 & 0.5 & $\mathrm{TC} 13134$ & APPE-F10" & 356 & 49.1 \\
\hline $\mathrm{R}(\mathrm{SCA})$ & $\%$ FIw SCA & $\%$ & 40.0 & 5.6 & $V($ S,EHX) & EHX SGV & $\mathrm{ft} / \mathrm{sec}$ & 1.8 & 0.0 & TC13231 & AFPW-F2" & 774 & 39.2 \\
\hline$R(Q, I N)$ & $\%$ Enrg in & $\%$ & 78.4 & 2.8 & FT18003 & CHX Flow & gpm & 17.6 & 0.2 & $\mathrm{TC} 13232$ & AFPW-F6" & 942 & 27.7 \\
\hline $\mathrm{R}(\mathrm{CHX})$ & CHX Ratio & $\%$ & 52.3 & 1.9 & FT19003 & EHX Flow & gpm & 10.1 & 0.1 & TC13233 & APPW-B6" & 645 & 30.8 \\
\hline$R(E H X)$ & EHX Ratio & $\%$ & 47.7 & 1.9 & PT15081 & Comb dP & in. $\mathrm{H} 2 \mathrm{O}$ & 47.0 & 1.2 & $\mathrm{TC} 13234$ & APPW-F10 & 813 & 38.1 \\
\hline $\mathbf{F}(\mathrm{PCA})$ & PCA F/w & scfm & 237.1 & 27.0 & $Q(C A)$ & CA Heal in & KBtu/hr & 99.8 & 3.8 & DOORS & CHXs On & 10 & 0 \\
\hline$F(E H X)$ & EHX FIw & scfm & 48.3 & 1.4 & $Q(C H X)$ & CHX HIRmv & $\mathrm{KB} t \mathrm{w} / \mathrm{hr}$ & 636.6 & 50.3 & COILS & EHXs On & 8 & 0 \\
\hline$F(T P A)$ & TPCA FlW & scfm & 292.0 & 29.4 & $Q(E H X)$ & EHX HIRmv & $\mathrm{KBtu} / \mathrm{hr}$ & 578.6 & 14.8 & BH A/C & & 2.2 & 0.0 \\
\hline $\mathrm{F}(\mathrm{SCA})$ & SCA PIw & $\operatorname{scfm}$ & 160.1 & 27.7 & Q(EHX,IN & $\mathrm{E} \mathrm{FG} \mathrm{Ht}$ in & $\mathrm{KBtu} / \mathrm{hr}$ & 2.1 & 0.2 & A/SRATIO & & 3.5 & 0.3 \\
\hline F(TAIR) & TCA FIw & scim & 486.8 & 17.3 & $\alpha(F)$ & Fuel Enrg in & KBtw/hr & 2473.3 & 75.9 & Feed Air & $\operatorname{scfm}$ & 18.6 & \\
\hline $\mathrm{F}(\mathrm{FG}, \mathrm{BH})$ & BH FIW & $\operatorname{scfm}$ & 586.8 & 5.0 & $Q(F G)$ & FG Enrg out & KBtu/hr & 291.1 & 3.1 & DC Air & $\operatorname{scfm}$ & 0.0 & \\
\hline$F(T F G)$ & TFG Fiw & scfm & 587.0 & 5.1 & $Q(N)$ & Tot Enrg in & $\mathrm{KBt} t \mathbf{w} \mathbf{h r}$ & 2575.2 & 74.4 & Purge Air & $\operatorname{scfm}$ & 15.5 & \\
\hline W(SR) & Recirc Rt & $\mathrm{lbs} / \mathrm{hr}$ & 9320 & 499.4 & Q(OUT) & Tot Enrg out & $\mathrm{KBtu} / \mathrm{hr}$ & 1999.9 & 87.7 & & & & \\
\hline
\end{tabular}




\begin{tabular}{|c|c|c|c|c|c|c|c|c|c|c|c|c|c|}
\hline $\mathrm{Tag}$ & Desc & Units & Average S & Sid Dev & HEAT-TRA & NSPER COEI & PPICIBND & & & & & & \\
\hline TC11011 & PCD Ex & ${ }^{\circ} \mathbf{F}$ & 1518 & 8.9 & -Combustor & & Number & of Doors in & Service $\Rightarrow$ & 10 & & & \\
\hline $\mathrm{TC} 11021$ & AFS Ex & $\bullet \mathbf{F}$ & 1384 & 8.7 & $C-H X$ & Height & Temp In & Temp Out & Bed Temp & Plow & $\mathbf{Q}$ & $\mathbf{U}$ & Heat Plux \\
\hline TC15001 & C Plenum & ${ }^{\circ} \mathbf{F}$ & 505 & 3.9 & Location & (fi) & $\cdot \mathbf{F}$ & $\bullet \mathbf{p}$ & $\bullet \mathbf{F}$ & gpm & Btwhr & Btw/ft ${ }^{2} b r^{\prime} P$ & Btult ${ }^{2} \mathrm{hr}$ \\
\hline TC15004 & C 1-1' & ${ }^{\circ} \mathbf{F}$ & 1537 & 15.9 & $2 \mathrm{E}, \mathrm{W}$ & 8 & 43 & 123 & 1587 & 3.60 & 144243 & 19.0 & 27739 \\
\hline $\mathrm{TC} 15005$ & C 1-2' & $\bullet \mathbf{F}$ & 1519 & 15.3 & 3NE,SW & 14 & 42 & 128 & 1537 & 3.60 & 155455 & 21.2 & 29895 \\
\hline TC15006 & C 1-3' & $\bullet \mathbf{F}$ & 1544 & 15.2 & 4SE,NW & 17.5 & 44 & 135 & 1511 & 4.30 & 195570 & 27.3 & 37610 \\
\hline TC15007 & C 1-4' & $\bullet p$ & 1513 & 14.8 & $5 E$ & 22.5 & 44 & 127 & 1534 & 2.10 & 87274 & 23.9 & 33567 \\
\hline TC15008 & C 1-4' & ${ }^{\circ} \mathbf{F}$ & 1530 & 15.7 & $6 \mathrm{NE}$ & 27.5 & 43 & 107 & 1517 & 1.80 & 57681 & 15.7 & 22185 \\
\hline TC15009 & C 1-4' & ${ }^{\circ} \mathbf{F}$ & 1515 & 14.9 & TSE,NW & 32.5 & 44 & 106 & 1493 & 3.80 & 116851 & 16.2 & 22471 \\
\hline TC15012 & C 2-6' & ${ }^{\circ} \mathbf{F}$ & 1545 & 15.7 & 8 & 37.5 & 128 & 226 & 1531 & 0.00 & 0 & 0.0 & 0 \\
\hline TC15013 & C 2-8' & ${ }^{\circ} \mathbf{F}$ & 1587 & 16.1 & & Overall & 43 & 122 & 1536 & 17.51 & 699893 & 19.0 & 26919 \\
\hline $\mathrm{TC} 15022$ & C 3-11' & ${ }^{\circ} \mathbf{F}$ & 1540 & 14.3 & & & & From Data & Sheets $\Rightarrow>$ & 19.20 & & & \\
\hline $\mathrm{TC} 15023$ & C 3-14' & ${ }^{\circ} \mathbf{F}$ & 1530 & 11.9 & $-\mathrm{EHX}-$ & & & & & & & & \\
\hline TC15024 & C 3-14' & ${ }^{\circ} \mathbf{P}$ & 1530 & 12.0 & Coils & No. of & Temp In & Temp Out & Bed Temp & Flow & $\mathbf{Q}$ & $U$ & Heat Flux \\
\hline TC15025 & C 3-14' & ${ }^{\circ} \mathbf{F}$ & 1549 & 13.1 & Used & Coils & $\stackrel{\circ}{F}$ & ${ }^{\circ} \mathbf{F}$ & ${ }^{\circ} \mathbf{P}$ & gpm & Btu/hr & $\mathrm{Btw} / \mathrm{ft}^{2} \mathrm{hr}^{\circ} \mathrm{F}$ & $\mathrm{Btu} / \mathrm{ft}^{2} \mathrm{hr}$ \\
\hline TC15032 & C 4-17.5' & ${ }^{\circ} \mathbf{F}$ & 1511 & 8.9 & $1-4,8,9$ & 8 & 42 & 100 & 1162 & 12.47 & 357685 & 56.1 & 59614 \\
\hline TC15042 & C 5-22.5' & ${ }^{\circ} \mathbf{F}$ & 1534 & 9.0 & $13-14$ & & & From Data & Sheet $s \Rightarrow$ & 13.70 & & & \\
\hline $\mathrm{TC} 15052$ & C 6-27.5' & ${ }^{\circ} \mathrm{F}$ & 1535 & 8.8 & & & & & & & & & \\
\hline TC15053 & C 6-27.5' & ${ }^{\circ} \mathrm{F}$ & 1535 & 9.5 & EMISSIC & ONS DATA & & & & & & & \\
\hline TC15054 & C 6-27.5' & ${ }^{\circ} \mathbf{F}$ & 1480 & 7.4 & & & & & & & & & \\
\hline TC15062 & C 7-32.5' & ${ }^{\circ} \mathbf{F}$ & 1493 & 5.8 & & As Measure & ed - & -1 & & Corrected to & - $3 \% 02-$ & ـ & \\
\hline TC15071 & C \&-37.5' & ${ }^{\circ} \mathrm{F}$ & 1531 & 9.6 & Tag & Units & Average & Std Dev & Tag & Units & Average & Std Dev & \\
\hline $\mathrm{TC} 15073$ & C 9-41' & ${ }^{\circ} \mathbf{F}$ & 1579 & 10.7 & SO2-A & $\mathrm{ppm}$ & 98 & 68.3 & SO2-A & ppm & 112 & $\overline{89.1}$ & \\
\hline TC15999 & Ambient & $\cdot \mathbf{F}$ & 68 & 2.0 & SO2-AE & $\mathrm{Ib} / \mathrm{MlM}$ Btu & 0.19 & 0.1 & & & & & \\
\hline $\mathrm{TC} 16001$ & EHX Plenm & ${ }^{\circ} \mathbf{F}$ & 113 & 3.1 & $\mathrm{SO} 2-\mathrm{B}$ & ppm & 12 & 11.4 & $\mathrm{SO} 2-\mathrm{B}$ & ppm & 10 & 9.7 & \\
\hline $\mathrm{TC} 16012$ & EHX 0.5' & ${ }^{\circ} \mathbf{F}$ & 1172 & 17.2 & SO2-BE & $\mathrm{Ib} / \mathrm{MM} \mathrm{Btu}$ & 0.02 & 0.0 & & & & & \\
\hline $\mathrm{TC} 16013$ & EHX 1.5' & ${ }^{\circ} \mathbf{F}$ & 1159 & 18.5 & $\mathrm{CO}$ & ppm & 7 & 2.6 & $\mathrm{CO}$ & ppm & 7 & 2.7 & \\
\hline TC16014 & EHX 2.7 & ${ }^{\circ} \mathbf{F}$ & 1156 & 16.6 & $\mathrm{CO} 2$ & $\%$ & 15.98 & 0.6 & $\mathrm{CO} 2$ & $\%$ & 17.84 & 2.0 & \\
\hline TC16015 & EHX 3.8' & ${ }^{\circ} \mathbf{F}$ & 1136 & 11.9 & $\mathrm{~N} 2 \mathrm{O}$ & ppm & 35 & 1.4 & $\mathrm{~N} 2 \mathrm{O}$ & ppm & 39 & 4.4 & \\
\hline TC16017 & EHX 5.3' & ${ }^{\circ} \mathbf{F}$ & 1089 & 7.6 & N2OE & Ib/Mm Btu & 0.05 & 0.0 & & & & & \\
\hline TC16018 & EHX Exit & ${ }^{\circ} \mathbf{F}$ & 1125 & 11.1 & NOx & ppm & 177 & 18.1 & NOx & ppm & 198 & 29.3 & \\
\hline $\mathrm{TC} 16021$ & Cre $A$ in & ${ }^{\circ} \mathbf{F}$ & 1551 & 10.2 & NOxE & $\mathrm{lb} / \mathrm{Mm}$ Btu & 0.24 & 0.0 & & & & & \\
\hline $\mathrm{TC} 16031$ & DC \&-36 & ${ }^{\circ} \mathbf{F}$ & 1529 & 13.4 & O2-A & $\%$ & 4.00 & 0.6 & & & & & \\
\hline $\mathrm{TC} 16032$ & DC 6-28' & ${ }^{\circ} \mathbf{F}$ & 1508 & 11.7 & O2-B & $\%$ & 4.73 & 1.4 & & & & & \\
\hline $\mathrm{TC} 16033$ & DC $4-18^{\prime}$ & ${ }^{\circ} \mathbf{F}$ & 1454 & 32.8 & & & & & & & & & \\
\hline $\mathrm{TC} 16034$ & DC3-9.5 & ${ }^{\circ} \mathbf{F}$ & 1480 & 45.5 & & & & & & & & & \\
\hline $\mathrm{TC} 16035$ & DC3-8.5 & ${ }^{\circ} \mathbf{F}$ & 1494 & 28.5 & & & & & & & & & \\
\hline $\mathrm{T}(\mathbf{A}, \mathbf{C})$ & Comb Temp & ${ }^{\circ} \mathbf{F}$ & 1536 & 11.6 & Tag & Desc & Units & Average & Std Dev & Tag & Desc & Average & Std Dev \\
\hline$T(A, E H X)$ & EHX Temp & ${ }^{\circ} \mathbf{p}$ & 1162 & 17.3 & $W(C)$ & Coal Fd Rt & $\mathrm{lbs} / \mathrm{hr}$ & 229 & 10.5 & TC13131 & AFPE-F2" & 679 & 54.0 \\
\hline $\mathrm{EA}$ & Excess Air & $\%$ & 23.5 & 4.4 & $W(S)$ & LS Fd Rt & lbs/hr & 4 & 0.0 & TC13132 & AFPE-F6" & 900 & 42.6 \\
\hline SR & S Reten & $\%$ & 77.7 & 15.1 & $V(F G)$ & FG SGV & $\mathrm{ft} / \mathrm{sec}$ & 13.0 & 1.0 & TC13133 & AFPE-B6" & 686 & 56.6 \\
\hline $\mathbf{R}(\mathrm{PCA})$ & \% Flw PCA & $\%$ & 78.6 & 4.8 & $V(S, C)$ & Comb SGV & $\mathrm{ft} / \mathrm{sec}$ & 11.8 & 1.0 & TC13134 & AFPE-F10" & 323 & 64.8 \\
\hline $\mathrm{R}(\mathrm{SCA})$ & $\%$ Flw SCA & $\%$ & 21.4 & 4.8 & $V(S, E H X)$ & EHX SGV & $\mathrm{ft} / \mathrm{sec}$ & 1.9 & 0.0 & TC13231 & APPW-F2" & 719 & 44.5 \\
\hline$R(Q, I N)$ & $\%$ Enrg in & $\%$ & 76.8 & 4.0 & FT18003 & CHX Flow & gpm & 17.5 & 0.3 & TC13232 & AFPW-P6" & 904 & 34.6 \\
\hline $\mathrm{R}(\mathrm{CHX})$ & CHX Ratio & $\%$ & 60.0 & 2.0 & FT19003 & EHX Flow & gpm & 12.5 & 0.1 & TC13233 & $A F P W-B 6^{n}$ & 622 & 40.0 \\
\hline$R(E H X)$ & EHX Ratio & $\%$ & 40.0 & 2.0 & PT15081 & Comb dP & in. $\mathrm{H} 2 \mathrm{O}$ & 36.3 & 2.4 & TC13234 & APPW-F $10^{\circ}$ & 773 & 50.1 \\
\hline$F(P C A)$ & PCA FIw & scfm & 261.9 & 27.7 & $Q(C A)$ & CA Heat in & KBtu/hr & 74.3 & 7.6 & DOORS & CHXs On & 10 & 0 \\
\hline$F(E H X)$ & EHX FIw & scfm & 57.3 & 1.4 & $Q(C H X)$ & CHX HeRmv & $\mathrm{KBtu} / \mathrm{hr}$ & 542.0 & 38.1 & COILS & EHXs On & 8 & 0 \\
\hline$F(T P A)$ & TPCA FIw & $\operatorname{sefm}$ & 317.0 & 25.0 & $Q(E H X)$ & EHX HIRmv & $\mathrm{KBtu} / \mathrm{hr}$ & 360.5 & 18.1 & BH A/C & & 1.9 & 0.0 \\
\hline $\mathrm{F}(\mathrm{SCA})$ & SCA Fiw & $\operatorname{scfm}$ & 51.5 & 22.0 & $Q$ QEHX,IN & E FG Ht in & KBtu/hr & 2.6 & 0.2 & ASSRATIO & & 2.9 & 0.1 \\
\hline F(TAIR) & TCA FIw & scfm & 403.9 & 31.2 & $Q(F)$ & Puel Enrg in & $\mathrm{KBtu} / \mathrm{hr}$ & 2031.8 & 94.6 & Feed Air & $\operatorname{scfm}$ & 19.3 & \\
\hline $\mathrm{F}(\mathrm{FG}, \mathrm{BH})$ & BH Flw & scfm & 485.3 & 5.8 & $Q(F G)$ & FG Enrg out & KBtu/hr & 240.8 & 2.9 & DC Air & scfm & 5.3 & \\
\hline$F(T F G)$ & TFG FIw & $\operatorname{scfm}$ & 485.3 & 5.8 & $Q(I N)$ & Tot Enrg in & KBtu/hr & 2110.5 & 95.5 & Purge Air & $\operatorname{scfm}$ & 15.5 & \\
\hline$W(S R)$ & Recirc Rt & $\mathrm{lbs} / \mathrm{hr}$ & 4093 & 410.9 & Q(OUT) & Tot Enrg out & $\mathrm{KBtu} / \mathrm{hr}$ & 1616.7 & 54.5 & & & & \\
\hline
\end{tabular}




\begin{tabular}{|c|c|c|c|c|c|c|c|c|c|c|c|c|c|}
\hline \multirow{2}{*}{$\frac{\text { Tag }}{\text { TC11011 }}$} & \multirow{2}{*}{$\frac{\text { Desc }}{\text { PCD Ex }}$} & \multirow{2}{*}{$\frac{\text { Units }}{{ }^{\circ} \mathrm{F}}$} & \multicolumn{2}{|c|}{ Average Std Dev } & \multicolumn{9}{|c|}{ HEAT-TRANSPER COEPPICIENTS } \\
\hline & & & 1526 & 8.9 & \multicolumn{2}{|c|}{-Combustor- } & \multicolumn{3}{|c|}{ Number of Doors in Service $\Longrightarrow$} & \multicolumn{2}{|l|}{10} & & \multirow{2}{*}{ Heat Flux } \\
\hline & AFS Ex & $\cdot p$ & 1407 & 7.2 & $C-H x$ & Height & Temp In & Temp Out & Bed Temp & Plow & $\mathbf{Q}$ & $\mathrm{U}$ & \\
\hline TC15001 & C Plenum & ${ }^{\circ} \mathbf{F}$ & 559 & 4.5 & Location & (ft) & $\bullet \mathbf{p}$ & •p & •p & $\mathrm{gpm}$ & Btu/hr & Btufft ${ }^{2} b r^{\circ} \mathrm{P}$ & Btw/ft ${ }^{2} h r$ \\
\hline TC15004 & C $1-1$ & $\cdot \mathbf{P}$ & 1529 & 14.2 & $2 \mathrm{E}, \mathrm{W}$ & 8 & 42 & 123 & 1576 & 3.58 & 144523 & 19.1 & 27793 \\
\hline TC15005 & C 1-2' & ${ }^{\circ} \mathbf{F}$ & 1512 & 14.1 & 3NE,SW & 14 & 43 & 131 & 1539 & 3.62 & 159058 & 21.7 & 30588 \\
\hline TC15006 & C $1-3$ ' & ${ }^{\circ} \mathbf{F}$ & 1537 & 13.8 & 4SE,NW & 17.5 & 45 & 141 & 1527 & 4.28 & 205267 & 28.5 & 39474 \\
\hline TC15007 & C 1-4' & ${ }^{\circ} \mathbf{F}$ & 1507 & 13.3 & $5 \mathrm{E}$ & 22.5 & 44 & 134 & 1546 & 2.06 & 92829 & 25.3 & 35703 \\
\hline TC15008 & C 1-4' & ${ }^{\circ} \mathbf{F}$ & 1522 & 14.5 & 6NE & 27.5 & 43 & 116 & 1538 & 1.78 & 65311 & 17.7 & 25120 \\
\hline TC15009 & C $1-4^{\prime}$ & ${ }^{\circ} \mathbf{F}$ & 1507 & 13.7 & 7SE,NW & 32.5 & 44 & 114 & 1524 & 3.78 & 130801 & 17.8 & 25154 \\
\hline TC15012 & C 2-6' & ${ }^{\circ} \mathbf{P}$ & 1529 & 13.2 & 8 & 37.5 & 134 & 320 & 1549 & 0.00 & 0 & 0.0 & 0 \\
\hline TC15013 & C 2-8' & ${ }^{\circ} \mathbf{F}$ & 1576 & 13.1 & & Overall & 42 & 127 & 1540 & 17.45 & 742817 & 20.2 & 28570 \\
\hline TC15022 & C 3-11' & ${ }^{\circ} \mathbf{F}$ & 1542 & 12.2 & & & & From Data & Sheet $: \Rightarrow>$ & 19.10 & & & \\
\hline TC15023 & C 3-14' & ${ }^{\circ} \mathbf{F}$ & 1537 & 12.6 & EHX- & & & & & & & & \\
\hline TC15024 & C 3-14' & ${ }^{\circ} \mathbf{F}$ & 1529 & 10.6 & Coils & No. of & Temp In & Temp Out & Bed Temp & Plow & Q & $\mathrm{U}$ & Heat Flux \\
\hline $\mathrm{TC} 15025$ & C 3-14' & ${ }^{9} \mathbf{P}$ & 1553 & 12.1 & Used & Coils & ${ }^{\circ} \mathbf{F}$ & ${ }^{\circ} \mathrm{F}$ & ${ }^{\circ} \mathbf{F}$ & gpm & Btu/hr & Btu/ft ${ }^{2} \mathrm{hr}^{\circ} \mathrm{F}$ & $\mathrm{Btu} / \mathrm{ft}^{2} \mathrm{hr}$ \\
\hline TC15032 & C 4-17.5' & ${ }^{4} \mathbf{F}$ & 1527 & 11.3 & $1-4,8$ & 5 & 42 & 139 & 1378 & 7.45 & 362426 & 78.0 & 96647 \\
\hline TC15042 & C 5-22.5' & ${ }^{\circ} \mathrm{F}$ & 1546 & 10.1 & $13-14$ & & & From Data & Sheets $\Rightarrow$ & 8.36 & & & \\
\hline TC15052 & C 6-27.5 & ${ }^{\circ} \mathrm{F}$ & 1553 & 10.0 & & & & & & & & & \\
\hline TC15053 & C 6-27.5' & ${ }^{\circ} \mathbf{F}$ & 1551 & 10.8 & EMISSIC & ONS DATA & & & & & & & \\
\hline TC15054 & C 6-27.5' & $\cdot \mathrm{F}$ & 1509 & 10.2 & & & & & & & & & \\
\hline TC15062 & C 7-32.5 & ${ }^{\circ} \mathbf{F}$ & 1524 & 10.0 & & As Measure & ed- & 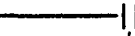 & & Corrected to & o $3 \% 02-$ & -1 & \\
\hline TC15071 & C 8-37.5' & ${ }^{\circ} \mathbf{F}$ & 1549 & 10.6 & Tag & Units & Average & Std Dev & $\mathrm{Tag}$ & Units & Average & Std Dev & \\
\hline TC15073 & C 9-41' & ${ }^{\circ} \mathbf{F}$ & 1592 & 12.4 & SO2-A & ppm & 10 & 6.5 & SO2-A & ppm & 12 & 8.0 & \\
\hline TC15999 & Ambient & ${ }^{\circ} \mathrm{P}$ & 72 & 2.2 & SO2-AE & $\mathrm{Ib} / \mathrm{MM} \mathrm{Btu}$ & 0.02 & 0.0 & & & & & \\
\hline $\mathrm{TC} 16001$ & EHX Plenm & ${ }^{\circ} \mathrm{F}$ & 120 & 3.7 & $\mathrm{SO} 2-\mathrm{B}$ & ppm & 12 & 7.1 & $\mathrm{SO} 2-\mathrm{B}$ & ppm & 10 & 6.1 & \\
\hline $\mathrm{TC} 16012$ & EHX 0.5' & ${ }^{\circ} \mathbf{F}$ & 1382 & 14.5 & SO2-BE & lb/MM Btu & 0.03 & 0.0 & & & & & \\
\hline TC16013 & EHX 1.5' & ${ }^{\circ} \mathbf{F}$ & 1371 & 14.7 & $\mathrm{CO}$ & ppm & 4 & 2.2 & Co & ppm & 5 & 2.8 & \\
\hline TC16014 & ЕHX 2.7 & ${ }^{\circ} \mathbf{F}$ & 1382 & 15.1 & $\mathrm{CO} 2$ & $\%$ & 13.97 & 0.6 & $\mathrm{CO} 2$ & $\%$ & 17.26 & 0.3 & \\
\hline TC16015 & EHX 3.8' & ${ }^{\circ} \mathrm{P}$ & 1366 & 13.6 & $\mathrm{~N} 2 \mathrm{O}$ & ppm & 33 & 3.8 & $\mathrm{~N} 2 \mathrm{O}$ & $\mathrm{ppm}$ & 41 & 4.8 & \\
\hline TC16017 & EHX 5.3' & ${ }^{\circ} \mathrm{F}$ & 1312 & 10.6 & N2OE & $\mathrm{Ib} / \mathrm{Mm} \mathrm{Btu}$ & 0.05 & 0.0 & & & & & \\
\hline TC16018 & EHX Exit & ${ }^{\circ} \mathbf{F}$ & 1332 & 18.4 & NOx & ppm & 205 & 7.3 & Nox & ppm & 254 & 18.2 & \\
\hline $\mathrm{TC} 16021$ & $\operatorname{Crc} A$ in & ${ }^{\circ} \mathbf{F}$ & 1559 & 10.1 & NOxE & $\mathrm{lb} / \mathrm{Mm}$ Btu & 0.32 & 0.0 & & & & & \\
\hline $\mathrm{TC} 16031$ & DC 8-36 & ${ }^{\circ} \mathrm{P}$ & 1545 & 13.1 & O2-A & $\%$ & 6.34 & 0.6 & & & & & \\
\hline $\mathrm{TC} 16032$ & DC 6-28' & ${ }^{\circ} \mathrm{F}$ & 1530 & 10.7 & O2-B & $\%$ & 6.43 & 0.6 & & & & & \\
\hline $\mathrm{TCl} 16033$ & $D C 4-18^{\prime}$ & ${ }^{\circ} \mathrm{F}$ & 1500 & 33.3 & & & & & & & & & \\
\hline $\mathrm{TC} 16034$ & DC3-9.5 & ${ }^{\circ} \mathrm{F}$ & 1540 & 32.8 & & & & & & & & & \\
\hline TC16035 & DC3-8.5 & ${ }^{\circ} \mathrm{F}$ & 1521 & 23.5 & & & & & & & & & \\
\hline$T(A, C)$ & Comb Temp & ${ }^{\circ} \mathbf{F}$ & 1540 & 11.0 & Tag & Desc & Units & Average & Std Dev & Tag & Desc & Average & Std Dev \\
\hline$\Gamma(A, E H X)$ & EHX Temp & ${ }^{\circ} \mathrm{F}$ & 1378 & 14.5 & $W(C)$ & Coal Fd Rt & $\mathrm{lbs} / \mathrm{hr}$ & 246 & 13.0 & TC13131 & AFPE-F2" & 737 & 41.5 \\
\hline EA & Excess Air & $\%$ & 43.5 & 6.2 & $W(\mathbf{S})$ & LS Fd Rt & lbs/hr & 7 & 0.3 & TC13132 & AFPE-F6" & 945 & 33.7 \\
\hline SR & S Reten & $\%$ & 97.4 & 1.7 & $V(\mathbf{F G})$ & FG SGV & $\mathrm{ft} / \mathrm{sec}$ & 16.1 & 0.9 & TC13133 & APPE-B6" & 744 & 49.6 \\
\hline $\mathrm{R}(\mathrm{PCA})$ & $\%$ F/w PCA & $\%$ & 60.3 & 2.5 & $v(S, C)$ & Comb SGV & $\mathrm{ft} / \mathrm{sec}$ & 14.6 & 0.8 & TC13134 & AFPE-F10" & 377 & 55.3 \\
\hline $\mathrm{R}(\mathrm{SCA})$ & $\%$ FIw SCA & $\%$ & 39.7 & 2.5 & $V(S, E H X)$ & EHX SGV & $\mathrm{ft} / \mathrm{sec}$ & 2.2 & 0.1 & TC13231 & AFPW-F2" & 771 & 36.9 \\
\hline$R(Q, I N)$ & \% Enrg in & $\%$ & 74.6 & 4.1 & FT 18003 & CHX Flow & $\mathrm{gpm}$ & 17.5 & 0.2 & TC13232 & AFPW-F6" & 948 & 27.8 \\
\hline $\mathrm{R}(\mathrm{CHX})$ & CHX Ratio & $\%$ & 60.4 & 1.5 & FT19003 & EHX Flow & gPm & 7.5 & 0.1 & TC13233 & AFPW-B6" & 672 & 32.5 \\
\hline$R(E H X)$ & EHX Ratio & $\%$ & 39.6 & 1.5 & PT15081 & Comb dP & in. $\mathbf{H} 20$ & 36.4 & 2.3 & TC13234 & AFPW-F10 & 827 & 40.0 \\
\hline $\mathrm{F}(\mathrm{PCA})$ & PCA FIw & scfm & 241.9 & 27.7 & $Q(C A)$ & CA Heat in & $\mathrm{KBt} / \mathrm{hr}$ & 101.0 & 6.2 & DOORS & CHXs On & 10 & 0 \\
\hline$F(E H X)$ & EHX Fiw & sefm & 58.3 & 1.2 & Q(CHX) & CHX HIR⿴囗十 & $\mathrm{KBtu} / \mathrm{hr}$ & 556.0 & 26.4 & colls & EHXs On & 5 & 0 \\
\hline$F(T P A)$ & TPCA Flw & $\operatorname{scfm}$ & 300.3 & 26.3 & $Q(E H X)$ & EHX HIRmv & $\mathrm{KBt} / \mathrm{h} / \mathrm{hr}$ & 363.5 & 11.0 & BH A/C & & 2.3 & 0.0 \\
\hline $\mathrm{F}(\mathrm{SCA})$ & SCA F/W & $\operatorname{scfm}$ & 162.1 & 9.3 & Q(EHX,IN & E FG Ht in & $\mathrm{KBt} / \mathrm{hr} r$ & 2.8 & 0.2 & A/SRATIO & & 3.9 & 0.1 \\
\hline F(TAIR) & TCA Fiw & $\operatorname{scfm}$ & 496.8 & 27.4 & $Q(F)$ & Fuel Enrg in & $\mathrm{KBtw} / \mathrm{hr}$ & 2186.8 & 123.0 & Feed Air & scfm & 19.3 & \\
\hline$F(F G, B H)$ & BH FIw & $\operatorname{scfm}$ & 594.5 & 10.4 & $Q$ FG) & FG Enrg out & $\mathrm{KBtu} / \mathrm{hr}$ & 295.1 & 5.8 & DC Air & scim & 5.2 & \\
\hline $\mathrm{F}(\mathrm{TFG})$ & TFG FIw & $\operatorname{sefm}$ & 594.5 & 10.4 & $Q(I N)$ & Tot Enrg in & $\mathrm{KBtu} / \mathrm{hr}$ & 2290.4 & 122.2 & Purge Air & $\operatorname{scfm}$ & 15.5 & \\
\hline W(SR) & Recirc Rt & $\mathrm{lbs} / \mathrm{hr}$ & 7542 & 781.8 & Q(OUT) & Tot Enrg out & KBtw/hr & 1692.1 & 33.1 & & & & \\
\hline
\end{tabular}




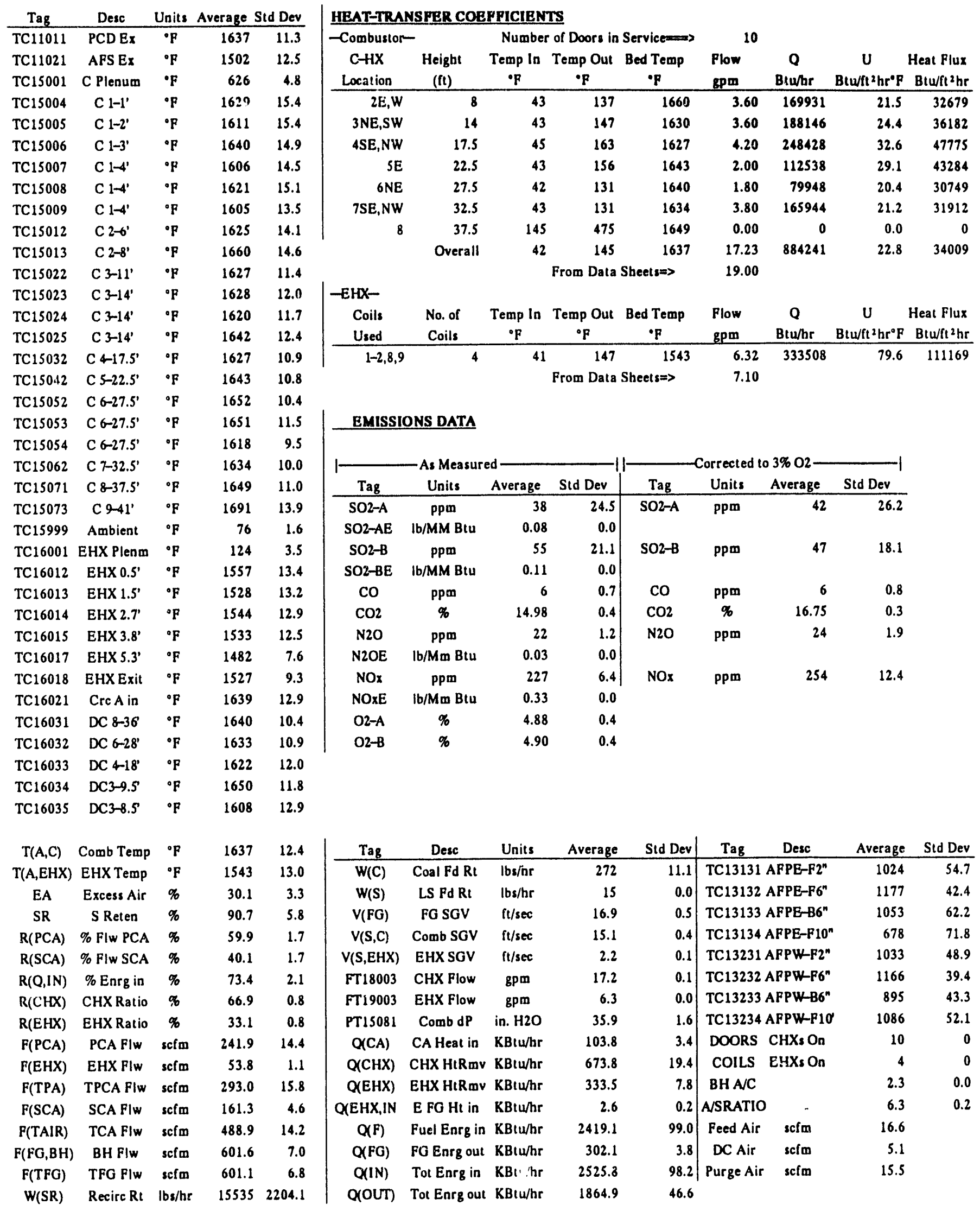




\section{APPENDIX E}

ASIAN LIGNITE TEST RESULTS 


\section{TABLE OF CONTENTS}

\section{Page}

LIST OF FIGURES $\ldots \ldots \ldots \ldots \ldots \ldots \ldots \ldots \ldots \ldots \ldots \ldots \ldots$.iii

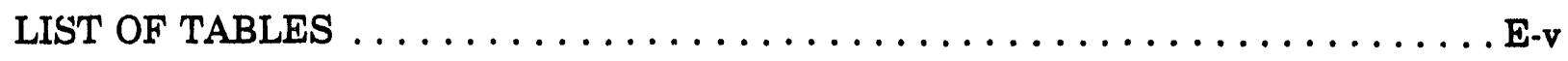

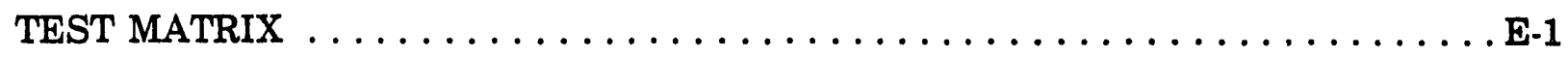

COAL AND LIMESTONE PROPERTIES $\ldots \ldots \ldots \ldots \ldots \ldots \ldots \ldots \ldots \ldots \ldots$

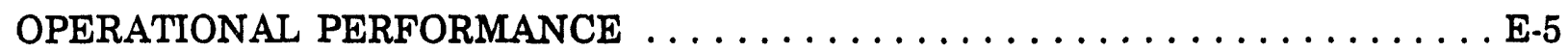

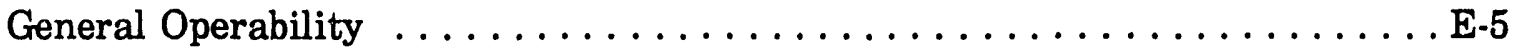

Summary of Results . ........................ E-6

Recirculation Rates and Size Distributions ................ E-6

Bottom Ash/Total Ash Split . . . . . . . . . . . . . . . . . E-9

Ash/Limestone Split . . . . . . . . . . . . . . . . . . . E E-9

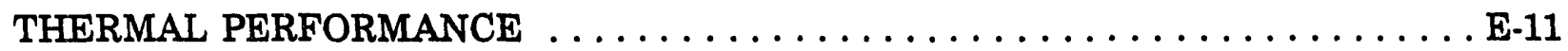

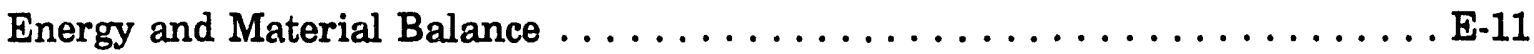

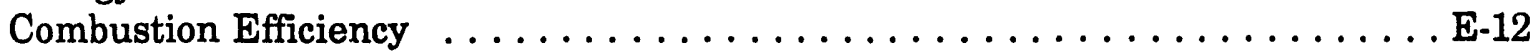

Boiler Efficiency . . . . . . . . . . . . . . . . . . . . E-14

Heat-Transfer Coefficient and Heat Flux $\ldots \ldots \ldots \ldots \ldots \ldots \ldots \ldots$ E-17

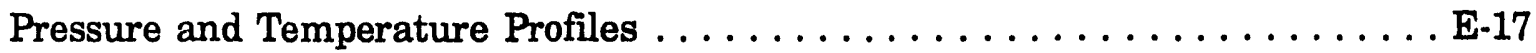

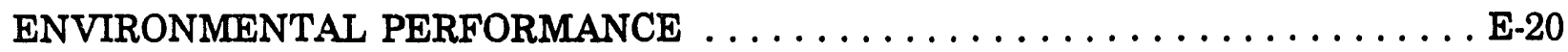

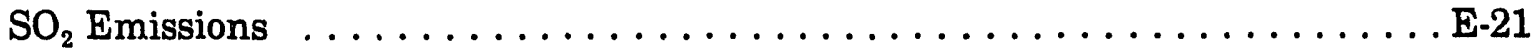

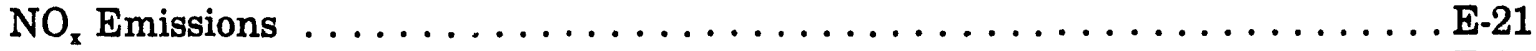

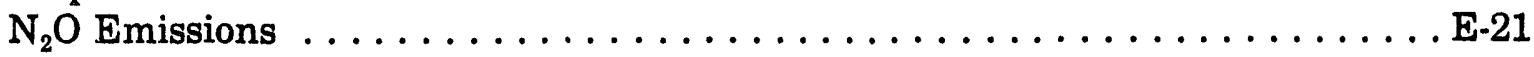

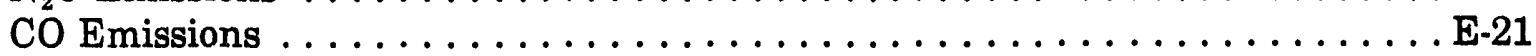

SINTERING, AGGLOMERATION, AND DEPOSIT EVALUATION . . . . . . . E-24

Bed Material Sintering and Agglomeration Potential . . . . . . . . . . . . E-24

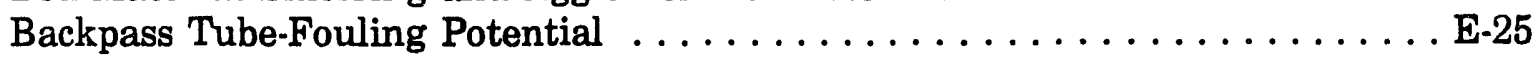

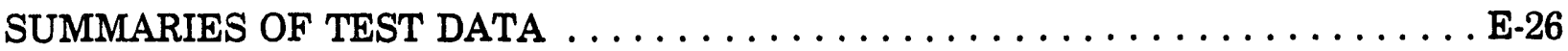




\section{LIST OF FIGURES}

Figure

Page

E-1 Size distributions of the coal $\ldots \ldots \ldots \ldots \ldots \ldots \ldots \ldots \ldots \ldots \ldots \ldots$

E-2 Size distributions of limestone $\ldots \ldots \ldots \ldots \ldots \ldots \ldots \ldots \ldots \ldots \ldots \ldots \ldots$

E-3 Downcomer, secondary cyclone, and baghouse ash size distributions ...... E-3

E-4 Combustion efficiency as a function of average combustor temperature . . . E-15

E-5 Combustor pressure profiles $\ldots \ldots \ldots \ldots \ldots \ldots \ldots \ldots \ldots \ldots \ldots \ldots \ldots$

E-6 Cornbustor temperature profiles $\ldots \ldots \ldots \ldots \ldots \ldots \ldots \ldots \ldots \ldots \ldots$

E-7 $\mathrm{SO}_{2}$ emissions as a function of average combustor temperature $\ldots \ldots \ldots \ldots$ E-22

E-8 $\mathrm{SO}_{2}$ retention as a function of calcium-to-sulfur molar ratio $\ldots \ldots \ldots \ldots \ldots$. . . 22

E-9 $\mathrm{NO}_{\mathrm{x}}$ emissions as a function of average combustor temperature $\ldots \ldots \ldots \ldots \mathrm{E}-23$

E-10 $\mathrm{N}_{2} \mathrm{O}$ emissions as a function of average combustor temperature $\ldots \ldots \ldots \ldots$ E-23

E-11 CO emissions as a function of average combustor temperature $\ldots \ldots \ldots \ldots$ E-24 


\section{LIST OF TABLES}

Table

$\underline{\text { Page }}$

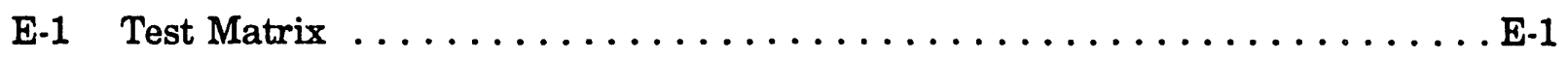

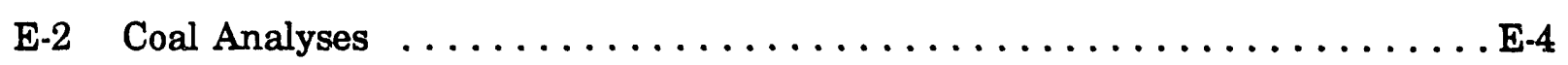

E-3 Average Limestone Analysis $\ldots \ldots \ldots \ldots \ldots \ldots \ldots \ldots \ldots \ldots \ldots \ldots$

E-4 Summary of Process Data $\ldots \ldots \ldots \ldots \ldots \ldots \ldots \ldots \ldots \ldots \ldots$

E-5 Solids Recirculation and Heat-Transfer Data $\ldots \ldots \ldots \ldots \ldots \ldots \ldots$

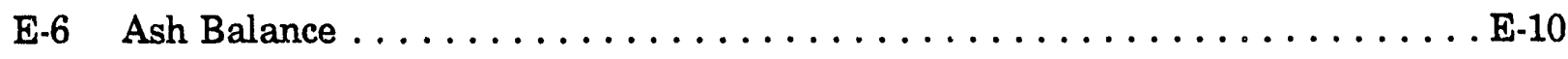

E-7 Material Derived from Coal Ash and Limestone Based on an Aluminum Material Balance .......................... E-10

E-8 Aluminum Material Balance $\ldots \ldots \ldots \ldots \ldots \ldots \ldots \ldots \ldots \ldots \ldots \ldots$

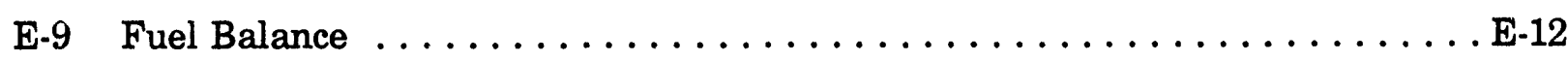

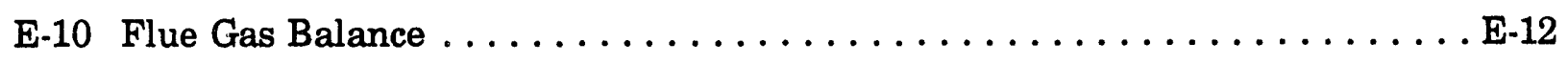

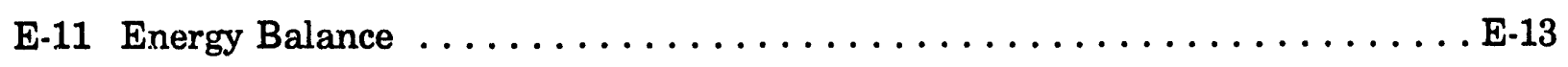

E-12 Material Balance . . . . . . . . . . . . . . . . . E

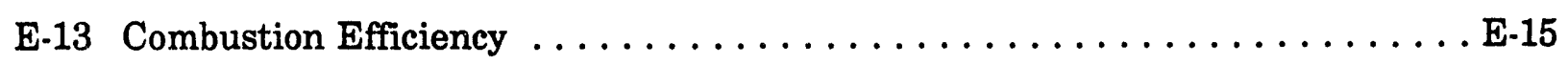

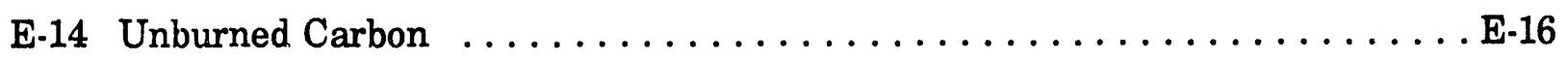

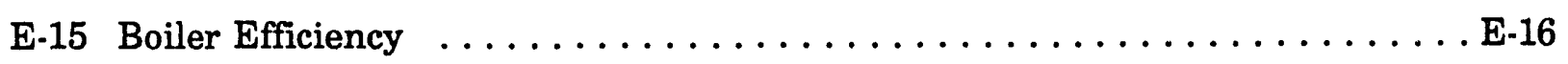

E-16 Individual Heat-Transfer Coefficients $\ldots \ldots \ldots \ldots \ldots \ldots \ldots \ldots \ldots$

E-17 Individual Heat Flux $\ldots \ldots \ldots \ldots \ldots \ldots \ldots \ldots \ldots \ldots \ldots \ldots \ldots \ldots$

E-18 Average Heat-Transfer Coefficient and Heat Flux $\ldots \ldots \ldots \ldots \ldots \ldots$ E-18

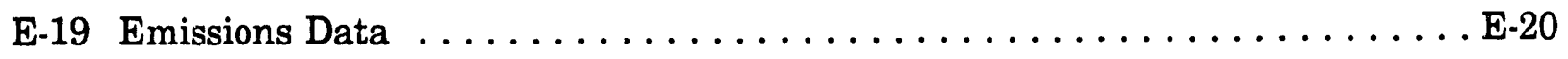

E-20 Analysis of Deposit from the Shell-and-Tube Heat Exchanger . . . . . . . E-26 


\section{TEST MATRIX}

The matrix of test parameters is shown in Table E-1. The coal and limestone feed rates were established in Test 1 to result in an upper combustor velocity of 18.0 feet per second, $90 \%$ sulfur retention, and $20 \%$ excess air. The coal feed rate was then held steady for the three remaining tests. The limestone feed rate, which was set to achieve $90 \%$ sulfur retention during Test 1, was held constant for Tests 2 and 3 . Combustion air flow rates were also held steady for the entire run; the superficial gas velocity varied with temperature during Tests 2 and 3 . The bed temperature was increased or decreased in these tests by removing or adding heat-transfer surface in the combustor and external heat exchanger. The target excess air level was $20 \%$, and the ratio of primary to secondary combustion air was 60:40 for all tests. Bed material was periodically drained to maintain a pressure drop across the bed of about 40 inches of water. Solids samples from the coal and limestone hoppers, combustor bed, baghouse, and secondary cyclone were taken every two hours during test periods. Samples of bed material and downcomer ash were taken routinely as specified between test periods.

\section{COAL AND LIMESTONE PROPERTIES}

The coal and limestone, which were loaded into 2000-lb (1000-kg) supersacks, were shipped overseas from the source mine in Asia to Hong Kong to Seattle, Washington, and by rail from Seattle to West Fargo, North Dakota. The supersacks were then loaded onto three trucks for shipping to Grand Forks, North Dakota. Two trucks arrived on Saturday, August 3, and the third arrived on Monday, August 5. A total of approximately 100,000 pounds of coal and 20,000 pounds of limestone were scheduled for delivery. Ten sacks of limestone and 41 sacks of coal were received.

The as-received coal consisted of a very high percentage of fines. The larger lumps crumbled easily into fines. The coal was dumped on the ground and mixed with a frontend loader prior to entering the coal preparation system. The as-received limestone was of good consistency--the majority of the material was between $3 / 4$ and $3 / 8$ inch. Samples were taken of the as-received and the as-prepared coal and limestone for size distribution analyses. The size distributions of the prepared coal used for each of the four tests is shown in Figure E-1. Figure E-2 contrasts the size distributions of the as-received and asprepared limestone which was used throughout the run.

\section{TABLE E-1}

Test Matrix

\begin{tabular}{ccccc}
\hline Test \# & Temp., ${ }^{\circ} \mathrm{F}$ & Ca/S & Gas Vel., ft/sec & Test Length, hr \\
\hline 1 & 1550 & As req. for 90\% ret. & 18.0 & 6 \\
2 & 1450 & Same as Test 1 & $18.0(-)$ & 4 \\
3 & 1650 & Same as Test 1 & $18.0(+)$ & 4 \\
4 & 1550 & Zero Limestone Feed & 18.0 & 4 \\
\hline
\end{tabular}




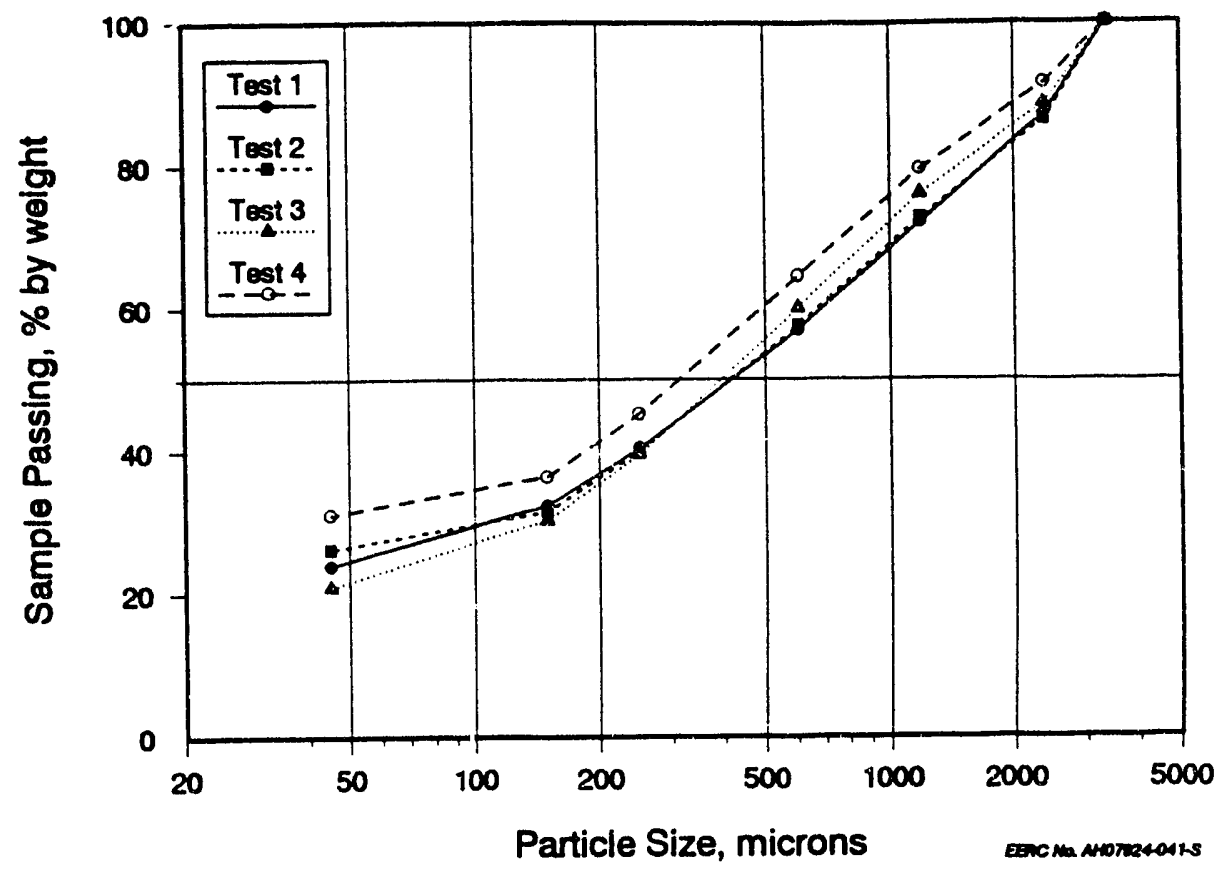

Figure E-1. Size distributions of the coal.

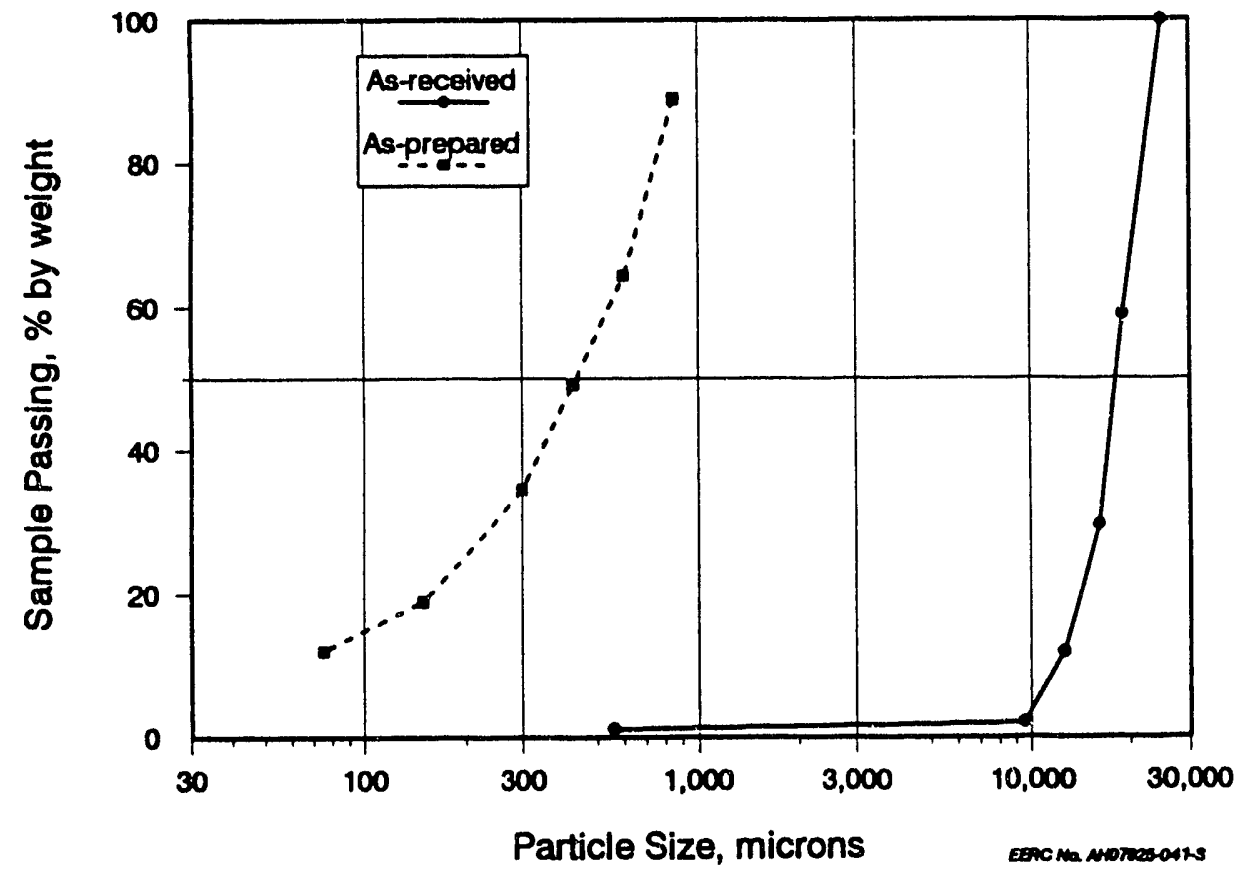

Figure E-2. Size distributions of limestone. 
Very little crushing was required for this coal. A few large pieces of rock were found that clogged the surge bin above the crusher; these pieces, probably overburden, were removed from the crusher and discarded. The size distribution of the as-crushed sample is shown in Figure E-1. Note that it is almost the same as the as-received sample.

Limestone was crushed separately using the Williams hammer-mill crusher and double-screened to $-16-\mathrm{mesh}(1.2-\mathrm{mm}$ or $1200-\mu \mathrm{m})+100$-mesh $(150-\mu \mathrm{m})$ size distribution. The limestone crushed well once-through, with only a small amount greater than 16 mesh (separated into barrels for additional crushing) and not many fires. The size distribution for an as-crushed limestone sample is shown in Figure E-3. About $12 \%$ was less than 200 mesh $(75 \mu \mathrm{m}) ; 90 \%$ was less than 20 mesh $(850 \mu \mathrm{m})$ with what appears to be a good distribution. The $d_{50}$ of $420 \mu \mathrm{m}$ was slightly larger than that specified for the test $(250 \mu \mathrm{m})$.

The sized coal and limestone from final screening were routed into 2-ton capacity coal totes which were on standby waiting to be transferred by forklift and crane to storage hoppers having net capacities of approximately 3500 pounds and 1000 pounds for the coal and limestone, respectively.

Proximate and ultimate analyses of the coal and XRFA of the coal ash and limestone were performed. Results of the coal analyses for each test period are shown in Table E-2, and the limestone analysis is shown in Table E-3. The coal is consistent with what was expected from the Asian lignite, with high levels of ash, sulfur, and calcium and low levels of sodium and potassium. The moisture level of the coal received $(\sim 17 \%)$ was less than the mine average of $\sim 27 \%$.

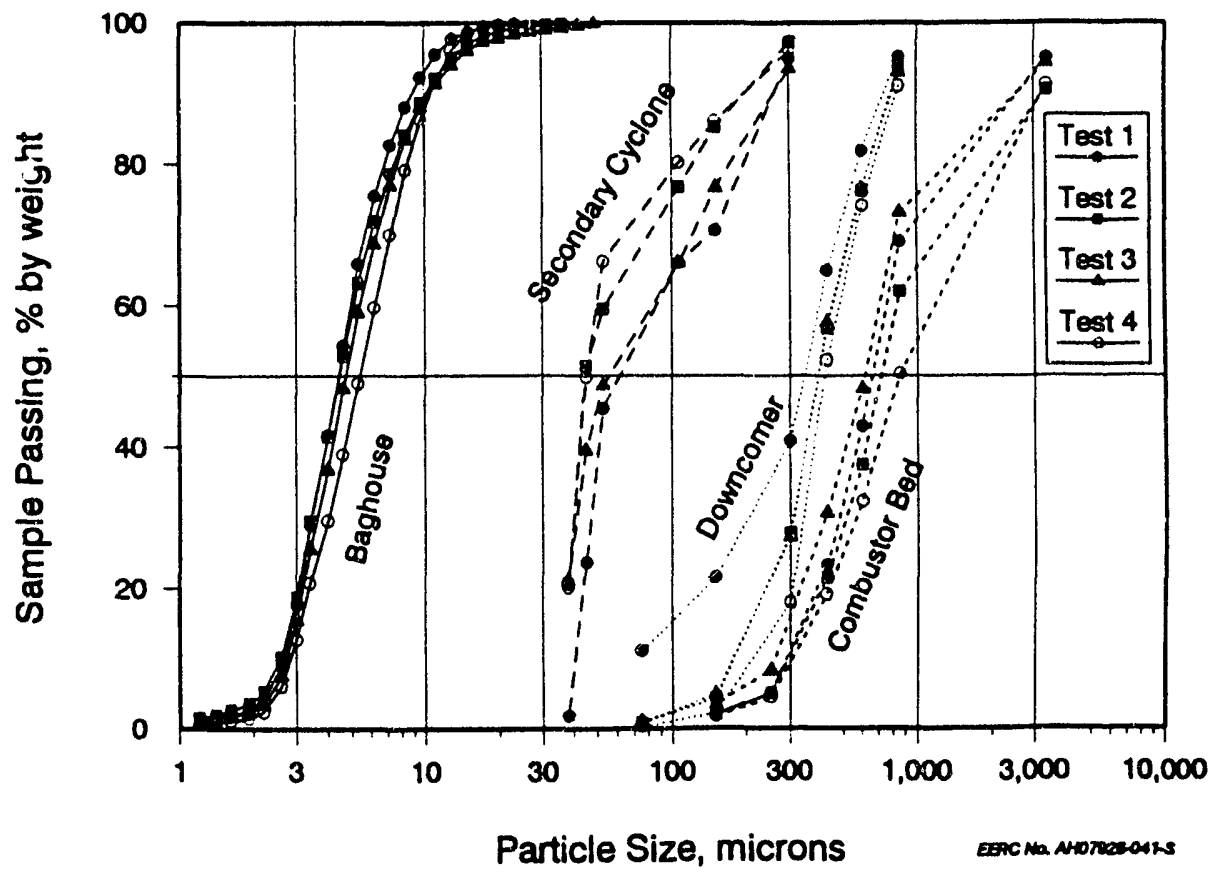

Figure E-3. Downcomer, secondary cyclone, and baghouse ash size distributions. 
TABLE E-2

Coal Analyses

\begin{tabular}{|c|c|c|c|c|}
\hline & Test 1 & Test 2 & Test 3 & Test 4 \\
\hline \multicolumn{5}{|c|}{ Proximate Analysis, as-received, wt\% } \\
\hline $\begin{array}{l}\text { Moisture } \\
\text { Volatile Matter } \\
\text { Fixed Carbon } \\
\text { Ash }\end{array}$ & $\begin{array}{r}17.0 \\
38.0 \\
6.4 \\
38.7\end{array}$ & $\begin{array}{r}17.6 \\
37.4 \\
6.7 \\
38.4\end{array}$ & $\begin{array}{r}16.1 \\
37.0 \\
8.6 \\
38.3\end{array}$ & $\begin{array}{r}17.4 \\
37.3 \\
8.7 \\
36.7\end{array}$ \\
\hline \multicolumn{5}{|c|}{ Ultimate Analysis, as-received, wt\% } \\
\hline $\begin{array}{l}\text { Carbon } \\
\text { Hydrogen } \\
\text { Nitrogen } \\
\text { Sulfur } \\
\text { Oxygen } \\
\text { Ash }\end{array}$ & $\begin{array}{r}24.6 \\
4.3 \\
0.6 \\
5.9 \\
25.9 \\
38.7\end{array}$ & $\begin{array}{r}24.6 \\
4.2 \\
0.6 \\
6.0 \\
26.2 \\
38.4\end{array}$ & $\begin{array}{r}25.1 \\
4.2 \\
0.7 \\
6.0 \\
25.7 \\
38.3\end{array}$ & $\begin{array}{r}25.6 \\
4.3 \\
0.7 \\
6.3 \\
26.4 \\
36.7\end{array}$ \\
\hline \multicolumn{5}{|c|}{ Ash Composition, as oxides, wt\% } \\
\hline $\begin{array}{l}\text { Calcium, } \mathrm{CaO} \\
\text { Magnesium, } \mathrm{MgO} \\
\text { Sodium, } \mathrm{Na}_{2} \mathrm{O} \\
\text { Silica, } \mathrm{SiO}_{2} \\
\text { Aluminum, } \mathrm{Al}_{2} \mathrm{O}_{3} \\
\text { Ferric, } \mathrm{Fe}_{2} \mathrm{O}_{3} \\
\text { Titanium, } \mathrm{TiO}_{2} \\
\text { Phosphorous, } \mathrm{P}_{2} \mathrm{O}_{6} \\
\text { Potassium, } \mathrm{K}_{2} \mathrm{O} \\
\text { Sulfur, } \mathrm{SO}_{3}\end{array}$ & $\begin{array}{r}23.8 \\
3.2 \\
0.2 \\
26.8 \\
11.3 \\
13.2 \\
0.2 \\
0.6 \\
1.0 \\
19.7\end{array}$ & $\begin{array}{r}19.0 \\
3.1 \\
0.3 \\
35.9 \\
12.7 \\
11.5 \\
0.2 \\
0.5 \\
1.2 \\
15.6\end{array}$ & $\begin{array}{r}18.0 \\
3.3 \\
0.3 \\
31.4 \\
13.1 \\
14.6 \\
0.2 \\
0.5 \\
1.2 \\
17.4\end{array}$ & $\begin{array}{r}18.8 \\
3.4 \\
0.3 \\
28.2 \\
12.5 \\
15.3 \\
0.2 \\
0.6 \\
1.2 \\
19.6\end{array}$ \\
\hline $\begin{array}{l}\text { High Heating Value, } \\
\text { moisture-free, Btu/lb }\end{array}$ & 4608 & 4582 & 4676 & 4925 \\
\hline $\begin{array}{l}\text { High Heating Value, } \\
\text { as-received, Btu/lb }\end{array}$ & 3824 & 3777 & 3922 & 4068 \\
\hline
\end{tabular}

TABLE E-3

Average Limestone Analysis (\% as oxides)

\begin{tabular}{lc}
\hline Component & Average \\
\hline Silica & 1.75 \\
Aluminum & 0.00 \\
Iron & 0.25 \\
Titanium & 0.03 \\
Calcium & 54.26 \\
Magnesium & 0.61 \\
Sodium & 0.06 \\
Potassium & 0.26 \\
Sulfur & 0.15 \\
\hline
\end{tabular}




\section{OPERATIONAL PERFORMANCE}

\section{General Operability}

\section{Week 1}

Operation of the unit to obtain steady-state conditions for the test matrix was not successful during the first week of testing. The first 24 to 32 hours were spent trying to maintain a consistent coal feed rate. Flowability of the coal was extremely poor.

Ratholing was observed in the storage hopper, making the transfer of coal to the weigh hopper difficult. During coal transfer, it was necessary to rod out the storage hopper, using a 3/8-inch tube with air flowing through it. The same phenomenon was apparently occurring in the weigh hopper as well, making steady coal feed difficult. Some success was achieved by adding an aeration port to the weigh hopper and making sure there was a good level of material in the weigh hopper. This was supplemented with banging on the hoppers and feed pipes.

When the coal feed problems had been adequately dealt with, anomalies in the operating conditions were observed. The operating conditions were characterized by high levels of oxygen and carbon monoxide in the flue gas, low bed temperature, low air flow and velocity in the combustor, and high flue gas flow rate. These conditions were discovered to be caused by a leak in the flue gas-to-air shell-and-tube heat exchanger. Air was leaking directly to the flue gas piping rather than passing through the combustor. This was verified by sampling flue gas prior to the air heater, for comparison with the $\mathrm{O}_{2}$ sample measured downstream of the air heater. As soon as the leak was verified, shutdown was initiated so that repairs could be made to the air heater.

The bed drain rate was quite high. The ash in the fuel appeared to be concentrated in the coarser fraction. There was a great deal of $1 / 4$ "-1/2" "rocks" observed in the material drained from the bed and in the material remaining on the distributor plate following shutdown. The coal was separated into two size fractions, greater than and less than $60 \mathrm{C}$ microns. A Btu analysis of these samples showed no preferential segregation of the ash in the fuel. The high bed drain rate was due, in part, to having both cyclones recirculating material back to the downcomer.

There was no evidence of any sintering of the bed due to its chemical composition, or any deposits of any kind or significance on the air distributor and loop seal nozzles, combustor refractory, cyclone and ducts, or the ash-fouling section. The coal that was received contained very low ash alkali $\left(\mathrm{Na}_{2} \mathrm{O}, \mathrm{K}_{2} \mathrm{O}\right)$, which explains the absence of fouling. In spite of the erratic conditions under which the unit was operated during this 40-hour period on coal, there was no evidence of any tendencies toward ash-related agglomeration, slagging, or fouling problems. This is extremely significant, since reducing conditions at high temperature existed in the combustor, cyclone, and fouling section at various times during the run.

There was only about a 2 to 3 hour period on Tuesday morning of the first week of testing that corresponded to general Test 1 conditions. An average data set calculated for that period was: 


$\begin{array}{lr}\text { Average Combustor Temperature, }{ }^{\circ} \mathrm{F} & 1543 \\ \text { Primary Air, scfm } & 199 \\ \text { Secondary Air, scfm } & 174 \\ \text { Flue Gas Flow, scfm } & 507 \\ \text { Superficial Gas Velocity, ft/sec } & 15 \\ \text { Coal Feed Rate, lb/hr } & 550 \\ \text { Limestone Feed Rate, lb/hr } & 76 \\ \text { Bed Pressure Drop, in. } \mathrm{H}_{2} \mathrm{O} & 45-50 \\ \text { Excess Air, \% } & 29 \\ \text { Sulfur Retention, \% (Based on } 5.9 \% \text { Coal S) } & 92 \\ \mathrm{NO}_{x}, \text { ppm (Corrected to } 3 \% \mathrm{O}_{2} \text { ) } & 51 \\ \mathrm{SO}_{2}, \mathrm{ppm} \text { (Corrected to } 3 \% \mathrm{O}_{2} \text { ) } & 1365 \\ \mathrm{CO}_{\text {, ppm (Corrected to } 3 \% \mathrm{O}_{2} \text { ) }} & 71\end{array}$

These data, coupled with visual inspection of the fly ash, showed that the fuel burns very well. Inherent $\mathrm{SO}_{2}$ capture by the coal ash is excellent (probably around $70 \%$ ).

\section{Week 2}

The second week of testing was successful in meeting the project goals. In addition to repairing the leak in the air-to-flue gas heat exchanger, more air purge lines were added to the coal weigh hopper to keep the coal flowing smoothly. There were still coal feed problems, resulting in fluctuations in emissions and occasional temperature drops of up to $100^{\circ} \mathrm{F}$, but, in most cases, the system stabilized near the desired conditions in a matter of minutes. Another significant change between Weeks 1 and 2 of testing was that the material collected in the secondary cyclone was reinjected during Week 1 , but collected to a barrel in Week 2.

\section{Summary of Results}

Upon completion of the run, data for each of the steady-state test periods were averaged. A summary of the process data for each test is presented in Table E-4. The four test periods correspond to those presented in the test matrix listed in Table E-1. Summaries of the run data are presented at the end of this appendix.

\section{¿ecirculation Rates and Size Distributions}

The solids recirculation rate was determined by calculating a heat balance around the external heat exchanger. The average solids recirculation rates for each test are shown in Table E-5. The recirculation rates were lower compared to those calculated from previous runs $(7,660$ to $15,750 \mathrm{lb} / \mathrm{hr})$, but this is not surprising, since 169 to 215 pounds of secondary cyclone ash which had previously been recycled to the downcomer was removed during this run. The relative recirculation rates for the four tests were consistent with the operating conditions for each test. The coal and limestone feed rates were essentially the same for the first three tests; the difference in recirculation rates for those three tests was due to the difference in average combustor temperature and, consequently, superficial gas velocity during Tests 2 and 3 . At the lower velocity in Test 2, a smaller maximum particle size was carried out of the combustor, resulting in a lower recirculation rate. Similarly, the higher velocity in Test 3 carried larger particles out of the combustor, resulting in a higher recirculation rate. The velocity in Test 4 was essentially the same as that in Test 1; the lower recirculation rate in Test 4 was due to the fact that no limestone was being added during that test, so the amount of solids in the bed was less. 


\section{TABLE E-4}

Summary of Process Data

\begin{tabular}{|c|c|c|c|c|}
\hline Test Number: & Test 1 & Test 2 & Test 3 & Test 4 \\
\hline $\begin{array}{l}\text { Time: } \\
\text { Date: }\end{array}$ & $\begin{array}{c}0030-0840 \\
8 / 14 / 91 \\
\end{array}$ & $\begin{array}{c}1230-1630 \\
8 / 14 / 91 \\
\end{array}$ & $\begin{array}{l}2030-0045 \\
8 / 14-15 / 91 \\
\end{array}$ & $\begin{array}{c}1245-1845 \\
8 / 15 / 91 \\
\end{array}$ \\
\hline $\begin{array}{l}\text { Coal Feed Rate, lb/hr } \\
\text { Limestone Feed Rate, lb/hr } \\
\text { Solids Recirculation Rate, lb/hr } \\
\text { Combustor } d \mathrm{P} \text {, in. } \mathrm{H}_{2} \mathrm{O}\end{array}$ & $\begin{array}{r}488 \\
141.4 \\
3830 \\
45.8\end{array}$ & $\begin{array}{r}479 \\
141.9 \\
3335 \\
50.0\end{array}$ & $\begin{array}{r}479 \\
145.4 \\
4269 \\
46.1\end{array}$ & $\begin{array}{r}479 \\
0.0 \\
3447 \\
43.3\end{array}$ \\
\hline $\begin{array}{l}\text { Combustion Air } \\
\text { EHX Flow, scfm } \\
\text { Primary Air, scfm } \\
\text { Secondary Air, scfm } \\
\text { Feed Assist Air, scfm } \\
\text { DC Aeration Air, scfm } \\
\text { Purge Air, scfm } \\
\text { Total Air, scfm } \\
\text { PA/SA, \% } \\
\text { Excess Air, \% } \\
\text { FG SGV, ft/sec } \\
\text { EHX SGV, ft/sec }\end{array}$ & $\begin{array}{r}47 \\
216 \\
176 \\
19 \\
12.2 \\
15.5 \\
485 \\
60 \\
24.4 \\
16.6 \\
1.7\end{array}$ & $\begin{array}{r}45 \\
184 \\
188 \\
19 \\
12.1 \\
15.5 \\
464 \\
55 \\
24.4 \\
15.2 \\
1.4\end{array}$ & $\begin{array}{r}47 \\
216 \\
179 \\
19 \\
12.0 \\
15.5 \\
489 \\
60 \\
24.2 \\
17.3 \\
1.8\end{array}$ & $\begin{array}{r}48 \\
203 \\
174 \\
19 \\
12.1 \\
15.5 \\
472 \\
59 \\
26.6 \\
16.1 \\
1.6\end{array}$ \\
\hline $\begin{array}{l}\text { Flue Gas } \\
\qquad \begin{array}{l}\text { Flow Rate, scfm } \\
\text { Oxygen, \% } \\
\mathrm{SO}_{2}, \mathrm{ppm} \\
\mathrm{CO}, \% \\
\mathrm{NO}_{x}, \text { ppm } \\
\mathrm{N}_{2} \mathrm{O}, \mathrm{ppm} \\
\mathrm{CO}_{2}, \%\end{array}\end{array}$ & $\begin{array}{r}536 \\
4.06 \\
1481 \\
0.0076 \\
122 \\
56 \\
16.8\end{array}$ & $\begin{array}{r}507 \\
4.05 \\
1852 \\
0.0082 \\
80 \\
108 \\
16.9\end{array}$ & $\begin{array}{r}519 \\
4.03 \\
2172 \\
0.0020 \\
143 \\
31 \\
17.5\end{array}$ & $\begin{array}{r}517 \\
4.37 \\
4399 \\
0.0080 \\
97 \\
75 \\
16.0\end{array}$ \\
\hline $\begin{array}{l}\text { Ash } \\
\text { Bottom Ash Discharge Rate, lb/hr } \\
\text { Bottom Ash Unburned Carbon, \% } \\
\text { Cyclone Ash Discharge Rate, lb/hr } \\
\text { Cyclone Ash Unburned Carbon, \% } \\
\text { Baghouse Ash Discharge Rate, lb/hr } \\
\text { Baghouse Ash Unburned Carbon, \% } \\
\text { Total Ash (meas.), lb/hr } \\
\text { Total Ash (calc.), lb/hr } \\
\text { Bottom Ash/Total Ash (meas.) \% }\end{array}$ & $\begin{array}{r}94 \\
1.07 \\
203 \\
0.78 \\
28.4 \\
0.50 \\
325 \\
321 \\
28.8\end{array}$ & $\begin{array}{r}127 \\
7.63 \\
197 \\
1.81 \\
9.7 \\
0.82 \\
333 \\
315 \\
38.0\end{array}$ & $\begin{array}{r}85 \\
0.70 \\
215 \\
0.54 \\
9.5 \\
0.19 \\
309 \\
324 \\
27.4\end{array}$ & $\begin{array}{r}12 \\
0.22 \\
169 \\
0.00 \\
12.1 \\
0.42 \\
192 \\
175 \\
6.1\end{array}$ \\
\hline
\end{tabular}


TABLE E-4 (continued)

\begin{tabular}{lcccc}
\hline Test Number: & Test 1 & Test 2 & Test 3 & Test 4 \\
Time: & $0030-0840$ & $1230-1630$ & $2030-0045$ & $1245-1845$ \\
Date: & $8 / 14 / 91$ & $8 / 14 / 91$ & $8 / 14-15 / 91$ & $8 / 15 / 91$ \\
\hline
\end{tabular}

Air and Gas Temperatures $\left({ }^{\circ} \mathrm{F}\right)$

Combustor Temperatures

Plenum

Section 1

Section 2

Section 3

Section 4

Section 5

Section 6

Section 7

Section 8

Section 9

PCD Exit

Average

EHX Temperatures

Plenum

0.5' above Distributor Plate

1.5' above Distributor Plate

2.7' above Distributor Plate

3.8' above Distributor Plate

5.3' above Distributor Plate

Average

Downcomer Temperatures

Section 3

Section 4

Section 6

Section 8

Cyclone Exit

Baghouse Inlet

Baghouse Outlet

ID Fan Inlet

Ambient

$\begin{array}{rrrr}609 & 547 & 639 & 592 \\ 1516 & 1423 & 1608 & 1518 \\ 1556 & 1465 & 1646 & 1563 \\ 1591 & 1506 & 1675 & 1603 \\ 1574 & 1490 & 1689 & 1584 \\ 1611 & 1522 & 1690 & 1622 \\ 1594 & 1497 & 1686 & 1589 \\ 1600 & 1476 & 1655 & 1560 \\ 1597 & 1470 & 1647 & 1548 \\ 1588 & 1511 & 1674 & 1598 \\ 1619 & 1509 & 1678 & 1597 \\ 1565 & 1471 & 1650 & 1564\end{array}$

$\begin{array}{rrrr}132 & 144 & 145 & 138 \\ 1316 & 1062 & 1603 & 1152 \\ 1283 & 1026 & 1353 & 1120 \\ 1268 & 1021 & 1365 & 1148 \\ 1057 & 845 & 1180 & 954 \\ 911 & 738 & 1022 & 825 \\ 1289 & 1036 & 1373 & 1140\end{array}$

$\begin{array}{rrrr}1574 & 1467 & 1653 & 1538 \\ 1577 & 1468 & 1639 & 1567 \\ 1598 & 1493 & 1660 & 1590 \\ 1621 & 1513 & 1678 & 1613 \\ 1612 & 1497 & 1662 & 1597 \\ 411 & 389 & 378 & 402 \\ 337 & 326 & 319 & 336 \\ 281 & 269 & 277 & 280 \\ 88 & 100 & 99 & 97\end{array}$

Primary cyclone collection efficiency is defined as one minus the ratio of fly ash collected to recirculation rate. The increased fly ash removal, as opposed to recirculation, from the secondary cyclone was the cause of the relatively low cyclone efficiency.

The particle-size distributions throughout the run were fairly consistent. Figure E-3 shows the particle-size distributions for the downcomer, secondary cyclone ash, and baghcuse ash for all four tests. 


\section{TABLE E-5}

Solids Recirculation and Heat-Transfer Data

\begin{tabular}{|c|c|c|c|c|c|c|c|c|c|c|}
\hline Test & $\begin{array}{c}\text { Temperature } \\
\left({ }^{\circ} \mathrm{F}\right)\end{array}$ & $\mathrm{Ca} / \mathrm{S}$ & $\begin{array}{l}\text { Excess } \\
\text { Air (\%) }\end{array}$ & $\begin{array}{c}\text { Primary } \\
\text { Air (\%) }\end{array}$ & $\begin{array}{c}\text { Solids } \\
\text { Recirculation } \\
(\mathrm{b} / \mathrm{h} \mathbf{x})\end{array}$ & $\begin{array}{l}\mathrm{DC}^{1} \\
\mathrm{~d}_{80} \\
(\mu \mathrm{m})\end{array}$ & $\mathrm{H}_{0}{ }^{2}$ & $\begin{array}{l}\text { Heat Fiux } \\
(\text { Btu/hr-f(t) }\end{array}$ & $\begin{array}{c}\text { Cyclone } \\
\text { Efficiency } \\
(\%)\end{array}$ & $\begin{array}{l}\text { Rocirculation } \\
\text { Ratio }\end{array}$ \\
\hline 1 & 1,565 & 2.3 & 24.4 & 60 & 3,830 & 348 & 14.6 & 24,021 & 93.97 & 11 \\
\hline 2 & 1,471 & 2.2 & 24.4 & 55 & 3,335 & 396 & 14.8 & 19,986 & 93.81 & 10 \\
\hline 3 & 1,650 & 2.1 & 24.2 & 60 & 4,269 & 394 & 15.7 & 23,926 & 94.74 & 12 \\
\hline 4 & 1,564 & 0.6 & 26.6 & 59 & 3,447 & 417 & 15.8 & 22,697 & 94.76 & 20 \\
\hline
\end{tabular}

${ }^{1}$ Downcomer.

${ }^{2}$ Heat-trangfer coefficient $\left(\mathrm{Btu} / \mathrm{hr} \cdot-\mathrm{ft}^{2} \cdot{ }^{\circ} \mathrm{F}\right)$

\section{Bottom Ash/Total Ash Split}

The ash balance for each test period, along with the averages for the entire run, are presented in Table E-6. Ash input to the system was composed of calculated quantities of coal and limestone ash, based on their respective analyses and feed rates. The limestonederived ash was further broken down into estimates of the sorbent which was either calcined or had undergone sulfation. The output was composed of mpasured quantities of bottom ash (drained from the combustor bed), fly ash removed from the secondary cyclone, and fly ash removed from the baghouse.

The ratios of bottom ash-to-total ash, as well as the percent closure, are included in Table E-6. The average closure for all tests was about 93\%. The bottom-to-total ash split ranged from about $27 \%$ to about $39 \%$ for the tests with limestone feed. The elimination of limestone feed for Test 4 resulted in a slower accumulation of bed material; the minimal bed drain required to maintain the desired pressure drop of $40^{\prime \prime} \mathrm{H}_{2} \mathrm{O}$ in the combustor resulted in a very low bottom ash/fly ash split of $6 \%$ for this test.

\section{Ash/Limestone Split}

Table E-7 presents data on the makeup of the bed material, the secondary cyclone drain, and the baghouse catch. A material balance was performed using alumina as a tracer, since it was present in relatively large quantities in the coal ash, but nonexistent in the limestone. This material balance was used to determine the split of ash and limestone at each solids removal point and is shown in Table E-8. The material balance closure is listed as a measure of possible error and is based on coal ash only. Also presented in Table E-7 is the percentage of ash fed into the combustor, calculated as the total ash in with the coal divided by the total ash in with the coal plus the sorbent equivalent mass inputs $\left(\mathrm{CaO}\right.$ and $\left.\mathrm{CaSO}_{4}\right)$.

For the tests with limestone, the contribution of the coal ash to the fly ash streams ranged from $59 \%$ to $68 \%$. This was similar to the ratio of the coal ash to limestone inputs, which was $62 \%$, indicating that both the coal ash and limestone were being elutriated at similar rates. The bed material drains for these tests indicated a buildup of material from the coal ash for Tests 1 and $2(72 \%$ and $80 \%)$ and a depletion in Test 3 (35\%). The buildup of ash could be attributed to the large clay inclusions that were left after the coal was burned out. The low number obtained for the percentage of ash for 
TABLE E-6

Ash Balance

\begin{tabular}{lrrrr}
\hline & Test 1 & Test 2 & Test 3 & Test 4 \\
\hline $\begin{array}{l}\text { Input, lb/hr } \\
\text { Ash }\end{array}$ & 200 & 192 & 198 & 175 \\
$\quad$ Sorbent* & & & & \\
$\quad$ CaO & 49 & 47 & 48 & 0 \\
CaSO & 74 & 78 & 80 & 0 \\
Total Solids In & 323 & 318 & 326 & 175 \\
Output, lb/hr & & & & \\
$\quad$ Bed Material & 94 & 127 & 85 & 12 \\
Cyclone Ash & 203 & 197 & 215 & 169 \\
Baghouse Ash & 28 & 10 & 10 & 12 \\
Total Solids Out & 325 & 333 & 309 & 192 \\
Closure, \% & 100.5 & 104.8 & 94.7 & 109.9 \\
Bottom Ash/Total Ash, \% & 28.8 & 38.0 & 27.4 & 6.1 \\
\hline
\end{tabular}

* The $\mathrm{CaO}$ and $\mathrm{CaSO}_{4}$ mass inputs are included to express sorbent equivalent mass inputs.

TABLE E-7

Material Derived from Coal Ash and Limestone Based on an Aluminum Material Balance (\%)

\begin{tabular}{|c|c|c|c|c|c|c|c|c|}
\hline & \multicolumn{2}{|r|}{ Test 1} & \multicolumn{2}{|r|}{ Test 2} & \multicolumn{2}{|r|}{ Test 3} & \multicolumn{2}{|r|}{ Test 4} \\
\hline & $\underline{\text { Ash }}$ & $\underline{\text { Limesto }}$ & $\underline{\text { Ash }}$ & Limesto & $\underline{\text { Ash }}$ & $\underline{\text { Limest }}$ & $\underline{\text { Ash }}$ & Limestone \\
\hline Feed, \% & 62 & 38 & 61 & 39 & 61 & 39 & 100 & 0 \\
\hline Bed Drain, \% & 72 & 28 & 80 & 20 & 35 & 65 & 88 & 12 \\
\hline Secondary Cyclone Drain, \% & 64 & 36 & 68 & 32 & 63 & 37 & 82 & 18 \\
\hline Baghouse Catch, \% & 60 & 40 & 65 & 35 & 59 & 41 & 63 & 37 \\
\hline Aluminum Balance Closure, \% & & 107 & & 125 & & 86 & & 89 \\
\hline
\end{tabular}

Test 3 may be a sampling artifact, where the larger particles may not have been included in the sample. The limestone feed was stopped for Test 4 . This is reflected by the higher percentage of coal ash in the bed (88\%) and secondary cyclone ash (82\%). If the bed had been completely turned over to an ash bed, these numbers would be $100 \%$. This indicates that some residual limestone was present in the bed during this test. The baghouse catch for Test 4 indicated only $63 \%$ of the material was derived from the coal ash. This indicates that the residual limestone in the bed was breaking up and producing fines in a greater proportion than fine ash derived from the coal. 
TABLE E-8

Aluminum Material Balance

\begin{tabular}{lrrrr}
\hline & Test 1 & Test 2 & Test 3 & Test 4 \\
\hline Coal Ash Feed Rate, lb/hr & 200.2 & 192.3 & 197.7 & 175.1 \\
$\mathrm{Al}_{2} \mathrm{O}_{3}$ in Coal Ash, \% & 11.3 & 12.7 & 13.1 & 12.5 \\
Secondary Cyclone Ash Out, lb/hr & 202.7 & 196.8 & 214.8 & 168.5 \\
$\mathrm{Al}_{2} \mathrm{O}_{3}$ in Secondary Cyclone Ash, \% & 7.2 & 8.6 & 8.2 & 10.2 \\
Ash from Coal, \% & 64.1 & 67.6 & 62.9 & 81.7 \\
Ash from Coal, lb/hr & 129.9 & 133.1 & 135.1 & 137.6 \\
$\mathrm{Baghouse} \mathrm{Ash} \mathrm{Out,} \mathrm{lb/hr}_{\mathrm{Al}_{2} \mathrm{O}_{3} \text { in Baghouse Ash, \% }}$ & 28.4 & 9.7 & 9.5 & 12.1 \\
Ash from Coal, \% & 6.8 & 8.3 & 7.7 & 7.9 \\
Ash from Coal, lb/hr & 59.9 & 65.0 & 59.0 & 62.9 \\
$\mathrm{Bed}_{\mathrm{Material} \mathrm{Out,} \mathrm{lb} / \mathrm{hr}}$ & 17.0 & 6.3 & 5.6 & 7.6 \\
$\mathrm{Al}_{2} \mathrm{O}_{3}$ in Bed Material, \% & 93.7 & 126.6 & 84.7 & 11.8 \\
Ash from Coal, \% & 8.1 & 10.1 & 4.6 & 11.0 \\
Ash from Coal, lb/hr & 71.9 & 79.5 & 35.3 & 88.0 \\
Total Ash from Coal, lb/hr & 67.3 & 100.7 & 29.9 & 10.4 \\
Closure, \% & 214.2 & 240.1 & 170.6 & 155.7 \\
\hline
\end{tabular}

\section{THERMAL PERFORMANCE}

\section{Energy and Material Balance}

The measured and theoretical fuel and flue gas flow rates are presented in Tables E-9 and E-10, respectively. The theoretical fuel feed rate was calculated using theoretical fuel characteristics, measured combustion air, and measured $\mathrm{O}_{2}$ and $\mathrm{CO}_{2}$ concentrations in the flue gas. The theoretical flue gas rates were calculated using the actual coal feed rate and excess air level for each test. The measured fuel feed rates were all higher than the theoretical values based on the measured combustion air flow. The measured flue gas flows were lower than theoretical values based on the measured coal feed rate.

The energy balances for the four tests are presented in Table E-11, both as Btu/hr and percentages. The energy input was made up of the energy potential of the fuel, the primary and secondary combustion air, the external heat exchanger fluidizing air, and the energy released from the sulfation of the sorbent. Measurable heat loss sources were the combustor heat exchange doors, the external heat exchanger cooling coils, the flue gas, the unburned carbon in the ash removed, the heat contained in the ash drained from the system, and the energy absorbed during calcination of the sorbent. Flue gas losses include a correction for leakage. The unmeasurable heat loss due to convection and radiation is based upon a correlation developed from previous testing that takes into account the average operational combustor temperature and the solid recirculation rate. The energy balance closure was good for all tests. 
TABLE E-9

Fuel Balance

\begin{tabular}{lcccc}
\hline & Test 1 & Test 2 & Test 3 & Test 4 \\
\hline Fuel Feed Rate, meas., lb/hr & 488 & 479 & 479 & 479 \\
Fuel Feed Rate, theor., lb/hr & 517 & 501 & 516 & 477 \\
Difference, \% & -6.1 & -4.5 & -7.8 & 0.5 \\
\hline
\end{tabular}

meas. = Feed rate calculated by linear regression performed on coal feed hopper weight loss over time.

theor. = Theoretical feed rate calculated on the basis of the coal analysis, the combustion air, and excess air for each test period.

TABLE E-10

Flue Gas Balance

\begin{tabular}{lcccc}
\hline & Test 1 & Test 2 & Test 3 & Test 4 \\
\hline Stack Gas Flow, meas., scfm & 536 & 507 & 519 & 517 \\
Stack Gas Flow, theor., scfm & 558 & 534 & 560 & 541 \\
Difference, \% & -4.1 & -5.2 & -7.9 & -4.6 \\
\hline
\end{tabular}

meas. = The flue gas flow measured during the run through an orifice located just upstream of the ID fan.

theor. = Theoretical flue gas flow calculated on the basis of the coal analysis and the theoretical coal feed rate for each test period.

The material balances for the four test periods are presented in Table E-12. The material balance inputs consist of combustion air, coal, and limestone feed rates. Outputs are flue gas (including a correction for leaks), drained bed material, baghouse ash, and secondary cyclone ash. The closures for all tests were fairly good.

\section{Combustion Efficiency}

The combustion efficiencies for each test are presented in Table E-13 and shown graphically in Figure E-4. The combustion efficiencies for the four tests ranged from about $89 \%$ (Test 2) to nearly $100 \%$ (Test 4). The unburned carbon was determined by the difference between loss on ignition (LOI), and for some tests, the carbon from carbonate (expressed as $\mathrm{CO}_{2}$ ). Carbonate analyses were not performed for Tests 3 and 4. The results of the unburned carbon calculations are shown in Table E-14. The data indicate that carbon burnout drops significantly for the Asian lignite at low operating temperatures. Combustion efficiencies also decreased with sorbent addition due to increased bed material drain requirements to maintain proper solids inventory. The combination of relatively high concentrations of unburned carbon in the ash streams and high drain rates during Test 2 resulted in the low reported combustion efficiency. 
TABLE E-11

Energy Balance

\begin{tabular}{|c|c|c|c|c|}
\hline & Test 1 & Test 2 & Test 3 & Test 4 \\
\hline \multicolumn{5}{|l|}{ Input, Btu/hr } \\
\hline $\begin{array}{l}\text { Coal } \\
\text { Primary Air } \\
\text { Secondary Air } \\
\text { EHX Air } \\
\text { Sorbent Sulfation }\end{array}$ & $\begin{array}{r}1,874,141 \\
124,684 \\
101,609 \\
2,295 \\
117,531\end{array}$ & $\begin{array}{r}1,788,165 \\
91,492 \\
93,129 \\
2,223 \\
123,862\end{array}$ & $\begin{array}{r}1,924,948 \\
129,650 \\
107,353 \\
2,392 \\
126,968\end{array}$ & $\begin{array}{r}1,842,565 \\
111,760 \\
95,548 \\
2,217 \\
0\end{array}$ \\
\hline Total & $2,220,260$ & $2,098,871$ & $2,291,310$ & $2,052,090$ \\
\hline \multicolumn{5}{|l|}{ Input, \% } \\
\hline $\begin{array}{l}\text { Coal } \\
\text { Primary Air } \\
\text { Secondary Air } \\
\text { EHX Air } \\
\text { Sorbent Sulfation }\end{array}$ & $\begin{array}{r}84.4 \\
5.6 \\
4.6 \\
0.1 \\
5.3\end{array}$ & $\begin{array}{r}85.2 \\
4.4 \\
4.4 \\
0.1 \\
5.9\end{array}$ & $\begin{array}{r}84.0 \\
5.7 \\
4.7 \\
0.1 \\
5.5\end{array}$ & $\begin{array}{r}89.8 \\
5.4 \\
4.7 \\
0.1 \\
0.0\end{array}$ \\
\hline Total & 100.0 & 100.0 & 100.0 & 100.0 \\
\hline \multicolumn{5}{|l|}{ Output, Btu/hr } \\
\hline $\begin{array}{l}\text { Flue Gas (sens.) } \\
\text { Ash (sens.) } \\
\text { Ash (chem.)* } \\
\text { Combustor } \\
\text { EHX } \\
\text { Sorbent Calcination } \\
\text { Conduction and Radiation Losses }\end{array}$ & $\begin{array}{r}1,076,276 \\
129,079 \\
38,584 \\
249,819 \\
348,304 \\
108,312 \\
215,363\end{array}$ & $\begin{array}{l}948,007 \\
122,815 \\
187,638 \\
311,779 \\
423,657 \\
108,695 \\
166,029\end{array}$ & $\begin{array}{r}1,117,927 \\
128,920 \\
24,954 \\
186,625 \\
359,456 \\
111,376 \\
259,331\end{array}$ & $\begin{array}{r}1,018,263 \\
75,941 \\
1,085 \\
411,272 \\
336,072 \\
0 \\
214,613\end{array}$ \\
\hline Total & $2,165,739$ & $2,268,620$ & $2,188,589$ & $2,057,245$ \\
\hline \multicolumn{5}{|l|}{ Output, \% } \\
\hline $\begin{array}{l}\text { Flue Gas (sens.) } \\
\text { Ash (sens.) } \\
\text { Ash (chem.)* } \\
\text { Combustor } \\
\text { EHX } \\
\text { Sorbent Calcination } \\
\text { Conduction and Radiation Losses }\end{array}$ & $\begin{array}{r}49.7 \\
6.0 \\
1.8 \\
11.5 \\
16.1 \\
5.0 \\
9.9\end{array}$ & $\begin{array}{r}41.8 \\
5.4 \\
8.3 \\
13.7 \\
18.7 \\
4.8 \\
7.3\end{array}$ & $\begin{array}{r}51.1 \\
5.9 \\
1.1 \\
8.5 \\
16.4 \\
5.1 \\
11.8\end{array}$ & $\begin{array}{r}49.5 \\
3.7 \\
0.1 \\
20.0 \\
16.3 \\
0.0 \\
10.4\end{array}$ \\
\hline Total & 100.0 & 100.0 & 100.0 & 100.0 \\
\hline Closure & 97.5 & 108.1 & 95.5 & 100.3 \\
\hline
\end{tabular}

* The heat of combustion coefficient for pure carbon is an average of values found in Perry's Chemical Engineering Handbook, Perry et al. (1984) and the Standard Handbook for Mechanical Engineers, Baumeister and Marks (1967). 
TABLE E-12

Material Balance

\begin{tabular}{|c|c|c|c|c|}
\hline & Test 1 & Test 2 & Test 3 & Test 4 \\
\hline \multicolumn{5}{|l|}{ Input, lb/hr } \\
\hline $\begin{array}{l}\text { Combustion Air } \\
\text { Additional Air } \\
\text { Coal Feed } \\
\text { Sorbent Feed }\end{array}$ & $\begin{array}{r}2007 \\
215 \\
517 \\
141\end{array}$ & $\begin{array}{r}1910 \\
214 \\
501 \\
142\end{array}$ & $\begin{array}{r}2025 \\
212 \\
516 \\
145\end{array}$ & $\begin{array}{r}1948 \\
214 \\
477 \\
0\end{array}$ \\
\hline \multicolumn{5}{|l|}{ Input, $\%$} \\
\hline $\begin{array}{l}\text { Combustion Air } \\
\text { Feed Assist Air } \\
\text { Coal Feed } \\
\text { Sorbent Feed }\end{array}$ & $\begin{array}{r}69.7 \\
7.5 \\
18.0 \\
4.9\end{array}$ & $\begin{array}{r}69.0 \\
7.7 \\
18.1 \\
5.1\end{array}$ & $\begin{array}{r}69.8 \\
7.3 \\
17.8 \\
5.0\end{array}$ & $\begin{array}{r}73.8 \\
8.1 \\
18.1 \\
0.0\end{array}$ \\
\hline Total Mass In & 100.0 & 100.0 & 100.0 & 100.0 \\
\hline \multicolumn{5}{|l|}{ Output, lb/hr } \\
\hline $\begin{array}{l}\text { Measured Flue Gas } \\
\text { Flue Gas Leaks } \\
\text { Ash Out } \\
\text { Bed Material } \\
\text { Baghouse } \\
\text { Cyclone Ash }\end{array}$ & $\begin{array}{r}2455 \\
101 \\
\\
94 \\
28 \\
203\end{array}$ & $\begin{array}{r}127 \\
10 \\
197\end{array}$ & $\begin{array}{r}85 \\
10 \\
215\end{array}$ & $\begin{array}{r}2366 \\
108 \\
\\
12 \\
12 \\
169\end{array}$ \\
\hline Total Mass Out & 2881 & 2781 & 2890 & 2667 \\
\hline \multicolumn{5}{|l|}{ Output, \% } \\
\hline $\begin{array}{l}\text { Measured Flue Gas } \\
\text { Flue Gas Leaks } \\
\text { Ash Out } \\
\text { Bed Material } \\
\text { Baghouse } \\
\text { Cyclone Ash }\end{array}$ & $\begin{array}{l}3.3 \\
1.0 \\
7.0\end{array}$ & $\begin{array}{r}83.7 \\
4.3 \\
\\
4.6 \\
0.3 \\
7.1\end{array}$ & $\begin{array}{r}82.8 \\
6.5 \\
\\
2.9 \\
0.3 \\
7.4\end{array}$ & $\begin{array}{r}88.7 \\
4.1 \\
\\
0.4 \\
0.5 \\
6.3\end{array}$ \\
\hline Total Mass Out & 100.0 & 100.0 & 100.0 & 100.0 \\
\hline Closure & 100.0 & 100.5 & 99.7 & 101.0 \\
\hline
\end{tabular}

\section{Boiler Efficiency}

Boiler efficiencies were calculated for each test period using a modified version of ASME PTC 4.1. The modifications to PTC 4.1 are those recommended in EPRI's "Atmospheric Fluidized-Bed Combustion Performance Guidelines." Basically, the modification is a method to account for the heat losses and gains associated with calcination and sulfation of the sorbent.

Table E-15 summarizes the results of the boiler efficiency calculations for each test. Boiler radiation and convective losses were assumed to be $0.4 \%$ of the heat input from the coal. Although these losses were much higher for our pilot plant, $0.4 \%$ was chosen to be representative of a full-scale system. An exit gas temperature of $300^{\circ} \mathrm{F}$ was used in the calculations. 


\section{TABLE E-13}

Combustion Efficiency

\begin{tabular}{lrrrr}
\hline & Test 1 & Test 2 & Test 3 & Test 4 \\
\hline Input & & & & \\
Coal Feed Rate, lb/hr & 517.4 & 500.8 & 516.1 & 477.1 \\
Coal Carbon, \% & 24.6 & 24.6 & 25.1 & 25.6 \\
Carbon Feed Rate, lb/hr & 127.3 & 123.2 & 129.5 & 122.1 \\
Total, lb/hr & 127.3 & 123.2 & 129.5 & 122.1 \\
Output & & & & \\
Bottom Ash Discharge Rate, lb/hr & & & & \\
Unburned Carbon, \% & 94 & 127 & 85 & 12 \\
Bottom Ash Carbon Discharge Rate, lb/hr & 1.07 & 7.63 & 0.70 & 0.22 \\
Secondary Cyclone Discharge Rate, lb/hr & 1.01 & 9.67 & 0.59 & 0.03 \\
Unburned Carbon, \% & 203 & 197 & 215 & 169 \\
Secondary Cyclone Carbon Discharge Rate, lb/hr & 0.78 & 1.81 & 0.54 & 0.00 \\
Baghouse Discharge Rate, lb/hr & 1.59 & 3.57 & 1.16 & 0.00 \\
Unburned Carbon, \% & 28 & 10 & 10 & 12 \\
Baghouse Carbon Discharge Rate, lb/hr & 0.50 & 0.82 & 0.19 & 0.42 \\
Total, lb/hr & 0.14 & 0.08 & 0.02 & 0.05 \\
Combustion Efficiency, \% & 2.74 & 13.32 & 1.77 & 0.08 \\
\hline
\end{tabular}

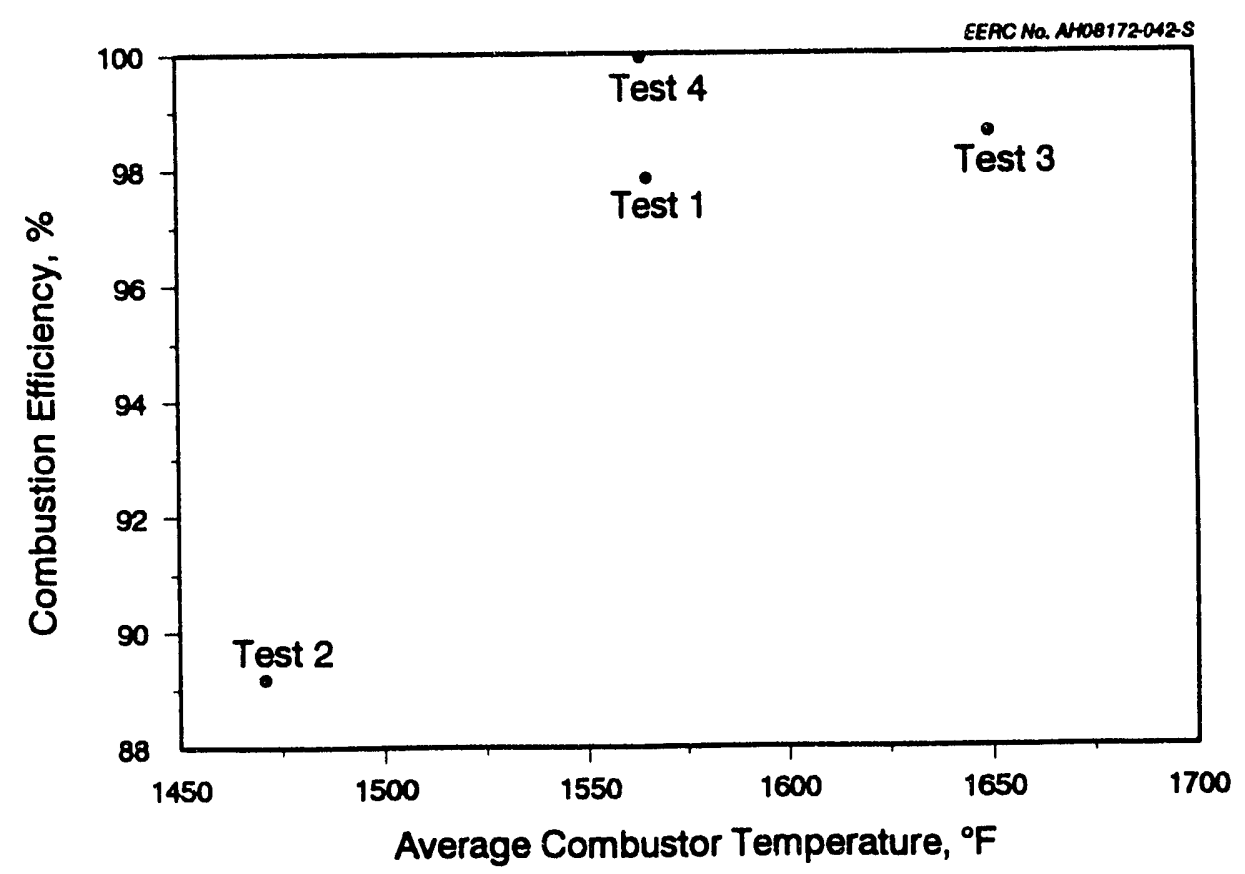

Figure E-4. Combustion efficiency as a function of average combustor temperature. 
TABLE E-14

Unburned Carbon (\%)

\begin{tabular}{|c|c|c|c|c|}
\hline & Test 1 & Test 2 & Test 3 & Test 4 \\
\hline Combustor Bed Material & & & & \\
\hline $\begin{array}{l}\text { Loss on Ignition } \\
\text { Carbonate (as } \mathrm{CO}_{2} \text { ) } \\
\text { Unburned Carbon }\end{array}$ & $\begin{array}{l}1.30 \\
0.83 \\
1.07\end{array}$ & $\begin{array}{c}10.70 \\
11.24 \\
7.63\end{array}$ & $\begin{array}{l}0.70 \\
\mathrm{ND}^{1} \\
0.70\end{array}$ & $\begin{array}{l}0.22 \\
\mathrm{ND} \\
0.22\end{array}$ \\
\hline \multicolumn{5}{|l|}{ Secondary Cyclone Ash } \\
\hline $\begin{array}{l}\text { Loss on Ignition } \\
\text { Carbonate }\left(\text { as } \mathrm{CO}_{2}\right) \\
\text { Unburned Carbon }\end{array}$ & $\begin{array}{l}0.94 \\
0.57 \\
0.78\end{array}$ & $\begin{array}{l}2.54 \\
2.66 \\
1.81\end{array}$ & $\begin{array}{l}0.54 \\
\text { ND } \\
0.54\end{array}$ & $\begin{array}{l}0.00 \\
\mathrm{ND} \\
0.00\end{array}$ \\
\hline \multicolumn{5}{|l|}{ Baghouse Ash } \\
\hline $\begin{array}{l}\text { Loss on Ignition } \\
\text { Carbonate }\left(\mathrm{as} \mathrm{CO}_{2}\right) \\
\text { Unburned Carbon }\end{array}$ & $\begin{array}{l}0.50 \\
\text { ND } \\
0.50\end{array}$ & $\begin{array}{l}0.93 \\
0.39 \\
0.82\end{array}$ & $\begin{array}{l}0.19 \\
\text { ND } \\
0.19\end{array}$ & $\begin{array}{l}0.42 \\
\text { ND } \\
0.42\end{array}$ \\
\hline
\end{tabular}

${ }^{1}$ Not determined.

TABLE E-15

Boiler Efficiency

\begin{tabular}{lrrrr}
\hline & Test 1 & Test 2 & Test 3 & Test 4 \\
\hline Assumed Flue Gas Exit Temp., ${ }^{\circ} \mathrm{F}$ & 300 & 300 & 300 & 300 \\
Losses, Btu/hr & & & & \\
Dry Gas & 132,387 & 126,908 & 134,127 & 128,523 \\
Water in Fuel & 104,809 & 105,027 & 99,011 & 98,919 \\
Comb. of Fuel Hydrogen & 14,803 & 13,394 & 14,643 & 13,682 \\
Unburned Carbon & 38,584 & 187,638 & 24,954 & 1,085 \\
Sorbent Calcination & 108,312 & 108,695 & 111,376 & 0 \\
Radiation and Convection* & 7,914 & 7,566 & 8,097 & 7,763 \\
Discharged Solids & 129,079 & 122,815 & 128,920 & 75,941 \\
Sorbent Sulfation & $-117,531$ & $-123,862$ & $-126,968$ & 0 \\
Total & 418,359 & 548,181 & 394,161 & 325,913 \\
Losses, \% & & & & \\
Dry Gas & 7.1 & 7.0 & 7.1 & 6.6 \\
Water in Fuel & 5.6 & 5.8 & 5.3 & 5.1 \\
Comb. of Fuel Hydrogen & 0.8 & 0.7 & 0.8 & 0.7 \\
Unburned Carbon & 2.1 & 10.4 & 1.3 & 0.1 \\
Sorbent Calcination & 5.8 & 6.0 & 5.9 & 0.0 \\
Radiation and Convection* & 0.4 & 0.4 & 0.4 & 0.4 \\
Discharged Solids & 6.9 & 6.8 & 6.9 & 3.9 \\
Sorbent Sulfation & -6.3 & -6.8 & -6.8 & 0.0 \\
Total & 22.4 & 30.3 & 21.0 & 16.7 \\
Boiler Efficiency, \% & 77.6 & 69.7 & 79.0 & 83.3 \\
\hline
\end{tabular}

* Assumes $0.4 \%$ radiative and convective losses. 
Boiler efficiencies with this coal were very low, $70 \%$ - $83 \%$, compared to the $85 \%$ $90 \%$ efficiencies calculated for other coals tested on this unit. The loss due to unburned carbon was greater than $10 \%$ for Test 2, the low-temperature test. Boiler efficiency losses due to dry flue gas was about $7 \%$ for all four tests; the moisture in the coal accounted for $5 \% \cdot 6 \%$ of the losses. The loss due to the removal of hot solids from the system was almost $7 \%$ for Tests 1 through 3 , and $4 \%$ for Test 4 ; the difference is that no limestone was added during Test 4 , so less material had to be removed to maintain solids inventory.

\section{Heat-Transfer Coefficient and Heat Flux}

During testing, combustor heat exchange surface used for heat removal included the doors in Sections 2, 3, 4, 6, 7, and 8. Flow rates and temperatures of the cooling water used in these heat exchange surfaces were monitored to allow calculation of heat-transfer coefficients and heat flux as a function of position in the combustor. In the external heat exchanger, the number of cooling coils used to control temperature ranged from 6 to 11 . Heat-transfer coefficient and heat flux are calculated for the EHX as a whole. The average values of heat-transfer coefficient and heat flux for each combustor section which contains one or more heat exchange doors, and for the external heat exchanger, have been calculated for each of the four tests and are presented in Tables E-16 and E-17. Table E-18 presents the average heat-transfer coefficient and heat flux in the combustor for the entire run, along with the average pressure drop across each combustor section containing a heat exchange door. These data are also summarized in Table E-5 to facilitate comparison to test conditions. The heat fluxes calculated for this run ranged from $19,986 \mathrm{Btu} / \mathrm{hr}-\mathrm{ft}^{2}$ for Test 2 to $24,021 \mathrm{Btu} / \mathrm{hr}$ - $\mathrm{ft}^{2}$ for Test 1 . These values are lower than the 24,500 to $35,800 \mathrm{Btu} / \mathrm{hr}$ - $\mathrm{ft}^{2}$ observed in previous runs on this unit. The heat flux in the external heat exchanger ranged from $53,122 \mathrm{Btu} / \mathrm{hr}-\mathrm{ft}^{2}$ for Test 2 to $80,362 \mathrm{Btu} / \mathrm{hr}-\mathrm{ft}^{2}$ for Test 3. These values are relatively low compared to EHX heat flux for other coals burned in this unit; while Center, Black Thunder, and Blacksville all had full-load tests with heat flux as low as 55,000, the same run's had maximum heat flux of 123,000 , 111,000 , and 98,000 , respectively. Like the low solids recirculation rates observed in this run, the low heat-transfer coefficients and heat flux in the combustor are due to the removal, rather than recirculation, of secondary cyclone ash.

There was not a lot of variability in combustor heat flux between tests. Test 4 had the lowest heat flux, probably because no limestone was being added during this test, resulting in a decrease in the amount of fine solids in the bed. In the EHX, however, both solids feed and operating temperature appear to affect heat flux, since the flux for Tests 2 and 4 are very similar.

\section{Pressure and Temperature Profiles}

The pressure and temperature profiles for Tests 1 through 4 are presented in Figures E-5 and E-6, respectively. Figure E-5 shows the dense phase in the lower portion of the combustor, similar to a bubbling fluidized bed, and the dilute phase in the rest of the combustor. The temperature profiles are quite uniform; areas of lower temperature are caused by heat-transfer doors in those sections of the combustor. 
TABLE E-16

Individual Heat-Transfer Coefficients (Btu/hr- $\left.\mathrm{ft}^{2}-{ }^{\circ} \mathrm{F}\right)$

\begin{tabular}{ccccccc}
\hline $\begin{array}{c}\text { Combustor } \\
\text { Section }\end{array}$ & Test 1 & Test 2 & Test 3 & Test 4 & Average & $\begin{array}{c}\text { Combustor } \\
\text { Height }\end{array}$ \\
\hline 2 & 23.4 & 21.6 & off & 20.0 & 21.7 & 7.5 \\
3 & off & off & off & 17.1 & 17.1 & 12.5 \\
4 & 14.0 & 12.6 & off & 14.2 & 13.6 & 17.5 \\
6 & 15.2 & 13.6 & off & 15.0 & 14.6 & 27.5 \\
7 & off & 11.7 & 14.1 & 13.0 & 12.9 & 32.5 \\
8 & 14.6 & 12.3 & 15.3 & 13.9 & 14.0 & 37.5 \\
Overall & 16.9 & 14.8 & 15.7 & 15.8 & 15.8 & \\
EHX & 59.3 & 58.4 & 63.9 & 55.2 & 59.2 & \\
\hline
\end{tabular}

TABLE E-17

Individual Heat Flux (Btu/hr-ft' $\left.{ }^{2}\right)$

\begin{tabular}{ccccccc}
\hline $\begin{array}{c}\text { Combustor } \\
\text { Section }\end{array}$ & Test 1 & Test 2 & Test 3 & Test 4 & Average & $\begin{array}{c}\text { Combustor } \\
\text { Height }\end{array}$ \\
\hline 2 & 33,115 & 28,928 & off & 29,066 & 30,370 & 7.5 \\
3 & off & off & off & 25,090 & 25,090 & 12.5 \\
4 & 20,213 & 17,350 & off & 20,637 & 19,400 & 17.5 \\
6 & 22,088 & 18,662 & off & 21,821 & 20,857 & 27.5 \\
7 & off & 15,927 & 21,673 & 18,556 & 18,719 & 32.5 \\
8 & 21,215 & 16,581 & 23,194 & 19,636 & 20,157 & 37.5 \\
Overall & 24,021 & 19,986 & 23,926 & 22,597 & 22,633 & \\
EHX & 67,811 & 53,122 & 80,362 & 56,012 & 64,327 & \\
\hline
\end{tabular}

TABLE E-18

Average Heat-Transfer Coefficient and Heat Flux

\begin{tabular}{cccc}
\hline Section & $\mathrm{dP}\left(\right.$ in $\left.\mathrm{H}_{2} \mathrm{O}\right)$ & $\mathrm{H}_{\circ}$ & Flux \\
\hline 2 & 31.9 & 21.7 & 30,370 \\
3 & 2.1 & 17.1 & 25,090 \\
4 & 1.4 & 13.6 & 19,400 \\
6 & 1.0 & 14.6 & 20,857 \\
7 & 0.8 & 12.9 & 18,719 \\
8 & 0.8 & 14.0 & 20,157 \\
$1-8$ & 55.6 & 15.8 & 22,633 \\
\hline
\end{tabular}

${ }^{1}$ Heat-transfer coefficient $\left(\mathrm{Btu} / \mathrm{hr}-\mathrm{ft}^{2}{ }^{\circ} \mathrm{F}\right)$. 


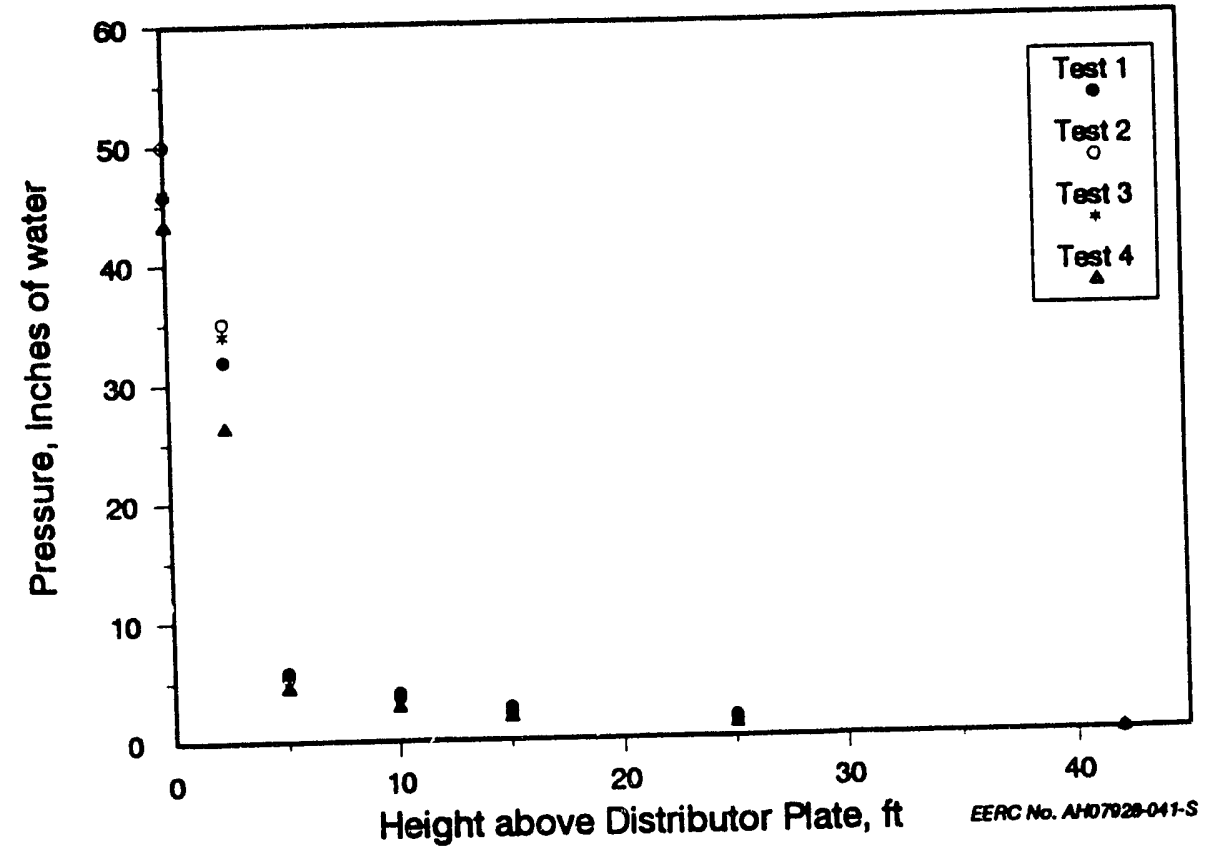

Figure E-5. Combustor pressure profiles.

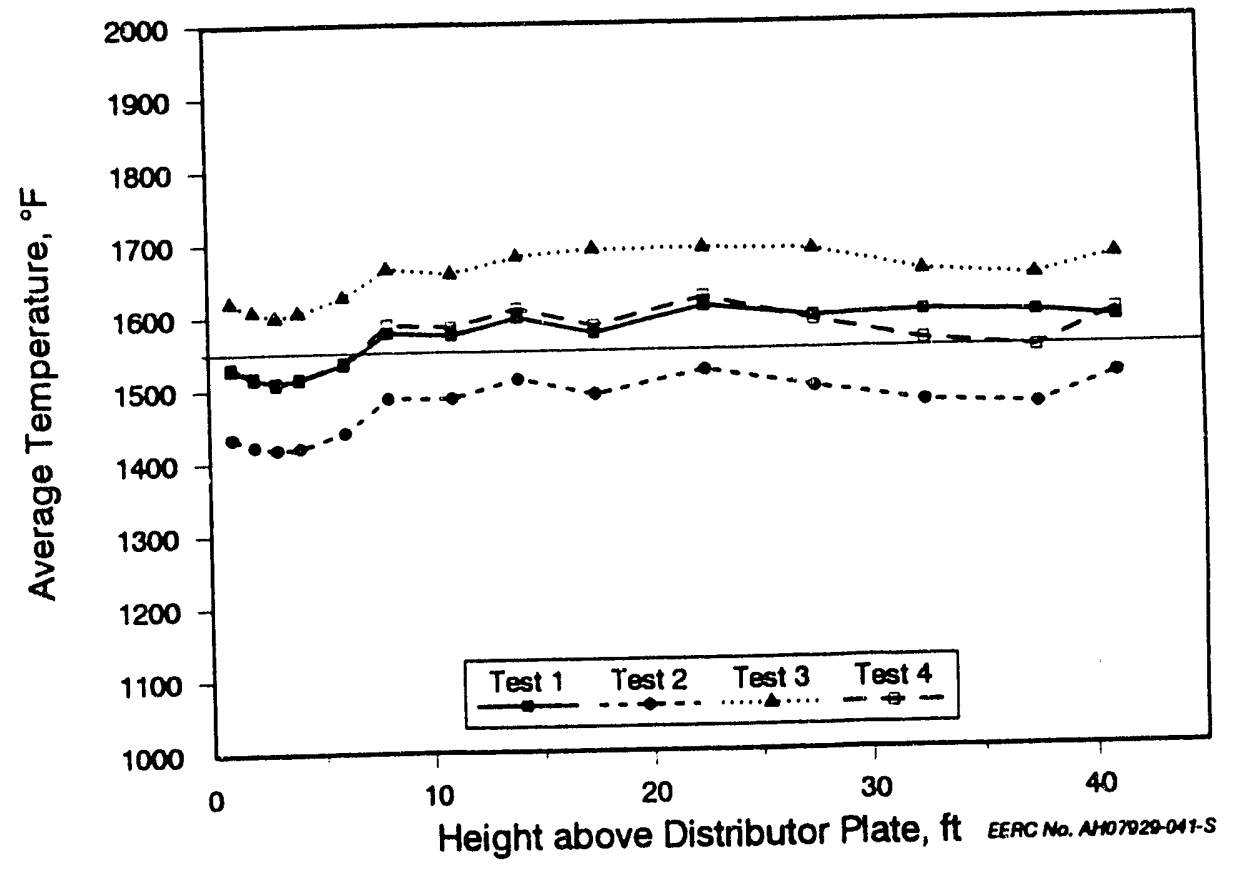

Figure E-6. Combustor temperature profiles. 


\section{ENVIRONMENTAL PERFORMANCE}

Average flue gas emissions for each of the four steady-state test periods are presented in Table E-19 and discussed in the following sections. All of the emissions are represented graphically as functions of average combustor temperature. The temperature was varied by adjusting the total amount of heat-transfer surface in use from one test period to another. The combustion air supply was held constant throughout the test burn, and, as such, the lower furnace and flue gas velocities were allowed to drift in response to higher or lower combustor temperatures. The trends noted in all cases were the same as expected based on previous experience.

TABLE E-19

Emissions Data

\begin{tabular}{|c|c|c|c|c|}
\hline & Test 1 & Test 2 & Test 3 & Test 4 \\
\hline $\mathrm{O}_{2}, \%$ & 4.06 & 4.05 & 4.03 & 4.37 \\
\hline $\begin{array}{l}\text { CO Content, ppm } \\
\text { CO Content, }{ }^{1} \text { ppm } \\
\text { CO Emission, lb/MM Btu }\end{array}$ & $\begin{array}{r}76 \\
81 \\
0.059\end{array}$ & $\begin{array}{r}87 \\
82 \\
0.06\end{array}$ & $\begin{array}{r}20 \\
22 \\
0.01\end{array}$ & $\begin{array}{r}94 \\
101 \\
0.076\end{array}$ \\
\hline $\begin{array}{l}\mathrm{CO}_{2} \text { Content, } \% \\
\mathrm{CO}_{2} \text { Content, } \%\end{array}$ & $\begin{array}{l}16.8 \\
17.8\end{array}$ & $\begin{array}{l}16.9 \\
17.9\end{array}$ & $\begin{array}{l}17.5 \\
18.5\end{array}$ & $\begin{array}{l}16.0 \\
17.3\end{array}$ \\
\hline $\begin{array}{l}\mathrm{NO}_{\mathrm{x}} \text { Content, } \mathrm{ppm} \\
\mathrm{NO}_{\mathrm{x}} \text { Content, }{ }^{1} \mathrm{ppm} \\
\mathrm{NO}_{\mathrm{x}} \text { Emission, } \mathrm{lb} / \mathrm{MM} \text { Btu }\end{array}$ & $\begin{array}{r}122 \\
130 \\
0.18\end{array}$ & $\begin{array}{r}80 \\
84 \\
0.12\end{array}$ & $\begin{array}{r}143 \\
151 \\
0.20\end{array}$ & $\begin{array}{r}97 \\
105 \\
0.15\end{array}$ \\
\hline $\begin{array}{l}\mathrm{N}_{2} \mathrm{O} \text { Content, } \mathrm{ppm} \\
\mathrm{N}_{2} \mathrm{O} \text { Content, }{ }^{1} \mathrm{ppm} \\
\mathrm{N}_{2} \mathrm{O} \text { Emission, lb/MM Btu }\end{array}$ & $\begin{array}{r}56 \\
59 \\
0.078\end{array}$ & $\begin{array}{r}108 \\
114 \\
0.152\end{array}$ & $\begin{array}{r}31 \\
32 \\
0.041\end{array}$ & $\begin{array}{r}75 \\
81 \\
0.107\end{array}$ \\
\hline $\begin{array}{l}\mathrm{SO}_{2} \text { Content, } \mathrm{ppm} \\
\mathrm{SO}_{2} \text { Content, }{ }^{1} \mathrm{ppm} \\
\mathrm{SO}_{2} \text { Emission, lb/MM Btu } \\
\mathrm{SO}_{2} \text { Retention (calc.), }{ }^{2} \%\end{array}$ & $\begin{array}{r}1481 \\
1573 \\
3.02 \\
90.3\end{array}$ & $\begin{array}{r}1852 \\
1966 \\
3.77 \\
88.1\end{array}$ & $\begin{array}{r}2172 \\
2304 \\
4.26 \\
86.2\end{array}$ & $\begin{array}{r}4399 \\
4761 \\
9.42 \\
70.1\end{array}$ \\
\hline $\begin{array}{l}\mathrm{Ca} / \mathrm{S} \text { Ratio (ls }{ }^{3} \text { only) } \\
\mathrm{Ca} / \mathrm{S} \text { Ratio (total) } \\
\mathrm{Ca} \text { Utiliz. (ls }{ }^{3} \text { only) } \\
\mathrm{Ca} \text { Utiliz. (total) }\end{array}$ & $\begin{array}{r}1.3 \\
2.21 \\
68.4 \\
40.9\end{array}$ & $\begin{array}{r}1.3 \\
2.02 \\
66.5 \\
43.7\end{array}$ & $\begin{array}{r}1.4 \\
2.01 \\
63.7 \\
42.9\end{array}$ & $\begin{array}{r}0.0 \\
0.63 \\
0.0 \\
111.8\end{array}$ \\
\hline $\begin{array}{l}\text { Alkali-to-Sulfur (total) } \\
\text { Alkali Utilization (total) }\end{array}$ & $\begin{array}{l}2.34 \\
38.7\end{array}$ & $\begin{array}{l}2.17 \\
40.6\end{array}$ & $\begin{array}{l}2.12 \\
40.6\end{array}$ & $\begin{array}{r}0.63 \\
110.4\end{array}$ \\
\hline $\begin{array}{l}\text { Average Combustor } \\
\text { Temperature, }{ }^{\circ} \mathrm{F} \\
\text { Moisture in Flue Gas, vol\% } \\
\text { Moist-Free Coal Carbon, \% } \\
\text { Moist-Free Coal Sulfur, \% }\end{array}$ & $\begin{array}{r}1565 \\
14.4 \\
29.0 \\
7.16\end{array}$ & $\begin{array}{r}1471 \\
14.2 \\
29.8 \\
7.30\end{array}$ & $\begin{array}{r}1650 \\
13.9 \\
29.9 \\
7.18\end{array}$ & $\begin{array}{r}1564 \\
13.9 \\
31.0 \\
7.60\end{array}$ \\
\hline $\begin{array}{ll}1 & \text { Corrected to } 3 \% \mathrm{O}_{2} \\
2 & \text { Moisture-free coal carbon } \\
3 & \text { limestone }\end{array}$ & & & & \\
\hline
\end{tabular}




\section{$\mathrm{SO}_{2}$ Emissions}

The average concentration of $\mathrm{SO}_{2}$ in the flue gas (corrected to $3 \% \mathrm{O}_{2}$ ) varied from 1570 to $4760 \mathrm{ppm}$ (3.02 to $9.22 \mathrm{lb} / \mathrm{MM} \mathrm{Btu}$ ), depending upon the operating temperature and ratio of calcium-to-sulfur in the system. Figure E-7 shows that the lowest $\mathrm{SO}_{2}$ emissions occurred under Test 1 conditions, during which the average combustor temperature was $1565^{\circ} \mathrm{F}$.

Figure E-8 is a plot of the measured sulfur retention versus total calcium-to-sulfur $(\mathrm{Ca} / \mathrm{S})$ ratio expressed on a molar basis. The plot shows that the $\mathrm{Ca} / \mathrm{S}$ ratio was slightly higher during Test 1 than it was for Tests 2 and 3. However, the effect of temperature on $\mathrm{SO}_{2}$ retention is evident from the figure. At similar $\mathrm{Ca} / \mathrm{S}$ ratios, sulfur retention was lowest at a temperature of $1650^{\circ} \mathrm{F}$, was somewhat higher at $1470^{\circ} \mathrm{F}$, and was greatest at $1565^{\circ} \mathrm{F}$. Overall, a $\mathrm{Ca} / \mathrm{S}$ ratio of approximately 2.1 (1.3 from limestone, 0.8 inherent with coal) was needed to achieve a $\mathrm{SO}_{2}$ retention of between $87 \%$ and $91 \%$ at all combustor temperatures tested. Test 4 was conducted without sorbent feed at an average combustor temperature of $1564^{\circ} \mathrm{F}$. As shown in Figure E-8, the alkali inherent in the coal ash was sufficient to achieve $70 \% \mathrm{SO}_{2}$ retention. A calculated calcium utilization of $111 \%$ for this test indicates residual limestone was responsible for some of the sulfur capture on Test 4.

The higher $\mathrm{Ca} / \mathrm{S}$ ratio used during Test 1 may have resulted in slightly greater $\mathrm{SO}_{2}$ retention and likely resulted in lower $\mathrm{SO}_{2}$ flue gas concentrations than if it were performed at the exact same $\mathrm{Ca} / \mathrm{S}$ as Tests 2 and 3 . Only a minor change in retention and emission numbers from those reported would be expected if the test were performed at a $\mathrm{Ca} / \mathrm{S}$ of 2.01 rather than 2.21 .

\section{$\mathrm{NO}_{\mathbf{x}}$ Emissions}

Flue gas emissions of $\mathrm{NO}_{\mathrm{x}}$ (corrected to $3 \% \mathrm{O}_{2}$ ) ranged from 84 to $151 \mathrm{ppm}(0.12$ to $0.20 \mathrm{lb} / \mathrm{MM} \mathrm{Btu}$ ). The effect of temperature on $\mathrm{NO}_{\mathrm{x}}$ emissions is shown in Figure E-9, with $\mathrm{NO}_{\mathrm{x}}$ increasing with increasing temperature. $\mathrm{NO}_{\mathrm{x}}$ emissions were approximately 25 ppm higher for Test 1 compared to Test 4, due to the catalytic effect of the limestone.

\section{$\mathrm{N}_{2} \mathrm{O}$ Emissions}

$\mathrm{N}_{2} \mathrm{O}$ emissions (corrected to $3 \% \mathrm{O}_{2}$ ) ranged from 32 to $114 \mathrm{ppm}(0.4$ to $0.15 \mathrm{lb} / \mathrm{MM}$ Btu). Figure E-10 shows how $\mathrm{N}_{2} \mathrm{O}$ decreases with increasing combustor temperature. Unlike $\mathrm{NO}_{\mathrm{x}}$ emissions, for which the addition of limestone resulted in higher emissions levels, $\mathrm{N}_{2} \mathrm{O}$ emissions were lower during Test 1 with limestone feed than during Test 4 without limestone.

\section{CO Emissions}

The as-measured emissions of CO varied from 20 to $94 \mathrm{ppm}$ during Week 2 steadystate testing, as shown in Figure E-11. In general, the CO concentrations decreased as the average operating temperature increased. One deviation from that trend was that the highest steady-state $\mathrm{CO}$ value resulted from Test 4 operation at an intermediate combustor temperature and zero sorbent feed. 


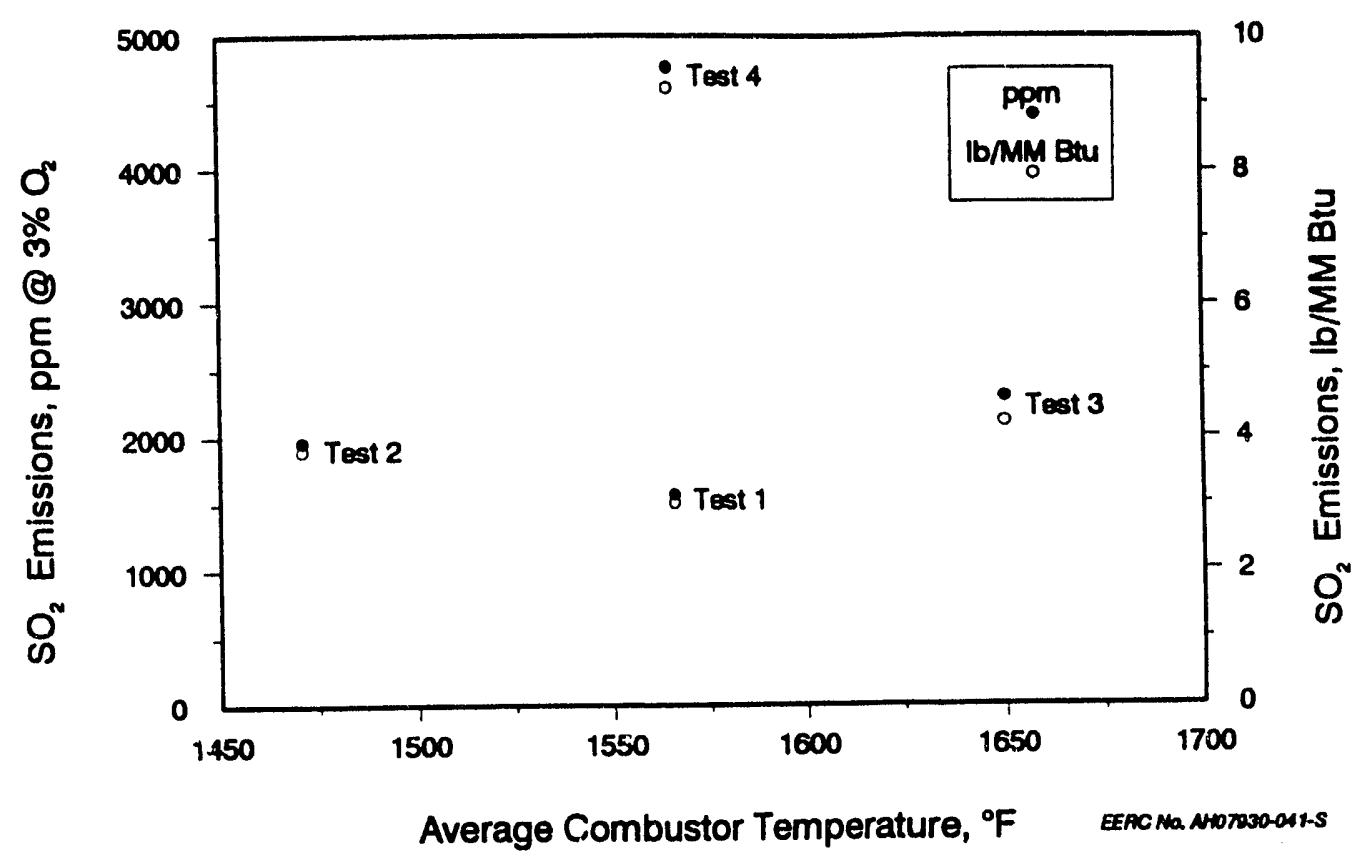

Figure E-7. $\mathrm{SO}_{2}$ emissions as a function of average combustor temperature.

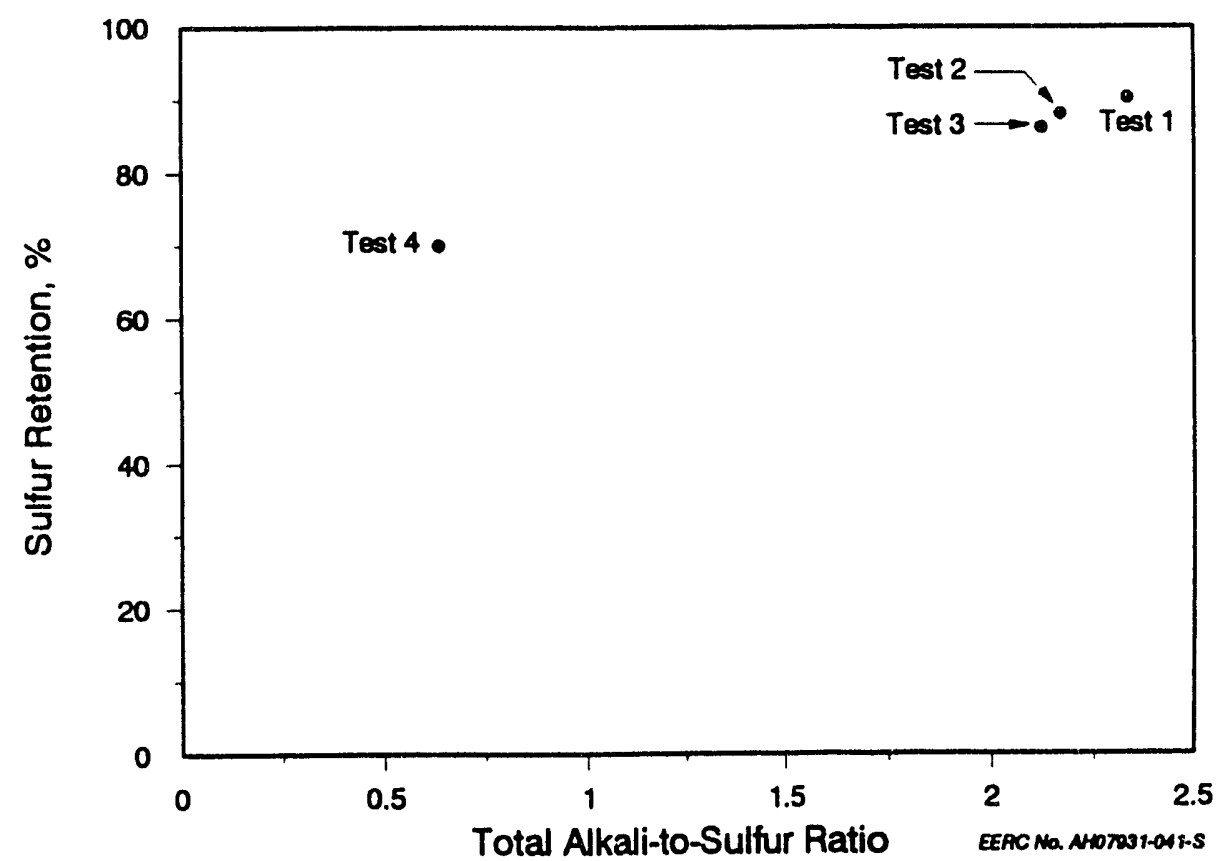

Figure E-8. $\mathrm{SO}_{2}$ retention as a function of calcium-to-sulfur molar ratio. 


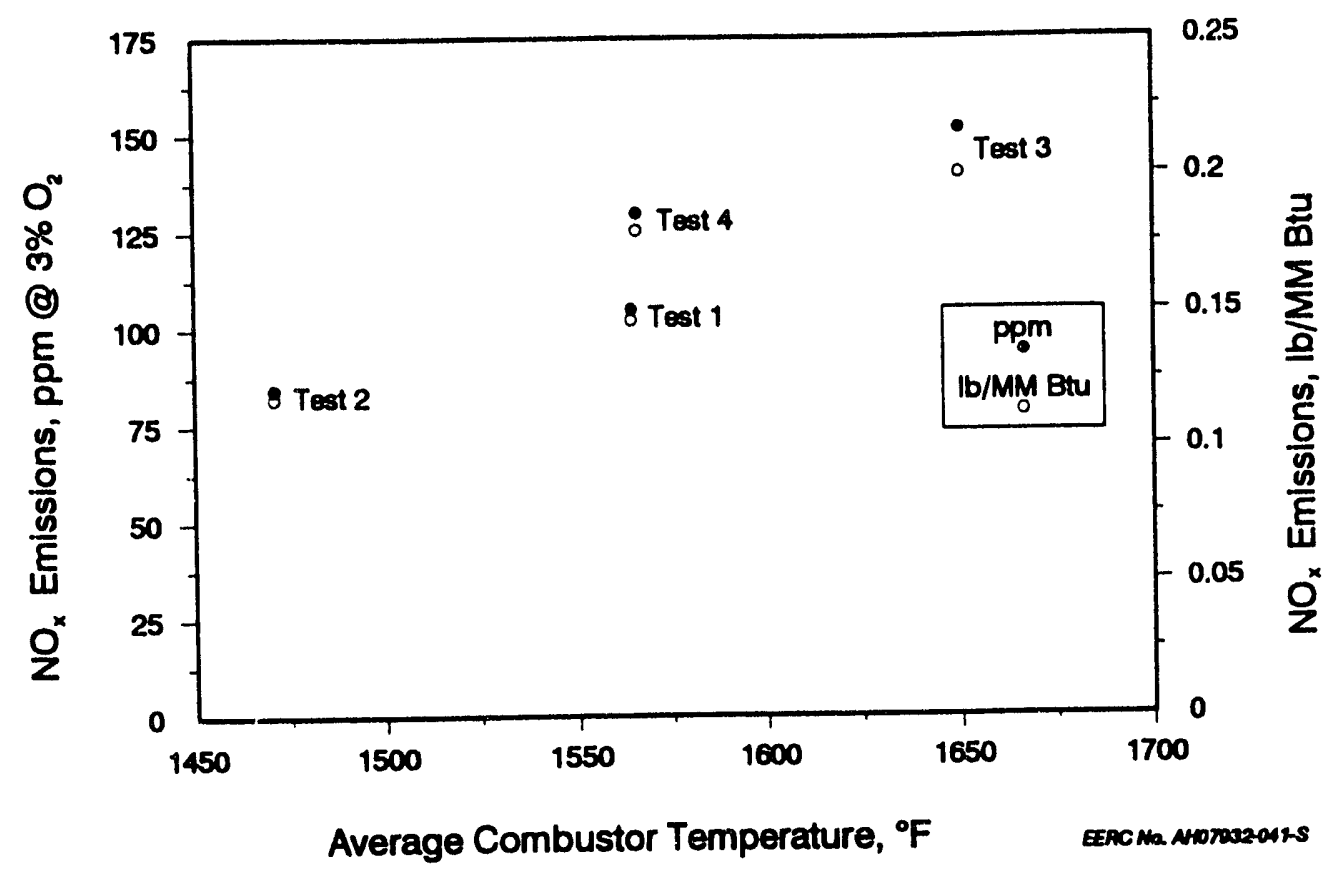

Figure E-9. NO emissions as a function of average combustor temperature.

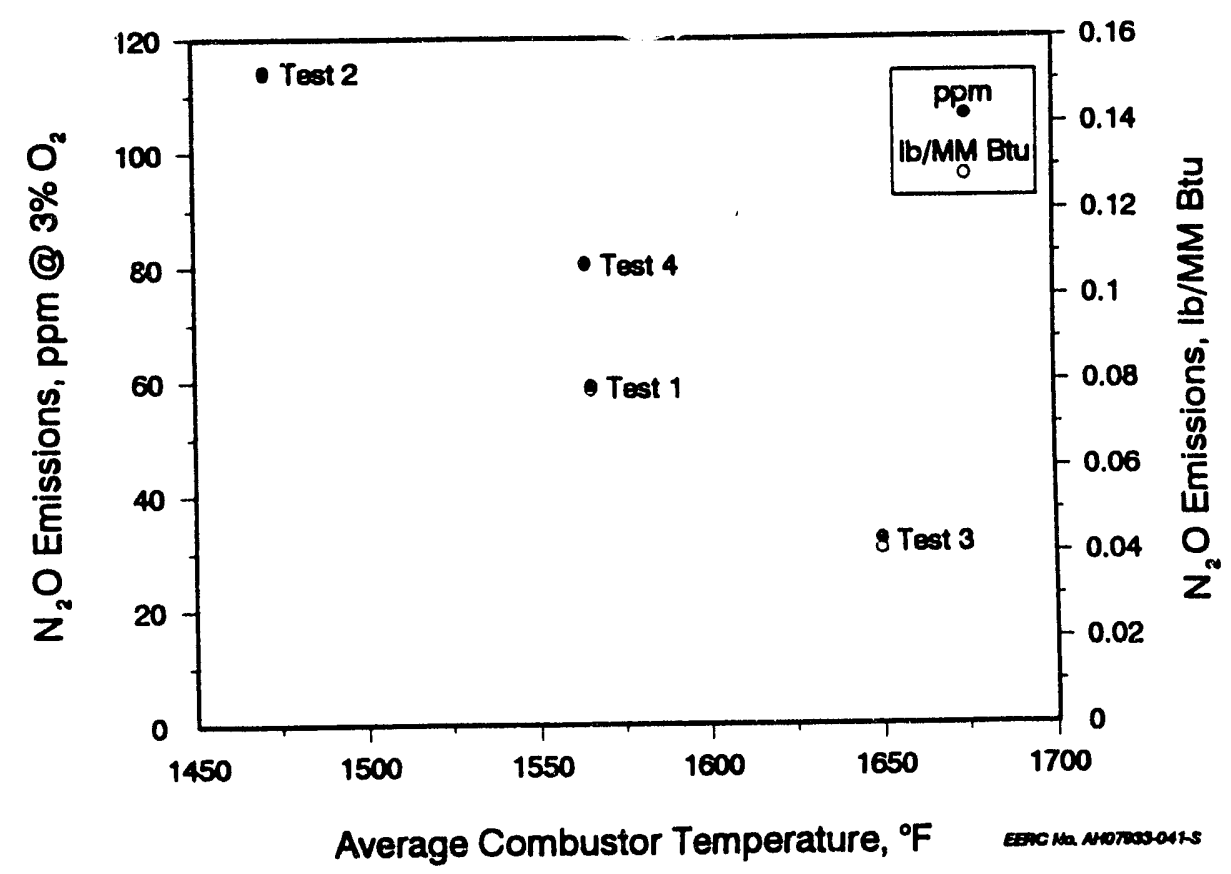

Figure E-10. $\mathrm{N}_{2} \mathrm{O}$ emissions as a function of average combustor temperature. 


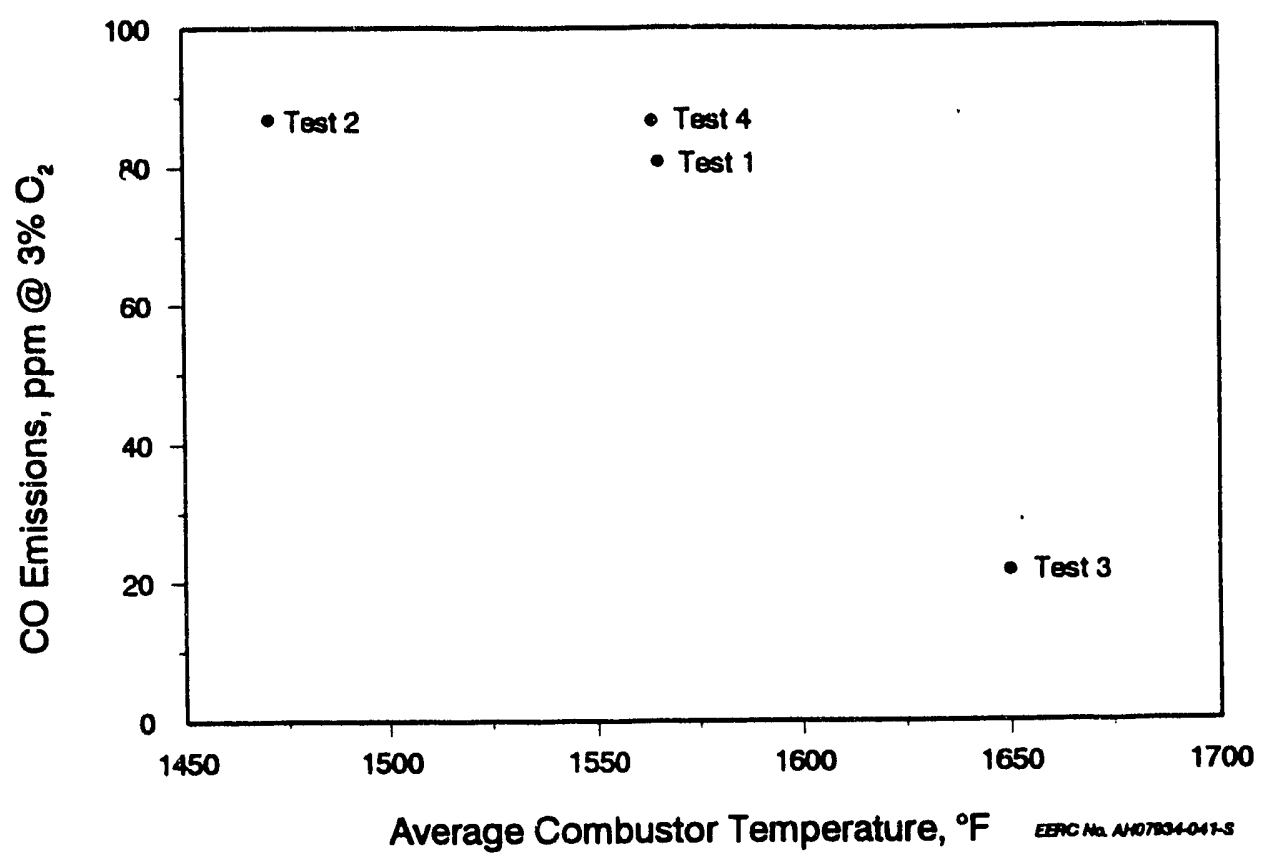

Figure E-11. CO emissions as a function of average combustor temperature.

The flue gas $\mathrm{CO}$ emissions measured during Week 1 were much more erratic and, on the average, much higher. This was due to the problems experienced with the air heater leaks, resulting in periods of time when reducing conditions were likely present within the combustor.

\section{SINTERING, AGGLOMERATION, AND DEPOSIT EVALUATION}

Although FBCs typically operate at relatively low temperatures, evidence from pilot, industrial, and utility boilers indicates that certain ash components can cause ash-related problems. These ash-related problems can manifest themselves as agglomeration and sintering of bed material, or as deposition on the heat exchange tube surfaces and refractory walls. These ash-related phenomena have been shown to cause a loss in steam temperature; operating difficulties; and, in some cases, unplanned shutdowns. Experience at the EERC has shown fuels with high sodium and potassium levels to be the most troublesome, particularly with bed agglomeration. Agglomerates the size of small cars have been reported by the user of a high-sodium North Dakota lignite ( $12 \% \mathrm{NaO}$ in the ash). High calcium and sulfur in the fuel have also been demonstrated to produce ash. related problems. Because of the nature of the ash from the source mine and experience burning this fuel in pc-fired systems, an important goal of this feasibility study was to determine the nature of any ash-related problems.

\section{Bed Material Sintering and Agglomeration Potential}

No evidence of bed material agglomeration or ash deposition in the combustor, downcomer, or external heat exchanger was noted during either week of testing. Based on the low sodium and potassium content in the Asian lignite received and tested in the 
EERC CFB pilot plant, it was expected that agglomeration would not be a concern. If lignite containing a higher alkali ( $N$ a plus $\mathrm{K}$ ) concentration is utilized, there could possibly be some occurrence of agglomeration. However, if $90 \%$ sulfur capture is required, the high bed drain rate that is required when feeding limestone would likely minimize any potential for agglomeration by the constant purge of the alkali from the bed. At the limestone feed rates used during this test, it is expected that the Asian lignite tested could be burned without agglomeration problems.

There were several upsets in operational conditions during the two weeks of testing that are more favorable for the formation of agglomerates, based on past experience at the EERC. At the end of the first week of testing, due to the leak in the air heater, conditions in the combustor were highly reducing, and, immediately before shutdown, there was a temperature excursion up to approximately $1720^{\circ} \mathrm{F}$. There were three separate occasions that forced a hot slump of the bed during the first week of testing. The last two hot slumps occurred without sufficient time available for the carbon present in the bed to completely burn out.

During the second week of testing, there was one intentional hot bed slump to retain heat in the combustor until a coal plug could be remedied. Several bed slumps were required during a short period of time on the final day of testing to restart the induced-draft blower, which tripped for electrical reasons. Despite all of these considerable process interruptions, as well as operation of the combustor at greatly reduced bed drain rates during the fir al 24 hours of Week 2, agglomeration was not a problem and is not expected to be a problem when firing this fuel in a full-scale unit.

A significant quantity of large bed material particles accumulated within the combustor during testing. It is likely that this was an accumulation of clay or rock that was fed into the combustor along with the coal. It is possible that an additional coalcleaning step might remove these impurities. If that is not feasible, consideration should be given to the design of a bed material drain system to remove large particles selectively.

\section{Backpass Tube-Fouling Potential}

Two air-cooled probes located at the exit of the cycione are used to investigate the degree of ash deposition or slagging that could be expected at the leading edge of the convective pass region of a circulating fluidized-bed boiler. Air flow to the probes was controlled to maintain a probe surface temperature of approximately $1000^{\circ} \mathrm{F}$. A thin layer of ash, less than $1 \mathrm{~mm}$ thick, was present on the probes at the conclusion of the run.

Postrun inspection of system components revealed a deposit which had formed on top of the shell-and-tube air-to-flue gas heat exchanger located at the exit of the ashfouling section. The deposit is a very fine-grained matrix, with most of the particles less than one micron. A few larger particles (1 to 10 microns) were found intermixed in the fine-grained matrix. The flow of the flue gas and possible erosion from larger ash particles produced a hill- and valley-like terrain on the deposit. The flue gas temperature entering the heat exchanger is approximately $1400^{\circ} \mathrm{F}$. An analysis of the deposit is given in Table E-20. The elemental analyses show that the deposit is primarily composed of calcium and sulfur, with a relatively large amount of iron. This composition differs from both the coal and the limestone analyses, showing an enrichment in the calcium, iron, and sulfur. Further analysis of this deposit using scanning electron microscopy point 
TABLE E-20

\begin{tabular}{lc} 
Analysis of Deposit from the Shell-and-Tube Heat Exchanger \\
\hline Oxides & $\frac{w t \%}{2.9}$ \\
$\mathrm{SiO}_{2}$ & 5.3 \\
$\mathrm{Al}_{2} \mathrm{O}_{3}$ & 3.3 \\
$\mathrm{Fe}_{2} \mathrm{O}_{3}$ & 15.1 \\
$\mathrm{TiO}_{2}$ & 0.0 \\
$\mathrm{P}_{2} \mathrm{O}_{5}$ & 0.9 \\
$\mathrm{CaO}$ & 35.6 \\
$\mathrm{MgO}$ & 4.7 \\
$\mathrm{Na} O$ & 0.1 \\
$\mathrm{~K}_{2} \mathrm{O}$ & 0.3 \\
$\mathrm{SO}_{3}$ & 34.1 \\
$\mathrm{Minerals}$ & Identified by XRD \\
Anhydrite $\left(\mathrm{CaSO}_{4}\right)$ & Major Phase \\
Maghemite $\left(\mathrm{Fe}_{2} \mathrm{O}_{3}\right)$ & Minor Phase \\
Hematite $\left(\mathrm{Fe}_{2} \mathrm{O}_{3}\right)$ & Minor Phase \\
\hline
\end{tabular}

count identified calcium sulfate as the primary phase. The most likely mechanism for the formation of this deposit is deposition of fine-grained calcium oxide on the face of the tube sheet. Sulfation of the calcium oxide and subsequent sintering of the particles produce a very hard, tenacious deposit. Some of the ash particles appear to have stuck to the deposit; however, it is unlikely that any of the constituents in these ash particles caused the deposit to form or gave it strength. The iron inclusions are probably from fine-grained pyrite being preferentially carried out of the combustor and deposited with the calcium oxide.

A similar phenomenon has been noted in pc-fired boilers firing high-calcium western United States subbituminous coals. In these systems, calcium sulfate-based deposits are found primarily in the reheat section of the boiler where flue gas temperatures range from $1650^{\circ}$ to $1200^{\circ} \mathrm{F}$. These deposits are very tenacious and difficult to remove using conventional soot blowers if they are allowed to build up and develop strength over time. It is recommended for any FBC built to burn this type of Asian lignite that a conservative design be used in the back pass ensuring adequate soot-blowing coverage to prevent buildup of calcium sulfate-based deposits.

\section{SUMMARIES OF TEST DATA}

This section contains the summaries of test data for each test period, including averages and standard deviations of many of the data points recorded by the computerized data acquisition system. 


\begin{tabular}{|c|c|c|c|c|c|c|c|c|c|c|c|c|c|}
\hline \multirow{2}{*}{$\frac{\mathrm{Tag}}{\mathrm{TC} 11011}$} & \multirow{2}{*}{$\frac{\text { Desc }}{\text { PCDEx }}$} & \multirow{2}{*}{$\frac{\text { Units }}{{ }^{\circ} \mathbf{F}}$} & \multicolumn{2}{|c|}{ Average Std Dev } & \multicolumn{9}{|c|}{ HEAT-TRANSPER COEPPICIENTS } \\
\hline & & & 1612 & 12.2 & -Combustor- & & Number 0 & of Doors in Se & Service $\Longrightarrow$ & 4 & & & \\
\hline $\mathrm{TC} 11021$ & AFS Ex & $\bullet \boldsymbol{F}$ & 1411 & 8.5 & CHX & Height & Temp In & Temp Out & Bed Temp & Flow & $\mathbf{Q}$ & & Heat Flux \\
\hline TC15001 & C Plenum & ${ }^{\circ} \mathbf{P}$ & 609 & 6.7 & Location & $(\mathrm{ft})$ & ${ }^{\circ} \mathbf{P}$ & $\bullet \mathbf{P}$ & $\cdot \mathbf{P}$ & gpm & Btu/hr & Btuftt ${ }^{2} h r^{\circ} \mathrm{F}$ & Bturte br \\
\hline TC15004 & C 1-1' & $\bullet \mathbf{P}$ & 1529 & 16.1 & $2 \mathrm{E}$ & 8 & 68 & 162 & 1578 & 1.83 & 86100 & 23.4 & 33115 \\
\hline TC15005 & C 1-2' & ${ }^{\circ} \mathrm{F}$ & 1516 & 14.6 & 2 & 14 & 148 & 189 & 1597 & 0.00 & 0 & 0.0 & 0 \\
\hline TC15006 & C 1-3' & ${ }^{\circ} \mathbf{F}$ & 1511 & 14.7 & 4SE & 17.5 & 67 & 129 & 1574 & 1.69 & 52554 & 14.0 & 20213 \\
\hline TC15007 & C 1-4' & $\bullet \mathbf{F}$ & 1508 & 14.5 & 6NE & 27.5 & 68 & 139 & 1594 & 1.63 & 57429 & 15.2 & 22088 \\
\hline TC15008 & C 1-4' & ${ }^{\circ} \mathbf{F}$ & 1520 & 15.1 & 7 & 32.5 & 149 & 198 & 1600 & 0.00 & 0 & 0.0 & 0 \\
\hline TC15009 & C 1-4' & ${ }^{\circ} \mathbf{F}$ & 1515 & 14.5 & $8 E$ & 37.5 & 69 & 141 & 1597 & 1.52 & 55159 & 14.6 & 21215 \\
\hline TC15012 & C 2-6' & ${ }^{\circ} \mathbf{F}$ & 1535 & 16.0 & & Overall & 67 & 143 & 1565 & 6.56 & 249819 & 16.9 & 24021 \\
\hline TC15013 & C 2-8' & $\cdot \mathbf{F}$ & 1578 & 14.2 & & & & From Data Sh & heet $8 \Rightarrow$ & 6.67 & & & \\
\hline TC15022 & C 3-11' & ${ }^{\circ} \mathbf{F}$ & 1574 & 14.1 & & & & & & & & & \\
\hline TC15023 & C 3-14' & ${ }^{\circ} \mathrm{F}$ & 1588 & 13.6 & $-E H X-$ & & & & & & & & \\
\hline TC15024 & $C^{3}-14^{\prime}$ & ${ }^{\circ} \mathbf{F}$ & 1603 & 14.6 & Coils & No. of & Temp In & Temp Out & Bed Temp & Flow & $\mathbf{Q}$ & $\mathbf{U}$ & Heat Flux \\
\hline TC15025 & C 3-14' & ${ }^{\circ} \mathrm{F}$ & 1599 & 14.8 & Used & Coils & ${ }^{\circ} \mathbf{F}$ & ${ }^{\circ} \mathbf{P}$ & ${ }^{\circ} \mathbf{F}$ & gpm & Btu/hr & $\mathrm{Btu} / \mathrm{ft}{ }^{2} \mathrm{hr}^{\circ} \mathrm{F}$ & $\mathrm{Btu} / \mathrm{ft}^{2} \mathrm{br}$ \\
\hline TC15032 & C 4-17.5' & ${ }^{\circ} \mathrm{P}$ & 1574 & 11.8 & $1-4,10-12$ & 7 & 67 & 147 & 1289 & 8.76 & 348304 & 58.1 & 66344 \\
\hline TC15042 & C 5-22.5' & ${ }^{\circ} \mathbf{F}$ & 1611 & 13.0 & & & & From Data Sh & heets $\Rightarrow$ & 8.95 & & & \\
\hline TC15052 & c 6-27.5' & $\cdot \mathbf{F}$ & 1607 & 12.2 & & & & & & & & & \\
\hline $\mathrm{TC} 15053$ & C 6-27.5' & ${ }^{\circ} \mathbf{F}$ & 1610 & 13.2 & & & & & & & & & \\
\hline TC15054 & C 6-27.5' & ${ }^{\circ} \mathrm{F}$ & 1566 & 11.4 & & & & & & & & & \\
\hline TC15062 & C 7-32.5 & $\bullet \mathbf{F}$ & 1600 & 12.6 & EMISSIONS & DATA & & & & & & & \\
\hline TC15071 & C 8-37.5' & ${ }^{\circ} \mathbf{F}$ & 1597 & 10.8 & & & & & & & & & \\
\hline TC15073 & C 9-41' & ${ }^{\circ} \mathbf{F}$ & 1588 & 13.0 & & As Measurec & ed - & & $-c$ & Corrected to & $3 \% 02$ & & \\
\hline TC15999 & Ambient & ${ }^{\circ} \mathrm{F}$ & 88 & 3.3 & $\mathrm{Tag}$ & Units & Average & Std Dev & $\mathrm{Tag}$ & Units & Average & Std Dev & \\
\hline TC16001 & EHX Plenm & ${ }^{\circ} \mathbf{F}$ & 132 & 4.3 & SO2-A & ppm & 1481 & 242.7 & SO2-A & Ppm & 1569 & 218.7 & \\
\hline TC16012 & EHX 0.5' & ${ }^{\circ} \mathrm{F}$ & 1316 & 22.7 & SO2-AE & $\mathrm{Ib} / \mathrm{MM} \mathrm{Btu}$ & 3.02 & 0.4 & & & & & \\
\hline TC16013 & EHX 1.5' & ${ }^{\circ} \mathbf{F}$ & 1283 & 20.2 & $\mathrm{SO} 2-\mathrm{B}$ & ppm & 1576 & 217.3 & SO2-B & ppm & 1686 & 181.9 & \\
\hline TC16014 & EHX 2.7 & ${ }^{\circ} \mathbf{F}$ & 1268 & 21.3 & SO2-BE & Ib/MM Btu & 3.18 & 0.5 & & & & & \\
\hline TC16015 & EHX 3.8' & ${ }^{\circ} \mathrm{F}$ & 1057 & 24.0 & co & ppm & 76 & 21.6 & $\mathrm{CO}$ & ppm & 80 & 21.5 & \\
\hline TC16017 & EHX 5.3' & ${ }^{\circ} \mathrm{F}$ & 911 & 15.5 & $\mathrm{CO} 2$ & $\%$ & 16.76 & 0.7 & $\mathrm{CO} 2$ & $\%$ & 17.8 & 0.3 & \\
\hline TC16018 & EHX Exit & ${ }^{\circ} \mathrm{F}$ & 1169 & 19.0 & $\mathrm{~N} 2 \mathrm{O}$ & ppm & 56 & 6.7 & $\mathrm{~N} 2 \mathrm{O}$ & ppm & 60 & 9.3 & \\
\hline TC16021 & CreA In & ${ }^{\circ} \mathrm{F}$ & 1619 & 10.6 & $\mathrm{~N} 2 \mathrm{OE}$ & $\mathrm{Ib} / \mathrm{MM}$ Btu & 0.08 & 0.0 & & & & & \\
\hline TC16031 & DC \&-36 & ${ }^{\circ} \mathrm{F}$ & 1621 & 13.1 & NOx & ppm & 122 & 9.2 & NOx & ppm & 130 & 14.5 & \\
\hline TC16032 & DC 6-28' & ${ }^{\circ} \mathbf{F}$ & 1598 & 12.0 & NOxE & $\mathrm{Ib} / \mathrm{MM} \mathrm{Btu}$ & 0.18 & 0.0 & & & & & \\
\hline TC16033 & DC 4-18 & ${ }^{\circ} \mathrm{F}$ & 1577 & 14.3 & O2-A & $\%$ & 4.06 & 0.8 & & & & & \\
\hline $\mathrm{TC} 16034$ & $D C 3-9.5$ & ${ }^{\circ} \mathrm{F}$ & 1600 & 21.0 & $O 2-B$ & $\%$ & 4.21 & 0.8 & & & & & \\
\hline TC16035 & DC3-8.5 & ${ }^{\circ} \mathrm{F}$ & 1548 & 22.7 & & & & & & & & & \\
\hline $\mathrm{T}(\mathrm{A}, \mathrm{C})$ & Comb Temp & ${ }^{\circ} \mathbf{P}$ & 1565 & 12.7 & Tag & Desc & Units & Average & Std Dev & $\mathrm{Tag}$ & Desc & Average & Std Dev \\
\hline $\mathrm{T}(\mathrm{A}, \mathrm{EHX})$ & EHX Temp & ${ }^{\circ} \mathbf{F}$ & 1289 & 21.1 & $W(C)$ & Coal Fd Rt & Ibs/hr & 487.5 & 37.7 & TC13131 A & AFPE-F2" & 951 & 39.9 \\
\hline EA & Excess Air & $\%$ & 24.4 & 6.0 & $W(S)$ & LS Fd Rt & lbs/hr & 141.4 & 3.6 & TC13132 & AFPE-F $6^{\prime \prime}$ & 1027 & 27.0 \\
\hline SR & S Reten & $\%$ & 90.4 & 1.3 & $V(F G)$ & FG SGV & $\mathrm{ft} / \mathrm{sec}$ & 16.8 & 0.9 & TC13133 A & AFPE-B6" & 710 & 33.5 \\
\hline $\mathrm{R}(\mathrm{PCA})$ & $\%$ FIw PCA & $\%$ & 59.6 & 2.6 & $V(S, C)$ & Comb SGV & $\mathrm{ft} / \mathrm{sec}$ & 13.1 & 0.7 & TC13134A & APPE-F10" & 730 & 71.4 \\
\hline $\mathrm{R}(\mathrm{SCA})$ & $\%$ FIw SCA & $\%$ & 40.4 & 2.6 & $V(\mathbf{S}, \mathbf{E H X})$ & EHX SGV & $\mathrm{ft} / \mathrm{sec}$ & 1.7 & 0.1 & TC13231 A & $A F P W-F 2^{n}$ & 924 & 31.3 \\
\hline$R(Q, I N)$ & $\%$ Enrg in & $\%$ & 68.9 & 4.4 & FT18003 & CHX Flow & gpm & 6.6 & 0.1 & TC13232 A & AFPW-F6" & 1086 & 24.9 \\
\hline $\mathrm{R}(\mathrm{CHX})$ & CHX Ratio & $\%$ & 41.4 & 1.5 & FT19003 & EHX Flow & gpm & 8.8 & 0.1 & TC13233 A & $A F P W-B 6^{n}$ & 747 & 26.4 \\
\hline$R(E H X)$ & EHX Ratio & $\%$ & 58.6 & 1.5 & PT15081 & Comb dP & in. $\mathrm{H} 2 \mathrm{O}$ & 45.8 & 3.6 & TC13234 A & AFPW-F10 & 995 & 33.3 \\
\hline $\mathrm{F}(\mathrm{PCA})$ & PCA Fiw & SCFM & 215.6 & 21.5 & $Q(C A)$ & CA Heat in & KBtu/hr & 97.7 & 5.8 & DOORS & $\mathrm{CHX}: \mathrm{On}$ & 4 & 0 \\
\hline$F(E H X)$ & EHX FIw & SCFM & 47.0 & 2.2 & $Q(\mathrm{CHX})$ & CHX HtRmv & KBtu/hr & 245.6 & 11.9 & COILS & EHXs On & 7 & 0 \\
\hline $\mathrm{F}(\mathrm{TPA})$ & TPCA FIw & SCFM & 260.7 & 23.6 & $Q(E H X)$ & EHX HtRmv & $\mathrm{KBtu} / \mathrm{hr}$ & 347.4 & 14.1 & BHAVC & & 2.0 & 0.1 \\
\hline$F(S C A)$ & SCA FIw & SCFM & 175.7 & 7.4 & Q(EHX,IN & FG Ht in & KBtu/hr & 2.0 & 0.2 & ASSRATIO & & 2.1 & 0.1 \\
\hline $\mathrm{F}(\mathrm{TCA}, \mathrm{F})$ & TCA Fiw & SCFM & 436.5 & 23.7 & $Q(F)$ & Fuel Enrg in & KBtu/hr & 1603.2 & 119.2 & Feed Air & $\operatorname{scfm}$ & 19.3 & \\
\hline $\mathrm{F}(\mathrm{FG}, \mathrm{BH})$ & BH Flw & SCFM & 535.6 & 14.8 & $Q(F G)$ & FG Enrg out & KBtu/hr & 265.9 & 7.3 & DC Air & $\operatorname{scfm}$ & 12.2 & \\
\hline$F(T F G)$ & TFG FIw & SCPM & 535.6 & 14.8 & $Q(I N)$ & Tot Enrg in & $\mathrm{KBtu} / \mathrm{hr}$ & 1702.9 & 118.6 & Purge Air & $\operatorname{sefm}$ & 15.5 & \\
\hline W(SR) & Recirc Rt & $\mathrm{Ibs} / \mathrm{hr}$ & 3830 & 402.3 & QOUT) & Tot Enrg out & $\mathrm{KBtu} / \mathrm{hr}$ & 1164.7 & 24.2 & & & & \\
\hline
\end{tabular}




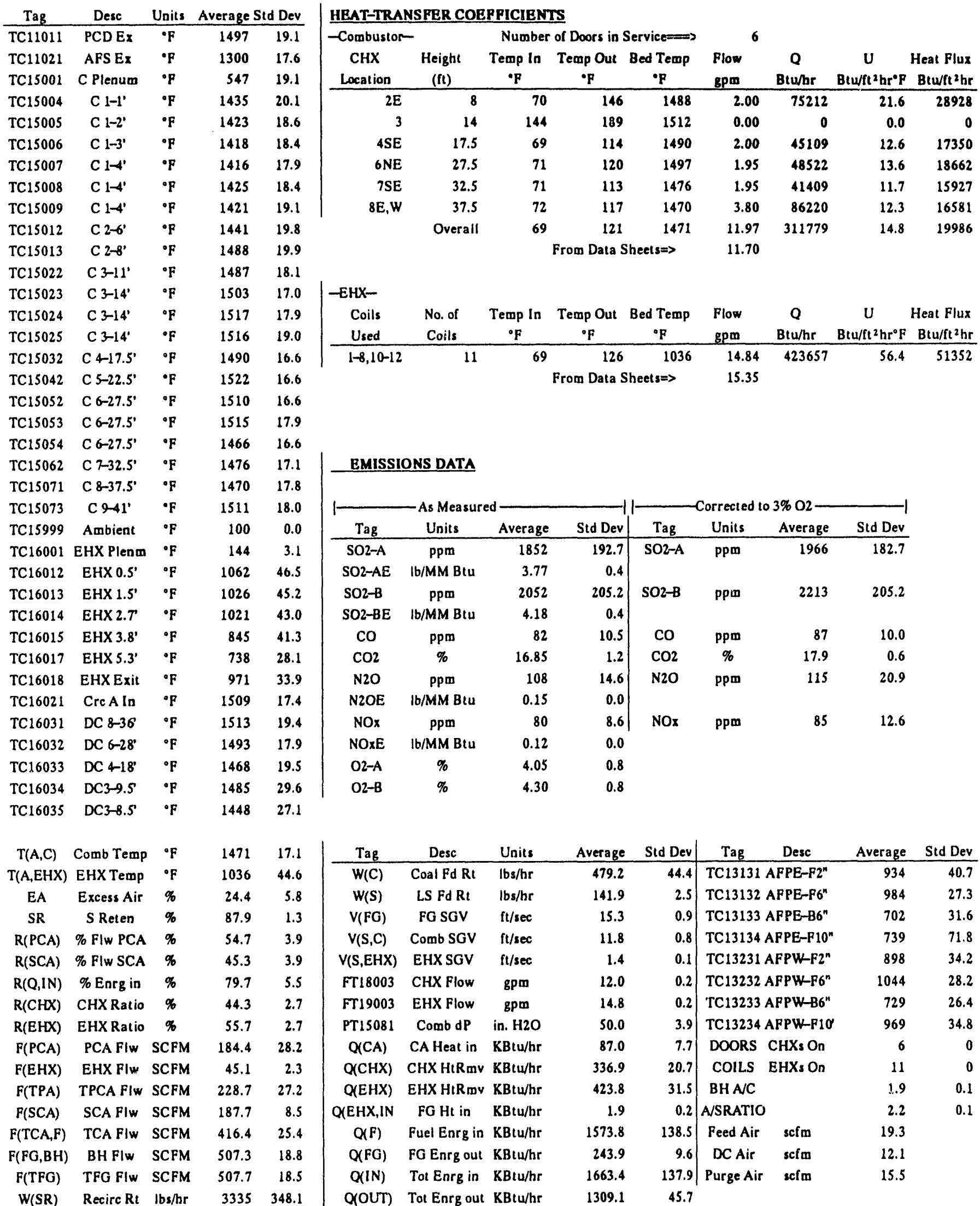




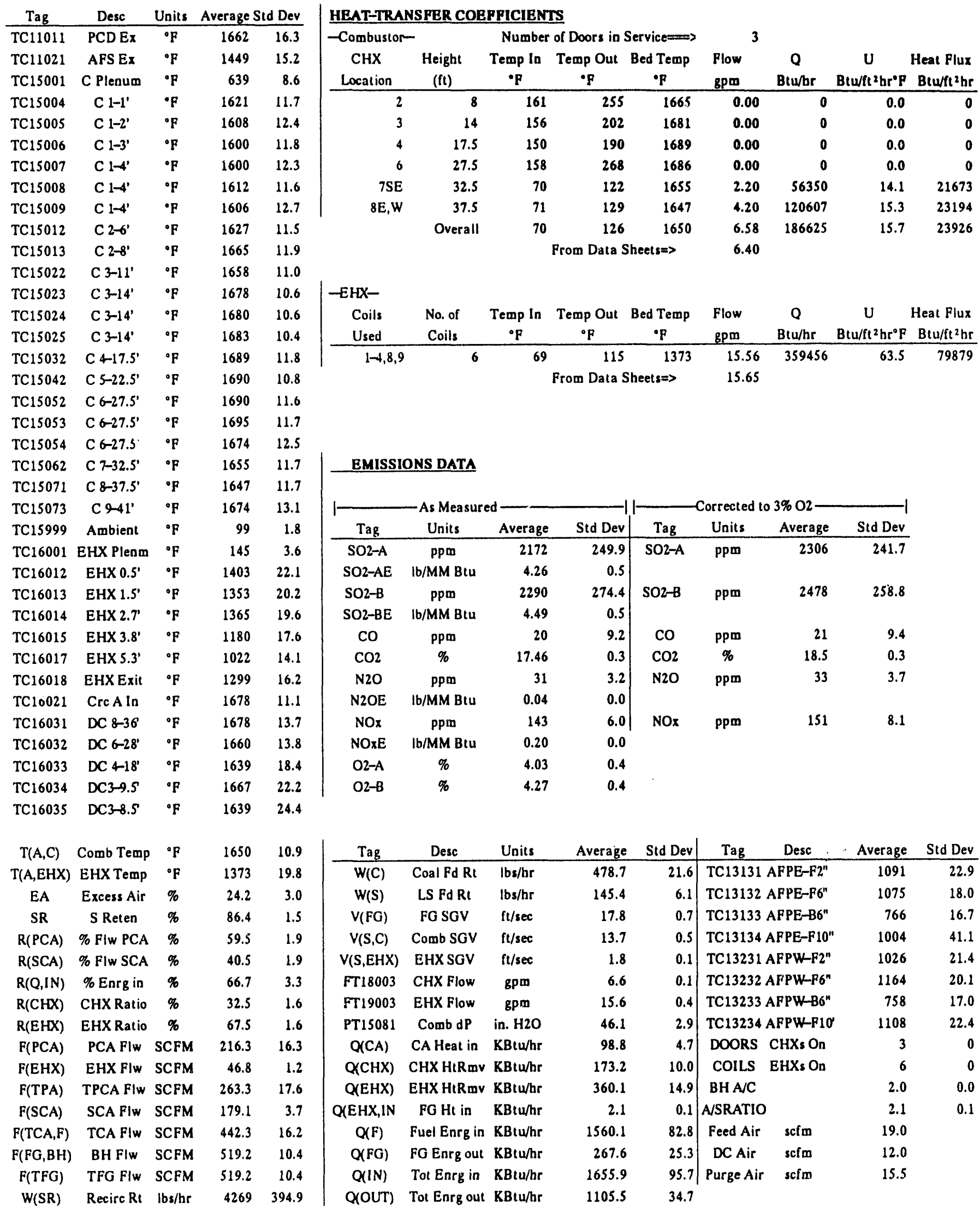




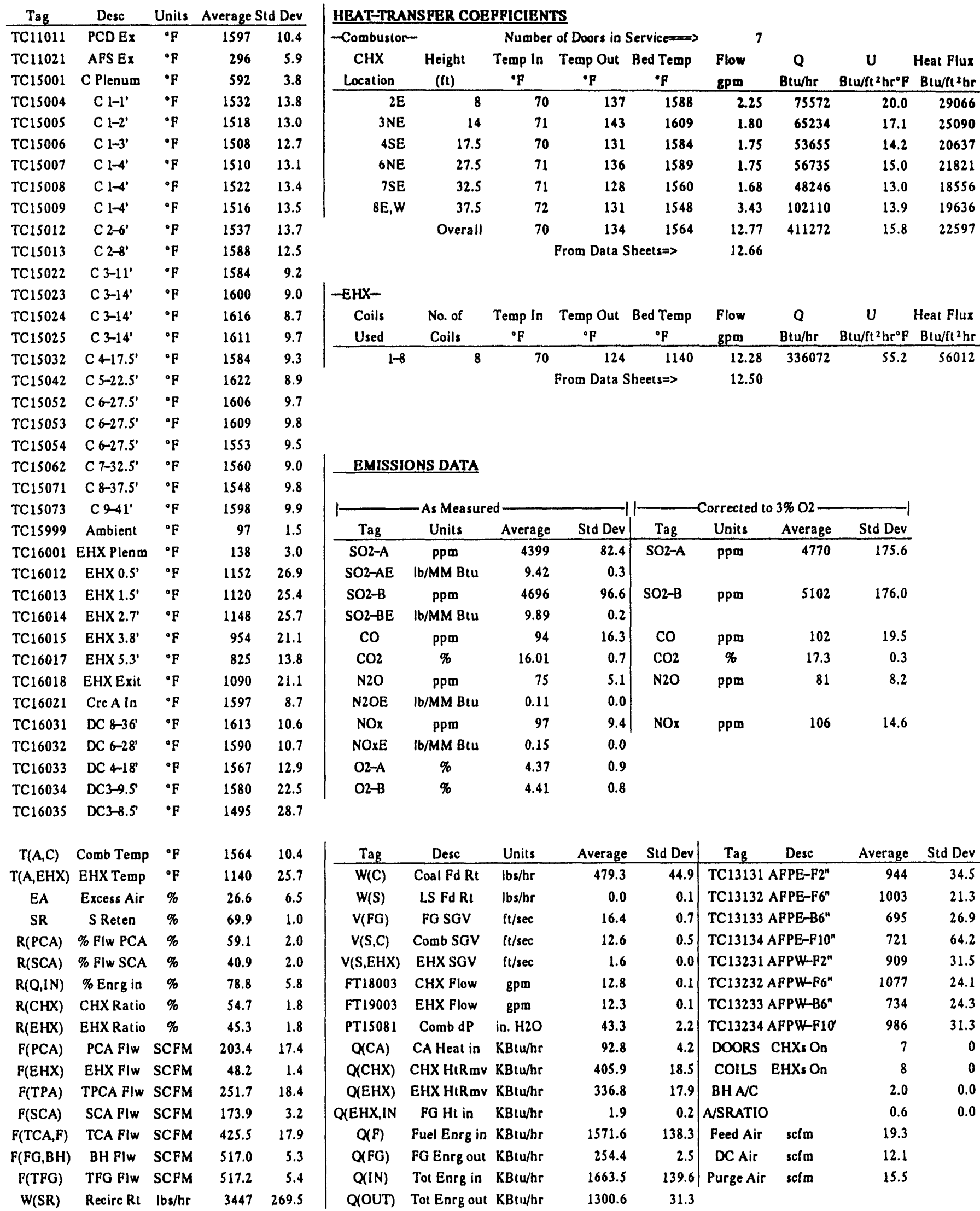




\section{APPENDIX F}

DESIGN, CONSTRUCTION, AND SYSTEM MODIFICATIONS 


\section{TABLE OF CONTENTS}

Page

LIST OF FIGURES $\ldots \ldots \ldots \ldots \ldots \ldots \ldots \ldots \ldots \ldots \ldots \ldots \ldots \ldots$ Fii

DESIGN AND CONSTRUCTION $\ldots \ldots \ldots \ldots \ldots \ldots \ldots \ldots \ldots \ldots \ldots \ldots \ldots$

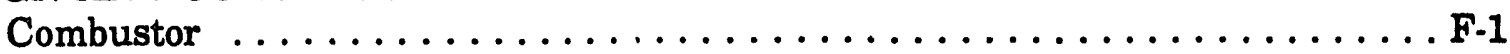

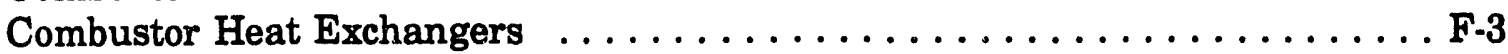

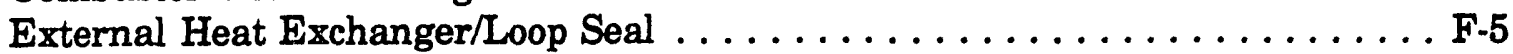

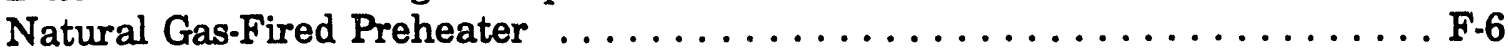

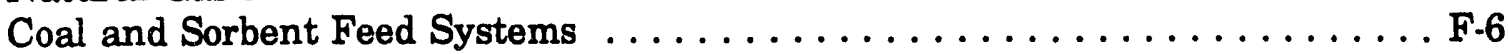

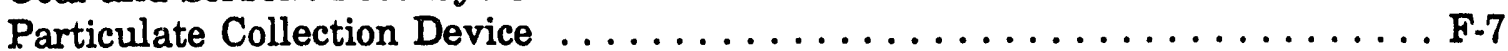

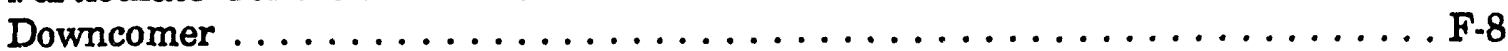

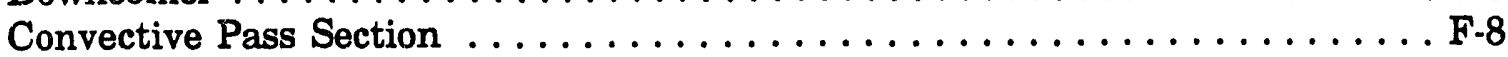

Flue Gas System . . . . . . . . . . . . . . . . . . . F-9

SYSTEM MODIFICATIONS $\ldots \ldots \ldots \ldots \ldots \ldots \ldots \ldots \ldots \ldots \ldots \ldots \ldots \ldots$

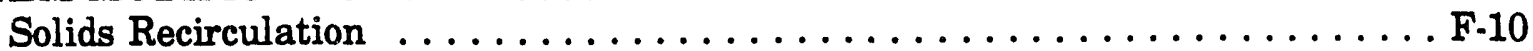

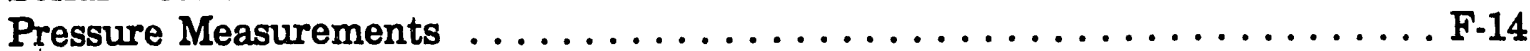

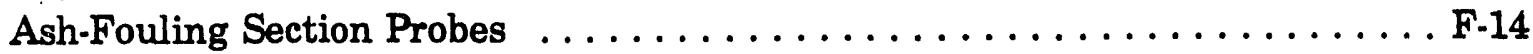

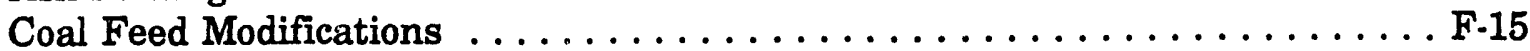

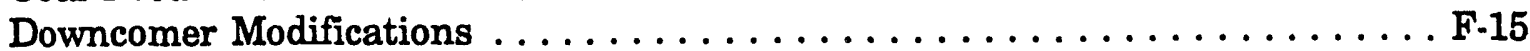

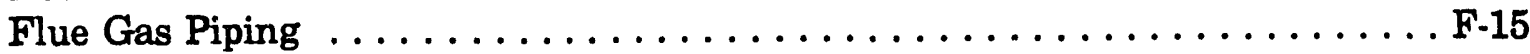

Heat-Transfer Surface . . . . . . . . . . . . . . . . . . F-16 


\section{LIST OF FIGURES}

Figure

Page

F-1 Original configuration of the EERC CFB system $\ldots \ldots \ldots \ldots \ldots \ldots \ldots$. . .

F-2 Cross-sectional views showing details of construction for the combustor sections, particulate collection device, ash-fouling section, downcomer sections, and the external heat exchanger . . . . . . . . . F-2

F-3 Details of construction for installation of removable water-cooled heat exchangers in refractory-lined combustor sections . . . . . . . . F.4

F-4 A schematic of chevron impaction collector configuration $\ldots \ldots \ldots \ldots \ldots$ F-8

F-5 Collector configuration used for Salt Creek bituminous testing $\ldots \ldots \ldots \ldots$ F-10

F-6 Chevron collector configuration used for Center lignite testing . . . . . . . F-12

F-7 Cross-sectional views showing details of construction for the combustor section, primary cyclone, ash-fouling section, downcomer section, and external heat exchanger $\ldots \ldots \ldots \ldots \ldots \ldots \ldots \ldots \ldots$ F-13

F-8 Details of construction for ash-fouling probes located in the ash-fouling section $\ldots \ldots \ldots \ldots \ldots \ldots \ldots \ldots \ldots \ldots \ldots$ F-14

F-9 Current configuration of the EERC CFB system $\ldots \ldots \ldots \ldots \ldots \ldots \ldots \ldots$ 


\section{DESIGN, CONSTRUCTION, AND SYSTEM MODIFICATIONS}

\section{DESIGN AND CONSTRUCTION}

\section{Combustor}

Figures F-1 and F-2 show the configuration of the system at the completion of shakedown in October 1989. As the project progressed, it was determined that, from a scaling point of view, it was desirable to construct the combustor as large as possible. The fluid dynamics of a full-scale system are more closely simulated as the pilot-scale size increases. A combustor with circular cross section was selected to have the smallest ratio of surface area to volume, resulting in the least amount of heat loss and the least amount of wall surface to affect the fluid dynamics for a given combustor cross-sectional area.

The final size determination of the CFB system was subject to the following additional constraints: cost of construction, space limitations of the construction site, and operational costs. As the combustor cross section increases, the size of auxiliary equipment increases proportionally, as do fuel requirements. The cost of operation increases somewhat, but is not a significant factor. Over the range of sizes considered (12inch to 20-inch inside diameter), manpower requirements needed to operate the system were not expected to vary significantly. A combustor with an inside diameter of 20 inches was selected as the upper size limit that could be constructed based upon budget constraints, EERC coal-handling capabilities, and structural constraints.

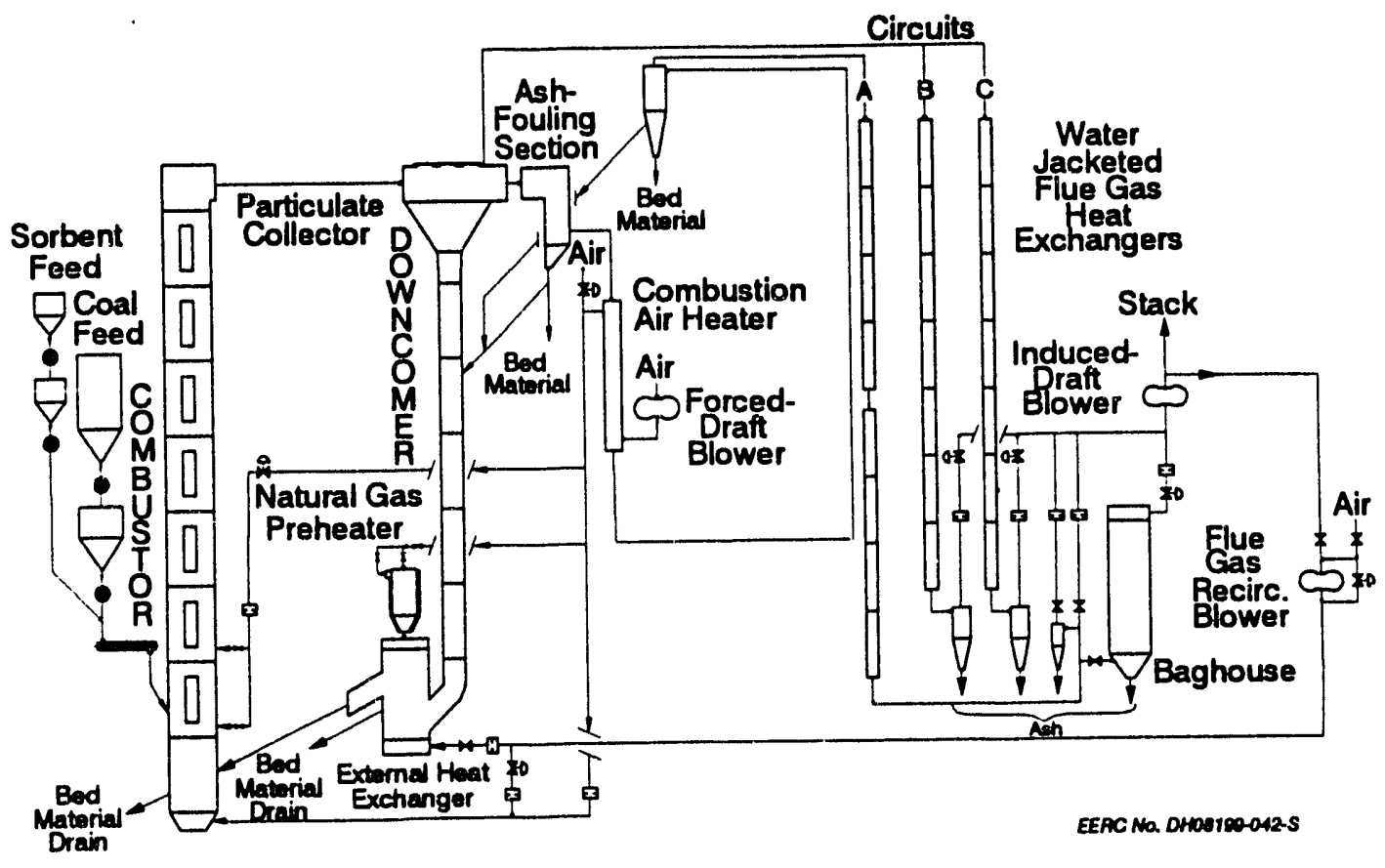

Figure F-1. Original configuration of the EERC CFB system. 


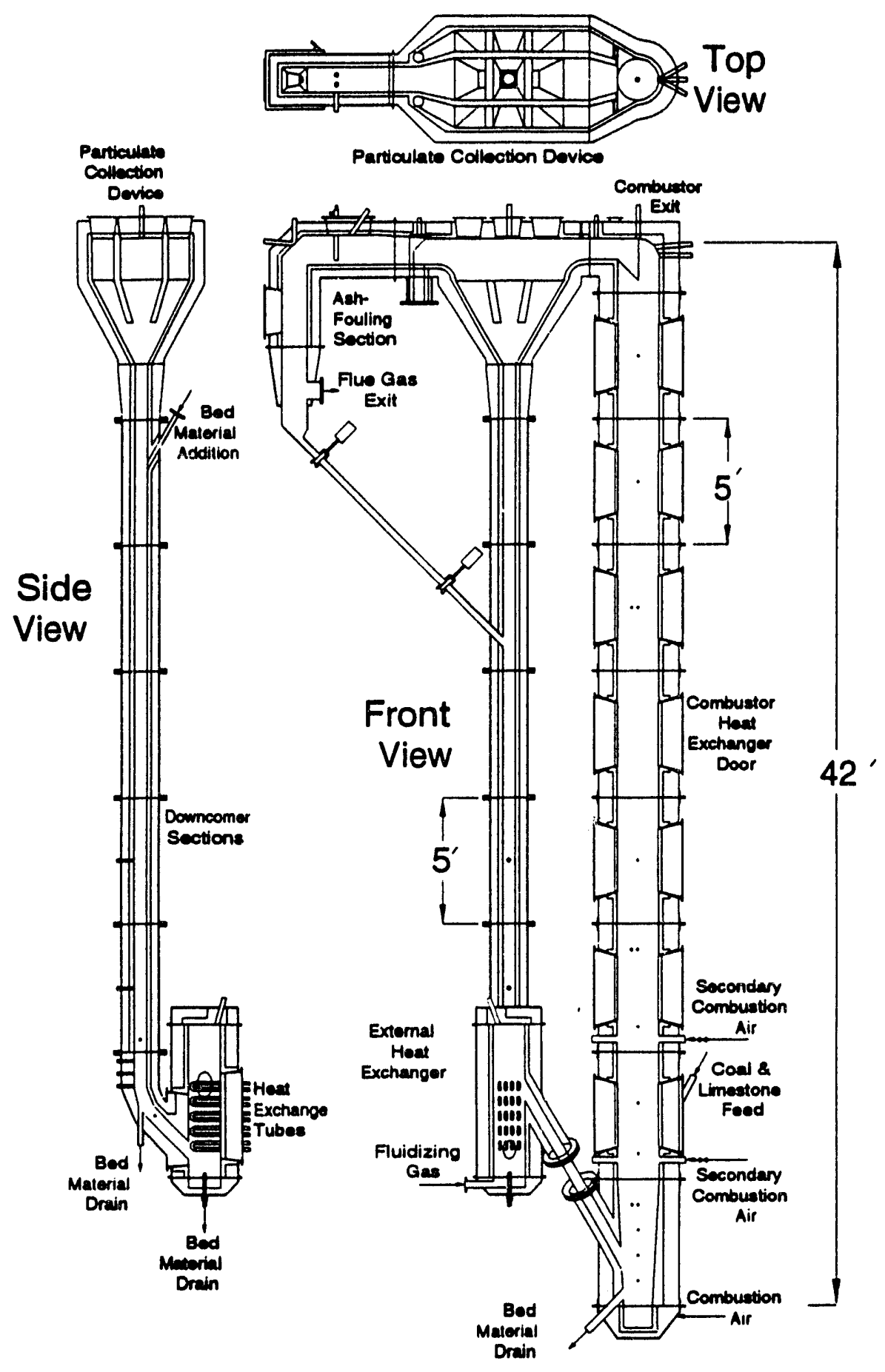

Figure F-2. Cross-sectional views showing details of construction for the combustor sections, particulate collection device, ash-fouling section, downcomer sections, and the external heat exchanger. 
The height of the combustor needed to be adequate for any physical and/or chemical reactions to occur. The combustor height also had to be sufficient to allow for the required amount of heat-transfer surface area to obtain a representative temperature profile throughout the combustor which would be comparable to a large-scale system. When operating at velocities similar to a large-scale system, height is the only factor affecting gas residence time. The height and diameter affect solids residence time in the combustor when operating at similar velocities and with the same bed particle-size distribution. Solids residence time affects heat transfer, sulfur capture, and carbon combustion efficiency. During operation there is a high concentration of solids along the combustor walls with a much more dilute phase in the core of the combustor. As the combustor cross section increases, the wall surface area to combustor volume ratio decreases, resulting in a corresponding decrease in overall solids density. In other words, there are more wall effects with a smaller combustor. So, to obtain similar overall solids density in a smaller system over its entire height, it is necessary to have a decreased height.

No acceptable mathematical criterion was found to determine what the appropriate height should be. The temperature distribution throughout the length of a pilot-scale CF P.C is related to the amount of refractory insulation and the arrangement of heattransfer surface. A height of $\mathbf{4 2}$ feet from distributor plate to the top of the combustor exit was selected as sufficient for installation of adequate heat-transfer surface and as a reasonable compromise of gas residence time and solids distribution in the combustor.

Combustor sections were fabricated from 5 -foot by 10 -foot sheets of $3 / 8$-inch-thick carbon steel resulting in an outside shell diameter of 381/2 inches for each 5-foot-high section. Two inches of abrasion-resistant refractory, along with seven inches of insulating refractory, result in an operational skin temperature for the combustor of less than $200^{\circ} \mathrm{F}$. Similar refractory installation was used for all other refractory-lined components. The refractory used was supplied by Premier Refractories and Chemicals, Inc. Secondary air addition was designed to be introduced at three separate levels through combustor Sections 1, 2, or 3. It is introduced normal to the combustor gas stream through four 3inch ports. Although it would be a significant modification, the combustor was designed so it is possible to alter the height by the removal or addition of combustor and downcomer sections.

\section{Combustor Heat Exchangers}

In some CFB boilers, only the waterwall heat-transfer surface extracts the heat generated in the combustor. Load is managed by varying bed temperatures, velocities, and excess air levels and, in some systems, by controlling the solids recirculation ratio. Other CFB boilers incorporate an external heat exchanger to provide added operational flexibility at the expense of additional initial capital expenditure. Design objectives were to have sufficient heat-transfer surface in the combustor and external heat exchanger to operate over the specified range of design conditions and, under certain conditions, have the option to operate with or without the use of external heat exchange.

To provide the required heat transfer in the combustor over the design conditions selected, it was calculated that a maximum of 14 water-cooled heat-transfer panels would be adequate. The water-cooled combustor heat exchangers used, as shown in Figure F-3, have a geometry similar to that of a waterwall surface. Heat-transfer surface in the 


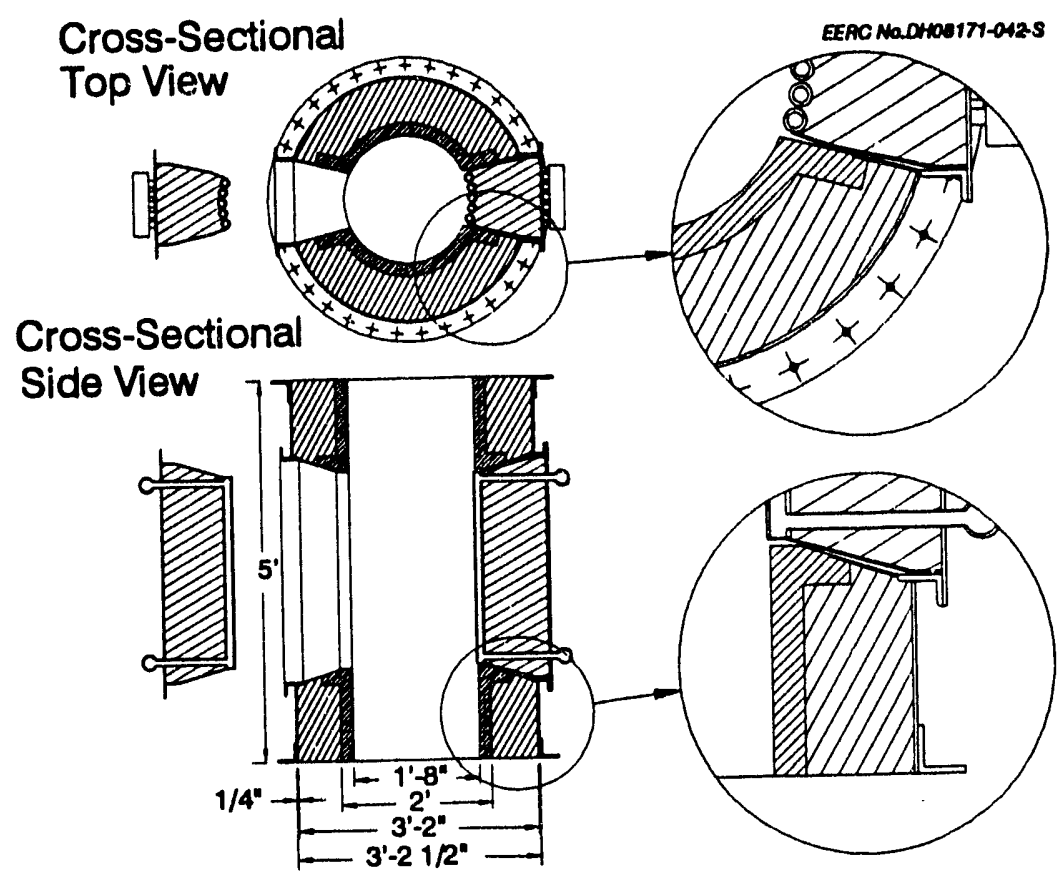

Figure F-3. Details of construction for installation of removable water-cooled heat exchangers in refractory-lined combustor sections.

combustor is controlled by regulating the flow of water through the heat-transfer panels. Air is used to cool the panels prior to the introduction of water to reduce thermal shock. The inlet and exit water temperatures for each panel are monitored and used to determine individual heat-transfer rates. Total water flow to the heat exchangers in the service is monitored with a turbine flowmeter. The water flow to individual heat exchange panels is controlled by globe valves and measured with rotameters.

Each heat exchange panel consists of five $2 \frac{1}{2}$-foot-long tubes with $1 \frac{1}{2}$-inch outside diameters. Type 304 stainless steel tubes were used with a standard 0.120-inch tube wall thickness. An alternate material considered was type 310 stainless steel, which is better suited to high-temperature operation, but significantly more expensive. Thus far, the 304 stainless steel has performed adequately. Parallel flow (as opposed to series flow) through the tubes of an individual panel was selected to result in less pressure drop when using cooling fluids other than water. Type 304 stainless steel inlet manifolds were designed and installed to supply uniform distribution of either air or water to the heat-transfer tubes. Type 304 stainless steel headers connect the inlet air/water piping to the inlet manifolds. Each inlet header contains an internal cylinder into which two sets of diametrically opposed holes have been drilled along its length. The holes on one side of the cylinder are 1-inch in diameter and allow air to flow into the heat-transfer tubes with as little restriction as possible. When the internal cylinder is rotated $180^{\circ}$, a set of $1 / 8-$ inch-diameter orifices line up with the manifold and ensure uniform water distribution to each of the five heat exchange tubes in the panel. The exit header is 2 -inch schedule 40 , type 304 stainless steel pipe. 
For the installation of heat-transfer surface in a circulating fluidized-bed system, consideration must be given to the potential for erosion and the penetration of particulates into almost any size opening. The particulate, after cycles of heating and cooling, can crack and fracture the refractory surfaces that it has penetrated. The heat exchange panels were designed so that the back side of the tubes are totally sealed from the inside combustor environment. There are 1/8-inch gaps between each heat-transfer tube in a panel which are welded shut. The outer metal frame around the tubes is composed of thin gage stainless steel sheeting and is welded to the tubes and outer door flange. When installed, the outer edges of the panel are approximately $1 / 2$ inch away from the inside refractory, opening into the combustor on all four sides. The stainless steel panel frame is constructed such that the 1/2-inch gap at the heat exchange panel (inner surface of the combustor) is reduced to approximately $1 / 8$ inch within a distance of about

3 inches from the inside combustor wall. Based upon input from Premier Refractories and Chemicals, Inc., this is a large enough gap so that particulates that do penetrate tend to fall back out and not cause problems. Pourable insulation is installed behind the tubes. The tube panels are slightly recessed in the doors to limit their exposure to erosion.

Shakedown and initial operation was with eight water-cooled heat exchange panels. The initial heat exchange configuration used was two heat exchange panels in each of combustor Sections 2 and 8 and a single panel in each of Sections 3, 4, 6, and 7 on the same side of the combustor. Blank refractory doors were installed in the other six locations.

\section{External Heat Exchanger/Loop Seal}

The option to remove additional heat in the external heat exchanger was installed to simulate CFB boilers that incorporate that type of heat removal. The external heat exchanger was designed to serve the dual purpose of heat removal and recirculating solids back into the combustor. It is refractory-lined with inside dimensions of 15 inches square by six feet high and is a bubbling fluidized bed with an operational superficial gas velocity of about $1.5 \mathrm{ft} / \mathrm{sec}$. The external heat exchanger was sized so it would be large enough for the installation of adequate heat-transfer surface and small enough so that excessive amounts of fluidizing gas would not be $\mathrm{r}$ zquired.

Solids from the downcomer enter the external heat exchanger/loop seal near the bottom of the 15-inch-square fluidized bed at an angle of 45 degrees. The recirculating solids are fluidized upward past the heat-transfer tubes which are described in detail below. The solids return line to the combustor is located 3 feet above the external heat exchanger distributor plate, has an inside diameter of 5 inches, and slopes down at $60^{\circ}$ into combustor Section 1. There is an additional three feet oi freeboard above the bubbling fluidized bed.

The heat exchange tubes are of a U-tube type configuration constructed out of 1-inch schedule 40, type 304 stainless steel pipe. They are installed in a removable door, so that they can be periodically replaced if required. The amount of heat removal is controlled by regulating the flow of water to the water-cooled heat exchange tubes. As originally designed and installed, twenty heat exchange tubes were arranged in the following configurations: two using a single tube, two with two tubes in series, two with three tubes in series, and two with four heat exchange tubes connected in series. There is a single inlet thermocouple in the inlet manifold, individual exit thermocouples for each of 
the eight sets of heat-transfer tubes, and also an exit thermocouple in the outlet manifold. Total water flow is measured with an in-line turbine flowmeter, and individual flow rates to each of the eight groups of tubes are controlled by globe valves and measured with rotameters.

\section{Natural Gas-Fired Preheater}

A means of preheating the combustor was required to bring the bed material to a sufficiently high temperature so that the coal would ignite when introduced into the combustor. Natural gas was selected for preheat due to its availability at the installation site. The preheater was sized to supply $600,000 \mathrm{Btu} / \mathrm{hr}$ of energy. The preheater has inner and outer cylindrical shelis constructed of type 304 stainless steel sheeting. The natural gas burner is bolted to the top of the external heat exchanger and fires downward. Air circulates through the outer, baffled cooling jacket to prevent the inner shell from overheating. The hot combustion gas from the burner combines with the cooling jacket air as it flows into the top of the external heat exchanger at approximately $1200^{\mathrm{C}} \mathrm{F}$. The hot gas then flows downward through the solids return into the combustor. The bed material present in the external heat exchanger is not fluidized during preheat to prevent any of the hot preheat gas from flowing upward through the downcomer. The solids in the combustor are preheated to at least $800^{\circ} \mathrm{F}$ before coal feed is initiated.

Air is supplied to the natural gas-fired preheater through a 4-inch bypass line from the forced-draft blower. A butterfly valve is used to isolate the preheater on the inlet side when not in use. A knife gate valve between the preheater and the external heat exchanger isolates the exit side. Two additional butterfly valves are installed in the lines to the burner and to the cooling jacket for control purposes. Natural gas flow is measured and controlled with a rotameter. A flame safety system is present to shut off the flow of natural gas if any of the following situations occur: 1) a flame is not present in the preheater, 2) combustion air is not being supplied to the preheat burner or cooling jacket, or 3 ) the burner air pressure is greater than the natural gas pressure being supplied to the preheater.

\section{Coal and Sorbent Feed Systems}

The EERC has on-site facilities for the preparation and storage of coal and sorbent brought in by truck or rail. Coal and sorbent can be crushed and sized as required before the start of a test and placed in transportable storage hoppers or in storage tote bins. From a survey by Burns \& McDonnell Engineering Company, the highest estimated coal size for use in a CFB system is 2 inches. This would be too large for most CFB systems, but is likely the size that Riley Stoker uses in its multisolids combustor. The lowest estimated coal size is 0.25 inches. The estimuted size range for limestone varied from 0.0059 inches to 0.125 inches.

The coal feed system was designed to handle at least $1000 \mathrm{lb} / \mathrm{hr}$ of up to minus 3/4-inch coal, and the sorbent feed system was designed for a maximum feed rate of 500 $\mathrm{lb} / \mathrm{hr}$ of material sized to miuus $1 / 4 \mathrm{inch}$. Limestone is generally the sorbent of choice for use as both a bed material and for sulfur capture. Some systems considered for controlling and measuring feed rates included various types of weigh belt feeders and lossin-weight systems incorporating screw feeders. A more cost-effective method was selected for controlling and measuring feed rates. Feed hoppers suspended from load cells measure weigist loss, and rotary valves, regulated by electronic speed controllers, govern feed rates. 
Coal and limestone are transported to the system in movable storage hoppers. The coal storage hoppers have net capacities of 3000 pounds. The two sorbent storage hoppers have 1000-lb net capacities. Coal is transferred through a 6 -inch knife gate valve into the coal weigh hopper, and limestone is transferred through a 4-inch rotary valve into the sorbent weigh hopper. There is one 6 -inch and one 4-inch rotary valve located below the coal and sorbent weigh hoppers, respectively, for controlling the coal and limestone feed rates. Each of the rotary valves is connected to electronic speed controllers.

The coal and limestone feed into a common 6-inch-square duct. A 3-inch-diameter stainless steel auger transports the coal/sorbent mixture horizontally to a 4-inch pipe. The top 2 feet of the 4-inch pipe is oriented vertically and then slopes into the combustor at an angle of 60 degrees. The feed pipe enters the combustor in Section 2 at a level of 6-feet above the combustor distributor plate. The gravity feed into the combustor has a pneumatic assist to help prevent plugging of the inclined section of 4-inch pipe.

\section{Particulate Collection Device}

The primary design objective for the particulate collection device was to collect solids of a representative cut point (the size of particles for which $50 \%$ of the median diameter of particles collected would be collected) similar to commercial systems. The size of the solids retained in the system is dependent upon the efficiency of the collection device used. A design cut point of 20 to 30 microns was calculated as the initial operational target for the pilot plant system such that the capture would be comparable to a full-scale system.

In general, small pilot plant cyclones are much more efficient in relation to the large cyclones used in full-scale CFB boilers, when compared at similar operating conditions, due to geometric factors. Operation of a pilot-scale CFB with a more efficient collector should result in higher combustion efficiency and better sulfur capture than is possible with a full-scale system. It was decided to design a collector that would be flexible enough to operate over a wide range of operational velocities and have the potential for adjusting the cut size of the particulate collected by the use of different geometries within the collector. The design selected was a particle impaction device, and an illustration of a typical set of collectors, as constructed and used, is shown in Figure F-4.

There were three ducts, referred to as Ducts A, B, and C, in the collector for parallel use when operating at either low, intermediate, or high velocities, respectively. Three removable doors were placed in the top of each of the three ducts to permit the placement of impaction plates for the collection of solids. A cut point of 200 microns was calculated for operation with no obstructions in the ducts. Different internal configurations could be installed in the ducts to allow various cut points to be collected. Slide valves at the entrance of Ducts $B$ and $C$ were in place to isolate those ducts when not in use. The center duct (Duct $A$ ) was the primary duct used at low-to-intermediate combustor velocities. Ducts $B$ and $C$ could be brought on-line one at a time as flows were increased in the combustor for different test conditions. Collector performance, modifications to the collector, and the subsequent replacement with a cyclone are discussed in later sections. 

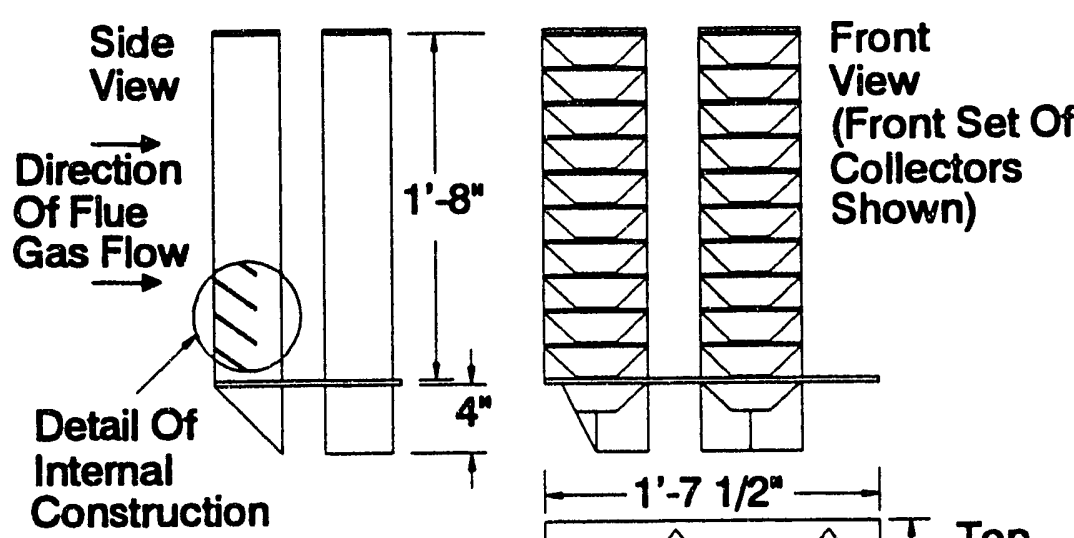

Construction

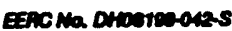

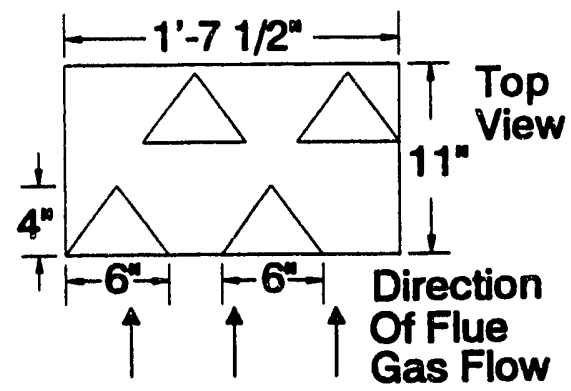

Figure F-4. A schematic of chevron impaction collector configuration.

\section{Downcomer}

Solids collected by the particulate collection device enter the downcomer, where they travel downward into the external heat exchanger. Downcomer sections were constructed from 18-inch schedule 10 carbon steel pipe, are refractory-lined with an inside diameter of 6 inches, and are 5 feet in length. There is a 2-inch layer of abrasion-resistant refractory on the inside, with $3 \%$ inches of insulating refractory between the hard refractory and the pipe. Aeration can be added at various heights in the downcomer, if required, to keep the solids moving more uniformly into the external heat exchanger. An inclined pipe is located in the top section of the downcomer for the addition of bed material at the start of the run and also during operation, if required.

\section{Convective Pass Section}

The operating temperatures of CFB boilers are generally below the temperatures for which ash deposition, fouling, and/or slagging occur for most coals. Operation of a CFB on coals with alkaline ash properties may cause convective pass ash deposition. The CFBC pilot plant ash-fouling section was designed to indicate the potential for ash deposition in the convective pass region of a CFB boiler. The geometry of the ash-fouling section is based upon experience gained from operation of the EERC pulverized coal-fired ash-fouling furnace. The ash-fouling section has a carbon steel shell, is refractory-lined, and was installed at the exit of Duct $A$ of the particulate collection device.

Ash-fouling probes were designed for installation into the ash-fouling hopper to simulate boiler tube surface. The probes were air-cooled to maintain surface temperatures 
typical of convective pass boiler tubes, and the metal surface temperatures were monitored by thermocouples. The first pair of probes were designed for installation in a removable door in the horizontal portion of the ash-fouling section (25- to $30-\mathrm{ft} / \mathrm{sec}$ nominal gas velocity) and were to be used for assessing potential ash deposition of sticky particles. The vertical portion of the ash-fouling section was designed for the installation of three pair of probes in a removable door to assess the tendency for ash to accumulate as a result of convective pass geometry. Pressure drop across the probe bank would be monitored to assess ash buildup during operation. Initial operation was with no ash-fouling probes in place (blank doors installed). A collection hopper is located at the bottom of the vertical duct of the ash-fouling section just upstream of the horizontal flue gas exit pipe. Due to the abrupt change in gas direction at the flue gas exit, some ash particles leave the gas stream and are collected in the ash-fouling section hopper.

\section{Flue Gas System}

The flue gas system was divided into three circuits, A, B, and C, to have the flexibility to operate over a wide range of operational velocities (13 to $23 \mathrm{ft} / \mathrm{sec}$ ) at operational combustion temperatures up to $1650^{\circ} \mathrm{F}$. Circuit $A$ is the primary circuit that remains in operation during all periods. It includes a shell-and-tube heat exchanger (combustion air heater) to preheat combustion air to approximately $500^{\circ} \mathrm{F}$, eight waterjacketed heat exchangers to reduce the flue gas temperature to $250^{\circ}$ to $400^{\circ} \mathrm{F}$ before entering the baghouse, and a pulse-jet baghouse for particulate emissions control. The combustion air heater operates only on the flue gas exiting the ash-fouling section, approximately 40 percent of the original design maximum gas flow. That is a sufficient quantity of flue gas to preheat the combustion air over all operating conditions.

A pulse-jet baghouse is in place to accommodate all of the Circuit A flue gas flow. Flue gas temperature into the baghouse is maintained from $250^{\circ}$ to $400^{\circ} \mathrm{F}$ during operation. Typical operation is at an air-to-cloth ratio of between 2 to 3 . Due to the confined area available for installation, a very compact baghouse, with inside dimensions of 2-foot 6-inch, by 3-foot 1 -inch plan area and 15 feet high was designed. The baghouse contains 20 woven fiiverglass bags five inches in diameter by 10 feet long. The bags are divided up into four sets of five bags each for pulse-cleaning purposes. Pulse duration and the interval between pulses is controlled by the data acquisition system. A bypass around the baghouse is used during start-up when preheating on natural gas to ensure that moisture will not condense out on the bags. An 18-inch-diameter stainless steel cyclone in the bypass section removes particulates when the baghouse bypass is open.

Circuits $B$ and $C$ each have seven water-jacketed heat exchangers to cool the flue gas and a 14-inch-diameter stainless steel cyclone for particulate removal. Some control of the exit flue gas temperature from any of the flue gas circuits is possible by turning water flow on or off to the water-jacketed sections. The amount of flue gas flow through an individual circuit is controlled by the use of 4 -inch flow control valves in Circuits B and C. All of the flue gas then combines into a single duct constructed of 8-inch stainless steel tubing and flows into the induced-draft blower, a positive displacement rotary blower. The rotational speed of the induced-draft blower is regulated by an electronic speed controller. A zero pressure balance point near the exit of the combustor is used as control for the speed of the induced-draft blower. 


\section{SYSTEM MODIFICATIONS}

Numerous modifications have been made to the system based on experiences with different coals, limestones, and operating conditions. The modifications made to each system are described below.

\section{Solids Recirculation}

Two initial modifications were made to the solids recirculation system. First, the capability of adding solids from the ash-fouling section hopper back into the downcomer was added. Then, the 18-inch baghouse bypass cyclone was relocated to recycle additional fines back into the downcomer. Both of these recycle loops contain two pneumatically actuated knife gate valves to prevent the bypass of flue gas from the downcomer.

Based upon results obtained during shakedown tests, cold-flow testing was performed to evaluate various impaction collection device configurations. Chevron collectors with internally sloped deflector plates were selected to be used in the particulate collection device during the Salt Creek test. The chevron collectors feature a geometry, illustrated in Figure F-4, that helps force the particulate to the back of the collectors. An opening along the back of each collector allows particulates to flow downward into the collection hoppers that feed into the downcomer. Three stages of collectors were utilized in Duct A during this test, shown in Figure F-5. The first two stages were intended to capture the majority of the particulates, while the third stage was designed to capture smaller particles. The first stage used four chevron collectors, two in

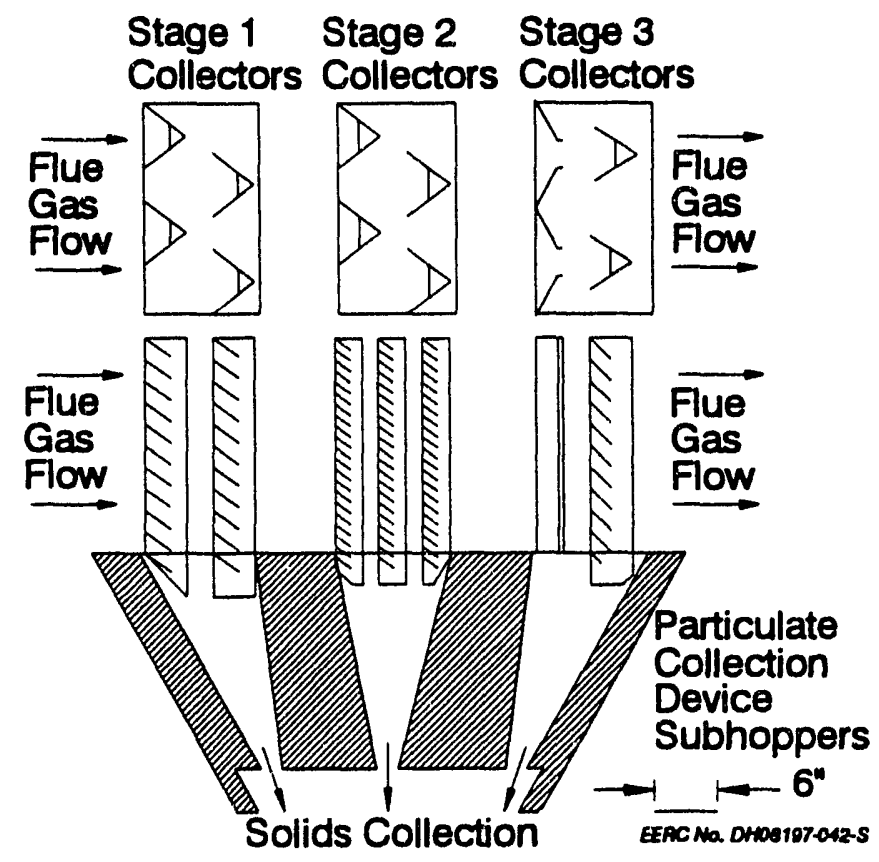

Figure F-5. Collector configuration used for Salt Creek bituminous testing. 
each of two rows. The second stage had a total of twelve chevron collectors, four in each of three rows. The third stage had a single row of four chevron collectors, each with a ventury-type configuration as an inlet to accelerate the flow into the collectors. Additional hard refractory was also installed in the Duct A hoppers to reduce the potential for flue gas to bypass between the various stages of chevron collectors.

At the conclusion of the two weeks of testing, the three sets of collectors were removed for inspection. It appeared that all four collectors in stage one had been operating properly. In the second stage, the four collectors in the back row were plugged with fine bed material, while the first two rows appeared to have been operating with some slight blockages at the top and bottom. The third stage of collectors were entirely plugged with bed material fines. The outer two inlet venturies on stage three had also warped, blocking much of the flow to the two outside collectors. It appears that a combination of factors caused the blinding of the back row of stage two and all of the stage three collectors. All of the stage two and stage three collectors were one-half the size of the ones used in stage one, resulting in a smaller exit to the collection hoppers. All of the individual collectors that drained onto the back slope of the hopper plugged off. There did not appear to be sufficient spacing between the collector drains and the refractory to allow solids to flow through. The stage three inlet venturies funneled all of the remaining fines into four collectors, overloading this stage with more material than could be handled.

Operational temperatures in the downcomer remained high throughout the testing, indicating good collector performance even though half of the chevron collectors were probably plugged off for most of the test. The design used for this test was not able to handle the large amount of recirculating fines. The recycle of the secondary cyclone catch to the downcomer may have influenced the plugging problems noted above. Some of the plugging problems encountered during this test were specific to the limestone used: it was a smaller size than had been originally specified for operation with this pilot facility and was extremely cohesive.

A modified configuration was used for Center lignite testing, shown in Figure F-6, to alleviate some of the problems that had been encountered. The stage one collectore did not change from the original design and were retained for use. Newly constructed stage two and stage three chevron collectors were slightly larger than the stage one collectors and had larger openings in the back for collected material to drain through, and the chevron deflector plates were positioned at a steeper angle $\left(50^{\circ}\right.$, compared to $35^{\circ}$ in the original design) to help reduce plugging. Stage two used the same layout as stage one with a total of four chevron collectors arranged in two rows of two. Stage three had the flow funneled through venturies into two chevron collectors.

At the conclusion of the first part of testing on Center lignite (following Test 6) all three sets of collectors were removed for inspection. In stage one, there was one chevron collector totally plugged and the remaining three were partially plugged to the degree that they did not appear to be capable of capturing solids for recirculation. Although the hopper directly below stage two was plugged, three of the four collectors from stage two were in good condition and appeared to have been available for particulate collection. It is not known if the hopper plugged off as a result of shutdown, or if this condition had occurred earlier in the run. Both of the collectors in stage three were totally plugged with bed material fines, as had occurred in the previous test. The stage three venturies were 


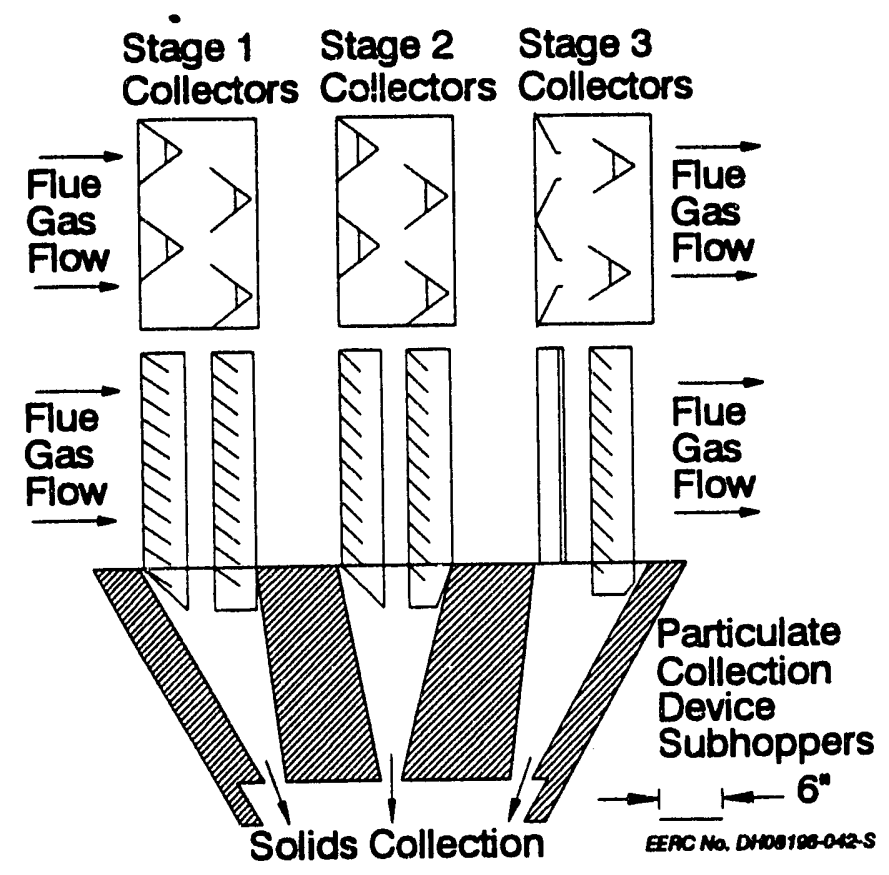

Figure F-6. Chevron collector configuration used for Center lignite testing.

designed to force the majority of the remaining uncollected fines into the stage three collectors. This likely overloaded the stage three collectors with more fines than could be handled under the operating conditions which were used.

Operational temperatures in the downcomer remained high throughout the Center lignite test, indicating good collector performance. However, visual inspection of the particulate collection device at the end of the run indicated that the only operational collectors were in stage two, and these were feeding into a plugged hopper. Some material was collected in the ash-fouling hopper and by the 18-inch secondary cyclone and was reintroduced into the downcomer. Downcomer temperatures, and solids samples which were taken, indicated that the material from the ash-fouling hopper and secondary cyclone was only a small proportion of the total bed material collected for recirculation. Some of the plugging problems encountered were likely related to the coal ash generated from the combustion of a high-alkaline-ash lignite coal. Minor plugging of the type encountered during the Center lignite test would not be significant when using a largescale cyclone for particulate collection.

A number of simple modifications to the particulate collection device were considered to allow for more long-term, reliable operation. It was decided at this point that a more prudent way to proceed was to replace the particulate collection device with a refractory-lined cyclone collector. The cyclone which was designed, shown incorporated into the system in Figure F-7, had a calculated cut point of $10 \mu \mathrm{m}$ at nominal operating conditions of $16.0 \mathrm{ft} / \mathrm{sec}$ and $1550^{\circ} \mathrm{F}$. The actual operational cut point was significantly larger than the predicted value, as was seen with the secondary cyclone. The main features of the cyclone are a main body inside diameter of 25 inches, inlet dimensions of 


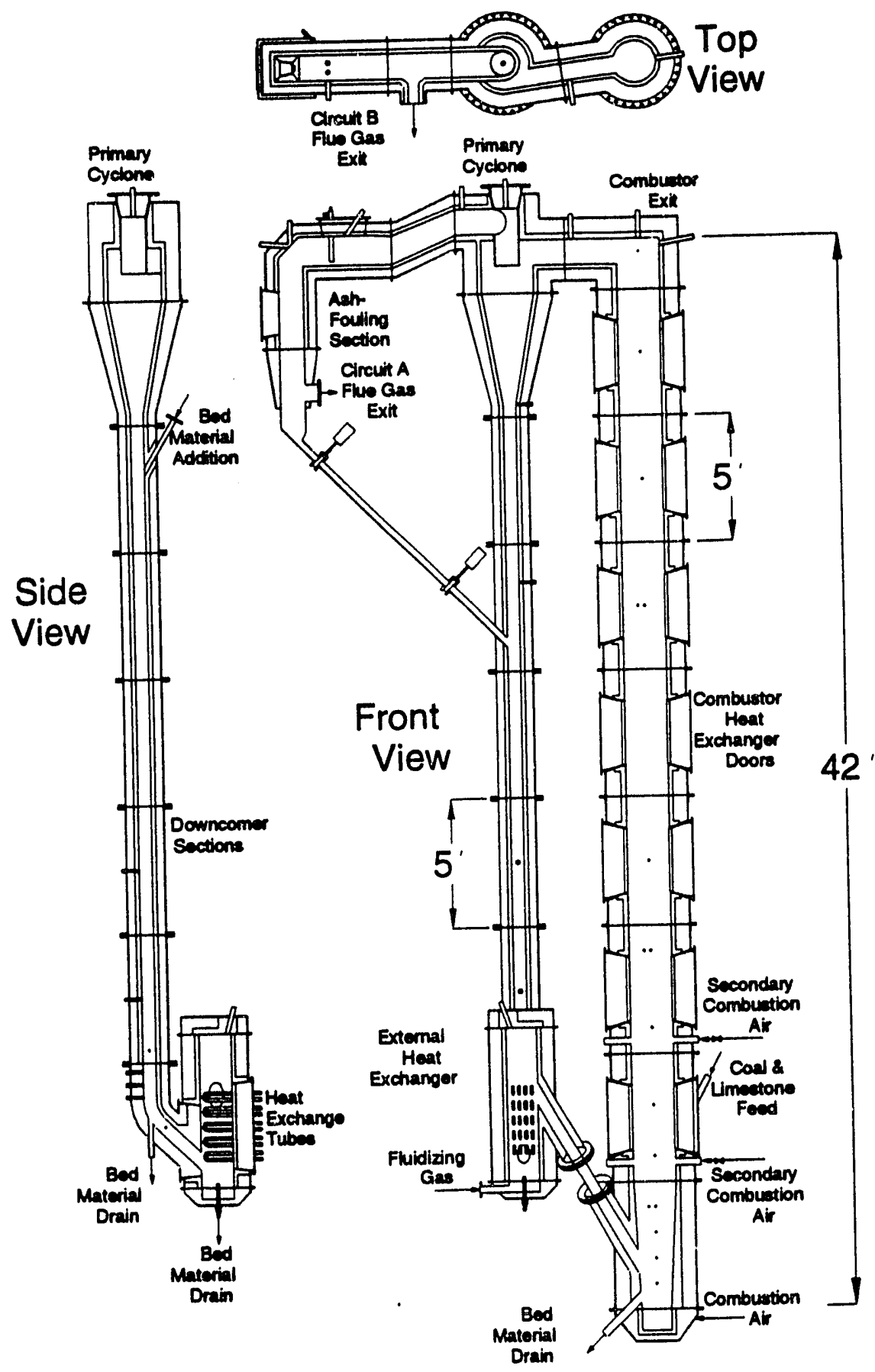

Figure F-7. Cross-sectional views showing details of construction for the combustor section, primary cyclone, ash-fouling section, downcomer section, and external heat exchanger.

8 inches wide by 12 inches high, and a 1.2-inch diameter type 810 stainless steel vortex finder. Operation with the 25 -inch primary cyclone was very successful. Operation was both with and without secondary cyclone catch recycle, depending upon the coal and limestone used. Further details are available in the individual test summaries located in the appendix. 
Visual inspections after each test consistently showed the refractory in the combustor and in the newly installed cyclone sections to be in very good shape. The type 310 stainless steel vortex finder in the primary cyclone shows no detectable warping or erosion.

\section{Pressure Measurements}

Pressure measurements are taken at various locations in the combustor, downcomer, external heat exchanger, and throughout the flue gas piping. Initially, 3/8-inch stainless steel tubes were installed as pressure probes through the refractory components. The probes at the bottom of the combustor and external heat exchanger would tend to plug off. Some initial success was obtained using a stainless steel screen welded to the ends of the probes, but soon the screens would blind so severely they could not be cleaned. During the Center lignite test, an air purge system was installed on all of the critical pressure tap locations in the combustor, downcomer, and external heat exchanger. The use of the continuous air purges turned out to be extremely successful in providing accurate pressure readings.

\section{Ash-Fouling Section Probes}

Two identical ash-fouling probes were designed for installation through the top removable door on the ash-fouling section. A detailed drawing of one of the probes and its relation to the ash-fouling duct is shown in Figure F-8. The ash-fouling probes were installed before the final week of testing with the Center lignite. The ash-fouling probes are air-cooled to maintain an outer skin temperature of approximately $1000^{\circ} \mathrm{F}$, as measured by four thermocouples in each probe. There are three thermocouples installed along the upstream side and a single thermocouple on the downstream side of each probe.

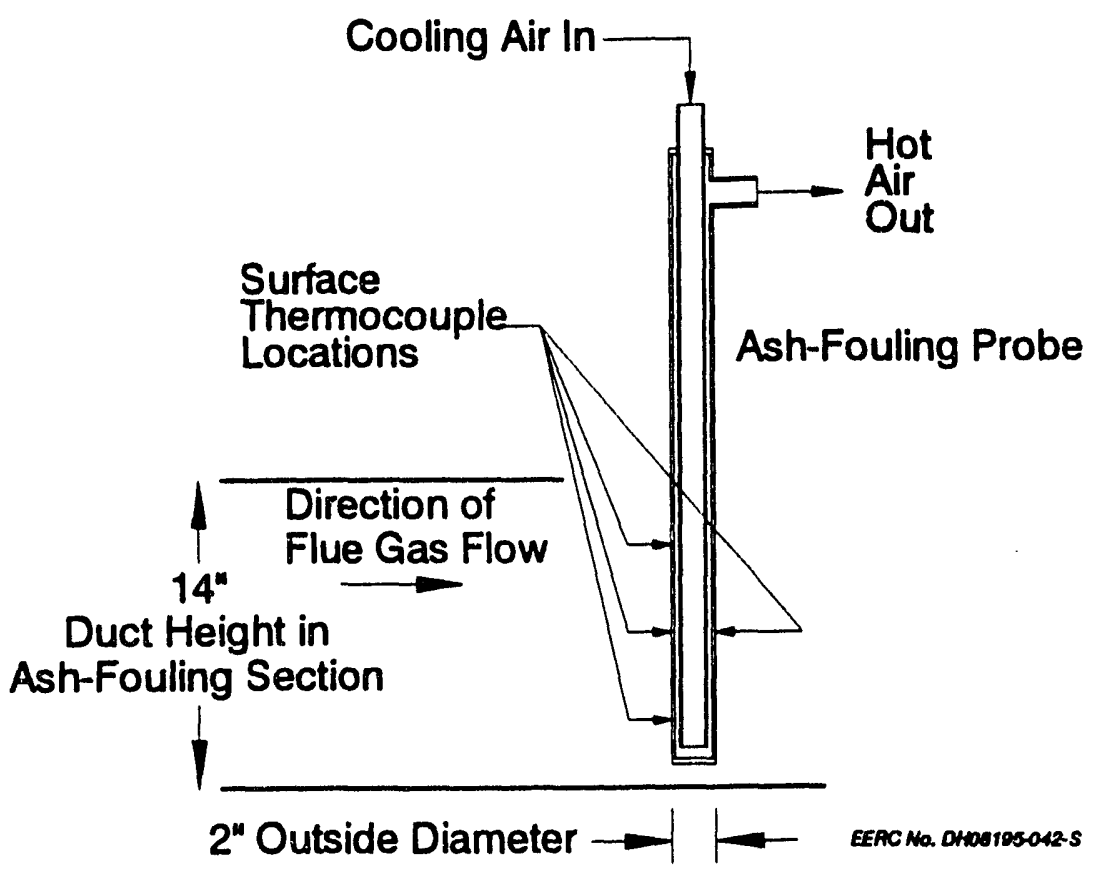

Figure F-8. Details of construction for ash-fouling probes located in the ash-fouling section. 


\section{Coal Feed Modifications}

Prior to testing with the Center lignite, a rotary seal valve was installed below the coal and limestone feed valves to limit the flow of flue gas from the combustor back into the feed system. This significantly reduced coal plugs that were occurring in the gravity feed line into the combustor.

Some temporary modifications were made on the coal feed hopper during testing with the Asian lignite. Numerous pressure taps were installed for purging around the bottom of the coal feed hopper. A series of timed purges about every 15 seconds at three different heights resulted in a sufficiently stable feed rate to complete the testing. Based upon the results of this testing, it was decided to modify the coal and limestone feed hoppers. The slope of the bottom sections was increased from 60 degrees to 75 degrees. Additionally, soft rubber sides were installed on the coal hopper to more easily collapse the coal in the hopper when it would bridge or rathole. This change was successful in reducing plugs in the hopper and allowed the identification of one final problem area. The pockets in the rotary valve used to meter the coal feed rate tended to become plugged over time, depending upon the characteristics of the coal being fed. To maintain stable coal feed rates, the rotational speed of the valve had to be periodically increased to compensate for the reduced rotary valve capacity. An air line was installed at the bottom of the rotary valve during Black Thunder testing to provide high-pressure pulses as needed. This was sufficient to open the rotary valve pockets as they plugged.

\section{Downcomer Modifications}

While testing with the Center lignite, using the newly installed 25-inch primary cyclone, a plug in the downcomer forced an early shutdown. Postrun inspection revealed a plug consisting of loosely packed fines in the downcomer and in the bottom cone of the cyclone. It appeared that with proper aeration, flow could have been maintained through the 6-inch-diameter downcomer. A manifold that allowed aeration to any of four different locations in the downcomer and at the bottom of the primary cyclone entrance was installed.

\section{Flue Gas Piping}

The initial system design required the ability to split the flue gas into three separate circuits. This was based upon the range of velocities over which the system was expected to operate and the calculation of superficial gas velocity from combustion air input. As a result of discussions at the sponsors meetings, the design range of operation remained the same, but it was decided to base the target superficial gas velocities on the total flue gas flow rate. This would result in the same actual velocity through the combustor regardless of the fuel being used. This also eliminated the need for the third flue gas circuit.

When the 25-inch primary cyclone was installed, both flue gas Circuits B and C were removed. Figure F-9 shows the current configuration of the entire CFB system. The capability to reinstall Circuit B still exists if required for testing at operational velocities greater than $18 \mathrm{ft} / \mathrm{sec}$. 


\section{Heat-Transfer Surface}

Prior to the Blacksville testing, four additional combustor heat exchange doors were fabricated and installed in the CFB. The added heat exchange capacity was installed in anticipation of the higher heat load which would be placed on the CFB during operation on the Blacksville bituminous coal. The new combustor heat exchange panels were added to Sections 3, 4, 5, and 7. Each of the new heat exchange doors were equipped with the same auxiliary hardware as the original doors.

During testing on the Blacksville coal, it was discovered that it was extremely difficult to bring the four-tube-in-series heat exchange coils in the external heat exchanger into service. The combination of high total pressure drop through the four coils and the relatively large amount of hot tube surface area would cause the initial flow of water to turn to steam, which would then reduce water flow and further increase the amount of steam generated. This usually resulted in the inability to successfully bring the heat exchanger on-line. The excessive steam which was generated would occasionally back up into the rotameters and also caused some breaks at soldered sweat fittings which were used at the time. Both situations were identified as safety hazards. All sweat fittings were subsequently replaced with stainless steel pipe and high-pressure compression fittings. The top four heat exchange tubes which made up one circuit were disconnected, since it was decided that they were located in the freeboard of the external heat exchanger and thus had a minimal effect on heat removal. The remaining four-tube-inseries heat exchanger was split into two sets of two-tube-in-series heat exchangers.

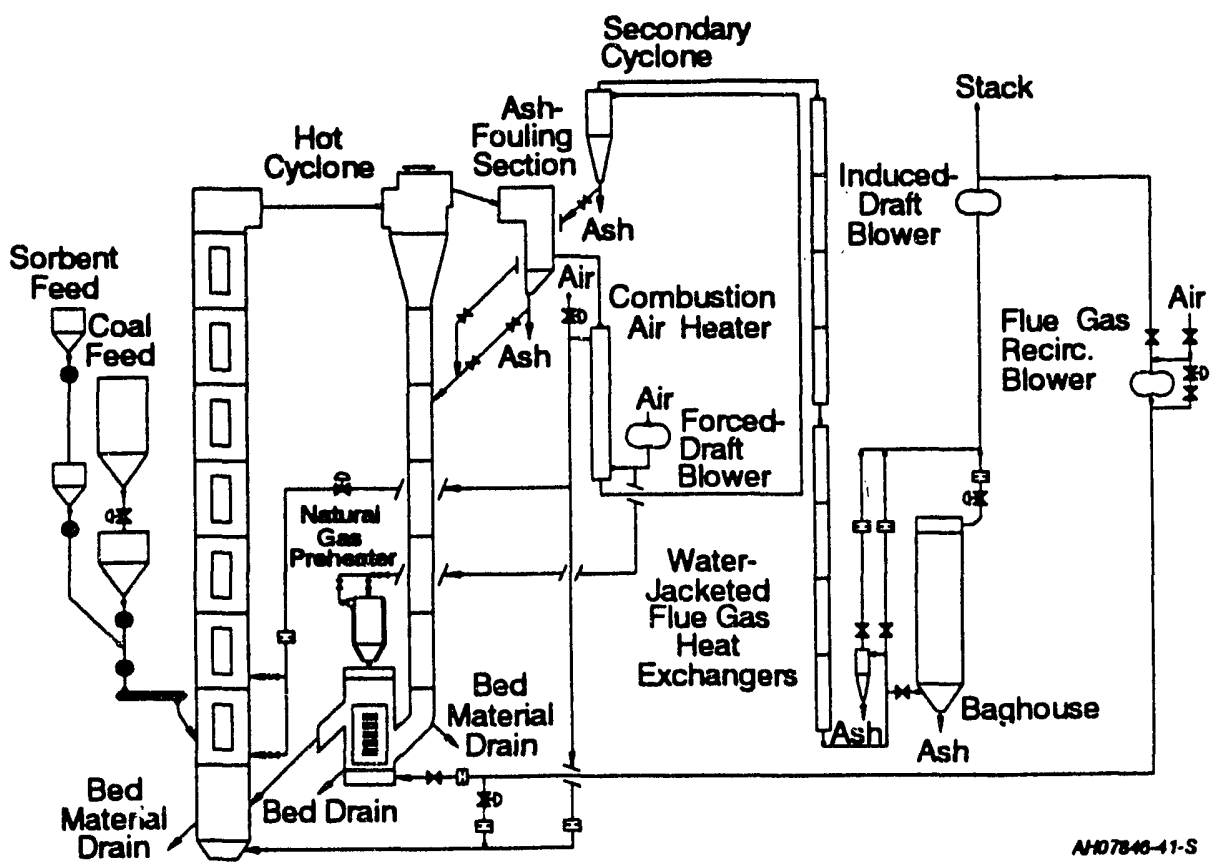

Figure F-9. Current configuration of the EERC CFB system. 
APPENDIX G

CALCULATIONS 


\section{TABLE OF CONTENTS}

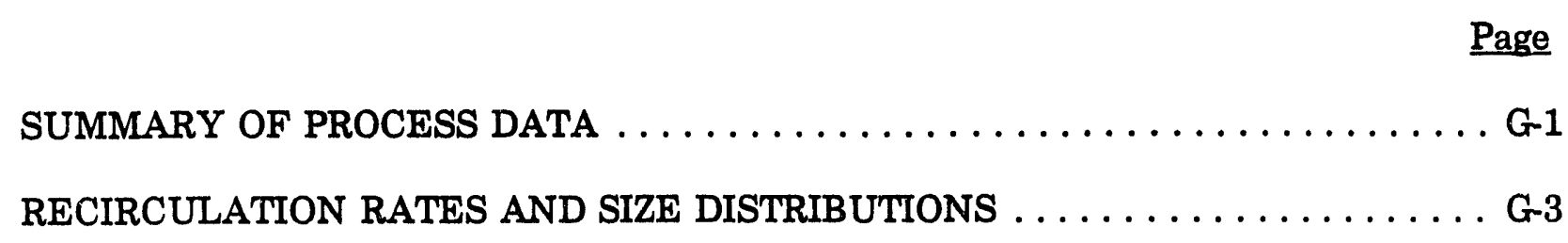

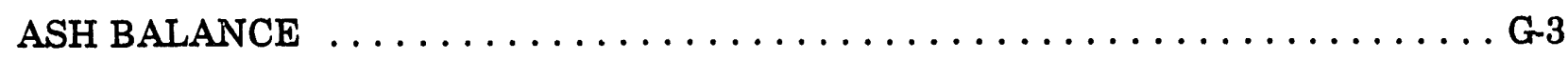

MATERIAL DERIVED FROM COAL ASH/ALUMINUM BALANCE $\ldots \ldots \ldots \ldots$ G-4 FUEL AND FLUE GAS BALANCES $\ldots \ldots \ldots \ldots \ldots \ldots \ldots \ldots \ldots \ldots$ G-4

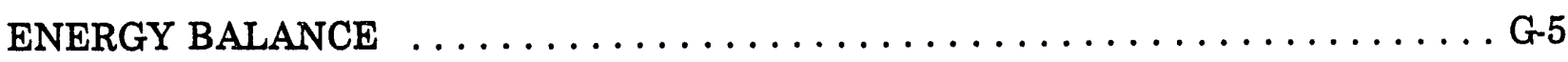

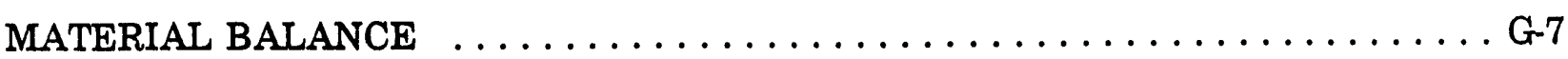
COMBUSTION EFFICIENCY $\ldots \ldots \ldots \ldots \ldots \ldots \ldots \ldots \ldots \ldots \ldots \ldots \ldots \ldots \ldots$

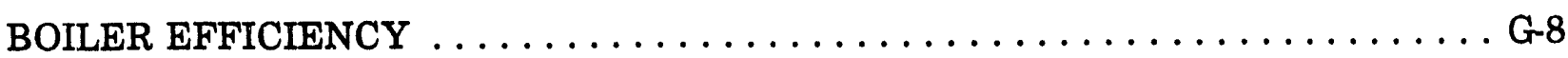
HEAT-TRANSFER COEFFICIENTS . . . . . . . . . . . . . . . . G-9

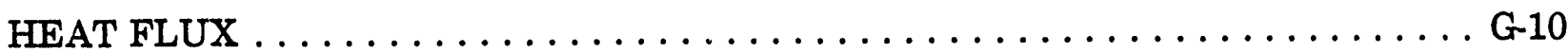

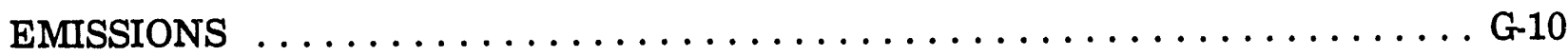


The following calculations are grouped according to the Table in which they appear in Appendices A through $E$. Several equations appear on more than one Table; these will be referenced back to their first occurrence.

\section{SUMMARY OF PROCESS DATA}

1. Coal Feed Rate (lb/hr)

The measured coal feed rate is based on the change in weight of the coal weigh hopper over a given period of time. The weigh hopper is suspended from a load cell which measures the weight of the hopper and any coal it holds. The data acquisition system receives a signal from the load cell every two seconds. The difference in hopper weight is calculated from values received 15 minutes apart. The weight difference for each 15-minute interval is divided by the time period and multiplied by 60 , and the average feed rate for each test period is presented. Intervals during which the initial hopper weight is less than the final hopper weight (as when the weigh hopper is filled) are not included in the average.

$$
\text { Coal Feed Rate }=\frac{\text { Hopper Weight @ Time } t(\mathrm{~min})-\text { Hopper Weight @ Time }(t+15)(\mathrm{min})}{\text { Time Interval (min) }} \times 60 \frac{\mathrm{min}}{\mathrm{hr}}
$$

2. Limestone Feed Rate (lb/hr)

The equation used for the limestone feed rate depends upon the limestone feed system in place. For the Salt Creek, Center, Blacksville, and Asian tests, a weigh hopper similar to that used for the coal was used. For the final Blacksville test and all the Black Thunder tests, an Accurate screw feeder was used. Hourly calibrations of the Accurate feeder were performed; calibrations consisted of collecting limestone exiting the screw feeder for a timed interval. The limestone collected in this manner was added to the combustor after it was weighed.

3. Solids Recirculation Rate (lb/hr)

The solids recirculation rate is determined from a heat balance around the external heat exchanger.

Solids Recirculation Rate $=\frac{\text { EHXX Heat Removal }+ \text { EHX Wall Losses }- \text { EHX Heat In }}{\text { Heat Capacity of the Solids } \times(\text { BHX Inlet Temperature }- \text { EHXX Exit Temperature })}$

Where EHX heat removal is given in Equation 37

EHX wall losses are assumed to be $35,000 \mathrm{Btu} / \mathrm{hr}$

EHX heat in is given in Equation 31

EHX inlet temperature is measured by thermocouple DC Sec $3 \cdot \mathbf{8 . 5}$

Heat capacity of the solids $\left(\mathrm{C}_{\mathrm{p}}\right)\left(\mathrm{Btu} / \mathrm{lb}-{ }^{\circ} \mathrm{F}\right)$ is given by:

$$
\begin{aligned}
C_{p}= & \left\{0.757+6 \times 10^{-4}\left[\left(\frac{T-32}{1.8}\right)+273\right]-1.68 \times 10^{4}\left[\left(\frac{T-32}{1.8}\right)+273\right]^{-2}\right\} \times 0.23884 \\
& \text { for } 0^{\circ} \mathrm{F}<\mathrm{T}<1067^{\circ} \mathrm{F} \text {, and } \\
C_{p}= & {\left[0.762+3.83 \times 10^{-4}\left(\frac{\mathrm{T}-32}{1.8}+273\right)\right] } \\
& \text { for } 1067^{\circ} \mathrm{F}<\mathrm{T}<2912^{\circ} \mathrm{F}
\end{aligned}
$$

Where $\mathrm{T}$ is the average solids temperature in ${ }^{\circ} \mathrm{F}$ 
4. Combustor Pressure Drop (dP) (inches of water)

Pressure taps are located throughout the system. The combustor pressure drop is the difference in pressure between the pressure tap located just above the distributor plate and the pressure tap located in the combustor exit.

5. Air and Flue Gas Flow Rates (scfm)

Most of the air and gas flow rates are measured with orifice plates, using the following equation to determine flow rates in scfm:

$$
\text { Flow Rate }=\text { Constant }\left(\frac{\mathrm{ft}^{3} \text { in }^{2} \sqrt{{ }^{\circ} \mathrm{R}}}{\mathrm{lb} \min }\right) \times \sqrt{\frac{d \mathrm{P}\left(\text { in. } \mathrm{H}_{2} \mathrm{O}\right) \times \mathrm{P}_{\text {acto }}(\mathrm{Psia})}{\text { Temperature }\left({ }^{\circ} \mathrm{F}\right)+460^{\circ} \mathrm{R}}}
$$

Constants: Primary Combustion Air Secondary Combustion Air Baghouse Flue Gas 894.19 Secondary Cyclone Flue Gas 558.87 10" Cyclone Flue Gas 971.25

The coal feed assist air, downcomer aeration air, and pressure tap purge air are measured with flowmeters, which measure acfm. This value is corrected to obtain scfm.

$$
\operatorname{scfm}=\operatorname{acfm} \times \sqrt{\frac{\text { Actual Pressure (psig) + Barometric Pressure (psia) }}{\text { Barometric Pressure (psia) }}}
$$

6. Primary-to-Secondary Air Split (PA/SA)

This is the ratio of primary to secondary combustion air. Total primary combustion air is the sum of the primary air (through the combustor distributor plate), EHX air, and downcomer aeration air. Total secondary combustion air consists of secondary air (through the secondary air ports), pressure tap purge air, and coal feed assist air.

7. Excess Air (\%)

All flue gas components are in $\%$.

$$
\text { Excess Air }=100 \times\left[\frac{\mathrm{O}_{2}-(0.5 \times \mathrm{CO})}{0.264 \times\left(100-\mathrm{CO}_{2}-\mathrm{CO}-\mathrm{O}_{2}\right)-\mathrm{O}_{2}+(0.5 \times \mathrm{CO})}\right]
$$

8. Combustor Superficial Gas Velocity (ft/sec)

SGV $=$ [Total Primary Air + Total Secondary Air (scfm)] $\times$ [Average Combustor Temperature $\left({ }^{\circ} \mathrm{F}\right)+460^{\circ} \mathrm{R}$ ]

$$
520^{\circ} \mathrm{R} \times 2.18 \mathrm{ft}^{2} \times 60 \frac{\mathrm{sec}}{\mathrm{min}}
$$


9. EHX Superficial Gas Velocity (ft/sec)

$$
\text { EHX SGV }=\frac{\text { EHX Flow Rate }(\mathrm{scfm}) \times\left(\text { Average EHX Temperature }\left({ }^{\circ} \mathrm{F}\right)+460^{\circ} \mathrm{R}\right]}{520^{\circ} \mathrm{R} \times 1.5625 \mathrm{ft}^{2} \times 60 \frac{\mathrm{sec}}{\mathrm{min}}}
$$

10. Bed Material/Cyclone Ash Add Rate ( $\mathrm{b} / \mathrm{hr})$

This is the total amount of each type of material, in pounds, added during a test period, divided by the test duration.

11. Bottom Ash/Cyclone Ash/Baghouse Ash Discharge Rate (lb/hr)

This is the total amount of each type of material, in pounds, removed from the system during a test period, divided by the test duration.

12. Average Combustor Temperature $\left({ }^{\circ} \mathrm{F}\right)$

The average combustor temperature is the average of fourteen thermocouples located at the following heights in the combustor: 1', 2', 3', 4', 6', 8', 11', 14', 17.5', $22.5^{\prime}, 27.5^{\prime}, 32.5^{\prime}, 37.5^{\prime}$, and 41' above the distributor plate.

13. Average EHX Temperature $\left({ }^{\circ} \mathrm{F}\right)$

The average EHX temperature is the average of three thermocouples located 0.5 , 1.5', and 2.7' above the EHX distributor plate.

\section{RECIRCULATION RATES AND SIZE DISTRIBUTIONS}

14. Cyclone Efficiency (\%)

$$
\text { Cyclone Efficiency }=\left(1-\frac{\text { Cyclone Ash Collected }(\mathrm{b} / \mathrm{hr})+\text { BH Ash Collected }(\mathrm{bb} / \mathrm{hr})}{\text { Solids Recirculation Rate }(\mathrm{bb} / \mathrm{hr})}\right) \times 100
$$

15. Recirculation Ratio

$$
\text { Recirculation Ratio }=\frac{\text { Recirculation Rate }}{\text { Coal Feed Rate } \times \frac{\% \text { Coal Ash }}{100}+\text { Sorbent Feed Rate }}
$$

\section{ASH BALANCE}

16. Coal Ash Input $(\mathrm{lb} / \mathrm{hr})$

$$
\text { Ash Input }=\text { Coal Feed Rate } \times \frac{\% \text { Coal Ash }}{100}
$$

17. Sorbent $\mathrm{CaO}$ and $\mathrm{CaSO}_{4}(\mathrm{lb} / \mathrm{hr})$

$$
\begin{aligned}
\text { Sorbent } \mathrm{CaO} & =\frac{56}{100} \times \text { Sorbent Feed Rate } \times\left(1-\frac{\% \text { Total Allali Utilization }}{100}\right) \\
\text { Sorbent } \mathrm{CaSO}_{4} & =\frac{136}{100} \times \text { Sorbent Food Rate } \times \frac{\% \text { Total Alkali Utilization }}{100}
\end{aligned}
$$

18. Ash Balance Closure (\%)

$$
\text { Closure }=\frac{\text { Total Solids Out }(\mathrm{lb} / \mathrm{hr})}{\text { Total Solids In }(\mathrm{lb} / \mathrm{hr})} \times 100
$$


19. Bottom Ash/Total Ash Split (\%)

$$
\text { Bottom Ash/Total Ash }=\frac{\text { Bed Material Out }(\mathrm{b} / \mathrm{hr})}{\text { Total Solids Out }(\mathrm{b} / \mathrm{hr})} \times 100
$$

\section{MATERIAL DERIVED FROM COAL ASH/ALUMINUM BALANCE}

20. Coal Ash Feed Rate (lb/hr)

$$
\text { Ash Input }=\text { Coal Feed Rate } \times \frac{\% \text { Coal Ash }}{100}
$$

21. Ash from Coal (\%)

$$
\text { Ash from Coal }=\left(\frac{\mathrm{Al}_{2} \mathrm{O}_{3} \text { in Bottom, Cyclone, or Baghouse Ash }}{\mathrm{Al}_{2} \mathrm{O}_{3} \text { in Coal Ash }}\right) \times 100
$$

22. Ash from Coal (lb/hr)

$$
\text { Ash from Coal }=\left(\frac{\text { Ash from Coal }(\%) \times \text { Bottom, Cyclone, or Baghouse Ash }(\mathrm{lb} / \mathrm{hr})}{100}\right)
$$

23. Solids Input from the Limestone in the Bed Material/Cyclone Ash/Baghouse Ash

These values are obtained by subtracting the percentage input from the coal for each ash stream from 100.

24. Total Ash from Coal (lb:hr)

Total Ash from Coal = $\Sigma$ Bottom, Cyclone, and Baghouse Ash from Coal

25. Closure (\%)

$$
\text { Closure }=\frac{\text { Total Ash from Coal }}{\text { Coal Ash }} \times 100
$$

\section{FUEL AND FLUE GAS BALANCES}

These values are determined using a computer program which calculates products of combustion. The inputs are the coal analysis (in percent), the percentage of excess air, and the combustion air flow rate.

26. Theoretical Fuel Feed Rate $(\mathrm{lb} / \mathrm{hr})$

$$
\begin{aligned}
& \text { Theoretical Air }=\left(\frac{\mathrm{lb} \mathrm{C}}{\mathrm{lb} \mathrm{Coal}} \times 11.53 \frac{\mathrm{lb} \mathrm{Air}}{\mathrm{lb} \mathrm{C}}\right)+\left(\frac{\mathrm{lb} \mathrm{H}_{2}}{\mathrm{lb} \mathrm{Coal}} \times 34.34 \frac{\mathrm{lb} \mathrm{Air}}{\mathrm{lb} \mathrm{H}}\right)+\left(\frac{\mathrm{lb} \mathrm{S}}{\mathrm{lb} \mathrm{Coal}} \times 4.29 \frac{\mathrm{lb} \mathrm{Air}}{\mathrm{lb} \mathrm{S}}\right)-\left(\frac{\mathrm{lb} \mathrm{O}}{\mathrm{lb} \mathrm{Codl}} \times 4.32 \frac{\mathrm{lb} \mathrm{Air}}{\mathrm{lb} \mathrm{O}}\right) \\
& \text { Total Air Required }\left(\frac{\mathrm{lb} \text { Air }}{\mathrm{lb} \text { Coal }}\right)=\text { Theoretical Air } \times\left(1+\frac{\text { \% Excess Air }}{100}\right) \\
& \text { Total Air Required }\left(\frac{\text { af }}{\mathrm{lb} \text { Coal }}\right)=\text { Total Air Required }\left(\frac{\mathrm{lb} \text { Air }}{\mathrm{lb} \text { Coal }}\right) \times 13.2 \frac{\mathrm{ft}^{3}}{\mathrm{Ib} \text { Air }} \\
& \text { Theoretical Fuel Feed }=\left(\frac{\text { Actual Air Flow Rate [scfm] }}{\text { Total Air Required } \frac{\mathrm{sef}}{1 \mathrm{~b} \mathrm{Coal}}}\right) \times 60 \frac{\mathrm{min}}{\mathrm{hr}}
\end{aligned}
$$


27. Theoretical Flue Gas Flow Rate (scfm)

Theoretical FG Flow Rate $=\Sigma$ Combustion Products $\left(\frac{\mathrm{lb}}{\mathrm{Ib} \text { Coal }}\right) \times\left(\frac{380 \frac{\mathrm{ft}^{3}}{\mathrm{Ib}}}{60 \frac{\min }{\mathrm{hr}}}\right) \times$ Theoretical Coal Feed Rate

28. Combustion Products $(\mathrm{lb} / \mathrm{lb}$ coal)

$$
\begin{aligned}
\mathrm{CO}_{2} & =\frac{\mathrm{lb} \mathrm{C}}{\mathrm{lb} \mathrm{Coal}} \times 3.66 \frac{\mathrm{lb} \mathrm{CO}_{2}}{\mathrm{lb} \mathrm{C}} \\
\mathrm{H}_{2} \mathrm{O} & =\left(\frac{\mathrm{lb} \mathrm{H}}{\mathrm{lb} \mathrm{Coal}} \times 8.94 \frac{\mathrm{lb} \mathrm{H}_{2} \mathrm{O}}{\mathrm{lb} \mathrm{Coal}}\right)+\frac{\mathrm{lb} \mathrm{H} \mathrm{O}}{\mathrm{lb} \mathrm{Coal}}+\left(\text { Total Air Required }\left(\frac{\mathrm{lb} \mathrm{Air}}{\mathrm{lb} \mathrm{Caal}}\right) \times 0.013 \frac{\mathrm{lb} \mathrm{H}_{2} \mathrm{O}}{\mathrm{lb} \mathrm{Coal}}\right) \\
\mathrm{O}_{2} & =\text { (Total Air Required - Theoretical Air) }\left(\frac{\mathrm{lb} \mathrm{Air}}{\mathrm{lb} \mathrm{Coal}}\right) \times 0.2313 \frac{\mathrm{b} \mathrm{O} \mathrm{O}_{2}}{\mathrm{lb} \mathrm{Air}} \\
\mathrm{N}_{2} & =\frac{\mathrm{lb} \mathrm{N}}{\mathrm{lb} \mathrm{Coal}}+\text { Total Air Required }\left(\frac{\mathrm{lb} \mathrm{Air}}{\mathrm{lb} \mathrm{Coal}}\right) \times 0.7685 \frac{\mathrm{lb} \mathrm{N}}{\mathrm{lb} \mathrm{Coal}}
\end{aligned}
$$

29. Closure (\%)

$$
\text { Closure }=\frac{\text { Measured Feed Rate }- \text { Theoretical Food Rate }}{\text { Theoretical Feed Rate }} \times 100
$$

\section{ENERGY BALANCE}

\section{Inputs}

30. Coal (Btw/hr)

9Energy in from Coal = HHV (as-received) $-1040 \frac{\mathrm{Btu}}{\mathrm{lb}} \times\left[\frac{1 \mathrm{~b} \mathrm{H}_{\mathrm{O}}}{\mathrm{lb} \mathrm{Coal}}+\frac{\mathrm{lb} \mathrm{H}_{2}}{\mathrm{lb} \mathrm{Coal}}-\frac{\left(\frac{1 \mathrm{~b} \mathrm{H}_{2} \mathrm{O}}{1 \mathrm{~b} \mathrm{Coal}}\right)}{9 \frac{\mathrm{lb} \mathrm{_{2 } \mathrm { O }}}{1 \mathrm{~b} \mathrm{H}_{2}}}\right] \times$ Coal Feod Rato

31. Primary/Secondary/EHX Air (Btu/hr)

Energy in from PA $=0.60 \frac{\mathrm{Btu}}{\mathrm{ft}^{3}{ }^{\circ} \mathrm{F}} \times$ PA Flow $\times($ Combustor Plenum Temperature - Ambient Temperature $) \times 60 \frac{\mathrm{min}}{\mathrm{hr}}$

Energy in from SA $=0.60 \frac{\mathrm{Btu}}{\mathrm{ft}^{3}{ }^{\circ} \mathrm{F}} \times$ SA Flow $\times($ Combustor Plenum Temperature - Ambient Temperature $) \times 60 \frac{\mathrm{min}}{\mathrm{br}}$

Energy in from EHX $=1.01 \frac{\mathrm{Btu}}{\mathrm{ft}^{3}{ }^{\circ} \mathrm{F}} \times$ EHLX Flow $\times($ EFX Plenum Temperature - Ambient Temperature $) \times 60 \frac{\mathrm{min}}{\mathrm{hr}}$

Assumes $600^{\circ} \mathrm{F} \mathrm{PA}$ and SA inlet temperatures and $110^{\circ} \mathrm{F} \mathrm{EHX}$ inlet temperature. 
32. Ash (chem.) (Btu/hr)

33. Sorbent Sulfation (Btu/hr)

$$
\text { Ash(chem) }=14,091 \frac{B t a}{\mathrm{lb} \mathrm{C}} \times\left[\left(\frac{\text { Cyclone Ash Added }\left(\frac{\mathrm{lb}}{\mathrm{hr}}\right)}{\frac{\mathrm{lb} \mathrm{C}}{\mathrm{lb} \text { Cyclone Ash }}}\right)+\left(\frac{\operatorname{Bed~Ash~Added~}\left(\frac{\mathrm{lb}}{\mathrm{hr}}\right)}{\frac{\mathrm{lb} \mathrm{C}}{\mathrm{lb} \mathrm{Bed} \mathrm{Ash}}}\right)\right]
$$

$$
\text { Sorbent Sulfation }=2150 \frac{\text { Btu }}{1 \mathrm{~b} \text { Limestone }} \times \text { Limestone Feed Rate } \times \frac{\left(\frac{\text { Sulfur Retention }}{\text { Total Albali/Sulfur }}\right)}{100}
$$

\section{Outputs}

34. Flue Gas (sensible) (Btu/hr)

Fine Gas Bnergy Out =

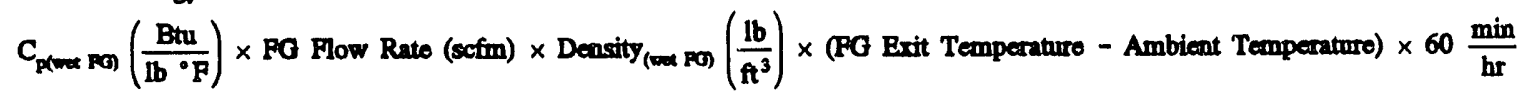

35. Ash (sensible) (Btu/hr)

Solids $=0.269 \frac{\text { Btu }}{1 b^{\circ} \mathrm{F}} \times$ Total Ash Discharge Rate $\times$ (Average Temperature - Ambient Temperature)

Where Total Ash = Bed Material Drain + Secondary Cyclone Ash + Baghouse Ash in $\mathrm{lb} / \mathrm{hr}$

36. Ash (chem.) (Btu/hr)

Ash (chem) $=$

14,091 $\frac{\text { Btu }}{\text { lb C }} \times\left[\left(\right.\right.$ BH Discharge $\left.\times \frac{\text { lb C }}{1 \mathrm{~b} \mathrm{BH} \mathrm{Ash}}\right)+\left(\right.$ Cyclone Discharge $\left.\times \frac{\text { lb C }}{\text { lb Cyclone Ash }}\right)+\left(\right.$ Bed Discharge $\left.\left.\times \frac{\text { lb C }}{\text { Ib Bed Ash }}\right)\right]$

37. Combustor and EHX Heat Exchangers (Btu/hr)

Heat Removal =

$$
\text { 8.34 } \frac{\mathrm{Btu}}{\mathrm{gal}^{\circ} \mathrm{F}} \times \text { Water Flow Rate }(\mathrm{gpm}) \times(\text { Water Temperature Out }- \text { Water Temperature In }) \times 60 \frac{\mathrm{min}}{\mathrm{hr}}
$$

38. Sorbent Calcination (Btw/hr)

$$
\text { Sorbent Calcination }=766 \frac{\mathrm{Btu}}{\mathrm{lb}} \times \text { Limestone Peed Rate }\left(\frac{\mathrm{lb}}{\mathrm{hr}}\right)
$$

39. Conduction and Radiation (Btu/hr)

$$
\text { Conduction and Radiation }=\text { (Average Combustor Temperature } \times \text { Slope })+ \text { Constant }
$$

For Tests SC and CL:

$$
\begin{aligned}
\text { Slope } & =482.65 \\
\text { Constant } & =-304,825 \\
\text { Slope } & =520.95 \\
\text { Constant } & =-600,132
\end{aligned}
$$

For Tests BT, BV, TL: 
40. Closure (\%)

$$
\text { Closure }=\frac{\text { Energy In }}{\text { Energy Out }} \times 100
$$

\section{MATERIAL BALANCE}

\section{Inputs}

41. Combustion/Additional Air (lb/hr)

$$
\begin{aligned}
& \text { Combustion Air }=0.076312 \frac{\mathrm{lb}}{\mathrm{ft}^{3}} \times 60 \frac{\mathrm{min}}{\mathrm{hr}} \times \text { (Primary + Secondary + EHX Air) (scfm) } \\
& \text { Additional Air }=0.0761,50 \frac{\mathrm{lb}}{\mathrm{ft}^{3}} \times 60 \frac{\mathrm{min}}{\mathrm{hr}} \times \text { (Feed Assist + Downcomer Assist + Purge Air) (scfm) }
\end{aligned}
$$

42. Bed Material/Cyclone Ash, Coal and Sorbent Feed Rates (lb/hr)

These values are the actual measured amounts, averaged over the length of the test period. The coal feed rate used here is the theoretical coal feed rate.

\section{Outputs}

43. Measured Flue Gas $(\mathrm{lb} / \mathrm{hr})$

$$
\text { Fluo Gas Out }=\text { Actual FG Flow Rate (scfm) } \times \text { Density }_{\text {(mat Po) }}\left(\frac{\mathrm{lb}}{\mathrm{ft}^{3}}\right) \times 60 \frac{\min }{\mathrm{hr}}
$$

44. Flue Gas Leaks (lb/hr)

Flue Gas Leaks $=$ (Theoretical FG Flow Rate - Actual FG Flow Rate) $(\mathrm{scfm}) \times$ Density $_{(\operatorname{mot}}$ PG) $\left(\frac{\mathrm{lb}}{\mathrm{ft}^{3}}\right) \times 60 \frac{\min }{\mathrm{hr}}$

45. Bottom Ash/Cyclone Ash/Baghouse Ash Out ( $\mathrm{lb} / \mathrm{hr})$

These values are the actual measured amounts, averaged over the length of the test period.

46. Closure (\%)

$$
\text { Closure }=\frac{\text { Material Out }}{\text { Material In }} \times 100
$$




\section{COMBUSTION EFFICIENCY}

\section{Inputs}

47. Coal/Bed Material/Cyclone Ash Carbon Feed Rates $(\mathrm{lb} / \mathrm{hr}$ )

$$
\begin{array}{ll}
\text { Coal Carbon Input } & =\text { Coal Feed Rate }\left(\frac{\mathrm{lb}}{\mathrm{hr}}\right) \times \frac{\mathrm{lb} \mathrm{C}}{\mathrm{lb} \text { Coal }} \\
\text { Bed Ash Carbon Input } & =\text { Bed Ash Add Rate }\left(\frac{\mathrm{lb}}{\mathrm{hr}}\right) \times \frac{\mathrm{lb} \mathrm{C}}{\mathrm{lb} \text { Bed Ash }} \\
\text { Cyclone Ash Carbon Input } & =\text { Cyclone Ash Add Rate }\left(\frac{\mathrm{lb}}{\mathrm{hr}}\right) \times \frac{\mathrm{lb} \text { C }}{\mathrm{lb} \text { Cyclone Ash }}
\end{array}
$$

\section{Outputs}

48. Bottom Ash/Cyclone Ash/Baghouse Ash Carbon Discharge Rate (lb/hr)

$$
\begin{aligned}
& \text { Bottom Ash Carbon }=\text { Bottom Ash Drain Rate }\left(\frac{\mathrm{lb}}{\mathrm{hr}}\right) \times \frac{\mathrm{lb} \mathrm{C}}{\mathrm{lb} \text { Bottom Ash }} \\
& \text { Cyclone Ash Carbon }=\text { Cyclone Ash Drain Rate }\left(\frac{\mathrm{lb}}{\mathrm{hr}}\right) \times \frac{\mathrm{lb} \mathrm{C}}{\mathrm{lb} \text { Cyclone Ash }} \\
& \text { BH Ash Carbon } \quad=\text { BH Ash Drain Rate }\left(\frac{\mathrm{lb}}{\mathrm{hr}}\right) \times \frac{\mathrm{lb} \mathrm{C}}{\mathrm{lb} \mathrm{BH} \mathrm{Ash}}
\end{aligned}
$$

49. Combustion Efficiency (Carbon Basis) (\%)

$$
\text { Combustion Efficiency }=\left(\frac{\text { Total Carbon In }- \text { Total Carbon Out }}{\text { Total Carbon In }}\right) \times 100
$$

\section{BOILER EFFICIENCY}

\section{Dry Gas Loss (Btu/hr)}

Dry Gas =

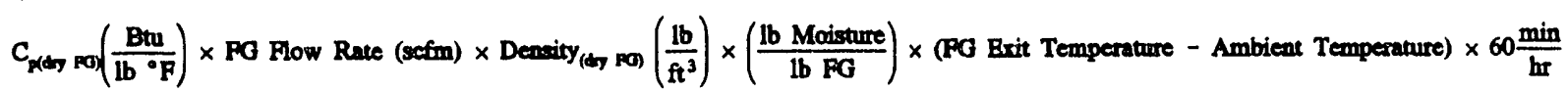

51. Water in the Fuel Loss (Btu/hr)

Water in Fuel $=$

$$
\text { Coal Feed Rate } \times \frac{\mathrm{lb} \mathrm{H}_{2} \mathrm{O}}{\mathrm{lb} \mathrm{Coal}} \times\left[1089 \frac{\mathrm{Bta}}{\mathrm{lb} \mathrm{H}_{2} \mathrm{O}}+0.46 \frac{\mathrm{Btu}}{\mathrm{lb} \mathrm{H}_{2} \mathrm{O}^{\circ} \mathrm{F}} \times \text { (FG Exit Temperature - Ambient Temperature) }\right]
$$


52. Combustion of Fuel Hydrogen Loss (Btu/hr)

Puel $\mathrm{H}=$

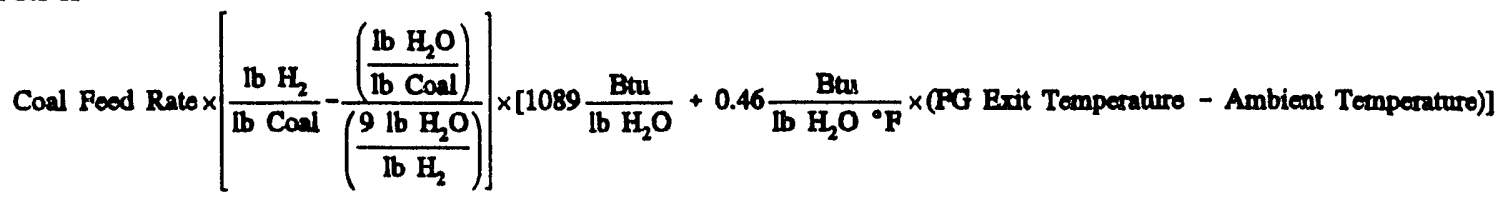

53. Unburned Carbon Loss (Btu/hr)

UnburnodCarton =

14,091 $\frac{\text { Btu }}{\mathrm{lb} \mathrm{C}} \times\left[\left(\right.\right.$ BH Discharge $\left.\times \frac{\mathrm{lb} \mathrm{C}}{\mathrm{lb} \mathrm{BH} \mathrm{Ash}}\right)+\left(\right.$ Cyclone Discharge $\left.\times \frac{\text { lb C }}{\mathrm{Ib} \mathrm{Cyclone} \mathrm{Ash}}\right)+\left(\right.$ Bed Discharge $\left.\left.\times \frac{\text { lb C }}{\mathrm{lb} \mathrm{Bed} \mathrm{Ash}}\right)\right]$

54. Sorbent Calcination Loss $(\mathrm{Btu} / \mathrm{hr})$

$$
\text { Sorbent Calcination }=766 \frac{\mathrm{Btu}}{\mathrm{lb}} \times \text { Limestone Feed Rate }\left(\frac{\mathrm{lb}}{\mathrm{hr}}\right)
$$

55. Radiation and Convection Loss (assumes $0.4 \%$ heat loss) (Btu/hr)

Radiation and Convection $=0.004 \times$ Coal Feed Rate $\times$ HHV (as-received)

56. Solids Loss (Btu/hr)

Solids $=$

$0.269 \frac{\text { Btu }}{1 \mathrm{~b}^{\circ} \mathrm{F}} \times$ Total Ash Discharge Rate $\left(\frac{\mathrm{lb}}{\mathrm{br}}\right) \times$ (Average Temperature - Ambient Temperature)

Where Total Ash = Bed Material Drain + Secondary Cyclone Ash + Baghouse Ash in $\mathrm{lb} / \mathrm{hr}$

57. Sorbent Sulfation Loss (Btu/hr)

$$
\text { Sorbent Sulfation }=-2150 \frac{\text { Btu }}{\text { lb Limestone }} \times \text { Limestone Feed Rate } \times \frac{\left(\frac{\text { Sulfur Retention }}{\text { Total Alloali/Sulfur }}\right)}{100}
$$

58. Boiler Efficiency Losses (\%)

Each boiler efficiency loss calculated with Equations 50 through 57 is converted to a percentage of the heat in from the fuel with the following equation:

$$
\operatorname{Loss}(\%)=\frac{\operatorname{Loss}\left(\frac{\mathrm{Btw}}{\mathrm{hr}}\right)(\text { from Equations } 50-57)}{\text { HHV (as-received) } \times \text { Coal Feed Rate }}
$$

59. Boiler Efficiency (\%)

Boiler Efficiency $=100-\Sigma$ Boiler Efficiency Losses $(\%)$ 


\section{HEAT-TRANSFER COEFFICIENTS}

60. Combustor Heat Transfer Coefficient (Btu/hr- $\left.\mathrm{ft}^{2} \cdot{ }^{\circ} \mathrm{F}\right)$

$$
\text { HTC }=\frac{\text { Energy Out (Equation 37) }\left(\frac{\mathrm{Btu}}{\mathrm{hr}}\right)}{2.6 \frac{\mathrm{ft}^{2}}{\mathrm{Door}} \times(\text { \# Doors }) \times(\text { Water Temperature Out }- \text { Water Temperature In) }}
$$

61. EXH Heat Transfer Coefficient $\left(\mathrm{Btu} / \mathrm{hr}-\mathrm{ft}^{2}{ }^{\circ} \mathrm{F}\right)$

$$
\text { HTC }=\frac{\text { Energy Out (Equation 37) }\left(\frac{\mathrm{Btu}}{\mathrm{hr}}\right)}{0.75 \frac{\mathrm{ft}^{2}}{\mathrm{Coil}} \times(\# \text { Coils }) \times(\text { Water Temperature Out }- \text { Water Temperature In) }}
$$

\section{HEAT FLUX}

62. Combustor Heat Flux (Btu/hr-ft $\left.{ }^{2}\right)$

$$
\text { Combustor Heat Flux }=\frac{\text { Energy Out (Bquation 37) }\left(\frac{\mathrm{Btu}}{\mathrm{hr}}\right)}{2.6 \frac{\mathrm{ft}^{2}}{\mathrm{Door}} \times \text { (" Doors) }}
$$

63. EHX Heat Flux (Btu/hr-ft $\left.{ }^{2}\right)$

$$
\text { EHX Heat Flux }=\frac{\text { Energy Out (Equation 37) }\left(\frac{B t u}{\mathrm{hr}}\right)}{0.75 \frac{\mathrm{ft}^{2}}{\text { Coil }} \times(\# \text { Coils })}
$$

\section{EMISSIONS}

64. $\mathrm{CO} / \mathrm{CO}_{2} / \mathrm{NO}_{x} / \mathrm{N}_{2} \mathrm{O} / \mathrm{SO}_{2}$ Emissions Corrected to $3 \% \mathrm{O}_{2}$

Corrected Concentration $=$ Measured Concentration $\times\left(\frac{3 \%-21 \% \text { in Air }}{\mathrm{O}_{2} \text { Concentration }-21 \% \mathrm{O}_{2} \text { in Air }}\right)$ 
65. $\mathrm{CO} / \mathrm{NO}_{2} / \mathrm{N}_{2} \mathrm{O} / \mathrm{SO}_{2}$ Emissions in $\mathrm{lb} / \mathrm{MM} \mathrm{Btu}$

$$
\begin{aligned}
& \mathrm{CO}\left(\frac{\mathrm{lb}}{\mathrm{MM} \mathrm{Btu}}\right)=\frac{2.33 \frac{\mathrm{lb} \mathrm{CO}}{\mathrm{lb} \mathrm{C}}}{\mathrm{Coal} \mathrm{HHV}\left(\frac{\mathrm{Btu}}{\mathrm{lb}}\right)} \times \frac{\left(\frac{\mathrm{Coal} \mathrm{C}}{100} \times \mathrm{CO}(\mathrm{ppm})\right)}{\left(\frac{\mathrm{CO}_{2}(\%)+\mathrm{CO}(\%)}{100}\right)} \\
& \mathrm{NO}_{x}\left(\frac{\mathrm{lb}}{\mathrm{MM} \mathrm{Btu}}\right)=\frac{3.83 \frac{\mathrm{lb} \mathrm{NO}_{\mathrm{x}}}{\mathrm{lb} \mathrm{C}}}{\mathrm{COal} \mathrm{HHV}\left(\frac{\mathrm{Btu}}{\mathrm{lb}}\right)} \times \frac{\left(\frac{\mathrm{Coal} \mathrm{C}}{100} \times \mathrm{NO}_{\mathrm{x}}(\mathrm{ppm})\right.}{\left(\frac{\mathrm{CO}_{2}(\%)+\mathrm{CO}(\%)}{100}\right)}
\end{aligned}
$$

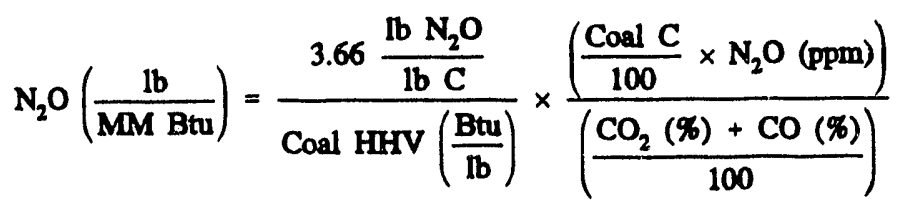

$$
\begin{aligned}
& \mathrm{SO}_{2}\left(\frac{\mathrm{lb}}{\mathrm{MM} \mathrm{Btu}}\right)=\frac{5.33\left(\frac{\mathrm{b} \mathrm{SO}_{2}}{\mathrm{lb} \mathrm{C}}\right)}{\mathrm{Coal} \mathrm{HHV}\left(\frac{\mathrm{Btu}}{\mathrm{Ib}}\right)} \times \frac{\left(\frac{\mathrm{Coal} \mathrm{C}}{100} \times \mathrm{SO}_{2}(\mathrm{ppm})\right)}{\left(\frac{\mathrm{CO}_{2}(\%)+\mathrm{CO}(\%)}{100}\right)}
\end{aligned}
$$

66. $\mathrm{SO}_{2}$ Retention (\%)

$$
\mathrm{SO}_{2} \text { Retention }=100-\frac{0.0267 \times \mathrm{SO}_{2}(\mathrm{ppm}) \times \% \mathrm{C} \text { in Coal }}{\left[\mathrm{CO}_{2}(\%)+\mathrm{CO}(\%)\right] \times \% \mathrm{~S} \text { in Coal }}
$$

67. $\mathrm{Ca} / \mathrm{S}$ Ratio (sorbent only)

$$
\mathrm{Ca} / \mathrm{S}=\frac{\text { Sorbent Feed Rate } \times \frac{\% \mathrm{CaO} \text { in Sorbent }}{56 \frac{\mathrm{lb}}{\mathrm{mol}}}}{\text { Coal Feed Rate } \times \frac{\% \mathrm{~S} \text { in Coal }}{32 \frac{\mathrm{lb}}{\mathrm{mol}}}}
$$

68. $\mathrm{Ca} / \mathrm{S}$ Ratio (total)

$$
\text { Total Ca/S }=\frac{\left(\text { Sorbent Feed Rate } \times \frac{\% \text { CaO in Sorbent }}{56 \frac{\mathrm{lb}}{\mathrm{mol}}}\right)+\left(\text { Coal Feed Rate } \times \% \text { Coal Ash } \times \frac{\% \text { CaO in Coal Ash }}{56 \frac{\mathrm{lb}}{\mathrm{mol}}}\right)}{\text { Coal Feed Rate } \times \frac{\% \mathrm{~S} \text { in Coal }}{32 \frac{\mathrm{lb}}{\mathrm{mol}}}}
$$

69. Calcium Utilization (\%)

$$
\text { Calcium Utilization }=\frac{\mathrm{SO}_{2} \text { Retention }}{\mathrm{Ca} / \mathrm{S} \text { (total) }}
$$



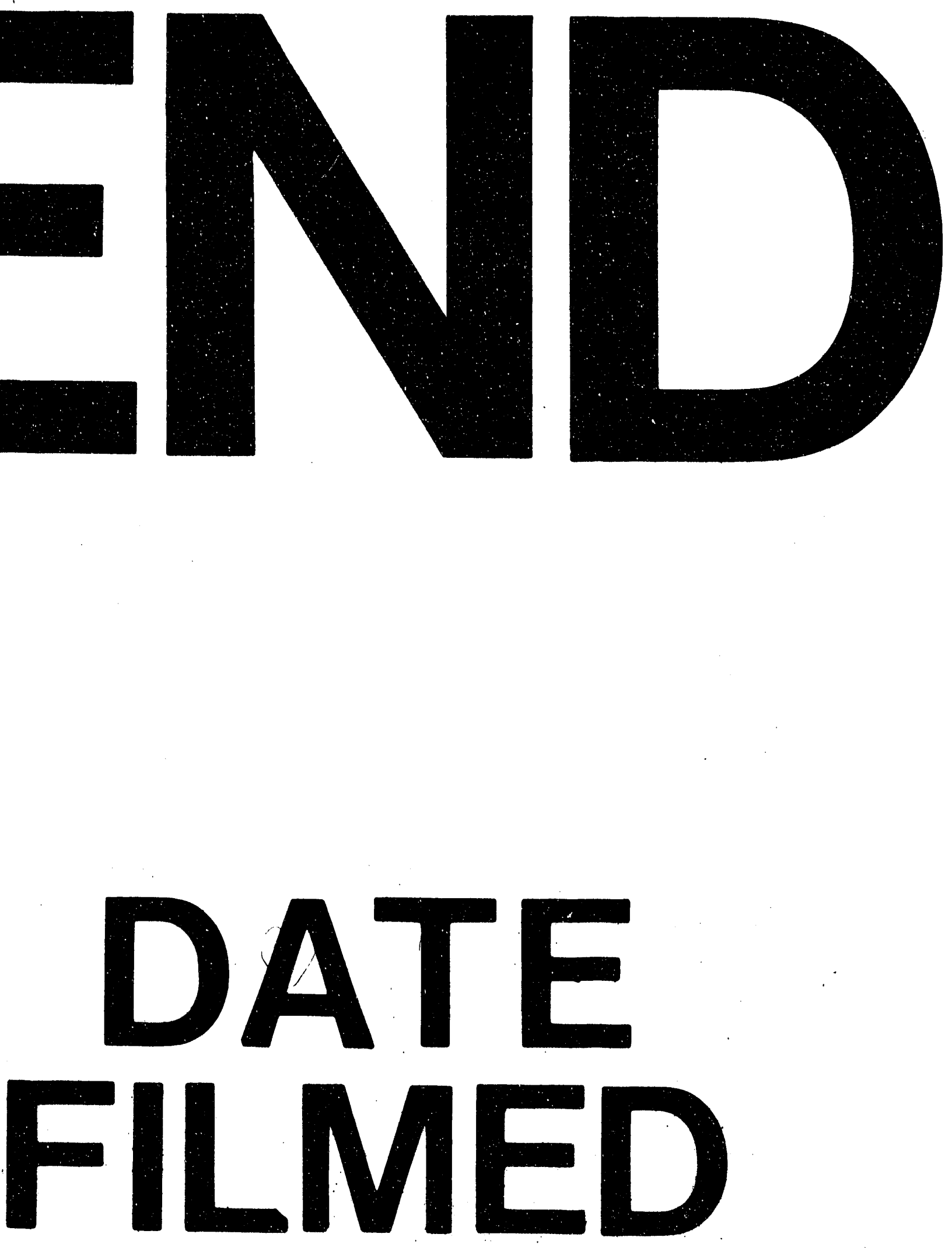

1

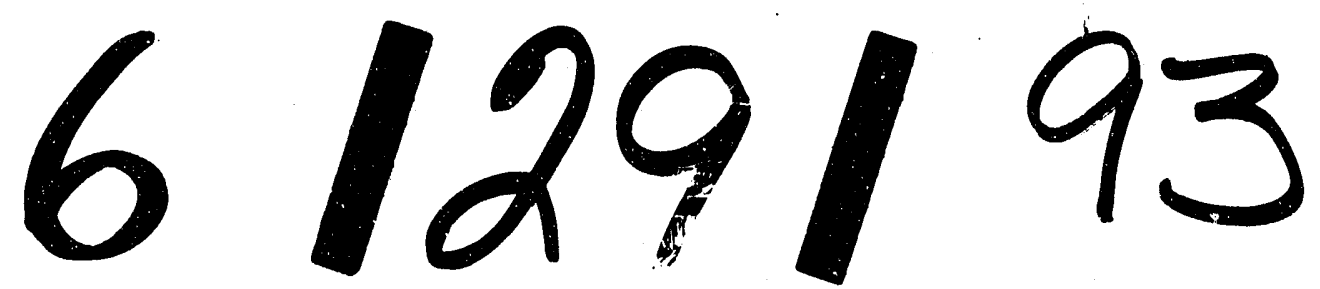


